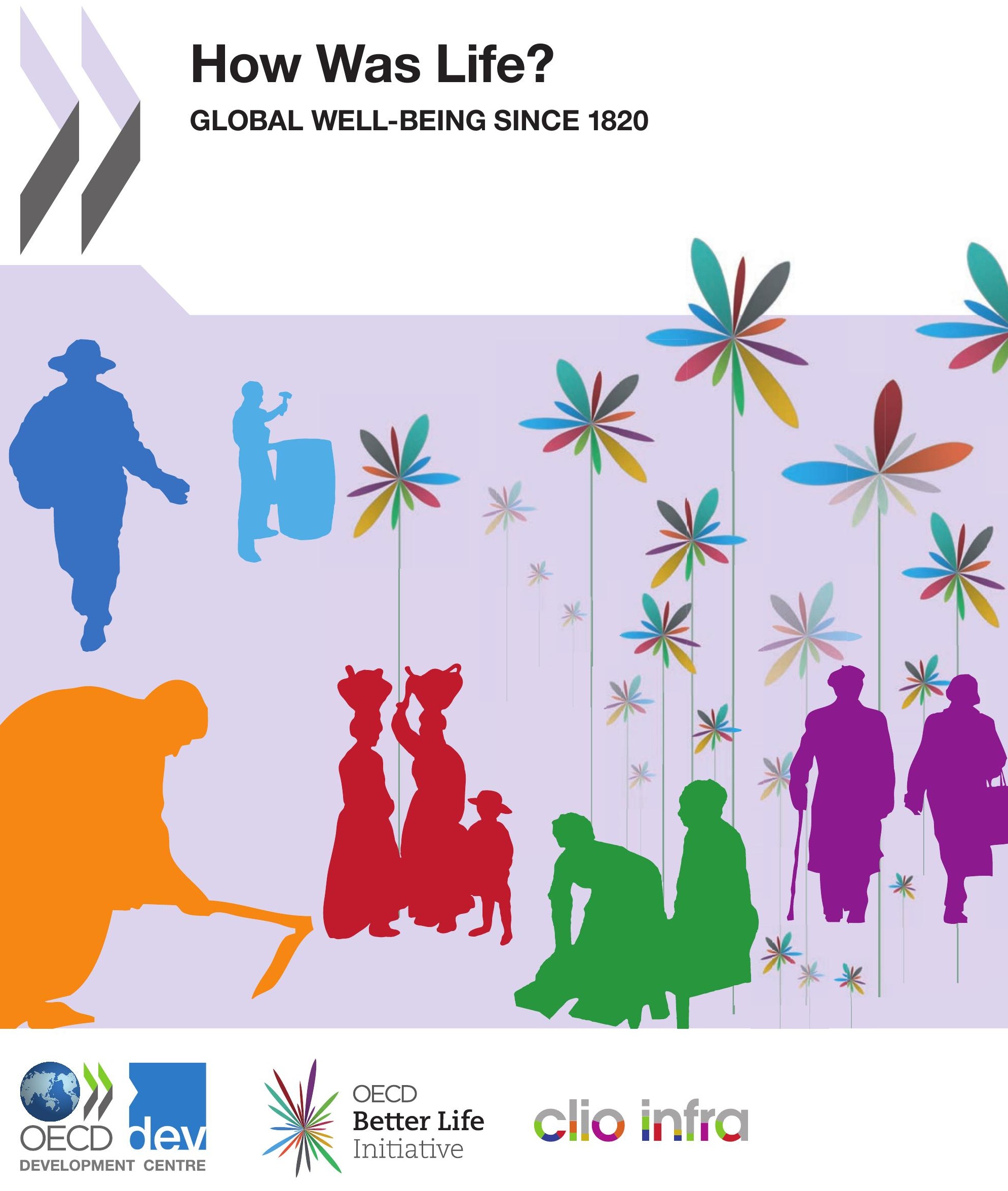





\title{
How Was Life?
}

\section{GLOBAL WELL-BEING SINCE 1820}

\author{
Edited by \\ Jan Luiten van Zanden, Joerg Baten, \\ Marco Mira d'Ercole, Auke Rijpma, \\ Conal Smith and Marcel Timmer
}


This work is published on the responsibility of the Secretary-General of the OECD. The opinions expressed and arguments employed herein do not necessarily reflect the official views of the Organisation or of the governments of its member countries

This document and any map included herein are without prejudice to the status of or sovereignty over any territory, to the delimitation of international frontiers and boundaries and to the name of any territory, city or area.

Please cite this publication as:

van Zanden, J.L., et al. (eds.) (2014), How Was Life?: Global Well-being since 1820, OECD Publishing.

doi: 10.1787/9789264214262-en

ISBN 978-92-64-21406-4 (print)

ISBN 978-92-64-21426-2 (PDF)

The statistical data for Israel are supplied by and under the responsibility of the relevant Israeli authorities. The use of such data by the OECD is without prejudice to the status of the Golan Heights, East Jerusalem and Israeli settlements in the West Bank under the terms of international law.

Corrigenda to OECD publications may be found on line at: www.oecd.org/about/publishing/corrigenda.htm.

(c) OECD, IISH 2014

You can copy, download or print OECD content for your own use, and you can include excerpts from OECD publications, databases and multimedia products in your own documents, presentations, blogs, websites and teaching materials, provided that suitable acknowledgment of the source and copyright owner is given. All requests for public or commercial use and translation rights should be submitted to rights@oecd.org. Requests for permission to photocopy portions of this material for public or commercial use shall be addressed directly to the Copyright Clearance Center (CCC) at info@copyright.com or the Centre français d'exploitation du droit de copie (CFC) at contact@cfcopies.com. 


\section{Foreword}

\section{FOLLOWING ANGUS MADDISON'S FOOTSTEPS}

$I^{2}$ 2001, the OECD Development Centre released Angus Maddison's book, The World Economy A Millennial Perspective, which was soon to become a classic in economic history for statisticians, economists and historians. Angus had a very long association with the Organisation for Economic Cooperation and Development (OECD), which he joined in 1953, and was one of the founding fathers of its Development Centre. This enthusiastic and thought-provoking "chiffrephile" - as he used to call himself - devoted much of his career to quantifying and analysing long-term growth in output as well as achievements in development and social welfare over the past millennium in as many countries of the world as possible. In doing this, he greatly contributed to one of the core missions of the OECD: providing the evidence for policy-making.

We are very pleased today, more than a decade after the release of Maddison's seminal work, to renew our association with his legacy. We do so through a report that both connects with and departs from his contributions to economic history. It connects, due to the report's long-term, global perspective, covering the period 1820-2010. It departs by going beyond GDP to encompass a broader set of dimensions that shape people's living conditions, such as their wages, longevity, education, height and personal security, among others.

The present volume represents the culmination of the efforts undertaken by a group of economic historians as part of an international, inter-disciplinary effort, the Clio-Infra project. We are releasing it in the context of the Better Life Initiative, which was launched by the OECD Secretary-General, Angel Gurría, in 2011 as part of the OECD's mission to design "better policies for better lives". The title of this book (How Was Life?) underscores the close alignment between the life dimensions covered in it and those included in the OECD report on well-being, How's Life? We regard this report as adding an essential historical perspective to our own work to compare countries' performance through a multi-dimensional (and multi-disciplinary) perspective that goes beyond OECD countries, as it is in the tradition of the Development Centre.

Issues of data quality will loom large for any historical report of such breadth and scope. To ensure historical consistency, the authors have relied on data sources and assumptions that are often cruder than those typically made by statistical offices in the production of their modern official statistics. For that reason, the data from the most recent period (e.g. from the 1970s or 1980s) may also differ from those found in OECD and its Development Centre's reports covering the same issues. While we believe that the data presented in this report draw on some of the best sources and expertise currently available to provide a consistent historical perspective, the report is not meant to provide a definitive word on these issues, but rather to encourage other specialists to engage in this field. 
Because of its global, historical and multi-dimensional scope, we hope that this book will continue the legacy of Angus Maddison's work, while providing a useful complement to the OECD Better Life Initiative.

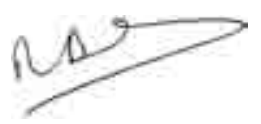

Martine Durand OECD Chief Statistician Director, Statistics Directorate

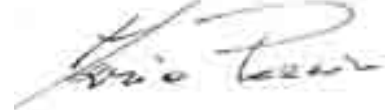

Mario Pezzini

Director, OECD Development Centre 


\section{Table of contents}

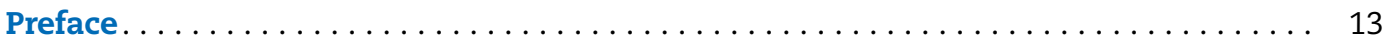

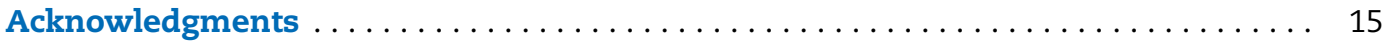

Readers' Guide........................................ 17

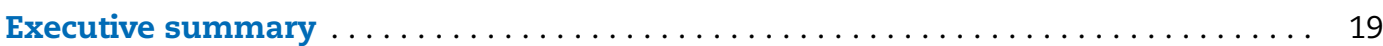

Chapter 1. Global well-being since $1820 \ldots \ldots \ldots \ldots \ldots \ldots \ldots \ldots \ldots \ldots \ldots \ldots$

By Jan Luiten van Zanden, Joerg Baten, Marco Mira d'Ercole, Auke Rijpma, Conal Smith and Marcel Timmer

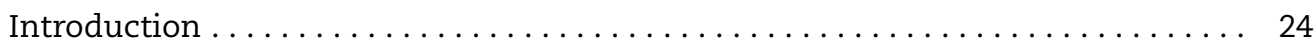

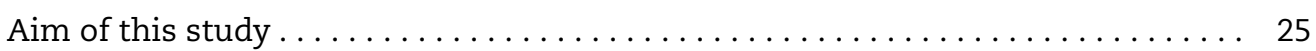

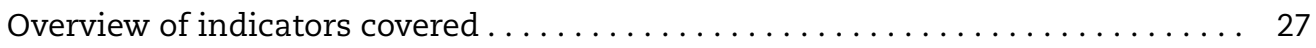

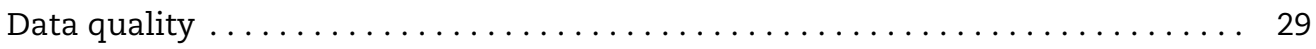

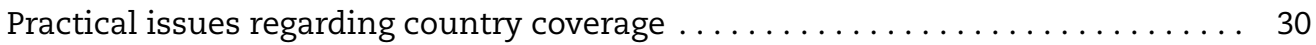

Main highlights .................................... 31

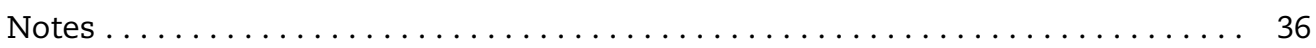

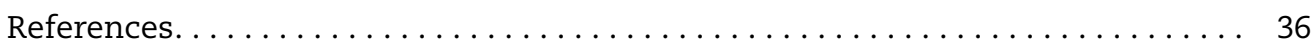

Chapter 2. Demographic trends since $1820 \ldots \ldots \ldots \ldots \ldots \ldots \ldots \ldots \ldots \ldots \ldots \ldots \ldots$

By Lotte van der Vleuten and Jan Kok

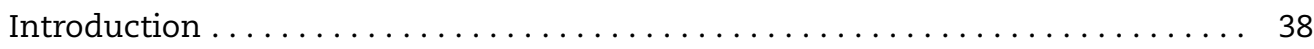

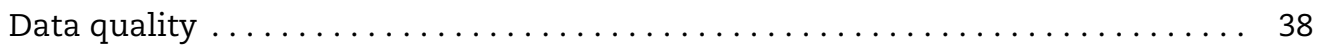

World population 1820-2000: trends and trajectories $\ldots \ldots \ldots \ldots \ldots \ldots \ldots \ldots 41$

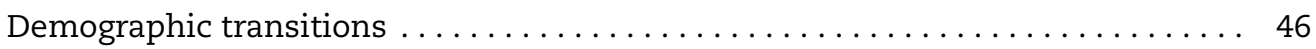

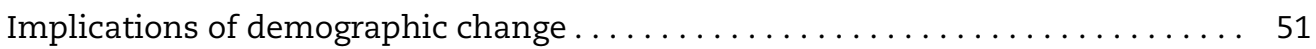

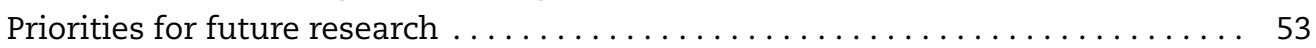

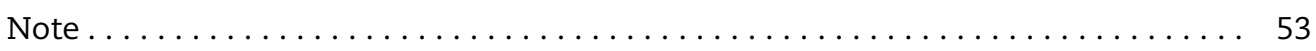

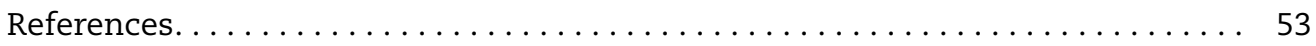

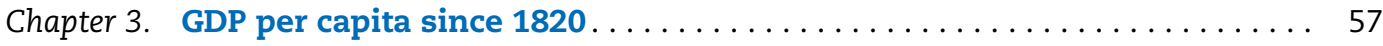

By Jutta Bolt, Marcel Timmer and Jan Luiten van Zanden

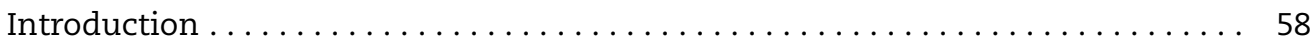

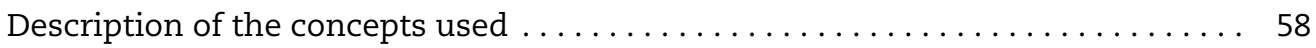

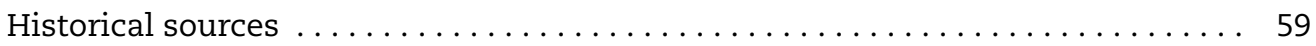

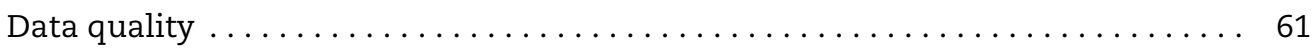

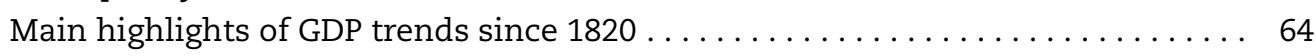

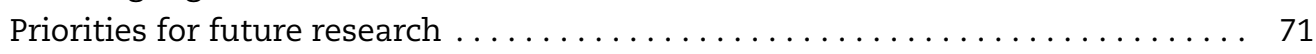

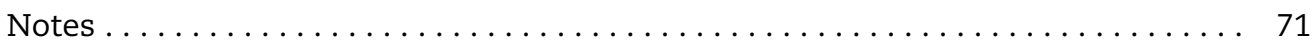

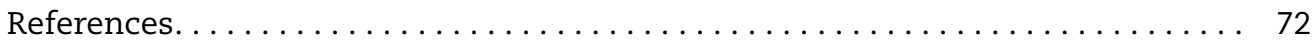




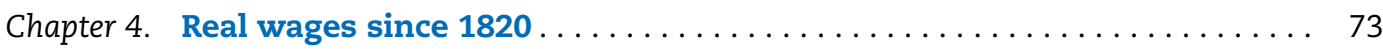

By Pim de Zwart, Bas van Leeuwen and Jieli van Leeuwen-Li

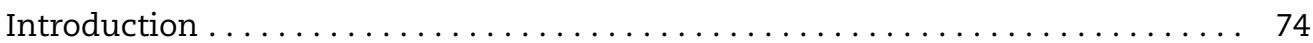

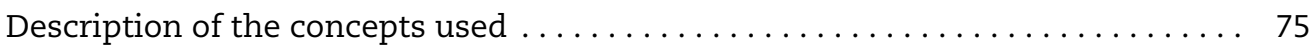

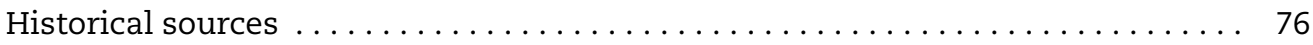

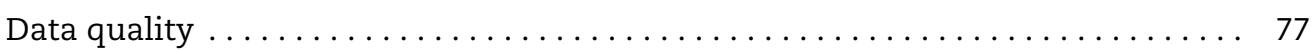

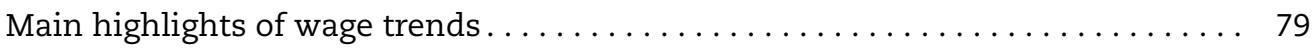

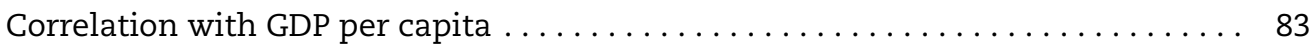

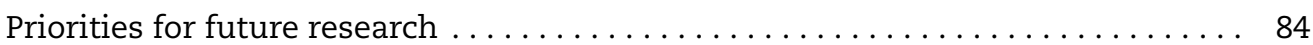

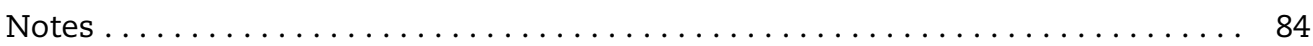

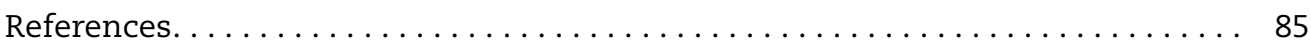

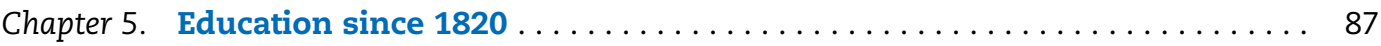

By Bas van Leeuwen and Jieli van Leeuwen-Li

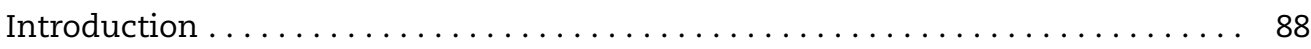

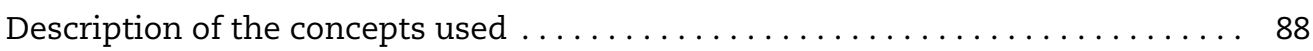

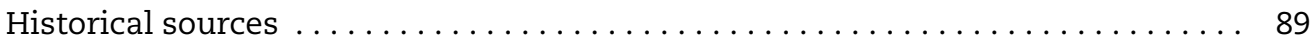

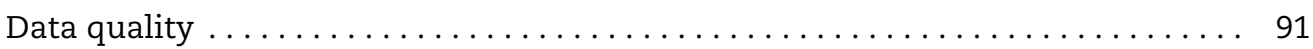

Main highlights of education trends. . . . . . . . . . . . . . . 93

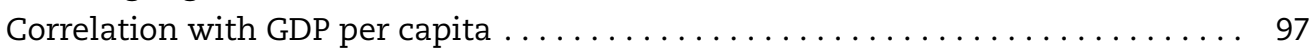

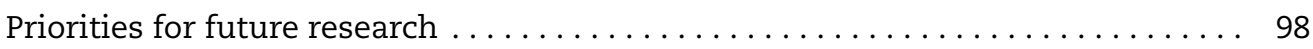

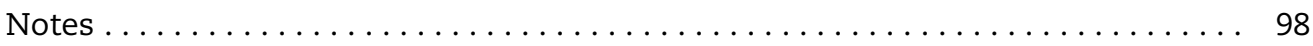

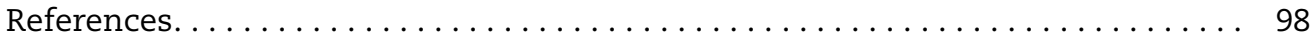

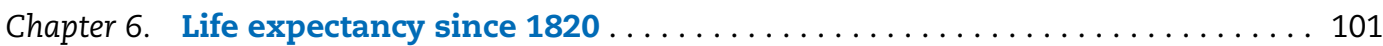

By Richard L. Zijdema and Filipa Ribeiro de Silva

Introduction ........................................ 102

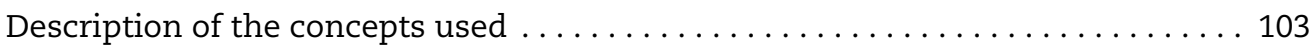

Historical sources . . . . . . . . . . . . . . . . . . . . . . . . . . . . . 104

Data quality . . . . . . . . . . . . . . . . . . . . . . . 104

Main highlights of life expectancy trends $\ldots \ldots \ldots \ldots \ldots \ldots \ldots \ldots \ldots \ldots \ldots \ldots \ldots \ldots \ldots$

Correlation with GDP per capita . . . . . . . . . . . . . . . . . . 110

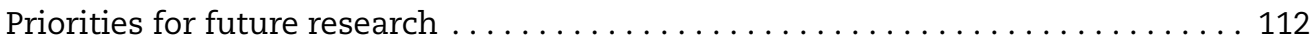

Notes . . . . . . . . . . . . . . . . . . . . . . . . . . . . . . . . . . . . 114

References . . . . . . . . . . . . . . . . . . . . . . . . . . . . . . 114

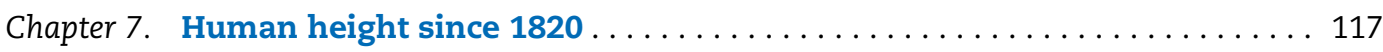

By Joerg Baten and Matthias Blum

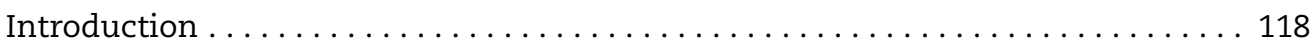

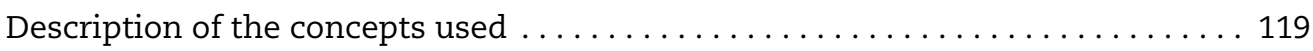

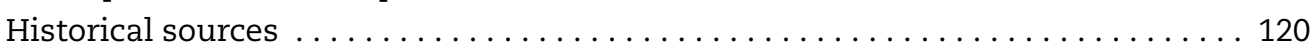

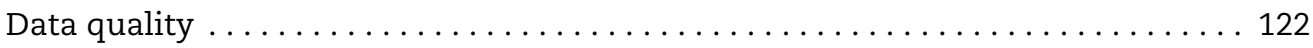

Main highlights of human height trends ...................... 124

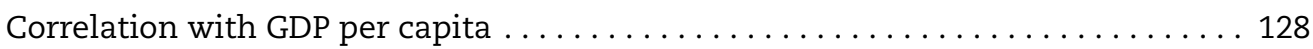

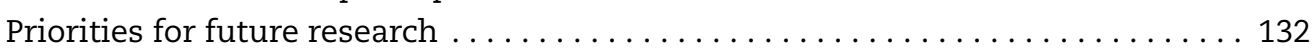

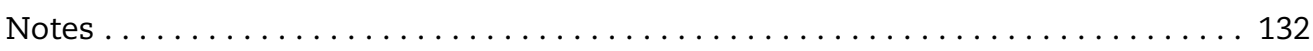

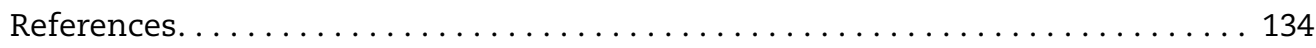




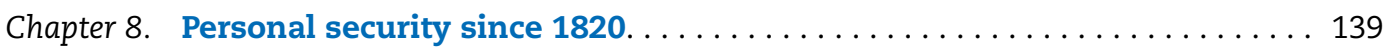

By Joerg Baten, Winny Bierman, Peter Foldvari, and Jan Luiten van Zanden

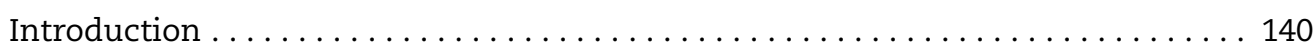

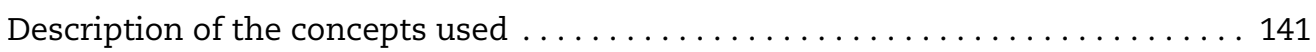

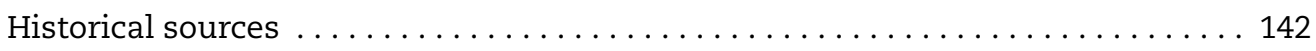

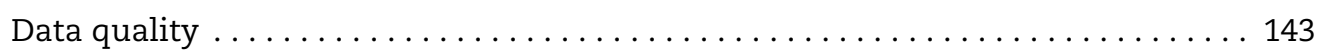

Main highlights of trends in personal security . . . . . . . . . . . . . 145

Correlation with GDP per capita . . . . . . . . . . . . . . . . . . . 154

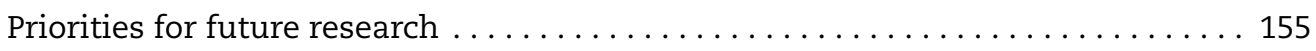

Notes . . . . . . . . . . . . . . . . . . . . . . . . . . . . . 157

References....................................... 157

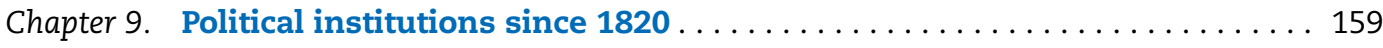

By Peter Foldvari and Katalin Buzasi

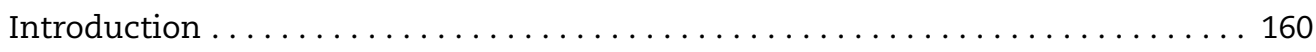

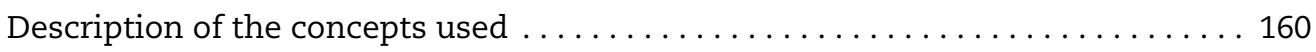

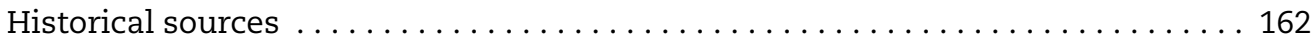

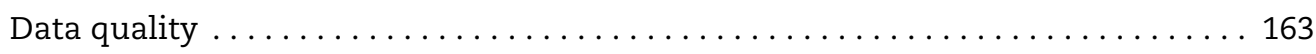

Main highlights of trends in political institutions $\ldots \ldots \ldots \ldots \ldots \ldots \ldots \ldots$

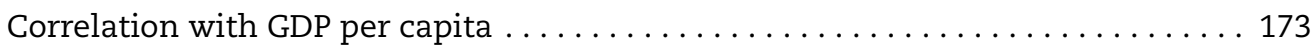

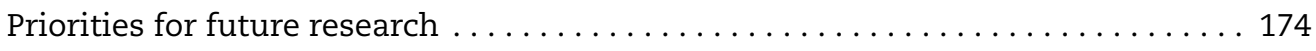

Notes ............................................ 175

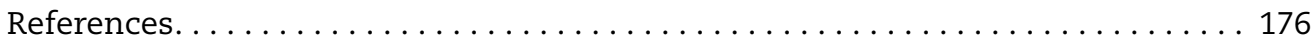

Chapter 10. Environmental quality since $1820 \ldots \ldots \ldots \ldots \ldots \ldots \ldots \ldots \ldots$

By Kees Klein Goldewijk

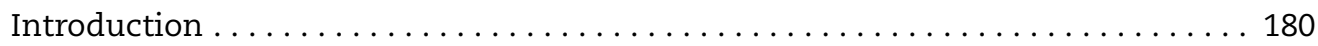

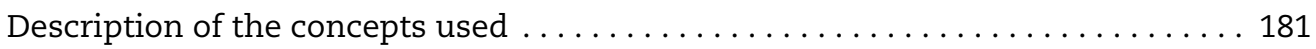

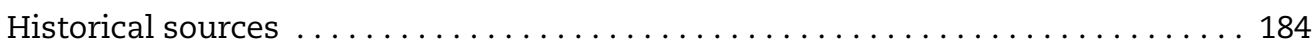

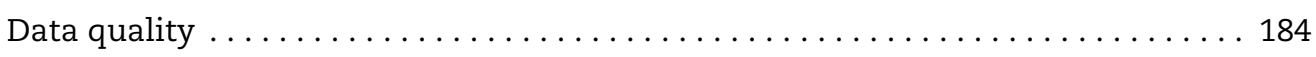

Main highlights of trends in environmental quality ............... 185

Correlation with GDP per capita . . . . . . . . . . . . . . . . . . . 194

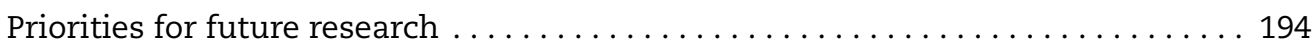

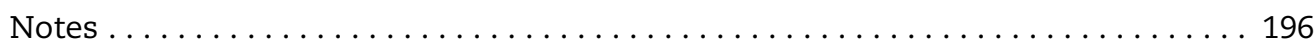

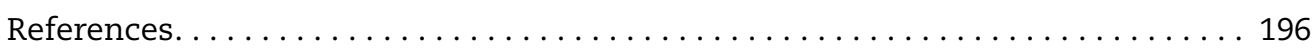

Chapter 11. Income inequality since $1820 \ldots \ldots \ldots \ldots \ldots \ldots \ldots \ldots \ldots \ldots . \ldots \ldots$

By Michail Moatsos, Joerg Baten, Peter Foldvari, Bas van Leeuwen and Jan van Zanden

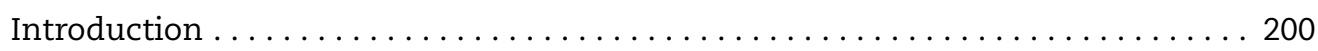

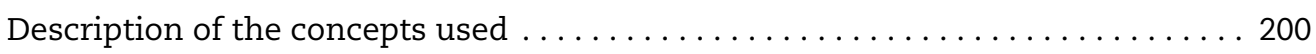

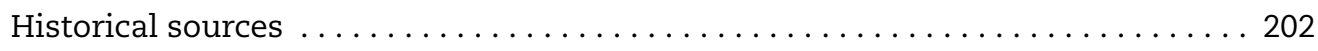

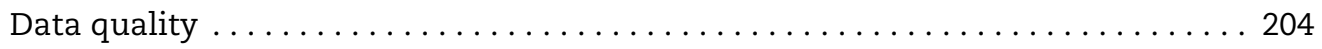

Main highlights of trends in income inequality . . . . . . . . . . . . 205

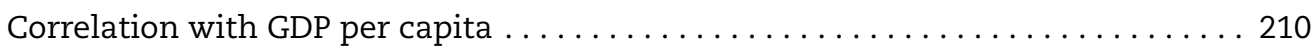

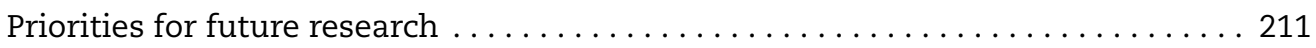

Notes ...................................... 212

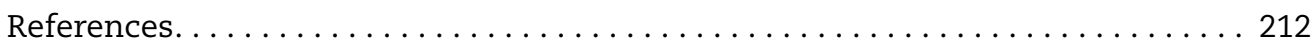




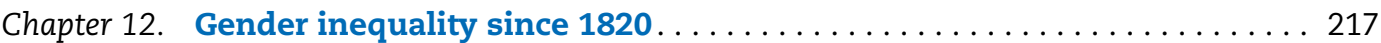

By Sarah Carmichael, Selin Dilli and Auke Rijpma

Introduction . . . . . . . . . . . . . . . . . . . . . . . . . . . . . . . . . . . . . . 218

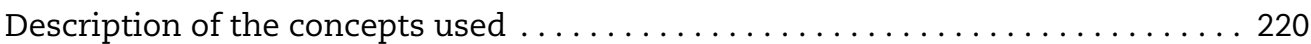

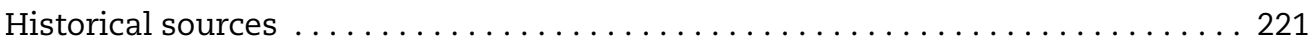

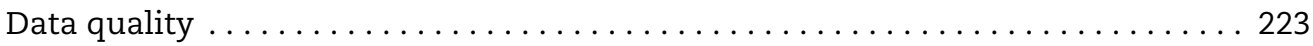

Main highlights of trends in gender inequality. . . . . . . . . . . . . . 225

Correlation with GDP per capita . . . . . . . . . . . . . . . . . . . . . . 239

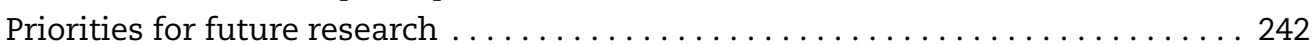

Notes . . . . . . . . . . . . . . . . . . . . . . . . . . . . . . . . . . . . . . . . . . . 244

References........................................... 245

Chapter 13. A composite view of well-being since $1820 \ldots \ldots \ldots \ldots \ldots \ldots \ldots 249$

By Auke Rijpma

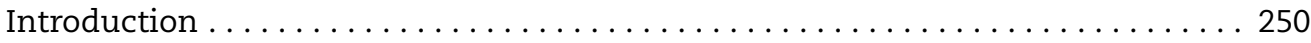

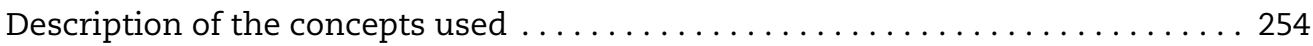

Main highlights of trends in composite indicators of human well-being . . . . . . 257

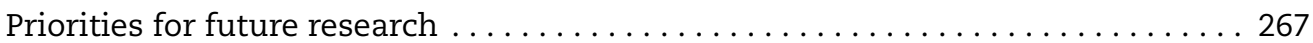

Notes . . . . . . . . . . . . . . . . . . . . . . . . . . . . . . . . . . . . . . . . . . . . 267

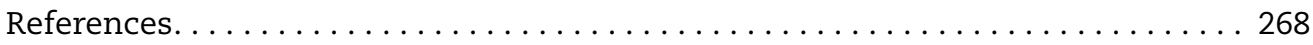

Tables

1.1. Dimensions covered in this volume and in the OECD Better Life Initiative . . . . 29

2.1. Quality of data on population by region and benchmark year, 1820-2008 . . . . . 40

2.2. Quality of data on fertility rates by region and benchmark year, 1820-2008 . . . 41

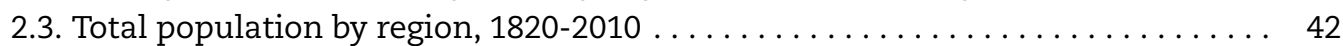

2.4. Total population in selected countries, $1820-2010 \ldots \ldots \ldots \ldots \ldots \ldots \ldots . \ldots 4$

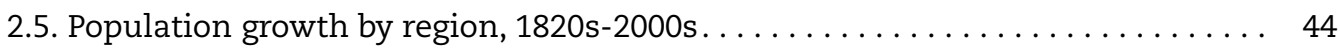

3.1. Quality of data on GDP by region and benchmark year, $1820-2000 \ldots \ldots \ldots \ldots 62$

3.2. Regional averages of GDP per capita, $1820-2010 \ldots \ldots \ldots \ldots \ldots \ldots \ldots \ldots 6$

3.3. Number of countries in GDP dataset by region and year, $1820-2010 \ldots \ldots \ldots \ldots 66$

3.4. GDP per capita in selected countries, $1820-2010 \ldots \ldots \ldots \ldots \ldots \ldots \ldots \ldots .67$

4.1. Content of subsistence baskets in selected regions and countries . . . . . . . 75

4.2. Quality of data on prices and wages by region and benchmark year,

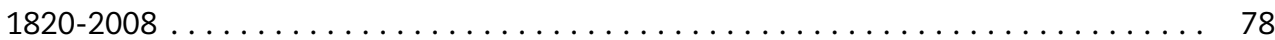

4.3. Labourers' and craftsmen's real wages and skill premium, 1930s-2000s . . . . 79

4.4. Regional averages of real wages of building labourers, 1820s-2000s . . . . . . . 80

4.5. Regional averages of real wages of building craftsmen, 1920s-2000s . . . . . . 80

4.6. Real wages of building labourers in selected countries, 1820s-2000s . . . . . . . 81

5.1. Literacy by years of schooling completed in the United States, 1947 . . . . . . . 91

5.2. Quality of data on years of education by region and benchmark year,

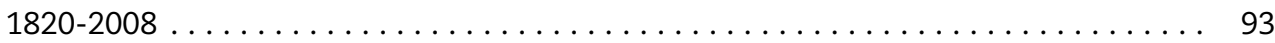

5.3. Population having attained at least basic education by region, $1870-2010 \ldots \ldots 94$

5.4. Average years of education by region, $1850-2010 \ldots \ldots \ldots \ldots \ldots \ldots \ldots$

5.5. Average years of education in selected countries, $1850-2000 \ldots \ldots \ldots \ldots .96$

6.1. Quality of data on life expectancy at birth by region and benchmark year,

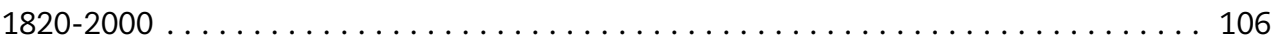

6.2. Regional averages of life expectancy at birth, 1820s-2000s . . . . . . . . . . 108

6.3. Life expectancy at birth in selected countries, 1820s-2000s . . . . . . . . . . . . 109 
7.1. Quality of data on population height by region

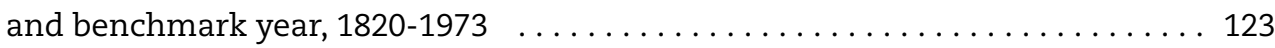

7.2. Regional averages of population height, 1820s $-1980 \mathrm{~s} \ldots \ldots \ldots \ldots \ldots \ldots \ldots . \ldots \ldots$

7.3. Population height in selected countries, 1820s-1980s . . . . . . . . . . . 127

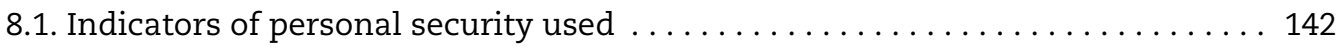

8.2. Quality of data on homicide rates by region and benchmark year,

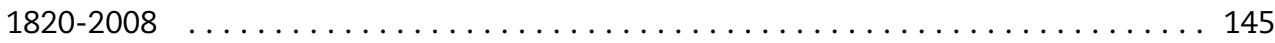

8.3. Long-term development of homicide rates in Europe, 13th-20th centuries . . . 146

8.4. Regional averages of homicide rates, 1820s-2000s . . . . . . . . . . . . . 149

8.5. Number of countries in the homicide dataset by region and decade,

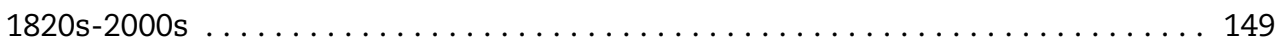

8.6. Homicide rates in selected countries, 1820s-2000s . . . . . . . . . . . . 150

8.7. Number of countries involved in internal and external conflicts,

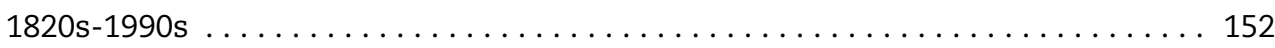

8.8. Probability of inhabiting a country with an internal armed conflict, by region, 1820 s-2000s . . . . . . . . . . . . . . . . . . . . . . 153

8.9. Probability of inhabiting a country with an external armed conflict,

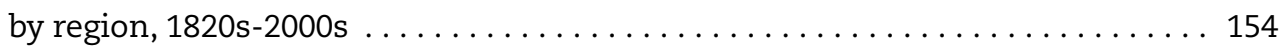

9.1. Indicators to measure democracy: polity2 and Index of Democracy. . . . . . 163

9.2. Quality of data on indicators on democracy . . . . . . . . . . . . . . . 164

9.3. Polity2 democracy indicator in selected countries, $1820 \mathrm{~s}-2000 \mathrm{~s} \ldots \ldots \ldots \ldots . .166$

9.4. Index of Democracy in selected countries, 1820s-1990s . . . . . . . . . . . 168

9.5. Regional averages of polity2 democracy scores, 1820s-2000s . . . . . . . . . 171

9.6. Regional averages of Index of Democracy scores, 1820s-2000s . . . . . . . . 171

9.7. Regional averages of participation scores in democracy, 1820s-2000s . . . . . 172

9.8. Regional averages of competition scores in democracy, 1820s-2000s . . . . . . . 172

10.1. Overview of selected environmental themes in How Was Life? . . . . . . . . . . 181

10.2. Quality of data on $\mathrm{SO}_{2}$ and $\mathrm{CO}_{2}$ emissions by region and benchmark year,

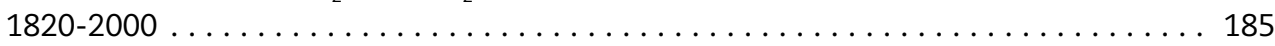

10.3. Quality of data on biodiversity indicator by region and benchmark year,

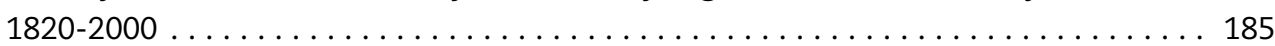

10.4. Regional averages of $\mathrm{SO}_{2}$ emissions per capita, $1820-2000 \ldots \ldots \ldots \ldots \ldots \ldots . \ldots 187$

10.5. $\mathrm{SO}_{2}$ emissions per capita in selected countries, $1820-2000 \ldots \ldots \ldots \ldots \ldots \ldots . \ldots 188$

10.6. Regional averages of mean species abundance, $1820-2000 \ldots \ldots \ldots \ldots \ldots \ldots . \ldots 190$

10.7. Mean species abundance in selected countries, $1820-2000$. . . . . . . . . . . . 191

10.8. Regional averages of $\mathrm{CO}_{2}$ emissions per capita, $1820-2000 \ldots \ldots \ldots \ldots \ldots \ldots . \ldots 192$

10.9. $\mathrm{CO}_{2}$ emissions per capita in selected countries, $1820-2000 \ldots \ldots \ldots \ldots \ldots \ldots . \ldots \ldots$

11.1. Estimates of income inequality by source and year, 1820-2000 . . . . . . . . . 204

11.2. Quality of data on income inequality by region and benchmark year,

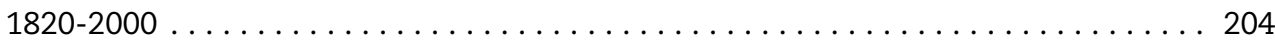

11.3. Income inequality in selected countries, $1820-2000 \ldots \ldots \ldots \ldots \ldots \ldots \ldots 206$

11.4. Gini coefficients of within-country and between-country inequality,

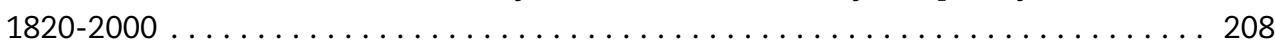

11.5. Regional averages of income inequality, $1820-2000 \ldots \ldots \ldots \ldots \ldots \ldots \ldots . \ldots 210$

12.1. Gender equality indicators, coverage and summary statistics. . . . . . . 222

12.2. Quality of data on ratios of boys to girls, parliamentary seats ratio, and marriage age ratio by region and benchmark year, $1820-2008 \ldots \ldots \ldots \ldots 225$

12.3. Gains in life expectancy at birth by gender, 1950-2000 . . . . . . . . . . . . 231

13.1. Well-being indicators, coverage and summary statistics . . . . . . . . . . 257 


\section{Figures}

1.1. Evolution of GDP per capita and selected well-being indicators, 1820-2000. . . 35

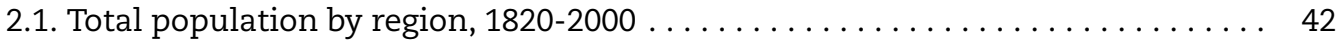

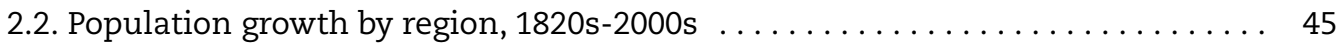

2.3. Regional averages of life expectancy at birth and total fertility rates,

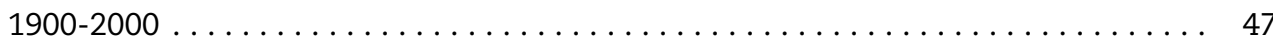

3.1. Regional averages of GDP per capita, $1820-2010 \ldots \ldots \ldots \ldots \ldots$. . . . . . . 68

3.2. Share of employment in manufacturing in selected countries, 1870-2005. . . . 69

3.3. Share of total consumption in GDP in selected countries, 1950-2010 . . . . . . 71

4.1. Regional averages of real wages of building labourers, 1820s-2000s . . . . . . . 82

4.2. Correlation between real wages of building labourers and GDP per capita,

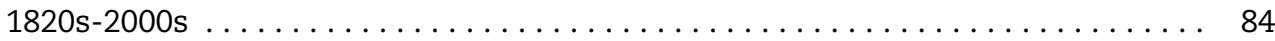

5.1. World development of literacy and attainment of at least basic education,

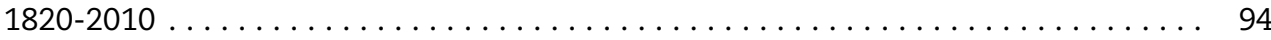

5.2. Correlation between average years of education and GDP per capita,

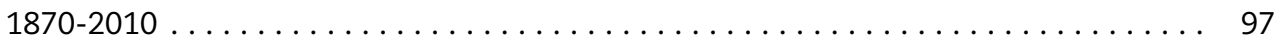

6.1. Regional averages of life expectancy at birth, 1820s-2000s . . . . . . . . . . 107

6.2. Infant mortality and life expectancy at birth in major world regions,

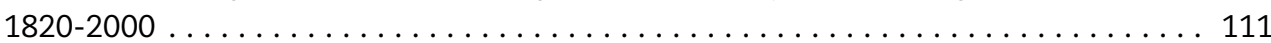

6.3. Correlation between life expectancy at birth and GDP per capita,

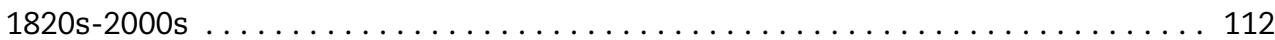

7.1. Regional averages of population height, $1820 \mathrm{~s}-1980 \mathrm{~s} \ldots \ldots \ldots \ldots \ldots$

7.2. Population heights and GDP per capita . . . . . . . . . . . . . . . . . . . . 129

7.3. Correlation between population height and GDP per capita, 1820s-1980s . . . . 131

7.4. Variation in height and GDP per capita in selected countries, 1810s-2000s . . . 131

8.1. Homicide rates in selected Western countries, $1950-2010$. . . . . . . . . . . . . 147

8.2. Worldwide homicide rates, $2000-2009$. . . . . . . . . . . . . . . . . . . . . 148

8.3. Probability of inhabiting a country with an armed conflict, 1820-2000 . . . . . 152

8.4. Correlation between homicide rates and GDP per capita, 1820s-2000s. . . . . . . 155

9.1. Global scores for Index of Democracy and polity2 of the Polity IV project,

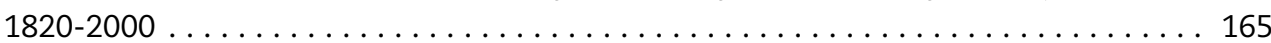

9.2. Index of Democracy: participation and competition, $1820-2000$. . . . . . . . 167

9.3. Correlation between polity2 index and GDP per capita, 1820s-2000s . . . . . . 173

9.4. Correlation between Index of Democracy and GDP per capita, 1820s-1990s . . . 174

10.1. Regional totals of $\mathrm{SO}_{2}$ emissions, $1820-2000 \ldots \ldots \ldots \ldots \ldots \ldots \ldots$

10.2. Regional totals of cropland and pasture, $1820-2000$. . . . . . . . . . . . 189

10.3. Regional totals of $\mathrm{CO}_{2}$ emissions, $1820-2000 \ldots \ldots \ldots \ldots \ldots 2$

10.4. Correlation between $\mathrm{SO}_{2}$ emissions per capita and GDP per capita, 1820-2000 . . . . . . . . . . . . . . . . . . . . . 195

10.5. Correlation between biodiversity (MSA) and GDP per capita, 1820-2000 . . . . 195

10.6. Correlation between $\mathrm{CO}_{2}$ emissions per capita and GDP per capita,

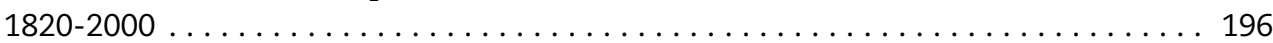

11.1. Global income distributions in selected years, $1820-2000 \ldots \ldots$. . . . . . . . 208

11.2. Correlation between Gini coefficients and GDP per capita in three time

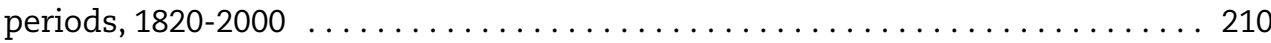

11.3. Correlation between Gini coefficients and GDP per capita, 1820-2000 . . . . . 211

12.1. Average life expectancy at birth, marriage age and average years of education for women and men in the 20th century 
12.2. Countries with gender-equal inheritance, 1920, 1980, $2000 \ldots \ldots \ldots \ldots \ldots 228$

12.3. Countries with female suffrage, 1913, 1950, $2000 \ldots \ldots \ldots \ldots \ldots \ldots \ldots \ldots 229$

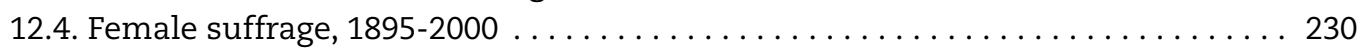

12.5. Ratio of life expectancy at birth of women to men by region, 1900s-2000s . . . 232

12.6. Ratio of girls to boys aged $0-5$ by region, 1900 s-2000s . . . . . . . . . . . . 234

12.7. Ratio of ages at marriage between women and men by region, 1900s-2000s. . . 235

12.8. Ratio of average years of education between women and men by region, 1950s-2000s ........................................ 237

12.9. Ratio of parliamentary seats held by women and men by region, 1900s-2000s ........................................... 238

12.10. Regional averages of the composite gender equality index, 1950s-2000s . . . . 240

12.11. Correlation between gender equality indicators

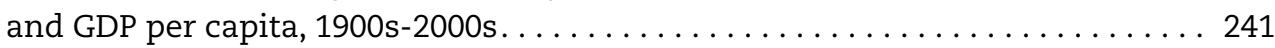

12.12. Various indicators of gender equality and GDP per capita, 1900s-2000s. . . . . 243

13.1. Correlation between well-being indicators and GDP per capita, 1820s-2000s . . 253

13.2. Regional averages of a composite well-being indicator, 1820s-2000s . . . . . . 259

13.3. Regional averages of a composite well-being indicator and standardised GDP per capita, 1820s-2000s. . . . . . . . . . . . . . . . . . . . . . . 260

13.4. Composite well-being indicator by region, latent variable model, 1820s-2000s ......................................... 262

13.5. Composite well-being indicator and GDP per capita in the United Kingdom, China, and India, 1820s-2000s . . . . . . . . . . . . . . . . . . . 264

13.6. Composite well-being indicator across countries, 1850, 1900 and 2000 . . . . . 265

13.7. Segmented relation between a composite well-being indicator and

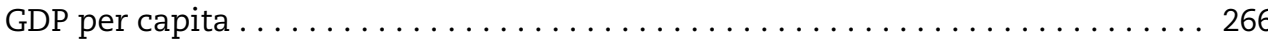

\section{Follow OECD Publications on:}

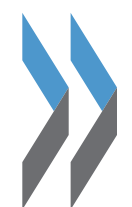

http://twitter.com/OECD_Pubs

f http://www.facebook.com/OECDPublications

in. http://www.linkedin.com/groups/OECD-Publications-4645871

Vout http://www.youtube.com/oecdilibrary

http://www.oecd.org/oecddirect/

\section{This book has...}

StatLinks त्ञात

A service that delivers Excel ${ }^{\circledast}$ files from the printed page!

Look for the StatLinks To download the matching Excel® spreadsheet, just type the link into your Internet browser, starting with the $h t t p: / / d x$.doi.org prefix, or click on the link from the e-book edition. 



\section{Preface}

by

Jan Luiten van Zanden, Utrecht University and Universities of Stellenbosch and Groningen, Joerg Baten, Tuebingen University,

Marco Mira d'Ercole, OECD Statistics Directorate,

Auke Rijpma, Utrecht University,

Conal Smith, OECD Statistics Directorate,

and

Marcel Timmer, University of Groningen

I

In 2011, the Organisation for Economic Cooperation and Development (OECD) published the report How's Life? Measuring Well-Being. This was the flagship publication of its Better Life Initiative, which aims to develop a new approach to the measurement of well-being, stressing its multi-dimensional character. The report was "a first attempt at the international level to go beyond the conceptual stage and to present a large set of comparable well-being indicators for OECD countries and, to the extent possible, other major economies". It was an important contribution to the "GDP and beyond" debate, which in recent years received new impetus from the Stiglitz, Sen and Fitoussi report in 2009.

At about the same time, a group of economic historians set up an international collaborative project to chart the various dimensions of the development of global inequality in the period 1500-2010 in a systematic way, making use of the most recent research carried out within the discipline of economic history. This research project, Clio-Infra, sponsored by the Netherlands Organisation for Scientific Research (NWO), the Royal Academy of Sciences (KNAW) and the universities of Utrecht and Groningen, also included the Maddison project, a collaborative effort to continue the work initiated by Angus Maddison to create a consistent dataset covering GDP, population and GDP per capita for the world economy for the past two millennia. Maddison had always maintained close contact with OECD, which in the 1990s and early 2000s published his major synthetic books on long-term economic growth in the world economy. People at the OECD wondered whether his work would be continued, and approached the Maddison project and Clio-Infra. This volume emerged from talks about how to continue the important work that Maddison pioneered, and how to add a historical dimension to the OECD's Better Life Initiative.

Economic history is a small discipline, with a few thousand professional practitioners doing research and teaching the next generation. Since the rise of "new economic history" in the United States in the 1960s, there has been a strong tendency within the discipline to find inspiration in economic theory and to apply quantitative methods and techniques. However, much of the research focuses on individual countries, regions or firms. For 
example, some economic historians have extensive knowledge about 18th century South Africa, or 19th century Indonesia, but have little ability to produce broader syntheses that are more widely relevant. Recently, global economic history has emerged as a new sub-discipline, posing questions about the "Great Divergence" (between Asia and Europe after the Industrial Revolution), or the continued "underdevelopment" of Africa. In order to answer such global questions, global datasets are required that cover the various dimensions of well-being and its determinants (such as institutions and geography).

As Angus Maddison has demonstrated in the past, such global datasets can be produced only after major efforts in peer-reviewed research and standardisation of the underlying national data. Therefore a collaborative effort is needed to deal with the complexities involved in gathering, systematising and analysing data from a wide variety of disparate sources. This requires teamwork, in which experts on various topics, regions and periods work together to create standardised datasets of key historical variables. This is the approach adopted by both The Maddison Project, which focuses on historical national accounts estimates, and the larger Clio-Infra project, which covers a larger number of dimensions and indicators of economic development and well-being.

This report is the product of collaboration between OECD and the Clio-Infra project to present a multidimensional view, along the lines of the Better Life Initiative, of the development of global well-being since 1820 . We hope that presenting these new data here and online will inspire social scientists to develop a new, more nuanced perspective of long-run changes in the world economy, and of how these changes have affected life for world's people. 


\section{Acknowledgments}

$\mathrm{T}$ his report has been prepared by a team of historians participating in the Clio-Infra project. Individual chapters of the report have been prepared by Lotte van der Vleuten and Jan Kok (Chapter 2); Jutta Bolt, Marcel Timmer and Jan Luiten van Zanden (Chapter 3); Pim de Zwart, Bas van Leeuwen and Jieli van Leeuwen-Li (Chapter 4); Bas van Leeuwen and Jieli van Leeuwen-Li (Chapter 5); Richard L. Zijdeman and Filipa Ribeiro de Silva (Chapter 6); Joerg Baten and Matthias Blum (Chapter 7); Joerg Baten, Winny Bierman, Péter Foldvari and Jan Luiten van Zanden (Chapter 8); Peter Foldvari and Katalin Buzasi (Chapter 9); Kees Klein Goldewijk (Chapter 10); Michail Moatsos, Jan Luiten van Zanden, Joerg Baten, Peter Foldvari and Bas van Leeuwen (Chapter 11); Sarah Carmichael, Selin Dilli, Auke Rijpma (Chapter 12); and Auke Rijpma (Chapter 13). Statistical assistance in the production of tables and figures has been provided by Winny Bierman (Clio-Infra) and Elena Tosetto (OECD), while editorial assistance was provided by Rachel Linden (OECD) and Patrick Hamm. Robertus Oosterwijk prepared Figure 12.1 in Chapter 12. Coordination of the report has been ensured by Jan Luiten van Zanden, Joerg Baten, Auke Rijpma and Marcel Timmer (within Clio-Infra), and by Marco Mira d'Ercole and Conal Smith (OECD Statistics Directorate) and Alexandre Kolev (OECD Development Centre). Linda Westerink and Winny Bierman assisted the Clio-Infra team in organising workshops.

The authors of individual chapters have benefitted from comments provided by the coordinators of the report, by other members of the Clio-Infra team, as well as by participants and discussants at a workshop organised by the OECD in cooperation with Clio-Infra held in Paris on 12-13 December 2013. Special thanks to Herman de Jong (University of Groningen) and Gilles Pison (Institut national d'études démographique, France) for their comments on Chapter 2; Steve Broadberry (London School of Economics) and Jennifer Ribarsky (OECD) for their comments on Chapter 3; Debin Ma (London School of Economics) and Alexandre Kolev (OECD Development Centre) for their comments on Chapter 4; Herman de Jong (University of Groningen) and Fabrice Murtin (OECD) for their comments on Chapter 5; Joerg Baten (Tuebingen University) and Gaetan Lafortune (OECD) for their comments on Chapter 6; Giovanni Federico (European University Institute, Florence) and Nicolas Herpin (Institut national de le statistique et des etudes économiques, France) for their comments on Chapter 7; Pieter Spierenburg (Erasmus University, Rotterdam) and Carlotta Balestra (OECD) for their comments on Chapter 8; Leticia Arroyo Abad (Middlebury College) and Christiane Arndt (OECD) for their comments on Chapter 9; Astrid Kander (University of Lund) and Myriam Linster (OECD) for their comments on Chapter 10; Branko Milanovic (City University of New York Graduate Center) and Michael Förster (OECD) for their comments on Chapter 11; Lex Heerma van Voss (Huygens Institute for the History of the Netherlands) and Gaelle Ferrant (OECD Development Centre) for their comments on Chapter 12; and Kyoji Fukao (Hitotsubashi University, Japan) and Romina Boarini (OECD) for their comments on Chapter 13. 
This report is published under the responsibility of the Secretary-General of the OECD. The opinions expressed and arguments employed herein do not necessarily reflect the official views of the Organisation or of the governments of its member countries. 


\section{Readers' Guide}

\section{Conventions}

- Throughout the report, data shown for world regions and for the world as a whole are population-weighted averages. The coverage of countries typically increases as more country data become available for more recent periods. In order to ensure more meaningful trends for world regions over time, imputations are made for missing countries. This adjustment procedure is explained in Chapter 1.

- Depending on the chapter, the data shown in the tables and figure may refer to either individual years or to decadal averages; in the latter case, the data are shown as "1990s" and the corresponding values are computed as decadal averages of the 1990-1999 period.

- Data quality varies across domains, regions and periods: an assessment of data quality is provided in a summary table within each chapter.

\section{For all figures, the following codes for countries and world regions are used:}

\begin{tabular}{|c|c|c|c|c|c|}
\hline \multicolumn{6}{|c|}{25 countries covered in this volume } \\
\hline ARG & Argentina & GBR & United Kingdom & POL & Poland \\
\hline AUS & Australia & IDN & Indonesia & RUS & Russian Federation \\
\hline BRA & Brazil & IND & India & SWE & Sweden \\
\hline CAN & Canada & ITA & Italy & THA & Thailand \\
\hline CHN & People's Republic of China & JPN & Japan & TUR & Turkey \\
\hline DEU & Germany & KEN & Kenya & USA & United States \\
\hline EGY & Egypt & MEX & Mexico & ZAF & South Africa \\
\hline ESP & Spain & NGA & Nigeria & & \\
\hline FRA & France & NLD & Netherlands & & \\
\hline \multicolumn{6}{|c|}{ World regions } \\
\hline WE & Western Europe & LA & Latin America and Caribbean & EA & East Asia \\
\hline EE & East Europe and former Soviet Union & SSA & Sub-Saharan Africa & SSEA & South and South East Asia \\
\hline wo & Western Offshoots & MENA & Middle East and North Africa & & \\
\hline
\end{tabular}

- Historical data labelled RUS may sometimes refer to data covering the former Soviet Union. When this occurs, it is mentioned in notes to the tables and figures.

- This document and any map included herein are without prejudice to the status of or sovereignty over any territory, to the delimitation of international frontiers and boundaries and to the name of any territory, city or area.

Signs and abbreviations: (..) is used to indicate missing values. 

How Was Life?

Global Well-being Since 1820

(c) OECD, IISH 2014

\section{Executive summary}

$\mathrm{H}$ development since the Industrial Revolution is to a large extent based on the evidence produced by historical national accounting in the tradition of Simon Kuznets and Angus Maddison. But trends in gross domestic product (GDP) per head do not fully reflect the various dimensions of well-being, such as life expectancy, education, personal security or inequality. Increasingly, measures of current human development are framed in terms of well-being rather than in solely economic terms, but can we do the same for the lives of our ancestors?

Economic historians and other social scientists have been producing data that cover non-material dimensions of well-being for some years, but so far they have not been compared systematically over time and space. There may be information on life expectancy in some European countries in the 19th century, for example, but it has not been possible to compare them with figures for Africa. As a result, most studies charting long-term development trends in the world still rely heavily on estimates of per capita GDP. This report aims to fill this gap. It presents for the first time systematic evidence on long-term trends in global well-being since 1820, providing estimates for a large sample of countries. Trends are charted for 25 countries, 8 world regions and the world economy as a whole. This is done by collecting, harmonising and documenting state-of-the-art estimates developed through the Clio-Infra project. This report presents the data and discusses data sources and limitations, provides an overview of trends, and pinpoints avenues for further research.

The report examines 10 individual dimensions of well-being, tracking them over time and space, then pulls them together in a new composite indicator. The dimensions covered reflect a broad range of material and non-material aspects of well-being: per capita GDP, real wages, educational attainment, life expectancy, height, personal security, political institutions, environmental quality, income inequality and gender inequality. Obviously, the data quality will differ across indicators, time and countries. This report presents the various historical datasets for each specific dimension of well-being, discusses their limitations and indicates where further progress can be made.

These new data open up the possibility to chart developments of well-being around the world in the past two centuries. They can be used to analyse the broad development paths of individual countries, or to analyse differences in performance across countries in one particular dimension. Due to its comprehensive and broad coverage in time and space, the data in this report allow asking broader questions. Does this new way of looking at human development give a fundamentally different picture from the one based on 
GDP estimates? Was the world more or less unequal if we look through the prism of wellbeing rather than of GDP? This report provides some initial answers by systematically investigating the correlations between GDP per capita and each of the other dimensions of well-being. Needless to say, statistical correlations are silent on possible causalities; they provide, however, a first necessary step towards a better understanding of complex relationships between the various facets of well-being and their determinants.

\section{Main findings}

The book provides evidence on historical trends in 10 different dimensions of wellbeing. For some of these dimensions the statistical correlation with the evolution of GDP per capita is strong. Education (as measured by literacy and educational attainment) and health status (as measured by life expectancy and height) improved strongly in many countries in the world, and there is a strong cross-section and over-time correlation with GDP per capita. Around 1820, less than 20\% of the world population was literate and this group was heavily concentrated in Western Europe. Literacy rates and schooling dramatically increased after 1945 in many regions in the world, reaching around 80\% of the world population in 2000. Life expectancy at birth was about 33 years in Western Europe around 1830, 40 years in 1880, and almost doubled in the period after, with the largest improvements occurring in first half of the 20th century. In the rest of the world, life expectancies started to increase from much lower levels, rising in particular after 1945. Worldwide life expectancy increased from less than 30 years in 1880 to almost 70 in 2000. There is strong evidence of a shift in the relationship between health status and GDP per capita over the past two centuries. Life expectancy improved around the world even when GDP per capita stagnated, due to advances in knowledge and the diffusion of health care technologies.

The statistical correlation with GDP per capita was much weaker for other well-being dimensions. Political institutions (as measured by electoral participation and competition) have greatly improved around the world in the past century. But their development was far from gradual, with sometimes violent swings in political rights in some countries. Also differences across countries in personal security (measured by homicide rates and exposure to conflict) do not correlate well with GDP per capita. Western Europe was already quite peaceful from the 19th century onwards, but homicide rates in the United States have been relatively high throughout the period considered. Large parts of Latin America and Africa are also violent crime "hotspots", and so is the former Soviet Union (especially since the fall of communism), while large parts of Asia show low homicide rates.

A negative correlation with GDP per capita is clearly in place when looking at quality of the environment. Biodiversity declined in all regions and worldwide as land use changed dramatically. Per capita emissions of $\mathrm{CO}_{2}$ increased after the industrial revolution in Western Europe and its Offshoots, accelerating in the mid-20th century as other regions increased their GDP, and is still increasing globally. Per capita emission of $\mathrm{SO}_{2}$ (a local pollutant) also increased alongside higher industrial production, but were curbed since the 1970s thanks to the advent of cleaner technologies.

Long-term trends in income inequality, as measured by the distribution of pre-tax household income across individuals, followed a U-shape in most Western European countries and Western Offshoots. It declined between the end of the 19th century until about 1970, followed by a rise. In Eastern Europe, communism resulted in strong declines 
in income inequality, followed by a sharp increase after its disintegration in the 1980s. In other parts of the world (China in particular) income inequality has been on the rise recently. The global income distribution, across all citizens of the world, was uni-modal in the 19th century, but became increasingly bi-modal between 1910 and 1970 and suddenly reverted to a uni-modal distribution between 1980 and 2000.

Gender inequality as measured by outcomes in health status, socio-economic status and political rights, has been on a declining trend over the past 60 years in most world regions. Only in East Asia and in Eastern Europe has the decline in gender inequality stalled since the 1980s. Differences in levels of gender inequality across regions remained, however, significant: Europe (including Eastern Europe) and the Western Offshoots performed best (albeit no country reached full gender equality). The Middle East and North Africa (mainly due to weak political rights) and South and Southeast Asia (due to skewed sex ratios at birth) performed worst.

The Composite indicator of well-being presented in this report indicates that progress in well-being has been widespread since the early 20th century, with the possible exception of Sub-Saharan Africa. The evidence presented in this report also suggests that since the 1970s between-country inequality in composite well-being has been lower than in GDP per capita, while being more pronounced in the period before.

Overall, this book collects, summarizes and critically discusses our current knowledge on long-term trends in global well-being over the past two centuries. While it provides a better view than one based on GDP per capita alone, weak spots remain in our knowledge, in particular concerning development in Africa before 1950 and in major Asian countries in the 19th century. It is hoped that this book will stimulate further research into these areas. 



\title{
Chapter 1
}

\section{Global well-being since 1820}

\author{
by \\ Jan Luiten van Zanden, Utrecht University, \\ Joerg Baten, Tuebingen University, \\ Marco Mira d'Ercole, OECD Statistics Directorate, \\ Auke Rijpma, Utrecht University, \\ Conal Smith, OECD Statistics Directorate \\ and \\ Marcel Timmer, University of Groningen
}

This chapter provides an introduction to, and summary of, the contents of this book. It outlines the aim of the project and provides an overview of the indicators covered, comparing them with those used in the OECD Better Life Initiative. The chapter also presents the criteria used throughout the report to assess the quality of the indicators used, and discusses practical issues concerning country and period coverage and calculation of regional trends. Finally, the chapter summarises the content of each chapter and their main highlights. 


\section{Introduction}

Global inequality in well-being across countries has been one of the persistent features of the world economy since, at least, the Industrial Revolution that began some 200 years ago. Around 1820 average real incomes in the richest regions in the world economy were at most about five times the levels in the poorest regions. And, as shown in this volume, the spread in terms of other welfare measures was even smaller. Since then a "Great Divergence" has occurred, resulting in the massive levels of inequality that characterise the world today. This has been a key issue addressed by the economics profession ever since Adam Smith wrote Wealth of Nations. Divergence is not a state of nature, however. We live in historical times and, from today's standpoint it would seem that, due to the rapid growth of real incomes in China, India and Africa the trend towards worldwide inequality reached a peak around the end of the 20th century (see Chapter 11). This suggests that we may be entering a new phase in the development of the world economy characterised by the catching-up of lagging regions instead of the forging ahead of advanced nations.

A great deal of what we know about long-term trends in welfare is based on the pioneering historical estimates of real gross domestic product (GDP) by Angus Maddison, summarised in his books The World Economy - a Millennial Perspective (2001) and The World Economy - Historical Statistics (2003). In his view, which is confirmed by more recent research, Western Europe was already much wealthier than the rest of the world at the start of the industrialisation process (i.e. around 1820). However, the ratio between the United Kingdom, the "productivity leader" at the time, and the poorest parts of the world was at most 5 to 1. The 19th century was a period of divergence, during which the rich became richer Western Europe and its Offshoots (the United States, Canada, Australia) profited from the technological changes unleashed by the Industrial Revolution, whereas other parts of the world economy (China, India, Indonesia) saw their GDP per capita fall or stagnate at best, due in part to de-industrialisation and colonial exploitation. During the first half of the 20th century, it was mainly the United States that forged ahead, but the Atlantic income gap that emerged as a result narrowed again during the post-war boom between 1950 and 1973. Gradually, other parts of the world also began to participate in the process of modern growth, sometimes helped by decolonisation. In particular East Asia fared well after the 1960s, and became the most dynamic centre of the world economy after 1980 when China also joined the convergence club. But economic growth in Africa has been much more incidental, and this continent has continued to lag behind the rest of the world economy. In this volume, we try to find out whether these patterns based on GDP are confirmed when we broaden the scope of analysis and include a number of other indicators reflecting broader trends in well-being.

The measurement of welfare by levels of GDP has been criticised for quite a long time, and this debate has in recent years received new impetus from the Stiglitz, Sen and Fitoussi report (2009). There is today an increasing awareness that GDP figures provide only a partial perspective on the multi-dimensional nature of well-being - what matters to people's 
lives. Many old and new indicators of quality of life, such as life expectancy and level of schooling, have been suggested to supplement GDP estimates. Much progress has been made in deriving complementary summary measures, such as the Human Development Index (HDI) of the UNDP (e.g. UNDP, 2010), and in constructing scoreboards on headline indicators, such as the one used by the OECD in its Better Life Initiative (e.g. OECD, 2013). This volume contributes to this debate by taking a long-term perspective of trends in wellbeing and development, and by systematically looking into the often-changing relationship between GDP per capita and these other indices of well-being. This long-term perspective is taken from today's standpoint (i.e. based on those concerns that most of today's observers would regard as critical to a good life) and is informed by statistical indicators that, while not always satisfying all of the present-day requirements for good quality statistics, provide the best long-term comparative assessment of the issues at hand.

\section{Aim of this study}

The aim of this volume is to provide a truly long-run perspective on measures of well-being that complement GDP per capita. Notwithstanding a few exceptions, most of the existing compilations of historical data cover the period since the Second World War. This report provides a variety of additional time-series going back to 1820, covering a wide range of countries in all regions in the world. We take the work done by Maddison and his co-workers as the starting point, and in Chapter 2 present the latest findings about changes in real GDP in the world economy over the past 200 years. The concept of GDP and related concepts such as national income have been used and (therefore) criticised so much that we sometimes forget what a good idea it was - and still is - to measure GDP when we want to a have a comparable indicator of economic output over time and across countries. GDP measures the quantity of goods and services produced (within the boundaries of the System of National Accounts) in a given country and year. It provides (subject to a number of conditions) a good proxy of the degree to which people in a certain society have command over goods and services, which is clearly a vital ingredient of their economic well-being. Economic historians consider the "sustained growth" of per capita output to be the most significant feature of the "modern" economy as it came into existence after the Industrial Revolution, as this phenomenon offered opportunities for improvement in many areas of life, such as health status and education. It is economic growth - driven by investment and technological change - that ultimately lifted a substantial part of the world population out of the mass poverty of the pre-industrial world. But how well did GDP per capita correlate with other indicators covering other dimensions of well-being? In certain cases, progress in health and life expectancy, or in access to education, may have been much faster than the increase of GDP per capita (perhaps due to autonomous changes in medical technology or in government policy regulating the schooling system). In other cases, during early industrialisation for example, improvements in the typical citizen's well-being may have seriously lagged behind economic growth, perhaps due to increased inequality within a country. In order to understand more fully the long-term patterns of development of the world economy, a much broader perspective on people's well-being is required. This is the overarching theme motivating our work.

The subsequent chapters present indicators for other dimensions of well-being, including the real wages of unskilled labourers (to capture trends at the bottom of the income pyramid), life expectancy, height, educational attainment, the quality of institutions (including human and political rights), gender inequality and income inequality. In 
addition, indicators of environmental stress are also presented. These various indicators of well-being have been constructed in a systematic way, with a particular emphasis on comparability both across countries and over time, in a truly Maddisonian tradition. The choice for particular indicators has been inspired by the multi-dimensional approach to well-being used in the OECD Better Life Initiative. The focus of the report is on the period after the Industrial Revolution, when the process of global divergence clearly accelerated, and because historical data and estimates are relatively abundant for this period. ${ }^{1}$ Based on these indicators, we provide a set of stylised trends that cover the entire world economy and all major regions. Data limitations put certain constraints on the indicators and countries that could be covered, but thanks to the ingenuity of historians working with a large variety of sources, we have been able to reconstruct various dimensions of well-being in a hopefully convincing way.

We believe that there is added value in developing long time-series of well-being indicators, beyond simply satisfying historical and scientific curiosity. Their usefulness derives from the increasing recognition that the processes of economic growth and development have deep historical roots. First of all, it has been found that many differences in well-being already existed before the Second World War and are highly persistent. Institutional differences have a similar persistence, as much of the recent literature on this topic illustrates. There is also a rapidly growing economic literature suggesting that "history matters", and that this is equally relevant for countries which have changed track and shown "unexpected" success in generating well-being for their citizens. The East Asian economies, Japan at first, gradually followed by Korea, Singapore, and China, are cases in point. Has the East Asian economic miracle resulted in equally dramatic increases in well-being? How should India's performance be assessed? And how does the United States compare in the long run with continental Western Europe, with its different socio-political institutions? These are some of the questions we can start answering on the basis of the historical data presented here.

The underlying ideas for approaching well-being are most clearly expressed by Sen (see for instance 1993) and Nussbaum (2000). The theoretical framework designed by Sen is based on the distinction between functionings and capabilities. Functionings can be interpreted as a person's actual achievements, i.e. what he or she manages to do or be. In other words, they comprise an individual's activities and his or her states of being, for example, being in a good health, being able to move freely, etc. Capabilities are the individual's real abilities to achieve these functionings, i.e. the person's freedoms to choose between different ways of living (Kuklys and Robeyns, 2004). The novelty and the advantage of this approach is that it breaks with the traditional utility or resource-based views of well-being that relate economic welfare to income or wealth, thereby enabling us to view life as a combination of various "doings and beings", with quality of life assessed in terms of the capability to achieve valuable functionings (Sen, 1993). While theoretically appealing, this framework is difficult to implement in empirical investigations. Therefore, Nussbaum (2000) identified ten different groups of capabilities that fit Sen's framework and helped to overcome the measurement-related problems to some extent. ${ }^{2}$ Some of these capabilities relate to the dimensions of well-being used by the OECD in its report How's Life? and also identified here. For example, the capabilities "Life" and "Bodily health" can be measured by "Life expectancy" (Chapter 5) and by "Height" (Chapter 6). Similarly, "Bodily integrity" is related to "Personal security" (Chapter 7), "Ability to control his or her environment" 
is related to "Political rights" (Chapter 9) and "Environmental quality" (Chapter 8) reflects Nussbaum's capability “Other species”.

\section{Overview of indicators covered}

The choice of indicators has been guided by three considerations: first, the theoretical literature such as Nussbaum's list of capabilities; second, the OECD's How's Life? report, to which this book adds an historical dimension; and third, the availability of historical and international comparative datasets. Table 1.1 provides an overview of the indicators covered in this volume. Each indicator is covered in a separate chapter and reflects a particular dimension of well-being. Most chapters focus on one key indicator (such as GDP per capita), but a single headline indicator is not available for all fields. Other chapters therefore present two indicators (for example, Chapter 9 presents two measures of political rights), or proxies covering various approaches to the dimension of well-being considered (for example, gender inequality is measured in this report in a number of complementary ways).

The topics covered in this report mirror the dimensions of well-being distinguished in the OECD's How's Life? report (see Table 1.1 below). Because of data limitations, this report does not cover housing conditions, work-life balance and social connections, which were included in the OECD report; conversely it includes separate chapters on gender and income inequalities over time. ${ }^{3}$ One further limitation of this historical report is that it does not cover subjective well-being - happiness, for example - for societies in the more distant past, as the types of surveys that are used today to elicit people's self-reports of their subjective well-being obviously did not exist then. The coverage of indicators is therefore somewhat different from the dimensions that feature in the How's Life? report, but the aim (i.e. to present a more balanced, multi-dimensional picture of well-being) is the same.

Below we introduce each indicator in turn, and briefly discuss the rationale for choosing it. Chapter 2, on demographic trends, set the stage for the rest of the volume by providing a brief summary of the development of the world's population between 1820 and the present. Next follow chapters providing evidence on the various dimensions of wellbeing:

- GDP per capita discusses the trends in economic growth in the world economy, based on the (updated) Maddison dataset (Chapter 3).

- Real wages supply an additional angle on material welfare, approached as the real wages of unskilled labourers: how much did they profit (or not) from GDP growth? (Chapter 4).

- Education is a basic ingredient of well-being; the chapter presents new data on the degree of schooling of the world's population (Chapter 5).

- Life expectancy, reflecting the health status of the population, is another fundamental dimension of people's capabilities (Chapter 6).

- Height is an important proxy for the quality of people's bodily health and nutrition, in particular during childhood (Chapter 7).

- Personal security - measured by the homicide rate and the incidence of warfare - is another major determinant of well-being reflecting "bodily integrity" (Chapter 8).

- Political institutions allow people to participate in political decision-making, and therefore to control their political environment (Chapter 9). 
- Environmental quality is obviously of great relevance for long-term well-being and shapes the sustainability of economic growth over time (Chapter 10).

- Income inequality relates to the distribution of income within countries and has a direct and indirect impact on well-being (Chapter 11).

- Gender inequality strongly affects the well-being of at least half, if not all of the world's population (Chapter 12).

- Composite views of well-being are discussed in the final chapter, which also summarises the key results of the volume (Chapter 13).

The availability of historical and international comparative datasets varies across indicators. The first two indicators, GDP per capita and real wages, are the workhorses of economic history for which large datasets are available. Both cover dimensions of material living conditions and nicely supplement each other: GDP per capita measures the average level of economic output and income, while real wages reflect the incomes of the bottom of the income pyramid. Income inequality is covered in Chapter 11. A second set of chapters focuses on quality of life (i.e. the non-material aspects of well-being), such as educational attainment (Chapter 5); life expectancy (Chapter 6); the "biological standard of living" as proxied by the development of the population's height (Chapter 7); personal security (Chapter 8); and political rights (Chapter 9). For all these dimensions, relatively good historical data are available making it possible to chart long-term trends, albeit for a more limited set of countries. Chapter 10 presents historical estimates of various indices of environmental quality, such as (the loss of) biodiversity and the increase of pollution $\left(\mathrm{SO}_{2}\right)$ : while this chapter covers many countries, the historical data are rather weak and relies mostly on model estimates. To trace gender inequality in Chapter 12, relatively good historical data are available. Chapter 13 describes long-term trends in overall well-being using a number of different ways of aggregating the trends highlighted in the previous chapters. This final chapter, which is highly experimental, aims to demonstrate that steps can be taken to provide a comprehensive measure of the long-term trends in well-being.

All the chapters present state-of-the-art datasets on the development of different dimensions of well-being, many of which are the result of recent research by the Clio-Infra team in cooperation with experts in specific fields (such as in the Maddison project). Often this research has already resulted in publications in international journals (see the lists of publications in the various chapters). There are different research traditions to build on: scholarly work on historical national accounting is well established since the 1950s, but similar research on, for example, long-term trends in personal security or environmental quality started only recently. This obviously also affects the quality of the historical datasets presented here. This report not only reviews the data and historical sources for the dimensions of well-being, but also challenges researchers to expand the available datasets and produce more high-quality data.

The unit of observation is, as in most comparative studies, the country, and this report typically presents average values per country. The data used for this report are available online through the Digital Object Identifier (DOI) link appearing just underneath the sources of each table and chart. More detailed and complete datasets are available on the Clio-Infra website (www.clio-infra.eu). 
Table 1.1. Dimensions covered in this volume and in the OECD Better Life Initiative

\begin{tabular}{ll}
\hline How Was Life? & How's Life? \\
\hline Income (GDP) & Income and wealth \\
Income inequality & Housing \\
(measures not available) & Jobs and earnings \\
Real wages & Health status \\
Life expectancy & Work-life balance \\
Height & Education and skills \\
(measures not available) & Social connections \\
Education & Personal security \\
(measures not available) & Civic engagement and governance \\
Personal security & Environmental quality \\
Institutions & Subjective well-being \\
Environmental quality & (covered in other chapters) \\
(measures not available) & \\
Gender inequality & \\
\hline Overall indicator of well-being & \\
\hline
\end{tabular}

\section{Data quality}

Much effort has been put into making the data comparable over time and space. But obviously, one is constrained by the amount and quality of the available historical sources. In order to help assess the quality of the data presented in this report, each chapter includes a table providing our own assessment. The data quality is assessed in terms of three criteria, i.e. credibility (the degree to which the sources of the data can be confidently relied on), accuracy (the extent to which the data are valid and reliably represent what they purport to measure), and comparability across countries (the extent to which data from different sources are collected under the same methodology and measure the same concept). Each chapter includes separate tables illustrating how data quality varies over time and across countries. Four classes of data are distinguished:

1. High-quality data are the product of an official statistical agency (national or international) or of using techniques that ensure equivalent credibility; high standards of accuracy are maintained, and data are collected by a consistent methodology for different countries;

2. Moderate-quality data are the product of historical research using sources and methods comparable with, but not necessarily similar to those applied by official statistical agencies; consistency over time and across countries is generally good, but there may be some small issues.

3. Low-quality data result from historical research in a data-scare environment that inevitably makes use of indirect data and estimates, resulting in some loss of accuracy; not all country estimates are based on data collected with the same methodology

4. Estimates data are those based on "guestimates", conjectures, and interpolation between benchmark years, where there may be significant inconsistencies between countries or gaps in coverage.

Various indicators sets are constructed within the framework of an international standard. For example, in the chapter on GDP per capita use is made of the results of the International Comparison Project (ICP) on estimating Purchasing Power Parities (PPPs) to 
generate a consistent system of (inter)national income accounts. In the chapter on real wages, the international standardisation method developed by Allen (2001) and Allen et al. (2011) is used to measure real wages as the number of subsistence-budgets that can be bought by an unskilled labourer. There are similar standards in the measurement of institutions and civil rights (such as the PolityIV dataset). This work is reflected in the chapters, which explain in detail which concepts are actually used and measured, and how international comparability is achieved. In many cases, the chapters refer to underlying working papers that give more details of the estimations involved.

For recent years, this report makes use as much as possible of OECD data, but it is not always possible to link recent datasets to the historical evidence collected and presented here. Therefore small discrepancies between the data presented here and in comparable OECD publications might exist for some series starting in the 1970s or 1980s.

\section{Practical issues regarding country coverage}

The unit of observation is, as in most comparative studies, the country, more specifically the 19th-21st century nation state. One of the recurrent issues in historical research is the changing borders of the countries that are studied. Germany in 2013 is different from Germany in 1989, 1938 and 1913 - not to mention Germany before 1871. This applies to almost all the countries covered, although not to the same extent. There are in principle two solutions to this problem. The first is the one used by Maddison, who created a dataset for GDP and population by taking the borders of 1990 as the starting point and correcting for changes in borders whenever these occurred. The second is to simply accept differences in countries' borders over time. This report relies on a combination of both approaches. In the chapters on GDP, income inequality and environmental quality, we have used the first method. In the other chapters, it was not possible to adopt the same approach, and we measure the level of democracy of actual states or the homicide rate in the historically existing countries. So, for 1913 or 1820 the Germany that is referred to in Chapter 3 is somewhat different from the Germany of Chapter 9. There are similar problems for most other countries, though these are usually of a much smaller magnitude for most Western countries, but possibly even larger for some of the countries that experienced colonisation and de-colonisation in the 19th and 20th centuries.

In addition to country-level data we also present average values for major world regions and, where possible, for the world as a whole. To construct these regional averages, we aggregate country data weighted by population, thus giving China a much bigger weight than Belgium or Nepal. The chapter on income inequality also presents estimates of global income inequality, i.e. the inequality of the distribution of income across all the world's inhabitants as if they were living in a single country.

In the presentation of the data we focus on long-term trends; hence, we present most estimates in the form of averages over a ten-year period, where the $1820 \mathrm{~s}$ refers to the average for 1820 to 1829, or in the form of specific benchmark years $(1820,1850,1870$, 1890,1913 , etc.). For historical societies we do not always have annual observations, and data were often interpolated such that "1820" may mean "observation closest to 1820 ". Alternatively, Chapter 7 on height presents data by birth cohorts, that is, people born in the 1820s, 1830s, etc. We also provide regional averages, distinguishing between eight world regions: Western Europe, Eastern Europe, the Western Offshoots, East Asia, South and Southeast Asia, the Middle East and North Africa, Sub-Saharan Africa, and Latin America. ${ }^{4}$ 
Eastern and Western Europe are divided (rather arbitrarily) by the former "iron curtain" (a border that is, however, almost identical to the Hajnal line separating the European marriage pattern and the Eastern European family system, used in many economichistorical and demographic studies (Hajnal, 1965)). Eastern Europe, as defined in this report, includes the territory of the former USSR, including its Asian parts. The Western Offshoots, a concept borrowed from Maddison, consists of the United States, Canada, Australia and New Zealand, regions of recent immigration from Western Europe that shared a common development path. East Asia consists of China, Hong Kong (China), Japan and Korea, while South- and Southeast Asia covers the rest of Asia, with the exception of the countries to the west of Afghanistan. The Middle East and North Africa (MENA) region covers all African countries bordering the Mediterranean plus Iran, the Middle East and Turkey. Finally, the Latin America and Caribbean region consists of the Americas except for the United States and Canada. Some regions are dominated by one large country (China towers over East Asia, the United States has a huge weight among the Western Offshoots). To deal with this, we also present additional tables with data for a sample of 25 countries, which together cover a large part of the world's population.

In calculating the regional averages, it was necessary to prevent one or a few unrepresentative countries driving the regional trends. For example, sometimes only historical data for South Africa are available within the Sub-Saharan Africa region. However, South African trends may not be representative for the wider region. Therefore data had to be imputed in order to increase country coverage. A method similar to that of Maddison was used. Years between two available benchmark observations (say 1820 and 1850) were interpolated based on the average growth rate for the country in that period (1820-1850). When the data had to be backwards extrapolated for a country, the growth rate from a similar country from the region (for which data were available) was taken and used to project its level backwards in time. Since it is undesirable to present data based largely on imputations, the regional averages were set to missing if the non-imputed countries covered less than $40 \%$ of the regional population. The exceptions to this rule are represented by the data on education, where the countries in Eastern Europe were judged to be sufficiently representative of the region to settle for a 30\% threshold, and homicide rates where a more stringent coverage threshold of $45 \%$ was used because of the high variation in homicide rates.

\section{Main highlights}

In the remainder of this chapter, we briefly summarise the most significant results, focusing on the question of the extent to which different measures of well-being shed new light on long-term trends in world development.

Chapter 2 sketches how the global population grew from about 1 billion at the start of the 19th century to more than 7 billion today, showing the huge challenge the world economy has faced over the past 200 years: how to feed, clothe and house this growing world population. This chapter describes how demographic systems rapidly changed around the world: mortality rates declined while fertility rates declined as well, albeit at lower and varying speeds. The first demographic transition took place in Western Europe and Western Offshoots during the 19th century. This had huge consequences for the age structure of the population, labour force participation, the role of women within the household, and for educational investment in children. Elsewhere the transition is still ongoing as new technologies in health and fertility control were introduced in the course 
of the 20th century, initiating a move away from high mortality and fertility to longer life expectancy and fewer children per women. Initially, this provided a demographic dividend facilitating economic growth, but soon this will turn into a burden as problems of ageing may have negative effects on economic growth.

Chapter 3 focuses on the spectacular growth of the output and income of the world economy since 1820. The world's average GDP per capita increased by a factor of 10 between 1820 and 2010; as total population increased seven-fold, total real GDP went up by a factor of 70. Yet this growth was spread very unevenly, resulting in a considerable increase in income disparities between countries. In 1820, the richest countries were about five times as wealthy as the poorest countries, while they were more than thirty times as well-off in 1950. This was driven by a process of rapid industrialisation. Only recently, as a result of the rapid growth experienced by China and India, has global income inequality begun to decline.

Chapter 4 provides evidence on the development of the real wages of unskilled labourers. This evidence largely confirms the results for the rise in GDP per capita. During the first half of the 19th century, the average unskilled labourer could barely maintain a family from his wage - only in parts of Western Europe and the Western Offshoots were real wages really above "subsistence", while in Africa they were probably below that threshold (but the number of observations is limited). In the 2000s, the average real wages of unskilled workers are about 8 times the level attained at the start of the 19th century. International differences in the real wages of unskilled workers have also become much larger, with Southeast Asia trailing behind and Africa catching up in recent decades. Another striking feature is the gap in real wages between the Western Offshoots, where real wages were very high already in the 19th century, and Western Europe, with a much lower wage level; this gap has closed only recently.

Chapter 5 looks at the advance of education, which has been as impressive, or perhaps even more impressive, than the growth in real income. In about 1820 , less than $20 \%$ of the world's population was literate, and this group was heavily concentrated in Western Europe and its Offshoots. Nowadays, the levels of literacy reach close to $100 \%$ almost everywhere, with Africa being the most significant exception at 64\%, and MENA and Southeast Asia at about $75 \%$. Much of this increase in literacy was achieved after 1945, often following de-colonisation, which was given an extra impetus by government efforts in this field. In the wake of the expansion of basic education, secondary and tertiary education also expanded, first in the Western Offshoots, then in Western Europe. More recently this became a global phenomenon, resulting in a strong increase in the average years of education in all parts of the world. The levels of global inequality are much lower for education than they are for real income, and they are declining, making education a significant force for greater equality of well-being around the world.

Chapter 6 shows that the slow decline seen in inequality in GDP per capita between the world's countries has also been witnessed in relation to life expectancy, particularly in recent generations. At the start of industrialisation, average life expectancy at birth was about 40 years in Western Europe and its Offshoots, and probably not higher than 25 to 35 years in most of the rest of the world. Only after the late 1890s did life expectancy start to rise significantly. Initially, this systematic rise in life expectancy was the result of the decline in infant mortality, but subsequently was due to a significant fall in mortality later in life. In the OECD countries, this process resulted in almost doubling life expectancy at 
birth - to almost 80 years - while elsewhere a process of catching up started after 1945 . The greater equality in life expectancy has presently allowed most world regions to reach an average life expectancy of about 60 to 70 years, with only Africa lagging significantly behind. However, within the world's regions, in the last two decades levels of life expectancy appear to be diverging once more.

Chapter 7 provides a somewhat different perspective on developments in health and nutritional status by looking at data on changes in people's height around the world since the 1820s. During the 19th century, the tall Americans, Canadians and Australians stood out, mirroring the high real wages earned in the Western Offshoots. However, during the middle decades of the 19th century, the difference between Western Europe and the rest of the world (Eastern Europe, East Asia) was marginal, in spite of the much higher real incomes in the former region. This changed after about 1870, when height began to increase in Western Europe, whereas it lagged elsewhere. Africans were relatively tall during much of the period studied, but experienced declining height in many countries after the 1960s. People in Southeast Asia stayed relatively short, which fits the real wage evidence for the region.

Chapter 8 is devoted to personal security, which is a fundamental capability but one that it is not easy to measure historically. This chapter relies on homicide rates (the number of intentional deaths per 100000 inhabitants) to get an idea of the spread of violence over time and space. There are striking patterns here: Western Europe was already quite peaceful from the 19th century onwards, but homicide rates in the United States (but not in other Western Offshoots) were and remain high by comparison. Large parts of Latin America and Africa are also violent crime "hotspots", and so is the former Soviet Union (especially since the fall of communism), while large parts of Asia have low homicide rates. The historical evidence is often patchy, however, for the non-Western world, with the exception of Japan.

Chapter 9 presents data on the evolution of political institutions, reflecting trends in civil rights. Two projects to measure this are discussed: the PolityIV dataset, which arguably reflects a typically United States perspective on this topic (the United States was already highly democratic at the start of the 19th century, and other countries converge - or not); and the Vanhanen dataset, which focuses on electoral participation and competition. Global averages show a rising trend in both cases, but also significant differences in timing. Both datasets show that the Western Offshoots and Western Europe took the lead in this process, while other parts of the globe often experienced a much less gradual evolution, with sometimes violent swings in political rights (as also happened in Western Europe during the 1930s and 1940s). Yet in the long run, there has been an impressive increase in the quality of political institutions, contributing significantly to people's well-being.

Chapter 10 looks at the quality of the environment, which is obviously important for well-being but not easy to quantify historically. The chapter presents historical trends in sustainability and environmental quality based on measures of biodiversity and emissions of $\mathrm{CO}_{2}$ and $\mathrm{SO}_{2}$. It finds evidence of long-term declines of biodiversity worldwide, as well as of increasing emissions. These indicators are mostly model based: biodiversity measures are derived from the GLOBIO model, while $\mathrm{CO}_{2}$ and $\mathrm{SO}_{2}$ emissions are mostly based on data on energy production. Assumptions and limitations are reviewed, including a warning about the partial and possibly biased nature of these indices, which give only a glimpse of the complex interactions between humanity and nature. 
Chapter 11 focuses on income inequality, a dimension that is related to people's well-being both directly and indirectly. The evidence about long-term trends on income inequality both within and between countries makes it possible to chart global inequality between 1820 and the present. Within-country income inequality over time shows a U-curve in most OECD countries, declining between the end of the 19th century until about 1970, followed by a rise that is very sharp in the Anglo-Saxon countries (United States, United Kingdom), and relatively modest in Continental Western Europe. Similar but often more extreme versions of this U-curve are found in Eastern Europe, where communism resulted in strong declines in income inequality, followed by a sharp increase after the disintegration of central planning. In other parts of the world (China in particular), recent trends have led to greater income inequality. Global income inequality was largely driven by between-country inequality, which went up until the 1950s, and stabilised since.

Chapter 12 is about gender inequality, a major determinant of the well-being of $50 \%$ (if not $100 \%$ ) of the world's population. The chapter documents the changes in different measures of gender inequalities via the construction of a gender inequality index reflecting inequalities in health, marriage, socio-economic status and political rights. The index shows strong progress in reducing gender discrimination during the past 60 years, but the differences between regions did not disappear in this period: Europe (including communist Eastern Europe) and the Western Offshoots performed best (but no country, not even Sweden, reached full gender equality), while MENA (due to weak political rights) and Southeast Asia (due to the many "missing girls") performed worst. One important outcome is the low score on the index (i.e. high gender equality) for former communist countries (before 1989), followed by a temporary decline after 1989.

Chapter 13 synthesises the results of the report by constructing a composite index of well-being. The crucial problems when constructing a composite index are, of course, how to determine a set of weights to calculate for the index, how to normalise the individual indices about the various dimensions of well-being and how to deal with missing observations. The chapter discusses various options, and their implications. Using a wide range of aggregation options, however, tends to show similar results. Progress in well-being was commonplace since the early 20th century, with the possible exception of Sub-Saharan Africa. Between-country inequality in well-being is also lower than it is when considering GDP alone. However, this is a phenomenon of the 1970s and after; before this time the increase in between-country inequality in well-being was actually more pronounced compared to GDP.

Most of the well-being indicators discussed in this book have a strong correlation with GDP, though this is less so with the indicators measuring political institutions, environmental quality, inequality and personal security (Figure 1.1). Generally speaking, the relationship with per capita GDP is much weaker up to 1870 , in part due to the quality of the data for the earlier period.

At the same time, the relation between well-being indicators sometimes changes noticeably. Preston (1975) has analysed this change for life expectancy and per capita GDP, observing that the same per capita GDP level was associated with much higher life expectancy in 1960 than in 1930 - the curve had shifted upwards. He suggested that this was due to improved healthcare technology. The long-term data presented in this book confirm this trend, from around 1900. 
Figure 1.1. Evolution of GDP per capita and selected well-being indicators, 1820-2000

Height (cm), life expectancy at birth (years), homicide rates (per 100000 ), education (years), $\mathrm{SO}_{2}$ pollution (ton $\mathrm{SO}_{2}$ per capita), $\mathrm{CO}_{2}$ pollution (kiloton $\mathrm{C}$ per capita), polity2 scores, income inequality (Gini coefficient) and per capita GDP (US dollars at 1990 PPP). Logarithmic fits for seven periods
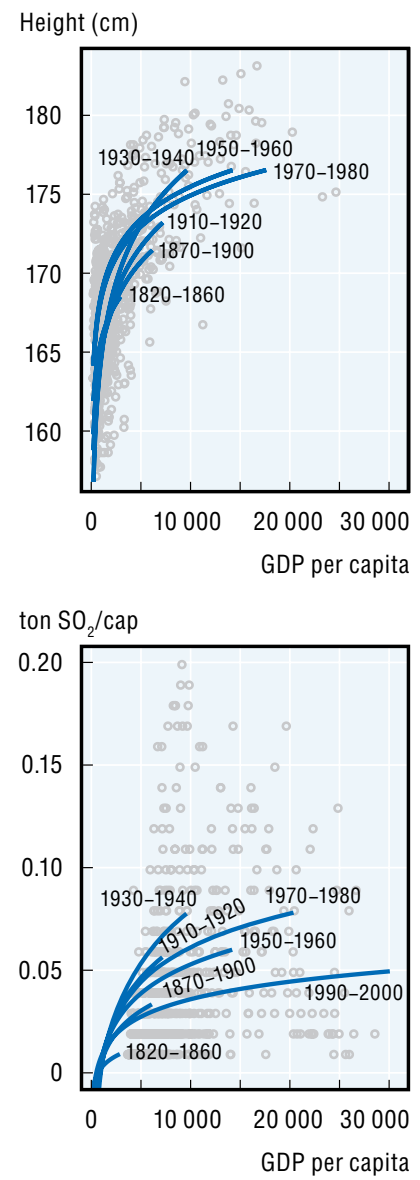

Source: Clio-Infra, www.clio-infra.eu
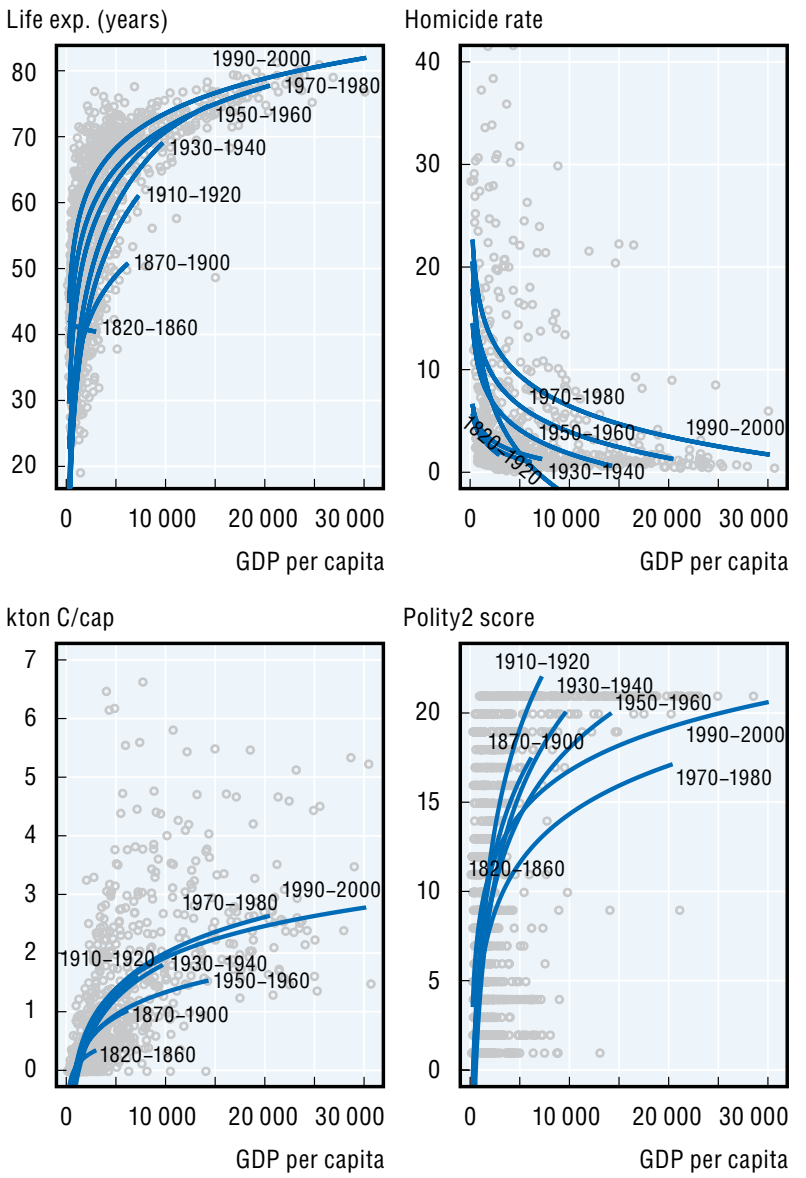
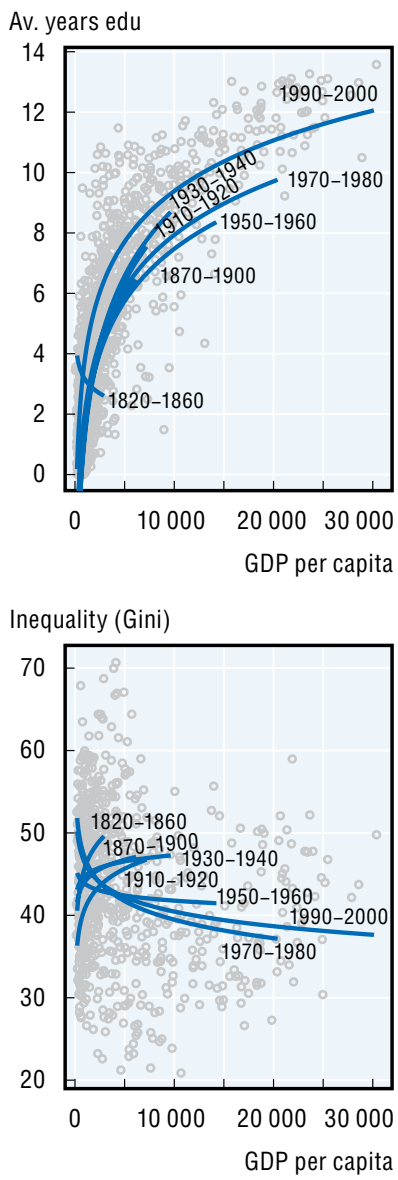

Life expectancy seems to be fairly unique in showing unambiguous improvements at the same income level. Height, for example, shows a stable relationship with GDP until at least the 1980s. However, there are also some interesting shifts to note. From 1950-60 onward homicide rates seem to be rising at a given level of income, but the scarcity of pre1980 data outside Western Europe means that this finding is subject to important caveats about data coverage. Education shows a shift after 1980, implying that at all levels of per capita GDP, average years of education have increased. Air pollution due to sulphur dioxide in the second half of the 20th century shows a downward shift relative to the first half of the century, showing production at similar income levels to be getting cleaner. Unfortunately, no such shift can be observed for carbon dioxide production. The curves for inequality and political institutions have shifted multiple times, showing the relation with per capita GDP to be unstable. 


\section{Notes}

1. But much new work has recently been done for the pre-1820 period; see Bolt and Van Zanden (2014) for a review.

2. These capabilities are: (1) life, (2) bodily health, (3) bodily integrity, (4) senses, imagination and thought, (5) emotions, (6) practical reason, (7) affiliation, (8) other species, (9) play and (10) control over one's environment.

3. The How's Life? framework considers inequality as a cross-cutting theme, relevant for each of the 11 dimensions of current well-being, rather than as a stand-alone dimension. OECD (2103) provides an in-depth focus on gender differences in well-being.

4. The regions used in this report are those used by Maddison in his own work for the OECD.

\section{References}

Allen, R. C. (2001), "The Great Divergence in European Wages and Prices from the Middle Ages to the First World War", Explorations in Economic History 38, pp. 411-447.

Allen, R. C. et al. (2011), "Wages, Prices, and Living Standards in China, 1738-1925: In Comparison with Europe, Japan, and India”, Economic History Review 64, pp. 8-38.

Bolt, J. and J.L. Van Zanden (2014), “The Maddison Project, Collaborative research on historical national accounts", Economic History Review, 67(3), pp. 627-651.

Hajnal, J. (1965), "European marriage patterns in historical perspective”, in D.V. Glass and D.E.C. Eversley, Population in History, Arnold, London. pp. 101-143.

Maddison, A. (2001), The World Economy: A Millennial Perspective, Development Centre Studies, OECD Publishing, http://dx.doi.org/10.1787/9789264189980-en.

Maddison, A. (2003), The World Economy: Historical Statistics, Development Centre Studies, OECD Publishing, http://dx.doi.org/10.1787/9789264104143-en.

Nussbaum, Martha C. (2000), Women and Human Development: The Capabilities Approach, Cambridge University Press, Cambridge.

OECD (2011), How's Life? Measuring Well-being, OECD Publishing, Paris, http://dx.doi.org/ 10.1787/9789264121164-en.

OECD (2013), How's Life? 2013: Measuring Well-being, OECD Publishing, Paris, http://dx.doi.org/ 10.1787/9789264201392-en.

Preston, S.H. (1975), “The Changing Relation between Mortality and Level of Economic Development”. Population Studies 29: 231-48. doi:10.2307/2173509.

Sen, A. (1993), "Capability and Well-Being" in M. Nussbaum and A. Sen, (eds.) The Quality of Life, Oxford Clarendon Press, New York, pp. 30-53.

Stiglitz, J.E., A. Sen and J.P. Fitoussi (2009), "Report by the Commission on the Measurement of Economic Performance and Social Progress", www.stiglitz-sen-fitoussi.fr/documents/rapport_anglais.pdf.

UNDP (2010), Human Development Report 2010: The Real Wealth of Nations: Pathways to Human Development, United Nations Development Programme, New York. 


\title{
Chapter 2
}

\section{Demographic trends since 1820}

\author{
by \\ Lotte van der Vleuten and Jan Kok, Radboud University, Nijmegen
}

The world population has grown from about 1 billion at the start of the 19th century to more than 7 billion today. This chapter describes how demographic systems rapidly changed around the world: mortality rates declined while fertility rates declined as well, albeit at lower and varying speeds. The first demographic transition took place in Western Europe and the Western Offshoots during the 19th century and had huge consequences for labour force participation, for the role of women, and for educational investment in children. Elsewhere the transition is still ongoing as new technologies in health and fertility control were introduced in the course of the 20th century, initiating a move away from high mortality and fertility rates to longer life expectancy and fewer children per women. Initially, this provided a demographic dividend facilitating economic growth, but soon this will turn into a demographic burden. 


\section{Introduction}

Demographic trends are closely intertwined with developments in well-being. The potential for economic growth is strongly affected by the speed of population growth and the age distribution of the population. In turn, these factors result from changing rates of mortality, fertility and in- or out-migration. The global population grew from about 1 billion at the start of the 19th century to more than 7 billion today. How demographic trends and other factors have impacted on the global distribution of wealth and well-being is explained in-depth in subsequent chapters. This chapter intends to "set the stage" for this study by providing some insights into the major population trends at the world level over the past two centuries.

The first section presents the basic features of world population growth, while also discussing the limitations of the data used here. The global population expanded dramatically, but there were also major shifts in the relative share of the different regions. During the period 1820-2000, the rates of population growth - and sometimes even decline - differed strongly across regions, with important implications for economic growth. For the world as a whole, demographic change in this period is a story of declining mortality, resulting in increased life expectancy, and declining fertility. However, the world's regions display different timings and paces for these declines, implying that each region had its own trajectory of change. In the next section we summarise the mainstream interpretations of the demographic transition, to show how lives were affected by altering demographic patterns. We should hasten to add that, given the scale, the variation, and the complexity of the changes involved, a real consensus on the interpretation of the demographic transition is not within reach (e.g. Szreter, 2011). In the final section, we reflect on how major demographic trends, in past, present and future times, lead to "virtuous" or "vicious" cycles of social and economic development.

\section{Data quality}

The evidence presented in this chapter is based on a combination of two datasets. The world population dataset developed by Angus Maddison (1995; 2006; 2010) forms the foundation of the population data, and it is supplemented with the Clio-Infra dataset on total population. Maddison's population estimates (1995; 2006; 2010) stem from a broad variety of sources and have been updated multiple times in the period between 1995 and 2009. Specific sources for the annual estimates of 1820-1950 are described in the country notes of his 1995 and 2006 books. Appendix A in these works deals with population estimates and the quantitative analysis used to estimate onwards from 1820. He either gathers estimations for benchmark years, or calculates these by assembling evidence on changes in population. The bulk of the sources can be found in the 1995 work, Monitoring the World Economy, 1820-1992. His population estimates for the years before 1950 are based mainly on census material and the work of historical demographers. For instance, for China, his dataset from 1820 until 1930 is based on the work of Liu and Hwang (1979, p. 82) and for the period from 1933 to 1953 on Perkins (1969, p. 16), using interpolation to 
create yearly estimates (Maddison 1995; 2006; 2007). The availability of pre-1950 data and estimates on Europe and the Western Offshoots are of the best quality, followed by those for Latin America and Asia, but the estimates on Africa are very weak.

The Clio-Infra dataset is developed by Klein Goldewijk, Beusen and Janssen (2010) as an essential part of the History Database of the Global Environment (HYDE 3.1). HYDE estimates historical population trends on the basis of a wide variety of statistical sources on varying administrative units. The historical population numbers of Maddison (2003), McEvedy and Jones (1978), Livi-Bacci (2007) and Denevan (1992) form the basis for the historical population estimates of various countries. These are supplemented with the subnational population data of Populstat (Lahmeyer, personal correspondence), which allows constructing time-series for each province or state of every country in the world. Current administrative units were kept constant over time, meaning that every historical source was adjusted to match the current boundaries (e.g. by taking fractions of former larger empires). Country and regional totals were checked against other historical estimates at the global, regional or national level (Klein Goldewijk, Beusen and Janssen, 2010). Combining the original population dataset by Maddison with the augmented one by Klein Goldewijk, Beusen, and Janssen leads to a more complete set of population estimations for the period between the 1820s and the 1900s.

Population data underlie many other types of data used in this report; they are employed to calculate indicators such as GDP per capita and average years of education, and are often used as weights to determine the relative importance of countries within regions. For periods before the 18th century, demographic data are also regularly used as a basis for conjectures about economic development. In other words, population data provide a fundamental statistical input used for many measures of well-being and economic development. However, some population figures are under scholarly debate, and it is important to separate facts from inferences and everything in between.

The reliability of population estimates varies considerably across world regions and periods, creating some comparability issues. For some areas, such as Western Europe, parts of Eastern Europe and the Western Offshoots, there is an ample supply of quantitative data available of fairly good quality, and the areas are well researched (e.g. in the European Fertility Project, see Coale and Watkins, 1986). In general, population estimates after the 1820s are fairly accurate for European countries and the Western Offshoots, and are typically the product of statistical agencies and of research by economic historians. For regions such as Latin America, the Middle East and North Africa, East Asia and Eastern Europe, 19th century data are less readily available, yet they still provide a basis for reasonable quantitative estimations. Other areas, such as Sub-Saharan Africa before the 1950s, or South-Southeast Asia before the 1900s, suffer from a lack of sources, and there is a high degree of academic disagreement about actual population figures (Austin, 2008; Maddison, 2006; Manning, 2010). Table 2.1 provides an overview of the quality of the data for the different world regions for benchmark years between the 1820s and 2000s.

The difference in data availability can lead to an overemphasis of the Western demographic experience. To counter such a narrow perspective, Maddison (1995; 2006) and others made "educated guesses" about population estimates for regions with little data available. These data are classified as quality type 4 in Table 2.1 (and shown as dotted lines in Figure 2.2). Most notably, pre-1950s population estimates for Sub-Saharan Africa are in class 4: for this region, almost no sources are available before the 1850s, one of the exceptions being the estimates of a 17th century Jesuit scholar who, however, failed to 
Table 2.1. Quality of data on population by region and benchmark year, 1820-2008

\begin{tabular}{|c|c|c|c|c|c|c|c|c|}
\hline & $\begin{array}{l}\text { Western } \\
\text { Europe } \\
\text { (WE) }\end{array}$ & $\begin{array}{c}\text { Eastern } \\
\text { Europe } \\
\text { (EE) }\end{array}$ & $\begin{array}{l}\text { Western } \\
\text { Offshoots } \\
\text { (WO) }\end{array}$ & $\begin{array}{l}\text { Latin } \\
\text { America } \\
\text { and } \\
\text { Caribbean } \\
\text { (LA) }\end{array}$ & $\begin{array}{c}\text { Sub-Saharan } \\
\text { Africa } \\
\text { (SSA) }\end{array}$ & $\begin{array}{l}\text { Middle East } \\
\text { and } \\
\text { North Africa } \\
\text { (MENA) }\end{array}$ & $\begin{array}{c}\text { East Asia } \\
(\mathrm{EA})\end{array}$ & $\begin{array}{c}\text { South and } \\
\text { South-East } \\
\text { Asia } \\
\text { (SSEA) }\end{array}$ \\
\hline 1820 & 2 & 3 & 2 & 4 & 4 & 4 & 3 & 4 \\
\hline 1870 & 2 & 3 & 2 & 2 & 4 & 3 & 3 & 4 \\
\hline 1913 & 2 & 2 & 2 & 2 & 4 & 3 & 3 & 3 \\
\hline 1950 & 1 & 1 & 1 & 2 & 3 & 2 & 2 & 2 \\
\hline 1973 & 1 & 1 & 1 & 1 & 1 & 1 & 1 & 1 \\
\hline 2008 & 1 & 1 & 1 & 1 & 1 & 1 & 1 & 1 \\
\hline
\end{tabular}

Note: 1. High quality; 2. Moderate quality: 3. Low quality; and 4. Estimates.

See the section on "Data Quality" in Chapter 1 for a description of the quality criteria.

Source: Clio-Infra, www.clio-infra.eu.

StatLink तiाs http://dx.doi.org/10.1787/888933096616

provide the underpinnings of his estimation. Few new data about that period are available, and therefore new population figures for this region are generally the fruit of the increased sophistication of estimation methods. In the 1930s, the total population for the SubSaharan region was estimated as hovering around 95 to 100 million between 1650 and 1850 (Willcox, 1931; Carr-Saunders, 1936). Since then, a new generation of scholars has approached the population estimates with more precision, by projecting backwards from 1900 estimates, assuming fluctuations in population growth due to the "exogenous" effects of slave trade and imported diseases (Durand, 1977; McEvedy and Jones, 1978). Current population estimates for Sub-Saharan Africa are estimated both backwards (backward projection from the 1950s) as well as sideways (employing adjusted growth rates from countries such as India) to get a more plausible view of population growth in Sub-Saharan Africa in the period before the 1950s (Austin, 2008; Manning, 2010; Frankema and Jerven, 2013). ${ }^{1}$

Population estimates are relatively easy to come by when compared to other types of demographic indicators. Data on fertility rates and life expectancy at birth, which are also used in this chapter to describe the "demographic transition", are of a different quality than population estimates. For both variables, good quality data - type 1 data - are available only after 1950. Before then, reasonable estimates of total fertility rates and life expectancy at birth are available only for Western Europe, the Western Offshoots and, to a lesser extent, Eastern Europe and East Asia.

To measure mortality risks, this chapter relies on data on life expectancy at birth, or the average number of years a newborn child would live if he or she experienced the age-specific mortality rates observed in a given year (Bongaarts, 2009). The quality of the data on life expectancy is the same as in Chapter 6 of this volume, where the data are described in detail. A well-known indicator of fertility is the total fertility rate (TFR), or the total number of births a woman would have by the end of her reproductive years if she experienced the age-specific fertility rates of a given year. The data on fertility rates are difficult to classify, due to the different methods of estimating the underlying concept. The starting date for the computation of data on total fertility rates was 1800 , and for many countries this benchmark is an educated guess in itself. The compilers of Gapminder's 
fertility database estimated total fertility rates (TFR) in different ways: while UN data were used for the period after 1959, for the preceding period the main source for Western nations and their Offshoots was the Princeton Fertility Project. When age-specific data were unavailable to calculate TFR, crude birth rates (CBR) were converted using a conversion table developed by Bogue et al. (1993). If CBR were also not available, data for TFR in 19501955 were extrapolated backwards for those countries. This approach was applied only to countries whose fertility transition was still to come: in these cases, the "natural" fertility rate of 1950-1955 was assumed to be similar to that of 1800 . For countries where the fertility transition had already occurred, earlier data were used to establish a "plateau" around which the TFR tends to fluctuate. Often, additional sources were used to estimate natural fertility. When both of the above options failed to deliver sensible results, two additional strategies were used: First, to use regional averages of neighbouring countries, sometimes with the addition of a few observations of the nation itself; and second, if extrapolations were impossible or assumptions failed a reasonableness test, countries were deleted from the database (Ajus, 2009, see Appendix 10). Table 2.2 provides our best effort at estimating the data quality for fertility for benchmark years between 1820 and 2000.

Table 2.2. Quality of data on fertility rates by region and benchmark year, 1820-2008

\begin{tabular}{|c|c|c|c|c|c|c|c|c|}
\hline & $\begin{array}{l}\text { Western } \\
\text { Europe } \\
\text { (WE) }\end{array}$ & $\begin{array}{l}\text { Eastern } \\
\text { Europe } \\
\text { (EE) }\end{array}$ & $\begin{array}{l}\text { Western } \\
\text { Offshoots } \\
\text { (WO) }\end{array}$ & $\begin{array}{l}\text { Latin } \\
\text { America } \\
\text { and } \\
\text { Caribbean } \\
\text { (LA) }\end{array}$ & $\begin{array}{c}\text { Sub-Saharan } \\
\text { Africa } \\
\text { (SSA) }\end{array}$ & $\begin{array}{l}\text { Middle East } \\
\text { and } \\
\text { North Africa } \\
\text { (MENA) }\end{array}$ & $\begin{array}{c}\text { East Asia } \\
(\mathrm{EA})\end{array}$ & $\begin{array}{c}\text { South and } \\
\text { South-East } \\
\text { Asia } \\
\text { (SSEA) }\end{array}$ \\
\hline 1820 & 3 & 4 & 3 & 4 & 4 & 4 & 4 & 4 \\
\hline 1870 & 2 & 4 & 2 & 4 & 4 & 4 & 4 & 4 \\
\hline 1913 & 2 & 3 & 2 & 4 & 4 & 4 & $3 / 4$ & 4 \\
\hline 1950 & 1 & 2 & 1 & 2 & 4 & 2 & 2 & 2 \\
\hline 1973 & 1 & 1 & 1 & 1 & 2 & 1 & 1 & 1 \\
\hline 2008 & 1 & 1 & 1 & 1 & 1 & 1 & 1 & 1 \\
\hline
\end{tabular}

Note: 1 . High quality; 2 . Moderate quality: 3. Low quality; and 4. Estimates.

See the section on "Data Quality" in Chapter 1 for a description of the quality criteria.

Source: Gapminder, http://www.gapminder.org/documentation/documentation/gapdoc008_v2.pdf.

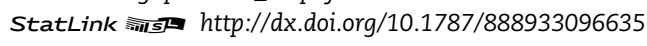

\section{World population 1820-2000: trends and trajectories}

From the beginning of the Common Era until the 18th century, the world population grew only very slowly, at an estimated $0.06 \%$ per year (Cleland, 2013). In the 18th and 19 th centuries, the annual growth rates accelerated to $0.5 \%$, mainly due to a slow decline in mortality in Europe and the Western Offshoots. Figure 2.1 shows how the world population, broken down by region, has grown between 1820 and 2010 (see also Tables 2.3 and 2.4). For a long time, the rate of population growth remained relatively modest, but it increased rapidly after 1950. Since the 1970s, the pace of population growth has slowed. Current forecasts are that the global population will keep on growing, at least until 2100, reaching an estimated total of 10.8 billion people (UN Statistics Division, 2013), more than ten times the population in 1800 .

Figure 2.1 also shows the long-standing prominent shares of both East Asia and South and Southeast Asia in the total world population. The share of East Asia diminished after 1860, due to an increase in the shares of both Western Europe and its Offshoots and Eastern 
Figure 2.1. Total population by region, 1820-2000

Millions of inhabitants

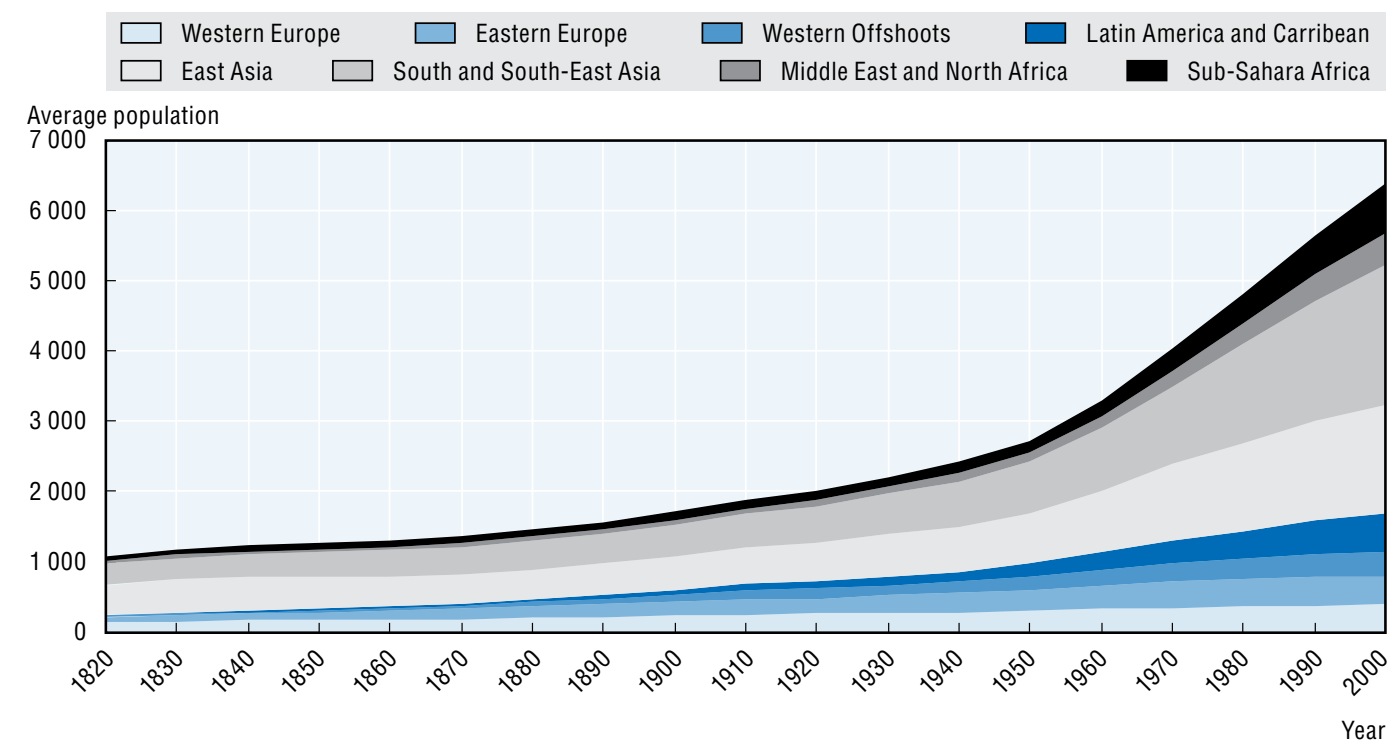

Note: For an assessment of data quality, see Table 2.1.

Source: Clio-Infra, www.clio-infra.eu.

StatLink न्ता SL http://dx.doi.org/10.1787/888933095514

Table 2.3. Total population by region, $\mathbf{1 8 2 0 - 2 0 1 0}$

Millions of inhabitants

\begin{tabular}{|c|c|c|c|c|c|c|c|c|c|}
\hline & $\begin{array}{c}\text { Western } \\
\text { Europe } \\
\text { (WE) }\end{array}$ & $\begin{array}{c}\text { Eastern } \\
\text { Europe } \\
\text { (EE) }\end{array}$ & $\begin{array}{l}\text { Western } \\
\text { Offshoots } \\
\text { (WO) }\end{array}$ & $\begin{array}{l}\text { Latin } \\
\text { America } \\
\text { and } \\
\text { Caribbean } \\
\text { (LA) }\end{array}$ & $\begin{array}{c}\text { East Asia } \\
\text { (EA) }\end{array}$ & $\begin{array}{c}\text { South and } \\
\text { South-East } \\
\text { Asia } \\
\text { (SSEA) }\end{array}$ & $\begin{array}{l}\text { Middle East } \\
\text { and } \\
\text { North Africa } \\
\text { (MENA) }\end{array}$ & $\begin{array}{l}\text { Sub-Saharan } \\
\text { Africa } \\
\text { (SSA) }\end{array}$ & World \\
\hline 1820 & 140 & 85 & 13 & 23 & 421 & 294 & 42 & 74 & 1091 \\
\hline 1830 & 158 & 91 & 17 & 27 & 458 & 316 & 44 & 76 & 1187 \\
\hline 1840 & 170 & 101 & 22 & 31 & 461 & 330 & 47 & 79 & 1241 \\
\hline 1850 & 176 & 109 & 31 & 32 & 445 & 342 & 49 & 83 & 1268 \\
\hline 1860 & 187 & 121 & 41 & 39 & 419 & 362 & 51 & 87 & 1307 \\
\hline 1870 & 198 & 133 & 51 & 42 & 415 & 376 & 53 & 92 & 1361 \\
\hline 1880 & 212 & 150 & 64 & 49 & 429 & 405 & 59 & 97 & 1466 \\
\hline 1890 & 227 & 170 & 78 & 58 & 449 & 429 & 65 & 102 & 1579 \\
\hline 1900 & 247 & 190 & 94 & 70 & 476 & 457 & 71 & 108 & 1713 \\
\hline 1910 & 264 & 222 & 114 & 83 & 518 & 485 & 73 & 115 & 1873 \\
\hline 1920 & 267 & 222 & 132 & 98 & 563 & 519 & 82 & 126 & 2009 \\
\hline 1930 & 284 & 241 & 147 & 118 & 601 & 587 & 90 & 140 & 2207 \\
\hline 1940 & 296 & 268 & 162 & 144 & 643 & 647 & 101 & 156 & 2417 \\
\hline 1950 & 314 & 280 & 192 & 188 & 736 & 710 & 126 & 189 & 2735 \\
\hline 1960 & 339 & 332 & 226 & 247 & 871 & 885 & 164 & 247 & 3312 \\
\hline 1970 & 361 & 366 & 255 & 319 & 1085 & 1114 & 214 & 320 & 4034 \\
\hline 1980 & 372 & 397 & 282 & 398 & 1251 & 1392 & 290 & 423 & 4805 \\
\hline 1990 & 386 & 412 & 316 & 479 & 1418 & 1705 & 374 & 554 & 5643 \\
\hline 2000 & 397 & 407 & 349 & 551 & 1525 & 2010 & 450 & 703 & 6392 \\
\hline 2010 & 409 & 377 & 377 & 589 & 1564 & 2243 & 504 & 820 & 6883 \\
\hline
\end{tabular}

Note: For an assessment of data quality, see Table 2.1.

Source: Clio-Infra, www.clio-infra.eu. 
Table 2.4. Total population in selected countries, 1820-2010

Thousands of inhabitants

\begin{tabular}{|c|c|c|c|c|c|c|c|c|c|c|c|c|c|c|c|c|c|c|c|c|c|c|c|c|c|}
\hline & & & & $\begin{array}{l}\text { stern Eurc } \\
\text { (WE) }\end{array}$ & & & & $\begin{array}{r}\text { Eastern } \\
\quad(E \\
\end{array}$ & $\begin{array}{l}\text { n Europe } \\
\text { EE) }\end{array}$ & Weste & $\begin{array}{l}\text { tern Offsh } \\
\text { (WO) }\end{array}$ & & $\begin{array}{r}\text { Latin } \\
\text { Cari }\end{array}$ & & & $\begin{array}{r}\text { Middl } \\
\text { and I } \\
\text { Africa ( }\end{array}$ & $\begin{array}{l}\text { dle East } \\
\text { North } \\
\text { (MENA) }\end{array}$ & & $\begin{array}{c}\text {-Saharan } \\
(\mathrm{SSA})\end{array}$ & & & & & $\begin{array}{l}\text { d South-Eas } \\
\text { (SSEA) }\end{array}$ & \\
\hline & GBR & NLD & FRA & DEU & ITA & ESP & SWE & POL & RUS & AUS & CAN & USA & MEX & BRA & ARG & EGY & TUR & KEN & $N G A$ & ZAF & $\mathrm{CHN}$ & JPN & IND & IDN & THA \\
\hline 1820 & 18916 & 2437 & 31901 & 25666 & 20473 & 3 12389 & 2495 & 10427 & 28123 & 274 & 1096 & 11019 & 7308 & 4479 & 534 & & 710074 & 2935 & 23764 & 966 & 373980 & 30374 & 208916 & 16256 & 4034 \\
\hline 1830 & 25323 & 2730 & 33970 & 29295 & 22148 & 313439 & 2989 & 11077 & 30071 & 359 & 1169 & 15125 & 364 & 5653 & 681 & 700 & 10455 & 082 & 24373 & 341 & 348 & 31480 & 1565 & 20217 & 3602 \\
\hline 1840 & 27586 & 3009 & 35589 & 32464 & 23615 & 14362 & 3272 & 12000 & 35621 & 492 & 1697 & 20197 & 8700 & 6862 & 870 & 5100 & 10815 & 3236 & 24998 & 301 & 412000 & 31814 & 230657 & 21961 & 3802 \\
\hline 1850 & 27684 & 3217 & 36865 & 34624 & 25181 & 15252 & 3606 & 13000 & 38615 & 935 & 2485 & 27306 & 662 & 7234 & 1100 & 500 & 11188 & 398 & 25639 & 261 & 55994 & 32535 & 9577 & 24211 & 230 \\
\hline 1860 & 29984 & . 3442 & 37933 & 37620 & 26904 & 415893 & 4042 & 14933 & 44361 & 1524 & 3369 & 35612 & 9371 & 9310 & 1420 & 4898 & 311574 & 3568 & 26297 & 746 & 368369 & 33751 & 248161 & 27163 & 4603 \\
\hline 1870 & 32749 & 3765 & 38265 & 40886 & 28629 & 16466 & 4346 & 16865 & 48113 & 1875 & 4035 & 44748 & 738 & 10665 & 1796 & 7049 & 911793 & 3756 & 27203 & 2547 & 362477 & 35429 & 54884 & 34260 & 5775 \\
\hline 1880 & 35892 & 4256 & 39608 & 35083 & 30484 & 17275 & 4652 & 19860 & 55393 & 2600 & 4633 & 56237 & 10984 & 12840 & 2719 & 6398 & 312235 & 3954 & 28141 & 2410 & 373368 & 38209 & 267137 & 38204 & 5804 \\
\hline 1890 & 39073 & 4786 & 40172 & 50294 & 32590 & 18118 & 4898 & 22854 & 63673 & 3421 & 5147 & 69196 & 12554 & 15829 & 3376 & 8893 & 3 12485 & 4162 & 29112 & 2958 & 388980 & 41688 & 281812 & 42521 & 6670 \\
\hline 1900 & 42817 & 5507 & 40852 & 58217 & 34888 & 19119 & 5272 & 24750 & 71523 & 3990 & 6130 & 83434 & 14292 & 19827 & 5591 & 10795 & 12740 & 4381 & 30116 & 4126 & 410244 & 46512 & 292440 & 47298 & 7753 \\
\hline 1910 & 45988 & 6354 & 40372 & 64620 & 37429 & 20470 & 5675 & 26677 & 89007 & 4839 & 7975 & 99737 & 14955 & 24461 & 7870 & 12144 & 415000 & 4611 & 31154 & 6153 & 444607 & 52626 & 304020 & 52374 & 8912 \\
\hline 1920 & 45171 & 7309 & 40255 & 62932 & 38962 & 22193 & 6019 & 26055 & 81797 & 5880 & 95211 & 115013 & 15770 & 30076 & 10193 & 13933 & 3142 & 4941 & 32452 & 6849 & 479600 & 59319 & 318590 & 57886 & 108 \\
\hline 1930 & 46818 & 8360 & 41881 & 66855 & 42273 & 324472 & 6228 & 29885 & 91131 & 6712 & 110631 & 127491 & 18595 & 36838 & 12942 & 15569 & 916093 & 5294 & 33804 & 8525 & 503386 & 68580 & 358420 & 67097 & 13870 \\
\hline 1940 & 49089 & 9324 & 40116 & 68425 & 4548 & 26702 & 6622 & 25221 & 112849 & 7395 & 124451 & 140223 & 23345 & 45781 & 15325 & 17862 & & 5672 & 35213 & 10341 & 531267 & 76885 & 385790 & 77746 & 171 \\
\hline 1950 & 50937 & 10707 & 44169 & 70114 & 48449 & 29199 & 7239 & 26980 & 106356 & 9193 & 158791 & 164744 & 32628 & 61137 & 18740 & 23630 & 23988 & 6522 & 36190 & 15221 & 603667 & 88967 & 390800 & 88292 & 23188 \\
\hline 1960 & 54071 & 12197 & 49317 & 75058 & 51765 & 32007 & 7712 & 31043 & 125422 & 11342 & 198871 & 192499 & 44605 & 82093 & 22111 & 29913 & 3 31593 & 9448 & 47530 & 19693 & 714953 & 98414 & 480300 & 105057 & 31663 \\
\hline 1970 & 56105 & 13578 & 53620 & 78406 & 55213 & 35467 & 8180 & 33839 & 134016 & 13618 & 230332 & 215026 & 59863 & 107668 & 25890 & 36901 & 139967 & 13300 & 63729 & 25547 & 9019441 & 110512 & 600800 & 130130 & 41688 \\
\hline 1980 & 56676 & 14482 & 56366 & 78080 & 56648 & 38416 & 8367 & 36949 & 143363 & 15637 & 258822 & 237482 & 75888 & 13598 & 30468 & 49186 & 50345 & 19436 & 84268 & 33562 & 10457641 & 120227 & 748200 & 162009 & 50853 \\
\hline 1990 & 58345 & 15394 & 59546 & 81216 & 57181 & 39695 & 8757 & 38498 & 148154 & 17900 & 294132 & 264876 & 91972 & 162355 & 35026 & 62772 & 61410 & 26706 & 108278 & 41733 & 11968361 & 125118 & 910789 & 192304 & 58420 \\
\hline 2000 & 60255 & 16300 & 62566 & 82363 & 58008 & 34270 & 8980 & 38580 & 143623 & 199923 & 320872 & 292989 & 104960 & 186420 & 38826 & 76142 & & 34071 & 134650 & 46986 & 12951981 & & 1074611 & 216177 & 637 \\
\hline 2010 & 61899 & 16653 & 62637 & 82057 & 60098 & 45317 & 9293 & 31445 & 126749 & 21512 & 338903 & 317641 & 110645 & 195423 & 40666 & 84474 & 475705 & 40863 & 158259 & 50492 & 13305851 & 126995 & 1214464 & 232517 & 68139 \\
\hline
\end{tabular}

Note: For an assessment of data quality, see Table 2.1.

Source: Clio-Infra, www.clio-infra.eu.

StatLink नiाst http://dx.doi.org/10.1787/888933096673 
Europe and the former Soviet Union. Since the 1970s, South and Southeast Asia, Latin America and the Caribbean and to some extent the Middle East and North Africa have claimed a larger share of the world population, mainly at the expense of Western Europe and East Asia. The population share of Sub-Saharan Africa is continuing to grow, despite the AIDS epidemic, frequent wars and famines. As we will discuss below, fertility rates in Sub-Saharan Africa have remained high until recently, whereas improvements in child health have contributed to continued population growth.

Over the past two centuries, the demographic experiences of the world's major regions have been very unequal, as can be seen in Figure 2.2. The figure presents decennial growth rates in percentages (see also Table 2.5). These growth rates are calculated on the basis of data of varying quality. Figure 2.2 provides some visual insight into the data quality by showing dotted lines instead of solids, in case of the lowest quality of data. This is when the rates are simply conjectures or "best (educated) guesses". In Figure 2.2, Western Europe appears as the only region with both stable and moderate population growth throughout the period. The growth curve for Eastern Europe and the Soviet Union was very erratic, reflecting the impact of the world wars and the economic and social crisis after the downfall of Communism. East Asia experienced a rate of population growth similar to that of Western Europe until the 1950s, with the exception of the 1850s and 1860s when the Taiping Rebellion took a large toll on the population of China (Maddison, 2007). Eastern Europe and the former Soviet Union, Western Europe and the Western

Table 2.5. Population growth by region, 1820s-2000s

Percentage growth per decade

\begin{tabular}{|c|c|c|c|c|c|c|c|c|c|}
\hline & $\begin{array}{c}\text { Western } \\
\text { Europe } \\
\text { (WE) }\end{array}$ & $\begin{array}{c}\text { Eastern } \\
\text { Europe } \\
\text { (EE) }\end{array}$ & $\begin{array}{l}\text { Western } \\
\text { Offshoots } \\
\text { (W0) }\end{array}$ & $\begin{array}{l}\text { Latin } \\
\text { America } \\
\text { and } \\
\text { Caribbean } \\
\text { (LA) }\end{array}$ & $\begin{array}{c}\text { East Asia } \\
\text { (EA) }\end{array}$ & $\begin{array}{c}\text { South and } \\
\text { South-East } \\
\text { Asia } \\
\text { (SSEA) }\end{array}$ & $\begin{array}{l}\text { Middle East } \\
\text { and } \\
\text { North Africa } \\
\text { (MENA) }\end{array}$ & $\begin{array}{c}\text { Sub-Saharan } \\
\text { Africa } \\
\text { (SSA) }\end{array}$ & Worlc \\
\hline $1820 \mathrm{~s}$ & 13.0 & 7.0 & 33.6 & 19.7 & 9.0 & 7.3 & 6.0 & 2.9 & 8.9 \\
\hline 1830s & 7.4 & 11.4 & 34.0 & 12.6 & 0.5 & 4.7 & 6.0 & 4.1 & 4.5 \\
\hline 1840s & 3.6 & 8.2 & 37.2 & 4.3 & -3.3 & 3.6 & 5.7 & 4.1 & 2.2 \\
\hline $1850 \mathrm{~s}$ & 6.1 & 11.1 & 31.9 & 20.3 & -5.9 & 5.9 & 3.5 & 4.9 & 3.1 \\
\hline 1860s & 5.9 & 9.7 & 25.6 & 9.5 & -0.9 & 3.6 & 4.4 & 6.6 & 4.1 \\
\hline 1870s & 7.3 & 12.5 & 25.5 & 16.9 & 3.3 & 7.9 & 10.6 & 5.0 & 7.7 \\
\hline 1880s & 7.1 & 13.3 & 22.5 & 18.0 & 4.6 & 5.7 & 10.7 & 5.3 & 7.7 \\
\hline $1890 \mathrm{~s}$ & 8.8 & 11.8 & 20.3 & 20.4 & 6.0 & 6.7 & 8.3 & 5.9 & 8.5 \\
\hline $1900 \mathrm{~s}$ & 6.9 & 16.9 & 20.3 & 18.1 & 8.9 & 6.1 & 2.4 & 6.3 & 9.3 \\
\hline $1910 \mathrm{~s}$ & 1.0 & 0.0 & 15.9 & 18.3 & 8.7 & 7.0 & 13.5 & 9.9 & 7.3 \\
\hline $1920 \mathrm{~s}$ & 6.4 & 8.8 & 11.4 & 20.2 & 6.7 & 13.1 & 8.8 & 10.7 & 9.9 \\
\hline $1930 \mathrm{~s}$ & 4.1 & 11.2 & 10.2 & 22.0 & 7.0 & 10.1 & 12.9 & 11.5 & 9.5 \\
\hline $1940 \mathrm{~s}$ & 6.3 & 4.4 & 18.6 & 30.6 & 14.5 & 9.7 & 24.5 & 21.4 & 13.2 \\
\hline 1950s & 8.0 & 18.5 & 17.9 & 31.8 & 18.3 & 24.7 & 30.1 & 30.5 & 21.1 \\
\hline 1960s & 6.3 & 10.2 & 12.5 & 29.0 & 24.6 & 25.8 & 30.3 & 29.8 & 21.8 \\
\hline 1970s & 3.1 & 8.4 & 10.8 & 24.6 & 15.3 & 25.0 & 35.7 & 32.1 & 19.1 \\
\hline 1980s & 3.7 & 4.0 & 11.9 & 20.4 & 13.3 & 22.4 & 28.9 & 30.9 & 17.4 \\
\hline 1990s & 2.9 & -1.3 & 10.5 & 15.2 & 7.6 & 17.9 & 20.5 & 26.8 & 13.3 \\
\hline $2000 \mathrm{~s}$ & 3.0 & -7.3 & 8.1 & 6.8 & 2.6 & 11.6 & 12.1 & 16.7 & 7.7 \\
\hline
\end{tabular}

Note: For an assessment of data quality see Table 2.1.

Source: Clio-Infra, www.clio-infra.eu. 
Figure 2.2. Population growth by region, 1820s-2000s

Percentage growth per decade
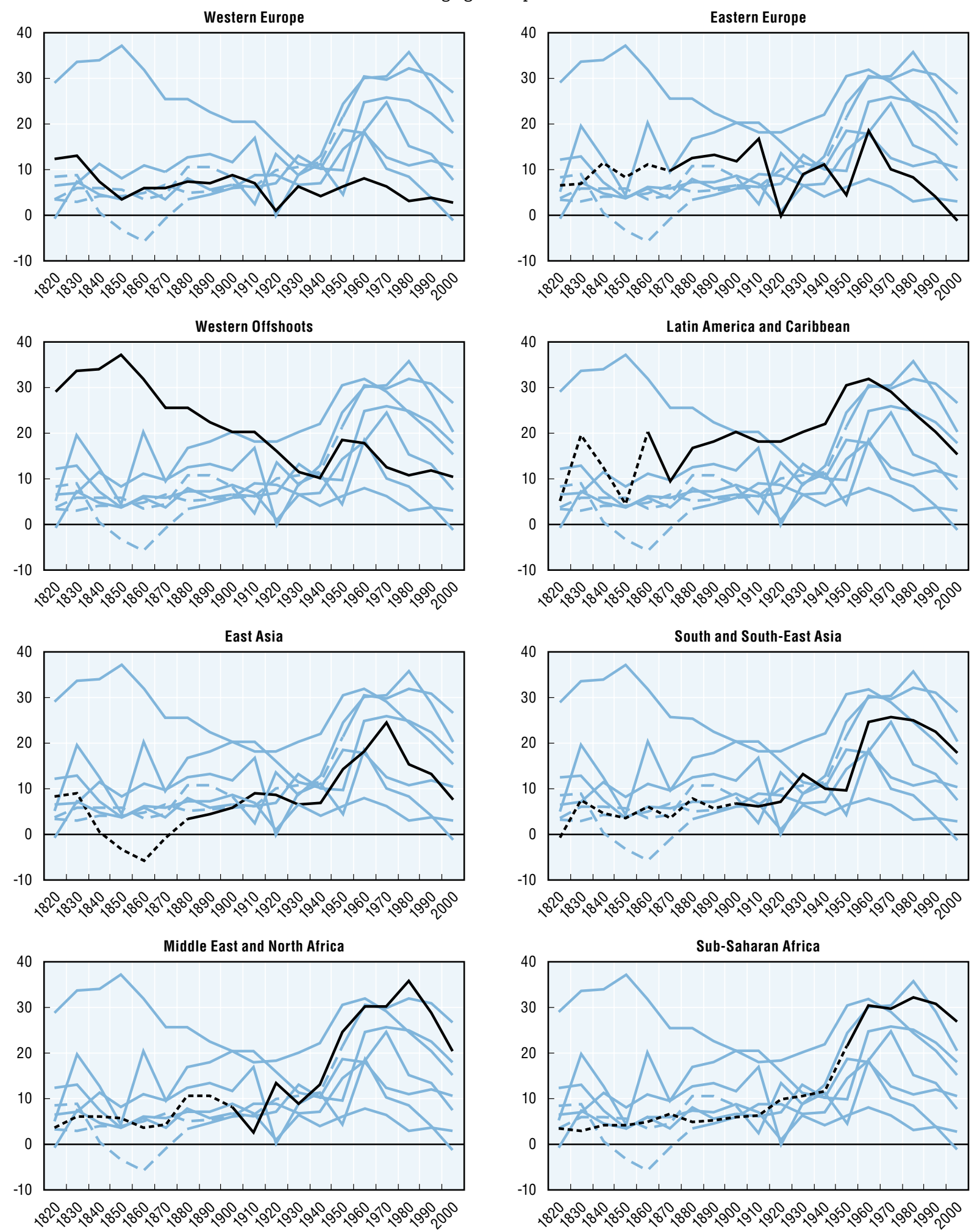

Note: For an assessment of data quality, see Table 2.1. Dotted lines indicate quality 4 data (low quality: guestimates, conjectures). Sources: Clio-Infra, www.clio-infra.eu. 
Offshoots experienced modest population growth after the 1950s. In these regions, the modest "baby boom" after the 1940s was not sustained, and population growth had already receded by the 1960s. The Western Offshoots are the only area where population growth was extremely high in the 19th and early 20th century, mainly reflecting the impact of inmigration. Similar patterns can be found for Latin America and the Caribbean. Between 1846 and 1940, approximately 55 to 58 million people left Europe for the Western Offshoots and Latin America, thus contributing strongly to moderating the population growth rates of Western and Eastern Europe and elevating the rates in the Western Offshoots and later in Latin America and the Caribbean.

All the other regions represented in Figure 2.2 experienced their strongest population growth in the period between 1950 and 1990. The East Asian population continued to increase strongly until the 1970s, but the Chinese one-child policy introduced in 1979 strongly slowed this pace. The MENA countries, South and Southeast Asia and Sub-Saharan Africa stand out with relatively slow population growth until 1950, and then a very rapid increase with a peak around 1970. Latin America and the Caribbean started out with relatively high population growth rates in the late 19th and early 20th century, exhibited a population boom between the 1940s and 1960s, and then entered a phase of declining growth rates ahead of the other regions in the 1970s. In the MENA region and Sub-Saharan Africa, population growth continued longer than in either Asia or Latin America. With respect to timing, the Sub-Saharan Africa trend reflects the trends in Asia and Middle East, but with only a limited decline after 2000. Currently Africa's population is growing faster than in any other region.

Until recently, most scholarly attention has gone to the intercontinental migration from Europe to the Americas. But between 1846 and 1940, in the same period as this major migration towards the Americas, similar huge population movements occurred in Asia. About 50 million people moved from India and southern China to Southeast Asia, the southern Indian Ocean Rim, and the South Pacific. Another estimated 50 million people moved from northeast Asia and Russia to Manchuria, Siberia, central Asia and Japan (McKeown, 2004). As large parts of these movements took place within Asia, their impact on the Asian population trend is relatively limited. But this migration impacted the sub-regions of Asia very strongly. Until recently, these global migration streams largely bypassed Africa. Currently, there is a strong migration from South to North America, which contributed to lowering the population growth rates in the former while raising rates in the latter (Cleland, 2013), as reflected in Figure 2.2. Europe's low rate of growth would have been negative, if not for the increased immigration, including asylum seekers, after the late 1980s (European Communities, 2002). The family reunion of former guest workers from Turkey and Morocco also played a major role in the increase in immigration.

\section{Demographic transitions}

The growth of the world population is determined by birth and death rates, and thus to a large extent by changes in the individual risks of having children and of dying. Demographic change in the past two hundred years has been characterised by a decline in mortality rates, followed by a decline in fertility rates. The quicker the fertility decline followed the onset of mortality decline, the more population growth was held in check. Figure 2.3 plots the demographic trajectory of selected world regions between 1900 and 2000. In the figure, the dotted lines indicate lower quality data, and should be treated with caution. All world regions followed - to a lesser or greater extent - the development sketched above, i.e. an overall move from low to high life expectancy and from high to low 
fertility rates, which implies a move from the upper left hand to the lower right hand corner of Figure 2.3. Greater distances between the labelled points indicate an increasing speed of change. Thus, in the earlier and more recent periods, life expectancy and fertility rates changed at a slower pace than in the period in-between. The example of East Asia shows how to trace the developments over time: for this region, the strongest changes occur after 1920, initially in the form of gains in life expectancy, but after 1960 also in combination with declining fertility rates. Figure 2.3 shows stark differences in how each region made this transition. In 1900 Western Europe had already started at a relatively low fertility level and relatively high life expectancy and has reached, by now, the highest life expectancy and lowest fertility rates. Apart from a brief period, its trajectory was not marked by increasing life expectancy running ahead of the fertility decline. A comparison between East Asia and Western Europe graphically illustrates the different speed at which the different fertility transitions took place. The space between the decennial observations is larger for East Asia than for Western Europe and the slope of the fertility decline between 1960 and 2000 is much steeper. In the MENA countries, there are periods when both life expectancy and fertility rates increased, a combination that ensured strong population growth. To a certain extent, these patterns are similar for the other regions.

Figure 2.3 highlights similar patterns for mortality and fertility rates. While some world regions may have experienced population growth longer than others, there is a trade-off between higher life expectancy and lower fertility rates. This historical and irreversible process has become known as the "demographic transition". Since the mid-19th century this transition has taken place everywhere in the world, albeit with strong regional differences in timing and consequences. In the process, several stages can be discerned. Already in

\section{Figure 2.3. Regional averages of life expectancy at birth and total fertility rates, $1900-2000$}

Years and number of births per woman

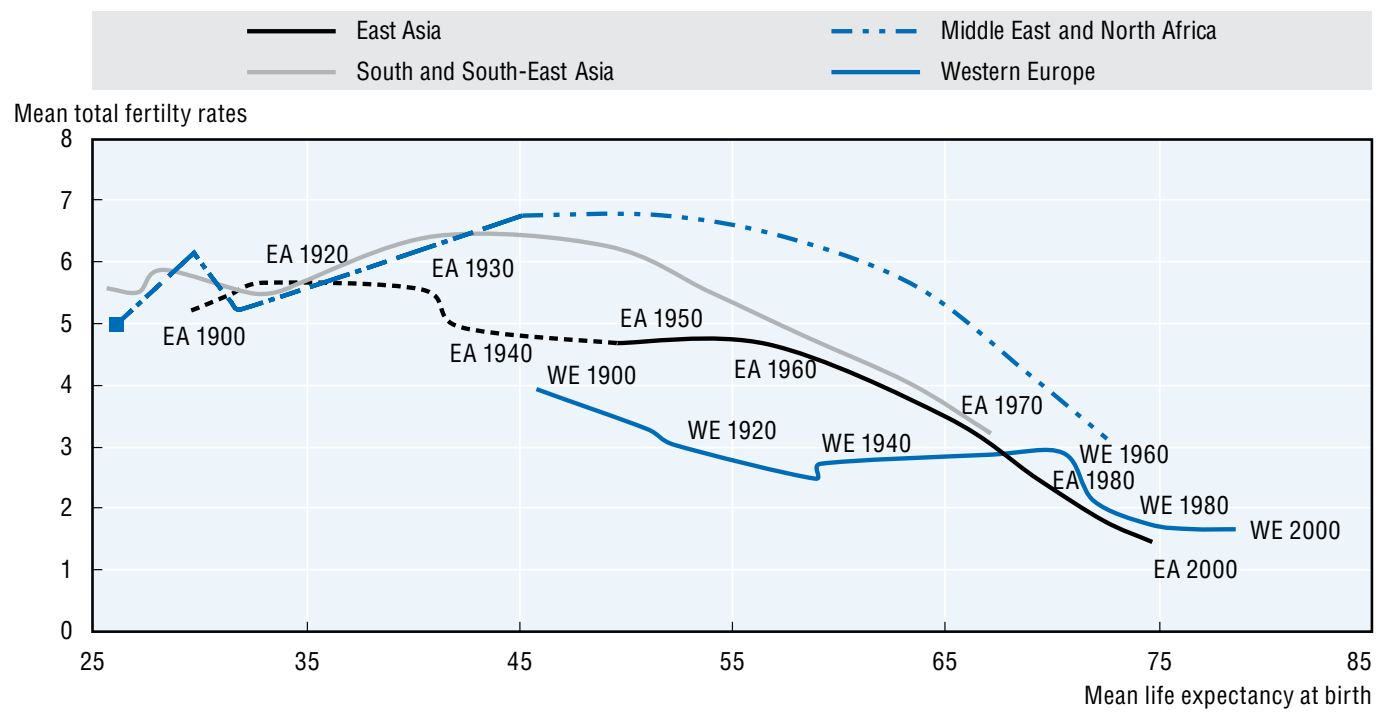

Notes: Dotted lines indicate quality 4 data (low quality). For an assessment of data quality, see Table 2.2.

Sources: Life expectancy at birth: Clio-Infra, www.clio-infra.eu; total fertility rates: Gapminder: Children per woman (total fertility), http://www.gapminder.org. 
the 18th century, mortality rates began to decline in a number of European countries and overseas territories. In some countries, notably France and the North American colonies as well as among the most advantaged groups in various countries (e.g. the aristocracy), the fertility rates also declined. In the 19th century these declines were briefly reversed when birth and death rates increased again. This upswing, whose drivers are still ill understood, formed the immediate precursor of rapid declines in mortality and fertility rates in most Western countries. At first, child mortality declined, followed by infant mortality. In these countries, weaker gains were also made in reducing adult mortality (Reher, 2011). In the first "wave" in Western Europe and its Offshoots, fertility rates began to decline shortly after the onset of mortality decline, with this decline mainly affecting older women once couples reached a desired family size. In most European regions, the onset of the decline (defined as a reduction of at least $10 \%$ in fertility from the previous decade) took place around 1900 (Coale and Watkins, 1986). In the second "wave" (1950s-1980s), developing countries - at first those with close ties to Europe - followed suit. However, these regions experienced a much larger gap between the start of the mortality decline and the start of the fertility decline, resulting in a relatively long period of strong population growth (Figure 2.2). Once begun, however, the declines were faster than in the "first wave" countries (Reher, 2004, p. 24).

The European fertility decline began in France in the 18th century, and then spread to other European countries in the 19th century. The pattern of this extension did not coincide neatly with that of industrialisation, urbanisation and rising living standards. The only factor that almost all European countries had in common was that the mortality decline preceded the fertility decline, which suggests that people responded to the burden of having larger families. Recent micro-level research has confirmed that 19th-century couples responded to the survival of their first-born children by ending their reproductive career, i.e. they stopped having additional children (Van Poppel et al., 2012; Reher and Sanz-Gimeno, 2007). Declines in infant and child mortality, in turn, were not strongly related to higher material well-being. A major factor in their decline was the amelioration of housing conditions and improved access to clean drinking water and milk in the late 19th century, especially in the cities (Costa and Steckel, 1997). Also of importance was the greater awareness of health risks due to better education in health and hygiene, especially of mothers (Reher, 2011; Mokyr and Stein, 1996).

Some European population groups were ahead of others in responding to new knowledge and lowering their fertility rates. The reason for this is that the ability and efficiency of couples to decide about their own procreation differed strongly from one socio-cultural group to another. According to Therborn (2004), agency, or the "sense of personal mastery", had always been stronger among the aristocracy than other groups. Also, rational (family) planning was more widespread among Protestants and Jews than Roman Catholics. Therborn also points out that the early fertility declines in France and North America followed experiences of revolutionary change, which expressed "personal mastery". More generally, the marriage pattern prevailing in Western Europe - as well as in North America - stimulated reproductive agency, characterised by the absence of arranged marriage, higher and similar ages at marriage for men and women, and the formation of a new household at marriage. Compared to couples in regions where co-residence in large and complex households was prevalent, European couples were themselves responsible for the impact of family size on the household's budget. For many centuries, the timing of marriage had been used to adjust procreation to economic circumstances. Within marriage, couples could to some extent "negotiate" whether, when and how they would delay or 
forego the arrival of a next child. Research shows that the deliberate spacing of births to tide the family over difficult periods was a common practice (e.g. Bengtsson and Dribe, 2006; Dribe and Scalone, 2010). Research also indicates that couples always had a moderate target family size in mind, and that they used stopping - albeit with widely varying success rates - to reach that target. The "techniques" employed were basic: abstinence, withdrawal, and prolonged breastfeeding.

The first wave of (Western) fertility decline was not related to technological innovation; for a long time, rubber contraceptive devices remained associated with illicit sex and did not enter married couples' bedrooms (Szreter and Fisher, 2010). The rapid fertility decline experienced by European countries in the late 19th century thus resulted from the willingness and capacity of couples to adjust family size (by delaying marriage and by controlling birth within marriage), combined with the perception that larger families were becoming too costly. The latter factor resulted from the growing awareness that children were much more likely to survive. Moreover, the compulsory schooling introduced in most of Western Europe in the 1870s and 1880s increased the financial costs of children and strengthened couples' motivation to limit the size of their families (Therborn, 2004; Murtin, 2013). Finally, the potential financial "benefits" of children were curbed by laws against child labour. Compulsory schooling and child labour laws reflected a growing cultural appreciation of the child, who was to be kept away from the labour market for as long as possible (Zelizer, 1985; Cunningham, 1995).

In the second wave, in which the demographic transition spread beyond the Western countries, fertility rates responded much later. Why was this so? Several factors played a role. First, mortality decline was much less an intrinsic part of societal transformations (industrialisation, spread of mass education, rise of secular social institutions such as labour unions) than it had been in Europe (Reher, 2004). Instead, it resulted from "imported" new medicines and sanitary and health programmes, sometimes aggressively promoted by governments. Second, traditional family norms and practices implied a different response to the larger size of families. New technologies facilitated fertility limitation, yet its implementation did not fit traditional practices as smoothly. Unlike in Western Europe, the burden of children could be carried by extended households and clans. Also, people in southern and eastern Asia had long-standing traditions of "post-natal" birth control, i.e. the adjustment of family size to circumstances (through infanticide or adoption). In large parts of Africa as well, "excess" children could easily be moved to families of kin as "foster children" (Isiugo-Abanihe, 1985). In many cultures, an outspoken preference for sons also limited the motivation for birth control (Mason, 2001). Often, the position of women in the internal hierarchies in joint family households depended on the number of sons they had. At the same time, governments were eager to promote the Western model of the nuclear family, which was highly associated with modernity and development. Thornton (2005) has described how this "developmental idealism" became a major factor in the demographic change experienced by the developing world after the Second World War. When such policies were implemented, China being the prime example, family limitation could be implemented at a much more rapid pace than in the first wave, due to new technologies and a faster spread of knowledge about the matter. Finally, in many countries, the period of 1950-1980 was characterised by relatively rapid economic growth, which moderated the effect of growing population pressure. Children could be sent to the expanding cities, limiting the need for birth control (Reher, 2004). 
"Classic" transition theory predicted that the world would move from one balanced, stable demographic system to another. However, there were strong fluctuations in vital rates in Western Europe and the Western Offshoots even in the early 20th century. These fluctuations have put in perspective the notion of a self-regulating demographic system, where moderate population growth was based on relatively small families. In the period between the First and Second World Wars, many Western countries already experienced below-replacement fertility rates. Contemporary commentators pointed at the remarkable increase of childless and one-child families, and blamed this on changing life styles (Van Bavel, 2010). At the time, most demographers expected the low fertility rates to last. In this context, the surge of birth rates in the 1950s came as a big surprise (a "birth quake"). Contrary to what is often assumed, the surge was not simply related to the postponement of marriages during the Second World War. In fact, in many Western countries the upward trend in fertility rates was already visible in the late 1930s or early 1940s. Moreover, the baby boom also took place in neutral countries such as Portugal and Sweden. So far, no convincing explanation has been given for this remarkable turn of events. Current research points towards the importance of lower opportunity costs of children for women. Post-war wages rose faster for men than for women, enlarging the gender gap, which stimulated the "breadwinner model" of women staying at home with children. Also, work opportunities for young women had deteriorated relative to older women who had found work during the war and held onto their jobs afterwards. In the 1960s, the retirement of these older women expanded the employment opportunities for younger women and heightened the opportunity costs of children (Van Bavel and Reher, 2013).

In retrospect, the 1940s and 1950s were the golden age of marriage and the breadwinner family in Europe and the Western Offshoots. Neither before nor afterwards had so many people followed a similar life course pattern, determined by marrying, leaving the labour market (women) and having children. All this was to change rapidly in the 1960s: the contraceptive pill decoupled sex from procreation, the sexual revolution decoupled sex from marriage, and the second feminist wave challenged traditional role models. Life courses rapidly lost their predictability, as marriage lost its function as the major initiation to adulthood and social respectability. An increasing part of the population chose to live alone, unmarried couples started to cohabit - initially as a first step towards marriage, but increasingly replacing marriage altogether - and marriages and consensual unions tended to end in separation more often. Furthermore, couples increasingly postponed the advent of children and opted for a very small or childless family. Not surprisingly, fertility rates have gone down once again to sub-replacement levels, and only very recently have there been signs of recovery in some European countries.

These sweeping changes in marriage and the family have been labelled the "second demographic transition". The cause is believed to be a change in the value structure of Western societies, and increasingly in non-Western ones too. The standard of living attained in the 1960s and afterwards has, for the first time in human history, created the opportunity to fulfil "post-materialist" needs, such as recognition, freedom of expression, and self-fulfilment (Lesthaeghe, 2010). Self-fulfilment also implies weaker commitment to lasting relationships, which is reflected in delays in family formation, an increase in living alone and divorce rates, higher cohabitation and fewer children. According to Lesthaeghe and other demographers, this is a truly new transition, not just the next stage of the first demographic transition. In this perspective, while the first transition was triggered by the 
desire of parents to give (a smaller number of) children better opportunities, the second transition is solely the result of a desire for self-fulfilment.

However, many recent global demographic changes, in particular the strong decline of fertility rates, cannot be interpreted solely as the global spread of Westernstyle individualism. In various regions, such as the former Soviet countries, the rise in cohabitation and the decline in fertility levels have been linked to the economic and social crises of the 1990s. Also, in developing and developed countries alike, traditional norms of kin obligations still constrain the decision-making of individuals and couples (e.g. Ochiai, 2011). In Italy, for instance, the prolonged economic dependence of youth on the older generation has led them to postpone parenthood (Dalla Zuanna, 2001). It has also been suggested that the discrepancy between a labour market that offers women greater opportunities and the traditional gender roles of women in the family may have contributed to strong declines in fertility rates in countries such as Italy and Spain (Kertzer et al., 2009; McDonald, 2000).The demographic transition seems far from completed, and global convergence towards a "Western" demographic model, if it ever occurs, is likely to be a protracted process (Wilson, 2011).

\section{Implications of demographic change}

Demographic trends are often described as the consequences of social, economic and cultural changes. However, there is increasing evidence that demography itself has played a major and partly autonomous role in the societal transformations of the past centuries. The differential impact of demographic trends explains to a large extent the persistent divergence of the economic fortunes of the developed and developing countries.

As we have seen, the first wave of the demographic transition is closely linked to the "modernisation" (e.g. improvements in health and education, increased individual "agency") of 19th-century western societies. However, the transition is also believed to have strongly stimulated progress by itself and to have set in motion a "virtuous cycle" of economic and social change (Reher, 2011). First, the transition changed the age structure of society. Initially, when infant and child mortality declined and fertility rates increased, the share of young people in the total population increased, adding to the burden on the working population. However, once fertility rates declined, the "youth bulge" did not become bigger: rather, it worked its way up in the population pyramid and added to the productive labour force. Thus began a period with decreasing dependency ratios - known as the "demographic dividend" - which may have supported economic growth. Of course, in time members of this age group will reach retirement and contribute to increasing oldage dependency ratios. Yet, their life-cycle savings, which they accumulated during the period of economic growth, may amount to a "second demographic dividend" mitigating the negative impact of an ageing population. Most authors underscore that the contribution of the demographic dividend to economic development depends on the ability of the economy to absorb the surplus of working-age population into the productive labour force. The time frame of this dividend - the "window of opportunity" - matters for the likelihood that countries will succeed in productively incorporating this surplus labour (Reher, 2011).

Second, reproduction became much more efficient. High fertility rates and high infant and child mortality meant that women had to spend large parts of their life-time in pregnancy and child care. With declining child mortality, the same number of children 
could be raised with a much lower investment of women's time. This meant women had more time to join the labour market. As women joined the labour market, the number of dependents to earners in the household decreased, with positive effects on the amount of economic resources available per household member. Third, children gained as well, in terms of health and education, from the increased parental time and care. Growing confidence in children's survival also meant that investment in children became more secure, which could stimulate parents to make a trade-off from a high quantity of children with low amounts of human capital, to a smaller quantity of children with a higher human capital stock. According to Reher (2011), parents' growing demand for education was an important factor in the spread of mass education, which added to the virtuous cycle of economic growth. The opportunity for upward social mobility is also part of the incentive structure of modern, industrial society. Greater chances of children from small families to rise on the social ladder (e.g. Van Bavel, 2006) may have induced other couples to keep their families small as well. Fourth, the rising population pressure fuelled by the earlier and stronger decline of mortality than of fertility was relieved through migration. Emigration opened up niches for those who stayed and stimulated the economies of the native countries through remittances. Moreover, a sizeable number of migrants returned, and brought their savings and human capital back to their native economies. Fifth, the decline of adult mortality implied that people could expect to live longer periods in relatively good health. This meant that more people could make realistic "life plans", adding to their "sense of personal mastery". Adult life expectancy improved due to the retreat of infectious diseases, better health provisions, and - in time - the lasting impact of the better care and resources they received as children in smaller families. Finally, the demographic transition may have contributed to the democratisation of countries in the 19th and 20th centuries. The decline in fertility rates - by lowering the speed of population growth, changing women's lives, and shifting the age structure towards adults - was associated with a greater likelihood that autocratic regimes are challenged as well as with greater political stability (Dyson, 2012).

By stimulating low dependency ratios, women's labour market participation, migration, human capital, social mobility, agency and even democracy, the demographic transition can be seen as part and parcel of a "virtuous cycle" of beneficial economic and social developments. Yet whether this cycle is similarly virtuous in the developing world remains to be seen. In the second wave in which the demographic transition spread to the developing world, positive effects occurred to a much more limited extent, if at all. One reason is the gap between the decline in mortality and the decline in fertility. In fact, some regions experienced an increase in fertility rates, and in some of them vital rates were high to begin with. The strong decline in mortality thus led to strong population growth and a relatively large youth bulge. Contrary to the first wave, mass emigration offers limited relief, as host countries have put up many barriers to immigration. The rapid decline of fertility and mortality rates also means that the second wave countries are heading toward strong population ageing in the near future. The shorter period of the demographic dividend implies a smaller period for redirecting resources to alleviate the shock of the future increase in old-age dependants (Pison, 2009). Reher (2011) has demonstrated this by estimating for a sample of countries the "window of opportunity" defined as the difference between the year when tolerable and even beneficial population growth sets in and the year when ageing becomes a major problem. In first wave countries, this time period was comfortably long: in Reher's example, 119 years in Sweden and 104 in Spain. In second wave countries in the sample, the period is much shorter: from 38 years in China to a 
mere 11 years in Morocco. Instead of benefiting from the demographic transition, it is more likely that the mismatch between rapid population growth and available resource adds to the burdens borne by developing countries, further exacerbating inequality in well-being within and between countries.

\section{Priorities for future research}

In demographic terms, the world is facing an uncertain future. In several areas, the decline of fertility below the replacement level is showing no sign of abating, resulting in net population decline. Population ageing is posing economic challenges to societies worldwide. For instance, governments are contemplating scenarios in which costly nursing homes are replaced by extended families. In some countries, this may fit with traditional norms and practices, but in others this may lead to a misfit between family institutions and policy-making. Demographic pressure, inequality and economic stagnation, coupled with ever-expanding communication and transport infrastructures, will continue to fuel the stream of migrants from poor to rich countries. Demographic forecasting is at the heart of policy-making. To improve the quality of forecasts, we will also have to work on our understanding of the past. Insight into the complex (cultural, economic and institutional) settings in which our predecessors were triggered to alter their family composition may still help in calibrating scenarios for the future.

Patterns of demographic change share strong similarities worldwide. Population growth is governed by the dynamics of mortality and fertility rates. Globally, the shift from high fertility rates and low life expectancy towards low fertility rates and high life expectancy has occurred in all the world's regions. Yet the speed and implications of these transitions are different and depend on the region-specific context. Not only does this add to existing inequalities in economic growth and well-being, but it also makes it harder to predict future demographic outcomes.

\section{Note}

1. The arguments for comparing Indian and African growth rates are discussed in Frankema and Jerven (2013), pp. 20-23. We note that these are preliminary estimations, and they have therefore not been added to the population dataset used.

\section{References}

Ajus, F. (2009), "Documentation for Children per Woman (TFR) for Countries and Territories", Version 2, Stockholm, The Gapminder Foundation. www.gapminder.org/documentation/documentation/ gapdoc008_v2.pdf.

Austin, G. (2008), "Resources, Techniques, and Strategies South of the Sahara: Revising the Factor Endowments Perspective on African Economic Development, 1500-20001", The Economic History Review, vol. 61/3), pp. 587-624. doi:10.1111/j.1468-0289.2007.00409.x.

Bengtsson, T. and M. Dribe (2006), "Deliberate Control in a Natural Fertility Population: Southern Sweden, 1766-1864”, Demography, vol.43/4, pp. 727-46, http://dx.doi.org/10.1353/dem.2006.0030.

Bogue, D.J. et al. (1993), Readings in Population Research Methodology: Fertility Research, United Nations Population Fund, Social Development Center, Chicago.

Bongaarts, J. (2009), "Human Population Growth and the Demographic Transition", Philosophical Transactions of the Royal Society B, Biological Sciences, Vol. 364/1532, pp. 2985-90. http://dx.doi. org/10.1098, rstb.2009.0137.

Carr-Saunders, A.M. (1936), World Population: Past Growth and Present Trends, Clarendon Press.

Cleland, J. (2013), "World Population Growth; Past, Present and Future", Environmental and Resource Economics, Vol. 55/4, pp. 543-54, http://dx.doi.org/10.1007/s10640-013-9675-6. 
Coale, A. J. and S. Cotts Watkins (eds), 1986, The Decline of Fertility in Europe, New York, Princeton University Press.

Costa, D.L. and R.H. Steckel (1997), "Long-Term Trends in Health, Welfare, and Economic Growth in the United States", in Health and Welfare during Industrialization, edited by R. H. Steckel and R. Floud, Vol.47/90, University of Chicago Press.

Cunningham, H. (1995), Children and Childhood in Western Society Since 1500, Pearson Education.

Dalla Zuanna, G. (2001), “The Banquet of Aeolus: A Familistic Interpretation of Italy's Lowest Low Fertility." Demographic Research 4 (May), Vol. 133/62, http://dx.doi.org/10.4054, DemRes.2001.4.5.

Denevan, W.M. (1992), The Native Population of the Americas in 1492, University of Wisconsin Press.

Dribe, M. and F. Scalone (2010), "Detecting Deliberate Fertility Control in Pre-Transitional Populations: Evidence from Six German Villages, 1766-1863", European Journal of Population / Revue Européenne de Démographie, Vol. 26/4, pp. 411-34, http://dx.doi.org/10.1007/s10680-010-9208-8.

Durand, J. D. (1977), "Historical Estimates of World Population: An Evaluation", Population and Development Review, Vol.3/3, pp. 253-96, http://dx.doi.org/10.2307/1971891.

Dyson, T. (2012), “On the Democratic and Demographic Transitions," Population and Development Review, Vol. 38 (Supplement), pp. 83-102.

European Communities (2002), European Social statistics, Migration, Luxembourg, Office for Official Publications of the European Communities.

Frankema, E. and M. Jerven (2013). "Writing History Backwards or Sideways: Towards a Consensus on African Population, 1850-present”, Working Paper 10. African Economic History Working Paper Series, www.aehnetwork.org/wp-content/uploads/2012/05/AEHN-WP-101.pdf.

Isiugo-Abanihe, U.C. (1985), “Child Fosterage in West Africa”, Population and Development Review, Vol. 11/1, pp. 53-73, http://dx.doi.org/10.2307/1973378.

Kertzer, D.I., M.J. White, L. Bernardi and G. Gabrielli (2009), "Italy's Path to Very Low Fertility: The Adequacy of Economic and Second Demographic Transition Theories", European Journal of Population/Revue Européenne de Démographie, Vol. 25/1, pp. 89-115, http://dx.doi.org/10.1007/s10680008-9159-5.

Klein Goldewijk, K., A. Beusen and P. Janssen (2010), "Long-Term Dynamic Modeling of Global Population and Built-up Area in a Spatially Explicit Way: HYDE 3.1", The Holocene, Vol. 20/4, pp. 565-73. http://dx.doi.org/10.1177/0959683609356587.

Lahmeyer, J., "Populstat Database. Growth of the Population per Country in a Historical Perspective, Including Their Administrative Divisions and Principal Towns", www.populstat.info/.

Lesthaeghe, R. (2010), "The Unfolding Story of the Second Demographic Transition", Population and Development Review, Vol. 36/2, pp. 211-51, http://dx.doi.org/10.1111/j.1728-4457.2010.00328.x.

Liu, P.K.C. and K. Hwang (1979), "Population Change and Economic Development in Mainland China since 1400" in Modern Chinese Economic History, edited by C. Hou and T. Yu, Vol. 30. Taipei: Academia Sinica.

Livi-Bacci, M. (2007), A Concise History of World Population, John Wiley and Sons.

Maddison, A. (2010), "Statistics on World Population, GDP and Per Capita GDP, 1-2008 AD", Horizontalfile_02-2010.Xls.

Maddison, A. (2007), Chinese Economic Performance in the Long Run, 960-2030 AD, Second Edition, Revised and Updated, Development Centre Studies, OECD Publishing, $h t t p: / / d x . d o i . o r g / 10.1787 / 9789264037632-e n$.

Maddison, A. (2006), The World Economy: Volume 1: A Millennial Perspective and Volume 2: Historical Statistics, Development Centre Studies, OECD Publishing, http://dx.doi.org/10.1787/9789264022621-en.

Maddison, A. (2003), The World Economy: Historical Statistics, Development Centre Studies, OECD Publishing, http://dx.doi.org/10.1787/9789264104143-en.

Maddison, A. (1995), Monitoring the World Economy, 1820-1992, Development Centre Studies, OECD Publishing.

Manning, P. (2010), "African Population: Projections, 1851-1961", in The Demographics of Empire: The Colonial Order and the Creation of Knowledge, edited by K. Ittmann, D.D. Cordell, and G. Maddox, Ohio UP. 
Mason, K.O. (2001), "Gender and Family Systems in the Fertility Transition", Population and Development Review, Vol. 27, pp. 160-76.

McDonald, P. (2000), "Gender Equity in Theories of Fertility Transition", Population and Development Review, Vol. 26/3, pp. 427-39, http://dx.doi.org/10.1111/j.1728-4457.2000.00427.x.

McEvedy, C. and R. Jones (1978), World Atlas of Population History, 1st ed. Hammondsworth, Penguin Books Ltd.

McKeown, A. (2004) “Global Migration 1846-1940”, Journal of World History, Vol. 15/2, pp. 155-89, http:// dx.doi.org/10.1353/jwh.2004.0026.

Mokyr, J. and R. Stein (1996), "Science, Health, and Household Technology: The Effect of the Pasteur Revolution on Consumer Demand", NBER Chapters, National Bureau of Economic Research, Inc. http://econpapers.repec.org/bookchap/nbrnberch/6067.htm.

Murtin, F. (2013), "Long-Term Determinants of the Demographic Transition, 1870-2000", Review of Economics and Statistics, Vol. 95/2, pp. 617-31, http://dx.doi.org/10.1162/REST_a_00302.

Ochiai, E. (2011), "Unsustainable Societies: The Failure of Familialism in East Asia's Compressed Modernity", Historical Social Research, Vol. 26, pp. 219-45.

Perkins, D. H. (1969), Agricultural Development in China: 1368-1968, Edinburgh, Edinburgh University Press.

Pison, G. (2009), "Population Ageing Will Be Faster in the South than in the North", Population and Societies, Vol. 457, pp. 1-4.

Reher, D.S. (2011), "Economic and Social Implications of the Demographic Transition", Population and Development Review, Vol. 37, 11-33, http://dx.doi.org/10.1111/j.1728-4457.2011.00376.x.

Reher, D.S. (2004), “The Demographic Transition Revisited as a Global Process", Population, Space and Place, Vol. 10/1, pp. 19-41, http://dx.doi.org/10.1002/psp.313.

Reher, D.S., and A. Sanz-Gimeno (2007), "Rethinking Historical Reproductive Change: Insights from Longitudinal Data for a Spanish Town", Population and Development Review, Vol. 33/4, pp. 703-27, http://dx.doi.org/10.1111/j.1728-4457.2007.00194.x.

Szreter, S. (2011), "Theories and Heuristics: How Best to Approach the Study of Historic Fertility Declines?" Historical Social Research/Historische Sozialforschung, Vol. 65-98.

Szreter, S. and K. Fisher (2010), Sex Before the Sexual Revolution: Intimate Life in England 1918-1963. Cambridge, Cambridge University Press.

Therborn, G. (2004), Between Sex and Power: Family in the World, 1900-2000, London, Routledge.

Thornton, A. (2005), Reading History Sideways: The Fallacy and Enduring Impact of the Developmental Paradigm on Family Life, University of Chicago Press.

UN Statistics Division (2013), World Population Prospects: The 2012 Revision, New York, United Nations.

Van Bavel, J. and D.S. Reher (2013), “The Baby Boom and Its Causes: What We Know and What We Need to Know", Population and Development Review, Vol. 39/2, pp. 257-88, http://dx.doi.org/10.1111/ j.1728-4457.2013.00591.x.

Van Bavel, J. (2010), "Subreplacement Fertility in the West before the Baby Boom: Past and Current Perspectives", Population Studies, Vol. 64/1, pp. 1-18, http://dx.doi.org/10.1080/00324720903362806.

Van Bavel, J. (2006), “The Effect of Fertility Limitation on Intergenerational Social Mobility: The QualityQuantity Trade-off during the Demographic Transition", Journal of Biosocial Science, Vol. 38/04, pp. 553-69, http://dx.doi.org/10.1017/S0021932005026994.

Van Poppel, D.S. Reher, A. Sanz-Gimeno, M. Sanchez-Dominguez and E. Beekink (2012), "Mortality Decline and Reproductive Change during the Dutch Demographic Transition: Revisiting a Traditional Debate with New Data", Demographic Research, Vol. 27 (August), pp. 299-338, http://dx.doi.org/10.4054/DemRes.2012.27.11.

Willcox, W. F. (1931), "Increase in the Population of the Earth and Its Continents since 1650" in International Migrations, Volume II: Interpretations, pp. 31-82, NBER. www.nber.org/chapters/c5103.pdf.

Wilson, C. (2011), "Understanding Global Demographic Convergence since 1950", Population and Development Review, Vol. 37/2, pp. 375-88, http://dx.doi.org/10.1111/j.1728-4457.2011.00415.x.

Zelizer, V.A. (1985), Pricing the Priceless Child: The Changing Social Value of Children, Princeton University Press. 



\title{
Chapter 3
}

\section{GDP per capita since 1820}

\author{
by \\ Jutta Bolt and Marcel Timmer, University of Groningen \\ and \\ Jan Luiten van Zanden, University of Utrecht, Groningen, Stellenbosch
}

Since 1820, the world economy experienced spectacular growth in output and income. This chapter builds upon the work by Angus Maddison and shows that the world's average GDP per capita increased by a factor of 10 between 1820 and the 2010. Yet, this growth was spread very unevenly, resulting in a considerable increase in average income disparities between countries. In 1820, the richest countries were about five times as wealthy as the poorest countries, whereas they were more than thirty times as well-off in 1950. This divergence was driven by a process of rapid industrialisation. Only recently, as a result of the rapid growth experienced by China and India, has global income inequality begun to decline. The chapter discusses the strong and weak spots in our current knowledge on historical GDP series and points to areas for future research. 


\section{Introduction}

Economic well-being - people's command over produced goods and services - can be assessed in an historical perspective through measures of gross domestic product (GDP) per capita, which is the natural point of departure for any historical investigation of wellbeing. GDP (per capita) is an important indicator for measuring the economic performance of countries, which is a central driver of people's economic well-being. This is true not only because an increased output of goods and services, which is what GDP measures, tends to translate into an increased ability by residents to buy these goods and services, but also because higher GDP provides the means for spending on non-material components of well-being, such as education and health. The growth of GDP and productivity thus had important consequences for changes in well-being over the past 200 years. Building on Angus Maddison's estimates of GDP and population in the world economy between Roman times and the present, this chapter presents trends in GDP per capita since 1820 in a global perspective. The key message from the chapter is that, overall, the world has experienced a substantial improvement in people's command over resources since the early 19th century. The average GDP per capita of the world's population has increased more than tenfold since 1820. Yet, this rise has benefitted different parts of the world very unequally. Until the mid-20th century, the more developed parts of the world grew much more rapidly than the poorer regions, contributing to the considerable increase in income inequality between countries. But poverty is not destiny, and there have been spectacular transitions of countries from poverty to richness over the last 200 years.

\section{Description of the concepts used}

Gross Domestic Product (GDP) and related concepts such as national income have been used and (therefore) criticised so much that we sometimes forget what a good idea it was - and still is - to measure it. Economic statistics were among the first statistics to be produced, and this long tradition has led to consistency in the way they are measured within the System of National Accounts. In terms of the development of economics and statistics, the System of National Accounts was "one of the great inventions of the 20th century". ${ }^{1}$ In principle, GDP summarises in a single figure the value of all the goods and services produced in a society, or alternatively, the value of the total income earned. ${ }^{2}$ From the perspective of people's well-being, the concept of household income would be more relevant to look at than that of the income of the economic system as a whole, which includes income accruing to other institutional sectors, such as firms or general government. Due to data limitations, the distinction between household and economy-wide income is largely ignored in this chapter. We do, however, provide a comparison between income and consumption (although at a national level) to partially address this problem (see below).

The GDP concept plays a central role in our thinking about economic growth and development, and a large part of economic theorising uses (changes in) GDP as the main variable to be explained. Macro-economic growth theory evolved only after the concept of 
GDP was defined clearly. Moreover, economic historians consider the "sustained growth" of per capita GDP as the most significant feature of the "modern" economy as it came into existence after the Industrial Revolution. It is GDP growth - driven by investment and technological change - that ultimately led a substantial part of the world's population out of the mass poverty of the pre-industrial world.

GDP includes both consumption and investment expenditure. From a welfare perspective, it makes sense to distinguish between the two, as the former pertains to current welfare, while the latter leads to the build-up of capital stock that enhances production capacity in the future. When the economy is fully using all its available resources, each society faces a fundamental trade-off between more consumption now or in the future. Therefore, to better track changes in current command over resources, one would like to have information on Gross National Disposable Income, or how much resources are available for consumption. Unfortunately, this measure is not available for the pre-1950 period. An alternative would be to look at what people actually spend on the consumption of goods and services, complemented by data on government consumption, as public expenditures on, for example, education and healthcare also increase people's well-being. ${ }^{3}$ Yet historical data on consumption are very scarce. This chapter therefore relies principally on data on GDP per capita to discuss the main developments in people's command over resources since 1820. Evidence for the most recent period also shows that consumption/GDP ratios can vary substantially across countries and tended to decline when rapid GDP growth set in.

Studies reconstructing historical national accounts generally contain series in national currencies of the individual countries. As our goal is to discern the long-term trends in people's command over resources across the globe between 1820 and today, we need data on GDP per capita that are expressed in a common currency, taking into account differences in price levels and consumption structures, both between countries and over time. This is important, as price levels are correlated with levels of economic development, i.e. prices are on average higher in more developed countries. Not taking this factor into account would lead to an overestimation of incomes in the developed countries. There are various ways to correct for differences in price levels. The data presented here are based on international prices, using common prices of goods and services averaged over all countries. In this way, the purchasing power of residents in each country, or how much one dollar can buy in one country relative to another, is taken into account.

\section{Historical sources}

For the recent period, official statistical agencies provide estimates of GDP and its components, which are harmonised and standardised by various international organisations (OECD, UN, World Bank). The relevant PPPs used to convert GDP values expressed in the prices of each specific country into an international standard are derived from the International Comparison Program (ICP) organised by the World Bank. ${ }^{4}$ However, international organisations do not produce historical time-series of real GDP. This is done in research-driven datasets such as the Penn World Tables, which go back to $1950,{ }^{5}$ and the so-called Maddison dataset, which goes back further in time. Based on a large set of individual country studies, Angus Maddison constructed a set of estimates of real GDP and GDP per capita for (almost) the entire world economy, going back to $1 \mathrm{AD}$, using PPPs for 1990 to express all national series in a common currency (Maddison, 2005, 2008). 
After his demise in 2010, a team of scholars set up "the Maddison project" to further extend and update this dataset. ${ }^{6}$ The initial results of this project were published recently (Bolt and Van Zanden, 2014), and provide the basis for this chapter. Most of the revisions undertaken by the Maddison project concerned the period before 1820, but new data for various regions and countries (e.g. Switzerland, South Africa, Russia, Singapore and various Latin American countries) have also been included. This has enabled us to fill various knowledge gaps in the original dataset created by Maddison. For the post-1820 period, however, these extensions did not significantly alter the picture of long-term economic growth provided by Maddison (Bolt and Van Zanden, 2014).

Research on the systematic measurement and international comparison of national income and product started in the 1930s, with major publications by Colin Clark and Simon Kuznets. After 1945, Kuznets set up an international team of scholars working in this field, with the explicit aim of constructing historical time-series of GDP and its components. This formed the basis for Kuznets' well-known studies into the process of "modern economic growth" published in the 1960s. Kuznets used estimates for a number of advanced countries, including Japan, covering a century of data. Since then, the number of historical studies quantifying economic growth has grown very rapidly; for almost all major countries there are now reconstructions of the historical national accounts going back to the early 19th century, and sometimes even much further back in time (e.g. for England going back to the 1260s, for Peru to 1700, and for Japan to 720 Bolt and Van Zanden, 2014). These historical studies use a large variety of sources to reconstruct the development of national income and product. This includes labour force and production censuses, tax records, data on international trade, wage and price data from various sources, etc.

Generally, the further one goes back in time, the scarcer the data become and the poorer the quality of the GDP estimates. Yet, especially in these circumstances, using the system of national accounts to reconstruct the development of the national product has great advantages. All sectors have their place in the system, and all contributions are calculated consistently. There are three ways to measure a country's GDP within the System of National Accounts: as the total output of goods and services, as the sum total of expenditures (such as consumption and investment), and as the total income earned (wages, profits, etc.). This allows one to use all the information available (about levels of output, income and expenditure) as pieces in a large jigsaw puzzle: almost never do we have all the pieces, but quite often the information is enough to obtain a good picture of the economy concerned.

The starting point in historical national accounting is establishing the size of the population. Population estimates, possibly complemented by labour force data, can be used to estimate the size of various sectors by determining employment per sector. Depending on data availability, population estimates can also be used to estimate the demand for agricultural consumption goods such as wheat and meat, which allows estimations of one part of the output of the agricultural sector. Population can also be used as a crosscheck to see whether estimated agricultural output, or output series for salt or cotton, etc., translates into a reliable estimate of per capita consumption.

The estimation of historical economic activity often starts from the output approach, complemented, depending on data availability, by information on income and expenditure. As described above, one way to establish (part of the) agricultural production is to use the demand for agricultural consumption goods. Information on yields and land under 
cultivation can also be used to calculate total agricultural output. Information on total land under cultivation can again be cross-checked by the total population to see whether the trends obtained are plausible. The output of cash crops can in most instances be obtained from export statistics. Care is taken to make imputations for the non-market production of food, which, especially in pre-industrial societies, was an important part of the economy. One way to circumvent this problem is to use information on population and real wages to establish the subsistence income.

Measuring the output and productivity of the service sector is more difficult than for the goods-producing sector. Frequently, the output of services is measured indirectly, for example, from the income side of the national accounts. An alternative way to measure the output of services is to use quantity indicators, or to assume that the output growth in services follows the output growth in commodity sectors.

Typically, the statistical coverage of these historical estimates is skewed towards the more dynamic sectors of the economy, such as foreign trade, shipping, railway transport and commercial agriculture. This means that the output of the industrial sector is typically better recorded than the output of large parts of the agricultural sector or of the service sector (e.g. domestic work). Conversely, government incomes and expenditures are generally relatively well documented.

\section{Data quality}

There are well-known limitations with regard to what GDP actually measures and how it is measured. One important limitation is that GDP does not include non-market services (other than dwelling services) produced and consumed within the household. This is especially important for historical analysis, as a larger part of consumption was produced by households in the past, implying that the growth of GDP may be biased upward as a result of the commercialisation of this part of consumption (for example, more people eat out instead of preparing their own food now than 50 years ago). Also, the way market activities are recorded has improved over time, implying that production might have been there for a long time, but that it starts to contribute to economic development only when it is recorded. Statistical improvements might therefore also lead to an upward bias in GDP growth. The GDP series presented here are adjusted to include the auto-consumption by farmers (the share of output that does not leave the farm), although the quality of these estimates varies across countries and over time.

How GDP is measured has limitations as well. The estimates of the national accounts of countries in the past - and in particular in the more distant past - are subject to certain margins of error. They are often based on partial data and on assumptions about the links between these data (e.g. the proceeds of a specific tax) and the economic activities they represent. In general, the further one goes back in time, the larger the margins of error will be, although there may be exceptions to this rule: we know more about Medieval England than, for example, 19th-century Sub-Saharan Africa, or pre-Colombian Latin America. Moreover, the quality of the data does not always linearly decrease further back in time. Occasionally, detailed censuses or sources make it possible to create a reliable benchmark estimate for a given year. Moreover, an international comparison of such benchmark estimates, e.g. for the Netherlands and parts of China in the early 1820s, makes it possible to check the consistency of the estimates. Also, international comparisons of real wages supply proxies that can be used to check the plausibility of the GDP estimates. For the period after the 1820s, the historical estimates presented here are deemed to be 
relatively good, although different researchers may reach different conclusions in the case of different countries, and the quality of these estimates will improve as new data sources are identified.

The historical data shown in this chapter are expressed in 1990 constant prices. In other words, a benchmark year PPP is estimated for the year 1990, which is used to compute a comparative GDP level for all countries in that year. From this benchmark year, the original GDP per capita series for all countries are extrapolated (backward and forward) using volume growth rates of GDP for the countries included in the set. The key characteristic of the constant price PPP approach for long-term analysis is that it replicates the relative moments of real GDP in national currencies. In other words, the original time series are unaffected by the choice of the benchmark year. The main drawback of this approach is that the underlying price structure of each economy is that of the benchmark year. As a result, a comparison of GDP levels between countries further away from 1990 might be biased, especially if the price structures of countries included in the comparison change in very different ways.

The quality of the National Accounts estimates made by official statistical agencies is generally high; however, some problems do remain even for the most recent period. Regular revisions of GDP estimates by these agencies - the result of new information and/or revisions of the internationally accepted System of National Accounts (SNA) - sometimes result in breaks in historical time series that limit comparison in time and space. The quality of the official statistics is related to the quality of censuses and, more generally, to the capacity of the government to register and "monitor" its population. In particular, new, relatively weak states may have an incentive to under-estimate their economic performance (e.g. to qualify for certain forms of international aid). Moreover, international comparisons are constrained by the limitations both of the PPP approach and of the various ICP-rounds carried out by the World Bank. Modern statistical work in this field began on a global scale in the 1950s. Almost all estimates for the period before the 1940s are the result of research in economic history, which also began in earnest in the 1950s, although a few official statistical agencies published studies on GDP and its components for earlier years. The classification of the quality of the historical estimates presented in Table 3.1 is based on what is known about available sources and studies (see Bolt and Van Zanden, 2014,

Table 3.1. Quality of data on GDP by region and benchmark year, 1820-2000

\begin{tabular}{|c|c|c|c|c|c|c|c|c|}
\hline & $\begin{array}{l}\text { Western } \\
\text { Europe } \\
\text { (WE) }\end{array}$ & $\begin{array}{c}\text { Eastern } \\
\text { Europe } \\
\text { (EE) }\end{array}$ & $\begin{array}{c}\text { Western } \\
\text { Offshoots } \\
\text { (WO) }\end{array}$ & $\begin{array}{l}\text { Latin } \\
\text { America } \\
\text { and } \\
\text { Caribbean } \\
(\mathrm{LA})\end{array}$ & $\begin{array}{c}\text { Sub-Saharan } \\
\text { Africa } \\
\text { (SSA) }\end{array}$ & $\begin{array}{c}\text { Middle East } \\
\text { and } \\
\text { North Africa } \\
\text { (MENA) }\end{array}$ & $\begin{array}{c}\text { East Asia } \\
(\mathrm{EA})\end{array}$ & $\begin{array}{c}\text { South and } \\
\text { South-East } \\
\text { Asia } \\
\text { (SSEA) }\end{array}$ \\
\hline 1820 & 3 & 4 & 3 & 4 & 4 & 4 & 3 & 4 \\
\hline 1870 & 2 & 3 & 3 & 3 & 4 & 4 & 3 & 4 \\
\hline 1920 & 2 & 3 & 2 & 3 & 4 & 3 & 3 & 3 \\
\hline 1950 & 1 & 1 & 1 & 1 & 1 & 1 & 1 & 1 \\
\hline 1970 & 1 & 1 & 1 & 1 & 1 & 1 & 1 & 1 \\
\hline 2000 & 1 & 1 & 1 & 1 & 1 & 1 & 1 & 1 \\
\hline
\end{tabular}

Note: 1. High quality; 2. Moderate quality; 3. Low quality; and 4. Estimates.

See the section on "Data Quality" in Chapter 1 for a description of the quality criteria.

Source: Clio-Infra, www.clio-infra.eu. 
for a recent overview). Most problematic are the estimates for Sub-Saharan Africa, which (with the exception of South Africa) are highly speculative for the pre-1950 period (and also weak for the second half of the 20th century). Western Europe, the Western Offshoots and Japan have the highest quality data for the 19th century. Moreover, various studies have been carried out to test the plausibility of the results gained through the backward projection of time-series linked to the 1990 benchmark created by Maddison; these studies generally confirm the robustness of the estimates based on this method (for example, the ratio between estimates of GDP per capita in 1820 for the Netherlands, on the one hand, and Indonesia or China, on the other hand, is confirmed by an independent benchmark for that year).

The number of countries for which long-term GDP per capita series are available varies considerably between regions (see Table 3.3). The best-covered regions are Western Europe and the Western Offshoots. For the other regions, the number of countries included increases substantially over time: from 9 in Latin America and 10 in the Middle East and North Africa in 1820, to 23 and 20, respectively, in 2010. The most important increase in coverage for all regions (except Europe and the Western Offshoots) took place after 1950.

This increase in country coverage within regions complicates the interpretation of the regional average. When levels of GDP per capita between countries in a region differ substantially, the regional average will be significantly influenced by the inclusion of more countries. For example, the increase in GDP per capita in Eastern Europe between 1940 and 1950 coincides with a more than doubling of the number of countries for which we have estimates. The same holds for Southeast Asia between 1930 and 1950, and for the Middle East and North Africa between 1910 and 1950. However, in other cases major changes in the regional GDP per capita do not reflect changes in country coverage. For the Middle East and North Africa, for example, there are substantial changes in GDP per capita between 1950 and 1960, although the country coverage during the period remains constant. Similarly, in Eastern Europe the number of countries covered remains constant between 1990 and 2000, while GDP per capita increases considerably. It is therefore important to verify what is driving changes in the regional GDP per capita before drawing conclusions.

Comparable data for Africa are so scarce that it is difficult to draw any general conclusions (the Sub-Saharan Africa estimates for the 19th century presented in Table 3.1 relate only to South Africa, and are therefore not representative for the region as a whole). The data availability and quality for many African countries in the post-1950 period also varies greatly (Lehohla, 2008; De Vries et al., 2013), and statistical capacities in many African countries increased significantly after 1990. This led various national statistical offices to revise their GDP levels upward in recent years (by as much as 62\% in Ghana, and 30\% in Malawi). The data used in this chapter do not yet reflect these upward revisions.

We know relatively little of China's long-run GDP growth and how it compares to other countries. The best documented pre-WWII year of the Chinese economy is 1933, which was a relatively good year, as the level of GDP per capita was higher than in the early 1950s. Based on scattered information from studies into different sectors and time periods prior to 1933 , the 1933 GDP per capita level has been extrapolated backwards to 1890 , which suggests that the Chinese economy had been largely stagnant in per capita terms. Recently, much work has been devoted to producing a detailed set of estimates of the structure and level of GDP in the most advanced part of the empire, the Yangtze Delta (in fact, in a part of that region, Hua-Lou district) in the 1820s (Li and Van Zanden, 2012). These benchmarks provide the first stepping stone for creating long-term time series of Chinese GDP. 


\section{Main highlights of GDP trends since 1820}

The evolution of GDP per capita since 1820 is a fairly well-known story, based largely on the Maddison dataset, with some good and some bad news. The good news is that since the 1820s the average GDP per capita of the world's population has increased by a factor of 10, a growth that contributed immensely to increased economic well-being. No region or country saw its real income decline in over this long period, although during shorter time periods - e.g. China in the 19th century, Eastern Europe after the abolition of central planning, parts of Africa during the 1980s and 1990s - real GDP per capita did fall substantially. The process of "modern growth" of GDP per capita started in the early 19th century and was primarily the result of the spread of the Industrial Revolution. It resulted in a strong decline in agriculture's share in the economy and the rise of manufacturing and services as sources of income and employment.

The bad news is that GDP growth was very unevenly distributed across the various regions: during the 19th century, rich countries became richer and poor countries fell behind, resulting in a substantial increase in global inequality in GDP per capita. Global inequality kept rising during the first half of the 20th century, when the United States economy grew more rapidly than the rest of the world. After the 1950s, however, this process slowly started to reverse. For the first time, the economic growth rates experienced by poor economies were of a similar magnitude as those of rich economies. And, since the 1970s, low-income countries, in particular in Asia, grew much faster than high-income countries. This picture does not change greatly when we move from GDP to consumer expenditure. Generally, cross-country differences are somewhat smaller in terms of consumption, due to the fact that in low-income countries consumption generally represents a higher share of GDP than it does in high-income countries. For middle-income countries - notably China the share of consumption was much lower than in other countries, which was reflected in the much higher investment share of these often rapidly-growing countries.

Already in the 1820s, GDP per capita in Western Europe and the Western Offshoots had forged ahead relative to the rest of the world (Table 3.2). This early divergence in per capita GDP between (North Western) Europe and Asia has been the topic of a fierce debate (Pomeranz, 2000; Parthasarathi, 1998; Broadberry and Gupta, 2006; Li and Van Zanden, 2012). The key question in this literature is whether the level of economic development (in terms of GDP per capita) in China (as well as India and Japan) before industrialisation was comparable to that in Western Europe. Most recent historical estimates in fact indicate that already in 1820 GDP per capita in (North) Western Europe (with an average value of about 1400 dollars) was much higher than in the rest of the world (with the exception of the United States - Bolt and van Zanden, 2014). For example, comparing the most advanced part of the Chinese empire (the Hua-Lou district) with the Netherlands (one of the more advanced parts of Western Europe) in 1820 shows a real income gap of about 40-50\% (Li and Van Zanden, 2012).

At the same time, substantial differences in GDP per capita existed within Western Europe. The richest country in 1820 was Great Britain, ${ }^{7}$ at around USD 2100 per capita, while the poorest country was Finland with an average of USD 781 per capita. North America (e.g. the United States, at around USD 1300) and the southern cone of Latin America (e.g. Argentina, with USD 998, and Uruguay, at USD 1165) came very close to the Western European average (or even surpassed it, as in the case of the United States). GDP per capita for Latin America was much lower, with an average value of USD 620. Other countries in the southern hemisphere had comparable low levels of GDP per capita: the average GDP 
per capita for the Cape Colony in 1820 was about USD 800, while it was even lower in Australia, at around USD 518. The most populous countries of the world - China, India, Indonesia - had GDP per capita ranging between USD 530 and USD 600 in 1820, about half the Western European level. Japan recorded a somewhat higher per capita GDP (USD 660), as did the Ottoman Empire (USD 740). Global inequality in GDP per capita was still modest: the wealthiest developed country (Great Britain) was "only" about four times as rich as the poorest one in 1820 (Australia, at USD 518).

Since 1820, the world has witnessed a spectacular growth of economic well-being and production capacity. On a global scale, GDP per capita has risen 10-fold since 1820 (Table 3.2). The average level of world GDP per capita increased from USD 650 in the 1820s to USD 1291 in the 1900s, and from USD 2405 in the 1950s to almost USD 7000 in the 2000s. However, growth in per capita GDP accelerated more slowly: it took about 80 years (from 1820 to 1900) for the world average level of GDP per capita to double, 55 years to double again (in 1956), and 45 years to double for the third time (in 1991).

In the long run, all countries (Tables 3.2 and 3.4) and regions (Figure 3.1) experienced gains in real income levels. China is the only country that experienced a strong decline in GDP per capita in the 19th century (Table 3.4). During the 20th century, and in particular after 1950, all parts of the world experienced real, and sometimes accelerating, economic

Table 3.2. Regional averages of GDP per capita, 1820-2010

US dollars at 1990 PPPs

\begin{tabular}{|c|c|c|c|c|c|c|c|c|c|}
\hline Decade & $\begin{array}{c}\text { Western } \\
\text { Europe } \\
\text { (WE) }\end{array}$ & $\begin{array}{c}\text { Eastern } \\
\text { Europe } \\
\text { (EE) }\end{array}$ & $\begin{array}{l}\text { Western } \\
\text { Offshoots } \\
\text { (W0) }\end{array}$ & $\begin{array}{l}\text { Latin } \\
\text { America } \\
\text { and } \\
\text { Caribbean } \\
\text { (LA) }\end{array}$ & $\begin{array}{c}\text { East Asia } \\
\text { (EA) }\end{array}$ & $\begin{array}{c}\text { South and } \\
\text { South-East } \\
\text { Asia } \\
\text { (SSEA) }\end{array}$ & $\begin{array}{c}\text { Middle East } \\
\text { and } \\
\text { North Africa } \\
\text { (MENA) }\end{array}$ & $\begin{array}{c}\text { Sub-Saharan } \\
\text { Africa } \\
\text { (SSA) }\end{array}$ & World \\
\hline 1820 & 1226 & .. & 1294 & 595 & 579 & .. & 580 & .. & 605 \\
\hline 1830 & 1344 & .. & 1489 & .. & .. & .. & .. & .. & .. \\
\hline 1840 & 1522 & .. & 1641 & .. & .. & .. & .. & .. & .. \\
\hline 1850 & 1589 & .. & 1809 & 663 & 599 & .. & .. & .. & 706 \\
\hline 1860 & 1823 & .. & 2200 & 676 & .. & .. & .. & .. & .. \\
\hline 1870 & 1976 & 719 & 2421 & 754 & 543 & 516 & 720 & .. & 837 \\
\hline 1880 & 2190 & .. & 3135 & 846 & .. & .. & .. & .. & .. \\
\hline 1890 & 2506 & 1002 & 3375 & 998 & 582 & 572 & .. & .. & 1058 \\
\hline 1900 & 2912 & 1273 & 4013 & 1129 & 607 & 597 & .. & .. & 1225 \\
\hline 1910 & 3172 & 1433 & 4915 & 1433 & .. & 674 & .. & .. & 1399 \\
\hline 1920 & 3070 & 927 & 5396 & 1540 & .. & 662 & .. & .. & 1381 \\
\hline 1930 & 4006 & 1597 & 6025 & 1795 & 723 & 756 & .. & .. & 1673 \\
\hline 1940 & 4472 & 2097 & 6837 & 1981 & .. & 749 & .. & .. & 1878 \\
\hline 1950 & 4518 & 2583 & 9258 & 2502 & 655 & 675 & 1459 & 843 & 2082 \\
\hline 1960 & 6825 & 3627 & 10954 & 3119 & 1082 & 814 & 1977 & 987 & 2709 \\
\hline 1970 & 10108 & 5138 & 14554 & 3977 & 1796 & 977 & 3020 & 1239 & 3599 \\
\hline 1980 & 13127 & 6216 & 18054 & 5436 & 2479 & 1196 & 4102 & 1282 & 4372 \\
\hline 1990 & 15919 & 6389 & 22347 & 5047 & 3782 & 1609 & 3807 & 1135 & 5023 \\
\hline 2000 & 19315 & 4950 & 27572 & 5848 & 5451 & 2198 & 4497 & 1099 & 5957 \\
\hline 2010 & 20841 & 8027 & 29581 & 7109 & 9804 & 3537 & 5743 & 1481 & 7890 \\
\hline
\end{tabular}

Note: For an assessment of data quality, see Table 3.1. Source: Clio-Infra, www.clio-infra.eu. 
Table 3.3. Number of countries in GDP dataset by region and year, 1820-2010

\begin{tabular}{|c|c|c|c|c|c|c|c|c|c|}
\hline & $\begin{array}{l}\text { Western } \\
\text { Europe } \\
\text { (WE) }\end{array}$ & $\begin{array}{c}\text { Eastern } \\
\text { Europe } \\
\text { (EE) }\end{array}$ & $\begin{array}{l}\text { Western } \\
\text { Offshoots } \\
\text { (W0) }\end{array}$ & $\begin{array}{l}\text { Latin } \\
\text { America } \\
\text { and } \\
\text { Caribbean } \\
\text { (LA) }\end{array}$ & $\begin{array}{c}\text { East Asia } \\
\text { (EA) }\end{array}$ & $\begin{array}{c}\text { South and } \\
\text { South-East } \\
\text { Asia } \\
\text { (SSEA) }\end{array}$ & $\begin{array}{l}\text { Middle East } \\
\text { and } \\
\text { North Africa } \\
\text { (MENA) }\end{array}$ & $\begin{array}{l}\text { Sub-Saharan } \\
\text { Africa } \\
\text { (SSA) }\end{array}$ & World \\
\hline 1820 & 11 & 1 & 3 & 9 & 5 & 9 & 10 & .. & 49 \\
\hline 1830 & 9 & .. & 3 & .. & .. & 2 & .. & .. & 15 \\
\hline 1840 & 10 & .. & 3 & .. & .. & 2 & .. & .. & 16 \\
\hline 1850 & 15 & 1 & 4 & 9 & 2 & 3 & .. & .. & 35 \\
\hline 1860 & 15 & .. & 4 & 9 & .. & 2 & .. & .. & 31 \\
\hline 1870 & 16 & 7 & 4 & 11 & 6 & 10 & 11 & .. & 67 \\
\hline 1880 & 15 & 1 & 4 & 10 & 1 & 3 & .. & .. & 35 \\
\hline 1890 & 15 & 8 & 4 & 11 & 2 & 4 & .. & .. & 45 \\
\hline 1900 & 15 & 8 & 4 & 11 & 3 & 6 & .. & .. & 48 \\
\hline 1910 & 16 & 8 & 4 & 11 & 6 & 10 & 11 & .. & 68 \\
\hline 1920 & 16 & 8 & 4 & 16 & 4 & 8 & 1 & .. & 58 \\
\hline 1930 & 16 & 7 & 4 & 17 & 4 & 8 & 1 & .. & 58 \\
\hline 1940 & 16 & 6 & 4 & 20 & 3 & 5 & 1 & .. & 56 \\
\hline 1950 & 16 & 14 & 4 & 23 & 7 & 15 & 21 & 46 & 146 \\
\hline 1960 & 16 & 14 & 4 & 23 & 7 & 15 & 21 & 46 & 146 \\
\hline 1970 & 16 & 29 & 4 & 23 & 7 & 15 & 21 & 46 & 161 \\
\hline 1980 & 16 & 14 & 4 & 23 & 7 & 15 & 21 & 46 & 146 \\
\hline 1990 & 16 & 28 & 4 & 23 & 7 & 15 & 21 & 46 & 160 \\
\hline 2000 & 16 & 28 & 4 & 23 & 7 & 15 & 21 & 46 & 160 \\
\hline 2010 & 16 & 28 & 4 & 14 & 5 & 12 & 18 & 20 & 117 \\
\hline
\end{tabular}

Note: For an assessment of data quality, see Table 3.1

Source: Clio-Infra, www.clio-infra.eu.

growth. Real declines in material standards of living over long periods are exceptional for the post-1950 period; the most important case was the decline in GDP per capita experienced in the former Soviet Union (by around one-third between 1990 and 2000), following the dismantling of the centrally planned economies (Bolt and van Zanden, 2014). But other regions also experienced disappointing GDP performance during those years. Sub-Saharan Africa, for example, experienced its "lost decades" during the 1980s and 1990s, while Latin America's growth performance was also quite poor in that period. East Asia, and to a lesser extent, South- and Southeast Asia, were the most dynamic parts of the world economy from the 1960s, although there were exceptions even in these regions: Japan, after catching up in the 1980s, experienced very slow growth since then (Table 3.4).

As described by Maddison (2001; 2003), world leadership in terms of GDP per capita (as well as labour productivity, measured as GDP per hour worked) has changed only a few times: the Netherlands was the productivity leader in the 17th and 18th centuries, until the United Kingdom took over world leadership after about 1780. The United Kingdom was in turn surpassed by the United States between 1870 and 1900, in terms of both GDP per capita and labour productivity. The Trans-Atlantic productivity gap widened substantially between 1900 and 1950, and Western Europe only started to catch up after 1950. The gap in GDP per capita between the United States and Western Europe persisted, however, partly due to higher levels of labour force participation and working hours in the United States (Maddison, 2001). 
Table 3.4. GDP per capita in selected countries, 1820-2010

US dollars at 1990 PPPs

\begin{tabular}{|c|c|c|c|c|c|c|c|c|c|c|c|c|c|c|c|c|c|c|c|c|c|c|c|c|c|}
\hline \multirow[b]{2}{*}{ Decade } & \multicolumn{7}{|c|}{$\begin{array}{l}\text { Western Europe } \\
\text { (WE) }\end{array}$} & \multicolumn{2}{|c|}{$\begin{array}{c}\text { Eastern Europe } \\
(\mathrm{EE})\end{array}$} & \multicolumn{3}{|c|}{$\begin{array}{l}\text { Western Offshoots } \\
\text { (W0) }\end{array}$} & \multicolumn{3}{|c|}{$\begin{array}{l}\text { Latin America and } \\
\text { Caribbean } \\
\text { (LA) }\end{array}$} & \multicolumn{2}{|c|}{$\begin{array}{c}\text { Middle } \\
\text { East and } \\
\text { North Africa } \\
\text { (MENA) }\end{array}$} & \multicolumn{3}{|c|}{$\begin{array}{c}\text { Sub-Saharan Africa } \\
(\mathrm{SSA})\end{array}$} & \multicolumn{2}{|c|}{$\begin{array}{l}\text { East Asia } \\
\text { (EA) }\end{array}$} & \multicolumn{3}{|c|}{$\begin{array}{c}\text { South and } \\
\text { South-East Asia } \\
\text { (SSEA) }\end{array}$} \\
\hline & GBR & NLD & FRA & DEU & ITA & ESP & SWE & POL & RUS & AUS & CAN & USA & MEX & BRA & ARG & EGY & TUR & KEN & NGA & ZAF & CHN & JPN & IND & IDN & THA \\
\hline 1820 & 2074 & 1874 & 1135 & .. & 1511 & .. & 888 & .. & .. & 518 & 904 & 1361 & 627 & 683 & 998 & 475 & 740 & .. & .. & 745 & 600 & .. & .. & 528 & 570 \\
\hline 1830 & 2227 & 1893 & 1191 & .. & 1507 &.. & 921 &.. & & 848 & 1000 & 1547 & .. & .. & .. & ... & &.. &.. & & .. & .. & .. & 525 & .. \\
\hline 1840 & 2521 & 2257 & 1428 & .. & 1537 & .. & 984 & .. & & 1374 & 1162 & 1690 & .. & .. & & & & .. & .. & 736 & .. & .. & .. & 564 & .. \\
\hline 1850 & 2330 & 2355 & 1597 & 1428 & 1481 & 1079 & 1076 & .. & .. & 1975 & 1330 & 1849 & 656 & 683 & 1251 & .. & & .. & .. & 654 & 600 & 681 & .. & 462 & .. \\
\hline 1860 & 2830 & 2392 & 1892 & 1639 & 1459 & 1236 & 1218 & .. & .. & 2894 & 1451 & 2241 & 573 & 680 & 1355 & .. & & .. & .. & 812 & .. & .. & .. & 523 & .. \\
\hline 1870 & 3190 & 2755 & 1876 & 1839 & 1542 & 1207 & 1345 & 946 & .. & 3273 & 1695 & 2445 & 651 & 713 & 1468 & 649 & 825 & .. & .. & 807 & 530 & 737 & 533 & 517 & 608 \\
\hline 1880 & 3477 & 2927 & 2120 & 1991 & 1589 & 1646 & 1480 & .. & .. & 4285 & 1816 & 3184 & .. & 752 & 1604 & .. & & .. & .. & 1439 & .. & 863 & & 665 & .. \\
\hline 1890 & 4009 & 3186 & 2376 & 2428 & 1690 & 1624 & 1635 & 1284 & 866 & 4458 & 2378 & 3392 & 976 & 794 & 2416 & .. & .. & .. & .. & 1148 & 540 & 1012 & 584 & 657 & 784 \\
\hline 1900 & 4492 & 3329 & 2876 & 2985 & 1855 & 1786 & 2083 & 1536 & 1196 & 4013 & 2911 & 4091 & 1319 & 678 & 2875 & .. & .. & .. & .. & 937 & 545 & 1180 & 599 & 734 & .. \\
\hline 1910 & 4611 & 3783 & 2965 & 3348 & 2176 & 1895 & 2543 & 1690 & 1348 & 5210 & 4066 & 4964 & 1694 & 769 & 3822 & .. & .. & .. & .. & 1151 & .. & 1304 & 697 & 807 & .. \\
\hline 1920 & 4548 & 4220 & 3227 & 2796 & 2153 & 2177 & 3004 & .. & 575 & 4766 & 3861 & 5552 & 1823 & 963 & 3473 & .. & .. & .. & .. & .. & .. & 1696 & 635 & 899 & .. \\
\hline 1930 & 5441 & 5603 & 4532 & 3973 & 2631 & 2620 & 4238 & 1994 & 1448 & 4708 & 4811 & 6213 & 1618 & 1048 & 4080 & .. & 1249 & .. & .. & 1413 & 568 & 1850 & 726 & 1087 & .. \\
\hline 1940 & 6856 & 4831 & 4042 & 5403 & 2897 & 2080 & 4855 &.. & 2144 & 6166 & 5368 & 7010 & 1852 & 1250 & 4161 & .. & 1675 & .. & .. & 2145 & .. & 2874 & 686 & 1127 & \\
\hline 1950 & 6939 & 5996 & 5186 & 3881 & 3172 & 2189 & 6739 & 2447 & 2841 & 7412 & 7291 & 9561 & 2365 & 1672 & 4987 & 910 & 1623 & 651 & 753 & 2535 & 448 & 1921 & 619 & 817 & 817 \\
\hline 1960 & 8645 & 8287 & 7398 & 7705 & 5456 & 3072 & 8688 & 3215 & 3945 & 8791 & 8753 & 11328 & 3155 & 2335 & 5559 & 991 & 2247 & 726 & 820 & 3041 & 662 & 3986 & 753 & 1015 & 1078 \\
\hline 1970 & 10767 & 11967 & 11410 & 10839 & 9367 & 6319 & 12716 & 4428 & 5575 & 12024 & 12050 & 15030 & 4320 & 3057 & 7302 & 1254 & 3078 & 915 & 1094 & 4045 & 778 & 9714 & 868 & 1231 & 1694 \\
\hline 1980 & 12931 & 14705 & 14766 & 14114 & 12927 & 9203 & 14937 & 5740 & 6427 & 14412 & 16176 & 18577 & 6320 & 5195 & 8206 & 2069 & 4022 & 1051 & 1305 & 4390 & 1061 & 13428 & 938 & 1898 & 2554 \\
\hline 1990 & 16430 & 17262 & 17647 & 15929 & 16313 & 12055 & 17609 & 5113 & 6894 & 17173 & 18872 & 23201 & 6085 & 4920 & 6433 & 2523 & 5399 & 1117 & 1112 & 3834 & 1871 & 18789 & 1309 & 2514 & 4633 \\
\hline 2000 & 21046 & 22148 & 20392 & 18944 & 18761 & 15724 & 20871 & 7309 & 5261 & 21378 & 22488 & 28702 & 7275 & 5418 & 8410 & 3258 & 6502 & 1013 & 1041 & 3920 & 3421 & 20481 & 1882 & 3229 & 6440 \\
\hline 2010 & 23777 & 24303 & 21477 & 20661 & 18520 & 16797 & 25306 & 10762 & 8660 & 25584 & 24941 & 30491 & 7716 & 6879 & 10256 & 4267 & 8225 & 1141 & 1876 & 5080 & 8032 & 21935 & 3372 & 4722 & 9372 \\
\hline
\end{tabular}

Note: For an assessment of data quality, see Table 3.1.

Source: Clio-Infra, www.clio-infra.eu. 


\section{Figure 3.1. Regional averages of GDP per capita, 1820-2010}

US dollars at 1990 PPPs

East Asia

GDP per capita (USD at 1990 PPP)

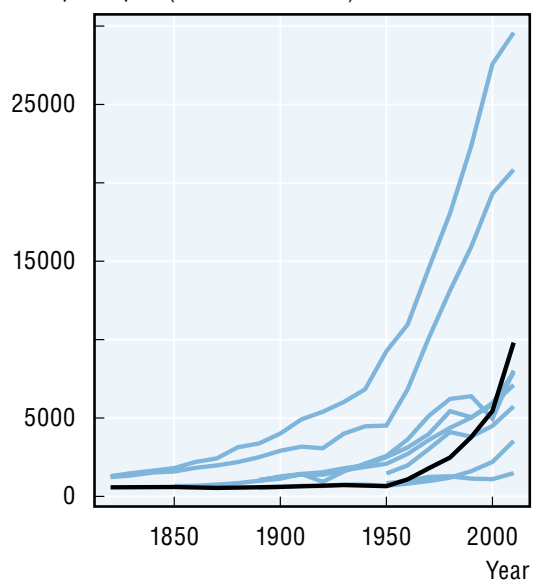

Middle East and North Africa

GDP per capita (USD at 1990 PPP)

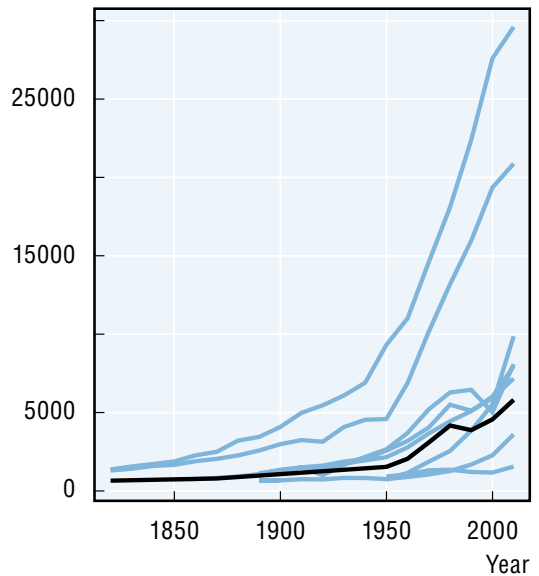

Western Europe

GDP per capita (USD at 1990 PPP)

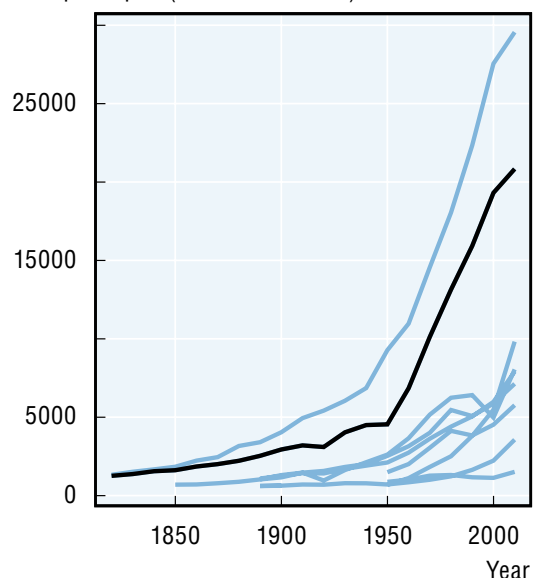

Eastern Europe and former Soviet Union GDP per capita (USD at $1990 \mathrm{PPP}$ )

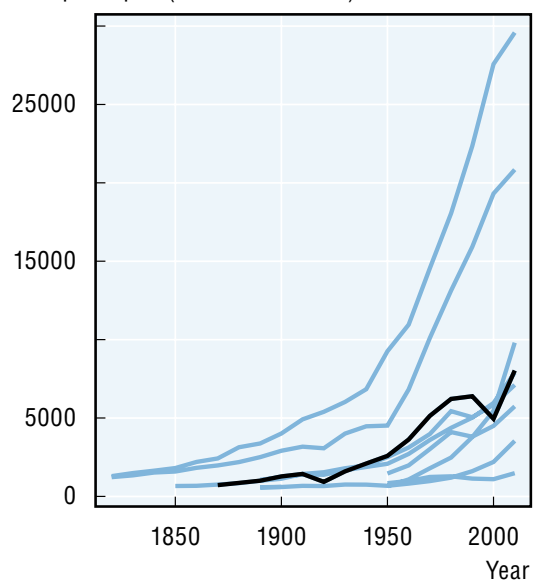

South and South-East Asia GDP per capita (USD at 1990 PPP)

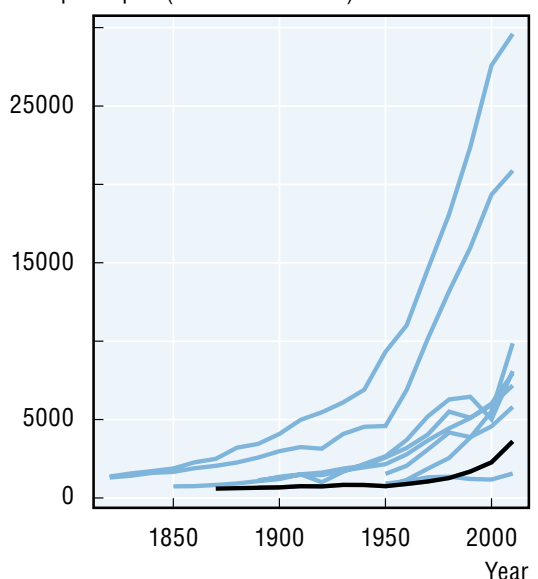

Western Offshoots

GDP per capita (USD at $1990 \mathrm{PPP}$ )

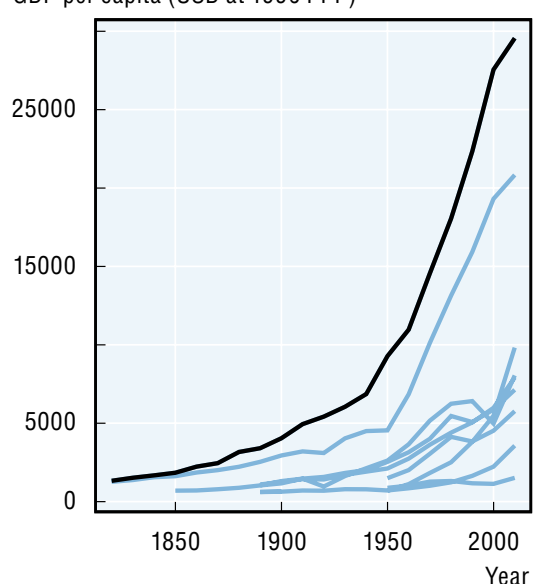

Latin America and Caribbean GDP per capita (USD at 1990 PPP)

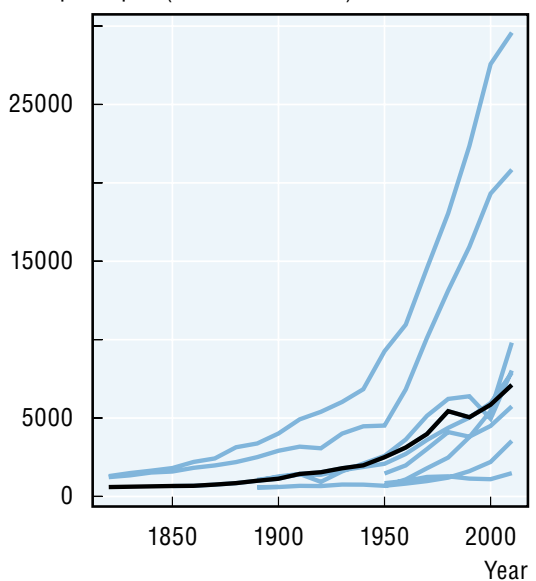

Sub-Saharan Africa

GDP per capita (USD at 1990 PPP)

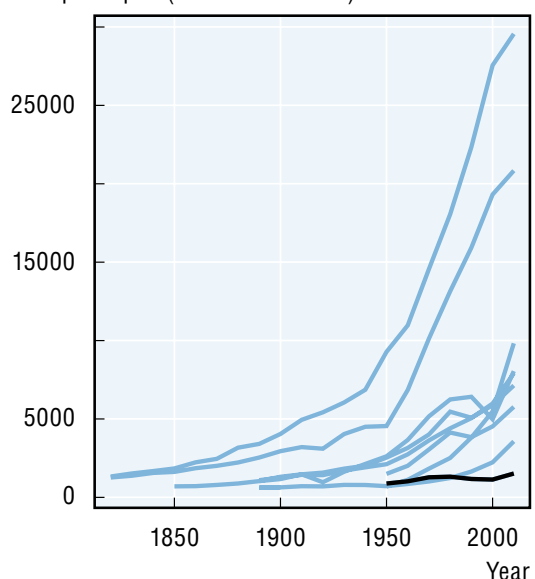

World

GDP per capita (USD at 1990 PPP)

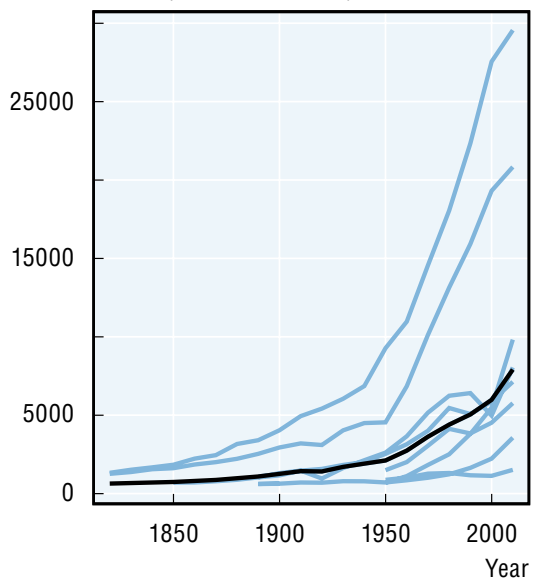

Note: For an assessment of data quality, see Table 3.1.

Source: Clio-Infra, www.clio-infra.eu. 


\section{Structural changes}

One way of relating technological leadership to changes in production capacity is to look at structural changes in the economy. The share of employment in manufacturing is especially relevant for making an historical analysis of this. This indicator allows us to observe the point at which economies shift from agriculture to manufacturing as the main source of production. This shift of economic activity from agriculture to first manufacturing and later services is one of the main drivers of modern economic growth (Kuznets, 1966).

Consistent information about employment broken down by economic sector is available only for a few countries. Figure 3.2 provides evidence on the world's first industrialising countries, the United Kingdom, the United States and Germany, and the two first industrialising countries is Asia, i.e. Japan and Korea, as well as China. The United Kingdom was the first country to experience a shift to manufacturing, with manufacturing having the largest share of employment already back in 1870 (33\%). It was only in the early 1950s that Germany took over in terms of manufacturing's share in employment. While this share continued to grow in Germany or to remain stable in the United Kingdom until 1970, in the United States the share of manufacturing started to decline from the early 1950s onward. Even at its height in 1953, the share of manufacturing in the United States was around six per cent smaller than in the United Kingdom and Germany. Since the 1970s, all three countries have experienced a rapid decrease in the share of people employed in manufacturing.

The Asian countries covered in Figure 3.2 industrialised much later than the Western world. But when industrialisation did start, it proceeded very rapidly. This is the main reason why Asia has been the most dynamic part of the world economy since the 1960s. Japan was the first non-Western country to reach a front position in the world economy, with employment in manufacturing overtaking the United States in the early 1960s, and the United Kingdom in 1980. However, Japan never overtook Germany, whose

Figure 3.2. Share of employment in manufacturing in selected countries, 1870-2005 Percentages

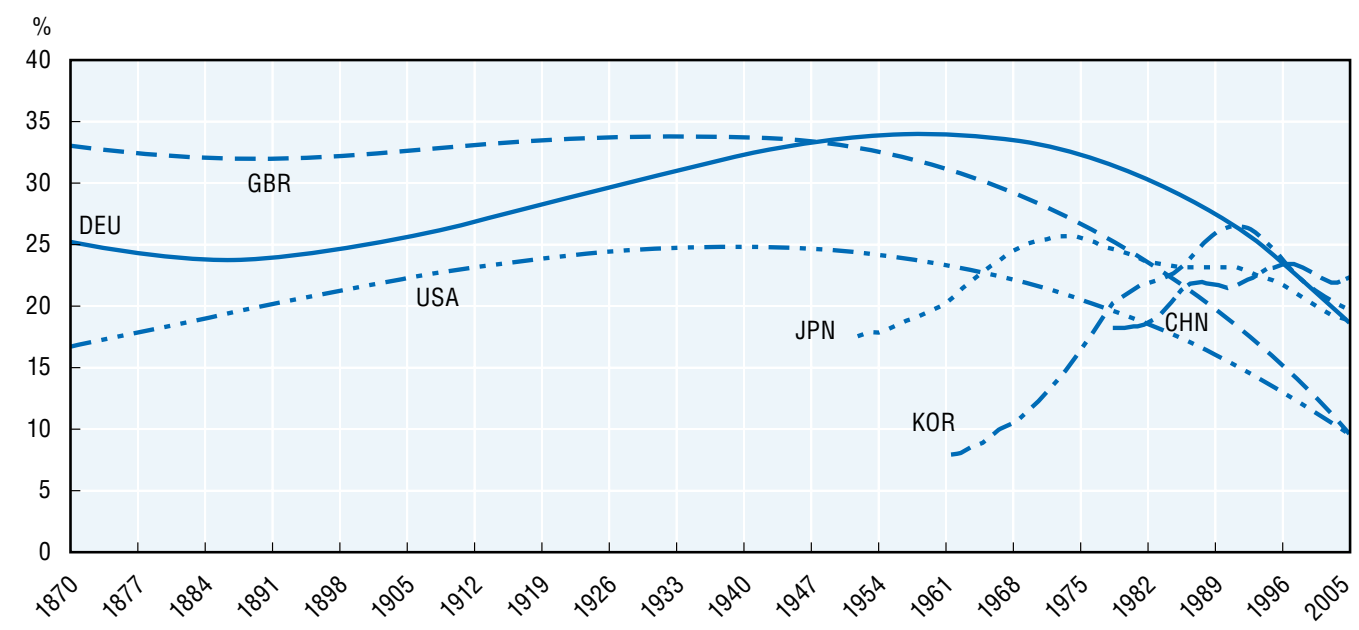

Note: For an assessment of data quality see Table 3.1.

Sources: Broadberry (2005) for the years 1870-1950; the 10-Sector database for 1950-2005, www.rug.nl/research/ggdc/data/ 10-sector-database ; accessed 27 November 2013; World Development indicators for China; the data for Japan, Korea and China are based on Timmer and De Vries (2007); the data for Germany, the United Kingdom and the United States are based on an update of Van Ark (1996). 
employment share in manufacturing after the 1970s decreased only slowly. South Korea, with a very low level of manufacturing in the first half of the 20th century, experienced rapid GDP growth after the 1950s, and by the early 1990s had the world's highest employment share in manufacturing. After this, employment in the manufacturing sector decreased nearly as sharply as it had increased prior to the 1990s. For China, data from the second half of the 1970s onwards highlight very rapid growth. China is the only country in this sample that has not (yet) experienced a hump shape in the share of employment in manufacturing. For all other countries, the available historical data show, first, an increase in employment in manufacturing (people moving from agriculture to industry), followed by a decline in employment in manufacturing (as people move out of manufacturing and into services).

\section{Consumption shares in GDP}

Several authors have argued that, from the perspective of current well-being, looking at consumption is more informative than looking at GDP as a whole. Consumer (and government) expenditure on goods and services has a direct link to material welfare, while this link is more indirect in the case of capital formation (investments), and only visible in the long term. Initially, when countries are poor, the share of consumption in GDP will be high, as current needs are met out of the available production. During the initial stages (or catch-up phase) of growth in GDP per capita, a country will need to invest more (Rostow, 1960). This means that fewer economic resources are available for consumption, hence the share of consumption will be lower. This implies that there is a trade-off between current and future consumption possibilities. If we look at this in a longer time perspective, this is exactly the pattern we observe. The Penn World Tables, covering all major countries in the world since the 1950s, show that in 2000 the share of consumer and government expenditure in GDP was on average $81 \%$ for low-income countries, whereas this share was $71 \%$ for high-income countries. For middle-income countries, this share (at 59\%) was even lower than in high-income countries, mainly due to the much higher investment share of these often rapidly-growing economies (Figure 3.3). China is a case in point, and a wellknown explample of "unbalanced" distribution of GDP: the share of consumption in GDP was only $46 \%$ in 2010 , while it was as high as $91 \%$ in 1952 . This reflects China's extremely rapid economic growth in recent decades, the result of a growth strategy that focuses on high levels of capital formation and exports.

Poor countries have a consumption share of $85 \%$ or even higher, as in the case of Ethiopia in recent decades (Figure 3.3). When countries start to grow, consumption declines to $75 \%$ or even lower. This can be clearly seen in the case of Japan, where consumption shares rapidly declined after 1950, followed by Korea and more recently by China (Figure 3.3). When economies are mature, the consumption rate tends to increase again, as in the case of Japan after 1990, or to remain high, as in the case of the United States and most Euopean countries (e.g. Sweden in Figure 3.3). Germany (also included in the figure) displays a specific pattern compared to the rest of Europe, with a consumption share that was much lower than in other countries in 1950, gains in the following years and declines again at the end of the century, reflecting high shares in investment.

Overall, international disparities in consumption per head are somewhat lower than in terms of GDP per capita, because poor countries tend to invest less and have smaller governments, both of which result in a higher share of consumption in GDP. 
Figure 3.3. Share of total consumption in GDP in selected countries, 1950-2010

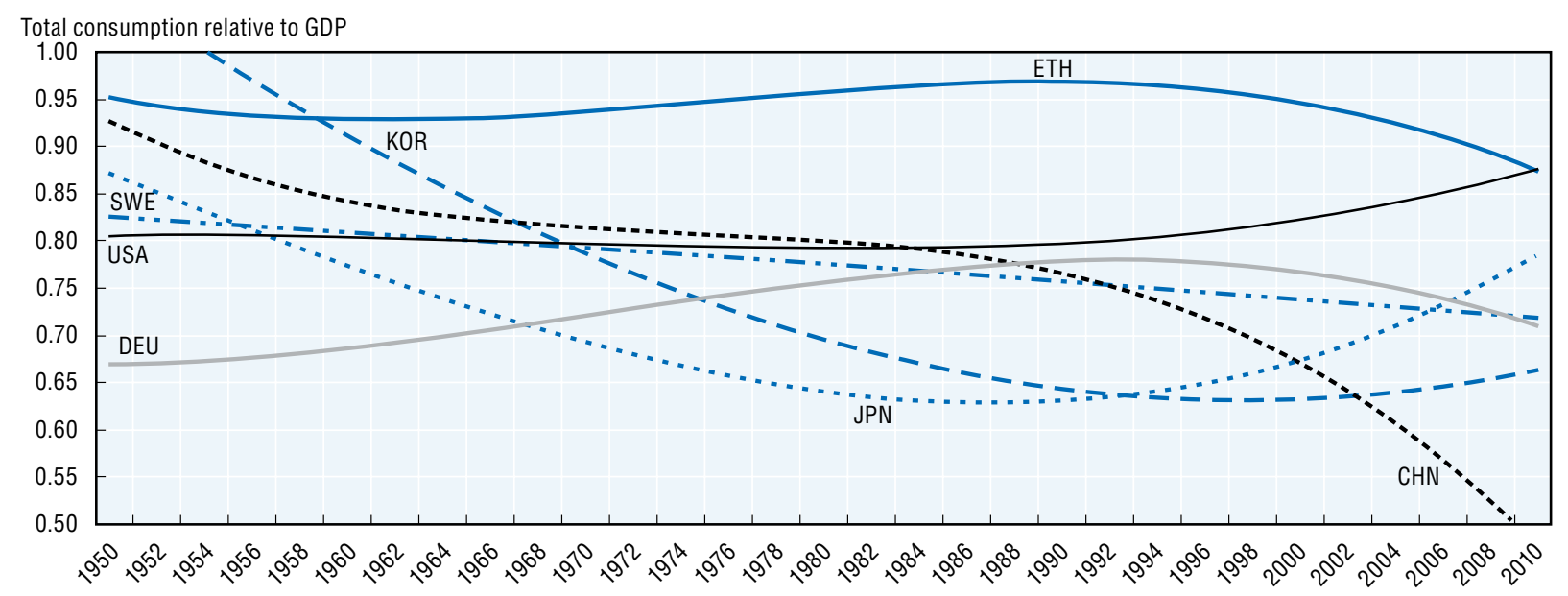

Note: For an assessment of data quality see Table 3.1 .

Source: Penn World Tables 8.0, www.rug.nl/research/ggdc/data/penn-world-table, accessed January 2014.

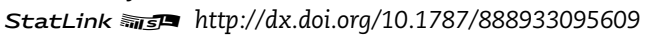

\section{Priorities for future research}

This chapter has presented the main trends in GDP per capita over the past 200 years, including the increase in global between-countries inequality up through the mid-20th century, followed by a slow reversal of that trend thereafter. An important blank spot in our knowledge of long-term economic development is Africa. Currently, most of the available income estimates start only in 1950. A number of scholars are trying to chart developments in economic well-being based on various methods, ranging from reconstructing historical national accounts to estimating real wages. Despite large between-country differences, the general picture painted by these innovative studies suggests that the average level of economic well-being in African countries was above subsistence from the 1870s onwards, and that most countries experienced an improvement until the 1950s. The increase appears to have been the most substantial in West Africa and only modest in most of East Africa, with the notable exception of Mauritius. More work is needed to construct consistent series of GDP for all African countries.

Another priority for further work is the use of the new PPP estimates from the 2005 and 2011 ICP rounds organised by the World Bank, which have produced new sets of PPPs for those years. The debate about the strengths and weaknesses of the 2005 PPPs is still ongoing, while the new 2011 PPPs may help to resolve this discussion and prepare the way for a thorough reassessment of relative levels of economic growth and well-being at the start of the 21st century.

\section{Notes}

1. See: Samuelson P. A. and W. D. Nordhaus (2000)

2. The identity between production and income holds only when ignoring the effect of changes in terms of trade (the price of a country's exports relative to its imports) and capital depreciation.

3. Money spent on investment is of course important for future consumption, and hence well-being.

4. See: World Bank, International Comparison Program (ICP). 
5. Feenstra, R. C., R. Inklaar and M. P. Timmer (2013).

6. See Bolt, J. and J.L. Van Zanden (2014).

7. Estimates up to 1850 apply to Great Britain, and from 1851 onwards to the United Kingdom.

\section{References}

Ark, B. (1996), "Sectoral Growth Accounting and Structural Change in Post-War Europe", in B. van Ark and N.F.R. Crafts, eds., Quantitative Aspects of Post-War European Economic Growth, CEPR/Cambridge University Press, pp. 84-164.

Bolt, J. and J.L. Van Zanden (2014), The Maddison Project. Collaborative research on historical national accounts, The Economic History Review, www.ggdc.net/maddison/maddison-project/home.htm.

Broadberry, S. and B. Gupta (2006), “The early modern great divergence: wages, prices and economic development in Europe and Asia, 1500-1800," Economic History Review, Vol. 59/1, pp. 2-31.

Broadberry. S.N. (2005), The productivity race, British manufacturing in international perspective, 1850-1990 (Cambridge: Cambridge University Press).

De Vries, G.J., M.P. Timmer, and K. de Vries (2013), "Structural Transformation in Africa: Static gains, dynamic losses," GGDC research memorandum 136.

Feenstra, R.C., R. Inklaar and M.P. Timmer (2013), “The Next Generation of the Penn World Table”, http:// www.rug.nl/research/ggdc/data/penn-world-table.

Kuznets, S. (1966), Modern Economic Growth, Yale University Press, New Haven, CT.

Lehohla, P. (2008), "Statistical Development in Africa in the Context of the Global Statistical System", Statistical Journal of the International Association for Official Statistics, Vol. 25/1, pp. 27-45.

Li, B., and J.L. van Zanden (2012), "Before the Great Divergence? Comparing the Yangzi Delta and the Netherlands at the Beginning of the Nineteenth Century", The Journal of Economic History, Vol. 72, pp. 956-989.

Maddison, A. (2003), The World Economy: Historical Statistics, Development Centre Studies, OECD Publishing, http://dx.doi.org/10.1787/9789264104143-en.

Maddison, A. (2001), The World Economy: A Millennial Perspective, Development Centre Studies, OECD Publishing, http://dx.doi.org/10.1787/9789264189980-en.

Nordhaus, W.D. (1999) The Health of Nations: The Contribution of Improved Health to Living Standards, Yale University, www.laskerfoundation.org/media/pdf/healthofnations.pdf.

Nordhaus, W.D. (1996). "Do Real-Output and Real-Wage Measures Capture Reality? The History of Lighting Suggests Not", in T. F. Bresnahan and R. J. Gordon, eds., The Economics of New Goods, Vol. 58, 1997, pp. 29-66.

Parthasarathi, p. (1998), "Rethinking wages and competitiveness in the Eighteenth century: Britain and South India", Past and Present, Vol. 158, pp. 79-109.

Pomeranz, K. (2000), The Great Divergence. China, Europe and the making of the modern world Economy (Princeton, 2000).

Rostow. W. W. (1960), The Stages of Economic Growth: A Non-Communist Manifesto (Cambridge: Cambridge University Press).

Samuelson P.A. and W.D. Nordhaus (2000), United States Department of Commerce Bureau of Economic Analysis Survey of Current Business: GDP: One of the Great Inventions of the 20th Century, www.bea.gou/scb/pdf/BEAWIDE/2000/0100od.pdf.

Timmer, M.P. and G.J. de Vries (2007), "A Cross-Country Database For Sectoral Employment And Productivity In Asia And Latin America, 1950-2005", GGDC Research memorandum GD-98, Groningen Growth and Development Centre, August 2007.

World Bank, International Comparison Program (ICP), http://icp.worldbank.org/. 


\section{Chapter 4}

\section{Real wages since 1820}

by

Pim de Zwart, Bas van Leeuwen and Jieli van Leeuwen-Li, International Institute of Social History and Utrecht University*

Wages are an important element of well-being, as they directly affect material living conditions. This chapter describes trends in real wages since 1820 for a wide set of countries derived with a standardized method that allows for comparisons over time and space. The main indicator is based on the real wage of an unskilled male labourer in the building industry. Its derivation is based on data on nominal wages adjusted by the price of a subsistence basket of goods. Strengths and weaknesses of this method are discussed. It is found that during the first half of the 19th century, real wages in large parts of the world were barely above subsistence, except for parts of Western Europe and in particular in the Western Offshoots. As in the case of GDP per capita, cross-country differences in real wages increased rapidly since 1820 , and diminished in the late 20th century.

* Acknowledgement: We thank Debin Ma, Alexandre Kolev, Auke Rijpma, the editors of this volume and other participants in the OECD workshop on historical well-being held at the OECD headquarters in Paris in December 2013; their contributions to the discussion helped to improve this chapter. This chapter was supported by the Fundamental Research Funds for the Central Universities in China (Jinan University). 


\section{Introduction}

Today, many people depend on paid employment for their household income and their means of subsistence. Recognising this, earlier OECD studies have emphasised the importance of working conditions, job security, remuneration and the quantity of work for individual well-being (OECD, 2011). In this chapter, we focus on one of these elements, namely, the remuneration of work. Wages are an important element of well-being, as they directly affect material living conditions. Earning a high wage allows people to improve their diet, expand their consumption possibilities and enjoy more leisure time, while low wages may result in poor and monotonous diets and an increased work effort in order to survive. Indirectly, a socially acceptable wage level may improve well-being by reducing inequality and enhancing one's self-respect, while also providing the means necessary to increase human capital through education. Furthermore, in light of the rise of paid employment (as opposed to self-employment), wages have increased in importance over time.

Real wages (the division of wages by prices) have thus long been a crucial variable in (historical) socio-economic research. They are at the centre of a great debate surrounding the development of the standard of living during the Industrial Revolution in England, the rise in economic inequality between Western Europe and Asia (the so-called "Great Divergence"), and the relation between skills and income. Acknowledging the great explanatory potential of wages and prices, historians have been collecting these data for a number of European countries from the Middle Ages until the early 20th century. As a result there is a relatively large volume of data available for Europe (as well as Japan and the United States) until the First World War, while other time periods and parts of the world, even though covered much less, are also receiving increasing attention.

A second problem, besides lack of data, is the lack of standardisation in the methodology for calculating comparable real wages even as late as the 1990s (Scholliers and Zamagni, 1995). Recently, however, a methodology pioneered by Robert Allen has been developed that allows the calculation of internationally comparable real wages over the long run (Allen, 2001; Allen et al., 2011). Armed with this new methodology, scholars have expanded real wage comparisons to include countries like India, China, Turkey, and different parts of the Americas and Africa.

The focus of these recent historical studies has been on the period before the 20th century, while at the same time economists comparing wages across the globe tend not to go back before the 1980s (e.g. Freeman and Oostendorp, 2001; Harsch and Kleinert, 2011). In this chapter we wish to bridge the gap between these efforts by historians and economists by creating a new, consistent global dataset of prices and wages for the 19th and 20th centuries. The next section will discuss the concepts and methodology employed; this is followed by discussion of historical sources and comparability issues. Then we describe the main trends in the wage data and finally the relationship with GDP per capita. 


\section{Description of the concepts used}

In most historical studies, the real wage - the purchasing power - of an unskilled male labourer in the building industry is calculated to gauge trends in well-being within one country. These studies deflate the nominal wage of a building labourer (the cash he picked up at the end of the working day or week) with his estimated living expenses (via a consumer price index). The building industry was one of the most important industries in the pre-industrial world, and the nature of the work had not changed much since medieval times. Evidence on building labourers in Britain during the industrial revolution suggests that the wages of building labourers are indicative of trends in average earnings (Allen, 2001). Consumer price indices (CPIs) are calculated on the basis of a basket of goods that reflects the actual consumption pattern of these workers. Calculating a CPI over time gives rise to a number of problems, as changes in relative prices between complementary goods and the introduction of new goods (e.g. due to technological progress or international trade) can cause the overstatement or understatement of true price increases. Additional problems arise if one wants to make international comparisons of real wages, as diets and consumption patterns can differ radically across the globe.

In order to deal with these issues, it was proposed to devise a basket of goods based on a standard amount of caloric and protein intake (Allen, 2001; Allen et al., 2011). Each basket provides a minimum of $1940 \mathrm{kcal}$ and at least 40 grams of protein per day, mainly from the cheapest carbohydrate available in the area. In many parts of Asia this was rice, in Africa maize or cassava, and in Northern Europe oats. Furthermore, the basket contains some additional basic food products, as well as small quantities of clothing and fuel (see Table 4.1). ${ }^{1}$ For this chapter we calculate how many daily subsistence baskets (the annual basket in Table 4.1 divided by 365) the daily wage of an unskilled male building labourer can buy. This therefore expresses the absolute level of the real wage based on a minimum subsistence basket.

Real wages calculated in this way not only allow comparisons over time and space, but also constitute an absolute measure of welfare, as this relates to the number of times an unskilled building labourer is able to purchase the minimum required subsistence basket

Table 4.1. Content of subsistence baskets in selected regions and countries

\begin{tabular}{lcccccc}
\hline & Unit & Northern Europe & China $^{2}$ & India $^{3}$ & Africa $^{4}$ & Latin America $^{5}$ \\
\hline Main staple & $\mathrm{kg}$ & $155-178$ & $171-179$ & $164-209$ & $185-413$ & $132-165$ \\
Beans/peas & $\mathrm{kg}$ & 20.0 & 20.0 & 20.0 &.. & 45.0 \\
Meat/fish & $\mathrm{kg}$ & 3.0 & 3.0 & 3.0 & 3.0 & 3.0 \\
Butter/oil/ghee & $\mathrm{kg}$ & 3.0 & 3.0 & 3.0 & 3.0 & 3.0 \\
Sugar & $\mathrm{kg}$ &.. &.. & 2.0 & 2.0 & 2.0 \\
Soap & $\mathrm{kg}$ & 1.3 & 1.3 &.. & 1.3 & 1.3 \\
Linen/cotton & $\mathrm{m}$ & 3.0 & 3.0 & 3.0 & 3.0 & 3.0 \\
Candles & $\mathrm{kg}$ & 1.3 & 1.3 &.. & 1.3 & 1.3 \\
Lamp oil & $\mathrm{litre}$ & 1.3 & 1.3 &.. & 1.3 & 1.3 \\
Fuel & $\mathrm{mbtu}$ & 3.0 & 3.0 &.. & 3.0 & 3.0 \\
\hline
\end{tabular}

Notes:

1. Allen et al. (2011) $155 \mathrm{~kg}$. oats for northwestern Europe, rye for northeastern Europe.

2. Allen et al. (2011): $171 \mathrm{~kg}$ rice in Suzhou and Canton; $179 \mathrm{~kg}$ sorghum in Beijing.

3. Allen (2007b): $164 \mathrm{~kg}$ rice or $209 \mathrm{~kg}$. millet.

4. Frankema and Van Waijenburg (2012): maize, millet, cassava, rice, wheat: depending on country and time.

5. Arroyo Abad et al. (2012): $165 \mathrm{~kg}$ maize in Mexico, Peru, Bolivia and Colombia; $132 \mathrm{~kg}$. wheat in Argentina and Chile. Source: Clio-Infra, www.clio-infra.eu. 
which, in turn, reflects something like the poverty line, defined by the World Bank as one dollar a day. ${ }^{2}$ Hence, using this methodology, if one has a price series for the products included in the basket, as well as nominal wage data, it is possible to make statements about the development of wages relative to a poverty line (the subsistence basket) over time and space.

It is important to note that the baskets defined in this way are implicit purchasing power parities. The fundamental difference, however, is that the standard purchasing power parities (PPPs) are calculated using the weights of GDP rather than of consumption, meaning that they also include non-consumption components. Second, PPPs are often available for only one (or at best a few) benchmark years. The other years are connected with this benchmark using a CPI/GDP deflator. Given the fast change in consumer baskets in the 20th century, which included many more (and more luxurious) products that are often relatively more expensive than the main staples, CPI and GDP deflators will increase faster than subsistence baskets and, hence, the real wages calculated using this basket will probably increase more over time than those calculated with conventional CPIs. Since the aim here is to include indicators of welfare, we opted for real wages based on a subsistence basket and calculated these for each country and each year separately (see Table 4.2). This choice does, however, have some obvious limitations, which will be discussed in the section on comparability and data limitations.

\section{Historical sources}

The wage and price series shown in this chapter are taken from three sources: A) a variety of studies on historical real wages that appeared in academic journals and books; B) the British Colonial Blue Books (circa 1840-1912); and C) the October Enquiries of the International Labour Organisation (1924-2008). These data were then converted into subsistence ratios, which indicate how many times the daily wage of a male unskilled construction labourer can buy the daily subsistence basket. This methodology has the advantage of providing an absolute yardstick to compare welfare across countries and time periods and, hence, is conceptually close (but not identical) to purchasing power parities. Finally, in order to fill gaps in the data, interpolations were made D) on the basis of real wages indices from the (older) literature.

A. To start, for much of the 19th century data we draw on economic histories. Much European data came from Allen's pioneering study (2001) on European wages and prices from the late Middle Ages to the First World War. ${ }^{3}$ Data for Istanbul came from the study by Ozmucur and Pamuk (2002), which was based on over 6000 account books from the soup kitchens of pious foundations and the Topkapı Palace. In addition, we took data for Japan from Bassino and Ma (2005), for several Southeast Asian countries from Van der Eng and Bassino (2013), for India from Allen (2007), for China from Allen et al. (2011), for Argentina, Bolivia, Chile, Colombia, Mexico and Peru from Arroyo Abad et al. (2012), for the United States from Allen et al. (2012), and for Indonesia from De Zwart and Van Zanden (2014). These studies each draw on a variety of sources that are too extensive to discuss here.

B. The Colonial Blue Books (1840-1912) contain data that were collected by the colonial administrators in the various colonies of the British Empire and sent each year to the Colonial Office in London, in response to questionnaires sent out by the latter. Frankema and Van Waijenburg (2012) worked with these data for nine British African colonies, with the earliest observation dating from 1870 . We extended their series, where possible, to 1850 , and added estimates for South Africa (De Zwart, 2011). In addition, we added 
data from several non-African colonies, especially in Oceania, Latin America and the Caribbean. Data from the Blue Books are not ideal, since price data do not always reflect retail prices (but prices for produce) and wages are not always representative for the majority of the population, but these are currently the only figures available for many of Europe's former colonial possessions.

C. Since 1924, the International Labour Organisation (ILO) has conducted an annual survey, called the October Inquiry, to obtain data on wages and prices worldwide. ${ }^{4}$ Every year the ILO has sent two questionnaires (one relating to wages and hours of work, the other to retail prices) to national statistical agencies, which were to complete the questionnaires with the information already available to them (and thus not to conduct specific surveys in order to supply the data). ${ }^{5}$ Hence, while the price data are roughly consistent, the wage information returned for the various countries could differ significantly; while some reported average wages per hour from an establishment survey, others reported legislated minimum or maximum wage rates for certain occupations, and others returned minimum wage rates based on collective agreements, etc. (see Freeman and Oostendorp, 2001). These wage data thus require some form of standardisation before they can be used. Since 1983, this work has been performed by Freeman and Oostendorp (2001), Harsch and Kleinert (2011), and Oostendorp (2012). In addition, the number of countries included expanded from 15 in 1924 to over 50 in the 1950s, after which the number of countries has fluctuated (after 1983 it sometimes contains data on over 130 countries!).

D. Real wage series for various countries in the 19th and 20th centuries are also available from other (older) literature (e.g. Mitchell, 2007; Williamson 1998; Scholliers and Zamagni, 1995) as well as from some more recent literature on wages and prices (e.g. Van Leeuwen, 2004; 2007). In addition, in a few cases we included special reports, such as on the period 1950-1970 in China for which little data are available (e.g. Survey on cities and counties in Guangxi, 1985; Yulin City Gazetteer, 1993). The lack of standardisation in the methodology makes direct comparisons on the basis of these data impossible. However, in order to deal with gaps in the data, those real wage series are used for interpolation in a few cases.

Hence, whereas most data after 1924 from the ILO are reported by official statistical agencies, the pre-1924 data are often from colonial reports, collective agreements, and more localised data from private institutions such as orphanages. Yet in both cases the data had to be reworked to become consistent. In addition, it may be asked how representative the pre-1924 data are for the economy as a whole (see the next section on comparability issues). The 20th century might be viewed as high-quality data, while the 19th century is often based on semi-official data that are often representative of only a part of the population and, hence, assumed to be of moderate quality (see Table 4.2). In general, however, all the series, even those in the later 20th century, rely to some extent on interpolations.

\section{Data quality}

After the price and wage data were collected, they needed to be standardised. This required first dealing with wage and price ranges. If ranges were reported, we took the logarithmic average of the wages, while for the prices we took the simple geometric mean. Second, standardisation required a modification of the territorial unit, since many of the data were given at the regional level, often with multiple cities/regions for one country. This modification was performed by taking averages across regions in one country. It is important to stress that virtually all our data stem from urban areas. This can make some difference. For example, in France in 1930 the hourly wage rate of a cabinet maker in Paris 
Table 4.2. Quality of data on prices and wages by region and benchmark year, 1820-2008

\begin{tabular}{|c|c|c|c|c|c|c|c|c|}
\hline & $\begin{array}{l}\text { Western } \\
\text { Europe } \\
\text { (WE) }\end{array}$ & $\begin{array}{c}\text { Eastern } \\
\text { Europe } \\
\text { (EE) }\end{array}$ & $\begin{array}{l}\text { Western } \\
\text { Offshoots } \\
\text { (WO) }\end{array}$ & $\begin{array}{l}\text { Latin } \\
\text { America } \\
\text { and } \\
\text { Caribbean } \\
\text { (LA) }\end{array}$ & $\begin{array}{c}\text { Sub-Saharan } \\
\text { Africa } \\
\text { (SSA) }\end{array}$ & $\begin{array}{l}\text { Middle East } \\
\text { and } \\
\text { North Africa } \\
\text { (MENA) }\end{array}$ & $\begin{array}{c}\text { East Asia } \\
\text { (EA) }\end{array}$ & $\begin{array}{c}\text { South and } \\
\text { South-East } \\
\text { Asia } \\
\text { (SSEA) }\end{array}$ \\
\hline 1820 & 3 & 3 & 3 & 3 & 3 & 3 & 3 & 3 \\
\hline 1870 & 3 & 3 & 3 & 3 & 3 & 3 & 3 & 3 \\
\hline 1913 & 2 & 3 & 3 & 3 & 3 & 3 & 3 & 3 \\
\hline 1950 & 2 & 3 & 3 & 3 & 3 & 3 & 3 & 3 \\
\hline 1973 & 2 & 2 & 2 & 2 & 2 & 2 & 2 & 2 \\
\hline 2008 & 2 & 2 & 2 & 2 & 2 & 2 & 2 & 2 \\
\hline
\end{tabular}

Note: 1. High quality; 2. Moderate quality; 3. Low quality; and 4. Estimates.

See the section on "Data Quality" in Chapter 1 for a description of the quality criteria.

Source: Clio-Infra, www.clio-infra.eu.

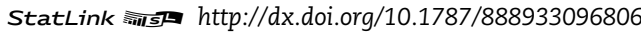

was 6.75 francs, versus 5.32 francs in the provincial cities. However, this qualification is less applicable to the case of the building labourers used in this chapter. The wage rate in Paris in 1930 for these labourers was, at 4.17 francs an hour, identical to the rate in provincial cities. Similar observations can be made for the developing economies. Third, arriving at a consistent dataset required a conversion into common units. As already mentioned, for prices this problem is less severe, since most prices are standard retail price data. However, wages can be reported in average rates, minimum or maximum rates, or earnings. Considering only the ILO data, it appears that $70 \%$ of the data concern average wage rates or comparable data, minimum rates and maximum rates account for $15 \%$ and $0.7 \%$ respectively, while earnings comprise the remaining $14 \%$ of observations. We followed the procedure of Freeman and Oostendorp (2001) and converted all data into average rates, because this reduces the error margin. This conversion was done using a regression analysis in which we regressed the wage on dummy variables, indicating country, industry, pay concept and time. This was necessary only for the period prior to 1984, since data from the later period were obtained from Oostendorp (2011), and were already converted into average rates. Finally, we converted all wages into daily rates; wages from the ILO were reported as hourly rates, and we have assumed an eight-hour working day for all countries throughout the entire time period. While it is clear that this assumption does not hold, consistent data on working hours per country per year have not yet been gathered. Future research may help to adjust our calculated real wage rates by providing information on working hours.

It is important to note that converting the resulting wage and price data into real wages following the method outlined above has several limitations. First, while this methodology works well for comparing the purchasing power of wages in pre-modern societies, this simple consumption basket will not be very accurate in places where real wages are relatively high, as people will certainly switch to a more luxurious consumption basket. A simple comparison of our price index with the CPI index suffices to show this. In the Netherlands between 1930 and 2000, our minimum consumption price index increased about 10 times, while the CPI increased 14 times. Hence, if one is interested in the development of purchasing power in e.g. the Netherlands alone between 1950 and 2010, other, more complex price indices might be more appropriate, as this would include a wide variety of new (and luxurious) goods. These could be obtained easily from statistical 
agencies. However, international comparison, and comparison over long time periods, requires the simplification and standardisation of estimates and calculations.

Second, how representative are wage labourers for the general working populace? Allen (2001) found the wage of an unskilled labourer in the building industry to be fairly representative for total wage development in the early modern period. This may have changed in the modern period and may differ per country. It has been argued that since the start of the 20th century in certain, especially developed countries, what has driven economic development is skills. In this case one might expect that it would be skilled wages rather than unskilled wages that mainly reflected general wage development. Table 4.3 reports the population-weighted wages of building labourers and craftsmen in the world. We can see that the skill premium over the past 60 years underwent a major decline, suggesting that the supply of skills in this field outpaced the demand. On the one hand, this was caused by the educational revolution during this period and, on the other, by the increasing development of technology in our societies, which has led to a reduction of the role of skilled building labour in favour of skilled people in services and mechanical engineering. More research into this issue is necessary. Yet for now we suggest that, when comparing wages globally, the most meaningful baseline is unskilled male wages in the building industry.

Table 4.3. Labourers' and craftsmen's real wages and skill premium, 1930s-2000s

Number of subsistence baskets that a daily wage buys, population-weighted global averages

\begin{tabular}{lccc}
\hline & Labourers & Craftsmen & Skill premium \\
\hline 1930 s & 13.4 & 27.3 & $104 \%$ \\
1940 s & 13.8 & 21.6 & $57 \%$ \\
1950 s & 16.8 & 26.3 & $57 \%$ \\
1960 s & 20.1 & 30.2 & $50 \%$ \\
1970 s & 26.4 & 38.9 & $47 \%$ \\
1980 s & 30.9 & 43.8 & $42 \%$ \\
1990 s & 35.3 & 54.6 & $55 \%$ \\
2000 s & 43.0 & 59.2 & $38 \%$ \\
\hline
\end{tabular}

Note: For an assessment of data quality, see Table 4.2.

Source: Clio-Infra, www.clio-infra.eu.

Third, in many pre-industrial developing economies, wage income is often only a small part of total household income. Only a part of the labour force was engaged in full-time wage employment. However, it is clear that the share of the population in paid employment has increased over the past 200 years. ${ }^{6}$ But even in the 21st century the share of wage employment clearly can differ by region. Whilst in Europe around $80 \%$ of the working population is in wage labour, in Sub-Saharan Africa this holds for only about 20/30\% (World Bank Development Report, Chap. 1, 2013). It is important to keep these limitations in mind when reviewing these data.

\section{Main highlights of wage trends}

It is clear that in general real wages have increased substantially over the past two centuries (Tables 4.4, 4.5 and 4.6, as well as Figure 4.1). While all regions show growth, real wages increased significantly more in Western Europe, the Western Offshoots and the Middle East and North Africa than in other regions; global inequality in terms of unskilled labourers' wages thus increased over these two centuries. 
Table 4.4. Regional averages of real wages of building labourers, 1820s-2000s Number of subsistence baskets that a daily wage buys, decadal averages

\begin{tabular}{|c|c|c|c|c|c|c|c|c|c|}
\hline & $\begin{array}{c}\text { Western } \\
\text { Europe } \\
\text { (WE) }\end{array}$ & $\begin{array}{c}\text { Eastern } \\
\text { Europe } \\
\text { (EE) } \\
\end{array}$ & $\begin{array}{c}\text { Western } \\
\text { Offshoots } \\
\text { (WO) }\end{array}$ & $\begin{array}{l}\text { Latin } \\
\text { America } \\
\text { and } \\
\text { Caribbean } \\
\text { (LA) }\end{array}$ & $\begin{array}{c}\text { East Asia } \\
(\mathrm{EA})\end{array}$ & $\begin{array}{c}\text { South and } \\
\text { South-East } \\
\text { Asia } \\
\text { (SSEA) }\end{array}$ & $\begin{array}{l}\text { Middle East } \\
\text { and } \\
\text { North Africa } \\
\text { (MENA) }\end{array}$ & $\begin{array}{c}\text { Sub-Saharan } \\
\text { Africa } \\
\text { (SSA) }\end{array}$ & Worlo \\
\hline $1820 \mathrm{~s}$ & 12.6 & 7.2 & .. & 5.7 & 3.3 & 4.1 & 6.5 & 2.9 & 5.7 \\
\hline $1830 \mathrm{~s}$ & 11.2 & 6.5 & .. & 7.0 & 2.8 & 5.2 & 3.8 & 3.1 & 5.6 \\
\hline $1840 \mathrm{~s}$ & 11.2 & 4.9 & .. & 4.0 & 2.8 & 4.2 & 3.7 & 3.4 & 5.2 \\
\hline 1850s & 11.0 & 6.3 & .. & 7.3 & 2.0 & 4.4 & 3.8 & 3.3 & 5.3 \\
\hline $1860 \mathrm{~s}$ & 11.5 & 8.1 & 43.9 & 6.6 & 2.8 & 4.7 & 5.2 & 3.1 & 6.3 \\
\hline 1870s & 12.5 & 8.1 & 50.2 & 7.6 & 3.8 & 4.1 & 5.1 & 3.4 & 7.2 \\
\hline 1880s & 14.7 & 9.8 & 62.6 & 9.0 & 4.3 & 4.5 & 5.0 & 4.1 & 9.0 \\
\hline $1890 \mathrm{~s}$ & 17.8 & 9.6 & 63.7 & 9.5 & 4.9 & 4.2 & 4.4 & 4.7 & 9.9 \\
\hline $1900 \mathrm{~s}$ & 19.0 & 13.1 & .. & 10.3 & 4.8 & 3.6 & 4.7 & 4.9 & 11.1 \\
\hline 1910s & 16.9 & 20.4 & 77.2 & 10.6 & 4.3 & 3.7 & 4.6 & 4.4 & 12.5 \\
\hline 1920s & 18.7 & 7.7 & 68.9 & .. & 3.9 & 4.1 & .. & 6.3 & 11.2 \\
\hline $1930 \mathrm{~s}$ & 24.8 & 9.9 & 74.1 & 12.4 & 4.0 & 5.3 & 8.1 & 7.6 & 13.4 \\
\hline $1940 \mathrm{~s}$ & 26.2 & 9.6 & 75.8 & 14.4 & 5.2 & 4.3 & 13.4 & 6.2 & 13.8 \\
\hline 1950s & 21.3 & 10.7 & 98.9 & 18.5 & 6.5 & 6.3 & 19.3 & 7.9 & 16.8 \\
\hline 1960s & 31.8 & 15.0 & 103.9 & 20.9 & 11.1 & 5.2 & 16.4 & 8.1 & 20.1 \\
\hline 1970s & 49.4 & 25.1 & 145.5 & 21.3 & 19.4 & 4.7 & 20.1 & 6.1 & 26.4 \\
\hline $1980 \mathrm{~s}$ & 64.8 & 27.8 & 143.7 & 26.0 & 26.3 & 7.8 & 41.3 & 8.0 & 30.9 \\
\hline 1990s & 105.2 & 29.2 & 168.1 & 29.9 & 26.9 & 8.5 & 46.2 & 11.0 & 35.3 \\
\hline $2000 \mathrm{~s}$ & 163.3 & 38.6 & 169.8 & 26.5 & 36.6 & 10.0 & 71.6 & 18.3 & 43.0 \\
\hline
\end{tabular}

Note: For an assessment of data quality, see Table 4.2.

Source: Clio-Infra, www.clio-infra.eu.

Table 4.5. Regional averages of real wages of building craftsmen, 1920s-2000s

Number of subsistence baskets that a daily wage buys, decadal averages

\begin{tabular}{|c|c|c|c|c|c|c|c|c|c|}
\hline & $\begin{array}{c}\text { Western } \\
\text { Europe } \\
\text { (WE) }\end{array}$ & $\begin{array}{c}\text { Eastern } \\
\text { Europe } \\
\text { (EE) }\end{array}$ & $\begin{array}{c}\text { Western } \\
\text { Offshoots } \\
\text { (W0) }\end{array}$ & $\begin{array}{l}\text { Latin } \\
\text { America } \\
\text { and } \\
\text { Caribbean } \\
\text { (LA) }\end{array}$ & $\begin{array}{c}\text { East Asia } \\
\text { (EA) }\end{array}$ & $\begin{array}{c}\text { South and } \\
\text { South-East } \\
\text { Asia } \\
\text { (SSEA) }\end{array}$ & $\begin{array}{c}\text { Middle East } \\
\text { and } \\
\text { North Africa } \\
\text { (MENA) }\end{array}$ & $\begin{array}{c}\text { Sub-Saharan } \\
\text { Africa } \\
\text { (SSA) }\end{array}$ & World \\
\hline $1920 \mathrm{~s}$ & 35.4 & 12.9 & 105.2 & .. & .. & .. & .. & .. & .. \\
\hline $1930 \mathrm{~s}$ & 40.6 & 17.0 & 124.1 & 26.3 & .. & 14.3 & 28.8 & 16.4 & 27.3 \\
\hline $1940 \mathrm{~s}$ & 36.3 & 14.2 & 117.3 & 24.6 & .. & 8.6 & 15.3 & 12.4 & 21.6 \\
\hline $1950 \mathrm{~s}$ & 31.8 & 14.3 & 135.2 & 31.7 & 13.4 & 12.4 & 34.2 & 13.0 & 26.3 \\
\hline $1960 \mathrm{~s}$ & 48.1 & 19.5 & 144.0 & 30.2 & 18.7 & 10.0 & 27.2 & 12.6 & 30.2 \\
\hline 1970 s & 67.8 & 31.0 & 202.2 & 33.0 & 32.2 & 8.6 & 31.5 & 10.4 & 38.9 \\
\hline 1980s & 88.4 & 32.7 & 191.3 & 36.7 & 42.2 & 10.7 & 64.1 & 12.7 & 43.8 \\
\hline 1990s & 144.6 & 33.7 & 202.9 & 37.8 & 67.4 & 11.8 & 70.4 & 17.1 & 54.6 \\
\hline $2000 \mathrm{~s}$ & 191.9 & 41.6 & 205.9 & 36.3 & 70.6 & 14.1 & 93.1 & 23.6 & 59.2 \\
\hline
\end{tabular}

Note: For an assessment of data quality see Table 4.2 .

Source: Clio-Infra, www.clio-infra.eu. 
Table 4.6. Real wages of building labourers in selected countries, 1820s-2000s

Number of subsistence baskets that a daily wage buys, decadal averages

\begin{tabular}{|c|c|c|c|c|c|c|c|c|c|c|c|c|c|c|c|c|c|c|c|c|c|c|c|c|c|}
\hline & \multicolumn{7}{|c|}{$\begin{array}{l}\text { Western Europe } \\
\text { (WE) }\end{array}$} & \multicolumn{2}{|c|}{$\begin{array}{c}\text { Eastern Europe } \\
\text { (EE) }\end{array}$} & \multicolumn{3}{|c|}{$\begin{array}{l}\text { Western Offshoots } \\
\text { (W0) }\end{array}$} & \multicolumn{3}{|c|}{$\begin{array}{l}\text { Latin America and } \\
\text { Caribbean } \\
\text { (LA) }\end{array}$} & \multicolumn{2}{|c|}{$\begin{array}{c}\text { Middle East } \\
\text { and North } \\
\text { Africa (MENA) }\end{array}$} & \multicolumn{3}{|c|}{$\begin{array}{l}\text { Sub-Saharan Africa } \\
\text { (SSA) }\end{array}$} & \multicolumn{2}{|c|}{$\begin{array}{l}\text { East Asia } \\
\text { (EA) }\end{array}$} & \multicolumn{3}{|c|}{$\begin{array}{c}\text { South and } \\
\text { South-East Asia } \\
\text { (SSEA) }\end{array}$} \\
\hline & GBR & NLD & FRA & DEU & ITA & ESP & SWE & POL & RUS & AUS & CAN & USA & MEX & BRA & ARG & EGY & TUR & KEN & NGA & ZAF & $\mathrm{CHN}$ & JPN & IND & IDN & THA \\
\hline $1820 \mathrm{~s}$ & 16 & 16 & 17 & 10 & 4 & 17 & .. & 9 & & .. & .. & .. & 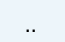 & & 13 & .. & 7 & & & .. & 3 & 4 & . & 4 & .. \\
\hline 1830s & 17 & 12 & 14 & 9 & 4 & 15 & .. & 8 & & .. & .. & .. & .. & .. & 18 & .. & 4 & .. & & .. & 3 & 3 & .. & 6 & .. \\
\hline 1840 s & 16 & 11 & 15 & 10 & 4 & 17 & .. & 6 & .. & .. & .. & .. & .. & .. & 10 & .. & 4 & .. & .. & .. & 3 & 4 & .. & 5 & .. \\
\hline $1850 \mathrm{~s}$ & 17 & 11 & 14 & 11 & 3 & 18 &.. & 8 &.. & .. &.. & .. &.. &.. & 23 &.. & 4 &.. &.. & 5 & 2 & 3 &.. & 5 &.. \\
\hline $1860 \mathrm{~s}$ & 17 & 10 & 16 & 12 & 4 & 16 & .. & 10 & .. & 33 & .. & .. & .. & .. & 23 & .. & 6 & .. & .. & 4 &.. & 3 &.. & 5 & .. \\
\hline 1870 s & 21 & 12 & 16 & 13 & 4 & 16 & .. & 10 &.. & 37 &.. &.. & .. &.. &.. &.. & 6 &.. & 4 & 5 & 3 & .. & 3 & 5 & .. \\
\hline $1880 \mathrm{~s}$ & 25 & 15 & 21 & 16 & 6 & 15 & .. & 12 &.. & 50 & .. &.. &.. &.. &.. & .. & 5 &.. & 4 & 7 & 4 & 7 & 4 & 5 & .. \\
\hline $1890 \mathrm{~s}$ & 28 & 20 & 28 & 20 & 7 & 15 &.. & 12 &.. & 52 & .. &.. &.. &.. &.. &.. & 5 &.. & 5 & 7 & 5 & 7 & 4 & 5 &.. \\
\hline $1900 \mathrm{~s}$ & 28 & 23 & 29 & 22 & 8 & 16 & .. & 16 & .. & .. & .. & .. & .. & .. & .. & .. & 5 & 4 & 6 & 9 & 5 & 9 & 4 & 5 & .. \\
\hline 1910s & 23 & 26 & 27 & 27 & 9 & 22 & 24 & 25 &.. & 65 &.. &.. &.. &.. &.. &.. & 6 & 5 & 5 &.. & 4 & 7 & 4 & 4 & 5 \\
\hline $1920 \mathrm{~s}$ & 30 & 31 & 13 & 22 & 13 & 14 & 32 & 9 &.. & 70 & 41 & 73 &.. &.. &.. & .. &.. & 7 & 4 &.. & 3 & 10 & 4 & 4 & 6 \\
\hline $1930 \mathrm{~s}$ & 37 & 38 & 19 & 27 & 15 & 18 & 45 & 13 & .. & 60 & 56 & 77 &.. & 11 & 28 &.. & 7 & 7 & 5 & 15 & 3 & 9 & 5 & 5 & 9 \\
\hline $1940 \mathrm{~s}$ & 41 & 27 & 15 & .. & 10 & .. & 42 & .. & .. & 58 & 52 & 76 & 9 & 10 & 42 & .. & .. & 7 & 4 & 13 & .. & 8 & 4 & 3 & .. \\
\hline $1950 \mathrm{~s}$ & 36 & 23 & 12 & 23 & 13 & 9 & 23 & 9 & .. & 68 & 76 & 103 & 7 & .. & 56 &.. &.. & 8 & 5 & 20 & 5 & 7 & 7 & 4 & 8 \\
\hline $1960 \mathrm{~s}$ & 49 & 24 &.. & 41 & 25 & 16 & 80 &.. &.. & 59 & 85 & 153 & 18 &.. & 37 &.. & .. & 11 & 5 & .. & 11 & 13 & 4 & 4 & 12 \\
\hline 1970s & 62 & 46 & 31 & 72 & 43 & 26 & 100 & .. & .. & 97 & 192 & 179 & 23 & 12 & 46 &.. & 25 & 11 & 5 &.. & 18 & 27 & 3 & 6 &.. \\
\hline $1980 \mathrm{~s}$ & 78 & 68 & .. & 124 & 89 & .. & 96 & .. & .. & 108 & 161 & 175 & 21 & .. & 36 & .. & .. & 8 & 5 & .. & 26 & 30 & 7 & 12 & 13 \\
\hline 1990s & 120 & .. &.. & 140 & 112 & .. &.. &.. & 19 & 140 & 126 & 185 & 8 & .. & .. & 8 & 28 & 7 & 11 & 17 & 22 & 40 & 10 & 13 & 24 \\
\hline $2000 \mathrm{~s}$ & 167 &.. & .. & .. & 114 & .. & .. & & 23 & 171 & 120 & 209 & 11 & .. & .. & 17 & 30 &.. & .. & .. & .. & 45 & 7 & 8 & 20 \\
\hline
\end{tabular}

Note: For an assessment of data quality see Table 4.2

Source: Clio-Infra, www.clio-infra.eu 
Figure 4.1. Regional averages of real wages of building labourers, 1820s-2000s

Number of subsistence baskets that a daily wage buys, decadal averages

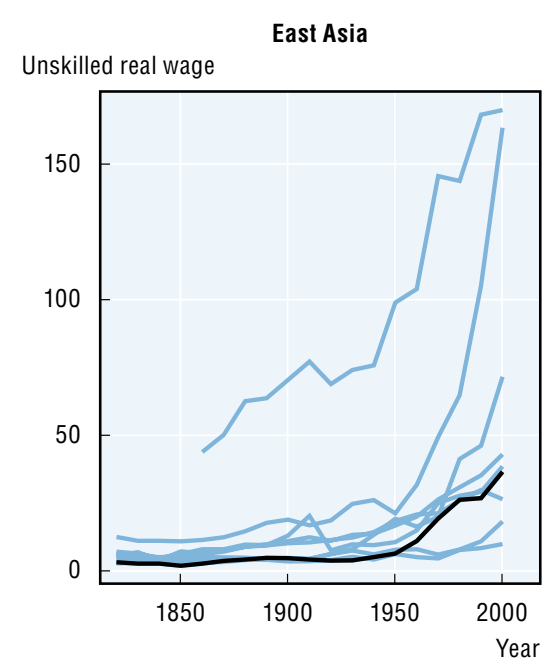

MENA
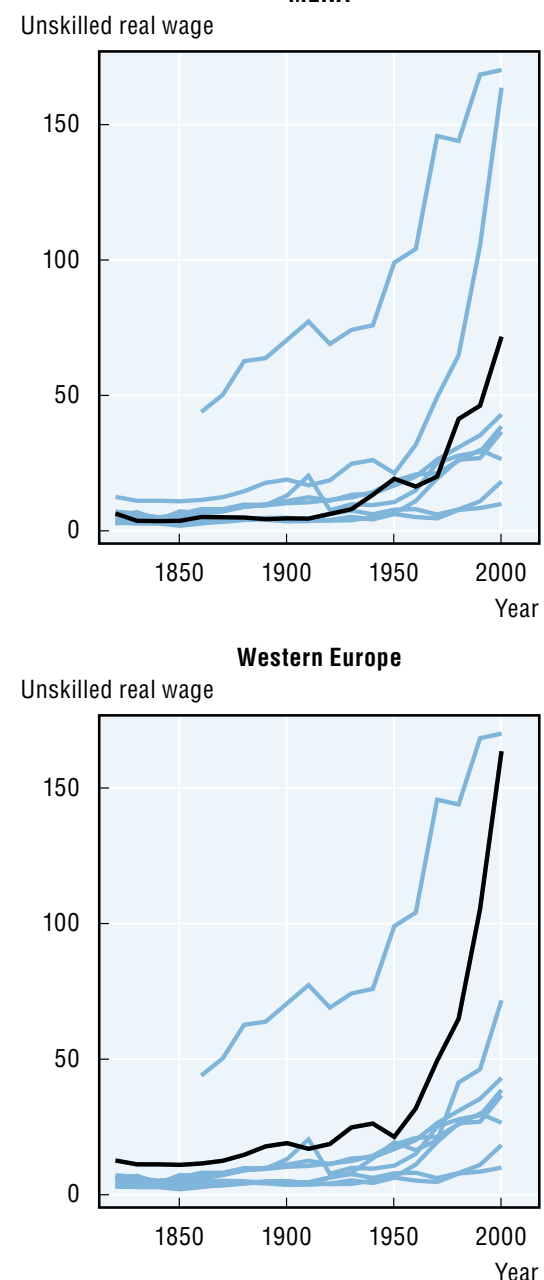

Eastern Europe and former Soviet Union Unskilled real wage

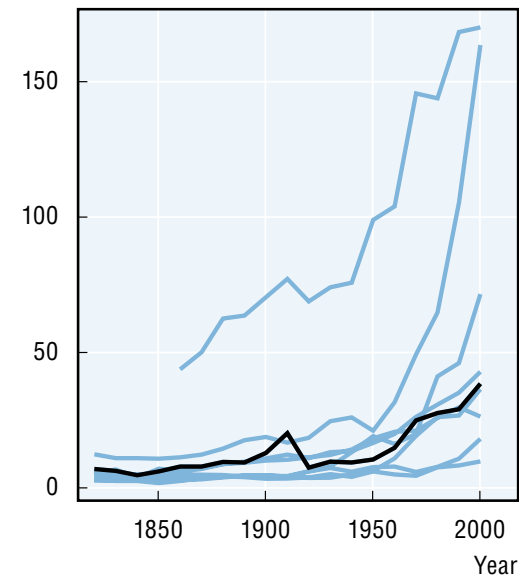

South and South-East Asia Unskilled real wage

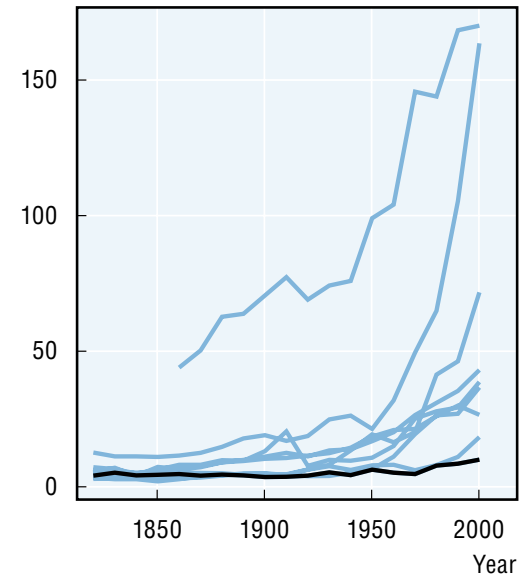

Unskilled real wage

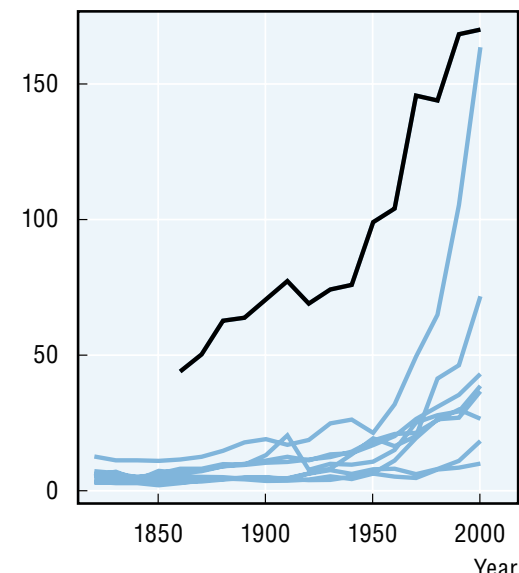

Latin America and Caribbean. Unskilled real wage

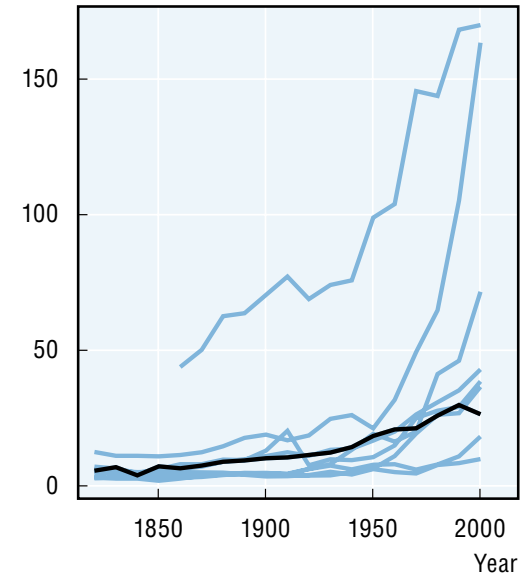

Sub-Saharan Africa

Unskilled real wage

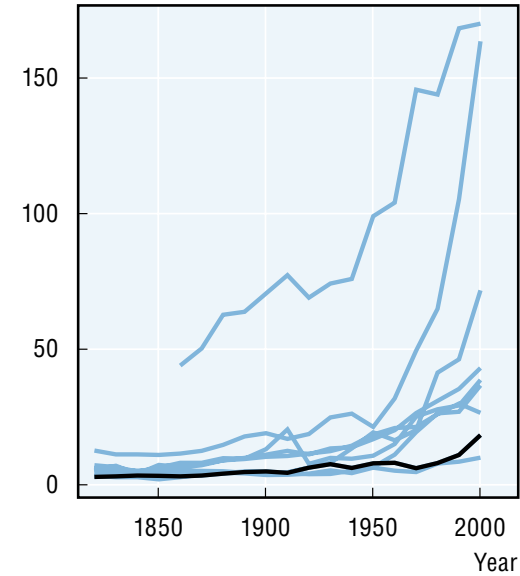

World

Unskilled real wage

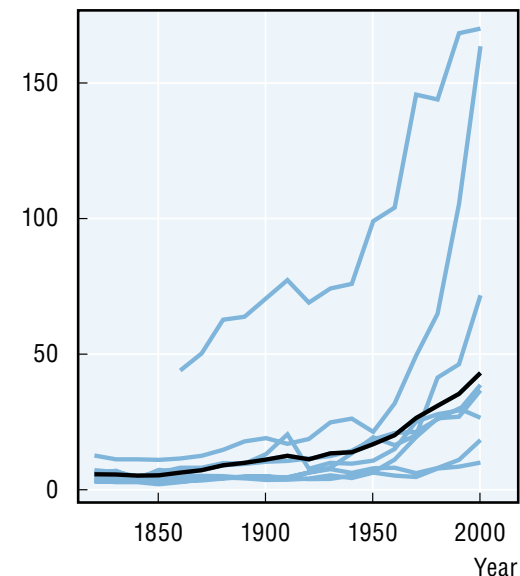

Note: For an assessment of data quality see Table 4.2.

Source: Clio-Infra, www.clio-infra.eu. 
Even though the starting position of all the main regions was more comparable in 1820 than in 2010, there were still big differences even then. Three rough groups can be distinguished: Sub-Saharan Africa, East Asia and Southeast Asia, which make up the poorest regions with real wages of around 3.5 times the subsistence basket; the Middle East and North Africa, Latin America and Eastern Europe, with real wages at around a factor of 6.5; and Western Europe and the Western Offshoots, which are clearly ahead with real wages of between a factor of 12 and 20. This gap also implied a completely different style of living: a male labourer's wage in Western Europe was able to pay about 12 times his daily minimum consumption. This meant a possibility for increased investment in education, as well as in healthcare and industrial products, which became a driving force in the consumer revolution.

The main remarkable feature was, however, the very high real wages of the Western Offshoots. Allen et al. (2012), who also find high subsistence ratios for the USA, argued that the wages in the (former) colonies were determined by the wages of the colonial power. In the case of Australia, New Zealand, Canada and the United States this means that wages were driven upwards by high wages in the United Kingdom. A second explanation might be relative prices: the price of staples - the main part of the consumption basket - was relatively low in these land-rich countries. If this is true, then the global convergence of staple prices in the 20th century may account for part of the catch-up by the European countries with the Western Offshoots.

Another remarkable development was the rapid increase in real wages in the Middle East and North Africa after the 1940s. From that point on real wages in the MENA countries grew much faster, mainly due to oil revenues, than those in Eastern Europe and Latin America, three regions that had been comparable in the 19th century. In the final group of countries, the ones that were poorest around the start of the 19th century, it is clear that only East Asia started to perform well, mainly driven by China's economic boom since the reform period of the 1970s. For Sub-Saharan Africa and Southeast Asia, however, we find that until the second half of the 20th century wages were relatively low, allowing the purchase of only between 5 and 14 times the daily consumption basket. Since a worker also has to eat during days he does not work, this barely leaves the ability to sustain a family.

\section{Correlation with GDP per capita}

Whereas in the richest macro region (Western Europe and the Western Offshoots) there seems to have been some convergence, there has been divergence with the other regions. Nevertheless, overall wages in the world have increased about eight times from the 1820 s to the 2000s, which is comparable with an approximate ten-fold increase in per capita GDP. This suggests a relatively strong correlation between real wages and per capita GDP. The relation between GDP and real wages, however, is still subject to discussion. Some studies suggest a close correlation between real wages and GDP (Bairoch, 1995; Stolz et al., 2012: 14), while others have emphasised the complex relationship between the two (Van Zanden, 1999, 2003, 2005; Ozmucur and Pamuk, 2002). The data in Figure 4.2 show a relatively close correlation between real wages and GDP per capita, which does not change much over time.

A discussion of these factors goes well beyond the scope of this chapter. Nevertheless, a few general observations can be made. As pointed out by Broadberry et al. (2013; 2014), growth in real wages will be lower than growth in GDP per capita if either the labour share in income goes down and the labour supply goes up, or if the CPI increases 
Figure 4.2. Correlation between real wages of building labourers and GDP per capita, 1820s-2000s

Pearson correlation coefficient and upper/lower bounds of $95 \%$ confidence interval per decade

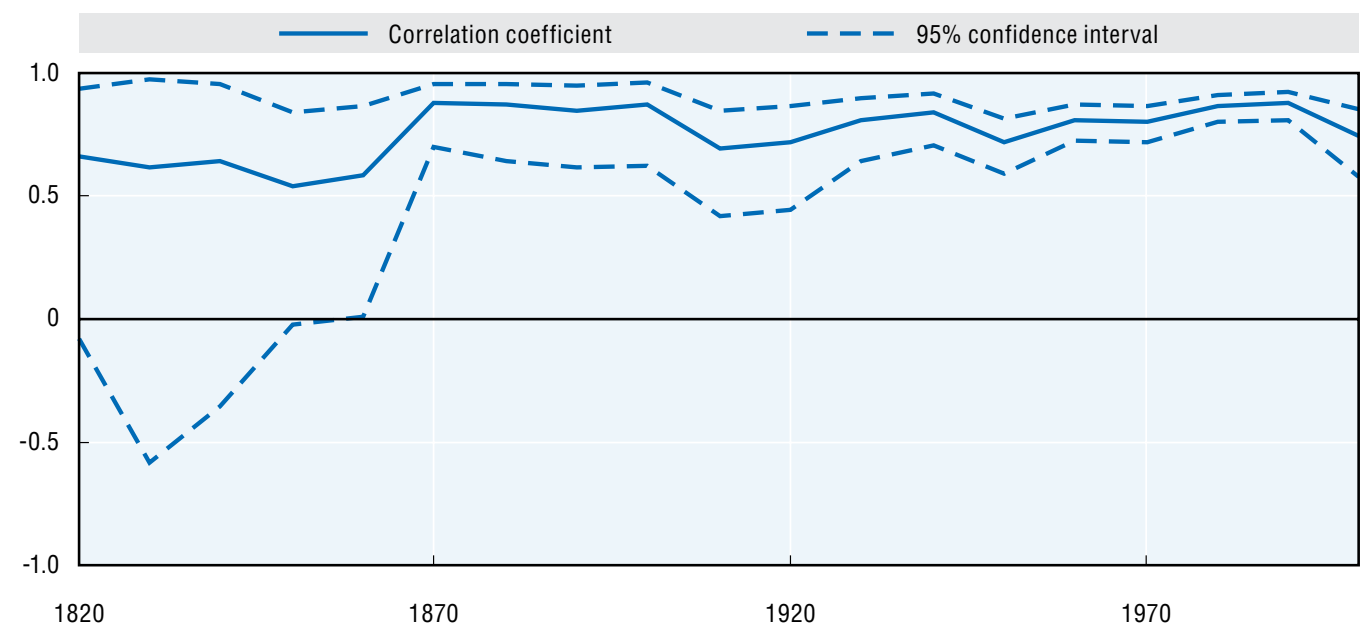

Note: For an assessment of data quality see Table 4.2.

Source: Clio-Infra, www.clio-infra.eu.

relative to the GDP deflator. We know from our previous discussion that the latter is not the case. In fact, our price index grew slower than most conventional indices due to our focus on a subsistence basket. Yet the labour supply has increased considerably over the past decades due mainly to the increased participation of women in the labour market (e.g. Rubery et al., 1998), while there has been a considerable reduction in the labour share in income especially from the mid-1980s onwards (e.g. EC, 2007; IMF, 2007; Guerriero, 2012). Overall this resulted in a slower growth in wage compensation than in per capita GDP.

\section{Priorities for future research}

Wages and prices are crucial sources of information about the development of wellbeing. Decent wages provide not only the satisfaction of having a well-paid job, but also the material income necessary for survival and, above survival, a comfortable existence. This report therefore tried to fill the lacuna that existed in the historical and economic record on wages and prices by creating a coherent dataset on them for as many countries as possible from the 19th century until the present.

Future research should focus on expanding the data for countries that were not included in our sources, or for those countries for which the series remain patchy. In addition, further evidence on wages for other occupations (skilled labour) and women's wages would also enhance our knowledge about trends in well-being as well as provide more information about the development of inequality and the demand for (and supply of) skilled workers across the world.

\section{Notes}

1. In earlier studies, the cost of the basket was multiplied by 3.15 in order to give a rough proxy for the budget of a nuclear family of four (two adults, plus two children each counting for one-half adult) including rent per adult (the additional 15\%). Dividing the annual nominal wage of an unskilled 
building labourer by the cost of subsistence makes it possible to examine whether, and to what extent, workers across the globe could afford the (subsistence) expenditures for themselves and their families. In this chapter we have adjusted this methodology slightly, as the constitution of the family has differed enormously over time and space (also see Chapter 2 on the demographic transition). The estimates presented here can, if necessary, be converted into subsistence ratios as used in the economic-historical literature by dividing the numbers by $\left(\left(3.15^{*} 365\right) / 250\right), 250$ being the assumed number of working days per year; see Allen et al. 2011.

2. A comparison between the subsistence ratio and the more famous World Bank poverty line of \$1.25 per day (in 2005 prices; or \$1 per day in 1990 prices) show that these correspond (Allen, 2012).

3. This includes various cities in England, the Netherlands, Belgium, France, Italy, Spain, Germany, Austria and Poland. His data builds on studies by the famous International Scientific Committee on Price History in the 1930s and 1940s.

4. Published for 1924 to 1945: International Labour Review; for 1934-57: Yearbook of Labour Statistics; 1951-63: Statistical Supplement to the International Labour Review; for 1964+ Bulletin of Labour Statistics; after 1983 data online.

5. Also see http://laborsta.ilo.org/applv8/data/labocte.html.

6. For more information on the rise of wage labour across the globe see the Global Collaboratory on the History of Labour Relations: https://collab.iisg.nl/web/labourrelations.

\section{References}

Allen, R.C. (2001), "The Great Divergence in European Wages and Prices from the Middle Ages to the First World War", Explorations in Economic History 38, pp. 411-447.

Allen, R.C. (2005), Real Wages in Europe and Asia: A First Look at the Long-term Patterns. In: R. C. Allen, T. Bengtsson, and M. Dribe (eds.), Living Standards in the Past New Perspectives on Well-Being in Asia and Europe. Oxford: Oxford University Press, pp. 157-185.

Allen, R.C. (2007), "India and the Great Divergence" in: T. J. Hatton, K. H. O”Rourke, and A. M. Taylor (eds.), The New Comparative Economic History, Essays in Honor of Jeffrey G. Williamson, MIT Press, Cambridge MA, pp. 9-32.

Allen, R.C. (2012), “The Relationship of Welfare Ratios to Food Security and the World Bank Poverty Line", presentation at the CLIO-INFRA Workshop on Real Wages, IISH, Amsterdam.

Allen, R.C. et al. (2011), "Wages, Prices, and Living Standards in China, 1738-1925: In Comparison with Europe, Japan, and India”, Economic History Review, Vol. 64, pp. 8-38.

Allen, R.C., T. Murphy and E. Schneider (2012), “The Colonial Origins of the Divergence in the Americas: A Labour Market Approach”, Journal of Economic History. Vol. 72, pp. 863-894.

Angelis, L. (2008), "GDP per capita or real wages? Makings sense of conflicting views on pre-industrial Europe”, Explorations in Economic History, Vol. 45/2, pp. 147-163.

Arroyo Abad, L. (2013), "Inestabilidad, Bienestar Económico y Costo de Vida en Venezuela durante el siglo XIX”, América Latina en la Historia Económica, Vol. 20, pp. 114-137.

Arroyo Abad, L., E. Davies and J.L. van Zanden (2012), "Between conquest and independence: Real wages and demographic change in Spanish America, 1530-1820," Explorations in Economic History 49, pp. 149-166.

Bairoch, P. (1995), "Wages as an Indicator of Gross National Product", in P. Scholliers (ed.), Real wages in the 19th and 20th century Europe, Historical and comparative perspectives, pp. 51-60.

Bassino, J.-P. and D. Ma (2005), "Japanese unskilled wages in international perspective, 1741-1913", Research in Economic History 23, pp. 229-248.

Broadberry, S. et al. (2012), "British Economic Growth, 1270-1870: an output-based approach", Studies in Economics 1203, Department of Economics, University of Kent.

Broadberry, S. et al. (2014 forthcoming), British GDP ca. 1270-1870, Cambridge: Cambridge University Press.

Broadberry, S, B. Campbell, and B. van Leeuwen (2013), "When did Britain Industrialise?" The Sectoral Distribution of the Labour Force and Labour Productivity in Britain, 1381-1851", Explorations in Economic History, Vol. 50, pp. 16-27.

Cha, M.S., "Wages in the Japanese colonial empire (Taiwan, Korea and Northeastern China)", Mimeo. 
de Zwart, P. (2011), "South African Living Standards in Global Perspective, 1835-1910", Economic History of Developing Regions, Vol. 26, pp. 49-74.

de Zwart, P. and J.L. van Zanden (2012), “Labour, wages and living standards in Java, 1640-1940”, European Review of Economic History.

European Commission (2007), The Labour Income Share in the European Union. Employment in Europe 2007, Directorate-General for Employment Social Affairs and Equal Opportunities, European Commission.

Frankema, E. and M. van Waijenburg (2012), "Structural impediments to African growth? New evidence from real wages in British Africa, 1880-1965", Journal of Economic History, Vol. 72/4, pp. 895-926.

Freeman, R.B. and R.H. Oostendorp (2001), “The Occupational Wages around the World Data File”, ILO Labour Review, 2001, Fall Issue.

Guerriero, M. (2012), "The labour share of income around the world: evidence from a panel dataset," Manchester Institute for Development Policy and Management, Development economics and public policy working paper series 32.

Harsch, D. and J. Kleinert (2011), "An Almost Ideal Wage Database Harmonizing the ILO October Inquiry”, IAW Discussion Papers 71, Institut für Angewandte Wirtschaftsforschung (IAW).

IMF (International Monetary Fund) (2007), “The Globalization of Labor", in: World Economic Outlook: Spillovers and Cycles in the Global Economy, International Monetary Fund, Washington D.C.

ILO (International Labour Organization, Laborsta, http://laborsta.ilo.org/ (accessed 2013).

Leeuwen, B. (2007), Human capital and economic growth in India, Indonesia and Japan: a quantitative analysis, $\mathrm{PhD}$ thesis Utrecht University.

Leeuwen, B. (2004) "Wage differentials and economic growth in India, Indonesia, and Japan, 1800-2000," Mimeo.

Mitchell, M.F. (2007), International historical statistics, Palgrave Macmillan, 6th Edition.

OECD (2011), How's Life?: Measuring Well-being, OECD Publishing, http://dx.doi.org/10.1787/9789264121164en.

Oostendorp, R.H. (2012), “The Occupational Wages around the World (OWW) Database: Update for 1983-2008”, NBER.

Oostendorp, R.H. (2005): “The Standardized ILO October Inquiry 1983-2003”, www.nber.org/oww/ Technical_document_1983-2003_standardizationu3.pdf.

Ozmucur, S. and S. Pamuk (2002), "Real Wages and Standards of Living in the Ottoman Empire, 1489-1914", Journal of Economic History, Vol. 62, pp. 293-321.

Rubery, J. et al. (1998), Women and European Employment, London and New York: Routledge.

Scholliers, P. and V. Zamagni (1995), Labour's Reward. Real wages and economic change in 19th and 20th century Europe, Edward Elgar, Aldershot and Vermont.

Stolz, Y., J. Baten and J. Reis (2013), "Portuguese living standards 1720-1980 in European comparison: Heights, income, and human capital”, Economic History Review, Vol. 66, pp. 545-578.

Guangxi People press (1985), 《广西市县概况》, 广西人民出版社, (Survey on cities and counties in Guangxi province), p. 551.

Guangxi People Press (1993), 《玉林市志》, 广西人民出版社1993年第1版),(Yulin City Gazetteer), p. 178.

World Bank (2013), World Development Report, Washington D.C.

van der Eng, P. and J.-P. Bassino (2013), “The First East Asian Miracle: Wages, Living Standards and the Foundations of Modern Economic Growth in Southeast Asia, 1880-1938", Paper presented at the 7th EuroSEAS conference, Lisbon, June.

van Zanden, J.L.(2005), "What Happened to the Standard of Living Before the Industrial Revolution? New Evidence from the Western Part of the Netherlands", in R.C. Allen, T. Bengtsson and Martin Dribe (eds.), Living standards in the past. New perspectives on well-being in Asia and Europe, pp. 173-194, Oxford University Press, Oxford.

van Zanden, J.L. (2003), "Rich and Poor Before the Industrial Revolution, a Comparison between Java and the Netherlands at the Beginning of the Nineteenth Century", Explorations in Economic History, Vol. 40, pp. 1-23.

van Zanden, J.L. (1999), "Wages and the standard of living in Europe, 1500-1800", European Review of Economic History, Vol. 2, pp. 175-197. 


\section{Chapter 5}

\section{Education since 1820}

by

Bas van Leeuwen and Jieli van Leeuwen-Li, Utrecht University*

Education provides many direct and indirect benefits to people's well-being. This chapter relies upon two indicators to describe educational inequalities around the globe since 1820: literacy rates and years of schooling. These indicators are based on merging two major datasets that rely mainly on population census data, and that have various strengths and limitations. The chapter shows that trends in education have a tight relationship with those in GDP per capita. In 1820, less than $20 \%$ of the world's population was literate, and this group was heavily concentrated in Western Europe and the Western Offshoots. Nowadays, levels of literacy are close to $100 \%$ almost everywhere, with Africa being the most significant exception (at 64\%). In the wake of the expansion of basic education, secondary and tertiary education also expanded in all parts of the world, first in the Western Offshoots, then in Western Europe. More recently this became a global phenomenon, resulting in a strong increase in the average years of education of the world population, from around 1 year in 1870, to 3 years after the Second World War, to more than 7 years in the new millennium.

* Acknowledgement: We thank Fabrice Murtin and Herman de Jong for comments on an earlier draft, and Lotte van der Vleuten for supplying us with some of the data on literacy. We would also like to thank the participants in the OECD workshop on historical well-being held at the OECD headquarters in Paris in December 2013; their contributions to the discussion helped to improve this paper. 


\section{Introduction}

Literacy and education is nowadays considered a prime right for all human beings. The right to literacy and an education has been declared a human right in Article 2 of the first protocol to the European Convention on Human Rights since 1952 and, since 1966, by Article 13 of the United Nations' International Covenant on Economic, Social and Cultural Rights. Indeed, it is hard to imagine our societies without some basic level of education, as this opens up opportunities for people and brings benefits in both the material and nonmaterial components of well-being (OECD, 2011a).

Having some basic level of literacy or education directly improves a person's wellbeing by providing more control over his or her life. After all, having some basic levels of reading and writing skills are necessary for everyday transactions in shops, commercial enterprise and household economics (e.g. Spence et al., 2009). In addition, being able to read and write allows enjoying activities that bring intrinsic pleasure to an individual, like reading or going to a museum of art (OECD, 2011b).

Literacy and education also affect well-being indirectly. This can be by enhancing economic development, as education may lead to more productive labour, or by using technology, which increases productivity (e.g. Romer, 1990). In addition, this may also have non-material effects such as increasing political stability (e.g. Alesina and Perotti, 1996), lowering crime rates (Sabates, 2008), improving health (OECD, 2010), or reducing inequality by increasing skills at the bottom of the income ladder (e.g. OECD, 2011a).

Yet, with some notable exceptions (e.g. Baier et al., 2006; Van Leeuwen and Foldvari, 2008a; Morrisson and Murtin, 2009; 2013; Foldvari et al., forthcoming), no estimates are available that provide a picture of the development of education and/or literacy over the past two centuries. In this chapter we will therefore try to remedy this issue by providing an admittedly tentative picture of educational development since the 1820 s.

\section{Description of the concepts used}

Our first indicator is literacy (i.e. the ability to read and write texts). It is important to stress though, that literacy in this sense acquired this meaning only in the late 19th century. Before then, the primary meaning of literacy had been "educated" or "learned" (Education for All, 2006, 148). The more limited interpretation that arose in the late 19th century mainly reflected the rapid increase in mass education, which consisted of little more than basic literacy and numeracy skills for the mass of the population. Around 1890 the ability to read and write had been acquired by around $20-40 \%$ of the population aged 15 years and older outside Europe and 60-70\% in Europe (UNESCO 1953, pp. 169-171). A mere 50 years later most developed countries had reached literacy levels of close to $100 \%$, while a significant rise had also taken place in the developing countries, re-instating the importance of the older definition of literacy as "education".

Literacy as a measure solely of the stock of knowledge in society was quickly made obsolete by 19th century economic and social developments. Technical change required 
a level of education that went beyond mere literacy in order to invent or operate new machines, and higher levels of education further increased personal security and the chance for a long and healthy life. By the 20th century, when in many countries literacy rates approached 100\%, this measure no longer provided much information about educational development, not to mention its inability to capture the increase in skills that can be acquired only at higher levels of education.

Therefore, many studies have proposed a version of educational attainment as a better measure, as it captures the number of people aged 15 or more who have followed either primary, secondary or higher levels of education (e.g. Barro and Lee 1993; 2010). This indicator is close, but not identical, to literacy, since some people who are literate may not have had an education while, vice versa, some people who had only a few years of schooling may have become illiterate over time. Although apparently uncontroversial, these levels of education and their educational contents may vary strongly between countries. In the 1970s UNESCO therefore designed the first International Standard Classification of Education (ISCED), which was revised in 1997 and 2011, which tries to incorporate existing national characteristics as much as possible. Here, primary education is defined as giving children a comprehensive schooling and laying a basis for possible further subjectoriented education. Primary education does not start before age 5 or after age 7 , and lasts no longer than about 6 years. Secondary education moves towards a more subject-oriented programme, educates for either the labour market or higher education, and lasts between 3 and 6 years. Finally, higher education is strongly subjected-oriented and basically covers all post-secondary education.

Even though educational attainment tells us that a person received some education, it does not tell us how long they did this. Educational attainment is therefore frequently converted into "average years of education", which is the number of years the average person aged 15 or over spent in formal education. While it can be argued that this variable captures education only to a limited extent, because it ignores the quality of education, it is still popular because it balances the existing quantitative evidence with a variable that captures the main stages in educational development. Therefore, in addition to literacy, this chapter uses average years of education as its second key indicator. Doing this has required the development of a dataset that covers 8 world regions and 146 countries, the sources for which will be discussed in the following section.

\section{Historical sources}

\section{Literacy}

The literacy data used were mainly taken from census data, since alternative sources, such as the number of people able to make a signature, may result in fundamentally different outcomes. The reason is that in most censuses literacy is defined in terms of the ability to read, write and understand a short, simple statement about everyday life, and this is not always consistent with the information derived from alternative sources such as signatures on marriage certificates.

The census data are derived from three main sources. For the period before 1950, we used the data from the UNESCO report on the Progress of Literacy in Various Countries Since 1900. This resulted in 173 observations for 30 countries. For the mid-20th century, we used the UNESCO report on Illiteracy at Mid-Century, which added another set of observations for 36 countries. Up to 1970 we used the UNESCO statistical yearbooks (various issues), followed 
by data from Gapminder ${ }^{1}$ from 1970 onwards. Finally, we included data for Tanzania from Egero and Henin (1967).

Unfortunately, these data run back only to the end of the 19th century, when this narrow concept of literacy first took root. Data on alternative measures, such as the number of people signing a marriage certificate, are available only for a very limited number of countries (mainly in Europe), and, in addition, do not conform completely to the definition given by UNESCO. Nevertheless, some data are available, such as from Mironov (1985) for European Russia, from Van Leeuwen (2007) for India, and from Pamuk and Van Zanden for several European countries (2007).

\section{Years of education}

As pointed out, once countries have come close to $100 \%$ literacy this indicator does not convey any further information, therefore many studies have reverted to average years of education in the population aged 15 and older. These studies are based on educational attainment by level of education, multiplied by the average time a student has spent at a certain level of education.

Many of these studies exist on a national level (e.g. Prados de la Escoura and Roses, 2010), yet a few scholars have created datasets on a wider scale, such as Barro and Lee $(1993 ; 2010)$ and Cohen and Soto (2007) for the entire world, and De la Fuente and Domenech (2000) for OECD countries. These datasets, however, supply estimates only at a few benchmark years from 1950 on. Three other datasets exist that have a wide coverage as well as a long temporal perspective. The first is by Baier et al. (2006), covering a set of countries at irregular intervals. A second, more comprehensive set of estimates is from Morrisson and Murtin (2009) for around 78 countries for 10-year intervals. A third set of estimates, from Van Leeuwen, Van Leeuwen-Li and Foldvari, has been published in a range of papers spread over the past years (e.g. Van Leeuwen and Foldvari, 2008a; Foldvari et al., forthcoming) and has been made available in a comprehensive format by Clio-Infra in 2012. The last two datasets, from Van Leeuwen et al. and Morrisson and Murtin, have been shown to be the ones with the widest coverage, the longest time span and the highest reliability (e.g. Foldvari et al., forthcoming). The methodology for the two is also roughly comparable, making it possible to combine the two sets of estimates into a single comprehensive dataset on educational development.

Without going into much detail on the exact computational strategies, the basic way most studies calculate years of education is to start with the available census data for the second half of the 20th century at decadal intervals. Three methods have been proposed to expand the number of observations (e.g. Wossman, 2003). First, there is the so-called perpetual inventory method. This method adds up all students over the past lifetime (about 60 years) and subtracts people who died. In this way, the number of people with certain levels of education is calculated. This method, however, has met with some severe criticism, since it does not correct for education-specific mortality (i.e. people with higher education generally live longer) and drop-outs (people who drop out of education before finishing their education). Hence, it will most likely underestimate the true levels of attainment. Second, there is the attainment census method. This method takes existing census data on educational attainment as its starting point and from there follows the perpetual inventory approach by adding new students and subtracting students in case of mortality. Consequently, even though the bias is less severe, it also results in lower-thanactual growth rates for educational attainment. Third, existing estimates in the census by 
age class are used to project education attainment, and hence years of education, backward and forward. This last method is used by Cohen and Soto and, more recently, in Barro and Lee (2010) and is judged to produce by far the most reliable estimates. For the pre-1950 period we rely on the perpetual inventory method, which is linked to the census data of the 1960s. Since we use annual observations, we can correct for drop-outs while assuming the percentage of repeaters is the same as in 1960. We did not correct for education-specific mortality, but this bias is likely to have been less in historical periods, meaning that the bias caused by this method is also likely to be smaller in the pre-1960 period.

The Van Leeuwen et al. and Morrisson-Murtin dataset used in this chapter relies for both datasets on a modified version of the Cohen and Soto (2007) data after 1960 and, before then, on a perpetual inventory method combined with back-projection. In certain cases, when no data existed for Cohen and Soto, we used either Barro and Lee (2010) as benchmarks, creating our own benchmark from existing census data, or a perpetual inventory method based on population and enrolment data mainly obtained from Mitchell (2007a, b, c), the UNESCO statistical yearbooks (various issues), the United States census bureau, Maddison (2007), the Colonial Blue Books for the British colonies (various issues), Lindert (2004) and the United States Department of Education (1993). These data were supplemented with historical data for the Netherlands from Albers (1997) and for England from DePleijt (2011).

Even though it is possible to create annual data by using a combination of backward and forward projections and the perpetual inventory method, this approach was not used here. This method, developed by Foldvari and Van Leeuwen (2009) and Foldvari, Van Leeuwen, and Van Leeuwen-Li (forthcoming), utilises the fact that backward extrapolation using the PIM method results in an overestimate while forward calculation results in an underestimate. When back- and forward-calculated over the same number of years, these biases cancel out. This allows us to arrive in the future at an annual dataset of years of education for the world.

\section{Data quality}

\section{Limitations of education and literacy as a measure of well-being}

The rise, and later decline, of the restricted concept of literacy can also be found in the data. The narrow concept of literacy, defined by UNESCO as the percentage of people age 15 and above "who can, with understanding, read and write a short, simple statement on their everyday life", became increasingly recorded in the data from the end of the 19th century onwards and started to decline in importance when literacy approached $100 \%$ at the end of the 20th century.

Table 5.1. Literacy by years of schooling completed in the United States, 1947 People aged 14 years and older

\begin{tabular}{lc}
\hline Years of education & Percentage literate \\
\hline none & 19.9 \\
1 year & 33.4 \\
2 years & 53.8 \\
3 years & 80.8 \\
4 years & 95.3 \\
\hline
\end{tabular}

Source: "Progress of literacy in various countries: a preliminary statistical study of available census data since 1900", UNESCO (Paris, 1953) (Table 152). 
At that time, people not only underwent more and more formal education, but the years they spend in this type of education also increased. With this development, the chance of permanent literacy increased as well. Table 5.1 shows that in 1947 in the United States, $19.9 \%$ of all persons without any formal education were literate. This increased from $33.4 \%$ after 1 year of education to $95.3 \%$ after 4 years of education. The interesting feature is that the more years of education people follow on average, the closer literacy and attainment will be.

But how about at the start of the 19th century when there was very little formal education? In that situation we might expect that the share of people without formal education who still have a certain level of literacy (recall that this level was $19.9 \%$ in the United States in 1947) is much lower, since very few people are around to teach them, and their parents will also have had limited or no literacy. Unfortunately, our attainment data does not stretch back to the start of the 19th century. Yet we can test this assumption by looking at those countries at the start of the 20th century with hardly any formal education. If our hypothesis is true, we would expect literacy to be below 19.9\%. For example, India in 1900 had an attainment of only $4.7 \%$ and a literacy of 6\%, while in Haiti in 1950 these figures had values of $15 \%$ and $10 \%$.

Hence, when formal education is very low, so are literacy rates. At higher levels of attainment, literacy rates can be expected to be lower than suggested by attainment, unless the few people that actually attained education all attain higher levels of education. ${ }^{2}$ Finally, at even higher levels of attainment, reached at the end of the 20th century, attainment and literacy rates once again start moving together.

With the rise of attainment the time spent in such education also started to increase, especially in the 20th century. Therefore, we include the more comprehensive indicator "average years of education" in this chapter. The choice of this indicator is a balance between the practical availability of data and the comprehensiveness of the indicator. After all, for the direct effect of education on well-being, for example to read a book or enjoy art, formal education, if provided in sufficient quantity, may very well be a good measure. After all, one does not need a high-quality university education to read a pamphlet, watch television or visit a museum. Neither are less easily quantifiable aspects of knowledge very important. Rarely are skills or on-the-job training important in this respect.

More problematic may be the indirect effects of education on well-being, both in terms of quantity and quality. Quantitatively, even though there is a large literature on job-searching where educational degrees are an important indicator for the employer (e.g. Autor and Dorn, 2013), factors such as innate ability, on-the-job training, learning by doing, and experience also play a role in finding jobs, and they affect personal income. In addition, besides adding to the quantity of knowledge, quality may play an important role in the relation between knowledge and per capita income (e.g. Romer, 1990). Educational development remains the most important component within the overall development of knowledge. Considering also its importance for direct effects on well-being, education is by far the variable that is most suited to being a proxy for well-being overall (e.g. Barro and Lee 1993; 2010).

In general, it can be assumed that any errors in the data presented here derive from three sources: first, the unreliability of the existing data; second, errors in converting to internationally comparable units; and third, the perpetual inventory method itself. Given the availability of census data and relatively reliable and homogenous enrolment 
rates, these problems are most likely less severe for the second half of the 20th century than for earlier periods. This obviously varies from country to country: before the 1970s the indicators are generally less reliable for African countries than for many European countries.

In order to give some indication of this, we subdivided the estimates into four classes (Table 5.2).Virtually all benchmark data after 1960 (i.e. 1960, 1970, 1980, 1990, 2000 and 2010) are derived indirectly from central statistical agencies and are therefore probably better classified as historical reconstructions. The remaining data are estimates.

Table 5.2. Quality of data on years of education by region and benchmark year, 1820-2008

\begin{tabular}{|c|c|c|c|c|c|c|c|c|}
\hline & $\begin{array}{l}\text { Western } \\
\text { Europe } \\
\text { (WE) }\end{array}$ & $\begin{array}{c}\text { Eastern } \\
\text { Europe } \\
\text { (EE) }\end{array}$ & $\begin{array}{l}\text { Western } \\
\text { Offshoots } \\
\text { (W0) }\end{array}$ & $\begin{array}{l}\text { Latin } \\
\text { America } \\
\text { and } \\
\text { Caribbean } \\
\text { (LA) }\end{array}$ & $\begin{array}{c}\text { Sub-Saharan } \\
\text { Africa } \\
\text { (SSA) }\end{array}$ & $\begin{array}{l}\text { Middle East } \\
\text { and } \\
\text { North Africa } \\
\text { (MENA) }\end{array}$ & $\begin{array}{c}\text { East Asia } \\
(E A)\end{array}$ & $\begin{array}{c}\text { South and } \\
\text { South-East } \\
\text { Asia } \\
\text { (SSEA) }\end{array}$ \\
\hline 1820 & 3 &.. &.. & .. &.. &.. &.. &.. \\
\hline 1870 & 3 & 4 & 3 & 4 & 4 & 4 & 4 & 4 \\
\hline 1913 & 3 & 3 & 3 & 3 & 3 & 3 & 3 & 3 \\
\hline 1950 & 2 & 2 & 2 & 2 & 3 & 3 & 3 & 3 \\
\hline 1973 & 2 & 2 & 2 & 2 & 2 & 2 & 2 & 2 \\
\hline 2008 & 2 & 2 & 2 & 2 & 2 & 2 & 2 & 2 \\
\hline
\end{tabular}

Note: 1. High quality; 2. Moderate quality; 3. Low quality; and 4. Estimates.

See the section on «Data Quality» in Chapter 1 for a description of the quality criteria.

Source: Clio-Infra, www.clio-infra.eu.

\section{Main highlights of education trends}

Using a combination of contemporaneous and historical data, we were able to estimate world literacy back to 1820 . In 1820 , roughly $12 \%$ of the world's people were literate, a number that doubled over the course of the 19th century, with another doubling between 1900 and 1990. Our data for educational attainment start only in 1870. However, utilising its relationship with literacy, a regression can be run to backcast attainment to 1820. Doing this indicates that about $17 \%$ of the world's population aged 15 and older had attained at least some basic education. We report this "best guess" figure as well as our other estimates of attainment until 2010 in Figure 5.1. As pointed out before, we do notice a divergence between educational attainment and literacy at the end of the 19th and start of the 20th century, which closed again at the end of the century.

This general picture of literacy and educational attainment hides large regional differences, however. Unsurprisingly, around 1870, the Western Offshoots and Western European countries had the highest attainment levels, at about $82 \%$ and $60 \%$ respectively, with Sub-Saharan Africa at a low 2\% (Table 5.3). This completely changed in the 21st century, when the share of the adult population with at least some basic education had increased to $79 \%$. By then, most regions had reached levels around $90 \%-100 \%$, except for South and Southeast Asia, the Middle East and North Africa, and Sub-Saharan Africa, which remained behind with attainment levels of around $60 \%$. 
Figure 5.1. World development of literacy and attainment of at least basic education, 1820-2010

Percentage of population aged over 15 literate or enrolled in formal education

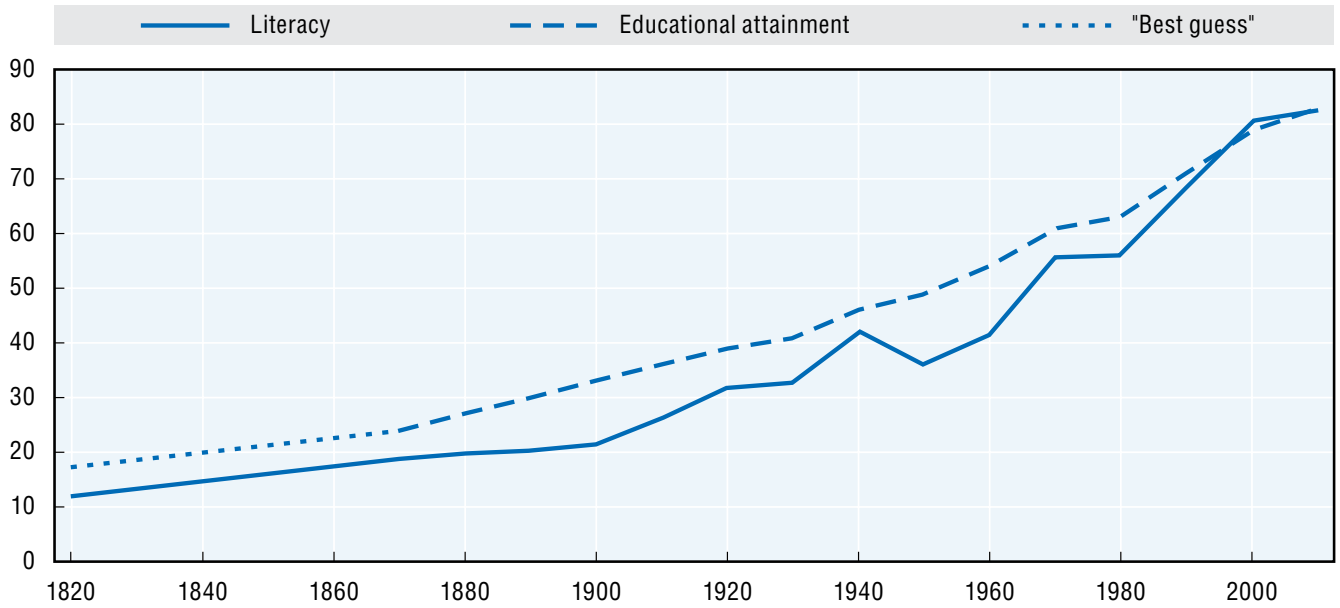

Note: For an assessment of data quality, see Table 5.2.

Source: Clio-Infra, www.clio-infra.eu.

Table 5.3. Population having attained at least basic education by region, $\mathbf{1 8 7 0 - 2 0 1 0}$ Percentage of population aged over 15 enrolled in formal education

\begin{tabular}{|c|c|c|c|c|c|c|c|c|c|}
\hline & $\begin{array}{l}\text { Western } \\
\text { Europe } \\
\text { (WE) }\end{array}$ & $\begin{array}{c}\text { Eastern } \\
\text { Europe } \\
\text { (EE) }\end{array}$ & $\begin{array}{l}\text { Western } \\
\text { Offshoots } \\
\text { (W0) }\end{array}$ & $\begin{array}{l}\text { Latin } \\
\text { America } \\
\text { and } \\
\text { Caribbean } \\
\text { (LA) }\end{array}$ & $\begin{array}{c}\text { East Asia } \\
(\mathrm{EA})\end{array}$ & $\begin{array}{c}\text { South and } \\
\text { South-East } \\
\text { Asia } \\
\text { (SSEA) }\end{array}$ & $\begin{array}{l}\text { Middle East } \\
\text { and } \\
\text { North Africa } \\
\text { (MENA) }\end{array}$ & $\begin{array}{c}\text { Sub-Saharan } \\
\text { Africa } \\
\text { (SSA) }\end{array}$ & World \\
\hline 1870 & 60.0 & 25.1 & 82.3 & 13.5 & 24.3 & 1.8 & 4.2 & 1.8 & 23.9 \\
\hline 1880 & 69.2 & 27.4 & 86.5 & 16.2 & 25.6 & 2.2 & 4.7 & 2.0 & 26.7 \\
\hline 1890 & 75.3 & 30.8 & 92.5 & 19.5 & 27.6 & 2.5 & 5.3 & 2.4 & 29.6 \\
\hline 1900 & 80.9 & 33.9 & 96.9 & 23.0 & 30.2 & 5.0 & 5.8 & 2.9 & 33.2 \\
\hline 1910 & 82.6 & 36.1 & 96.7 & 26.7 & 32.8 & 6.3 & 7.1 & 3.6 & 35.6 \\
\hline 1920 & 86.7 & 49.1 & 98.0 & 32.0 & 35.9 & 8.6 & 7.5 & 4.4 & 38.6 \\
\hline 1930 & 86.8 & 64.4 & 98.8 & 35.7 & 37.9 & 11.5 & 8.7 & 6.3 & 40.9 \\
\hline 1940 & 90.9 & 92.8 & 100.0 & 42.7 & 42.1 & 15.2 & 10.5 & 9.5 & 45.9 \\
\hline 1950 & 91.3 & 97.1 & 100.0 & 54.0 & 45.8 & 19.7 & 14.0 & 13.4 & 49.0 \\
\hline 1960 & 93.9 & 98.5 & 100.0 & 55.5 & 56.2 & 25.6 & 21.1 & 20.4 & 53.7 \\
\hline 1970 & 96.0 & 98.5 & 100.0 & 65.4 & 71.8 & 34.4 & 28.8 & 25.1 & 60.9 \\
\hline 1980 & 98.6 & 98.5 & 100.0 & 71.5 & 72.4 & 40.5 & 39.4 & 32.1 & 63.0 \\
\hline 1990 & 99.5 & 99.7 & 100.0 & 83.3 & 80.0 & 53.7 & 55.2 & 45.2 & 71.1 \\
\hline 2000 & 99.6 &.. & 100.0 & 90.0 & 87.1 & 65.9 & 66.3 & 58.4 & 78.5 \\
\hline 2010 & 99.8 & .. & 100.0 & 93.5 & 89.8 & 70.3 & 73.8 & 65.4 & 81.5 \\
\hline
\end{tabular}

Note: For an assessment of data quality, see Table 5.2.

Source: Clio-Infra, www.clio-infra.eu.

StatLink 司IST http://dx.doi.org/10.1787/888933095742

The reasons for this massive spread of formal education relate to the development of channels through which education affects well-being, i.e. the direct relation with wellbeing, as well as indirect material and immaterial benefits. The demand for education by the population increased because it supplied social standing and access to the market, while its supply increased because the government wanted to educate citizens who 
were able to participate in the political process (e.g. Glaeser et al., 2007). This increase in mass education then took on its own dynamic, in which the demand for and supply of education both increased, albeit in certain regions more than in others (e.g. Murtin and Viarengo, 2011).

These basic numbers (see Tables 5.4 and 5.5) show that education has spread throughout the world at an ever increasing rate throughout the 20th century, giving the great majority of the world population access to the written word. Gaps between regions as well as between the sexes have diminished. The direct effect on well-being was an enormous increase in people's potential to enjoy the written word. Indeed, as shown by Plopeanu et al. (2014), the number of printed book titles in the United Kingdom increased in the 19th century from about 1000 to more than 6000 a year, suggesting an increasing demand for books and literature. However, Africa remained significantly behind: in the 1950s in Europe the number of book titles per million inhabitants per year was 343 versus a mere 28 in Africa. There was also immense progress in terms of indirect effects on well-being. In many countries higher levels of education contributed to economic growth, because of the adoption or invention of new technologies that increased labour productivity (e.g. Van Leeuwen and Foldvari, 2008a), increased life expectancy (Castelló-Climent and Doménech, 2007), empowered women (Nussbaum, 2003) and reduced crime (Eicher et al., 2009).

Technological developments also create counter-forces to this trend. For example, an increasing amount of information is available via the internet. Even though the number of books in Africa increased, the continent lagged massively in access to this new medium

Table 5.4. Average years of education by region, $\mathbf{1 8 5 0 - 2 0 1 0}$ Years

\begin{tabular}{|c|c|c|c|c|c|c|c|c|c|}
\hline & $\begin{array}{l}\text { Western } \\
\text { Europe } \\
\text { (WE) }\end{array}$ & $\begin{array}{c}\text { Eastern } \\
\text { Europe } \\
\text { (EE) }\end{array}$ & $\begin{array}{c}\text { Western } \\
\text { Offshoots } \\
\text { (W0) }\end{array}$ & $\begin{array}{l}\text { Latin } \\
\text { America } \\
\text { and } \\
\text { Caribbean } \\
\text { (LA) }\end{array}$ & $\begin{array}{c}\text { East Asia } \\
\text { (EA) }\end{array}$ & $\begin{array}{c}\text { South and } \\
\text { South-East } \\
\text { Asia } \\
\text { (SSEA) }\end{array}$ & $\begin{array}{l}\text { Middle East } \\
\text { and } \\
\text { North Africa } \\
\text { (MENA) }\end{array}$ & $\begin{array}{c}\text { Sub-Saharan } \\
\text { Africa } \\
\text { (SSA) }\end{array}$ & World \\
\hline 1850 & .. & .. & .. & .. & 0.8 & .. & .. & .. & 0.9 \\
\hline 1860 & .. & .. & .. & .. & 0.8 & .. & .. & .. & 1.0 \\
\hline 1870 & 3.5 & 0.9 & 5.5 & 0.6 & 1.0 & 0.1 & 0.2 & 0.1 & 1.2 \\
\hline 1880 & 4.0 & 1.0 & 5.9 & 0.8 & 1.1 & 0.1 & 0.3 & 0.1 & 1.3 \\
\hline 1890 & 4.5 & 1.2 & 6.5 & 0.9 & 1.1 & 0.2 & 0.3 & 0.1 & 1.5 \\
\hline 1900 & 5.0 & 1.5 & 7.0 & 1.1 & 1.3 & 0.3 & 0.4 & 0.1 & 1.7 \\
\hline 1910 & 5.5 & 1.7 & 7.5 & 1.4 & 1.4 & 0.4 & 0.4 & 0.2 & 2.0 \\
\hline 1920 & 5.9 & 2.1 & 7.8 & 1.7 & 1.5 & 0.5 & 0.5 & 0.2 & 2.2 \\
\hline 1930 & 6.2 & 2.7 & 8.5 & 2.0 & 1.7 & 0.7 & 0.6 & 0.3 & 2.5 \\
\hline 1940 & 6.6 & 3.8 & 8.9 & 2.4 & 2.0 & 1.0 & 0.8 & 0.5 & 2.8 \\
\hline 1950 & 7.0 & 4.7 & 9.6 & 3.0 & 2.4 & 1.3 & 1.1 & 0.8 & 3.2 \\
\hline 1960 & 7.8 & 5.4 & 10.2 & 3.7 & 3.3 & 1.7 & 1.6 & 1.2 & 3.8 \\
\hline 1970 & 9.0 & 6.5 & 10.9 & 4.4 & 4.3 & 2.4 & 2.2 & 1.6 & 4.5 \\
\hline 1980 & 10.1 & 8.1 & 11.8 & 5.3 & 5.5 & 3.2 & 3.3 & 2.1 & 5.3 \\
\hline 1990 & 11.0 & 9.4 & 12.7 & 6.7 & 6.4 & 4.0 & 4.7 & 3.0 & 6.1 \\
\hline 2000 & 11.5 & 10.3 & 13.0 & 7.6 & 7.7 & 5.1 & 6.0 & 3.8 & 7.2 \\
\hline 2010 & 11.9 & 11.3 & 13.5 & 8.1 & 8.4 & 5.7 & 6.7 & 4.2 & 7.7 \\
\hline
\end{tabular}

Note: For an assessment of data quality, see Table 5.2. Source: Clio-Infra, www.clio-infra.eu. 
Table 5.5. Average years of education in selected countries, $\mathbf{1 8 5 0 - 2 0 0 0}$ Years

\begin{tabular}{|c|c|c|c|c|c|c|c|c|c|c|c|c|c|c|c|c|c|c|c|c|c|c|c|c|c|}
\hline & \multicolumn{7}{|c|}{$\begin{array}{l}\text { Western Europe } \\
\text { (WE) }\end{array}$} & \multicolumn{2}{|c|}{$\begin{array}{c}\text { Eastern Europe } \\
\text { (EE) }\end{array}$} & \multicolumn{3}{|c|}{$\begin{array}{l}\text { Western Offshoots } \\
\text { (WO) }\end{array}$} & \multicolumn{3}{|c|}{$\begin{array}{l}\text { Latin America and } \\
\text { Caribbean } \\
\text { (LA) }\end{array}$} & \multicolumn{2}{|c|}{$\begin{array}{l}\text { Middle East } \\
\text { and North } \\
\text { Africa (MENA) }\end{array}$} & \multicolumn{3}{|c|}{$\begin{array}{c}\text { Sub-Saharan Africa } \\
\text { (SSA) }\end{array}$} & \multicolumn{2}{|c|}{$\begin{array}{l}\text { East Asia } \\
\quad(\mathrm{EA})\end{array}$} & \multicolumn{3}{|c|}{$\begin{array}{c}\text { South and } \\
\text { South-East Asia } \\
\text { (SSEA) }\end{array}$} \\
\hline & GBR & NLD & FRA & DEU & ITA & ESP & SWE & POL & RUS & AUS & CAN & USA & MEX & BRA & ARG & EGY & TUR & KEN & NGA & ZAF & $\mathrm{CHN}$ & JPN & IND & IDN & THA \\
\hline 1820 & 1.8 & 2.0 & .. & .. & .. & .. & .. & .. & .. & .. & .. & .. & .. & .. & .. & .. & .. & .. & .. & .. & .. & .. & .. & .. & .. \\
\hline 1830 & 1.9 & 2.0 & .. & .. & .. & .. & .. & .. & .. & .. & .. & .. & .. & .. & .. & .. & .. & .. & .. & .. & .. & .. & .. & .. & .. \\
\hline 1840 & 2.2 & 2.5 & .. & .. & .. & .. & .. & .. & .. & .. & .. & .. & .. & .. & .. & .. & .. & .. & .. & .. & .. & .. & .. & .. & .. \\
\hline 1850 & 2.6 & 3.0 & .. & .. & .. & .. & .. & .. & .. & 1.1 & .. & .. & .. & .. & .. & .. & .. & .. & .. & .. & 0.8 & .. & .. & .. & .. \\
\hline 1860 & 3.1 & 4.0 & .. & .. & .. & .. & .. & .. & .. & 1.5 & .. & .. & .. & .. & .. & .. & .. & .. & .. & .. & 0.8 & .. & .. & .. & .. \\
\hline 1870 & 3.6 & 5.1 & 4.1 & 5.4 & 0.8 & 1.5 & 4.2 & .. & 0.9 & 3.1 & 5.7 & 5.6 & 0.6 & 0.5 & 1.5 & 0.2 & 0.3 & 0.2 & 0.0 & 1.1 & 1.0 & 1.0 & 0.1 & 0.0 & 0.2 \\
\hline 1880 & 4.4 & 5.2 & 4.9 & 5.7 & 1.3 & 2.0 & 4.6 & .. & 1.0 & 4.2 & 6.2 & 6.0 & 0.7 & 0.6 & 1.6 & 0.2 & 0.3 & 0.3 & 0.0 & 1.1 & 1.1 & 1.1 & 0.1 & 0.0 & 0.2 \\
\hline 1890 & 4.8 & 5.4 & 5.8 & 6.1 & 1.9 & 2.6 & 5.0 & .. & 1.1 & 5.3 & 6.7 & 6.6 & 0.9 & 0.6 & 1.8 & 0.2 & 0.4 & 0.4 & 0.0 & 1.1 & 1.1 & 1.5 & 0.2 & 0.0 & 0.3 \\
\hline 1900 & 5.3 & 5.6 & 6.3 & 6.5 & 2.4 & 3.1 & 5.5 & .. & 1.2 & 6.2 & 7.1 & 7.1 & 1.1 & 0.7 & 2.1 & 0.3 & 0.5 & 0.4 & 0.0 & 1.1 & 1.2 & 2.2 & 0.3 & 0.0 & 0.3 \\
\hline 1910 & 5.9 & 5.8 & 7.0 & 7.0 & 2.8 & 3.5 & 5.9 & .. & 1.3 & 7.1 & 7.6 & 7.5 & 1.3 & 0.9 & 2.5 & 0.4 & 0.5 & 0.5 & 0.0 & 1.1 & 1.2 & 2.9 & 0.4 & 0.1 & 0.4 \\
\hline 1920 & 6.3 & 6.1 & 7.5 & 7.5 & 3.4 & 3.7 & 6.2 & 2.4 & 1.9 & 7.7 & 8.0 & 7.8 & 1.4 & 1.0 & 3.1 & 0.4 & 0.6 & 0.6 & 0.0 & 1.4 & 1.3 & 3.9 & 0.5 & 0.1 & 0.4 \\
\hline 1930 & 6.7 & 6.4 & 7.7 & 7.7 & 3.9 & 3.8 & 6.5 & 2.5 & 2.5 & 8.4 & 8.5 & 8.5 & 1.5 & 1.3 & 3.7 & 0.7 & 0.6 & 0.7 & 0.0 & 1.9 & 1.3 & 5.0 & 0.7 & 0.2 & 0.5 \\
\hline 1940 & 7.2 & 6.8 & 8.0 & 8.2 & 4.4 & 4.6 & 6.8 & 3.0 & 3.9 & 8.9 & 8.8 & 8.9 & 1.9 & 1.6 & 4.5 & 1.0 & .. & 0.8 & 0.2 & 2.4 & 1.5 & 5.8 & 0.9 & 0.4 & 1.0 \\
\hline 1950 & 7.7 & 7.1 & 8.1 & 8.5 & 5.0 & 4.9 & 7.4 & 3.2 & 5.0 & 9.4 & 9.2 & 9.6 & 2.5 & 2.4 & 5.4 & 1.5 & 1.2 & 1.2 & 0.4 & 3.1 & 1.7 & 6.8 & 1.2 & 0.9 & 1.8 \\
\hline 1960 & 8.9 & 8.0 & 8.4 & 9.7 & 5.5 & 5.6 & 8.5 & 4.2 & 6.6 & 10.0 & 9.5 & 10.3 & 3.4 & 3.1 & 6.2 & 1.6 & 2.2 & 1.9 & 1.1 & 4.0 & 2.5 & 8.6 & 1.5 & 1.7 & 2.6 \\
\hline 1970 & 10.2 & 9.0 & 10.0 & 11.1 & 6.6 & 6.4 & 9.7 & 5.3 & 7.9 & 10.7 & 9.9 & 11.1 & 4.4 & 3.8 & 6.8 & 1.8 & 3.1 & 2.8 & 1.3 & 4.9 & 3.5 & 10.1 & 2.0 & 3.0 & 3.2 \\
\hline 1980 & 11.4 & 10.0 & 11.1 & 12.3 & 7.8 & 7.3 & 11.0 & 6.7 & 9.1 & 11.9 & 11.2 & 11.9 & 5.5 & 4.7 & 7.7 & 3.1 & 4.2 & 4.0 & 1.5 & 5.2 & 4.6 & 11.0 & 2.7 & 3.8 & 4.1 \\
\hline 1990 & 12.2 & 10.7 & 11.5 & 13.1 & 9.1 & 8.4 & 11.8 & 7.6 & 9.8 & 12.7 & 12.2 & 12.7 & 6.9 & 6.6 & 7.8 & 5.2 & 5.3 & 5.2 & 2.7 & 5.8 & 5.6 & 11.8 & 3.3 & 6.1 & 6.6 \\
\hline 2000 & 13.1 & 11.3 & 11.8 & 12.9 & 10.3 & 9.5 & 11.5 & 8.8 & 9.4 & 13.0 & 12.8 & 13.0 & 8.0 & 7.5 & 8.4 & 6.8 & 6.3 & 6.1 & 4.0 & 7.4 & 6.9 & 12.7 & 4.5 & 7.3 & 7.6 \\
\hline
\end{tabular}

Note: For an assessment of data quality, see Table 5.2.

Source: Clio-Infra, www.clio-infra.eu. 
for the written word: whereas in the West close to $90 \%$ of the population has access to the internet, in Africa the figure is closer to $10-20 \%$. Similarly, the relation between education and material well-being has changed over time. In the 19th century the Western countries were still at the top of technical innovation, with about five years of education, a level that the African countries reached only at the end of the 20th century. But in the late 20th century the technological frontier had shifted upwards. MacMahon (1998) points out that the importance of secondary and higher education has increased over time, while Petrakis and Stamatakis (2002) elaborate on this by showing that the more economically developed a country is, the more important secondary and higher education are for economic development. But even in the less developed countries it is likely that the importance of secondary and higher education increases over time (e.g. Liu and Stengos, 1999). For example, Krueger and Lindahl $(2001,1130)$ estimated for the OECD that the effect of years of education on per capita GDP had an inverted U-shape, with a peak at around 7.5 years of education. The developing economies are substantially below this peak, suggesting that currently the effect of education on per capita GDP is low, and perhaps even insignificant.

\section{Correlation with GDP per capita}

It is important to stress nevertheless that, even though education may, in certain instances, have a limited (or changing) effect on per capita GDP over time, this does not imply that there is a low correlation between education and per capita income (see Figure 5.2). Disregarding the period before 1870, since there are simply too few observations to arrive at sensible correlations, we arrive, from 1870 onwards, at a correlation between these two indicators that is persistently high.

The reason for this tight relationship is that not only is education important for increasing per capita income, but per capita income may also affect education when countries invest significantly in the development of an education system, as is the case

\section{Figure 5.2. Correlation between average years of education and GDP per capita, 1870-2010}

Pearson correlation coefficient and upper/lower bounds of $95 \%$ confidence interval

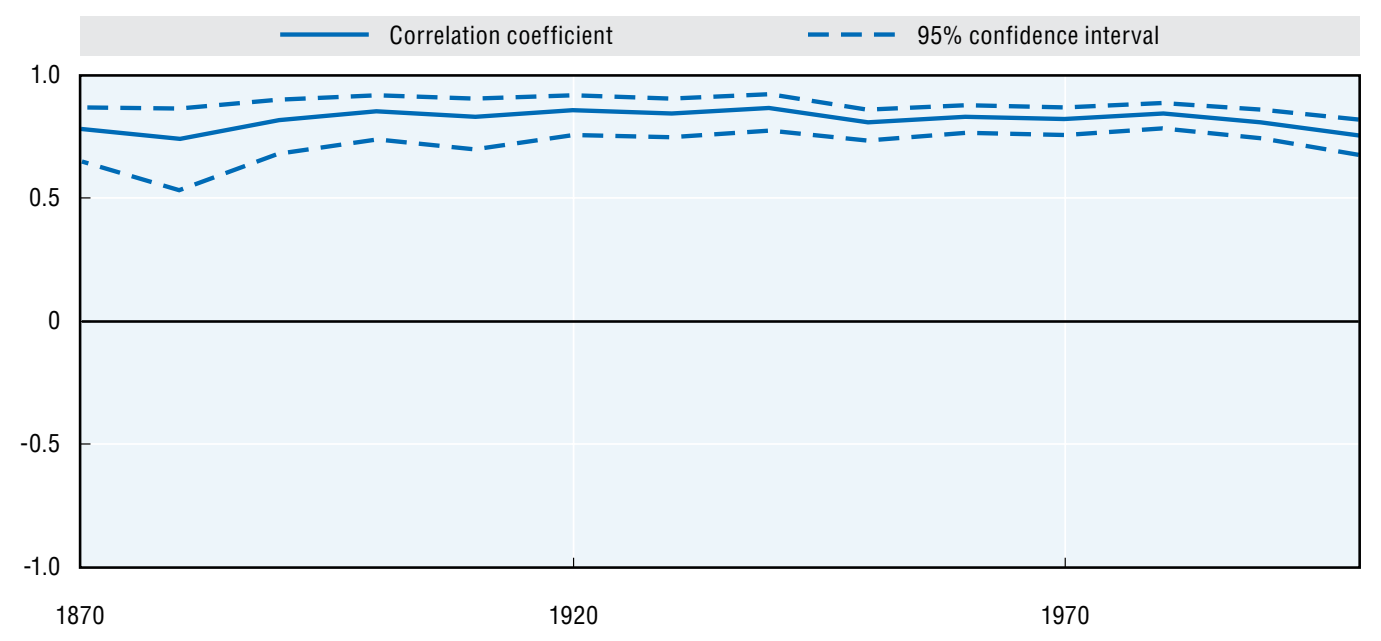

Note: For an assessment of data quality, see Table 5.2.

Source: Clio-Infra, www.clio-infra.eu. 
for many developing economies. In addition, the relationship between education and per capita income may also run through a plethora of other indicators, such as health and corruption.

\section{Priorities for future research}

Literacy and education are crucial variables determining well-being, since they not only directly influence a person's intrinsic agency, but also indirectly affect well-being in material (e.g. per capita income and wages) and immaterial terms (e.g. lower crime rates, higher life expectancy). In this chapter, we made an attempt to quantify literacy and education worldwide between the mid-19th century and 2010. In doing so we combined data from Van Leeuwen et al. and Morrison and Murtin into a single comprehensive database, which will be expanded further in the future.

Over time there has been convergence in levels of literacy and educational attainment, with only Africa lagging substantially behind. This convergence becomes less, or even turns into a divergence, once one corrects for the level of education: the Western countries and Western Offshoots still lead in terms of secondary and higher education.

These findings seem to suggest that, at least in terms education, there has been a massive improvement in well-being. However, two factors may still prove to be obstacles. First, over time the playing field is also changing: countries that try to catch up in terms of education meet increasingly higher demands in terms of their levels of education before the education they impart becomes as productive as in the developed countries. For example, where in the 19th century 2-4 years of education was enough to have a productive workforce, nowadays a country needs close to 6 or 7 years in order for education to begin to have a positive impact on per capita income. Second, there is still a significant difference across countries in terms of the quality of education, with the developed countries maintaining a significant lead (Van Leeuwen and Foldvari, 2008b). This will be work for the future. For the late 20th century several test scores are available which can be used to quantify educational quality, but for earlier periods we have to rely on alternative measures such as educational expenditure and teacher-pupil ratios.

\section{Notes}

1. See Gapminder.

2. This is easy to see from the numbers in Table 5.2. If we assume for simplicity's sake that everyone has only 2 years of education and that educational attainment is $40 \%$, this implies that we can calculate literacy to be $40 \% * 53.8+60 \% * 19.9=33.5 \%$, i.e. literacy is lower than attainment.

\section{References}

Albers, R. (1997), "Human capital and economic growth: operationalising growth theory, with special reference to the Netherlands in the 19th century", GGDC Research memorandum, GD-34.

Alesina, A. and R. Perotti (1996), "Income Distribution, Political Instability, and Investment", European Economic Review, Vol. 40/6, pp. 1203-1228.

Autor, D.H. and D. Dorn (2013), "The Growth of Low Skill Service Jobs and the Polarization of the U.S. Labor Market", American Economic Review, Vol. 103, pp. 1553-1597.

Baier, S., G. Dwyer, and R. Tamura (2006), "How Important are Capital and Total Factor Productivity for Economic Growth?" Economic Inquiry, Issue 44, pp. 23-49.

Barro, R.J. and J.-W. Lee (2010), "A New Data Set of Educational Attainment in the World, 1950-2010", NBER Working Paper, No. 15902. 
Barro, R.J. and J.-W. Lee (1993), "Institutional comparisons of educational attainment", Journal of Monetary Economics, Vol. 32/3, pp. 363-394.

Blue books of the British colonies (various issues).

Castelló-Climent, A. and R. Doménech (2008), "Human Capital Inequality, Life Expectancy and Economic Growth”, Economic Journal, Vol. 118/528, pp. 653-677.

Cohen, D. and M. Soto (2007), “Growth and human capital: good data, good results", Journal of Economic Growth, Vol. 12/1, pp. 51-76.

de Pleijt, S. (2011), "The Role of Human Capital in the Process of Economic Development: The Case of England, 1307-1900”, CGEH working paper no. 21.

Egero, B. and R.A. Henin (1967), "The population of Tanzania: an analysis of the 1967 population census”, CENSUS COLUME 6.

Eicher, T., G.C. arcía-Peñalosa and T. Van Ypersele, (2009), "Education, corruption, and the distribution of income", Journal of Economic Growth, Vol. 14 /3, pp 205-231.

Földvári, P. and B. Van Leeuwen (2009), "Average years of education in Hungary: annual estimates 1920-2006”, Eastern European Economics, Vol. 47/2, pp. 5-20.

Földvári, P., B. Van Leeuwen and J. Van Leeuwen-Li (forthcoming), "Educational and income inequality in Europe, 1870-2000", Cliometrica, Forthcoming.

Fuente, A. and R. Doménech (2000), "Human Capital in Growth Regressions: How Much Difference Does Data Quality Make?” OECD Economics Department Working Papers, No. 262 (2000), pp. 2-68.

Gapminder, Literacy rate, adult total (\% of people ages 15 and above), www.gapminder.org/data/, accessed 20 May 2013.

Glaeser, E.L., G.A.M. Ponzetto and A. Shleifer, (2007), “Why does democracy need education?” Journal of Economic Growth, Vol. 12/2, pp. 77-99.

Krueger, A.B. and M. Lindahl, (2001), "Education for Growth: Why and For Whom?” Journal of Economic Literature, Vol. 39/4, pp. 1101-1136.

Lindert, P.H. (2004), Growing Public: Social Spending and Economic Growth since the Eighteenth Century Vol. 2., Cambridge: Cambridge Univ. Press.

Liu, Z. and Th. Stengos (1999), "Non-Linearities in Cross-Country Growth Regressions: A Semiparametric Approach", Journal of Applied Econometrics, 14 (5), pp. 527-538.

MacMahon, W.W. (1998), "Education and Growth in East Asia”, Economics of Education Review, Vol. 17/2, pp. 59-172.

Maddison, A. (2007), "Contours of the World Economy, 1-2030 AD", Essays in Macro-Economic History, Oxford University Press, Oxford.

Mironov, B.N. (1985), “Gramotnost' v Rossii 1797-1917 godov”, Istoria SSSR, Vol. 4, pp. 137-153.

Mitchell, B.R. (2007), International Historical Statistics: Africa, Asia \& Oceania, 1750-2005, Palgrave Macmillan (5th edition), Basingstoke [etc.].

Mitchell, B.R. (2007), International Historical Statistics: The Americas, 1750-2005,: Palgrave Macmillan (5th edition).

Mitchell, B.R. (2007), International Historical Statistics: Europe, 1750-2005, Basingstroke [etc.]: Palgrave Macmillan (5th edition).

Morrisson, Ch. and F. Murtin (2009), “The Century of Education”, Journal of Human Capital, Vol. 3/1, pp. 1-42.

Morrisson, C. and F. Murtin (2013), “The Kuznets curve of human capital inequality: 1870-2010”, Journal of Economic Inequality, 11 (3), pp. 283-301.

Murtin, F. and Viarengo, M. (2011), "The expansion and convergence of compulsory schooling in Western Europe, 1950-2000”, Economica, 78 (311), pp. 501-522.

Nussbaum, M. (2003), “Women's Education: A Global Challenge”, Signs: Journal of Women in Culture and Society, 29 (2), pp. 325-355.

OECD (2011a), “Towards an OECD Skills Strategy”, Document Presented at the OECD Ministerial Council Meeting, Paris. 
OECD (2011b), How's Life?: Measuring Well-being, OECD Publishing, Paris, http://dx.doi.org/10.1787/ 9789264121164-en.

OECD (2010), Improving Health and Social Cohesion through Education, Educational Research and Innovation, OECD Publishing, http://dx.doi.org/10.1787/9789264086319-en.

Pamuk, S. and J.L. Van Zanden, (2007), “Standards of living, 1700-1870", third conference of "Unifying European Experience: Lessons of Pan-European Development", Marie Curie Training Network, London.

Pamuk, S. and J.L. van Zanden, (2010), "Standards of Living”, The Cambridge Economic History of Modern Europe, edited by Stephen Broadberry, and Kevin H. O'Rourke, Cambridge University Press.

Petrakis, P.E. and D. Stamatakis (2002), "Growth and Educational Levels: A Comparative Analysis", Economics of Education Review, Vol. 21/5, pp. 513-521.

Plopeanu, A., P. Foldvari, B. Van Leeuwen and J.L. Van Zanden (2014), "Where do ideas come from? Book production and patents in a global and temporal perspective", European Journal of Science and Theology, 10 (3), pp. 113-119.

Prados de la Escosura, L. and J. Rosés, (2010), "Human capital and economic growth in Spain, 1850-2000", Explorations in Economic History, Vol. 47/4, pp. 520-32.

Romer, P. (1990), “Endogenous Technological Change”, Journal of Political Economy, 98 (5), part 2, pp. 71-102.

Sabates, R. (2008), “Educational attainment and juvenile crime, Area-level analysis using three cohorts of young people", British Journal of Criminology, Vol. 48, pp. 395-409.

Spence, J., S.J. Aiston and M.M. Meikle (eds.) (2009), Women, education and agency, 1600-2000, Routledge, New York.

UNESCO (United Nations Educational, Scientific and Cultural Organization) (2006), Literacy for Life, Education for All, Global Monitoring Report, UNESCO Publishing, Paris.

UNESCO, Statistical Yearbook 1963-1999, UNESCO 1964-1999, Paris.

UNESCO (1957), World Illiteracy at Mid-Century, Paris: UNESCO, Paris.

UNESCO (1953), Progress of literacy in various countries: a preliminary statistical study of available census data since 1900, UNESCO, Paris.

United States Department of Commerce, United States Census Bureau, International database, downloaded from: www.census.gov/population/international/data/idb/informationGateway.php.

United States Department of Education (1993), 120 years of American education: a statistical portrait, USA: National Center for Education Statistics, http://nces.ed.gov/pubs93/93442.pdf.

van Leeuwen, B. and P. Földvári (2008a), "Human Capital and Economic Growth in Asia 1890-2000: a time-series analysis", Asian Economic Journal, Vol. 22/3, pp. 225-240.

van Leeuwen, B. (2007), Human capital and economic growth in India, Indonesia and Japan: A quantitative analysis: 1870-2000, PhD thesis Utrecht University.

van, Leeuwen, B. and P. Földvári, (2008b), "How much human capital does Eastern Europe have? Measurement methods and results", Post-Communist Economies, Vol. 20/2, pp. 189-201.

Wößmann, L. (2003), “Specifying Human Capital”, Journal of Economic Surveys, Vol. 17/3, pp. 239-270. 


\title{
Chapter 6
}

\section{Life expectancy since 1820}

\author{
by \\ Richard L. Zijdeman, International Institute of Social History, Stirling University \\ and \\ Filipa Ribeiro de Silva, University of Macau
}

Health status is a key dimension of well-being. This chapter describes long-term trends in life expectancy at birth by combining a wide variety of international databases, while maintaining some coherence in the methods used. In addition, the chapter presents data on the infant mortality rate. It shows that, on a global scale, life expectancy at first diverged in the late 19th and early 20th century, reflecting higher life expectancy in Western Europe and the Western Offshoots. From the second half of the 20th century onwards, life expectancy improved in other parts of the world as well (with the exception of Sub-Saharan Africa), leading to a global convergence in life expectancy. Within the world's regions, levels of life expectancy appear to have started diverging once more during the last three decades. 


\section{Introduction}

Health status is a key dimension of well-being, and one of the most salient for an appreciation of historical changes in people's living conditions. Good health contributes to well-being both directly and indirectly - directly, since health status is universally valued, and together with having a good job, people in most OECD countries consider health to be the most important element for their well-being (OECD, 2011). Health also contributes to well-being indirectly, since bad health hampers the quality of, or the amount of time spent in, other activities bearing on people's well-being, such as employment, education, worklife balance, civic engagement and social connections. Health status is also important when assessed at the level of sub-groups of the population: when some sub-groups suffer disproportionally from bad health, this puts the well-being of society at large at risk and may hamper health progress for other sub-groups (WHO, 2013).

Health status can be studied through different measures of morbidity and mortality. Morbidity concerns factors that compromise health, such as illness and injury. Mortality concerns death-related aspects, for example, the timing and cause of death and the characteristics of those affected. Mortality is easier to measure than morbidity, since death is clear-cut, while there is much variation in illness, such as the type, severity, occurrence and duration.

Because of the measurement problems with morbidity, this chapter relies solely on measures of mortality to describe cross-country variations and changes over time in people's health status. Most of the indicators of morbidity typically included in OECD reports are based on survey methods that gained popularity only after the Second World War. While there are some late 19th or early 20th century surveys that touch upon morbidity, the scope of these surveys is much too local for the purpose of describing differences between countries in morbidity over historical times. In contrast, long time-series of mortality data exist for various countries. The analyses in this chapter focus on a key measure of mortality: life expectancy at birth. While the infant mortality rate is another key measure of mortality, we only touch upon patterns of infant mortality to study its association with life expectancy at birth.

The need for global mortality data covering long periods of time is underlined by the theoretical debate on the epidemiological transition since the 18th century. One branch of this debate has focused on the changing relationship between mortality, on one side, and the level of economic development, on the other (Preston, 1975, 2007). With a similar interest but with a somewhat different approach, Omran (1971) tried to capture developments in mortality in a theoretical framework based on three different eras, encompassing the major shifts in health up until 1970. In the first age of "pestilence and famine", life expectancy is low (between 20 and 40 years) and mortality rates fluctuate, since epidemic, famine and war are key determinants of death. In the second age of "receding pandemics", mortality rates decline as epidemics decline in number and severity. As a result, life expectancy goes 
up to about 50 years and then continues to increase during the third era of "degenerative and man-made diseases". More recently, a fourth era has been suggested by Omran and others to explain unanticipated developments in recent decades, such as the stagnation of life expectancy in a number of Eastern European countries, the increase in longevity beyond the age of 75, and the downfall in life expectancy in Africa as a result of HIV/AIDS (Vallin and Meslé, 2004).

While it is beyond the scope of this chapter to test Omran's original framework or its various "extensions" (e.g. Olshansky and Ault, 1986; Rogers and Hackenberg, 1987; Omran, 1998; Olshansky et al., 1998; Vallin and Meslé, 2004), it is inspired by the critique of Omran's framework for failing "to grasp the global nature and historical sequence of the mortality transition as it spread" (Caldwell, 2001). Using historical data for many regions in the world, we provide a more nuanced view about the gradual increase and convergence in life expectancy around the world over the past two centuries.

\section{Description of the concepts used}

The two standard indicators used in this chapter to describe geographical and temporal differences in longevity since the 1820s are period life expectancy at birth and infant mortality. Period life expectancy is the age that a person of a particular age is expected to reach based on the age-specific mortality rates prevailing at a specific point in time, in this case the year of birth. Thus, life expectancy is based on the mortality rates of all age groups in one specific period.

When interpreting life expectancy at birth, one needs to realise that the life expectancy rate is only an average: this means that some people will not live long enough to match the life expectancy rate, while others will surpass it. It is also important to consider that in countries and time periods where infant mortality is high, rapid improvements in infant mortality will translate into strong gains in life expectancy at birth. This gain will overestimate to some extent the gains in longevity experienced by the rest of the population.

The choice for this particular measure of life expectancy is in line with the literature comparing life expectancies over time and in different countries. While there are more precise measures of life expectancy, such as cohort life expectancy (Wilmoth, 2005), these measures typically require projecting into the future the mortality rates of more recent cohorts. Doing this requires making a set of assumptions, which may differ across different countries or time periods, thereby complicating comparative research (ONS, 2013).

In addition to life expectancy, this chapter also briefly touches on the infant mortality rate as a second indicator of health status. The infant mortality rate is defined here as the number of children who die before reaching the age of one, expressed per 100 live births. Infant mortality is an internationally recognised indicator of health, and is included in the UN framework of health statistics and the OECD How's Life? framework. Infant mortality rates are among the most frequently used indicators of health status, especially for longer time-series (Sköld et al., 2011). Although the infant mortality rate applies only to a specific part of the population, it provides important information about whether death occurs at early or later ages (OECD, 2011). Furthermore, since infants are especially vulnerable to epidemics, long-term changes in infant mortality rates provide insight into a population's capacity to deal with outbreaks of disease. 


\section{Historical sources}

There are various data repositories for information on historical trends in life expectancy at birth. With the exception of historical time series for Finland and Australia, for which we relied on data from Kannisto, Nieminen and Turpeinen (1999) and the Australian Bureau of Statistics (2008), respectively, the data used in this chapter are derived from five major repositories: the OECD.Stat database library (OECD), the United Nations World Population Prospects Database (UN WPP), the Human Mortality Database (HMD), the Montevideo-Oxford Latin American Economic History Database (MOxLAD) and Gapminder.

The OECD provides data on life expectancy derived from the (national) statistics of member countries, mainly from the 1950s onwards. Data from the UN WPP cover a wider range of countries from 1950 onwards, based on data derived from various national sources (UN, 2012). Life expectancy data from the HMD cover most European countries, but also include a number of other countries, such as Chile, Japan, Australia and the United States. The HMD is characterised by its uniformity in measuring life expectancy at birth as well as by its historical scope, providing life expectancy data for more than a century for several countries (http://www.mortality.org). The MOxLAD provides data for 20 countries in Latin America for the entire 20th century (http://www.lac.ox.ac.uk/moxladdatabase). Finally, Gapminder, an online repository containing time-series of development series for countries around the world, provides life expectancy data from a large number of sources (Johansson and Lindgren, 2011). For reasons of comparability, elaborated upon in the section below, this chapter relies on a selection from these sources, i.e. data from the Estonian Interuniversity Population Research Centre (http://www.popest.ee/node/32), the Human Life-Table Database (HLD, http://www.lifetable.de), the Riley files (Riley, 2005a, 2005b, 2005c) and life expectancy rates for England (Wrigley et al., 1997).

\section{Data quality}

Comparing life expectancy over long periods of time and between different countries requires addressing a number of issues and data limitations. One generic issue when using data on period life expectancy is the influence of changing infant mortality rates on life expectancy at birth.

A first issue when comparing life expectancy data between countries and over time is the fact that there are differences in how data are gathered. In recent decades, major advances have been made in collecting life expectancy data for a large number of countries around the world. However, for earlier time periods such uniform methods of data collection did not exist or were used only in more developed parts of the world. As a result, life expectancy calculations in different countries are based on more complete and comparable data sources today than in the past, and is better in richer than in poorer countries, especially in earlier time-periods.

A second issue concerns differences in the methodology used for constructing life tables. While the repositories from which the data described in this chapter are drawn all focus on mortality data, they differ in terms of their geographical, temporal and methodological scope, resulting in life expectancy calculations characterised by different margins of error. For example, while the Human Mortality Database emphasises uniformity in methods, and is therefore limited to a specific set of countries and time periods, other repositories of life expectancy data aim to provide as many estimates as possible. The 
increase in data coverage made available by these other sources is accompanied by the cost of expanding the margins of error and potentially limiting comparability.

This chapter covers a long historical time period, while maintaining some coherence in the methods used to calculate life expectancy at birth. The first database used is the HMD, which is the source of data for $23 \%$ of the observations included in our database. This chapter relies on HMD estimates of life expectancy for the total population rather than the civilian population, as the latter, which control for increased mortality rates that occur during wars, exist only for a few countries.

The second database used for this chapter comes from the OECD, which contains data from national statistics agencies and has extensive documentation on its sources. However, the number of countries in the OECD database is limited and overlaps to a large extent with the HMD, accounting for less than $2 \%$ of our database. For non-OECD countries as well as for OECD countries before the 1950s, this chapter relies on the UN WWP, which has a larger geographical scope and provides data for the last 60 years. Just over $70 \%$ of the data presented are derived from the UN WWP. However, estimates from the UN WWP are limited in two ways. First, while uniform methods have been used to estimate life expectancy in various countries, data quality and availability required the use of a variety of methods to estimate life expectancy for all countries and time periods. Second, the UN WPP estimates are provided for 5-year time periods, creating generally smoother curves for life expectancy over time than would be obtained when using yearly data.

For a number of countries and time periods we draw on region-specific databases. The database by Wrigley et al. (1997) provides information on life expectancy in England in the 17th, 18th and early 19th century. ${ }^{1}$ For Latin American countries, the data used in this chapter are from the MOxLAD database. For Australia we use data from the ABS (2008), and for Finland we rely on data by Kanisto et al. (1999). Finally, for Estonia, we use data from the Estonian Interuniversity Population Research Centre. Taken together, all of these regionspecific databases provide for just over $1 \%$ of the data.

Finally, for all countries and periods that were not covered by the above sources, this chapter relied on data available in Gapminder, with the following provisos. First, we excluded any of the estimates calculated by the Gapminder team themselves. ${ }^{2}$ Second, we do use the data from the Human Life-Table Database (HLD) provided by Gapminder, but these estimates are more uniform than the underlying reality. ${ }^{3}$ The HLD provides somewhat less than $1 \%$ of all cases in our database.

Another selection of the Gapminder data concerns the estimates provided by Riley (2005a, 2005b, 2005c), who compiled and assessed around 700 sources on historical life expectancy. While Gapminder includes both preferred and "not-preferred" sources as well as a list of estimates from the Riley bibliography, the data used in this chapter are those included in the Riley "preferred files", which have been evaluated through a thorough peerreview process. In total, the Riley preferred files make up just over $3 \%$ of the data.

Quality indicators for world regions and selected countries are provided in Table 6.1 for the selected benchmark years. In cases where the quality of the sources varied within the decade, the lower quality is reported unless the higher-quality data represent more than two-thirds of the available observations. The overall quality of the data is deemed as "good", although somewhat less for earlier periods in some of the less developed parts of the world. Empty cells in Tables 6.1 and 6.2 indicate that work remains to be done to identify indicators of life expectancy for earlier periods in time. 
Table 6.1. Quality of data on life expectancy at birth by region and benchmark year, 1820-2000

\begin{tabular}{|c|c|c|c|c|c|c|c|c|}
\hline & $\begin{array}{c}\text { Western } \\
\text { Europe } \\
\text { (WE) }\end{array}$ & $\begin{array}{c}\text { Eastern } \\
\text { Europe } \\
\text { (EE) }\end{array}$ & $\begin{array}{c}\text { Western } \\
\text { Offshoots } \\
\text { (W0) }\end{array}$ & $\begin{array}{l}\text { Latin } \\
\text { America } \\
\text { and } \\
\text { Caribbean } \\
\text { (LA) }\end{array}$ & $\begin{array}{l}\text { Sub-Saharan } \\
\text { Africa } \\
\text { (SSA) }\end{array}$ & $\begin{array}{l}\text { Middle East } \\
\text { and } \\
\text { North Africa } \\
\text { (MENA) }\end{array}$ & $\begin{array}{c}\text { East Asia } \\
\text { (EA) }\end{array}$ & $\begin{array}{c}\text { South and } \\
\text { South-East } \\
\text { Asia } \\
\text { (SSEA) }\end{array}$ \\
\hline 1820 & 2 & .. & .. & .. & .. & .. & .. & .. \\
\hline 1870 & 2 & .. & .. & .. & .. & .. & 3 & .. \\
\hline 1920 & 2 & 2 & 2 & 3 & .. & .. & 2 & .. \\
\hline 1950 & 1 & 1 & 1 & 1 & 1 & 1 & 1 & 1 \\
\hline 1970 & 1 & 1 & 1 & 1 & 1 & 1 & 1 & 1 \\
\hline 2000 & 1 & 1 & 1 & 1 & 1 & 1 & 1 & 1 \\
\hline
\end{tabular}

Note: 1. High quality; 2. Moderate quality; 3. Low quality; and 4. Estimates. See the section on «Data Quality» in Chapter 1 for a description of the quality criteria.

Source: Clio-Infra, www.clio-infra.eu.

StatLink नiाIs http://dx.doi.org/10.1787/888933096901

\section{Main highlights of life expectancy trends}

This section describes regional patterns and changes over time in period life expectancy rates at birth by looking, first, at life expectancy rates for major regions in the world, and second, at between-country variation within these regions.

In all regions, life expectancy at birth increased by about 30 years in the period since the 1820s, but regions differ in the timing and speed of this improvement, as can be seen in Figure 6.1 and Table 6.2, which provide population-weighted averages of life expectancy rates for the eight world regions considered in this report in the 19th and 20th centuries. Note that these regional averages span different time-periods, as they are computed only if data are available for at least $50 \%$ of the countries in each region. With the exception of the Western Offshoots and Sub-Saharan Africa, for which the pattern is less clear, in all regions life expectancy rates resemble S-shaped curves, with a period of rapid increase in life expectancy between two periods of slower progress. The timing of the period of rapid improvement in life expectancy varies between regions, with Western Europe and its Offshoots showing rapid improvements already in the early 20th century, while the Middle East and North Africa region experienced rapid improvement nearly five decades later. The divergence in levels of life expectancy caused by the different timings of these periods of fast improvements in life expectancy narrowed over recent decades, reducing the gap in life expectancy to about 10 years in the top six regions of the world. Nevertheless, absolute differences in life expectancy between major world regions appear to be bigger today than they were a century ago. In other words, while life expectancy has improved all around the world, in some regions, such as Western Europe and its Offshoots, it improved by more (about 40 years) than in other regions, such as Sub-Saharan Africa (about 20 years).

To what extent has the increase in life expectancy experienced by all the world's regions benefitted all countries within the regions? One difficulty in answering this question is that, for earlier periods, there are fewer data points than for later periods. Despite this hurdle, it is clear that the development towards higher life expectancy differs between countries (Table 6.3) and that there are clear similarities in patterns of convergence and divergence within world regions. 
Figure 6.1. Regional averages of life expectancy at birth, 1820s-2000s

Years, decadal averages

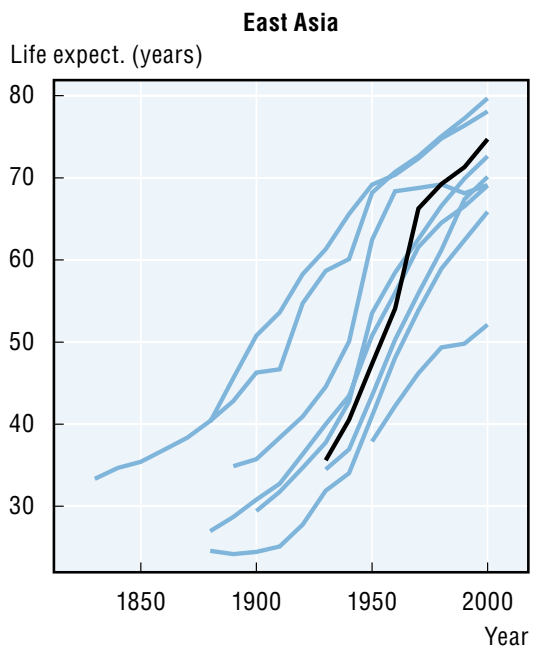

Middle East and North Africa

Life expect. (years)

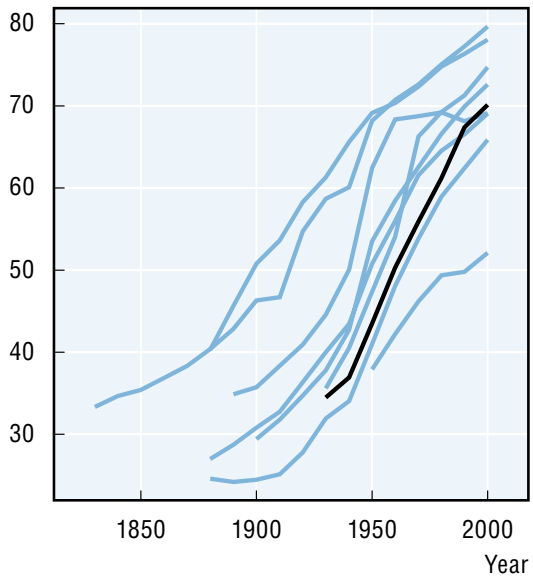

Western Europe

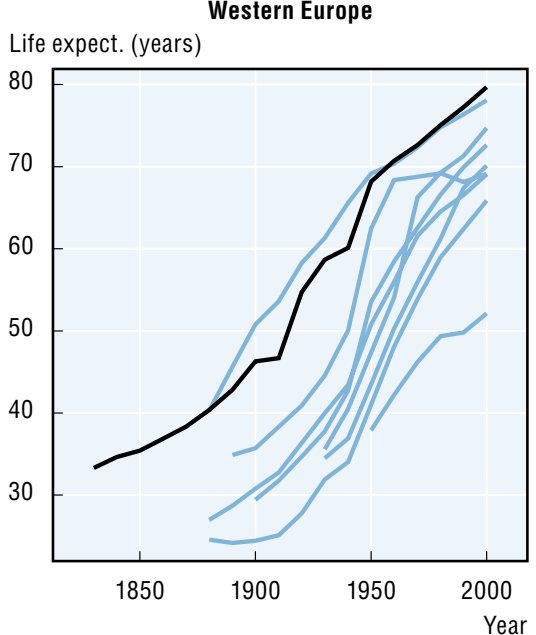

Eastern Europe and former Soviet Union

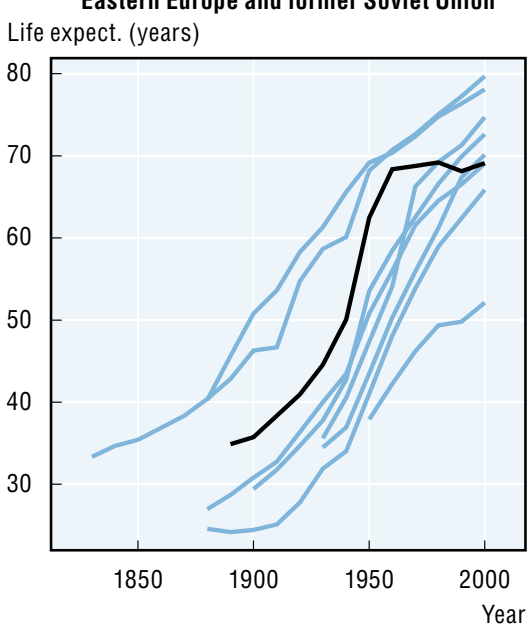

South and South-East Asia Life expect. (years)

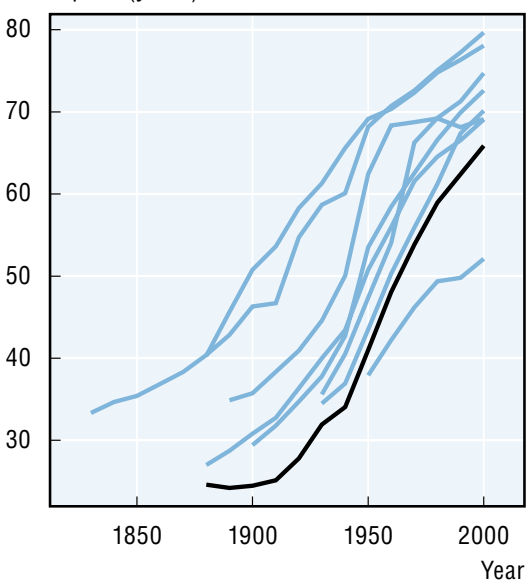

Western Offshoots

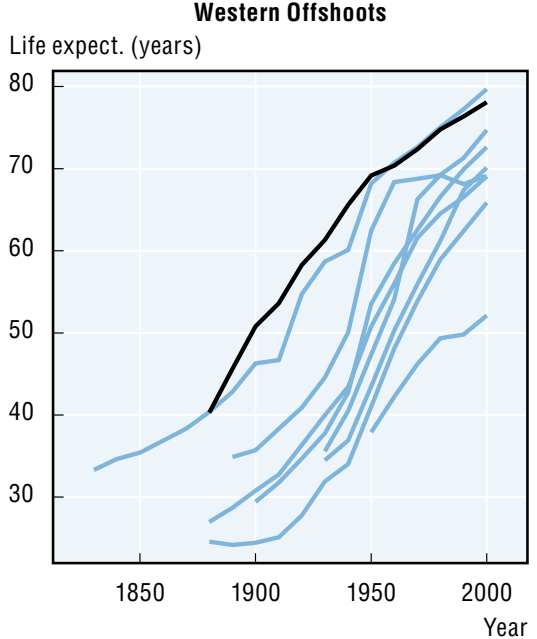

Latin America and Caribbean Life expect. (years)

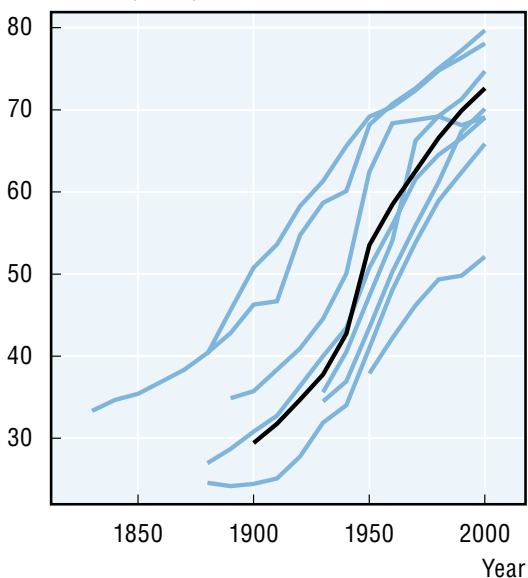

Sub-Saharan Africa

Life expect. (years)

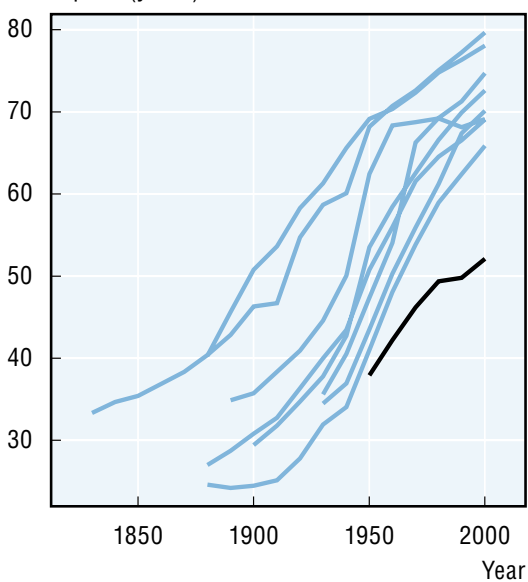

World

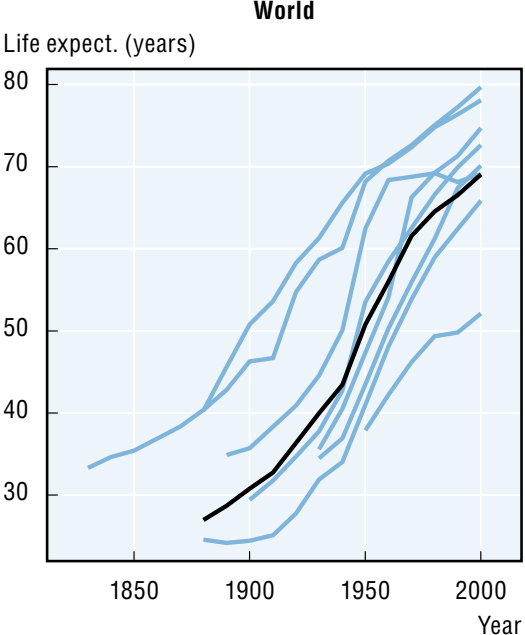

Note: For an assessment of data quality, see Table 6.1.

Source: Clio-Infra, www.clio-infra.eu. 
Table 6.2. Regional averages of life expectancy at birth, 1820s-2000s

Years, decadal averages

\begin{tabular}{|c|c|c|c|c|c|c|c|c|c|}
\hline & $\begin{array}{c}\text { Western } \\
\text { Europe } \\
\text { (WE) }\end{array}$ & $\begin{array}{c}\text { Eastern } \\
\text { Europe } \\
\text { (EE) }\end{array}$ & $\begin{array}{c}\text { Western } \\
\text { Offshoots } \\
\text { (W0) }\end{array}$ & $\begin{array}{l}\text { Latin } \\
\text { America } \\
\text { and } \\
\text { Caribbean } \\
\text { (LA) }\end{array}$ & $\begin{array}{c}\text { East Asia } \\
(E A)\end{array}$ & $\begin{array}{c}\text { South and } \\
\text { South-East } \\
\text { Asia } \\
\text { (SSEA) }\end{array}$ & $\begin{array}{l}\text { Middle East } \\
\text { and } \\
\text { North Africa } \\
\text { (MENA) }\end{array}$ & $\begin{array}{c}\text { Sub-Saharan } \\
\text { Africa } \\
\text { (SSA) }\end{array}$ & World \\
\hline $1820 \mathrm{~s}$ & .. & .. & .. & .. & .. & .. & .. & .. & .. \\
\hline $1830 \mathrm{~s}$ & 33.4 & .. & .. & .. & .. & .. & .. & .. & .. \\
\hline $1840 \mathrm{~s}$ & 34.7 & .. & .. & .. & .. & .. & .. & .. & .. \\
\hline $1850 \mathrm{~s}$ & 35.5 & .. & .. & .. & .. & .. & .. & .. & .. \\
\hline $1860 \mathrm{~s}$ & 36.9 & .. & .. & .. & .. & .. & .. & .. & .. \\
\hline 1870 s & 38.3 & .. &.. & .. & .. & .. & .. & .. & .. \\
\hline $1880 \mathrm{~s}$ & 40.4 & .. & 40.3 & .. & .. & 24.6 & .. & .. & 27.0 \\
\hline $1890 \mathrm{~s}$ & 42.9 & 34.9 & 45.6 & .. & .. & 24.2 & .. & .. & 28.7 \\
\hline $1900 \mathrm{~s}$ & 46.3 & 35.8 & 50.8 & 29.4 & .. & 24.5 & .. & .. & 30.8 \\
\hline 1910s & 46.7 & .. & 53.6 & 31.8 & .. & 25.1 & .. & .. & 32.8 \\
\hline $1920 \mathrm{~s}$ & 54.7 & 40.9 & 58.3 & 34.7 & .. & 27.8 & .. & .. & 36.4 \\
\hline $1930 \mathrm{~s}$ & 58.7 & 44.6 & 61.3 & 37.8 & 35.6 & 31.9 & 34.5 & .. & 40.0 \\
\hline $1940 \mathrm{~s}$ & 60.1 & 50.1 & 65.6 & 42.8 & 40.5 & 34.1 & 37.0 & .. & 43.5 \\
\hline $1950 \mathrm{~s}$ & 68.2 & 62.5 & 69.2 & 53.5 & 47.4 & 41.0 & 43.5 & 37.9 & 50.8 \\
\hline $1960 \mathrm{~s}$ & 70.7 & 68.4 & 70.4 & 58.5 & 54.1 & 48.1 & 50.3 & 42.2 & 56.0 \\
\hline 1970s & 72.6 & 68.7 & 72.4 & 62.5 & 66.3 & 53.8 & 55.9 & 46.2 & 61.6 \\
\hline 1980s & 75.1 & 69.2 & 74.8 & 66.6 & 69.2 & 58.9 & 61.2 & 49.4 & 64.6 \\
\hline $1990 \mathrm{~s}$ & 77.2 & 68.2 & 76.3 & 69.9 & 71.3 & 62.4 & 67.4 & 49.8 & 66.6 \\
\hline $2000 \mathrm{~s}$ & 79.7 & 69.1 & 78.1 & 72.6 & 74.7 & 65.9 & 70.1 & 52.1 & 69.1 \\
\hline
\end{tabular}

Note: For an assessment of data quality, see Table 6.1.

Source: Clio-Infra, www.clio-infra.eu.

The various countries in Western Europe and the Western Offshoots have experienced convergence in levels of life expectancy from the 1890s onwards. In the case of Western Europe, the pattern of convergence was preceded by a trend towards divergence during most of the 19th century. While in both regions life expectancy is still increasing, life expectancy has diverged again within the Western Offshoots since the 1970s.

South and Southeast Asia is also characterised by a growing convergence in life expectancy. However this trend did not start until the 1960s. Whether this trend was preceded by a period of growing divergence is difficult to say, as the number of data points available for this region differs over time (and hence the variation in life expectancy as well).

The countries in the Middle East and North Africa as well as the countries in Latin America and the Caribbean show a pattern towards greater divergence in life expectancy. As in the case of Western Europe, in both of these regions a small group of countries outperformed most others, with the latter catching up over time. Two differences stand out in comparison to Western Europe and the Western Offshoots. First, the trend towards convergence started much later, in the 1950s for Latin America and in the 1960s for the MENA region. Second, in both regions a small group of countries was unable to keep up with the pace of improvement in life expectancy experienced elsewhere. 
Table 6.3. Life expectancy at birth in selected countries, 1820s-2000s

Years, decadal averages

\begin{tabular}{|c|c|c|c|c|c|c|c|c|c|c|c|c|c|c|c|c|c|c|c|c|c|c|c|c|c|}
\hline & \multicolumn{7}{|c|}{$\begin{array}{l}\text { Western Europe } \\
\text { (WE) }\end{array}$} & \multicolumn{2}{|c|}{$\begin{array}{c}\text { Eastern Europe } \\
(\mathrm{EE})\end{array}$} & \multicolumn{3}{|c|}{$\begin{array}{l}\text { Western Offshoots } \\
\text { (WO) }\end{array}$} & \multicolumn{3}{|c|}{$\begin{array}{l}\text { Latin America and } \\
\text { Caribbean } \\
\text { (LA) }\end{array}$} & \multicolumn{2}{|c|}{$\begin{array}{l}\text { Middle East } \\
\text { and North } \\
\text { Africa (MENA) }\end{array}$} & \multicolumn{3}{|c|}{$\begin{array}{c}\text { Sub-Saharan Africa } \\
(\mathrm{SSA})\end{array}$} & \multicolumn{2}{|c|}{$\begin{array}{c}\text { East Asia } \\
(\text { EA) }\end{array}$} & \multicolumn{3}{|c|}{$\begin{array}{c}\text { South and } \\
\text { South-East Asia } \\
\text { (SSEA) }\end{array}$} \\
\hline & GBR & NLD & FRA & DEU & ITA & ESP & SWE & POL & RUS & AUS & CAN & USA & MEX & BRA & ARG & EGY & TUR & KEN & NGA & ZAF & $\mathrm{CHN}$ & JPN & IND & IDN & THA \\
\hline $1820 \mathrm{~s}$ & 41.0 & .. & 38.9 & .. & .. & .. & 41.6 & .. & .. & .. & .. & .. & .. & .. & .. & .. & .. & .. & .. & .. & .. & .. & .. & .. & .. \\
\hline $1830 \mathrm{~s}$ & 40.7 & .. & 39.0 & .. & .. & .. & 41.3 & .. & .. & .. & 39.0 & .. & .. & .. & .. & .. & .. & .. & .. & .. & .. & .. & .. & .. & .. \\
\hline $1840 \mathrm{~s}$ & 40.3 & .. & 40.5 & .. & .. & .. & 43.6 & .. & .. & .. & 40.3 & .. & .. & .. & .. & .. & .. & .. & .. & & .. & .. & .. & .. & \\
\hline $1850 \mathrm{~s}$ & 40.8 & 37.0 & 39.7 & .. & .. & .. & 42.0 & .. & .. & .. & 41.1 & .. & .. & .. & .. & .. & .. & .. & .. & .. & .. & .. & .. & .. & .. \\
\hline $1860 \mathrm{~s}$ & 41.1 & 37.5 & 41.6 & .. & .. & .. & 44.8 & .. & .. & .. & 41.6 & .. & .. & .. & .. & .. & .. & .. & .. & .. & .. & 36.4 & .. & .. & .. \\
\hline 1870 s & 42.3 & 39.1 & 41.3 & 38.4 & 32.7 & .. & 46.8 & .. & .. & .. & 42.6 & .. & .. & .. & 33.2 & .. & .. & .. & .. & .. & .. & 36.7 & .. & .. & .. \\
\hline $1880 \mathrm{~s}$ & 44.6 & 42.9 & 43.5 & 39.4 & 35.7 & 29.5 & 49.8 & .. & .. & 49.0 & 44.7 & 39.4 & . & ... & 32.9 & .. & .. & .. & .. & & .. & 37.2 & 25.4 & .. & \\
\hline $1890 \mathrm{~s}$ & 45.7 & 46.8 & 45.1 & 42.4 & 40.5 & 32.1 & 52.3 & .. & 31.9 & 53.0 & 45.2 & 45.2 & 26.6 & .. & 33.6 & .. & .. & .. & .. & .. & .. & 37.9 & 24.3 & .. & .. \\
\hline $1900 \mathrm{~s}$ & 49.1 & 51.6 & 48.0 & 45.5 & 43.8 & 39.0 & 55.3 & .. & 30.5 & 57.0 & 48.6 & 50.6 & 27.8 & 29.0 & 39.4 & .. & .. & .. & .. & .. & .. & 38.9 & 23.7 & .. & .. \\
\hline $1910 \mathrm{~s}$ & 52.7 & 55.1 & 44.3 & 44.8 & 42.7 & 41.0 & 57.1 & .. & & .. & 52.5 & 53.3 & 28.0 & 31.0 & 45.2 & .. & .. & .. & .. & .. & .. & 40.4 & 23.6 & .. & \\
\hline $1920 \mathrm{~s}$ & 58.4 & 61.7 & 54.2 & 57.4 & 50.7 & 45.7 & 61.7 & & 32.6 & 62.5 & 58.0 & 58.0 & 34.4 & 32.0 & 49.6 & 31.4 & .. & 23.9 & .. & . & .. & 43.4 & 26.2 & 30.0 & \\
\hline $1930 \mathrm{~s}$ & 61.6 & 66.2 & 58.2 & 61.5 & 56.0 & 49.9 & 64.6 & 49.8 & 36.0 & 65.4 & 61.9 & 61.0 & 38.6 & 34.0 & 53.5 & 33.2 & 35.4 & 26.4 & .. & .. & 33.7 & 48.2 & 30.1 & 33.8 & 40.3 \\
\hline $1940 \mathrm{~s}$ & 65.0 & 65.6 & 57.7 & 60.5 & 56.9 & 55.6 & 68.8 & . & 47.0 & 67.5 & 65.6 & 65.4 & 43.7 & 39.6 & 57.4 & 34.0 & 34.7 & 28.8 & .. & .. & 39.0 & 49.2 & 32.6 & 27.5 & 43.3 \\
\hline $1950 \mathrm{~s}$ & 69.9 & 72.3 & 68.1 & 68.2 & 67.3 & 65.8 & 72.3 & 63.6 & 61.9 & 69.8 & 69.5 & 69.1 & 53.0 & 52.2 & 63.5 & 43.8 & 42.3 & 43.5 & 35.0 & 46.5 & 44.8 & 64.2 & 37.9 & 40.5 & 52.7 \\
\hline $1960 \mathrm{~s}$ & 71.3 & 73.5 & 71.0 & 70.2 & 70.2 & 70.5 & 73.7 & 69.0 & 69.2 & 70.9 & 71.7 & 70.2 & 59.9 & 56.9 & 65.5 & 50.5 & 51.2 & 49.4 & 39.3 & 50.9 & 51.7 & 70.1 & 45.1 & 48.7 & 57.5 \\
\hline 1970s & 72.5 & 74.5 & 73.0 & 71.6 & 72.8 & 73.3 & 75.0 & 70.6 & 68.5 & 72.5 & 73.5 & 72.2 & 64.3 & 60.8 & 68.0 & 54.9 & 55.9 & 55.0 & 43.4 & 54.6 & 65.4 & 74.1 & 52.4 & 55.6 & 61.9 \\
\hline $1980 \mathrm{~s}$ & 74.6 & 76.4 & 75.3 & 74.2 & 75.5 & 76.3 & 76.7 & 70.9 & 68.6 & 75.5 & 76.2 & 74.6 & 69.2 & 64.5 & 70.6 & 61.7 & 61.7 & 59.2 & 46.2 & 59.7 & 68.3 & 77.6 & 57.0 & 61.1 & 67.7 \\
\hline $1990 \mathrm{~s}$ & 76.6 & 77.5 & 77.8 & 76.6 & 78.0 & 78.0 & 78.6 & 71.8 & 66.5 & 78.1 & 78.1 & 76.0 & 72.0 & 68.4 & 72.7 & 66.7 & 69.1 & 56.0 & 46.2 & 60.8 & 70.4 & 79.9 & 60.2 & 65.5 & 70.5 \\
\hline $2000 \mathrm{~s}$ & 78.9 & 79.3 & 80.2 & 79.2 & 80.8 & 80.3 & 80.5 & 74.9 & 66.1 & 80.9 & 80.2 & 77.6 & 73.8 & 71.7 & 74.8 & 69.5 & 72.8 & 55.1 & 48.8 & 52.5 & 73.9 & 82.2 & 64.0 & 68.8 & 72.4 \\
\hline
\end{tabular}

Note: For an assessment of data quality, see Table 6.1.

Source: Clio-Infra, www.clio-infra.eu. 
In East Asia, there appears to be a slight trend towards convergence since the 1950s. Around that year, there was a clear divergence in life expectancy, although betweencountry differences in life expectancy narrowed again more recently.

The countries in Eastern Europe and the former Soviet Union experienced a trend towards convergence as well since the 1950s, at least up until 1990. However, the two groups of countries at the higher and lower end of the distribution of life expectancy never fully converged in the 20th century, and the gap between these groups of countries widened further in the first decade of the 21st century.

Finally, Sub-Saharan Africa was the only region in the world where life expectancy was not just much lower than in other regions but also did not converge between countries over the second half of the 20th century. In the 2000s, life expectancy at birth was still below the age of 50 in more than a quarter of all countries in Sub-Saharan Africa.

To summarise, on a global scale life expectancy at first diverged in the late 19th and early 20th century due to an increase in life expectancy in Western Europe and the Western Offshoots. From the second half of the 20th century onwards, life expectancy improved in other parts of the world as well (with the exception of Sub-Saharan Africa), leading to a global trend towards convergence in life expectancy. However, this picture obscures differences between countries within regions, for in the last (two) decade(s) in several world regions, levels of life expectancy have been diverging once more.

A decline in infant mortality rates played a key role in driving the upward trend in life expectancy globally over the past 150 years. ${ }^{4}$ Figure 6.2 shows trends in infant mortality and life expectancy for the main world regions since 1820. Infant mortality decreased considerably over the past few decades in almost all of all the world regions, although less so in Western Europe and the Western Offshoots where this decline dates back to the 1890s. Despite the universal character of the decline in infant mortality, differences in infant mortality remain large, ranging between 150 deaths per 1000 live births in many countries in Sub-Saharan Africa to levels close to zero in several countries in Western Europe.

Although there is less data on infant mortality than on life expectancy, both in terms of the countries and years covered, the resemblance between the upward trend in life expectancy and the downward trend in infant mortality is striking. Changes in the two series start at about the same point in time; further, both the speed of improvement and intra-regional differences appear to be similar. These findings mainly reflect the fact that most of the observed improvement in life expectancy at birth is driven by the increasing survival rate of infants. Obviously, improvements in infant mortality rates do not explain changing patterns in life expectancy entirely, and life expectancy for adults has genuinely increased. This can easily be seen in, for example, Western Europe and the Western Offshoots, where levels of infant mortality have stabilised in more recent decades, while life expectancy has continued to increase.

\section{Correlation with GDP per capita}

Longevity and GDP per capita are connected in multiple ways, and the two variables are likely to mutually affect each other. Life expectancy affects the productive capacity of a given population, implying that higher life expectancy might lead to higher economic growth (Fogel, 1997 and 2003; Barker, 1998; Gluckman and Hanson, 2005 and 2006; Case, Fertig and Paxon, 2005; Hoddinott et al., 2008). Individuals who live longer are also likely to invest more in their education, resulting in higher wages (Sachs and Malaney, 2002) and increased retirement 
Figure 6.2. Infant mortality and life expectancy at birth in major world regions, 1820-2000

Number of deaths before age one per 100 live births and years, country observations

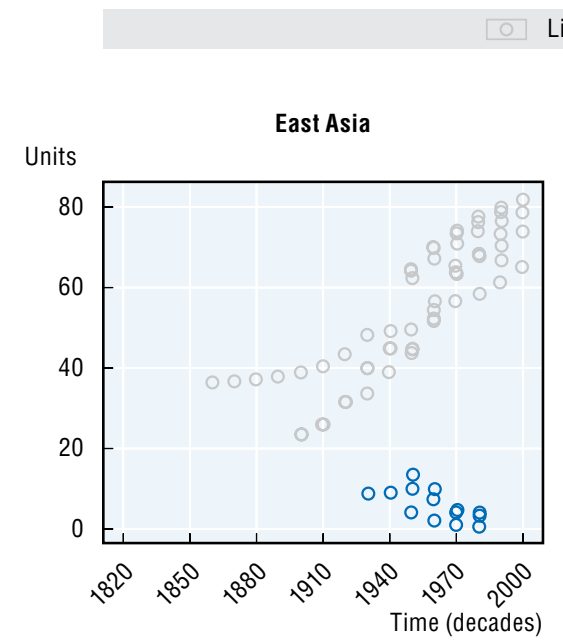

Life expectancy at birth

0 Infant mortality

Infant Mortality and Life Expectancy
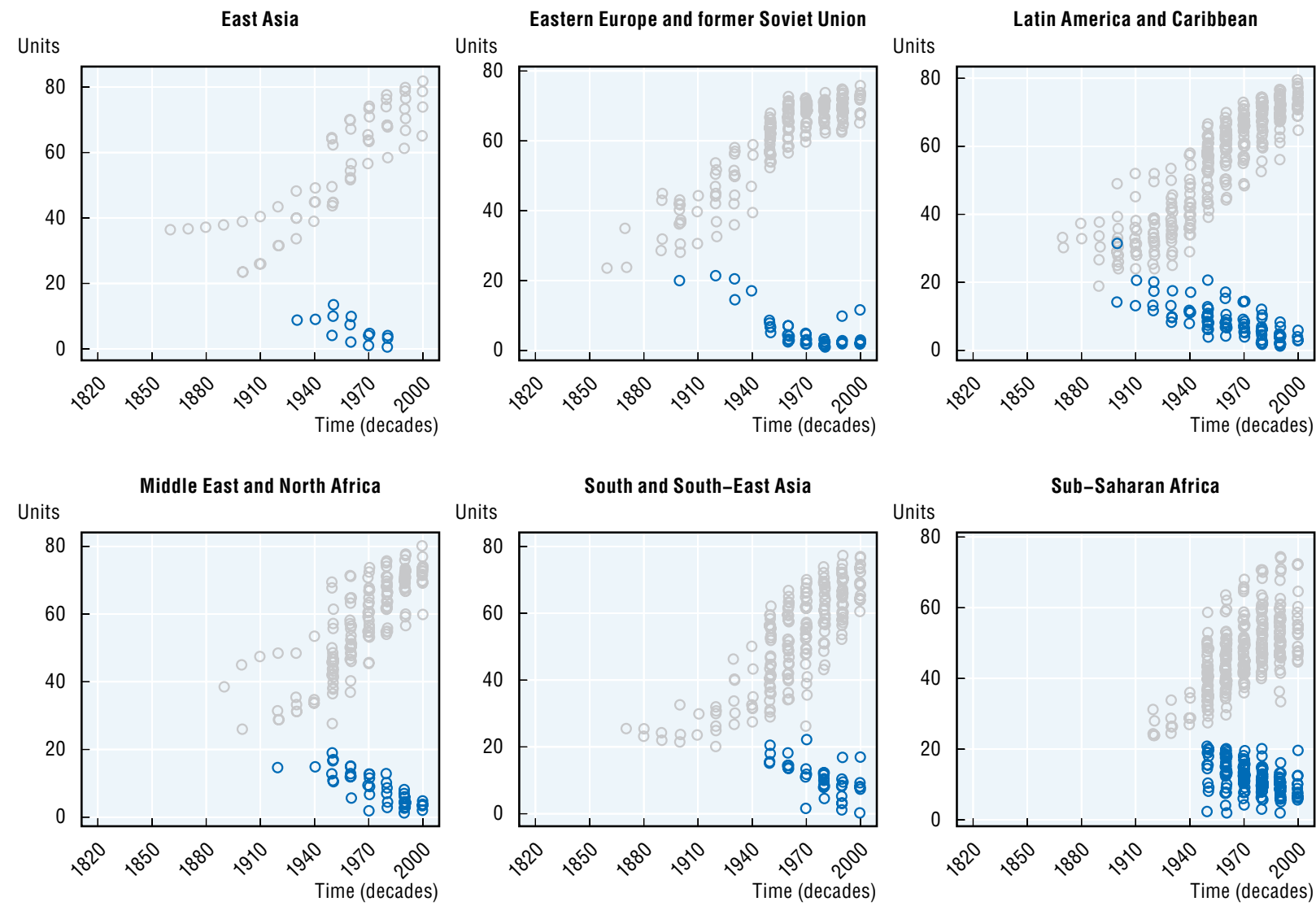

Units

South and South-East Asia
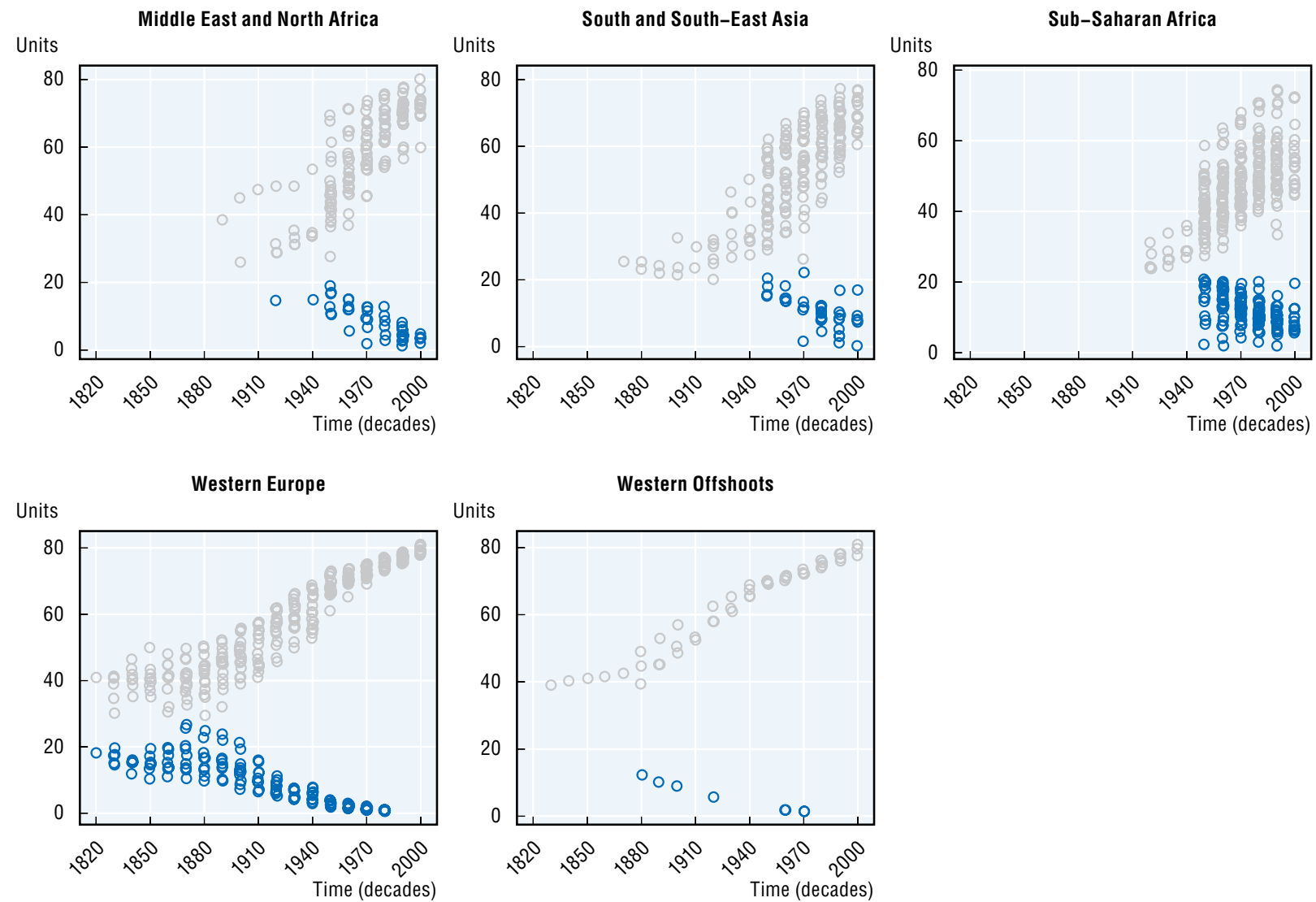

Note: For an assessment of data quality, see Table 6.1.

Source: Clio-Infra, www.clio-infra.eu.

savings (Bloom, Canning and Sevilla, 2004), and thus leading to an increased productive capacity at the country level. However, as argued by Acemoglu and Johnson (2007) and by Ashraf et al. (2008), higher life expectancy at birth does not necessarily lead to an increase in GDP per capita, since an increase in longevity increases population size as well. 
Increases in GDP could result in greater longevity as well. Increased GDP may result in higher health care expenditure, and the establishment of public health care programmes and the construction of health care facilities have been linked to improved health status (Preston, 1975 and 2007; Szreter and Mooney, 1998; Szreter and Woolcock, 2003). Furthermore, increased GDP may on the individual level result in increased expenditure on foods that are more expensive, but also healthier. Better health is also linked to nutrition in utero and in early childhood, and proper nutrition can have a considerable effect on life expectancy (Willward and Baten, 2007).

Figure 6.3 shows the extent to which GDP per capita and life expectancy at birth are associated and how this relationship has changed over time. For each decade, the strength of the correlation is given, while, in a way, the $95 \%$ confidence intervals reflect the fact that for the earlier time points we have much less data available. The image for the 20th century is clear. Throughout the 20th century there was a moderately positive correlation between life expectancy at birth and GDP. The relation was stable, and about half of the variability in life expectancy and GDP is associated with each other. The interpretation for the 19th century is much more complicated, given the size of the confidence intervals. However, it does seem clear that the association between life expectancy and GDP was not as strong in the 19th century as it was in the 20th, if there was an association at all.

\section{Figure 6.3. Correlation between life expectancy at birth and GDP per capita, 1820s-2000s}

Pearson correlation coefficient and upper/lower bounds of $95 \%$ confidence interval per decade

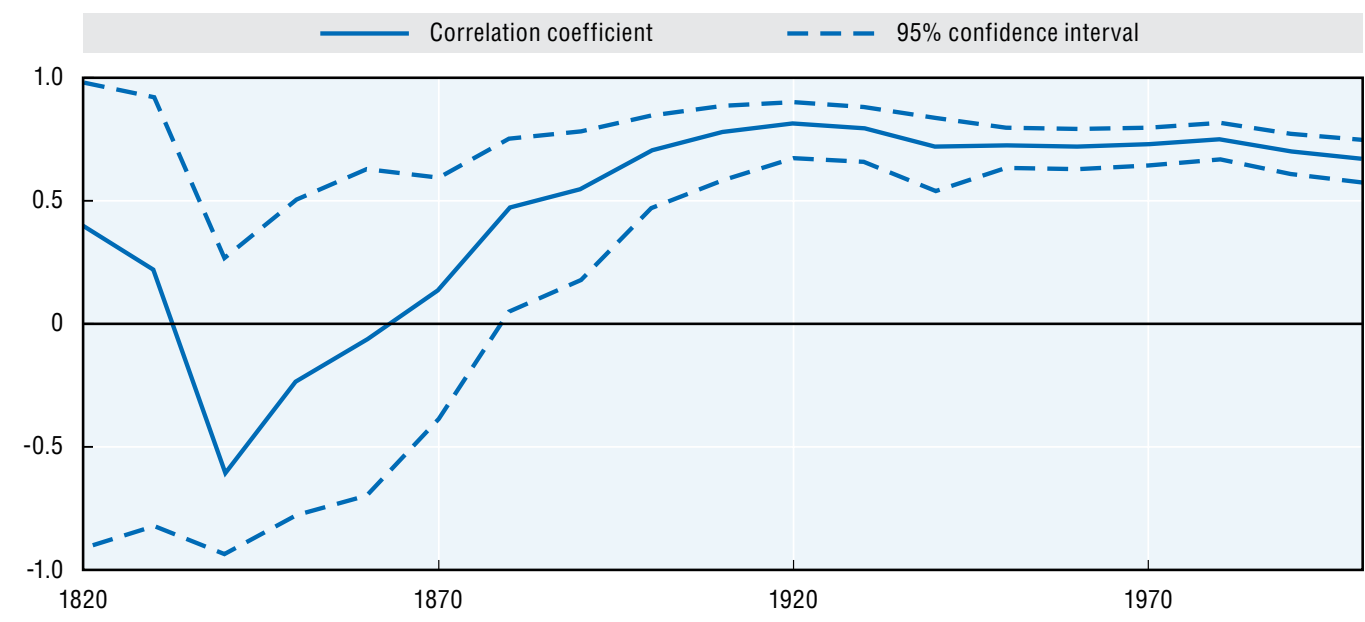

Note: For an assessment of data quality, see Table 6.1.

Source: Clio-Infra, www.clio-infra.eu.

StatLink त्नाIS http://dx.doi.org/10.1787/888933095837

\section{Priorities for future research}

Because of a lack of historical data on people's morbidity, the evidence presented in this chapter was limited to two measures of mortality, i.e. period life expectancy at birth and infant mortality rates. Even for these measures, however, there is much scope for improvement in terms of the collection of historical data, the harmonisation of calculation methods and analytical approaches. 
One problem is that the existing historical population records for some countries have not yet been digitised. This includes some Western countries, but especially countries that were colonised and have population records that have not been converted into a machinereadable format. While this is time-consuming, the feasibility of this approach is illustrated by the History of Labour Relations project (http://www.historyoflabourrelations), which is currently digitising India census data, the Out of Africa project (http://www.cgeh.nl/outafrica), which is digitising Ugandan Anglican marriage registers, and the Counting colonial populations project, which is digitising and processing 18th and 19th century demographic data for Angola, Mozambique, Guinea-Bissau and Brazil.

A second way to improve mortality data would be to shift the focus from countries to sub-national units, such as the départements in France or the Länder in Germany or subpopulations such as the elite. Variation in mortality rates and transitions may be better understood when local characteristics are taken into account (e.g. see for 19th century empirical evidence Caselli and Vallin, 2002; Ekamper and Van Poppel, 2008). Exploring the universality of Omran's epidemiological framework using long time-series and a regional approach allows for more rigorous testing of hypotheses and adds to the debate on global transitions in health. The important insights that can be gained by comparing subpopulations with the overall population are perhaps best illustrated by Harris (2004), who showed that in England between 1550 and 1750 Ducal families and the general population had similar life expectancies at birth of about 40 years, but that in the century after that life expectancy for Ducal families increased to about 60 years, while it barely increased for the general population. Deaton (2013) argues that this gap is unlikely to be related to levels of nutrition (Ducal families had access to more and better nutrition in the period before 1750), but is likely instead to be explained by greater scientific knowledge about medicine, since new health care methods "were confined to those who were wealthy and well informed". Thus by looking at specific sub-populations, we are able to hypothesise and test causal mechanisms that have increased life expectancy.

A third improvement would be to calculate cohort period life expectancy for historical time periods. While calculating cohort life expectancy for cohorts that are still alive requires making assumptions, such assumptions are not needed for cohorts that lived in the past. Cohort life expectancy would thus provide a more accurate picture of the longevity of historical cohorts, and would take into account periods of increased mortality, for example, due to outbreaks of disease, famine or war.

Finally, we must stress the need for global long-term comparative evidence on morbidity in order to come to an understanding of developments in health status. Health status encompasses both mortality and morbidity, as is evident in Omran's epidemiological transition framework, in which the eras between transitions are identified by types of disease. Pioneering studies on 19th century morbidity show the feasibility of studying morbidity in the 19th century and already shed some light on the interplay between increased longevity and changes in morbidity in past societies (see, for example, Elman and Myers, 1999, and Padiak, 2005). However, the interplay is complex. Greater success in overcoming disease may result in increased longevity, but also in new types of (degenerative) disease. A first step towards a comparative, long-term research agenda would be to identify the available archives, such as census data, military data, ship logs, industrial records and hospital records. 
The incorporation of these suggestions into the future research agenda for the study of population health will help gather more information on indicators that are useful for measuring health status. This will expand the knowledge and understanding of the academic community and the broad public about the evolution of humanity's health status over the past centuries.

\section{Notes}

1. It should be noted however that the estimates for England referring to the 20th century include Wales and sometimes Scotland.

2. The documentation of the Gapminder database includes various warnings explicitly advising users not to use Gapminder's own estimations on life expectancy, since they rely on basic assumptions and simplistic models, making the estimates unsuitable for statistical analysis (Johansson and Lindgren, 2011).

3. The reason for this is that the original data in the HLD refer to life expectancy at birth for men and women separately. To calculate life expectancy at birth for the total population, Gapminder used a fixed ratio of men to women rather than country- and time-specific measures on the number of men and women.

4. Data on infant mortality rates are available for download from the Clio-Infra database, with sources described in Baten and Blum (2014). These data comprise information on infant mortality for various countries in all world regions for decadal years since 1820 .

\section{References}

Acemoglu, D. and S. Johnson (2014), "Disease and Development: A Reply to Bloom, Canning, and Fink", Journal of Political Economy, Forthcoming.

Acemoglu, D. and S. Johnson (2007), "Disease and Development: The Effect of Life Expectancy on Economic Growth", Journal of Political Economy Vol. 115, No. 6, pp. 925-985.

Ashraf, Q. H., Ashley L. and D. N. Weil (2008), "When does Improving Health Raise GDP?" National Bureau of Economic Research Working Paper Series No. 14449.

Australian Bureau of Statistics (2008), Australian Historical Population Statistics - 3105.0.65.001, www.abs.gov.au/AUSSTATS/abs@.nsf/mf/3105.0.65.001, accessed 8 February 2014

Barker, D.J.P. (1998), Mothers, Babies and Health in Later Life, second edition, Churchill Livingstone, Edinburgh, ed.

Baten, J. and M. Blum (2014), "Why are you tall while others are short? Agricultural production and other proximate determinants of global heights", European Review of Economic History, (forthcoming).

Bloom, D.E., D. Canning and P.N. Malaney (1999), "Demographic Change and Economic Growth in Asia", Center for International Development, Working Paper No. 015, Harvard University.

Bloom, D.E., D. Canning and G. Fink (2009), "Disease and Development Revisited," National Bureau of Economic Research Working Paper Series, No. 15137.

Bloom, D.E., D. Canning and J. Sevilla (2004), "The Effect of Health on Economic Growth: A Production Function Approach", World Development, Vol. 32/1, pp. 1-13.

Bloom, D.E. and D. Canning (2000), "The Health and Wealth of Nations", Science, Vol. 287/5456.

Caselli G. and J. Vallin (2002), "Variations géographiques de la mortalité", in G. Caselli, J. Vallin et G. Wunsch(eds.), Démographie : analyse et synthèse. III. Les déterminants de la mortalité, - INED (Institut national études démographiques), Paris, pp. 373- 416.

Caldwell, J.C. (2001), "Population Health in Transitation", Bulletin of the World Health Organization, Vol. 79/2, pp. 159-170.

Deaton, A. (2013), The Great Escape: Health, Wealth, and the Origins of Inequality, Princeton University Press, Princeton and Oxford.

Elman, Cheryl and George C. Myers (1999), Geographic Morbidity Differentials in the late nineteenthCentury United States", Demography, Vol. 36/4, pp. 429-433. 
Ekamper, P. and F. van Poppel (2008), “Zuigelingensterfte per gemeente in Nederland, 1841-1939”, (Infant Mortality per community in the Netherlands, 1841-1939), Bevolkingstrends, statistisch kwartaalblad over de demografie van Nederland, Vol. 6/1, pp. 23-29.

Harrison, B. (2004), "Public Health, Nutrition, and the Decline of Mortality: The McKeown thesis revisted", Social History of Medicine, 17/3, pp. 379-407.

Fogel, R.W. (2003), The Escape from Hunger and Premature Death, 1700-2100: Europe, America and the Third World, Cambridge University Press, Cambridge.

Fogel, R.W. (1997), "New findings on secular trends in nutrition and mortality: Some implications for population theory", Handbook of Population and Family Economics, M.R. Rosenzweig and O. Stark (eds.), Elsevier Science, Vol. 1A, pp. 433-481.

Gluckman P. and Hanson M. (2006), Mismatch: Why our World no Longer Fits our Bodies, Oxford University Press, Oxford.

Gluckman, P.D. and Hanson M. (2005), The Fetal Matrix: Evolution, Development, and Disease. Cambridge University Press, Cambridge.

Hoddinott, J. et al. (2008), "Effect of a Nutrition Intervention during Early Childhood on Economic Productivity in Guatemalan Adults", Lancet, Vol. 371/9610, pp. 411-416.

Johansson, K. and M. Lindgren (2011), Documentation for Life Expectancy at birth (years) for countries and territories. www.gapminder.org/documentation/documentation/gapdoc004.pdf, accessed: October 7, 2013.

Kannisto, V., Nieminen, M. and O. Turpeinen (1999), "Finnish life tables since 1751", Demographic Research, Vol. $1 / 1$.

Millward, R. and J. Baten (2007), “Population and Living Standards, 1914-45”, Cambridge Economic History of Europe. Cambridge University Press, Cambridge.

OECD (2007), "Data sources, definitions and methods", Health Data 2007: Statistics and Indicators for 30 Countries, OECD Publishing, Paris, http://stats.oecd.org/glossary/detail.asp?ID=1530, accessed October 3, 2013.

OECD (2011), How's Life? Measuring well-being. OECD Publishing, Paris, http://dx.doi.org/ 10.1787/9789264121164-en

ONS (Office for National Statistics, United Kingdom) (2013), Life expectancy at birth and at age 65 for local areas in England and Wales, 2009-11, ONS, London, http://www.ons.gov.uk/ons/rel/subnational-health4/ life-expectancy-at-birth-and-at-age-65-by-local-areas-in-england-and-wales/2009-11/stb.html\#tabMethods-, Text in paper: www.ons.gou.uk/ons/dcp171778_320078.pdf

Olshansky, S. Jay, A. Carnes Bruce and C. Cassel (1990), "In search of Mathuselah: estimating the upper limits to human longevity", Science, Vol. 250, pp. 634-640.

Olshansky, S.J. et al. (1998), "Emerging infectious diseases: the Fifth stage of the epidemiologic transition?", World Health Statistics Quarterly/Rapport trimestriel de statistiques sanitaires, Vol. 51/2-3-4, pp. 207-217, in Historical epidemiology : mortality decline, and old and new transitions in health, special number edited by F. Odile.

Omran, A.R. (1998), "The epidemiologic transition theory revisited thirty years later", World Health Statistics Quarterly/Rapport trimestriel de statistiques sanitaires, Vol. 51/2-3-4, pp. 99-119, in Historical epidemiology : mortality decline, and old and new transitions in health, special number edited by F. Odile.

Padiak, J. (2005), "The role of morbidity in the mortality decline of the nineteenth century: evidence from the military population at Gibraltar 1818-1899", History of Medicine and Allied Sciences, Vol. 60/1, pp. 73-95.

Preston, S.H. (2007), "The changing relation between mortality and level of economic development", International Journal of Epidemiology, Vol. 36/3, pp. 484-490. http://dx.doi.org/10.1093/ije/dym075, PMID 17550952.

Preston, S.H. (1975), "The Changing Relation between Mortality and Level of Economic Development", Population Studies, Vol. 29/2, pp. 231-248, http://dx.doi.org/10.2307/2173509, JSTOR 2173509.

Riley, J.C. (2005a), "Estimates of Regional and Global Life Expectancy, 1800-2001", Population and development review, Vol. 31/3, (September), pp. 537-543

Riley, J.C. (2005b), "The Timing and Pace of Health Transitions around the World", Population and development review, Vol. 31/4, (December), pp. 741-764. 
Riley, J. C. (2005c), "Bibliography of Works Providing Estimates of Life Expectancy at Birth and Estimates of the Beginning Period of Health Transitions in Countries with a Population in 2000 of at Least 400 000", www.lifetable.de/RileyBib.htm, 2008-12-10].

Rogers, R.G. and R. Hackenberg (1987), “Extending epidemiologic transition theory: A new stage”, Social Biology, Vol. 34, pp. 234-243.

Sachs, J.D. and A.M. Warner (1997), "Sources of Slow Growth in African Economies", Journal of African Economies, Vol. 6/3, pp. 335-376.

Sachs, J. and P. Malaney (2002), “The Economic and Social Burden of Malaria,” Nature, Vol. 415/6872.

Sköld, P. et al. (2011), "Infant Mortality of Sami and Settlers in Northern Sweden: The Era of Colonization: 1750-1900", Global Health Action, Vol. 4, http://dx.doi.org/10.3402/gha.v4i0.8441.

Szreter, S. and G. Mooney (1998), "Urbanization, Mortality, and the Standard of Living Debate: New Estimates of the Expectation of Life at Birth in Nineteenth-century British Cities", The Economic History Review, Vol. 51/1, pp. 84-112. http://dx.doi.org/10.1111/1468-0289.00084.

Szreter, S. and M. Woolcock (2003), "Health by association? Social capital, social theory and the political economy of public health", International Journal of Epidemiology, Vol. 33/1, pp. 650-657, http://dx.doi. org/10.1093/ije/dyh013.

UN (2012), World Population Prospects Database: Definition of Major Areas and Regions. 2012 Revision. UN, PD online publication, http://esa.un.org/wpp/Excel-Data/country-classification.pdf

Vallin, J. and F. Meslé (2004), "Convergences and divergences in mortality, A new approach to health transition", Demographic Research, Vol. 2/2, pp. 12-43.

WHO (2013), Health Handbook, http://apps.who.int/iris/bitstream/10665/85345/1/9789241548632_eng.pdf.

Wilmoth, J.R. (2005), "On the relationship between period and cohort mortality", Demographic Research, Vol. 13/11, pp. 231-280.

Wrigley E.A. et al. (1997) English population history from family reconstitution 1580-1837, Cambridge University Press, Cambridge. 


\title{
Chapter 7
}

\section{Human height since 1820}

\author{
by \\ Joerg Baten, Tuebingen University \\ and \\ Matthias Blum, Technische Universität München
}

\begin{abstract}
Average height is an important indicator of people's well-being. It is also a relatively undistorted and easy-to-measure indicator, which makes it particularly suitable for comparisons across time and space. Drawing upon an extensive body of research, the chapter describes the strengths and weaknesses of this indicator. It finds that during the 19th century, average height in Western Offshoots was much higher than elsewhere. Differences between Western Europe and the rest of the world (Eastern Europe, East Asia) were marginal, in spite of the much higher real incomes in the former region. This changed after about 1870, when people's height began to increase in Western Europe, whereas this lagged behind elsewhere. Africans were relatively tall during much of the period studied, but experienced declining height in many countries after the 1960s. People in Southeast Asia stayed relatively short throughout the period.
\end{abstract}




\section{Introduction}

Human development and the size and shape of people's bodies would seem to be unrelated. However, there is much evidence that the average height of large numbers of individuals can be considered an important indicator of people's welfare. Development economists and other specialists in the fields of nutrition and health have studied the share of stunted (i.e. shorter than expected) children. The rationale underlying these studies is that the human body reduces its growth if the nutritional situation worsens beyond a certain minimum, or if diseases reduce the available amount of nutrients. The reflection of nutritional or health-related problems in the human body provides a relatively undistorted indicator, whereas many other welfare proxies (such as calories or protein per capita, real income, etc.) require quite complicated measurement procedures, which are particularly difficult to obtain in developing countries and in historical studies. However, anthropometric data require a set of techniques in order to be transformed into informative and undistorted indicators. This chapter reviews these methods, and provides evidence on differences in human stature between countries and regions since the 1820 s.

By providing a comprehensive dataset on average human height across all world regions, this chapter provides an alternative view of the history of human well-being and health status. It suggests that human height has increased globally since the late 19th century, and that Africa is the only part of the world where height has steadily declined in the past two decades. Human stature has been used as a proxy indicator for health, especially for time periods and societies in which other indicators are not available or are of unclear quality. For example, evidence on height is available for Africa, Southeast Asia and other world regions during the 19th century, a period for which other well-being indicators are very scant.

But what does it mean that height is a proxy indicator? The value of an additional year of life is relatively obvious for any human being, whereas an additional centimetre of height does not have a direct meaning. Height developments and differences (across countries and periods) only reveal their importance if their correlation with other components of health and the "Biological Standard of Living" (Komlos 1985 suggested this term) is known to the observer. This correlation is quite well-established (even if there are some exceptions), and the further we go back in time, the closer the correlation. But even in 20th century Norway, a correlation was shown: Robert F. Fogel - drawing on the research of Waaler (1984), who measured several thousand Norwegian men and then followed them in a longitudinal study - reported in his Nobel Prize lecture (1994) that as late as the 1960 s and 1970 s a $17.5-\mathrm{cm}$ height deficit meant for a Norwegian man a $71 \%$ higher risk of dying in the next period of their life, a staggering difference when one considers that at the time Norway's nutritional ratings were unmatched. Having analysed height data for the birth cohorts of 1860, 1900 and 1950, Baten and Komlos (1998) concluded that every centimetre above a given population's average height translated into a 1.2 year increase in life expectancy. ${ }^{1}$ Thus a mere half-centimetre 
deviation from the population average is significant, representing six months of life. The correlation between height and longevity is even closer among children (Billewicz and MacGregor, 1982; Martorell and Habicht, 1986).

Another implication of the fact that height is only a proxy indicator of health status is that governments have not viewed it as an important reflection of their own policies. Some governments engaged in "window-dressing" when development indicators such as national income, life expectancy, school enrolment, etc., were published: for example, the Soviet Union tried to make its statistics look better than they were in reality, while Nazi Germany did the same. A proxy indicator of well-being that we study today, in the 21st century, but whose informative value was not clear to contemporaries, will be less vulnerable to manipulation. Indeed, several studies on the communist countries and Nazi Germany have revealed that human stature provides important insights there were hidden when looking at other indicators.

\section{Description of the concepts used}

Human stature is a well-established indicator for the biological standard of living, positively correlated, along with good health and longevity, with a nutritious diet. ${ }^{2}$ In the 1980s, Robert F. Fogel, Richard Steckel and John Komlos pioneered its use in the field of economic history, and a large body of literature has emerged since (Steckel, 2009; Komlos and Baten, 2004). Anthropometric studies of individual countries have made a significant contribution to welfare analysis over the past several decades, and have provided the basis for a number of collective analyses, in which several studies are presented and compared (e.g. Steckel and Floud, 1997; Komlos and Baten, 1998).

Most studies in anthropometric history rely on adult stature, which is most strongly influenced by environmental factors during the first years of life (especially the first three years after birth). Even if there is a moderate influence also during teenage years, the birth decade is the usual category by which historical height evidence is organised, and this convention is also used in this chapter. ${ }^{3}$ This has the implication that the time series presented here end in the 1980s, as not all persons born during the 1990s have reached their final adult stature yet.

What are the most important determinants of the biological standard of living? A population's average height is in large part a function of the disease environment and the availability of high-protein foodstuffs (chiefly meat and dairy products). The impact on anthropometric values of high-quality proteins and calcium has been described in terms of a bottleneck (Baten, 2010). The bottleneck concept implies that other food items necessary for a balanced diet, such as fruit, vegetables and grains, were much more easily available, whereas protein was expensive to produce in densely populated areas over most of the period under study. The historical record indicates that humans have always needed large amounts of protein to generate the antibodies needed to fight infectious disease, and today's underdeveloped countries are no exception. Milk in particular helps to create antibodies (Grigg, 1995; De Beer, 2012)). Added to this protein effect is that of the disease environment, which is often approximated with infant mortality rates (Baten and Blum, 2012a and 2014).

This chapter also compares height trends with GDP per capita, used as a measure of aggregate economic production. Countries with higher GDP are able to generate not only more high-quality foodstuffs but also, at least since the last century, more medical goods 
and services. However, a variety of issues may drive a wedge between economic production and the biological standard of living.

If historians are beginning to use height as a valid complement to conventional welfare indicators, this is because it has some specific advantages. A given income level permits the purchase of a given quality and quantity of food and medical services, and is thereby correlated with health status, which in turn is correlated with height. However, this income-height correlation is not one-to-one, as it is modified by important inputs not traded in the marketplace but provided as public goods, such as infant-nutrition programmes and public hospitals. This may lead to deviations between purchasing power-based and height-based measures of human well-being. Moreover, income measures fail to account for differences in people's command over resources within households. While the anthropometric approach cannot account for every potential influence in a given population, it permits economists and historians to capture important aspects of the biological standard of living (Komlos, 1985; Steckel, 1995), particularly in developing countries, which were hitherto neglected because of the lack of reliable data. The well-known Maddison dataset (2001), for example, provides only rough estimates for per capita GDP in many such countries prior to 1910 . While height is not without its deficiencies as a measure of a given population's standard of living, it generates insights into global changes, and is particularly valuable as a countercheck as well as a complement to conventional indicators, permitting more reliable results than might otherwise be the case.

\section{Historical sources}

This section provides a selective description of the more prominent studies on which our dataset on human height is based. Thanks to the existence of a considerable body of scholarly work, long-term time series are today available for a considerable number of countries around the world; however, in other cases, the available evidence remains limited. The availability of data varies among world regions, but over the past decade it has significantly increased. Western Europe and European settlements have been the object of numerous studies, while there are a few studies for other world regions (e.g. Floud, Wachter and Gregory, 1990; Floud, 1994; Baten and Komlos, 1998; Steckel and Floud, 1997). Costa and Steckel (1997) combined all United States studies in a trend estimate that is based on a number of individual studies using data from the military and prison records for the 19th century (see also Zehetmayer, 2011). More recently, Southern Europe has been added to the dataset (A'Hearn, 2003; Pesacchi, 2008; Martínez-Carrión, 1994). Garcia and Quintana-Domeque (2007) and Hatton and Bray (2010) extended the European dataset, while Whitwell, de Souza and Nicholas (1997) provided evidence for Australia.

Evidence for both Eastern Europe and Central Asia has been provided by Mironov $(1999,2004)$, thanks to a combination of archival and contemporary anthropological data (see also Mironov and A'Hearn, 2008). Mironov's estimates of Russian and various other Eastern European height data provide a valuable overview of this region, even if Wheatcroft (1999) has offered a different interpretation. Data for central Asia can be drawn from the so-called demographic and health surveys (DHS) conducted from the 1980s onward that allow to cover birth decades after the 1940s, while anthropologists have provided data for the birth period 1960-89 in Eastern Europe (e.g. Bielicki and Hulanicka, 1998; Vignerova and 
Blaha, 1998). Among Komlos' many studies are several on those regions of southeastern Europe that once composed the Habsburg Empire (1985, 1989, 2007). Kopczynski has done likewise for Poland (2006).

For pre-1950 Latin America, data on Argentina and Colombia - mainly based on prisoner lists, military and especially passport samples - have been provided by Salvatore (1998, 2004), Salvatore and Baten (1998), López-Alonso and Porras (2003), Meisel and Vega (2004a, 2004b), Carson (2005, 2008), and recently Baten and Carson (2010). Brazil, Peru, and Argentina have been recently studied by Baten, Pelger and Twrdek (2009) and Twrdek and Manzel (2010). In addition, there is scattered information regarding the Indian populations in these and other countries (Bogin and Keep, 1998).

India, Asia and the Middle East and North Africa are only modestly documented. We have access to Indian height data for the early 20th century (Guntupalli and Baten, 2006) but also for birth cohorts dating as far back as the early 19th century (Brennan, McDonald and Shlomowitz, 1994a, 1994b, 1997 and 2000). Although the latter studies are based on labourmigrant heights, which are not necessarily a representative sample of India's population, the authors offer persuasive arguments that these height estimates were equivalent to those of the population as a whole. For Japan, evidence is provided by Mosk (1996), Bassino (2006), Shay (1994) and Honda (1997), while for China estimates are available through Morgan (2006), Baten and Hira (2008) and Baten, Ma, Morgan and Wang (2010). The latest of several studies of Korea is one for North Korea by Pak, Schwekendiek and Kim (2010). As for Southeast Asia, a modest amount of data on this region is available (Bassino and Coclanis, 2008, for Myanmar/Burma; van der Eng, 1995, Baten, Stegl and van der Eng, 2009, for Indonesia; Murray, 2002, for the Philippines). Estimates for the Middle East and North Africa in the late 19th and early 20th centuries have been provided by Stegl and Baten (2009). Data from the Demographic and Health Surveys (DHS) programme allow computing a trend estimate for Turkey and Egypt during the period 1950-89, while the 1970s and 1980s have been the object of a number of anthropological studies.

African height data on freed slaves and military recruits permit a rough estimate for the early 19th century (Eltis, 1982; Austin, Baten and van Leeuwen, 2012). Eltis (1982) argued that the height discrepancy between freed slaves and others was negligible, because height was not an important pricing criterion; while slave heights varied from region to region, regional prices did not reflect this variation. Furthermore, any height differences among freed slaves were diminished by Africa's own demand for the strongest (and thus presumably the tallest) workers available, because Africa was a labour-scarce world region herself. At the same, there is no evidence that the slave market established anything like the military's minimum-height requirement. A comparison of soldiers' and slaves' height data indicates that the latter did not suffer from significant bias (Austin, Baten and van Leeuwen, 2012). For Africa during the period 1890-1930, a large number of anthropological studies are available: for example, estimates for the two major Kenyan peoples, the Kikuyu and the Maasai (Orr and Gilks, 1931), as well as recent studies for a broader set of population groups (Moradi, 2009a; Austin, Baten and Moradi, 2008). The problem of potential survivor bias in the African DHS datasets, which span the years 1945-89, has been addressed and resolved by Moradi (2005).

As a result of all these studies, the coverage of height estimates for almost all countries in the world is quite comprehensive (Baten and Blum, 2012a), and for many countries, continuous time series are available. 


\section{Data quality}

Depending on the type of historical sources used, a number of methodological issues need to be considered. How can we estimate trends in world height over a period spanning nearly two centuries? Needless to say, in some cases height estimates are compromised by regional selectivity biases and other factors. The estimates presented in this chapter have been collected in as accurate a way as possible under the present circumstances, recording height by province whenever possible, and adjusting calculations to take into account any modifications of national borders. An assessment of data quality is provided in Table 7.1.4

Only certain combinations of countries and birth decades are sufficiently well documented to contribute to our estimates; for instance, no evidence is available for the Middle East and North Africa in the early 19th century, largely because of the absence of precise height measurements in Ottoman Empire military data, which categorised each recruit as small, medium or large, and as barefaced or bearded. In most other world regions, however, army data are available for the early 19th century.

The year 1950 marks a turning point in that, from that moment on, population censuses, health surveys and similar sources include height data on women - in fact, considerably more than on men - because institutions other than the military, particularly those related to the health sciences, began to take an interest in them. The fact that there is a correlation, if not a simple one, between male and female heights is now beyond dispute (Baten and Murray, 2000; Moradi and Guntupalli, 2014), which justifies our substituting one set for another when necessary. Objections to this strategy might be raised by those who accept the female-resiliency hypothesis, which holds that for biological reasons the average height of a given female population is more resistant to adverse conditions than is the average height of their male counterparts. Some evidence from small prehistoric samples supported this hypothesis. However, drawing on the largest height sample available to date, Guntupalli (2005) has gone far to disprove this hypothesis for the last two centuries. Since the vast majority of historical height estimates are for men, we transform all estimates into male equivalents, estimating specific regression equations for each world region in order to account for potential differences (Baten and Blum, 2012). ${ }^{5}$

To construct this database, we have taken great care to identify all the biases that may have been generated by the institutional context - enlistment in the military, incarceration in prison and sale in the slave trade, chiefly - in which heights were recorded. ${ }^{6}$ Estimates from voluntary soldier samples were included in the database only if satisfactory statistical methods had been used by the researchers who collected such data to eliminate the height bias of truncated samples. ${ }^{7}$

As for those institutional contexts that are specific to certain world regions and time periods, Baten and Blum (2012) have included them in a series of bias-analysis regressions, each designed to expose a potential bias typical of a given region or time period. For example, the estimates used here rely partially on prison samples for Latin America and North America in the 19th century, whereas those for most European countries are based on conscript samples, which as a rule cover a broader portion of the social spectrum; and anthropological samples were virtually the sole source for certain world regions. In order to assess the impact of datasets that were potentially unrepresentative, Baten and Blum (2014) have produced estimates including and excluding these: in most cases the differences were negligible. 
Self-reported heights are particularly prevalent in Western countries in the later 20th century. Since, according to a number of studies, men tend to overestimate their own height, the corrective recently proposed by Hatton and Bray (2010), which Baten and Blum (2012) have tested for accuracy, has been adopted here.

In the case of data for the Middle East and Africa, a drawback of early anthropological studies is that the importance of identifying individuals by birth cohort was not yet understood, as it was assumed that the physical measurements of a population did not evolve from one decade to the next. The result is that, when using anthropological data, Baten and Blum (2012a) had to approximate birth decades, and accept the possibility that a small proportion of those individuals identified as belonging to a given cohort actually belonged in one of the two adjacent ones. ${ }^{8}$

When Baten and Blum (2012a) regressed human stature in a global sample of almost 100 countries on a full set of country and birth-decade dummies and on those potentialbias variables, all coefficients of the latter variables turned out to be statistically insignificant. $^{9}$

The question of what role genetics, as well as nutrition, may play in determining a given population's average height was often raised in the early years of anthropometric research (Blum, 2013). It turns out that, while genes are a key determinant of an individual's height, genetic deviations from the mean cancel each other out when analysing groups of individuals. Moreover, there is considerable evidence that it is environmental conditions, not genes, which account for today's height gap between rich and poor populations, including those inhabiting a single nation. Habicht et al. (1974), for example, found that the height gap between the rich and poor populations in Nigeria was even wider than that between high-ranking groups in a typical low-income country and in the United States. ${ }^{10}$ Similar conclusions were reached by Fiawoo (1979) in his study of Ghana, by Eksmyr (1970), based on data on several Ethiopian ethnic groups, and by Graitcer and Gentry (1981), who studied Egypt, Haiti and Togo. The height distribution for children from rich families in Graitcer and Gentry (1981) are also in line with those for the United States. Of course, not all height differentials are due to environmental conditions: African bushmen and pygmies, for example, spring to mind, but these groups account for only a small percentage of their respective nations' populations.

Table 7.1. Quality of data on population heights by region and benchmark year, 1820-1973

\begin{tabular}{|c|c|c|c|c|c|c|c|c|}
\hline & $\begin{array}{c}\text { Western } \\
\text { Europe } \\
\text { (WE) }\end{array}$ & $\begin{array}{c}\text { Eastern } \\
\text { Europe } \\
\text { (EE) }\end{array}$ & $\begin{array}{l}\text { Western } \\
\text { Offshoots } \\
\text { (W0) }\end{array}$ & $\begin{array}{l}\text { Latin } \\
\text { America } \\
\text { and } \\
\text { Caribbean } \\
\text { (LA) }\end{array}$ & $\begin{array}{c}\text { Sub-Saharan } \\
\text { Africa } \\
\text { (SSA) }\end{array}$ & $\begin{array}{l}\text { Middle East } \\
\text { and } \\
\text { North Africa } \\
\text { (MENA) }\end{array}$ & $\begin{array}{c}\text { East Asia } \\
\text { (EA) }\end{array}$ & $\begin{array}{c}\text { South and } \\
\text { South-East } \\
\text { Asia } \\
\text { (SSEA) }\end{array}$ \\
\hline 1820 & 2 & 2 & 2 & 3 & 4 & .. & 3 & .. \\
\hline 1870 & 2 & 2 & 2 & 2 & 3 & 2 & 3 & 3 \\
\hline 1913 & 2 & 2 & 2 & 2 & 3 & 2 & 3 & 2 \\
\hline 1950 & 1 & 2 & 1 & 1 & 1 & 2 & 1 & 2 \\
\hline 1973 & 1 & 2 & 1 & 1 & 1 & 2 & 1 & 2 \\
\hline
\end{tabular}

Note: 1. High quality; 2. Moderate quality; 3. Low quality; and 4. Estimates. See the section on «Data Quality» in Chapter 1 for a description of the quality criteria.

Source: Clio-Infra, www.clio-infra.eu. 
However, the evidence presented here on Africa has potential for improvement, because the estimates sometimes relied on small numbers of cases for the early period, and typically on only one institutional context (such as measurements of slaves, prisoners or soldiers, or anthropological studies). In contrast, in other world regions, we can often compare evidence from different institutional contexts, which reduces the likelihood of measurement error. For example, early South African evidence comes from Xhosa labourers who worked as temporary labourers on Western Cape farms. This may lead to an upward bias, if only the healthiest and strongest individuals were accepted as labourers (despite the argument of Brennan et al., 1994a, 1994b, 1997, 2000, that this bias was not strong in the South Asian case).

Table 7.1 provides a snapshot assessment of the quality of the height indicators used here. The table relies on slightly different criteria - relative to other chapters in this report to create four classes of data, as in the other chapters, because height was never a part of official statistical reporting:

- Institutional data: the evidence is the product of international institutions, such as the Demographic and Health Surveys and the Eurostat compilations, which aim at high standards of representativeness of their sampling procedures.

- High-quality data: the product of economic-historical research that assessed the possibility of sample-selection bias in the sources by using secondary characteristics (such as comparing the occupational structure of samples with the occupational structure of representative censuses, and re-weighting samples to become representative), or which relied on sources that are unlikely to be affected by sample selection bias.

- Moderate-quality data: estimates from historical research that relied on sources that could be affected by sample selection biases, or that made use of indirect data and estimates.

- Low quality data: estimates based on guesses, conjectures and interpolation between benchmark years.

It should be noted that Table 7.1 reports averages. In some world regions, some countries might have had weaker data.

\section{Main highlights of human height trends}

Figure 7.1 and Table 7.2 show adjusted height estimates of world regions for the entire 1810-1980 period based on the population-weighted averages of 156 countries (Baten and Blum, 2012b). Several groups of world regions can be distinguished:

- The Western Offshoots had very high anthropometric values for much of the period under study. Height in these countries declined slightly towards the level prevailing in other regions until the late 19th century, then started to grow again.

- Both Western Europe and those countries in Eastern Europe that experienced socialist rule recorded a strong upward trend in average height after the 1880s. However, once the USSR came into being the height gap between Western and Eastern Europe increased (Komlos, 1999; Mironov, 2006). In contrast, average height in Latin America, the Middle East and North Africa was at relatively high levels in the 19th century but experienced only modest increases during the 20th century (Salvatore, 2004). 
Figure 7.1. Regional averages of population heights, 1820s-1980s

Centimetres, decadal averages
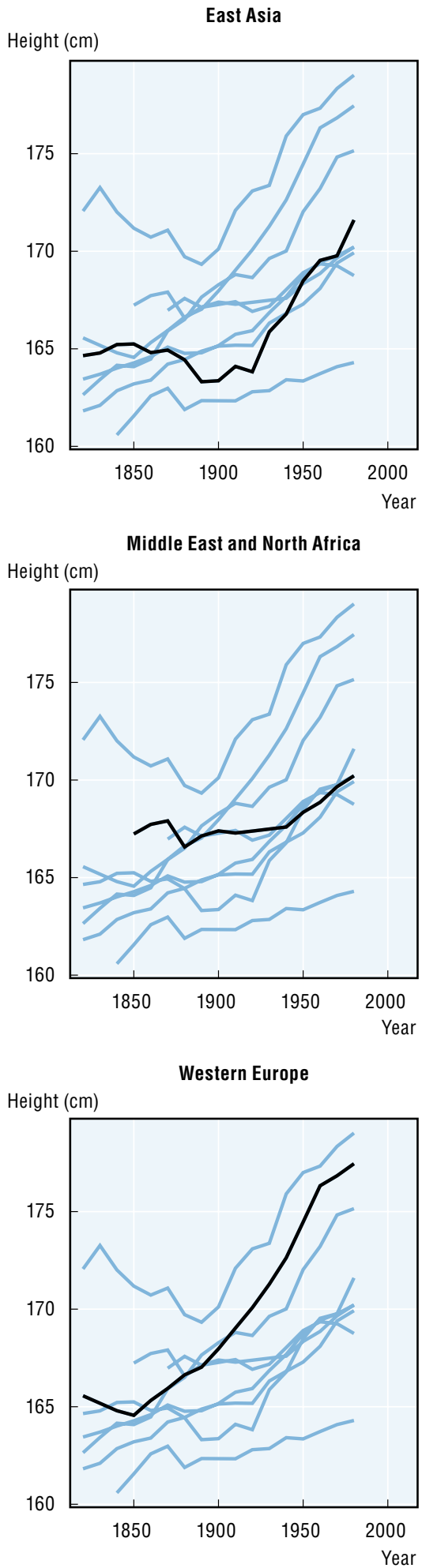

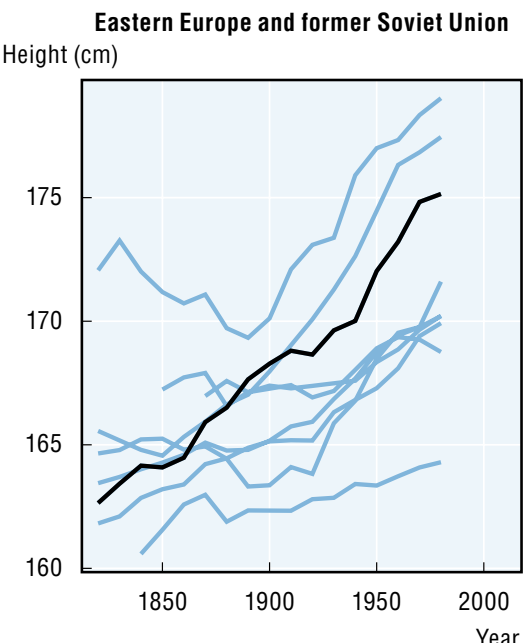

South and South-East Asia Height $(\mathrm{cm})$
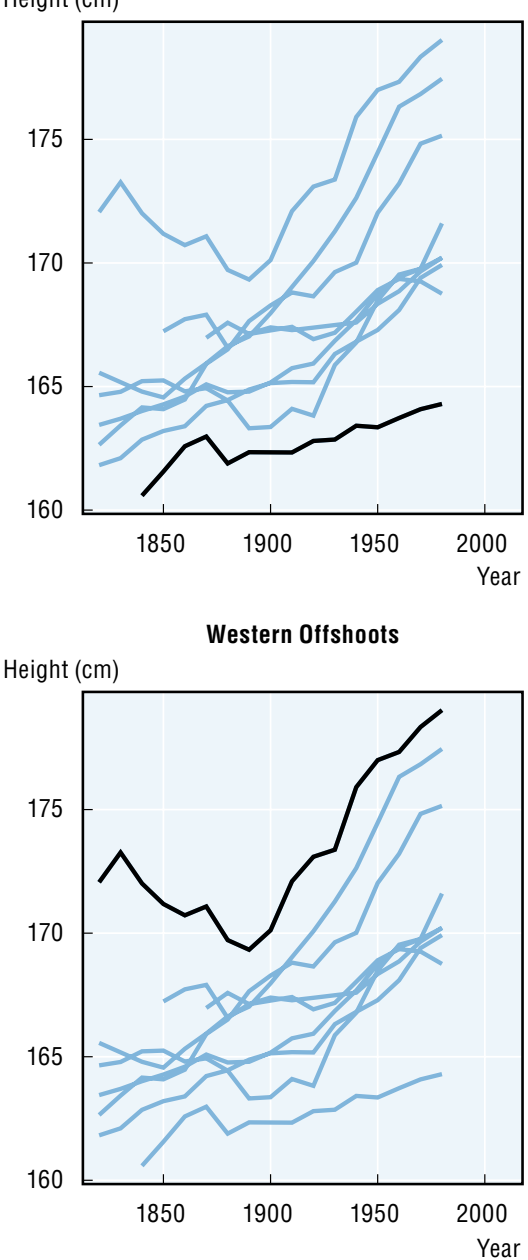

Latin America and Caribbean

Height (cm)

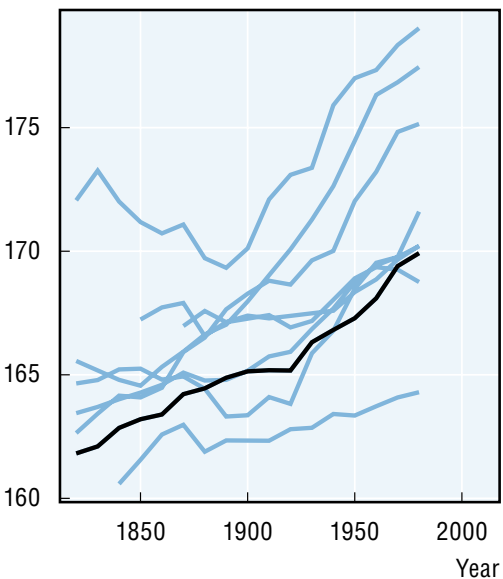

Sub-Saharan Africa Height $(\mathrm{cm})$

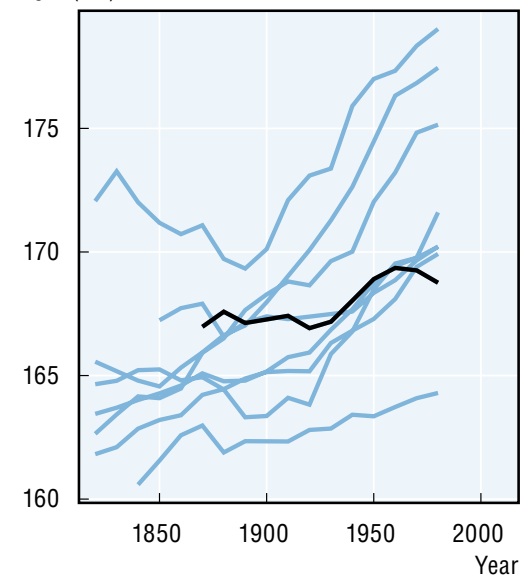

World Height $(\mathrm{cm})$

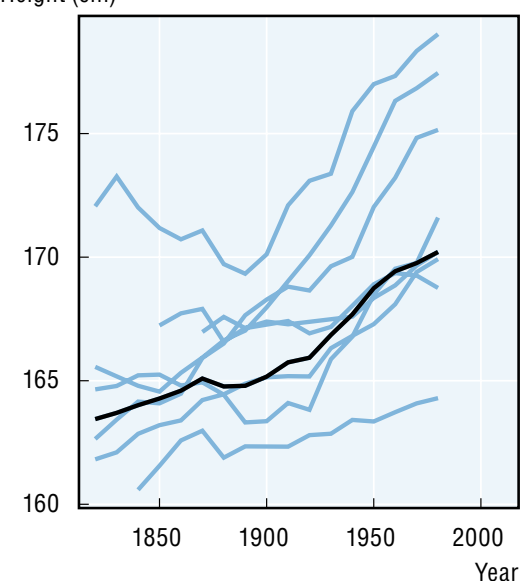

Notes: For an assessment of data quality, see Table 7.1. In reproductions, please cite as Baten and Blum, 2014 (in: European Review of Economic History).

Source: Clio-Infra, www.clio-infra.eu. 
Table 7.2. Regional averages of population heights, $1820 \mathrm{~s}-1980 \mathrm{~s}$

Centimetres, decadal averages

\begin{tabular}{|c|c|c|c|c|c|c|c|c|c|}
\hline & $\begin{array}{c}\text { Western } \\
\text { Europe } \\
\text { (WE) }\end{array}$ & $\begin{array}{c}\text { Eastern } \\
\text { Europe } \\
\text { (EE) }\end{array}$ & $\begin{array}{c}\text { Western } \\
\text { Offshoots } \\
\text { (W0) }\end{array}$ & $\begin{array}{c}\text { Latin } \\
\text { America } \\
\text { and } \\
\text { Caribbean } \\
\text { (LA) }\end{array}$ & $\begin{array}{c}\text { East Asia } \\
\text { (EA) }\end{array}$ & $\begin{array}{c}\text { South and } \\
\text { South-East } \\
\text { Asia } \\
\text { (SSEA) }\end{array}$ & $\begin{array}{l}\text { Middle East } \\
\text { and } \\
\text { North Africa } \\
\text { (MENA) }\end{array}$ & $\begin{array}{c}\text { Sub-Saharan } \\
\text { Africa } \\
\text { (SSA) }\end{array}$ & World \\
\hline $1820 \mathrm{~s}$ & 165.6 & 162.6 & 172.1 & 161.8 & 164.6 & .. & .. & .. & 163.4 \\
\hline $1830 \mathrm{~s}$ & 165.2 & 163.4 & 173.3 & 162.1 & 164.8 & .. & .. & .. & 163.7 \\
\hline $1840 \mathrm{~s}$ & 164.8 & 164.2 & 172.0 & 162.9 & 165.2 & 160.6 & .. & .. & 164.0 \\
\hline $1850 \mathrm{~s}$ & 164.6 & 164.1 & 171.2 & 163.2 & 165.2 & 161.6 & 167.2 & .. & 164.3 \\
\hline $1860 \mathrm{~s}$ & 165.3 & 164.5 & 170.7 & 163.4 & 164.8 & 162.6 & 167.7 & .. & 164.6 \\
\hline 1870 s & 165.9 & 165.9 & 171.1 & 164.2 & 164.9 & 163.0 & 167.9 & 167.0 & 165.1 \\
\hline $1880 \mathrm{~s}$ & 166.6 & 166.5 & 169.7 & 164.5 & 164.4 & 161.9 & 166.6 & 167.6 & 164.8 \\
\hline $1890 \mathrm{~s}$ & 167.0 & 167.6 & 169.3 & 164.9 & 163.3 & 162.3 & 167.1 & 167.1 & 164.8 \\
\hline $1900 \mathrm{~s}$ & 168.0 & 168.3 & 170.1 & 165.1 & 163.4 & .. & 167.4 & .. & 165.2 \\
\hline 1910s & 169.0 & 168.8 & 172.1 & 165.2 & 164.1 & 162.3 & 167.3 & 167.4 & 165.7 \\
\hline $1920 \mathrm{~s}$ & 170.1 & 168.6 & 173.1 & 165.2 & 163.8 & 162.8 & 167.4 & 166.9 & 165.9 \\
\hline 1930s & 171.3 & 169.6 & 173.4 & 166.3 & 165.9 & 162.9 & .. & 167.2 & 166.9 \\
\hline $1940 \mathrm{~s}$ & 172.6 & 170.0 & 175.9 & 166.8 & 166.8 & 163.4 & 167.6 & 168.0 & 167.7 \\
\hline 1950 s & 174.5 & 172.0 & 177.0 & 167.3 & 168.5 & 163.4 & 168.3 & 168.9 & 168.7 \\
\hline $1960 \mathrm{~s}$ & 176.3 & 173.2 & 177.3 & 168.1 & 169.5 & 163.7 & 168.9 & 169.4 & 169.4 \\
\hline 1970 s & 176.8 & 174.8 & 178.3 & 169.4 & 169.8 & 164.1 & 169.7 & 169.3 & 169.8 \\
\hline $1980 \mathrm{~s}$ & 177.5 & 175.1 & 179.0 & 169.9 & 171.6 & 164.3 & 170.2 & 168.8 & 170.2 \\
\hline
\end{tabular}

Notes: For an assessment of data quality, see Table 7.1. In reproductions, please cite as Baten and Blum, 2014 (in: European Review of Economic History).

Source: Clio-Infra, www.clio-infra.eu.

- East Asia and Sub-Saharan Africa remained throughout the entire period near the global average, with the exception of East Asia during the late 19th century, where average height was significantly lower. Africa is the only world region in which the average height has steadily declined over the last two decades (Moradi, 2005).

- Average height in South and Southeast Asia remained at a low level throughout the period under study. While no upward trend of any significance occurred in South Asia since the end of the 19th century, Southeast Asia experienced a slight upward trend; at the start of the period, average height in this region was at an even lower level than for its neighbours (Brennan, McDonald, Shlomowitz, 1994a, 1994b, 1997 and 2000; Guntupalli and Baten, 2006; Baten, Stegl and van der Eng, 2010).

In sum, after the 1880s, global heights increased on average, but also became more unequal.

Some country developments are particularly interesting and are discussed below (see Table 7.3 on height trends in 25 countries). In the Americas, between-country differences of stature were particularly pronounced. Mexico displayed the shortest level in the early 19th century, at just over $160 \mathrm{~cm}$, followed by Brazil. On the top end of the spectrum, the United States, Canada and Australia were leading in anthropometric values, also worldwide. North Americans and Australians born in the New World were much taller than the European population from which they originated, thanks to an abundant food supply. Argentina's anthropometric level was initially similar to the Western Offshoots, but when population 
Table 7.3. Population heights in selected countries, 1820s-1980s

Centimetres, decadal averages

\begin{tabular}{|c|c|c|c|c|c|c|c|c|c|c|c|c|c|c|c|c|c|c|c|c|c|c|c|c|c|}
\hline & \multicolumn{7}{|c|}{$\begin{array}{l}\text { Western Europe } \\
\text { (WE) }\end{array}$} & \multicolumn{2}{|c|}{$\begin{array}{l}\text { Eastern Europe } \\
\text { (EE) }\end{array}$} & \multicolumn{3}{|c|}{$\begin{array}{l}\text { Western Offshoots } \\
\text { (W0) }\end{array}$} & \multicolumn{3}{|c|}{$\begin{array}{l}\text { Latin America and } \\
\text { Caribbean } \\
\text { (LA) }\end{array}$} & \multicolumn{2}{|c|}{$\begin{array}{l}\text { Middle East } \\
\text { and North } \\
\text { Africa (MENA) }\end{array}$} & \multicolumn{3}{|c|}{$\begin{array}{c}\text { Sub-Saharan Africa } \\
\text { (SSA) }\end{array}$} & \multicolumn{2}{|c|}{$\begin{array}{l}\text { East Asia } \\
\text { (EA) }\end{array}$} & \multicolumn{3}{|c|}{$\begin{array}{c}\text { South and } \\
\text { South-East Asia } \\
\text { (SSEA) }\end{array}$} \\
\hline & GBR & NLD & FRA & DEU & ITA & ESP & SWE & POL & RUS & AUS & CAN & USA & MEX & BRA & ARG & EGY & TUR & KEN & NGA & ZAF & CHN & JPN & IND & IDN & THA \\
\hline $1820 \mathrm{~s}$ & 169.1 & 165.1 & 163.9 & 167.3 & 165.8 & .. & .. & .. & 162.1 & .. & 171.5 & 172.2 & 160.4 & 164.3 & 169.9 & & & .. & 162.2 & .. & 165.8 & & .. & .. & .. \\
\hline $1830 \mathrm{~s}$ & 166.7 & 164.2 & 164.0 & 166.8 & 164.1 & 161.0 & 168.1 & .. & 163.0 & .. & 171.5 & 173.5 & 160.4 & 164.8 & 170.9 & .. & .. & .. &.. &.. & 165.8 & . &.. &.. & .. \\
\hline 1840s & 166.5 & 164.5 & 164.3 & 166.6 & 162.0 & 163.7 & 167.9 & 163.1 & 164.2 & .. & 170.4 & 172.2 & 162.5 & 164.6 & 169.6 & .. & & .. & .. & .. & 166.2 & . & 160.3 & 160.4 & .. \\
\hline 1850s & 165.6 & 165.3 & 165.2 & 163.8 & 162.9 & 162.5 & 168.4 & .. & 163.4 & 170.0 & 172.5 & 171.1 & 163.4 & 164.5 & 168.2 & 166.3 & 168.7 & .. & .. & .. & 166.2 & & 161.8 & 160.6 & .. \\
\hline $1860 \mathrm{~s}$ & 166.6 & 166.5 & 165.4 & 165.5 & 163.1 & 162.7 & 169.3 & 165.5 & 163.3 & 170.6 & 172.0 & 170.6 & 162.9 & 165.0 & 167.4 & 167.7 & 169.1 &.. & .. & .. & 165.7 & & 163.0 & 160.4 & 160.1 \\
\hline $1870 \mathrm{~s}$ & 167.2 & 167.1 & 165.5 & 166.9 & 163.5 & 162.6 & 170.3 & 166.3 & 165.8 & 170.1 & 171.2 & 171.1 & 163.7 & 166.5 & 167.6 & 166.9 & 170.1 &.. & 165.6 &.. & 165.8 &.. & 163.8 & 158.1 & 161.5 \\
\hline $1880 \mathrm{~s}$ & 167.9 & 168.5 & 165.9 & 167.9 & 163.9 & 163.9 & 171.2 & 166.8 & 166.6 & 171.1 & 171.2 & 169.5 & 163.9 & 166.1 & 167.6 & 163.0 & 167.4 & 164.5 & 167.9 & .. & 165.3 & 157.8 & 162.4 & 158.6 & 162.3 \\
\hline 1890s & 167.4 & 169.4 & 166.1 & 168.6 & 164.7 & 164.0 & 172.4 & 167.2 & 168.3 & 171.3 & 170.7 & 169.1 & 163.9 & 167.1 & 167.8 & & 168.4 & 166.0 & .. & 170.4 & 164.0 & 157.8 & 163.0 & 158.8 & 161.0 \\
\hline $1900 \mathrm{~s}$ & 169.4 & 170.9 & 166.8 & 169.2 & 165.6 & 164.6 & 172.8 & 166.6 & 169.2 & 172.3 & 169.9 & 170.0 & 163.9 & 167.5 & 167.9 & 166.2 & 168.4 & 166.7 & .. & 169.9 & 164.0 & 158.7 & .. & 159.0 & 162.1 \\
\hline $1910 \mathrm{~s}$ & 170.9 & 172.6 & 167.8 & 170.5 & 166.3 & 165.1 & 173.2 & 169.0 & 169.1 & 172.7 & 171.5 & 172.1 & 163.7 & 166.5 & 168.2 & 166.2 & 167.9 & 168.1 & 166.8 & 169.7 & 164.7 & 159.6 & 162.9 & 159.6 & 161.5 \\
\hline $1920 \mathrm{~s}$ & 171.0 & 173.5 & 168.5 & 173.3 & 167.3 & 165.6 & 168.3 & & 167.0 & 172.8 & 173.0 & 173.1 & 161.1 & 166.6 & 169.0 & 165.1 & 169.3 & 167.7 & 165.6 & 169.2 & 164.2 & 160.7 & 163.5 & 160.9 & 161.3 \\
\hline $1930 \mathrm{~s}$ & 173.9 & 174.1 & 169.9 & 174.0 & 168.1 & 165.2 & 175.5 & 173.0 & 167.9 & .. & 172.7 & 173.4 & 165.5 & 167.0 & 169.8 & & 169.3 & .. & 164.6 & 170.0 & 166.5 & 161.4 & 163.7 & 160.7 & 161.2 \\
\hline $1940 \mathrm{~s}$ & 174.9 & 177.5 & 171.7 & 175.2 & 169.3 & 166.3 & 178.5 & 170.5 & 169.0 & .. & 174.6 & 176.1 & 165.8 & 167.1 & 170.6 & 167.5 & 167.2 &.. & 167.2 & 168.2 & 167.4 & 162.6 & 164.0 & 160.4 & .. \\
\hline $1950 \mathrm{~s}$ & 176.0 & 178.7 & 173.2 & 176.8 & 171.3 & 170.8 & 179.3 & 173.2 & 172.0 & .. & 177.0 & 177.1 & 165.1 & 168.2 & 170.8 & 170.1 & 166.6 & 169.9 & 168.5 & 170.1 & 169.2 & 163.6 & 163.5 & 161.7 & .. \\
\hline $1960 \mathrm{~s}$ & 176.9 & 182.2 & 174.9 & 178.9 & 173.0 & 174.2 & 180.1 & 175.3 & 173.6 & 176.3 & 178.3 & 177.3 & 166.4 & 169.0 & .. & 170.6 & 167.4 & 170.7 & 169.8 & 169.5 & 170.0 & 165.7 & 163.9 & 162.4 & .. \\
\hline 1970s & 177.1 & 182.3 & 175.1 & 179.4 & 174.1 & 175.2 & 180.0 & .. & 177.0 & 178.4 & 178.8 & 178.3 & .. & 171.6 & .. & 171.2 & 168.6 & 170.9 & 169.7 & 168.9 & 170.0 & 166.8 & 164.3 & 163.1 & .. \\
\hline $1980 \mathrm{~s}$ & 176.8 & 182.7 & 176.5 & 180.5 & 174.5 & 175.6 & 180.4 & 177.4 & 177.0 & .. & 179.6 & 179.0 & 167.8 & 171.7 & .. & 171.3 & & 171.2 & 169.5 & 168.1 & 171.5 & 171.7 & 164.4 & 164.0 & .. \\
\hline
\end{tabular}

Notes: For an assessment of data quality, see Table 7.1. In reproductions, please cite as Baten and Blum, 2014 (in: European Review of Economic History).

Source: Clio-Infra, www.clio-infra.eu.

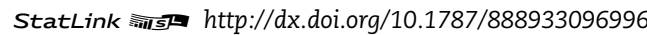


density grew, heights in Argentina declined slightly, converging to Brazilian heights around 1900. Various countries in the region experienced declining heights during the 1880s and 1890s.

Previous studies suggested two different explanations for the decline in height in the late 19th century in different world regions, namely the Americas, Africa and Asia. In the Americas, immigration and rapid population growth reduced the available protein per capita (and inequality was growing, with negative health effects). In addition, urbanisation sometimes led to a worsening disease environment. In Asia and Africa, in contrast, a wave of cattle plague was probably the most important factor leading to lower average height (Stegl and Baten, 2009; Baten et al., 2010), although other factors also contributed. With respect to the most recent period, Komlos (2009) argued that the height-advantage in the United States, relative to Europe, declined, while the gap between black and white United States residents increased. In the case of black United States women, their height declined - relative to white women - by 1.42 centimetres during the 1980s; black United States women were shorter than Western European women, including the Spanish and Italians (Komlos, 2009).

Average heights in Asia (including the Asian part of Turkey) displayed less variation than in the Americas. Turkey and China topped the height league in the region, with Turkey losing its prime position to China around the mid-20th century. At the lower end, Indonesia and Japan recorded the lowest height, although in Japan heights increased dramatically over the 20th century, reaching a joint top position with China in the 1980s. The tremendous growth in average height in Japan and the partial globalisation of its cuisine might have contributed to this spectacular growth. India and Thailand took middle positions in Asia.

Finally, Europe started short and ended very tall. Only the richest country, the United Kingdom, had high anthropometric levels in the 1810s and 1820s, but when industrialisation and urbanisation reached its maximum speed around the mid-19th century, the British also became short, at least relative to United States Americans of English ancestry. Scandinavia (Sweden in Table 7.3) had the lead in most of the period, but the Dutch took over after their welfare state expanded and after it became technologically feasible to transport highquality protein (contained in milk, for example) to such a densely settled country in large quantities.

These technological possibilities were lacking in Southern Europe (Italy, Spain) until much later. Only over the last half century have young Spaniards and Italians become almost as tall as other Europeans. In general, Europe started its dramatic height increase after the 1870s and 1880s, and this increase included the East (Poland, Russia) as well as the West. Northwestern Europe (including Germany) was always slightly ahead, according to this indicator - but far behind the New World in the early 19th century.

\section{Correlation with GDP per capita}

Height and GDP per capita are complementary measures of the standard of living. GDP per capita is a measure of the value of the final goods and services produced within a country in a given time period, and captures the aggregate production of the economy, whereas height is more closely correlated with nutrition and health care. While their correlation was initially stressed in the literature (Fogel et al., 1982), evidence over the past two decades indicates that they should be regarded as indicators that sometimes do not move in parallel. Significant deviations have been found not only between average height and GDP but also between height and real wages for unskilled labour (Margo and Steckel, 
1983; Komlos, 1998). However, these findings are based largely on data for the United Kingdom and the United States, and the correlation between real wages and heights was much closer in most other countries (Baten, 2000). Figure 7.2 shows that, across countries, the correlation between height and GDP per capita is significant, but also that it flattens out among more developed countries.

Jamaica displays higher anthropometric values than GDP per capita in the 1910s. This result is interesting, because Jamaica is often cited as an example of an early achiever of high life expectancy, despite its low income level (see the health chapter in this volume). The biological standard of living in Jamaica has entered the literature as "The Jamaica Paradox" (Riley, 2005). Riley wondered why Jamaica had a relatively high life expectancy in spite of its low income per capita. The fact that the majority of the Jamaican population had African slave ancestors also did not encourage an expectation of a high life expectancy, because in other Latin American countries regions with high concentrations of former slaves (Brazil's Northeast and Colombia's lowlands) typically had low levels of welfare. However, Jamaica differed in some important ways. First, some aspects of the British educational system, which provided basic literacy, had survived in former colonies like Jamaica: with basic literacy and numeracy, people are usually better able to take care of their own health. Riley also noted that the government invested substantially in public health, extending access to poorer people. Another factor that may explain the Jamaica Paradox was the relatively high level of gender equality: former French and British colonies in the Caribbean had a remarkably similar level of basic numeracy for both genders. Osmani and Sen (2003) have argued that gender equality is an important determinant of the health status of the next generation. In most societies, women have a large impact on child care, as well as on children's health and education. For height - and for longevity, before countries reach a certain level of GDP per capita and world market integration - the proximity to protein is also an important advantage.

Figure 7.2. Population heights and GDP per capita

Centimetres and US dollars at 1990 PPP

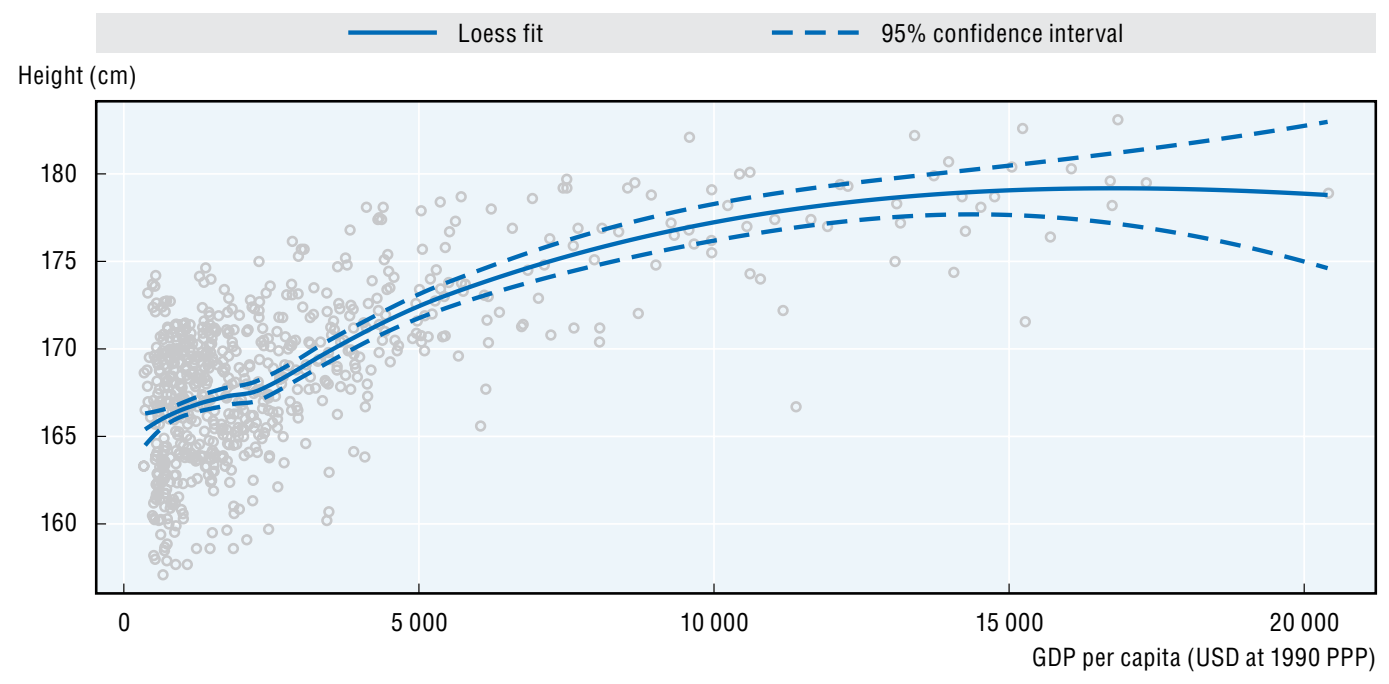

Notes: For an assessment of data quality, see Table 7.1. In reproductions, please cite as Baten and Blum, 2014 (in: European Review of Economic History).

Source: Clio Infra, www.clio-infra.eu. 
Jamaica had a large number of cattle per capita, and in any case the rates were many times higher than in most Asian countries of the same income level.

If we consider three other examples - Norway, with taller heights than expected from GDP values, and Italy and Vietnam with shorter heights - the latter two determinants of health might have similar effects: Norway had substantial proximity to protein production, and gender inequality was traditionally low (partly because women had an active role in dairy farming). By contrast, in both Italy and Vietnam, gender inequality was substantially higher, and cattle per capita numbers were low during the late 19th century.

How close is the correlation between average height and GDP per capita over time? Before 1870, and for the 1880s and 1890s, estimates on height and GDP are available for fewer than 30 countries, making statistical inference questionable. This may explain the fact that the correlations before the 1870s are smaller than afterwards (Figure 7.3). After the $1870 \mathrm{~s}$, the correlation is always around 0.6 to 0.8 . During the 20th century, the closest correlation occurs during the 1940s, i.e., the most disrupted period for the world economy. One possible explanation is that the biological standard of living during this decade depended mostly on country-specific resources and productive capacity, whereas in the post-war period transfers of resources and knowledge about medical technologies played an increasing role in mitigating the income-health relationship.

Heights can also be used to study inequality between countries in the world economy. How has inequality between a sample of 25 countries changed over time? (for the definition of this group, see Table 7.3) Figure 7.4 shows the coefficient of variation between countries, which is a standard measure of dispersion between countries (O'Rourke and Williamson, 1999), with countries weighted by their population size. In general, there is a tendency towards a greater dispersion of the average height in the different countries from the 1870s to the 1970s (the line with diamonds in Figure 7.4). If we compare the dispersion of GDP levels for the same period, the trend is very similar (the rectangles in the same figure). However, the volatility of GDP dispersion is slightly greater in the 19th century than in previous periods. ${ }^{11}$

In general, the 1940s and 1950s represent the period when inequality has increased most rapidly for both height and income. In spite of WWII, this was a period when medical and hygienic knowledge spread around the world. Also, the quality of nutrition could be improved in the Western Offshoots as well as in Eastern and Western Europe due to the diffusion of fertiliser and agricultural machinery and technology. But in general, the 20th century height increase in the richer countries can be attributed to improvements in health rather than in nutrition. In contrast, the large countries of the developing world experienced particularly difficult times in the 20th century. For example, China suffered particularly from military conflicts and institutional changes, while India suffered from those factors as well as from civil wars between religious groups.

The GDP dispersion suggests that the 1980s were a turning point towards much less between-country inequality. The 2000s display a coefficient of variation among the 25 countries that was as low as it had ever been in the 20th century. Conversely, when using the interpolation method suggested by Baten and Blum (2012a, 2012b) for the early 19th century, we find that anthropometric dispersion did not change very much from the 1810 s to the 1870 s. $^{12}$ 


\section{Figure 7.3. Correlation between population heights and GDP per capita,} 1820 s-1980s

Pearson correlation coefficient and upper/lower bounds of $95 \%$ confidence interval per decade

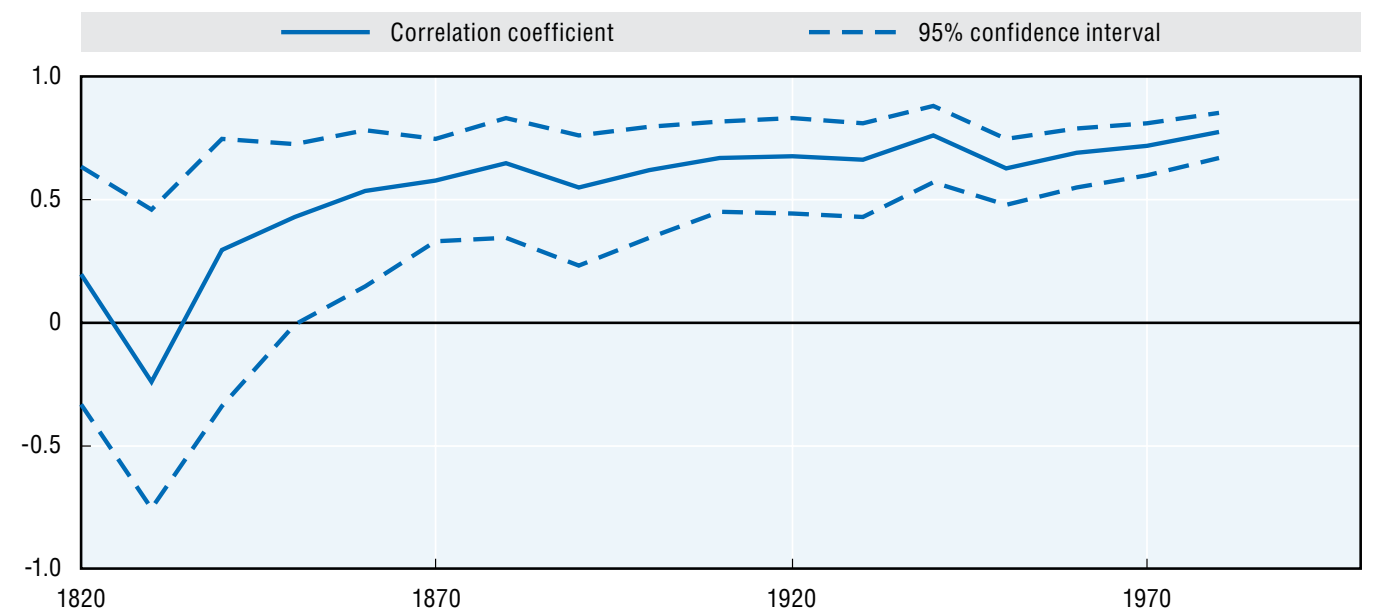

Note: For an assessment of data quality, see Table 7.1.

Source: Clio-Infra, www.clio-infra.eu.

\section{Figure 7.4. Variation in height and GDP per capita in selected countries, 1810s-2000s}

Coefficient of variation, including interpolated series, decadal averages

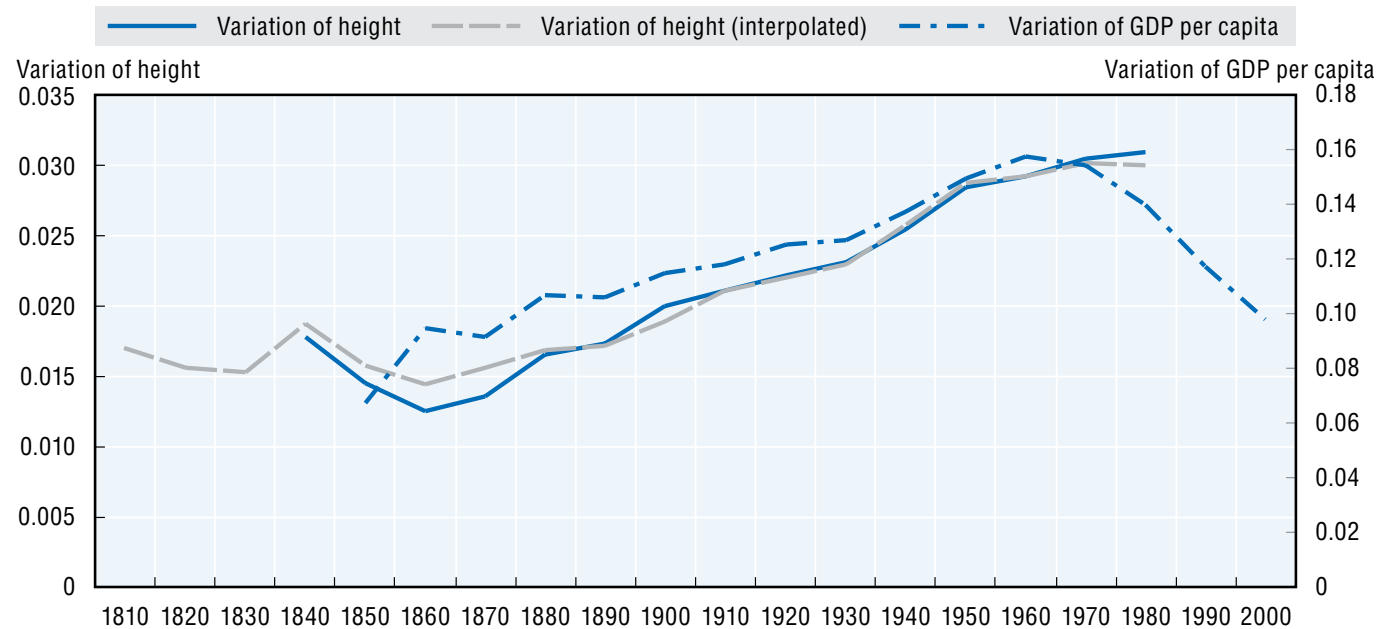

Notes: All values are weighted by population size. Height values are available between the 1840s and 1980s for 17 countries (1840s), 19, 21, 22, 23, 22, 23 (1900s), 25, 24, 22, 22, 23 (1950s), 23, 20, 19 (1980s). Interpolated height values are available: 22 for the 1810s-1850s, and 25 for 1860s-1980s. GDP values are available between the 1850s and 2000s for 18 countries (1850s), 16, 21, 16, 20, 19 (1900s), 21, 20, 20, 17, 23 (1950s), 23, 24, 23, 24, 24(2000s). For an assessment of data quality, see Table 7.1. In reproductions, please cite as Baten and Blum, 2014 (in: European Review of Economic History).

Source: Clio-Infra, www.clio-infra.eu. 


\section{Priorities for future research}

What should be the future priorities for the study of human stature as a development indicator? The greatest potential probably lies in extending the existing evidence back to preindustrial and ancient times. Steckel and Rose (2002) as well as Koepke and Baten (2005 and 2008) have pioneered the use of long bones for reconstructing height trends in those early periods of human development. The potential for mobilising additional data in this field is large. For example, the rapid construction of highways in China over the last decade has required numerous archaeological excavations. It seems that a large number of human bones were simply stored in buildings next to the highways and await more detailed analysis. Other countries in the Middle East, Central Asia, Eastern Europe and Southern Africa also have great potential for anthropometric analysis; both the tropics and subtropics might provide samples of long bones to study.

Another priority for further research could be to develop a measure of inequality based on long bone data, if income inequality measures to calibrate and compare these can be developed. Apart from projects for the pre-modern period, a number of gaps should be addressed by future research, such as the study of heights in the Middle East for the early 19th century or clarifying the selectivity of slaves relative to the population from which they were captured.

Finally, several gaps could be filled by developing a good model for the height selectivity of migrants. To what degree were migrants similar in height to their native population? If they were different, were the determinants of positive or negative height selectivity similar to the migrant selectivity of education (Borjas, 1987; Stolz and Baten, 2012)? Finally, studies on regional differences in height are required in the future, especially for the developing world. While this chapter has focused on national averages, regional variation within countries can sometimes be as large as international differences.

\section{Notes}

1. The third cohort analysed by Baten and Komlos (1998) refers to those who attained adulthood at some point between the 1970s and the present. Baten and Komlos (1998) also found that differences in the coefficient linking height and life expectancy among the three cohorts were negligible.

2. The term "biological standard of living" was coined by Komlos in 1985 . One of the rare exceptions to the height-longevity correlation is that of the relatively short, because protein-deprived, Japanese prior to the economic boom of the 1960s; their longevity was above average, thanks to the high value they put on personal hygiene, the importance of which was underscored by health-related instruction in the schools.

3. This implies that adult height data for the cohort born in the 1960 s should be confronted with indicators for other well-being dimensions referring to the 1960s, because height reflects the health situation in the first years after birth, and other well-being indicators (such as periodspecific mortality) reflect the situation when they are measured.

4. The criteria used to create the four classes of data differ from those used in other chapters, because height was never a part of official statistical reporting. Evidence is the product of: 1) international institutions, such as the Demographic and Health Surveys and the Eurostat compilations, which aimed at high standards of representativeness of their sampling procedures, or 2) economichistorical research that assessed the possibility of sample-selection bias in the sources by using secondary characteristics (such as comparing the occupational structure of samples with the occupational structure of representative censuses, or using numeracy for the same purpose, and re-weighting samples to become representative), or which relied on sources that are unlikely to have had sample selection bias, or 3) economic historical research, based on sources that could contain sample selection bias, or making use of indirect data and estimates, or 4) guesstimates, conjectures or interpolation between benchmark years. 
5. It is also reasonable to assume that a teenage conscript from a malnourished population has yet to reach his maximal height. In such a case, we calculate what their height will be when they reach adulthood by applying the method presented in Baten and Komlos (1998). See the notes to Table 1 in Baten and Komlos (1998).

6. The databases presented here were also corrected, to the extent possible, for other types of social, ethnic and regional biases.

7. One could imagine that height samples based on volunteer army records might also be affected by another type of sample selectivity: in fact, the preference for joining the military as an income opportunity will decline in times of war, but might increase in periods of high unemployment and low relative wages in the civilian sector. With respect to the first factor, this is because better-off (and taller) people might have avoided the risk of being killed in a war, and hence did not join the army during this period, whereas in peacetime some well-off people might have considered the army. With respect to the second factor, the social composition of those joining a voluntary army might have differed between prosperous and depressed periods. Among the poorer and less educated strata, a certain share might have always joined the army. Conversely, among the wealthier strata, one could imagine a higher share might have joined the army during bad times, because civilian jobs were less easy to obtain and poorly paid. Fortunately, less than $10 \%$ of global height samples in our database were derived from volunteer army or prison records (i.e. samples that were potentially selective). Height series estimated based on this type of source were carefully examined by comparing height series from other institutional contexts, or some other information in the sources (occupational structure, literacy, numeracy) was compared to census records of the time, in order to assess how representative the samples considered were. In order to mitigate the effects of labour markets at the time of recruitment (or war risk), anthropometric historians have used samples taken only in one or very few years that were homogenous in terms of the labour market and military situation.

8. Koepke and Baten $(2005,2008)$ and Stegl and Baten (2009) estimated average heights in such cases by using a large number of studies that reflect in sum the changes over time, because if a study was done in the 1940s, the birth decades of mostly the 1910s were covered, and if a study was done in the 1960s, the birth decades of the 1930s could be covered, and so on. It should also be noted that time trends that result from such estimations resemble moving averages in that they smooth out the evolution of height averages. For example, if there was a height decline among a given population during the 1880 s, but only $70 \%$ of the individuals in the dataset belonged to the 1880 s cohort (the remaining 30\% having been born in the previous cohort), the decline would appear to be smoother than it was in fact.

9. The coefficients were also small in most cases, with the exception of the coefficient for slave-based samples, which was however statistically insignificant. Thus, in the special case of slaves, it may very well be that an insufficient amount of data, for the purposes of comparison, accounts for the large coefficient. For other anthropometric studies, a very important result is that prisoners and voluntary soldiers did not differ significantly from other height sources - this had been an issue in many earlier studies.

10. The following review of the literature is based on Moradi and Baten (2005).

11. For the 1870s, GDP estimates are available for 21 countries, but for the 1880s only for 16 (including a number of poorer countries).

12. To compensate for such missing values, we applied the best possible interpolation strategy: wherever possible, we identified an estimated benchmark level for each country that allows obtaining levels close to true height values for the country to be interpolated. We then used the variation over time of other, nearby countries with similar characteristics. Linear interpolation was to be avoided, because of the risk that it might obscure certain fluctuations: for instance, declines that occurred in certain countries during the second half of the 19th century. Instead, we opted for backward- and forward-projection techniques, using the country-specific benchmark years and obtaining the changes between benchmark and estimated decades from a similar and neighbouring country. For example, the change from the 1870 s to the 1880 s in Iraq was more similar to the change in Iran over the same period than one would conclude from the results of a linear interpolation in Iraq between 1870 and 1890. Keeping the height level with the 1870 Iraq benchmark guarantees its accuracy. 


\section{References}

A'Hearn, B. (2003), “Anthropometric Evidence on Living Standards in Northern Italy, 1730-1860", Journal of Economic History, Vol. 63, pp. 351-381.

Austin, G., J. Baten and B. van Leeuwen, (2012), "The biological standard of living in early nineteenthcentury West Africa: new anthropometric evidence for northern Ghana and Burkina Faso", The Economic History Review, Vol. 65/4, pp. 1280-1302.

Austin, G., J. Baten and A. Moradi (2008), "Exploring the evolution of living standards in Ghana, 18802000: An anthropometric approach", Working paper, London School of Economics /Tuebingen/ Oxford.

Bassino, J.-P. (2006), "Inequality in Japan (1892-1941): Physical Stature, Income and Health", Economics and Human Biology, Vol. 4/1, pp. 62-88.

Bassino, J.-P. and P. Coclanis, (2008), "Economic transformation and biological welfare in colonial Burma: Regional differentiation in the evolution of average height", Economics and Human Biology, Vol. 6/2, pp. 212-227.

Baten, J. (2000), "Heights and real wages in the 18th and 19th centuries: an international Overview", Jahrbuch fuer Wirtschaftsgeschichte 2000-1, pp. 17-32.

Baten, J. and M. Blum (2012a), "Growing Tall but Unequal: New Findings and New Background Evidence on Anthropometric Welfare in 156 Countries, 1810-1989", Economic History of Developing Regions, Vol. 27/1.

Baten, J. and M. Blum (2012b), "An Anthropometric History of the World, 1810-1980: Did Migration and Globalization Influence Country Trends?” Journal of Anthropological Sciences, Vol. 90.

Baten, J. and M. Blum (2014): "Why are you tall while others are short? Agricultural production and other proximate determinants of global heights", European Review of Economic History (forthcoming 2014).

Baten, J. and S.A. Carson, (2010), "Latin American anthropometrics, past and present - An overview," Economics and Human Biology, Vol. 8/2, pp. 141-144.

Baten, J. and S. Hira, (2008), "Anthropometric Trends in Southern China, 1830-1864", Australian Economic History Review, Vol. 48/3, pp. 209-226.

Baten, J. and J. Komlos, (1998), "Height and the Standard of Living", Journal of Economic History, Vol. 57/3, pp. 866-870.

Baten, J., D. Ma, S. Morgan and Q. Wang (2010), "Evolution of Living Standards and Human Capital in China in the 18-20th Centuries: Evidences from Real Wages, Age-heaping, and Anthropometrics", Explorations in Economic History, Vol. 47/3, pp. 347-359.

Baten, J., and J. Murray (2000), Heights of Men and Women in Nineteenth Century Bavaria: Economic, Nutritional, and Disease Influences, Explorations in Economic History 37, pp. 351-369.

Baten, J., I. Pelger and L. Twrdek (2009), "The Anthropometric History of Brazil, Lima (Peru), and Argentina during the 19th and early 20th Century", Economics and Human Biology Vol. 7/4, pp. 319-333.

Baten, J., M. Stegl and P. van der Eng (2013), “The biological standard of living and body height in colonial and post-colonial Indonesia, 1770-2000", Journal of Bioeconomics, Vol. 15/2013, pp. 103-122.

Bielicki, T. and B. Hulanicka (1998), "Secular Trend in Stature and Age at Menarche in Poland" in Bodzar, B.E. and Susanne, C. (eds.) Secular Growth Changes in Europe, Budapest: Eötvös University Press, pp. 263-279.

Billewicz, W. Z. and McGregor, I. A (1982) “A Birth-to-Maturity Longitudinal Study of Heights and Weights in Two West African (Gambian) Villages 1951-1975", Annals of Human Biology, Vol, 9/ 4, pp. 309-320.

Blum, M. (2013), Cultural and genetic influences on the "Biological Standard of Living", Historical Methods, Vol. 46/1, pp. 19-30.

Bogin, B. and R. Keep (1998), "Eight Thousand Years of Human Growth in Latin America: Economic and Political History Revealed by Anthropometry", in J. Komlos, and J.Baten, (eds.), The Biological Standard of Living in Comparative Perspective Stuttgart, Steiner.

Borjas, G.J. (1987) "Self-Selection and the Earnings of Immigrants", The American Economic Review 77/4, pp. 531-553. 
Brennan, L., J. MacDonald and R. Shlomowitz (1994a), "The Heights and Economic Well-being of North Indians under British Rule”, Social Science History, Vol. 18, pp. 271-307.

Brennan, L., J. McDonald and R. Shlomowitz (1994b), "Trends in the economic well-being of South Indians under British rule: the anthropometric evidence", Explorations in Economic History, Vol. 31, pp 225-260.

Brennan, L., J. McDonald and R. Shlomowitz (1997), "Towards an anthropometric history of Indian under British rule," Research in Economic History, Vol. 17, pp. 185-246.

Brennan, L., J. McDonald and R. Shlomowitz (2000), "Change in the stature of North Indians from British rule", Jahrbuch für Wirtschaftsgeschichte, pp. 129-148.

Carson, S.A (2005), "The Biological Standard of Living in 19th Century Mexico and in the American West", Economics and Human Biology, Vol. 3/3, pp 405-419.

Carson, S.A. (2008), “The Stature and Body Mass of Mexicans in the Nineteenth-Century United States", The Journal of Interdisciplinary History, Vol. 39/2, pp. 211-232.

Costa, D.L. and R.H. Steckel (1997), "Long-term Trends in Health, Welfare, and Economic Growth in the United States", in Health and Welfare during industrialization, Richard H. Steckel and Roderick Floud (eds.), University of Chicago Press, Chicago.

De Beer, H. (2012), "Dairy products and physical stature: A systematic review and meta-analysis of controlled trials", Economics and Human Biology, Vol. 10/3, pp. 299-309.

Eksmyr, R. (1970), "Anthropometry in privileged Ethiopian preschool children", Acta Paediatrica Scandinavica, Vol. 59, pp. 157-163.

Eltis, D. (1982), "Nutritional Trends in Africa and the Americas: Heights of African, 1819-1839", Journal of Interdisciplinary History, Vol. 12, pp. 453-475.

Fiawoo, D.K. (1979), Physical Growth and the School Environment: A West African Example", in W. A. Stini ed., Physiological and Morphological Adaptation and Evolution, The Hague, 1979, pp. 301-314.

Floud, R. (1994), “The Heights of Europeans since 1750: A New Source for European Economic History", in J. Komlos (ed.) Stature, Living Standards, and Economic Development. Essays in Anthropometric History, University of Chicago Press, Chicago, pp. 9-24.

Floud, R., K.W. Wachter and A.S. Gregory (1990), Height, health and history: Nutritional status in the United Kingdom, 1750-1980, Cambridge University Press, Cambridge.

Fogel, R.W., S.L. Engerman and J. Trussell (1982), "Exploring the Uses of Data on Height: The Analysis of LongTerm Trends in Nutrition, Labor Welfare, and Labor Productivity”, Social Science History, Vol. 6, pp. 401-421.

Fogel, R. (1994), "Economic growth, population theory, and physiology: The bearing of long-term processes on the making of economic policy", American Economic Review, Vol. 84/3, pp. 369-395.

Floud, R. et al. (2011), The Changing Body: Health, Nutrition and Human Development in the Western World since 1700, Cambridge University Press, Cambridge.

Garcia, J. and C. Quintana-Domeque, (2007), "The evolution of adult height in Europe: a brief note", Economics and Human Biology Vol. 5, pp. 340-349.

Graitcer, P. and E. Gentry (1981), “Measuring Children: One Reference for All”, The Lancet 8 August 1981, pp. 297-299.

Grigg, D. (1995), “The Pattern of World Protein Consumption”, Geoforum, Vol. 26/1, pp. 1-17.

Guntupalli, A. (2005), "Essays on Indian Anthropometric Development”, Ph.D. dissertation, University of Tuebingen.

Guntupalli, A.M. and J. Baten (2006), “The Development and Inequality of Heights in North, West and East India, 1915-44", Explorations in Economic History, Vol. 43/4, pp. 578-608.

Habicht, J.-P. et al. (1974), "Height and Weight Standards for Preschool Children: How Relevant Are Ethnic Differences?", Lancet, Vol. 303/7858, pp. 611-615.

Harris, B. (1994), "Health, Height, and History: An Overview of Recent Developments in Anthropometric History", Social History of Medicine 7, pp. 297-320.

Hatton, T. and B.E. Bray (2010), "Long run trends in the heights of European men, 19th-20th centuries", Economics and Human Biology.

Hatton, T. (2014), "How have Europeans grown so tall?”, Oxford Economic Papers, Vol. 66(2), pp. 349-372. 
Honda, G. (1997), “Differential Structure, Differential Health: Industrialization in Japan, 1868-1940”, in Steckel, R. and Floud, R. (eds.), Health and Welfare during Industrialization, University of Chicago Press, Chicago.

Koepke, N. and J. Baten (2005), "The Biological Standard of Living in Europe during the Last Two Millennia", European Review of Economic History, Vol. 9/1, pp. 61-95.

Koepke, N. and J.Baten (2008), "Agricultural Specialization and Height in Ancient and Medieval Europe", Explorations in Economic History Vol. 45, pp. 127-146.

Komlos, J. (1985), "Stature and Nutrition in the Habsburg Monarchy: The Standard of Living and Economic Development in the Eighteenth Century", American Historical Review, Vol. 90/5, pp. 1149-61.

Komlos, J. (1998), "Shrinking in a Growing Economy? The Mystery of Physical Stature during the Industrial Revolution", The Journal of Economic History Vol. 58, pp. 778-95

Komlos, J. (2009), "Recent Trends in Height by Gender and Ethnicivity in the US in Relation to Levels of Income", NBER Working Paper 14635.

Komlos, J. and J. Baten (2004), "Looking Backward and Looking Forward: Anthropometric Research and the Development of Social Science History", Social Science History, pp. 1-24.

Komlos, J. and J. Baten (1998), The Biological Standard of Living in Comparative Perspective, Stuttgart.

Kopczynski, M. (2007). "Agrarian reforms, agrarian crisis and the biological standard of living in Poland, 1844-1892", Economics and Human Biology, Vol. 5, no. 3, pp. 458-470.

López-Alonso, M. and R.P. Condey, (2003), “The Ups and Downs of Mexican Economic Growth: the Biological Standard of Living and Inequality 1870-1950", Economics and Human Biology 1-2, pp. 169-186.

Maddison, A. (2001), The World Economy: A Millennial Perspective, Development Centre Studies, OECD Publishing, Paris, http://dx.doi.org/10.1787/9789264189980-en.

Margo, R. and R.H. Steckel (1983), "Heights of Native Born Northern Whites during the Antebellum Period", Journal of Economic History 43, pp. 167-74.

Martínez-Carrión, J.M.M. (1994), “Stature, Welfare, and Economic Growth, in Nineteenth-Century Spain: The Case of Murcia", in J. Komlos (ed.) Stature, Living Standards, and Economic Development. Essays in anthropometric History, University of Chicago Press, Chicago, pp. 76-92.

Martorell, R. and J.-P. Habicht, (1985) "Growth in Early Childhood in Developing Countries", in F. Falkner and J. M. Tanner (eds.), Human Growth: A Comprehensive Treatise, pp. 241-262.

Meisel, A. and M. Vega, (2005), “The biological standard of living (and its convergence) in Colombia, 1870-2003 A tropical success story", Economic and Human Biology, Vol. 5/1, pp. 100-122.

Mironov, B.N. (1999), "New Approaches to Old Problems: The Well-Being of the Population of Russia from 1821 to 1910 as Measured by Physical Stature", Slavic Review, Vol. 58/1, pp. 1-26.

Mironov, B.N. (2004), Zhiznennyi uroven' Sovetskoi Rossii pri Staline po antropometricheskim dannym. In: Ekonomicheskaia istoria. Ezhegodnik. Moskva: ROSSPEN, 2004. S. 565-588. [B. N. Mironov, "(The Nutrition Standard of Life in the Soviet Russia under Stalin on the Anthropometric Data)". in The Economic History. A Year-book, 2004, ROSSPEN, pp. 565-588: data on those measured 1927, born 1907. Author provided data.]

Mironov, B. and B. A'Hearn. (2008), “Russian Living Standards under the Tsars: Anthropometric Evidence from the Volga", Journal of Economic History, Vol. 68/3, pp. 900-929.

Moradi, A. (2005), “Height, Political Violence and Economic Development in Africa 1950-2000", Ph.D. thesis Tuebingen, available on University Library Tuebingen server.

Moradi, A. and A.M. Guntupalli (2014), "What Does Gender Dimorphism in Stature Tell Us About Discrimination in Rural India, 1930-1975?"Gender Bias: Health, Nutrition and Work.

Moradi, A. (2009a), “Towards an Objective Account of Nutrition and Health in Colonial Kenya: A Study of Stature in African Army Recruits and Civilians, 1880-1980", The Journal of Economic History 69, pp. 719-754.

Morgan, S. (2006), “The biological standard of living in South China during the 19th century: Estimates using data from Australian immigration and prison records", Paper prepared for the Asia/Pacific Economic and Business History Conference, QUT, Brisbane, 16-18 February 2006. 
Morgan, S. (2009), "Stature and economic development in South China, 1810-1880", Explorations in Economic History, Vol. 46/1, pp. 53-69.

Mosk, C. (1996), Making Health Work; Human Growth in Modern Japan, University of California Press, Oakland.

Murray, J.E. (2002), “Height and Weight of Early 20th Century Filipino Men”, Annals of Human Biology, Vol. 29/3, pp. 326-333.

Nafziger, E.W. (2012), Economic Development, 5th Edition, Cambridge University Press, Cambridge.

O’Rourke, K. and J. Williamson (1999), Globalization and History, Massachusetts Institute of Technology Press, Cambridge, Massachusetts.

Orr, J.B. and J.L. Gilks (1931), "Studies of Nutrition: The Physique and Health of Two African Tribes", Medical Research Council, Special Report Series No. 155. (Thanks to A. Moradi for providing this report.)

Osmani, S. and A. Sen (2003), "The hidden penalties of gender inequality: fetal origins of ill-health", Economics and Human Biology 1 (2003), pp. 105-121.

Pak, S., D. Schwekendiek and H.K. Kim, (2011), "Height and Living Standards in North Korea, 1930s-1980s", Economic History Review, Vol. 64, pp. 142-158.

Peracchi, F. (2008), "Height and Economic Development in Italy, 1730-1980", American Economic Review, Vol. 98/2, pp. 475-81.

Riley, J.C. (2005), Poverty and Life Expectancy: The Jamaica Paradox, Cambridge University Press, Cambridge.

Salvatore, R. and J. Baten (1998), "A Most Difficult Case of Estimation: Argentinian Heights, 1770-1840", in J. Komlos and J. Baten, (eds.) The Biological Standard of Living in Comparative Perspective, pp. 90-96, Franz Steiner,

Shay, T. (1994), “The level of Living in Japan, 1885-1938: New Evidence”, in: Komlos, J. (ed.) Stature, Living Standards, and Economic Development: Essays in Anthropometric History, University of Chicago Press, Chicago.

Singer, J. David and M. Small (1972), The Wages of War, 1816-1965: A Statistical Handbook. New York, www.correlatesofwar.org, accessed 31 March, 2010.

Steckel R.H. and R. Floud, eds. (1997), Health and Welfare during Industrialization, University of Chicago Press, Chicago.

Steckel, R. (2009), “Heights and human welfare: Recent developments and new directions", Explorations in Economic History, Vol. 46, pp. 1-23.

Steckel, R. and J. Rose (2002), The Backbone of History: Health and Nutrition in the Western Hemisphere, Cambridge University Press, Cambridge.

Stegl, M. and J. Baten (2009), "Tall and Shrinking Muslims, Short and Growing Europeans: an Anthropometric History of the Middle East, 1840-2007", Explorations in Economic History Vol. 46 (2009), pp. 132-148.

Stolz , Y. and J. Baten (2012), "Brain Drain in the Age of Mass Migration: Does Relative Inequality Explain Migrant Selectivity?”, Explorations in Economic History Vol. 49/2012, pp. 205-20.

Twrdek, L. and K. Manzel (2010), "The seed of abundance and misery: Peruvian living standards from the early republican period to the end of the guano era (1820-1880)", Economics and Human Biology, Vol. 8/2, pp. 145-152.

Vignerová, J. and P. Bláha (1998, “The Growth of the Czech Child During the Past 40 Years" in Bodzar, B.E. and Susanne, C., (eds.), Secular Growth Changes in Europe. Budapest, Eötvös University Press, pp. 263-279.

Wheatcroft, S.G. (1999), “The great leap upwards: anthropometric data and indicators of crises and secular change in Soviet welfare levels, 1880-1860", Slavic Review, Vol. 58/1, pp. 27-60.

Whitwell, G., C. de Souza and S. Nicholas (1997), "Height, Health, and Economic Growth in Australia, 1860-1940", in: Steckel, R.H. and Floud, R. (eds.) Health and Welfare during Industrialization, The University of Chicago Press, Chicago, pp. 379-422.

Zehetmayer, M. (2011), "The continuation of the antebellum puzzle: stature in the US, 1847-1894", European Review of Economic History, Vol. 15/2, pp. 313-327. 



\title{
Chapter 8
}

\section{Personal security since 1820}

\author{
by \\ Joerg Baten, University of Tuebingen, \\ and
}

Winny Bierman, Peter Foldvari, and Jan Luiten van Zanden, Utrecht University

Personal security reflects a crucial component of well-being. This chapter relies on homicide rates (the number of intentional deaths per 100000 inhabitants) to trace changes of violence in time and space. It finds that Western Europe was already quite peaceful from the 19th century onwards, but homicide rates in the United States have been high by comparison. Large parts of Latin America and Africa are also violent crime "hotspots", and so is the former Soviet Union (especially since the fall of communism), while large parts of Asia show low homicide rates. Homicide rates are in general negatively correlated with GDP per capita - the richer a country, the lower the level, but there are important exceptions. In addition, the chapter describes changes in the probability that a random individual lives in a country experiencing an armed internal or external conflict. 


\section{Introduction}

Personal security is a very important component of well-being. Security is not only reduced by poor health or poverty - which are examined in separate chapters in this volume - but also by serious crime, war and other large-scale conflicts. These pose potentially important threats to people's security, hence recent trends in homicide rates, for example, have received great attention by the general public (UNOCD, 2011). Other threats to personal health and life cannot be studied with consistency using the currently available data. For example, consistent evidence is not available on terrorism, environmental hazards or work accidents for the 19th and early 20th century - at least not on a global scale.

People's well-being is certainly higher if they do not fear becoming a victim of crime, especially a serious crime like homicide. Nor does a person have to be a direct victim of a crime to be affected: if a close relative or friend is a victim, this invariably has a disastrous influence on that individual's welfare (OECD, 2011). A change in crime level may also have a significant impact on well-being; a rise in violent crime, even if the absolute level is still relatively low, may contribute to feelings of insecurity when this receives a lot of media coverage. On the other hand, a declining crime level may lead people to have greater trust that the government is effective in its actions. There are striking patterns here: Western Europe was already quite peaceful from the 19th century onwards, for example, while homicide rates in the United States were, and remain, high by comparison.

Why focus on this type of crime and not others? Development specialists as well as historians of crime have studied homicide rates more often than other crimes for a number of reasons:

- Homicide is relatively clearly defined, whereas most other crimes were interpreted and counted differently in various cultures and periods.

- The degree of measurement error is hence probably lower than for other crimes.

- Social differences for this type of crime are comparatively modest. All social groups are affected by this type of crime, although poorer social strata are more likely to be victims.

- Homicide is a very important crime - for the victim, for the offender, and for the public, which might consequently invest large resources to detect and prevent it.

- Earlier studies have argued that other violent crimes tend to be correlated with homicide rates (OECD, 2011).

Apart from the focus on this main indicator of personal security, the homicide rate, the chapter also examines the incidence of civil war and of war between countries. Both events obviously present large risks for personal security and individual survival. For 
both kinds of large-scale conflicts, it would be ideal to know the number of victims per capita. However, this level of detail is not available for many countries in early periods. In particular, in the 19th century the developing countries did not have consistent statistics on deaths from large-scale conflict. Hence, in order to obtain consistent information also on the earlier periods and poorer countries, we estimate the probability that an individual living in a particular country is affected by a large-scale conflict (war or civil war) in a given decade, and aggregated this by world region.

\section{Description of the concepts used}

We use the official definition of intentional homicide as "unlawful death deliberately inflicted on one person by another person" (OECD, 2011). ${ }^{1}$ This excludes inter-state warrelated killing, because soldiers at least are legitimised to kill each other in such situations. The victims of the civilian population killed in inter-state war-related activities are traditionally also excluded from homicide rates, as are victims of civil war, even if this might not be clear a priori from the definition above. This makes it even more important to consider these three indicators - victims of homicide, of external conflict and of internal conflict - together. As the population size is obviously important for the number of homicides, the ratio of homicides per 100000 inhabitants is calculated. The large size of the denominator already indicates that homicide is a rare crime in most societies, even in historical periods (OECD, 2011).

The Conflict Catalog by Peter Brecke (1999) is the data source used for large-scale conflicts, which are conflicts with 32 or more deaths. It is not the only data source that covers the entire period studied here, but it has the advantage of including all major conflicts both between and within countries. Other datasets, such as the UNDP/PRIO database, include only conflicts with more than 1000 casualties (Blattman and Miguel, 2010). Another high-quality alternative data source is the Correlates of War (http://www.correlatesofwar. org/), which covers the sample period and also has more data on the number of casualties than the Conflict Catalogue. However, these are battle casualties and as a result strongly underestimate total fatalities. ${ }^{2}$

Brecke's Conflict Catalog includes data on 3213 internal (revolutions, rebellions, civil wars and unrest, ethnic cleansings) and external conflicts (wars, interventions) from 1400 to 2000. The original dataset does not make an explicit distinction between internal and external conflicts. This distinction was made by the authors based on the catalogue's description, complemented by online information sources. This resulted in two binary datasets, where a country that was involved in a conflict in a given year is assigned the value one, and zero otherwise. A country was classified as a participant in an external conflict if it was either officially at war, or if it actively participated in a conflict by sending troops. As a result, even if a country was involved in a conflict, it is possible that its territory was relatively safe (like Canada or Australia during the Second World War). The same bias does not apply for internal conflicts, which all happened on the country's own soil.

Table 8.1 described the concepts and sources for the three types of threats to personal security that are considered in this chapter. 
Table 8.1. Indicators of personal security used

\begin{tabular}{|c|c|c|}
\hline Concept & Description & Sources \\
\hline Homicide & $\begin{array}{l}\text { Unlawful death deliberately inflicted on one person by } \\
\text { another person }\end{array}$ & Various, see text; sample period $1820-2010$. \\
\hline Internal conflict & $\begin{array}{l}\text { Armed conflicts that took place within a single country, } \\
\text { like revolutions, uprisings, civil wars or unrests; also } \\
\text { genocides and political cleansings are identified as } \\
\text { internal conflicts. } \\
\text { Armed conflicts in which at least two countries were } \\
\text { involved. Any country that was officially involved in the } \\
\text { conflict is classified as participant, regardless of the } \\
\text { geographical location of actual combat zones. }\end{array}$ & $\begin{array}{l}\text { Conflict Catalog by Peter Brecke (Brecke 1999). The data } \\
\text { is based on secondary sources, like historical atlases, } \\
\text { monographs, articles, encyclopedias. While the original } \\
\text { dataset covers } 1400-2000 \text {, we only use the post } 1820 \\
\text { period. }\end{array}$ \\
\hline
\end{tabular}

\section{Historical sources}

The most important source for contemporary homicide rates is UNODC statistics, which cover the period from the 1950s to the present, but with very uneven coverage of countries and world regions. The most important dataset that incorporates the UNODC statistics, supplemented with a large number of historical time series, is the Comparative Homicide Time Series (CHTS) dataset, which was put together by Martthi Lehti and Tapio Lappi-Seppälä (from the Finnish National Research Institute of Legal Policy [NRILP]). This integrates the available time series from various international agencies (including WHO) and the available historical work on homicide rates in a consistent framework, and is therefore a very valuable source for this chapter. As explained in the introduction to the NRILP-CHTS dataset, the researchers tried as much as possible to rely on public health statistics (cause-of-death data) and criminal justice data, and (as a last resort) digital media sources have been used to supplement the time series (Lehti, 2013). The second important source of historical data is the Historical Violence Database, which is the product of an interdisciplinary project that focused on the history of violence (http://cjrc. osu.edu/research/interdisciplinary/hud). Moreover, we would like to mention the historical research carried out by Manuel Eisner, who has charted, for parts of Europe, the longterm evolution of this form of violent crime since the late Middle Ages and constructed national time-series of homicide rates covering 17 European countries over a period of 160 years, from 1840 to the present. Eisner collected these estimates from three sources: previous publications, official statistical publications, and by approaching scholars and statistical offices for specific data (Eisner, 2008). Finally, we have scanned a large number of historical sources and studies to extend the dataset, in particular for the pre-1950 period.

To construct homicide rates, basically two sources can be used: data from criminal justice records (courts, police) and data from public health statistics (based on the causes of death statistics). For some countries both sources are available, demonstrating small differences in coverage. Mortality or public health statistics are considered more reliable than criminal justice statistics for two reasons. First, because there are simply more historical public health data available than there are criminal justice data, and second, because the criteria used to determine cause of death and the legal definition of homicide are less fickle in the public health statistics (Eisner, 2008, p. 293). We therefore expect that 
criminal records are more likely to underestimate the actual numbers of homicides than mortality statistics, but for the recent period the differences are on average small and in the opposite direction. For a sample of 26 countries for which we have data from both sources, we calculated an average homicide rate based on criminal records of 14.2 per 100000 population, and based on death statistics of 12.6 per 100000 , but reassuringly the coefficient of correlation between both samples was as high as $0.98 .{ }^{3}$ For the recent period, police statistics for Western Europe sometimes show higher homicide rates than do the medical statistics, because foreigners who are killed in a Western European country show up in the police records, but not in the medical statistics (because these refer often to the country of citizenship, not to the country in which the homicide took place). Globalisation and international integration also affects the "landscape of murder".

Thanks to the existence of a considerable body of scholarly work, long-term time series are available for some countries, especially in Western Europe and North America. However, in other countries the documentation before 1950 is limited. Hence, the availability of data varies among world regions. Western Europe and European settlements have been the object of homicide studies even for the period before 1950. Evidence for other world regions is mostly limited to the post-1950 period, but we were able to compile some earlier evidence for a small number of countries in Latin America (Brazil), Asia (Sri Lanka, Japan) and Africa (South Africa).

The sources for Brecke's Conflict Catalog include secondary literature, monographs, articles, encyclopaedias and historical atlases. The dataset employs non-English sources as well, notably in Chinese, Japanese and Russian. The detailed list of sources can be found in the appendix of Brecke (1999). The catalogue is still being expanded to add new variables.

\section{Data quality}

\section{Homicide rates}

Three issues should be kept in mind when interpreting historical homicide rates:

\section{Do homicide data represent overall crime rates?}

Homicide, when compared with other crimes such as contact or property crimes, is a crime that does not occur very often. This leaves the question of whether homicide rates can be used as an indicator for overall crime rates in a given society. As already explained, homicide rates are an accepted indicator of overall violence in modern countries. The OECD How's Life? report states:

There is a strong correlation between the number of international homicides and the percentage of people who declare having been assaulted [... and the] child death rate due to negligence, maltreatment or physical assault. [...] OECD countries with high homicide rates also experience

high levels of physical assault, both inside and outside the household. This suggests that we can talk about an "overall level of crime/insecurity" experienced by society (OECD, 2011, 250).

However, this does not mean that homicide rates and overall rates of violence always correlate; it is possible that over time and between different places the level of correspondence varies. To examine whether any correlation exists between homicide rates and rates of other types of crime, data are needed for both the homicide rates and the rates for other crime; unfortunately, the figures on other types of crime are usually not 
available (but see Tornu, 2013, for an analysis of trends in other kinds of crime). As Eisner mentioned, an attempt had been made - by Petri Karonen - to measure the correlation between homicide and other types of violence in the past. In the case of some Swedish cities, there seems to have been a link in the 16th and 17th centuries (Eisner, 2003, p. 94) However, this does not mean that the trends in homicide rates have always reflected overall crime rates. Using homicide rates as an indicator for overall crime rates is therefore not without difficulties.

\section{How big is the "dark figure"?}

There is always a question as to how many homicides are not reported and recorded. The homicide rates that are available have come to the attention of the police and/or the medical officials, but murders may go unrecorded. As can be imagined, retrieving useful and accurate sources becomes more difficult the further back in time one goes. The availability and quality of data are also lower in the case of present-day low-income countries (Eisner, 2012, p. 3). The probability of a large "dark figure" can also be influenced by the forensic technologies present in a society. To give an example, Eisner has noted that infanticide in 19th century Europe has probably been underestimated in the data because it was easy to disguise and difficult to prove (Eisner, 2008, p. 293).We therefore consider all our homicide rates as lower bound estimates.

\section{How reliable are the available data?}

Time series of official homicide rates have their limitations. As mentioned above, how crimes are recorded can differ between different periods, especially in the case of criminal justice records. Eisner has given the example of "the legal definition of 'infanticide', which varies significantly between countries and over time. Some countries subsume it under murder and manslaughter, others have specific provisions but with varying content. In contrast, the statistical definition as the intentional killing of a child below age one is much more universally applicable" (Eisner, 2008, p. 293). Furthermore, what is perceived as homicide can change over time, and can also differ between societies. For example, the estimate of the homicide rate can become problematic during times of civic or political unrest, war or genocide. The bureaucratic system may not be in the best state to record homicides. Moreover, it may become difficult to determine the cause of death during a war or genocide (Eisner, 2012). ${ }^{4}$ Another limitation is that the available estimates for historic societies are often based on case studies on a small geographical scale, and not on national sources. The representativeness of these local studies for entire countries is questionable. National estimates for modern states can also hide regional and even local differences in homicide rates.

A more technical bias is the change in the lethality of violence over time. The share of persons dying from the same type of severe violence has declined substantially during the last 200 years (OECD, 2011: 248, citing Aebi, 2004). Medicine could not do much to help victims of violence until the early 19th century. After this, a modest increase in survival rates set in. After the 1970s and especially after the widespread use of cell phones (which reduced the time until an emergency team would appear), the share of deaths following heavy violence declined. This obviously creates a small downward bias in the long-term estimates. Table 8.2 provides an overall assessment of the quality of the data on homicides used in this chapter. 


\section{Internal and external conflicts}

For civil wars, the scholarly discussion of data limitations and comparability issues fills entire bookshelves. We have already mentioned some of the main problems: countries may be involved with large-scale external conflicts without this having a large effect on the population's well-being (in particular when wars are fought on foreign soil), and the scale of conflicts are not taken into account. For example, the Taiping rebellion with its perhaps 20 million casualties has the same "value" as the Spartacist revolt in Germany in 1919 with 119 victims. Unfortunately, we lack the systematic data to control for this. The sources include secondary literature, monographs, articles, encyclopaedias and historical atlases. One should bear in mind that only those conflicts are included that have been recorded, which makes it likely that the number of conflicts will be underestimated as we head back in time, and especially for pre-1870s Africa. In addition, changes in borders are likely to introduce an error in the calculation since population data are available only for current borders, while conflict data is based on historical (changing) borders. Since there were fewer countries in the 19th century than in the 20th, we can expect that this also introduces a bias in the trend for the 19th century.

Table 8.2. Quality of data on homicide rates by region and benchmark year, 1820-2008

\begin{tabular}{ccccccccc}
\hline & & \multicolumn{9}{c}{$\begin{array}{c}\text { Latin } \\
\text { America } \\
\text { Western } \\
\text { Europe } \\
\text { (WE) }\end{array}$} & $\begin{array}{c}\text { Eastern } \\
\text { Europe } \\
\text { (EE) }\end{array}$ & $\begin{array}{c}\text { Western } \\
\text { Offshoots } \\
\text { (W0) }\end{array}$ & $\begin{array}{c}\text { Caribbean } \\
\text { (LA) }\end{array}$ & $\begin{array}{c}\text { Sub-Saharan } \\
\text { Africa } \\
\text { (SSA) }\end{array}$ & $\begin{array}{c}\text { Middle East } \\
\text { and } \\
\text { North Africa } \\
\text { (MENA) }\end{array}$ & $\begin{array}{c}\text { East Asia } \\
\text { (EA) }\end{array}$ & $\begin{array}{c}\text { South and } \\
\text { Asia } \\
\text { (SSEA) }\end{array}$ \\
\hline 1820 & 3 &.. &.. &.. & 4 &.. &.. &.. \\
1870 & 3 &.. &.. & 3 &.. &.. &.. &.. \\
1913 & 1 & 1 & 1 & 1 &.. &.. & 1 & 1 \\
1950 & 1 & 1 & 1 & 1 &.. &.. & 1 & 1 \\
1973 & 1 & 1 & 1 & 1 & 1 & 1 & 1 & 1 \\
2008 & 1 & 1 & 1 & 1 & 1 & 1 & 1 & 1 \\
\hline
\end{tabular}

Note: 1. High quality; 2. Moderate quality; 3. Low quality; and 4. Estimates. See the section on "Data Quality" in Chapter 1 for a description of the quality criteria.

Source: Clio-Infra, www.clio-infra.eu.

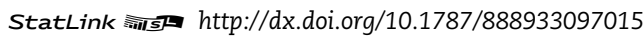

\section{Main highlights of trends in personal security}

\section{Homicide rates}

Historical research on long-term trends in crime has focused very much on the spectacular decline of the homicide rate in Western Europe since the late Middle Ages (Eisner, 2003; Spierenburg, 2008). In the 13th-15th centuries, homicide rates of between 30 and 50 per 100000 were usual - and the rate may have been even higher in Italy - but from the 16th century onwards all regions for which data are available registered a sharp long-term decline (see Table 8.3). In North-western Europe, this continued until the start of the 20th century, at which point the homicide rate had fallen to about 1 per 100000 . In Italy (and probably also in Eastern Europe, for which historical data are much scarcer), the decline was less dramatic, but it eventually reached about the same levels as in Western Europe (Table 8.3). The literature discussing the reasons for this pacification of Western 
Table 8.3. Long-term development of homicide rates in Europe, 13th-20th centuries Homicides per 100000 inhabitants

\begin{tabular}{|c|c|c|c|c|c|}
\hline & England & $\begin{array}{l}\text { Netherlands } \\
\text { and Belgium }\end{array}$ & Scandinavia & $\begin{array}{c}\text { Germany } \\
\text { and Switzerland }\end{array}$ & Italy \\
\hline 13th-14th centuries & 23 & 47 & .. & 37 & (56) \\
\hline 15th century & .. & 45 & 46 & 16 & (73) \\
\hline 16th century & 7 & 25 & 21 & 11 & 47 \\
\hline \multicolumn{6}{|l|}{ 17th century: } \\
\hline first half & 6 & (6) & 24 & 11 & (32) \\
\hline second half & 4 & 9 & 12 & (3) & .. \\
\hline \multicolumn{6}{|l|}{ 18th century: } \\
\hline first half & 2 & 7 & 3 & (7) & (12) \\
\hline second half & 1 & 4 & 0.7 & (8) & 9 \\
\hline $1800-1824$ & 2 & 2 & 1 & 3 & 18 \\
\hline $1825-49$ & 1.7 & .. & 1.4 & 4 & 15 \\
\hline $1850-74$ & 1.6 & 0.9 & 1.2 & 2 & 12 \\
\hline $1875-99$ & 1.3 & 1.5 & 0.9 & 2.2 & 5.5 \\
\hline $1900-1924$ & 0.8 & 1.7 & 0.8 & 2 & 3.9 \\
\hline $1925-49$ & 0.8 & 1.3 & 0.6 & 1.4 & 2.6 \\
\hline $1950-74$ & 0.7 & 0.6 & 0.6 & 0.9 & 1.3 \\
\hline $1975-94$ & 1.2 & 1.2 & 1.2 & 1.2 & 1.7 \\
\hline
\end{tabular}

Note: For an assessment of data quality, see Table 8.2.

Source: Eisner, M. (2003), "Long-term historical trends in violent crime", Crime and Justice; A Review of Research, Vol. 30, pp. 83-142, table 1.

Europe points to various forces behind the decline, such as the process of state formation, resulting in the monopolisation of violence by the state, and changes in modes of behaviour and legal codes (in the tradition of Elias, called "civilisation"), which resulted in less violent methods of conflict resolution (Spierenburg, 2008; Pinker, 2011).

A similar decline occurred in the United States, but, due to the different "starting condition", the levels of violence were much higher there than in Western Europe, and the gap persisted into the 20th and even the 21st century. Whereas in Western Europe during the 20th century the homicide rate fluctuated between 0.5 and 2 per 100000 , it ranged from about 5 to 10 in the US, without showing a clear trend towards converging to the European level (see Figure 8.1 below). The "divergent" development of violence in the United States is one of the puzzles of historical criminological research. As Figure 8.1 shows, other Western Offshoots such as Canada and Australia, with potentially similar frontier legacies, converged to the European levels well before 1950, but the United States persisted on its own trajectory. One interpretation is that "democracy came too early" (Spierenburg, 2006). Whereas in Europe the state first disarmed the population, and then became democratic, in the United States democracy preceded the creation of a monopoly of violence, which made it almost impossible to ban or suppress gun ownership. Figure 8.1 also highlights the rise in crime during the 1960s and early 1970s, which was strongest in the United States but also occurred in many other countries. Homicide rates from a sample of 16 major European 
Figure 8.1. Homicide rates in selected Western countries, 1950-2010

Homicides per 100000 inhabitants

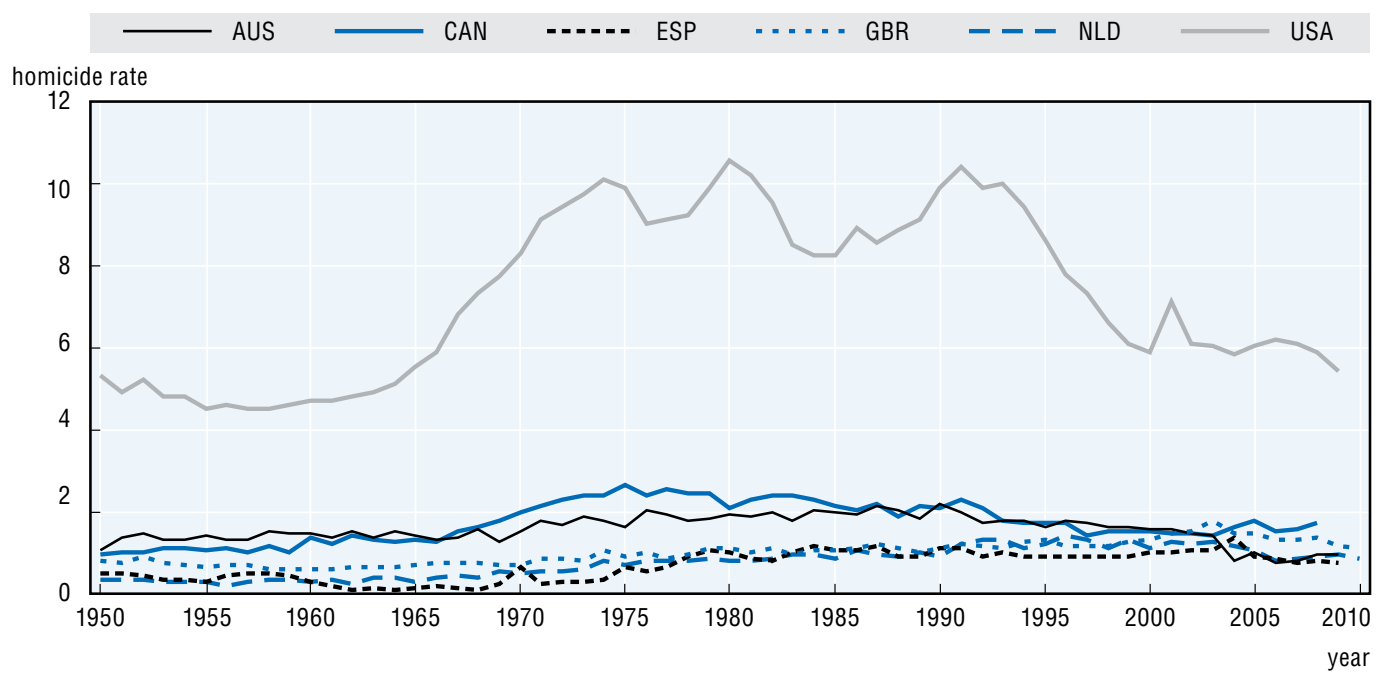

Note: For an assessment of data quality, see Table 8.2.

Source: Clio-Infra, www.clio-infra.eu.

countries almost doubled between the 1960s and 1990s (from 0.84 to 1.56 per 100 000), but fell again thereafter (to 1.31 in the next decade). The rise was particularly strong in the United Kingdom and Ireland, where homicide rates roughly doubled between the 1970s and 2000s, whereas France and Germany saw almost no increase. Italy, Spain and Sweden saw increases of around 50\% (Spierenburg, 2008).

This crime "bulge", also noticeable in other crime and violence-related statistics, has been linked to the anti-authoritarian "liberation" of the 1960s, to demographic changes (going through the post-war population explosion), to weapons laws, and to the rise of organised crime and the trade in drugs (Pinker, 2011; Spierenburg, 2008). Eastern Europe saw a similar, but even more extreme increase in crime after the collapse of communism in the early 1990s. Homicide rates in Russia rose from the already high level of 9.8 per 100000 in 1988 to 32.4 in 1994, but declined afterwards to the still rather high level of 15.1 in 2009. In the much more peaceful Poland the figures for the same years are 1.8 (1988), 3.0 (1994 also the peak in the Polish series) and 1.1 (2009) (see also Table 8.6).

Western Europe may have seen a similar "bulge" of crime earlier, as the long-run series of Sweden illustrates. During the first stage of industrialisation - between 1750 and 1830 - there was probably a comparable rise in homicides, perhaps also linked to the "liberal" ideas of the Enlightenment. That period was also characterised by the - heavily debated - concept of the "first sexual revolution", because of the rise in the number of illegitimate births (Shorter 1972, Kok 1991). But this period of increased "deviant" behaviour (also known at the time as a version of the "social question") was soon followed by renewed processes of social integration. However, improvements in recording techniques can also potentially explain a part of the increase in homicides.

The huge decline of criminal violence in Western Europe has been the topic of some debate. It plays a large role in Stephen Pinker's book, The Better Angels of our Nature, in which he develops the idea of an overall decline in violence in the past hundreds of 
years; the argues that other forms of violence (war, genocide, the death penalty) also show a somewhat similar decline, in particular when measured on a per capita basis. Pinker (2011) identifies five causes of this increased security: the rise of the modern nation-state, with its monopoly of violence; commercial and economic development that enhance the peaceful coexistence of nations; an increased respect for the interest and values of women; "cosmopolitarianism", resulting from increased literacy and the development of the media; and finally, the increased role of reason in interpersonal and international exchanges. It is indeed striking that the decline of the homicide rate started relatively early in the part of Europe that experienced the earliest development of the nation-state - following in the wake of the Reformation, with its stress on literacy (to read the Bible) - and an equally early commercialisation of economic life.

Contemporary world maps of the homicide rate also show the very low levels of criminal violence in Western Europe (see Figure 8.2). When moving away from the North Sea, one finds higher levels of violence in Eastern Europe (where an "eruption" of violence happened after the collapse of communism), in the southern margins of Europe, and in particular when crossing the Mediterranean into Africa and parts of the Middle East (but statistics may be misleading here: as already mentioned, Iraq, for example, has a strikingly low homicide rate, which apparently excludes the impact of terrorism and clan warfare). The "darkest" regions in the world - those with the lowest levels of personal security - are clearly Central and Southern Africa, Latin America (the Colombia/Venezuela region having the highest rates during this period), and Russia, while Afghanistan and Burma stand out within Asia.

Our data add historical perspective to this global map of crime (Tables 8.4-8.6). Because the number of countries on which the regional averages are based varies, trends are sometimes difficult to interpret. We have already sketched the most significant trends: the gap between the Western Offshoots (dominated by the US) and Western Europe; the

Figure 8.2. Worldwide homicide rates, 2000-2009

Homicides per 100000 inhabitants

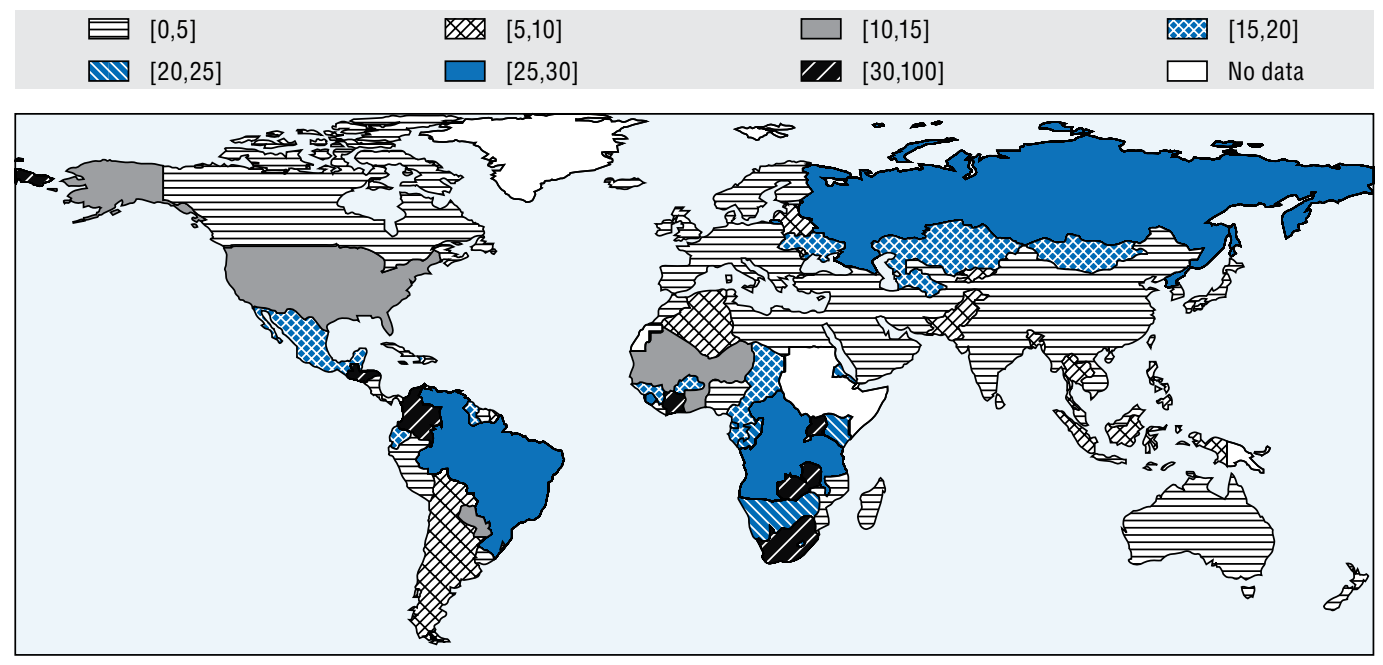

Note: For an assessment of data quality, see Table 8.2.

Source: Clio-Infra, www.clio-infra.eu. 
Table 8.4. Regional averages of homicide rates, 1820s-2000s

Homicides per 100000 inhabitants, decadal averages

\begin{tabular}{|c|c|c|c|c|c|c|c|c|c|}
\hline & $\begin{array}{c}\text { Western } \\
\text { Europe } \\
\text { (WE) }\end{array}$ & $\begin{array}{c}\text { Eastern } \\
\text { Europe } \\
(\mathrm{EE})\end{array}$ & $\begin{array}{l}\text { Western } \\
\text { Offshoots } \\
\text { (W0) }\end{array}$ & $\begin{array}{c}\text { Latin } \\
\text { America } \\
\text { and } \\
\text { Caribbean } \\
\text { (LA) }\end{array}$ & $\begin{array}{c}\text { East Asia } \\
(E A)\end{array}$ & $\begin{array}{c}\text { South and } \\
\text { South-East } \\
\text { Asia } \\
\text { (SSEA) }\end{array}$ & $\begin{array}{l}\text { Middle East } \\
\text { and } \\
\text { North Africa } \\
\text { (MENA) }\end{array}$ & $\begin{array}{l}\text { Sub-Saharan } \\
\text { Africa } \\
\text { (SSA) }\end{array}$ & World \\
\hline 1820s & 3.5 & .. & .. & .. & .. & .. & .. & .. & .. \\
\hline $1830 \mathrm{~s}$ & 3.4 & .. & .. & .. & .. & .. & .. & .. & .. \\
\hline $1840 \mathrm{~s}$ & 3.4 & .. & .. & .. & .. & .. & .. & .. & .. \\
\hline $1850 \mathrm{~s}$ & 3.0 & .. & .. & .. & .. & .. & .. & .. & .. \\
\hline $1860 \mathrm{~s}$ & 2.9 & .. & .. & .. & .. & .. & .. & .. & .. \\
\hline $1870 \mathrm{~s}$ & 2.7 & .. & .. & .. & .. & .. & .. & .. & .. \\
\hline $1880 \mathrm{~s}$ & 2.5 & .. & .. & .. & .. & .. & .. & .. & .. \\
\hline 1890s & 2.4 & .. & .. & .. & .. & .. & .. & .. & .. \\
\hline $1900 \mathrm{~s}$ & 2.2 & .. & 2.5 & .. & .. & .. & .. & .. & .. \\
\hline 1910s & 2.1 & .. & 5.5 & .. & .. & .. & .. & .. & .. \\
\hline $1920 \mathrm{~s}$ & 2.2 & .. & 7.2 & .. & .. & .. & .. & .. & .. \\
\hline $1930 \mathrm{~s}$ & 1.4 & .. & 7.3 & .. & .. & .. & .. & .. & .. \\
\hline $1940 \mathrm{~s}$ & 1.5 & .. & 5.2 & .. & .. & .. & .. & .. & .. \\
\hline $1950 \mathrm{~s}$ & 1.1 & .. & 4.3 &.. & .. & 2.8 & .. & .. & .. \\
\hline $1960 \mathrm{~s}$ & 0.9 & .. & 5.1 & 12.4 & .. & 3.2 & .. & .. & .. \\
\hline 1970s & 1.1 & .. & 8.2 & 11.9 & .. & 4.0 & .. & .. & 9.4 \\
\hline $1980 \mathrm{~s}$ & 1.3 & 6.4 & 8.0 & 16.9 & .. & 4.6 & .. & .. & 7.3 \\
\hline 1990s & 1.4 & 13.6 & 7.5 & 21.3 & .. & 5.1 & .. & .. & 7.6 \\
\hline $2000 \mathrm{~s}$ & 1.2 & 11.8 & 5.3 & 20.8 & 1.8 & 4.6 & 2.2 & 19.3 & 6.9 \\
\hline
\end{tabular}

Note: For an assessment of data quality, see Table 8.2.

Source: Clio-Infra, www.clio-infra.eu.

StatLink तiाlst http://dx.doi.org/10.1787/888933097053

Table 8.5. Number of countries in the homicide dataset by region and decade, $1820 \mathrm{~s}-2000 \mathrm{~s}$

\begin{tabular}{|c|c|c|c|c|c|c|c|c|}
\hline & $\begin{array}{l}\text { Western Europe } \\
\text { (WE) }\end{array}$ & $\begin{array}{c}\text { Eastern Europe } \\
\text { (EE) }\end{array}$ & $\begin{array}{l}\text { Western } \\
\text { Offshoots } \\
\text { (WO) }\end{array}$ & $\begin{array}{l}\text { Latin } \\
\text { America } \\
\text { and } \\
\text { Caribbean } \\
\text { (LA) }\end{array}$ & $\begin{array}{l}\text { East Asia } \\
\text { (EA) }\end{array}$ & $\begin{array}{c}\text { South and } \\
\text { South-East Asia } \\
\text { (SSEA) }\end{array}$ & $\begin{array}{l}\text { Middle East } \\
\text { and } \\
\text { North Africa } \\
\text { (MENA) }\end{array}$ & $\begin{array}{c}\text { Sub-Saharan } \\
\text { Africa } \\
\text { (SSA) }\end{array}$ \\
\hline $1820 \mathrm{~s}$ & 10 & 0 & 0 & 0 & 0 & 0 & 0 & 1 \\
\hline $1830 \mathrm{~s}$ & 10 & 0 & 0 & 1 & 0 & 0 & 0 & 0 \\
\hline $1840 \mathrm{~s}$ & 10 & 0 & 0 & 1 & 0 & 0 & 0 & 0 \\
\hline 1850 s & 11 & 0 & 0 & 1 & 0 & 0 & 0 & 0 \\
\hline $1860 \mathrm{~s}$ & 12 & 0 & 0 & 1 & 0 & 0 & 0 & 0 \\
\hline 1870 s & 13 & 0 & 0 & 1 & 0 & 0 & 0 & 0 \\
\hline $1880 \mathrm{~s}$ & 13 & 1 & 0 & 1 & 1 & 1 & 0 & 0 \\
\hline $1890 \mathrm{~s}$ & 12 & 0 & 0 & 0 & 2 & 1 & 0 & 0 \\
\hline $1900 \mathrm{~s}$ & 12 & 0 & 2 & 1 & 2 & 1 & 0 & 1 \\
\hline $1910 \mathrm{~s}$ & 12 & 0 & 3 & 1 & 2 & 1 & 0 & 1 \\
\hline $1920 \mathrm{~s}$ & 14 & 3 & 4 & 1 & 1 & 1 & 0 & 0 \\
\hline $1930 \mathrm{~s}$ & 14 & 2 & 4 & 1 & 1 & 1 & 0 & 0 \\
\hline $1940 \mathrm{~s}$ & 13 & 2 & 4 & 4 & 1 & 1 & 1 & 1 \\
\hline $1950 \mathrm{~s}$ & 19 & 3 & 4 & 14 & 2 & 5 & 2 & 1 \\
\hline $1960 \mathrm{~s}$ & 19 & 4 & 4 & 29 & 2 & 4 & 3 & 2 \\
\hline 1970 s & 19 & 4 & 4 & 36 & 2 & 4 & 4 & 1 \\
\hline 1980s & 20 & 23 & 4 & 33 & 4 & 4 & 4 & 5 \\
\hline $1990 \mathrm{~s}$ & 21 & 27 & 4 & 38 & 5 & 10 & 9 & 4 \\
\hline $2000 \mathrm{~s}$ & 21 & 28 & 4 & 42 & 8 & 19 & 21 & 46 \\
\hline
\end{tabular}

Note: For an assessment of data quality, see Table 8.2.

Source: Clio-Infra, www.clio-infra.eu. 
Table 8.6. Homicide rates in selected countries, 1820s-2000s

Homicides per 100000 inhabitants, decadal averages

\begin{tabular}{|c|c|c|c|c|c|c|c|c|c|c|c|c|c|c|c|c|c|c|c|c|c|c|c|c|c|}
\hline & \multicolumn{7}{|c|}{$\begin{array}{l}\text { Western Europe } \\
\text { (WE) }\end{array}$} & \multicolumn{2}{|c|}{$\begin{array}{l}\text { Eastern Europe } \\
\text { (EE) }\end{array}$} & \multicolumn{3}{|c|}{$\begin{array}{l}\text { Western Offshoots } \\
\text { (WO) }\end{array}$} & \multicolumn{3}{|c|}{$\begin{array}{l}\text { Latin America } \\
\text { and Caribbean } \\
(\mathrm{LA})\end{array}$} & \multicolumn{2}{|c|}{$\begin{array}{c}\text { Middle East } \\
\text { and North } \\
\text { Africa (MENA) }\end{array}$} & \multicolumn{3}{|c|}{$\begin{array}{c}\text { Sub-Saharan Africa } \\
\text { (SSA) }\end{array}$} & \multicolumn{2}{|c|}{$\begin{array}{l}\text { East Asia } \\
\text { (EA) }\end{array}$} & \multicolumn{3}{|c|}{$\begin{array}{c}\text { South and } \\
\text { South-East Asia } \\
\text { (SSEA) }\end{array}$} \\
\hline & GBR & NLD & FRA & DEU & ITA & ESP & SWE & $\mathrm{POL}$ & RUS & AUS & CAN & USA & MEX & BRA & ARG & EGY & TUR & KEN & NGA & ZAF & $\mathrm{CHN}$ & JPN & IND & IDN & THA \\
\hline $1820 \mathrm{~s}$ & 1.6 &.. & 1.5 & 2.4 & 8.0 & 8.8 & 1.2 & .. & .. & .. & .. & .. & .. &.. & .. & .. & .. & .. &.. & 5.2 & .. & .. & .. &.. & .. \\
\hline $1830 \mathrm{~s}$ & 1.6 & .. & 1.5 & 2.4 & 8.0 & 8.8 & 1.3 & .. & .. & .. & .. & .. & .. & 5.6 & .. &.. & .. & .. & .. & .. & .. & .. & .. & .. & .. \\
\hline $1840 \mathrm{~s}$ & 1.6 & & 1.5 & 2.4 & 8.0 & 8.8 & 1.7 & .. &.. & .. & .. & .. &.. & 2.8 & .. & .. & .. & .. & .. &.. & .. & .. & .. & .. & .. \\
\hline $1850 \mathrm{~s}$ & 1.6 & 0.8 & 1.4 & 1.5 & 7.0 & 8.3 & 1.1 & .. &.. & .. &.. &.. & .. & 5.6 & .. &.. & .. & .. &.. &.. &.. &.. &.. & .. &.. \\
\hline $1860 \mathrm{~s}$ & 1.6 & 0.8 & 1.4 & 1.5 & 7.0 & 8.3 & 1.1 & .. & .. & .. & .. & .. & .. & 5.5 & .. & .. & .. & .. &.. & .. & .. & .. &.. & .. & .. \\
\hline 1870s & 1.4 & 0.8 & 1.4 & 1.6 & 6.3 & 6.9 & 1.1 &.. &.. & .. & .. &.. &.. & 5.9 &.. &.. & .. & .. & .. & .. & .. &.. &.. & .. & .. \\
\hline $1880 \mathrm{~s}$ & 1.3 & 0.9 & 1.4 & 1.6 & 5.7 & 5.5 & 0.9 & .. & .. & .. & .. & .. & .. & 4.2 & .. & .. & .. & .. & .. & .. & .. &.. &.. & .. & .. \\
\hline $1890 \mathrm{~s}$ & 1.2 & 0.9 & 1.4 & 1.6 & 5.7 & 5.5 & 0.9 &.. &.. &.. & .. &.. &.. & .. &.. & .. & .. &.. &.. &.. &.. & 3.6 &.. &.. &.. \\
\hline $1900 \mathrm{~s}$ & 0.9 & 0.6 & 1.5 & 2.1 & 3.9 & 4.5 & 0.9 &.. &.. & 2.2 &.. & 2.6 &.. &.. &.. &.. &.. &.. &.. &.. &.. & 3.4 &.. &.. &.. \\
\hline $1910 \mathrm{~s}$ & 0.7 & 0.4 & 1.5 & 2.1 & 3.6 & 4.5 & 0.7 &.. &.. & 1.5 & 1.5 & 6.1 & .. &.. & .. & .. & .. &.. &.. &.. &.. & 2.8 &.. &.. &.. \\
\hline $1920 \mathrm{~s}$ & 0.7 & 0.3 & 1.3 & 2.0 & 5.2 & 3.0 & 0.5 & .. & .. & 1.2 & 1.4 & 8.1 & .. & .. & .. & .. & .. & .. & .. & .. &.. & .. & .. & .. & .. \\
\hline $1930 \mathrm{~s}$ & 0.8 & 0.4 & 1.1 & 1.8 & 1.9 & 1.4 & 0.5 & .. & .. & 1.0 & 1.4 & 8.2 & .. & .. & .. & .. & .. & .. &.. & .. &.. & .. & .. & .. & .. \\
\hline $1940 \mathrm{~s}$ & 0.8 & 0.5 & 1.1 & 1.8 & .. & 1.4 & 0.5 &.. & .. & 1.1 & 1.1 & 5.8 & .. & .. & .. &.. &.. & .. &.. &.. & .. & .. & .. & .. & .. \\
\hline $1950 \mathrm{~s}$ & 0.7 & 0.3 & 1.1 & 1.0 & 2.4 & 0.4 & 0.7 & 1.1 &.. & 1.4 & 1.1 & 4.8 & 30.7 &.. & .. & 1.1 &.. & .. & .. & .. & .. & 2.2 & 2.5 &.. & 8.4 \\
\hline $1960 \mathrm{~s}$ & 0.7 & 0.4 & 1.1 & 1.1 & 1.2 & 0.2 & 0.7 & 1.0 &.. & 1.4 & 1.4 & 5.7 & 20.2 &.. & 6.0 & 1.1 &.. &.. &.. & .. &.. & 1.5 & 2.5 &.. & 12.9 \\
\hline 1970s & 0.9 & 0.7 & 0.9 & 1.2 & 1.5 & 0.6 & 1.1 & 1.1 &.. & 1.8 & 2.4 & 9.4 & 16.6 & 8.3 & 6.3 & 1.1 & 0.8 &.. &.. & .. &.. & 1.2 & 2.9 & .. & 18.9 \\
\hline $1980 \mathrm{~s}$ & 1.1 & 0.9 & 1.1 & 1.2 & 1.8 & 1.0 & 1.3 & 1.7 & 10.8 & 2.0 & 2.2 & 9.1 & 18.1 & 14.5 & 4.8 & 0.7 & 0.5 &.. &.. & .. &.. & 0.9 & 3.5 &.. & 17.1 \\
\hline $1990 \mathrm{~s}$ & 1.2 & 1.2 & 1.0 & 1.1 & 2.7 & 0.9 & 1.2 & 2.7 & 24.6 & 1.8 & 1.8 & 8.6 & 16.4 & 22.2 & 4.6 &.. & 1.5 & .. & 1.4 & 58.3 & .. & 0.6 & 4.2 & .. & 8.3 \\
\hline $2000 \mathrm{~s}$ & 1.4 & 1.1 & 0.7 & 0.6 & 2.5 & 1.0 & 1.0 & 1.5 & 24.0 & 1.1 & 1.6 & 6.1 & 10.9 & 26.4 & 6.1 & 1.0 & 0.6 & 20.4 & 1.5 & 41.7 & 1.6 & 0.5 & 3.1 & 8.5 & 6.4 \\
\hline
\end{tabular}

Note: For an assessment of data quality, see Table 8.2.

Source: Clio-Infra, www.clio-infra.eu. 
convergence process within Western Europe (Table 8.3); the absence of convergence in Eastern Europe (but Poland moves to Western European levels, Russia does not); the very high levels of violence in Latin America; the strikingly low registered homicide rates in the MENA; and the great variation in both Africa and Asia, regions for which historical data are scarce. There is no clear trend in global homicide rates - changes in the world average are again heavily influenced by variations in the number of countries for which data are available. Most regions for which we have long-run series show a slow decline in homicides; Latin America is probably the exception here. But this decline ends in the 1960s in Western Europe and its Offshoots, and in the 1990s in the (post-) communist world.

A number of reasons have been suggested to explain homicide rates (LaFree, 1999; Paré, 2006; Pratt and Cullen, 2005; Nivette, 2011). It has been argued that inequality fuels homicide, partly because of envy-related effects, and perhaps also because of high psychological pressure on people in countries with substantial inequality. Countries such as South Africa, Brazil and Russia have both high homicide rates and either high inequality levels or recent experience of strong increases in inequality (in the case of Russia). Another important determinant is the presence of criminal gangs, especially gangs involved in drug trafficking. This helps to explain the high levels of crime in much of Latin America. A large share of all drugs traded in the United States pass through Honduras, which has a horrendous homicide rate. The same was true until recently for Colombia, even if the Colombian homicide rate has declined substantially over the last few years. A related factor is the share of young males in the age pyramid. Most victims and most offenders are aged 20 to 30, and most of them are male. Ageing societies in contrast seem to be less murderous, even after controlling for other criteria.

\section{Internal and external conflicts}

Another way to look at personal security against a premature, violent death is to estimate the probability that an average individual inhabits a country that is involved in a conflict (Figure 8.3). This is estimated by the average occurrences of a conflict in a given country in a given year (a binary variable) weighted by population (Table 8.7).

In the period 1820-2000 the number of countries involved in some kind of conflict increased slightly, but this is not surprising as the number of countries also increased during that period. Note one interesting trend: the number of countries involved in an external conflict declined considerably, from 20.9 in the 1820 s to 7.6 in the 1990s, while the number of countries with an internal conflict increased from 7.6 to 24.1 in that same period (Table 8.7). This time period coincides with decolonisation (especially from the 1950s onward) and increasing democratisation around the world (see the chapter on political institutions).

Figure 8.3 exhibits a downward trend both for internal and external conflicts. Not surprisingly, in terms of personal security the most dangerous periods were between the mid-1840s and 1860s (the Crimean War, the Opium Wars, the American Civil War and a number of uprising in Qing China) and between the 1930s and 1940s. It should be noted, however, that due to population-weighting conflicts that involve populous countries like China, Russia and India might have a disproportionate effect on these results. Nevertheless, Figure 8.3 suggests that by the end of the 20th century internal conflicts had become much more important determinants of individual safety than external conflicts, or wars. 
Table 8.7. Number of countries involved in internal and external conflicts, 1820s-1990s

Decadal averages

\begin{tabular}{|c|c|c|c|c|c|}
\hline & \multicolumn{3}{|c|}{ Number of countries involved in } & \multicolumn{2}{|c|}{$\begin{array}{l}\text { Probability of a random individual to be involved } \\
\text { in a country having (in percentages) }\end{array}$} \\
\hline & Internal conflicts & External conflicts & Any conflicts & Internal conflicts & External conflicts \\
\hline $1820 \mathrm{~s}$ & 8 & 21 & 29 & 35 & 23 \\
\hline 1830s & 10 & 19 & 29 & 12 & 18 \\
\hline $1840 \mathrm{~s}$ & 9 & 16 & 26 & 18 & 32 \\
\hline $1850 \mathrm{~s}$ & 13 & 11 & 24 & 42 & 34 \\
\hline 1860s & 8 & 20 & 29 & 34 & 3 \\
\hline 1870s & 6 & 16 & 22 & 29 & 17 \\
\hline 1880s & 5 & 24 & 28 & 4 & 25 \\
\hline $1890 \mathrm{~s}$ & 5 & 28 & 33 & 5 & 37 \\
\hline 1900s & 6 & 21 & 27 & 2 & 27 \\
\hline 1910s & 7 & 23 & 30 & 3 & 37 \\
\hline 1920s & 5 & 12 & 17 & 3 & 27 \\
\hline 1930s & 7 & 10 & 17 & 24 & 34 \\
\hline 1940s & 8 & 17 & 25 & 22 & 41 \\
\hline $1950 \mathrm{~s}$ & 13 & 14 & 26 & 23 & 24 \\
\hline 1960s & 24 & 12 & 36 & 34 & 2 \\
\hline 1970s & 22 & 10 & 32 & 22 & 22 \\
\hline 1980s & 25 & 12 & 37 & 12 & 23 \\
\hline 1990s & 24 & 8 & 32 & 28 & 11 \\
\hline
\end{tabular}

Note: For an assessment of data quality, see Table 8.2.

Source: Brecke, P (1999), Violent Conflicts 1400 A.D. to the Present in Different Regions of the World, Paper prepared for the 1999 Meeting of the Peace Science Society www.inta.gatech.edu/peter/PSS99_paper.html and Clio-Infra, www.clio-infra.eu.

Figure 8.3. Probability of inhabiting a country with an armed conflict, 1820-2000 Percentages

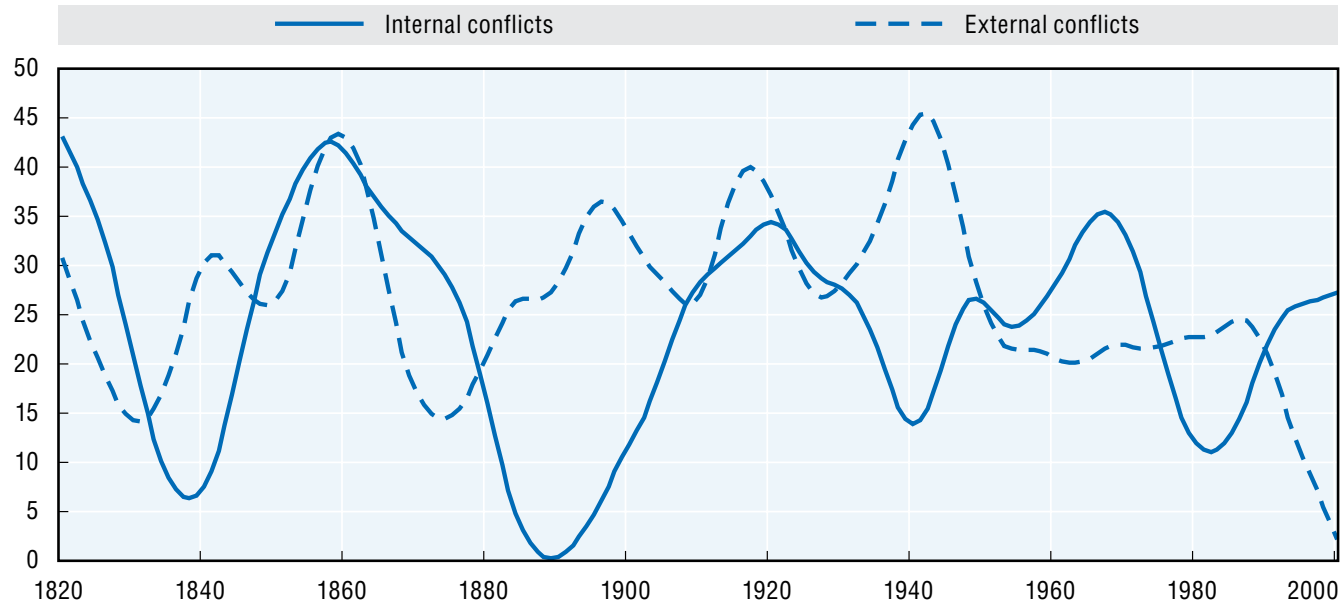

Note: For an assessment of data quality, see Table 8.2. Hodrick-Prescott filter with $\lambda=100$ was used for smoothing of the data.

Source: Brecke, P (1999), Violent Conflicts 1400 A.D. to the Present in Different Regions of the World, Paper prepared for the 1999 Meeting of the Peace Science Society www.inta.gatech.edu/peter/PSS99_paper.html and Clio-Infra, www.clio-infra.eu.

StatLink त्ञाजा http://dx.doi.org/10.1787/888933095970 


\section{Regional trends}

Tables 8.8 and 8.9 report the estimated probability that an individual was involved in an armed conflict by region and per decade; the global totals differ from those presented in Table 8.7 because they are weighted by population. The dominance of countries with large populations is even more visible here: the probabilities regarding an internal conflict in East Asia are basically driven by unstable Chinese internal politics, including the Taiping rebellion, the Boxer uprising, the Civil War during the Republican era in the 1920s and 1930s, and the Cultural Revolution in the 1960s. Similarly, the Western Offshoots are dominated by the USA. Until the 1950s the two most unstable regions were clearly East Asia and Eastern Europe. The prominence of the latter is due particularly to the numerous uprisings in Russia during the 19th century followed by the Civil War and the political cleansings that were also classified as an internal armed conflict. Sub-Saharan Africa had relatively few (recorded) internal conflicts during the colonial era, and it is only after decolonisation that a strong increase can be seen in the likelihood of internal violence. Still, even in these years the probability remains much lower than the values observed for East Asia and Southeast Asia. If we only focus on the last 50 years, it comes as no surprise that the most stable regions are the Western Offshoots (USA, Canada, Australia and New Zealand) and Western Europe. Internal instability is not evenly distributed in time: there were certain decades that proved to be especially unstable, like the 1850s and 1860s, the 1910s and 1920s, and the 1960s, when the average person had 3-4 conflict years per decade, while the most stable years were the 1870s and 1880s, the 1830s and the 1980s, when only a single year or even less brought some internal conflict.

\section{Table 8.8. Probability of inhabiting a country with an internal armed conflict, by region, 1820 s-2000s}

Percentages, decadal averages

\begin{tabular}{|c|c|c|c|c|c|c|c|c|c|}
\hline & $\begin{array}{c}\text { Western } \\
\text { Europe } \\
\text { (WE) }\end{array}$ & $\begin{array}{c}\text { Eastern } \\
\text { Europe } \\
\text { (EE) }\end{array}$ & $\begin{array}{l}\text { Western } \\
\text { Offshoots } \\
\text { (W0) }\end{array}$ & $\begin{array}{l}\text { Latin } \\
\text { America } \\
\text { and } \\
\text { Caribbean } \\
\text { (LA) }\end{array}$ & $\begin{array}{c}\text { East Asia } \\
(\mathrm{EA})\end{array}$ & $\begin{array}{c}\text { South and } \\
\text { South-East } \\
\text { Asia } \\
\text { (SSEA) }\end{array}$ & $\begin{array}{l}\text { Middle East } \\
\text { and } \\
\text { North Africa } \\
\text { (MENA) }\end{array}$ & $\begin{array}{c}\text { Sub-Saharan } \\
\text { Africa } \\
\text { (SSA) }\end{array}$ & World \\
\hline $1820 \mathrm{~s}$ & 7.3 & 40.0 & 0.0 & 6.7 & 80.8 & 0.2 & 9.4 & 2.0 & 34.6 \\
\hline $1830 \mathrm{~s}$ & 26.5 & 45.9 & 27.1 & 30.8 & 9.9 & 1.3 & 0.0 & 1.5 & 11.7 \\
\hline $1840 \mathrm{~s}$ & 17.5 & 18.5 & 0.9 & 43.2 & 36.2 & 1.4 & 6.1 & 1.3 & 18.4 \\
\hline $1850 \mathrm{~s}$ & 4.9 & 2.7 & 43.5 & 38.2 & 90.5 & 20.9 & 3.0 & 1.1 & 41.6 \\
\hline $1860 \mathrm{~s}$ & 3.4 & 6.4 & 52.8 & 13.3 & 95.4 & 1.1 & 0.2 & 0.0 & 34.4 \\
\hline $1870 \mathrm{~s}$ & 9.2 & 7.5 & 0.9 & 10.9 & 91.7 & 0.2 & 0.0 & 0.1 & 29.4 \\
\hline $1880 \mathrm{~s}$ & 0.4 & 0.0 & 0.7 & 3.1 & 9.3 & 0.5 & 0.3 & 8.3 & 3.6 \\
\hline 1890s & 2.0 & 3.9 & 0.0 & 22.8 & 9.2 & 0.5 & 0.0 & 8.6 & 4.8 \\
\hline $1900 \mathrm{~s}$ & 1.3 & 22.4 & 0.0 & 2.7 & 60.9 & 0.0 & 13.9 & 4.1 & 20.4 \\
\hline 1910s & 5.4 & 21.5 & 8.7 & 30.5 & 86.7 & 0.1 & 0.0 & 1.2 & 30.0 \\
\hline $1920 \mathrm{~s}$ & 12.4 & 20.8 & 0.0 & 7.6 & 78.6 & 16.0 & 2.8 & 0.7 & 30.4 \\
\hline $1930 \mathrm{~s}$ & 16.9 & 50.2 & 0.0 & 16.0 & 60.7 & 0.5 & 0.0 & 0.0 & 24.1 \\
\hline $1940 \mathrm{~s}$ & 6.1 & 32.5 & 0.0 & 2.0 & 42.1 & 22.0 & 8.1 & 1.2 & 21.6 \\
\hline $1950 \mathrm{~s}$ & 0.0 & 39.6 & 0.0 & 11.8 & 16.6 & 47.7 & 3.6 & 3.4 & 22.8 \\
\hline $1960 \mathrm{~s}$ & 3.1 & 34.9 & 59.7 & 18.1 & 41.9 & 41.7 & 3.9 & 16.3 & 33.5 \\
\hline $1970 \mathrm{~s}$ & 15.9 & 0.0 & 17.0 & 14.1 & 50.5 & 14.1 & 7.4 & 12.2 & 22.4 \\
\hline $1980 \mathrm{~s}$ & 15.1 & 0.6 & 0.0 & 19.7 & 0.3 & 17.1 & 16.7 & 29.1 & 12.0 \\
\hline 1990s & 8.0 & 10.0 & 0.0 & 13.7 & 0.0 & 64.1 & 2.2 & 25.5 & 27.8 \\
\hline
\end{tabular}

Note: For an assessment of data quality, see Table 8.2

Source: Clio-Infra, www.clio-infra.eu. 
Table 8.9. Probability of inhabiting a country with an external armed conflict, by region, 1820s-2000s

Percentages, decadal averages

\begin{tabular}{|c|c|c|c|c|c|c|c|c|c|}
\hline & $\begin{array}{l}\text { Western } \\
\text { Europe } \\
\text { (WE) }\end{array}$ & $\begin{array}{c}\text { Eastern } \\
\text { Europe } \\
\text { (EE) }\end{array}$ & $\begin{array}{l}\text { Western } \\
\text { Offshoots } \\
\text { (W0) }\end{array}$ & $\begin{array}{l}\text { Latin } \\
\text { America } \\
\text { and } \\
\text { Caribbean } \\
\text { (LA) }\end{array}$ & $\begin{array}{c}\text { East Asia } \\
(\mathrm{EA})\end{array}$ & $\begin{array}{c}\text { South and } \\
\text { South-East } \\
\text { Asia } \\
\text { (SSEA) }\end{array}$ & $\begin{array}{l}\text { Middle East } \\
\text { and } \\
\text { North Africa } \\
\text { (MENA) }\end{array}$ & $\begin{array}{l}\text { Sub-Saharan } \\
\text { Africa } \\
\text { (SSA) }\end{array}$ & World \\
\hline $1820 \mathrm{~s}$ & 29.5 & 45.1 & 21.5 & 37.4 & 0.0 & 46.0 & 12.6 & 4.8 & 22.6 \\
\hline $1830 \mathrm{~s}$ & 29.0 & 39.6 & 9.5 & 13.0 & 9.0 & 18.1 & 12.3 & 4.7 & 17.6 \\
\hline $1840 \mathrm{~s}$ & 49.0 & 22.4 & 26.3 & 10.0 & 27.1 & 43.9 & 0.0 & 8.7 & 32.1 \\
\hline $1850 \mathrm{~s}$ & 37.4 & 42.1 & 0.0 & 2.2 & 54.2 & 15.8 & 6.5 & 12.3 & 33.6 \\
\hline $1860 \mathrm{~s}$ & 50.4 & 47.2 & 51.9 & 32.1 & 37.7 & 12.6 & 3.2 & 7.8 & 30.4 \\
\hline 1870 s & 38.6 & 29.3 & 43.4 & 4.2 & 9.1 & 10.2 & 0.0 & 14.6 & 16.5 \\
\hline $1880 \mathrm{~s}$ & 53.5 & 16.3 & 0.0 & 4.8 & 26.6 & 17.9 & 0.0 & 40.2 & 25.4 \\
\hline $1890 \mathrm{~s}$ & 77.6 & 25.7 & 35.1 & 1.1 & 28.6 & 36.6 & 0.0 & 42.1 & 36.5 \\
\hline $1900 \mathrm{~s}$ & 56.8 & 13.2 & 61.7 & 5.4 & 21.8 & 21.5 & 0.0 & 25.9 & 27.1 \\
\hline $1910 \mathrm{~s}$ & 59.0 & 40.8 & 34.9 & 2.4 & 46.7 & 27.1 & 0.0 & 17.8 & 36.9 \\
\hline $1920 \mathrm{~s}$ & 52.0 & 34.1 & 8.7 & 0.3 & 55.2 & 0.4 & 2.8 & 0.2 & 26.8 \\
\hline $1930 \mathrm{~s}$ & 40.3 & 31.2 & 1.0 & 2.6 & 67.6 & 26.7 & 1.7 & 0.0 & 34.4 \\
\hline $1940 \mathrm{~s}$ & 54.2 & 23.9 & 49.3 & 1.6 & 57.7 & 45.3 & 2.7 & 2.4 & 41.1 \\
\hline $1950 \mathrm{~s}$ & 34.8 & 4.5 & 0.0 & 0.7 & 59.3 & 12.9 & 8.3 & 3.3 & 24.0 \\
\hline $1960 \mathrm{~s}$ & 14.8 & 8.9 & 0.0 & 1.1 & 25.1 & 34.1 & 2.3 & 10.1 & 20.2 \\
\hline 1970s & 1.2 & 0.0 & 0.0 & 0.0 & 8.5 & 58.4 & 2.3 & 12.6 & 21.8 \\
\hline $1980 \mathrm{~s}$ & 1.5 & 0.5 & 16.8 & 1.5 & 25.6 & 39.8 & 12.9 & 12.0 & 23.0 \\
\hline $1990 \mathrm{~s}$ & 6.0 & 1.9 & 18.6 & 0.7 & 0.0 & 26.3 & 0.1 & 4.9 & 11.3 \\
\hline
\end{tabular}

Note: For an assessment of data quality, see Table 8.2.

Source: Clio-Infra, www.clio-infra.eu.

With regard to external conflicts, the picture changes fundamentally. Considering the entire period from 1820 to 2000, Western Europe had the most wars, even though after the Second World War these were usually limited to ex-colonies outside Europe (Indochina, Indonesia and the Middle East in 1956). It is only from the 1970s on that Western Europe becomes the least likely region to participate in wars. The second and third most warlike regions are East Asia and South and Southeast Asia, where a relatively peaceful period started only during the 1990s. It may be a bit surprising but wars were the least likely in the MENA countries, where despite the frequent Arab-Israeli conflicts, lasting only a few weeks at most, wars were quite infrequent after the 1830s, as well as in Latin America, where after the "lost decades" (1820s-1860s) the number of wars was extremely low.

\section{Correlation with GDP per capita}

Homicide rates are in general negatively correlated with GDP per capita. In recent years this correlation has been quite strong and significant, and has not shown a particular trend (Figure 8.4). So in general, rich countries have relatively low levels of personal violence, and poor countries relatively high levels. However, there are many exceptions to this rule - such as the United States (combining high wealth but high homicide rates) and Nigeria or Egypt (poor but low homicide rates). This illustrates that economic factors play only a limited role in determining levels of personal security and that personal security has only a limited influence on economic growth. 
The literature also suggests that there is a negative relationship between civil wars and GDP per capita; Blattman and Miguel (2010) estimate that in the period 1960-2006 the incidence of civil war was highest (almost 30\%) for the poorest countries and lowest (close to zero) for the richest countries. This negative link is a recent development, however. On the basis of the Brecke dataset, it can be shown that for most years the correlation coefficients between GDP per capita and conflicts are close to zero. There are some exceptions, however. For internal conflicts and GDP per capita we find a negative correlation after 1945, which becomes significant at the 5\% level after 1983 (confirming the Blattman and Miguel findings). The relationship between external conflicts and GDP per capita is significant and positive during the Second World War, when apparently the rich countries fought among themselves. The correlation between wars and per capita income becomes negative from the 1960 s on, but it remains insignificant.

Figure 8.4. Correlation between homicide rates and GDP per capita, 1820s-2000s Pearson correlation coefficient and upper/lower bounds of $95 \%$ confidence interval per decade

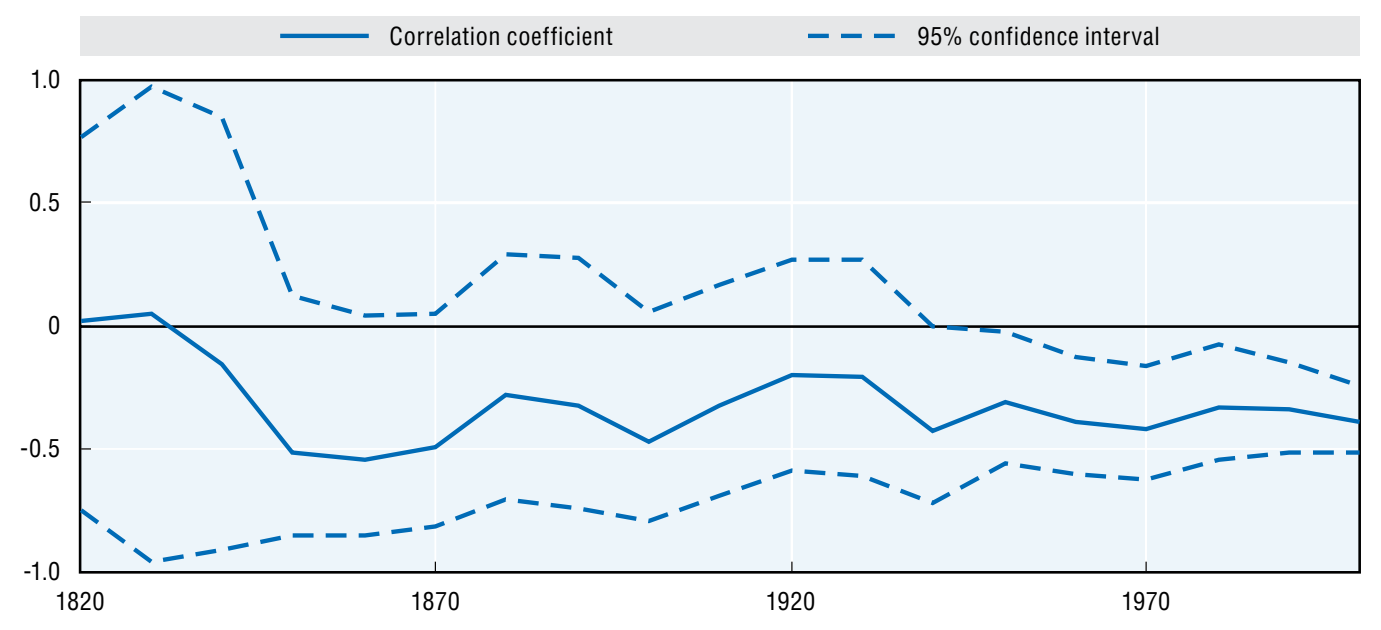

Note: For an assessment of data quality, see Table 8.2.

Source: Clio-Infra, www.clio-infra.eu.

\section{Priorities for future research}

What should be the priorities for the study of homicide as an indicator of well-being in the future? The greatest potential probably lies in extending the existing evidence back to early times in developing countries, and in documenting regional evidence. There are archival sources that document the activity of the police and the courts in punishing murderers. However, it is challenging to identify the different pieces of evidence and their potential sample selection biases and measurement error in historical data. Careful counterchecking of sources from different institutional contexts (such as from vital statistics and police records, and from prisons) might help to identify issues with measurement errors. Also, studies on the determinants of homicides are crucial if we want to understand what encourages and what prevents this type of crime: how effective have police systems been? Did all social groups trust the police, or was the tolerance of some homicides preferred 
over cooperation with the police? How large was social inequality, and is it really a core determinant of homicide? Finally, the existence of criminal gangs needs to be studied and wherever possible also quantified.

We now know a great deal about long-term trends in homicides in Western Europe and have begun to understand why this relatively violent society gradually became pacified. Much is still unclear about how other parts of the world developed in this respect. A link with processes of state formation, in which the monopoly of violence was successfully claimed by the state, is suggested by the evidence produced here: outside Europe it is regions with ancient states, such as the Middle East and East Asia, which have shown the lowest levels of violent crime. Regions with relatively young states, such as Latin America and in particular Africa, have much higher homicide rates on average.

We did not observe a gradual decline of violence, as was suggested by Pinker (2011). However, this is partly explained by the difference in time periods covered. When Pinker's data on homicides covers the same time period, the trend is similar to that presented here, but he focuses on a longer-term decline dating back to the Middle Ages, and calculates the impact of conflict via the risk of death rather than via the risk of living in a country participating in a conflict.

Both homicides and conflict correlate negatively with GDP per capita - but while for personal violence this negative link was relatively strong, for group violence this relationship emerged only recently, in the last 50 years or so. Much more striking are the huge international differences in violent crimes, which show a large degree of persistence. The high homicide rate of the US, so much higher than that of "comparable" countries (Canada, Australia, the UK), is a case in point. In Latin America and parts of Sub-Saharan Africa, criminal violence also seems to be self-perpetuating and to be undermining the well-being of the population living in those parts of the world. High levels of inequality are often part of the explanation, but it should be realised that the poor really pay the price for the kind of "organised" violence that is characteristic of Johannesburg or Rio de Janeiro, because the rich have the resources to protect themselves against it. High levels of personal violence are therefore arguably one of the most important reasons for extremely low levels of well-being all over the globe.

Clearly this also applies to the consequences of civil war and inter-state warfare. Until the mid 1940s, there was not a clear correlation between GDP per capita and both forms of organised violence. In the 19th century no part of the world was so heavily involved in warfare as Western Europe (continuing a tradition of almost incessant warfare going back to the Middle Ages). But this has now changed, and warfare is increasingly associated with poverty. This negative link between collective violence and GDP per capita, increasingly evident since the middle of the 20th century, is therefore one of the most significant negative feedback loops in underdevelopment, sometimes resulting in extreme destitution (Collier, 2007). The examples of both the decline of organised violence in Western Europe and its endemic character in parts of Latin America and Sub-Saharan Africa demonstrate the relevance of integrating violence in the approach to measure well-being. 


\section{Notes}

1. See: UNODC (2014)

2. For World War One, the Correlates of War reports 8587000 dead, while current estimates of total fatalities are around 15-17 million. Similarly, for the Spanish Civil War (1936-39) 466300 military causalities are reported, but the total number of deaths is estimated at between 500000 and 1 million.

3. The difference was largely due to a few Latin American countries such as Venezuela and St. Kitts, which had extremely high murder rates according to criminal statistics, but somewhat lower estimates for the homicide rate according to death statistics (for Venezuela, 47.7 and 34.5 per 100 000).

4. For example, the low level of official homicide rates in contemporary Iraq is striking (2 per 100000 in 2008); in this case this measure fails to register the actual level of violence in the country; estimates for Afghanistan (3.4 in 2004) may be equally misleading.

\section{References}

Blattman, C. and E. Miguel (2010) Civil War, Journal of Economic Literature, Vol. 48/1, pp. 3-57.

Brecke, P. (1999), Violent Conflicts 1400 A.D. to the Present in Different Regions of the World, Paper prepared for the 1999 Meeting of the Peace Science Society www.inta.gatech.edu/peter/PSS99_paper.html.

Collier, P. (2007), The Bottom Billion. Why the poorest countries are failing and what can be done about it, Oxford University Press, Oxford.

Eisner, M. (2003), "Long-term historical trends in violent crime”, Crime and Justice; A Review of Research, Vol. 30, pp. 83-142.

Eisner, M. (2008), “Modernity strikes back? The latest increase of interpersonal violence (1960-1990) in a historical perspective", International Journal on Conflict and Violence, Vol. 2/2, pp. 288-316.

Eisner, M. (2012), “What causes large scale variation in homicide rates?”, working paper, July 2012, Historical Violence Database, http://cjrc.osu.edu/research/interdisciplinary/hud.

Kok, J. (1990), "The Moral Nation. Illegitimacy and bridal pregnancy in the Netherlands from 1600 to the present", Economic and Social History in the Netherlands, Vol. 2, pp. 7-37.

LaFree, G. (1999), "Homicide: Cross-National Perspectives”, in M. D. Smith, and M. A. Zahn, Studying and Preventing Homicide. Issues and Challenges, pp. 115-139, Sage Publications, Inc, London.

Lehti, M. (2013), “NRILP Comparative Homicide Time Series (NRILP-CHTS)”, National Research Institute of Legal Policy, Research Brief, Vol. 32/2013, Helsinki.

Nivette, A.E. (2011), "Cross-National Predictors of Crime: A Meta-Analysis" Homicide Studies, NRILP Comparative Homicide Time Series (version 25-10-2013), National Research Institute of Legal Policy, www.optula.om.fi/en/Etusivu/Julkaisut/1368802881488.

OECD (2011), "Personal security", in OECD, How's Life?: Measuring Well-being, OECD Publishing, Paris, http://dx.doi.org/10.1787/9789264121164-13-en.

Paré, P.-P. (2006), Income Inequality and Crime across Nations Reexamined (Dissertation), The Pennsylvania State University.

Pinker, S. (2011), The Better Angels of Our Nature: Why Violence Has Declined, Viking Books, New York.

Pratt, T.C. and F.T Cullen, (2005), "Assessing Macro-Level Predictors and Theories of Crime: A MetaAnalysis", Crime and Justice: A Review of Research, Vol. 32, pp. 373-450.

Richardson, L.F. (1960), "Statistics of Deadly Quarrels", edited by Q. Wright and C.C. Lienau, The Boxwood Press, Pittsburgh.

Shorter, E. (1972), "Sexual change and illegitimacy: the European experience”, in R. Bezucha, ed., Modern European Social History, Lexington/Toronto, pp. 231-269.

Spierenburg, P. (2006), "Democracy came too early: a tentative explanation for the problem of American homicide", American Historical Review, Vol. 111, pp. 104-114.

Spierenburg, P. (2008) A History of Murder, Polity Press, Cambridge.

Torny, M. (2013), “Understanding Crime Trends in Italy and elsewhere”, University of Minnesota Law School, Legal Studies Research Paper Series. Research Paper No. 13-42. 
UNOCD (United Nations Office on Drugs and Crime) (2014), Intentional homicide, rate per 100000 population, http://www.unodc.org/documents/data-and-analysis/IHS-rates-05012009.pdf.

UNOCD (United Nations Office on Drugs and Crime) (2011), Global Study on Homicide. Trends, Contexts, Data, UNOCD, Vienna.

Von Hoffer, H. (2008), Brott och straff i Suerige: Historiskkriminalstatistik 1750-2008, Diagram, tabeller och kommentarer, (Crime and punishment in Sweden: Historical criminal statistics 1750-2008, graph, tables, and comments), Kriminologiskainstitutionen, Stockholms Universitet, Stockholm. 


\section{Chapter 9}

\section{Political institutions since 1820}

by

Peter Foldvari and Katalin Buzasi, Utrecht University

Political institutions determine the degree of freedom people enjoy and their capacity to influence their social and political environment. This chapter provides historical evidence on the evolution of political institutions drawing upon two major research projects: the PolityIV dataset and the Vanhanen dataset, which focuses on electoral participation and competition. Strengths and weaknesses of both databases are discussed. The chapter shows that global averages are tending to rise according to both datasets, but with significant differences in timing. Both datasets also show that the Western Offshoots and Western Europe took the lead in this process, while other parts of the globe often experienced a much less gradual evolution, with occasional violent swings in political rights. Yet in the long run, there has been an impressive improvement in the quality of political institutions worldwide. 


\section{Introduction}

Political institutions to a large extent determine the degree of freedom people enjoy, and their capacity to influence their social and political environment, and their quality is therefore fundamental for well-being. Since the seminal works of Douglass North (1990, $1989,1973)$, political institutions have been considered relevant factors for people's wellbeing through their influence on economic performance as well as on other domains of social life, including democracy and happiness (Frey and Stutzer, 2002; Przeworski et al., 2000). Although institutions are popular research topics, when it comes to empirical analysis one has to cope with the difficulties of defining and measuring rather elusive concepts. According to North, institutions are the "rules of the game", or literally, "the humanly devised constraints that shape interaction. In consequence, they structure incentives in human exchange, whether political, social, or economic". ${ }^{1}$

Since this concept is quite broad, the empirical literature has adapted it so as to identify and measure different types of institutions that influence economic and social outcomes in various ways. The past two decades have thus witnessed the launch of a number of databases that provide information on the quality of political institutions. Much of the available historical data on institutions goes back at least a century and focuses on democracy and governance, which is most relevant for the purposes of this chapter. This chapter is therefore largely concerned with democracy, an area where the interrelation of political institutions with well-being is well established.

First of all, in the long run democracy is a prerequisite of good governance, which allows other key institutions such as the rule of law and protection of property rights to evolve: these latter institutions have an indirect but significant effect on factor accumulation and material welfare. Second, governments in democratic countries are usually supportive to education, as it acts as a stabilising factor, while authoritarian regimes often perceive it as a threat to their power base (Glaeser et al., 2007). Finally, an individual's ability to have a say in political decisions in democracies lessens the likelihood of violent conflict, such as war, civil unrest or civil war.

This chapter relies on composite measures of democracy to capture the individual's possibilities to affect his or her social environment and the decision-making process. The analysis is limited to measures that are available for long time periods. As these measures are aggregated from underlying sub-indices, the chapter also presents measures of different aspects of political stability, the population's participation in elections and the relative weight of the winning party in parliament (competition).

\section{Description of the concepts used}

When aiming to examine the relationship between political institutions and wellbeing in the long run, one has to cope with several difficulties. First, in the past decade various scholars have contributed to the measurement of institutions with a dozen new concepts plus measures and data. The spectrum of measures incorporated in the term "political institutions" includes the rule of law, which assesses the authority of law within 
societies in general, as well as the corruption that people perceive in everyday life; the quality of governments; the extent of democracy; the nature of elections; the stability and duration of political regimes; and even the characteristics of constitutions. ${ }^{2}$ Second, the temporal and geographical scope of most indicators is rather limited, making them weak tools for any comparative historical investigation.

Long-term data on democracy are available from a variety of secondary sources, such as the polity2 index, the Vanhanen index, the Banks CNTS Data Archive, the Boix et al. dataset for political regimes, and the Varieties of Democracy dataset. One indicator that could be used as a proxy of governance is the state antiquity index ${ }^{3}$ (Bockstette et al., 2002; Chanda and Putterman, 2007): however, this index shows only a very small variation over time, providing meaningful and visually appealing information only in a cross-sectional analysis. ${ }^{4}$ For this reason the scope of this chapter is limited to measures of democracy.

While in its broadest sense democracy is understood as "rule by the people", in both theory and practice this concept is defined in many ways. One important consideration underlying the various definitions and measures of democracy is the distinction between "minimalist" (or thin) and "wider" (or thick) approaches (Coppedge, 2005). The minimalist view focuses only on the basic attributes of democracy: while this approach helps to identify those instances that fulfil "thin" criteria, it is often too general to allow detailed comparisons between countries. Most currently-used measures of democracy follow this minimalist strategy, which corresponds closely to the concept of "polyarchy" introduced by Robert Dahl (1971)..$^{5}$ In contrast, the wider concept attempts to identify and integrate all important aspects of democracy: its drawback is that, since it might be difficult to find cases that fulfil all these requirements, this approach might lose its analytical value. ${ }^{6}$

None of the existing approaches and measures are able to identify and account for all the relevant aspects of democracy. Rather, they conceptualise and measure it along a limited number of dimensions; Coppedge et al. (2011) argue that most studies of democracy can be classified based on seven key principles or concepts:

- The "electoral conception" identifies the key element of a working democracy as the competition of leadership groups.

- The "liberal approach" stresses the importance of transparency, civil liberty, rule of law, horizontal accountability and minority rights. These features are seen as key elements of democracy in their own right, and not merely as support for political competition.

- The "majoritarian conception" highlights the principle that the will of the majority should be sovereign, i.e. the many should prevail over the few.

- The "consensual approach" highlights the importance of the presence of as many political perspectives as possible, rather than decision-making by narrow majorities.

- The "participatory democracy" conception is viewed as a descendant of the direct model of democracy, derived from the experience of Athens. The key idea is unease at delegating authority to representatives. The most important element of democracy is therefore voting and the presence of fora where citizens can share their voice and opinions (assemblies, social movements, etc.).

- The "deliberative conception" focuses on the process through which decisions are reached in a polity. A deliberative process is one in which public reasoning focused on the common good motivates political decisions.

- Finally, an "egalitarian democracy" aims to achieve political equality (equal participation, equal representation, equal protection and equal resources). 
Although some of the above concepts might contradict each other to some extent, all existing definitions and measures of democracy involve some combination of these dimensions.

Finally, in order to understand the causes for the vagueness and lack of transparency of current methods of evaluating democracy, it is important to bear in mind that the original concept of democracy is based predominantly on the views and practices of the Western developed world. Thus, it is not surprising that in the second half of the 20th century, as a number of states transitioned from authoritarian regimes to something different, the application of the Western democratic definition came under challenge. Although the newly emergent states in Eastern Europe, Latin America, Asia and Africa fulfilled certain requirements of democracy, they also exhibited some specific features that just didn't quite fit. Consequently, scholars in the field were encouraged to find ways to bridge the existing theory and deal with the realities of the changing world, which has led to numerous new approaches. Even the newest and most popular concepts are often accused of a lack of ability to make a proper evaluation of authoritarian regimes with "good" policies (Glaeser et al., 2004).

\section{Historical sources}

This chapter is based on two historical measures: the polity2 index and the Index of Democracy. The polity IV dataset $\mathrm{Z}$ elaborated by Marshall, Jagger and Gurr (2011) is designed to capture the political regime of each country. In this dataset, countries are assigned a score ranging between +10 (fully democratic) and -10 (fully autocratic) over the period from 1800 to 2010 . This composite index is based on six component variables: i) the regulation of chief executive recruitment; ii) the competitiveness of executive recruitment; iii) the openness of executive recruitment; iv) executive constraints; v) the regulation of participation; and vi) the competitiveness of participation. These six components are used to compute a composite "autocracy and democracy index", which ranges between 0 and 10. The polity IV value that is used in this chapter is computed by subtracting the value of autocracy from the value of democracy 8

The Index of Democracy 9 by Vanhanen $(1984,1997,2003)$ is a composite score of political competition (one minus the share of votes by the winning party) and political participation (the percentage of the adult population who cast a ballot in the elections). A score of zero indicates the lack of participation or competition. Participation depends fundamentally on two factors: the enfranchisement of the population, and the voter turnout at elections; while competition reflects the dominance of a single political opinion within the parliament. While a significant majority of seats may contribute to stability, the predominance of a single party may hurt the expression of alternative views and the probability of a future change in government 10

Both the polity2 and the Index of Democracy measures are considered as a minimalist approach to democracy (Munck and Verkuilen, 2002). Competition and participation (the two main dimensions of the Vanhanen index) correspond to the electoral and participatory concept in the scheme of Coppedge et al. (2011). The polity2 index does not easily map to a single theory. The indicators of executive recruitment are straightforward, so finding a match is relatively easy. The second and third indicators refer to the practice of competitive elections, while the last one captures the constraints on the executives. Even though the regulation of participation and the competitiveness of participation components refer in name to participation, they are not related to voting and the rule by citizens, but rather to the possibility for political groups to be included in the political process, which again is more related to competition than to participation. For a systemised description, see Table 9.1. 
Table 9.1. Indicators to measure democracy: polity2 and Index of Democracy

\begin{tabular}{|c|c|c|c|c|c|c|}
\hline $\begin{array}{l}\text { Name of } \\
\text { indicator }\end{array}$ & Definition & $\begin{array}{l}\text { Number of } \\
\text { countries }\end{array}$ & Time span & $\begin{array}{c}\text { Main } \\
\text { elements }\end{array}$ & Components & $\begin{array}{l}\text { Corresponding concept } \\
\text { in the Coppedge scheme }\end{array}$ \\
\hline \multirow[t]{6}{*}{ Polity2 } & \multirow{6}{*}{$\begin{array}{l}\text { Aggregate measure of the } \\
\text { political regimes on a }-10 \text { (fully } \\
\text { authoritarian) to }+10 \text { (fully } \\
\text { democratic) scale. }\end{array}$} & \multirow[t]{6}{*}{187} & \multirow[t]{6}{*}{$1800-2010$} & \multirow[t]{6}{*}{$\begin{array}{l}\text { Democracy } \\
\text { Autocracy }\end{array}$} & $\begin{array}{l}\text { Regulation of chief executive } \\
\text { recruitment }\end{array}$ & - \\
\hline & & & & & $\begin{array}{l}\text { Competitiveness of executive } \\
\text { recruitment }\end{array}$ & Electoral \\
\hline & & & & & $\begin{array}{l}\text { Openness of executive } \\
\text { recruitment }\end{array}$ & Electoral \\
\hline & & & & & Executive constraints & Liberal \\
\hline & & & & & Regulation of participation & $\begin{array}{l}\text { Electoral, } \\
\text { (consensual, majoritarian) }\end{array}$ \\
\hline & & & & & $\begin{array}{l}\text { The competitiveness of } \\
\text { participation }\end{array}$ & $\begin{array}{l}\text { Electoral, } \\
\text { (consensual, majoritarian) }\end{array}$ \\
\hline \multirow{2}{*}{$\begin{array}{l}\text { Index of } \\
\text { Democracy by } \\
\text { Vanhanen }\end{array}$} & \multirow[b]{2}{*}{$\begin{array}{l}\text { The product of the participation } \\
\text { (Percentage of the adult } \\
\text { population voting in the } \\
\text { elections }(0-100 \%) \text { ) and the } \\
\text { competition }(0 \text { ne minus the } \\
\text { share of votes by the winning } \\
\text { party in a national election } \\
(0-100 \%)) \text { indices. Its value is } \\
\text { between } 0 \text { and } 100 \text {, with } 100 \\
\text { being the maximum theoretically } \\
\text { possible level of democracy. }\end{array}$} & \multirow[t]{2}{*}{189} & \multirow[t]{2}{*}{$1810-2000$} & \multirow{2}{*}{$\begin{array}{l}\text { Competition } \\
\text { Participation }\end{array}$} & Competition & Electoral \\
\hline & & & & & Participation & Participatory \\
\hline
\end{tabular}

\section{Data quality}

The first and most obvious limitation of the measures presented in this chapter is the availability of data. The polity2 indicator is available only for countries with a population of 500000 or more, which still provides relatively large country coverage. Smaller states and islands in the Caribbean and the Pacific areas are included only in the Vanhanen dataset.

Another pitfall related to data availability concerns the viability of comparisons between regions over time. Although time series for most countries in Western Europe, the Western Offshoots, East Asia, and Latin America and the Caribbean are available for earlier periods, in the remaining territories the overall picture on democracy in early times depends highly on only a few observations in both datasets. This is because most of these areas were either colonies of Western European imperia or did not exist (countries of the former Soviet bloc) in their current form. Most Sub-Saharan African countries enter the dataset after the 1950s when they became independent and authoritarian regimes developed. Thus the values of the regional democracy measures (discussed in the following sections) related to the 19th century and the beginning of the 20th century basically mirror the situation in three countries: Ethiopia, Liberia and South Africa. The same applies to South and Southeast Asia. Only Afghanistan, Bhutan, Nepal and Thailand are considered before the middle of the 20th century. Democracy values for former colonies (Malaysia, Philippines, Papua New Guinea, etc.) are provided only after independence. Certain countries (Armenia, Georgia, Turkmenistan etc.) came into existence after the dissolution of the Soviet Union, and thus are included in our datasets from the 1990s onwards. For Bulgaria, Hungary, Romania, Russia and Serbia, data are provided from the early and 
mid-1800s. The Northern African MENA countries (Algeria, Libya, Morocco and Tunisia) were colonised by European countries until the first half of the 20th century, before which data are not available (except for Morocco). In this region democracy measures are available for Iran, Morocco (before colonisation), Oman and Turkey from 1800 onwards.

Beyond the country coverage, a more important difference between the two datasets arises from differences in the theory underlying them. While both measures adopt Dahl's (1972) conceptual framework, which identifies competition and participation as the two key attributes of democracy, their measurement strategy is fundamentally different, even though both can be seen as minimalist approaches (i.e. they omit certain aspects of democracy in exchange for empirical feasibility). The polity2 measure assigns scores on an ordinal scale to six components, some of which are less important than others; the index also focuses on the regulatory aspects of participation (i.e. whether or not elections are competitive) rather than on the actual degree of participation (Munck and Verkuilen, 2002). Vanhanen, on the other hand, chooses a single empirical proxy for each of the attributes, i.e. the share of the adult population who voted in the last elections, and the degree of dominance of the winning party in the elections, thereby measuring the two concepts on an interval scale (as percentages) 11 Reich (2002) noted a further problem with the polity2 score, which is that about $62 \%$ of the countries cluster near the extremes of the score $( \pm 6-10)$, which leads to a bimodal distribution. Regimes with intermediate scores are thus difficult to classify.

Finally, the method of aggregation, i.e. combining all component scores into a single measure, is different in the two datasets. The polity2 score is aggregated as a weighted average of the scores, while Vanhanen multiplies the two attributes into an overall index, which, since the components vary between 0 and 1, often results in low aggregate scores, often below $20 \%$. Both methods lack theoretical justification and an empirical comparison of alternative weighting methods. Furthermore, the polity2 score may suffer from doublecounting as a result of redundant indicators (Munck and Verkuilen, 2002).

As for the quality of the underlying sources (Table 9.2), Vanhanen's strategy allows for the direct use of national and international statistical sources, and - for statistically more problematic regions -of secondary sources. The documentation of sources for the Vanhanen index makes it possible to classify the data quality level as either 1 or 2, depending on the country. Unfortunately, the polityIV project does not supply a list of sources. The polity2 aggregate is based on expert opinion using secondary historical sources: this is closest to category 3 in the classification adopted in this report.

A real strength of the two datasets is that they consistently use the same data and process them in the same way, as a result of which the data are highly comparable over time and space. Nor does the data quality change over time.

Table 9.2. Quality of data on indicators on democracy

\begin{tabular}{lc}
\hline Indicator & Data quality \\
\hline Polity2 (Polity IV) & 3 \\
Participation (Index of Democracy) & 1 and 2 \\
Competition (Index of Democracy) & 1 \\
\hline
\end{tabular}

Note: 1. High quality; 2. Moderate quality; 3. Low quality; and 4. Estimates. See the section on «Data Quality» in Chapter 1 for a description of the quality criteria.

Source: Clio-Infra, www.clio-infra.eu. 


\section{Main highlights of trends in political institutions}

\section{Description of global trends}

The world witnessed three main waves of democratisation and two reverse waves over the past 200 years (Huntington, 1993 and 1991). The first wave (1828-1926) was rooted in the American and French revolutions. Then the dominant political process in the 1920s and 1930s (1922-1942) was a shift away from democracy and towards more authoritarian regimes. This reversal was more relevant in countries that adopted democratic forms just before or after the First World War. The second wave of democratisation (1943-1962) started with the Second World War and was followed by a second reversal (1958-1975). The third wave of democratisation (1974 to present times) started with the overthrow of the Portuguese dictatorship, which was the first episode in a long process in which more than thirty countries replaced autocratic regimes with democratic ones 12

Figure 9.1 presents the global trend in the degree of democracy based on the polity2 score and the Index of Democracy (ID) by Vanhanen. Even though these two measures are based on somewhat different theoretical understandings of democracy, they lead to very similar conclusions: the world has become more democratic during the 19th and 20th centuries. There is, however, a striking difference in the speed and timing of the democratisation process. The polity2 score suggests that a worldwide democratisation began in the 1860s and lasted until the 1960s, restarting only in the 1980s. Conversely, the Index of Democracy points to a modest improvement during the 19th century, and strong improvements around the 1920s and at the end of the Second World War. The reason for these differences lies in the different conceptual framework of the two indicators. In case of the polity2 score, if a country fulfils certain qualitative conditions, as do the United States, the United Kingdom and Canada, they are given a high score (Table 9.3); in this respect, the polity2 score is more representative of de jure political rights. Vanhanen's Index of Democracy is based on actual

\section{Figure 9.1. Global scores for Index of Democracy and polity2 of the Polity IV project, 1820-2000}

Values in percentages and scale from -10 to +10

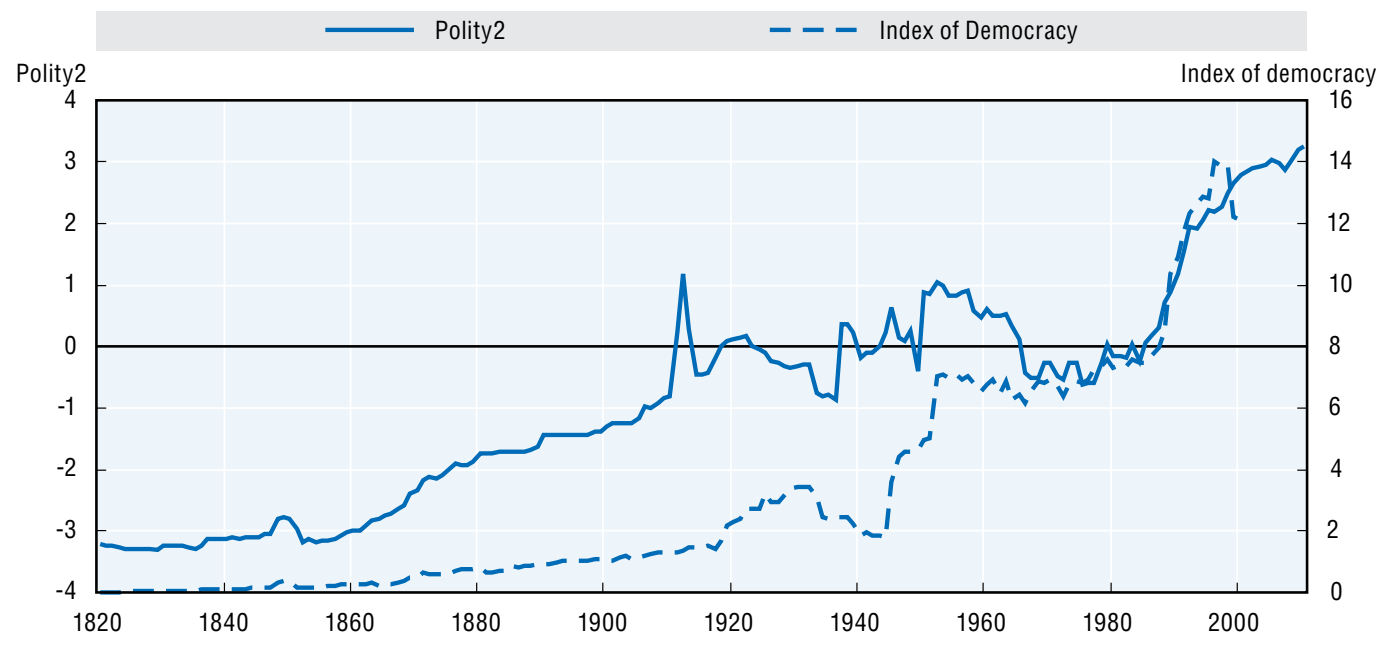

Note: For an assessment of data quality, see Table 9.2.

Source: Clio-Infra, www.clio-infra.eu. 
data on election results, and more reflects how political rights are actually translated into practical application (which is more in line with the capability concept of Sen (2003) and with a de facto understanding of institutions). As Figure 9.2, Table 9.3 and 9.4 suggest, using Vanhanen's concept we find strong overall improvements in countries that had a relatively high polity2 score already in the 19th century. What is more, the primacy of the United States in terms of democracy is not straightforward once measured by the Index of Democracy, since it suggests that United Kingdom overtook the United States around 1919, and preserved its leading position until 2000.

The general trend in Figure 9.1 is also affected by the weighting scheme used, as populous countries dominate the overall score. This is especially striking in the polity2 score in 1912-14, when the temporary improvement of the degree of democracy in China (as a result of the 1911 revolution and the establishment of the republic) in Table 9.3 caused a positive spike in the average score (Figure 9.1). No comparable overall spike is observed in the Index of Democracy.

Figure 9.2 shows the global trend of the two components of Vanhanen's Index of Democracy, i.e. competition and participation. Due to the multiplicative aggregation used by this index, the participation component (with the least variability of the two) mostly determined the movement of the composite index in Figure 9.1. It refers back to the case of China as discussed just above. The improvements in China as the most populous country cause a spike in the competition component in 1910, but this is offset by the zero value of participation and thus cannot be traced in the overall measure. Nevertheless, the two components show a strong correlation: while the right to vote on a global scale was limited to less than $5 \%$ of the total population at the end of the 19th century, this experienced a strong increase during the 1940s. Figure 9.2 also reveals an important aspect of the democratisation process. The share of the population that votes in elections depends on two factors: one is the share of the population that has the political right to vote, while the other is the actual voter turnout. While historical information on the latter component

Figure 9.2. Index of Democracy: participation and competition, 1820-2000 World average, percentages

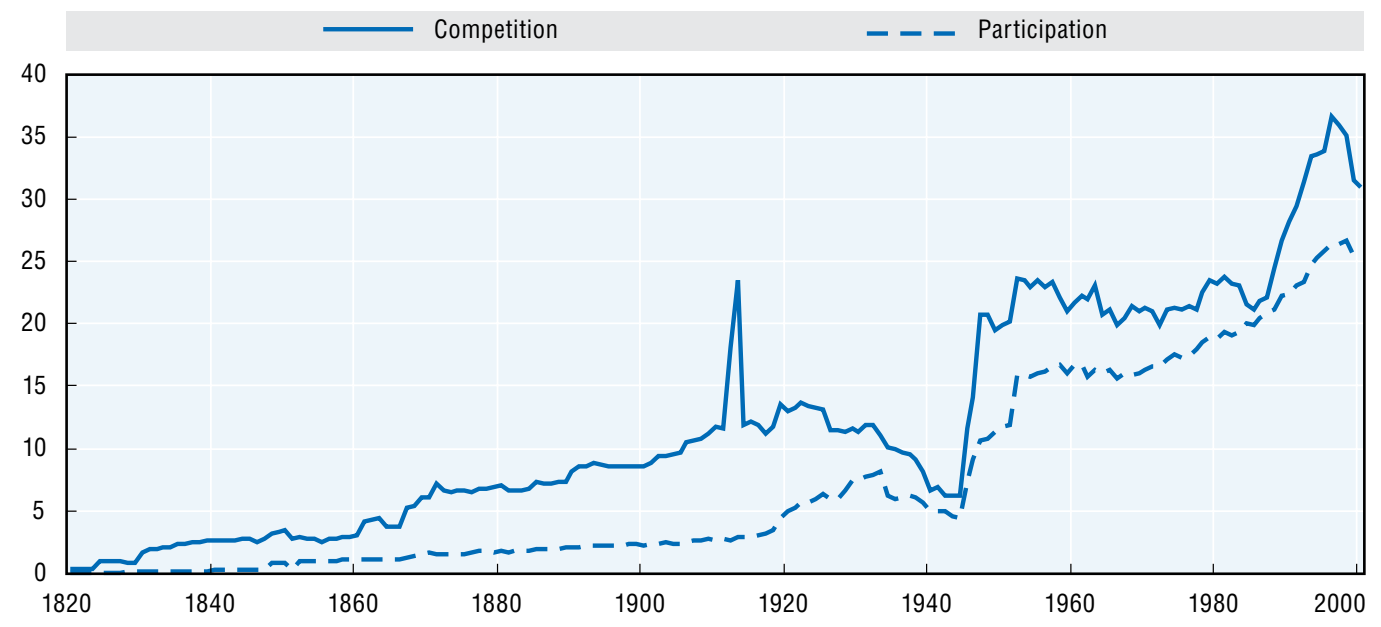

Note: For an assessment of data quality, see Table 9.2 Source: Clio-Infra, www.clio-infra.eu. 
Table 9.4. Index of Democracy in selected countries, $1820 \mathrm{~s}-1990 \mathrm{~s}$

Decadal averages

\begin{tabular}{|c|c|c|c|c|c|c|c|c|c|c|c|c|c|c|c|c|c|c|c|c|c|c|c|c|c|}
\hline & \multicolumn{7}{|c|}{$\begin{array}{l}\text { Western Europe } \\
\text { (WE) }\end{array}$} & \multicolumn{2}{|c|}{$\begin{array}{l}\text { Eastern Europe } \\
\text { (EE) }\end{array}$} & \multicolumn{3}{|c|}{$\begin{array}{l}\text { Western Offshoots } \\
\text { (WO) }\end{array}$} & \multicolumn{3}{|c|}{$\begin{array}{l}\text { Latin America and } \\
\text { Caribbean } \\
\text { (LA) }\end{array}$} & \multicolumn{2}{|c|}{$\begin{array}{c}\text { Middle East } \\
\text { and North } \\
\text { Africa (MENA) }\end{array}$} & \multicolumn{3}{|c|}{$\begin{array}{c}\text { Sub-Saharan Africa } \\
\text { (SSA) }\end{array}$} & \multicolumn{2}{|c|}{$\begin{array}{l}\text { East Asia } \\
\text { (EA) }\end{array}$} & \multicolumn{3}{|c|}{$\begin{array}{c}\text { South and } \\
\text { South-East Asia } \\
\text { (SSEA) }\end{array}$} \\
\hline & GBR & NLD & FRA & DEU & ITA & ESP & SWE & POL & RUS & AUS & CAN & USA & MEX & BRA & ARG & EGY & TUR & KEN & NGA & ZAF & $\mathrm{CHN}$ & JPN & IND & IDN & THA \\
\hline $1820 \mathrm{~s}$ & 0.04 & 0.00 & 0.00 & 0.00 & .. & 0.00 & 0.19 & .. & 0.00 & .. & .. & 1.59 & 0.00 & 0.00 & 0.00 & .. & 0.00 & .. & .. & .. & 0.00 & 0.00 & .. & .. & 0.00 \\
\hline $1830 \mathrm{~s}$ & 0.63 & 0.00 & 0.05 & 0.00 & & 0.00 & 0.19 &.. & 0.00 & .. & .. & 4.31 & 0.00 & 0.00 & 0.00 & & 0.00 & .. & & .. & 0.00 & 0.00 & .. & .. & 0.00 \\
\hline $1840 \mathrm{~s}$ & 0.92 & 0.00 & 1.50 & 0.00 & .. & 0.00 & 0.19 & .. & 0.00 & .. & .. & 6.81 & 0.00 & 0.00 & 0.00 & .. & 0.00 & .. & .. & .. & 0.00 & 0.00 & .. & .. & 0.00 \\
\hline 1850s & 0.96 & 0.31 & 1.38 & 0.00 & .. & 0.00 & 0.19 & .. & 0.00 & .. & .. & 7.00 & 0.00 & 0.00 & 0.06 & .. & 0.00 & .. & .. & .. & 0.00 & 0.00 & .. & .. & 0.00 \\
\hline $1860 \mathrm{~s}$ & 1.30 & 0.45 & 1.77 & 0.44 & 0.44 & 0.51 & 0.17 & .. & 0.00 & .. & 3.89 & 7.09 & 0.02 & 0.00 & 0.09 & .. & 0.00 & .. & .. & .. & 0.00 & 0.00 & .. & .. & 0.00 \\
\hline $1870 \mathrm{~s}$ & 2.23 & 0.98 & 8.12 & 1.99 & 0.38 & 1.62 & 0.12 & .. & 0.00 & .. & 4.37 & 7.95 & 0.01 & 0.00 & 0.51 & .. & 0.00 & .. & .. & .. & 0.00 & 0.00 & .. & .. & 0.00 \\
\hline $1880 \mathrm{~s}$ & 3.37 & 1.32 & 7.42 & 2.51 & 0.96 & 0.22 & 0.19 & .. & 0.00 & .. & 6.27 & 9.50 & 0.00 & 0.00 & 0.54 & .. & 0.00 & .. & .. & .. & 0.00 & 0.00 & .. & .. & 0.00 \\
\hline $1890 \mathrm{~s}$ & 4.56 & 3.34 & 10.37 & 2.84 & 0.99 & 1.10 & 0.36 & .. & 0.00 & .. & 8.51 & 9.77 & 0.00 & 0.14 & 0.17 & .. & 0.00 & .. & .. & .. & 0.00 & 0.11 & .. & .. & 0.00 \\
\hline $1900 \mathrm{~s}$ & 4.52 & 6.32 & 14.70 & 2.83 & 1.42 & 1.60 & 1.41 & .. & 0.00 & 11.78 & 8.48 & 8.00 & 0.00 & 0.27 & 0.34 & .. & 0.01 & .. & .. & .. & 0.00 & 0.19 & .. & .. & 0.00 \\
\hline 1910s & 7.15 & 9.46 & 14.89 & 3.77 & 5.36 & 1.55 & 7.39 & 12.18 & 0.00 & 17.42 & 8.34 & 8.96 & 0.03 & 0.50 & 1.71 & .. & 0.01 & .. & .. & 2.34 & 0.00 & 0.32 & .. & .. & 0.00 \\
\hline 1920s & 18.33 & 26.37 & 15.02 & 20.27 & 4.71 & 0.37 & 18.24 & 13.50 & 0.00 & 21.56 & 18.18 & 11.21 & 0.91 & 0.53 & 4.29 & 0.00 & 0.00 & .. & .. & 2.22 & 0.00 & 0.97 & .. & .. & 0.00 \\
\hline 1930s & 22.48 & 31.68 & 16.42 & 11.24 & 0.15 & 13.02 & 24.44 & 4.23 & 0.00 & 29.86 & 20.81 & 13.63 & 0.47 & 0.00 & 4.23 & 0.00 & 0.00 & .. & .. & 2.64 & 0.00 & 2.10 & .. & .. & 0.00 \\
\hline 1940s & 23.58 & 34.48 & 27.79 & 2.90 & 12.55 & 0.00 & 24.50 & 1.01 & 0.00 & 30.37 & 21.38 & 16.61 & 1.36 & 3.19 & 4.89 & 0.00 & 2.30 & .. & .. & 4.16 & 0.00 & 11.80 & 1.77 & 0.00 & 0.00 \\
\hline $1950 \mathrm{~s}$ & 28.01 & 35.57 & 28.44 & 15.76 & 32.87 & 0.00 & 29.09 & 0.86 & 0.00 & 27.90 & 20.88 & 16.67 & 2.89 & 9.24 & 11.95 & 0.00 & 17.84 & .. &.. & 4.32 & 0.00 & 22.20 & 13.00 & 3.50 & 0.18 \\
\hline $1960 \mathrm{~s}$ & 26.89 & 36.56 & 17.93 & 15.38 & 36.52 & 0.00 & 29.82 & 0.39 & 0.00 & 27.82 & 22.88 & 17.52 & 2.39 & 4.00 & 13.93 & 0.00 & 16.67 & 1.38 & 6.54 & 2.81 & 0.00 & 21.62 & 15.11 & 0.00 & 0.25 \\
\hline 1970s & 29.92 & 38.52 & 30.94 & 15.96 & 38.42 & 9.85 & 36.01 & 0.37 & 0.00 & 29.88 & 24.57 & 17.56 & 3.23 & 0.00 & 5.60 & 1.13 & 17.92 & 0.00 & 1.50 & 2.20 & 0.00 & 27.00 & 15.98 & 3.77 & 1.77 \\
\hline 1980s & 31.76 & 40.40 & 34.34 & 16.84 & 42.79 & 29.44 & 36.66 & 13.51 & 0.77 & 31.30 & 25.98 & 17.25 & 7.33 & 2.86 & 17.11 & 1.86 & 16.76 & 0.00 & 4.49 & 2.20 & 0.00 & 26.18 & 16.90 & 4.05 & 4.51 \\
\hline $1990 \mathrm{~s}$ & 32.26 & 39.42 & 31.15 & 33.96 & 42.60 & 35.83 & 36.90 & 24.02 & 24.43 & 34.85 & 27.15 & 19.98 & 16.41 & 24.76 & 26.15 & 3.06 & 31.09 & 7.55 & 1.77 & 11.60 & 0.00 & 28.59 & 19.87 & 5.62 & 9.02 \\
\hline
\end{tabular}

Notes: For an assessment of data quality, see Table 9.2. RUS 1920s-1980s: refers to the Soviet Union.

Source: Clio-Infra, www.clio-infra.eu. 
is not available, the OECD (2011) demonstrated a substantial reduction in voter turnout in OECD countries during the last few decades. The dominant process behind the rising participation index shown in Figure 9.2 is the expansion of political rights to different segments of society.

\section{Regional trends 13}

The three waves of the democratisation process described above can be illustrated by Tables 9.5, 9.6, 9.7 and 9.8, which show trends in the two democracy indices by the main geographical areas (Huntington, 1993). These regional data highlight the special role played by political institutions in different historical contexts. Tables 9.3 and 9.4 in the previous section might also be used to follow the characteristics of trends in certain major countries of each region.

A range of measurement and technical issues should be kept in mind when interpreting the evidence for North America and Europe. The United States in the early 19th century is often cited as an early example of modern democracy. However, rules for suffrage were not uniform across the United States states, and only white males who met certain conditions on property were allowed to vote. The 19th and 20th centuries saw a process of extension of the franchise in the United States (often as a result of wars, Keyssar, 2009), first to include all white men in the 1820s, then to native Americans and women in the 1920s, and finally to the Afro-American population from the 1860s until the 1960s. A similar increase in the share of population with the right to vote can be observed in Europe during the 1920s with the introduction of universal suffrage there. But looking only at the share of the population that votes in elections can be misleading. One region that experienced a heavy increase in electoral participation was post-1945 Eastern Europe, which had recorded only quite limited improvements in terms of democracy during the inter-war period, but had participation rates of around $60-70 \%$ under the state-socialist regimes (in the 1950s: Bulgaria 65.6\%, Hungary 58.3\%, Poland $48.2 \%$ ). Still, these elections were held under a one-party system, with no real political alternative being offered to the voters. This is reflected in the lack of political competition, as shown in Table 9.8, where the score for Eastern Europe is close to $0 \%$ in this period. The degree of political competition also depends on the political structure. In the two-party system of the United States, Table 9.8 displays remarkably stable political competition over time, while political segmentation in Western and Northern Europe led to an increase in competition. There is also evidence of an increasing convergence in political competition between Europe and America, while Asia and Africa seem to be lagging behind, due to the presence of one-party systems (China, North Korea, Laos and Vietnam) or dominant-party systems (Singapore, Indonesia, Malaysia, Cambodia, Kazakhstan, Yemen, Syria, etc.).

The democratic transition of the post-communist Eastern European countries is a well-researched topic. Since these countries have different cultural features and historical experience compared to those in Western Europe, their membership in the European Union has raised some challenges in terms of policy formation (Kubicek, 2013, Petrovic, 2013). Although both the polity2 scores and the Index of Democracy suggest an increase in democracy from the 1980s onwards in Eastern Europe (Tables 9.5 and 9.6), both indices declined in the last years of the 20th century. Since the constitutional system did not change much in that period, the polity 2 index shows only a very moderate decline. The decrease in democracy is more drastic when measured by the Index of 
Democracy. Tables 9.7 and 9.8 reveal that a decline in both participation and political competition drove the observed lowering of the democracy scores for the Eastern Europe and post-Soviet states. This was to a lesser degree a result of increasing dominance by the winning party, leaving less room for dissenting opinions in national parliaments. The observed trend mainly reflects a reduction in participation (especially in Bulgaria, Hungary and Poland). While this decline in political participation is typically explained by voter disenchantment, Pacek et al. (2009) suggest that it reflects a rational decision by voters to vote only when the stakes are high. Nevertheless, even Pacek et al. find evidence of a negative empirical relationship between voter turnout and macroeconomic indicators like inflation and unemployment.

Major changes in political institutions have also taken place in the Sub-Saharan African region over the past fifty years. Between 1956 and 1970, more than thirty African countries gained independence from their former European colonisers. However, this decolonisation typically resulted in the establishment of authoritarian regimes (see the low competition scores). These events are reflected in Tables 9.3, 9.4, 9.5 and 9.6. The only country in the region that maintained democratic practices constantly over this entire period is Botswana. The improvement in both indices around 1980 reflected some shortlived changes in Burkina Faso, Ghana, Nigeria, Senegal, Tanzania and Uganda. Conversely, since the 1990s most Sub-Saharan African countries have experienced a steady increase in both the polity2 and the Index of Democracy.

Latin America played only a limited role in the second democratisation wave, via popularly elected governments in Argentina, Colombia, Peru and Venezuela in the mid1940s. However, this effort did not last long, and both Argentina and Peru moved back towards limited democracy in subsequent years (although some British colonies in the Latin America region that became independent in the 1960s maintained long-lasting democratic institutions, e.g. Jamaica and Trinidad and Tobago in 1962, Barbados in 1966). In the 1960s and 1970s, military regimes were established in several countries (Peru in 1962; Brazil and Bolivia in 1964; Argentina in 1966; Ecuador in 1972; Uruguay and Chile in 1973). Since the late 1970s, the region has experienced a steadily improvement in political institutions.

Within Asia, there are striking differences between South and South-eastern Asia on the one hand and East Asia on the other. In the late 1950s and early 1960s, military rule in Pakistan and Korea, guided democracy in Indonesia, and emergency rule in India temporarily reduced the democracy scores for both regions. As part of the third wave of democratisation, however, India returned to the democratic path in 1977, and in the 1980s Pakistan and the Philippines also restored democratic rule. Even though Japan and South Korea both achieved a high level of democracy after 1945 and 1987, respectively, the low score for China dominates the picture, making East Asia the least democratic region in today's world.

The Middle Eastern and North African (MENA) countries have lagged in the democratisation process. Several studies show that countries with Muslim majorities exhibit less democracy (Potrafke, 2012; Borooah and Paldam, 2007; Barro, 1999). Abundant oil resources might also hinder the establishment of democratic institutions (Aslaksen, 2010; Badawi and Makdisi, 2007; Ross, 2001), as this increases the chance that ruling elites are not willing to share control over these resources. 
Table 9.5. Regional averages of polity2 democracy scores, 1820s-2000s

Values on $-10 /+10$ scale, decadal averages

\begin{tabular}{|c|c|c|c|c|c|c|c|c|c|}
\hline & $\begin{array}{l}\text { Western } \\
\text { Europe } \\
\text { (WE) }\end{array}$ & $\begin{array}{c}\text { Eastern } \\
\text { Europe } \\
\text { (EE) }\end{array}$ & $\begin{array}{l}\text { Western } \\
\text { Offshoots } \\
\text { (W0) }\end{array}$ & $\begin{array}{c}\text { Latin } \\
\text { America } \\
\text { and } \\
\text { Caribbean } \\
\text { (LA) }\end{array}$ & $\begin{array}{c}\text { East Asia } \\
(\mathrm{EA})\end{array}$ & $\begin{array}{c}\text { South and } \\
\text { South-East } \\
\text { Asia } \\
\text { (SSEA) }\end{array}$ & $\begin{array}{l}\text { Middle East } \\
\text { and } \\
\text { North Africa } \\
\text { (MENA) }\end{array}$ & $\begin{array}{l}\text { Sub-Saharan } \\
\text { Africa } \\
\text { (SSA) }\end{array}$ & World \\
\hline $1820 \mathrm{~s}$ & -4.2 & -4.2 & 7.7 & -1.5 & -6.1 & -0.3 & -3.2 & .. & -3.3 \\
\hline $1830 \mathrm{~s}$ & -3.4 & -4.1 & 7.8 & -2.7 & -6.1 & -0.3 & -3.1 & .. & -3.2 \\
\hline $1840 \mathrm{~s}$ & -2.2 & -3.8 & 8.3 & -3.0 & -6.1 & -0.2 & -3.0 & .. & -3.0 \\
\hline $1850 \mathrm{~s}$ & -3.2 & -4.3 & 7.3 & -3.0 & -6.1 & -0.2 & -3.2 & .. & -3.1 \\
\hline $1860 \mathrm{~s}$ & -3.3 & -4.7 & 7.0 & -3.3 & -5.5 & -0.2 & -3.3 & .. & -2.8 \\
\hline $1870 \mathrm{~s}$ & -0.4 & -4.5 & 8.8 & -3.2 & -5.2 & -0.2 & -3.3 & .. & -2.1 \\
\hline $1880 \mathrm{~s}$ & 1.4 & -4.1 & 9.1 & -3.3 & -5.2 & -0.2 & -3.1 & .. & -1.7 \\
\hline $1890 \mathrm{~s}$ & 2.6 & -4.1 & 9.4 & -2.7 & -5.1 & -0.2 & -3.0 & .. & -1.4 \\
\hline $1900 \mathrm{~s}$ & 3.6 & -3.3 & 9.7 & -2.9 & -5.1 & -0.3 & -1.8 & .. & -1.1 \\
\hline 1910s & 4.4 & -1.5 & 9.7 & -1.4 & -3.2 & -0.3 & -0.1 & 0.2 & -0.1 \\
\hline $1920 \mathrm{~s}$ & 5.1 & -0.2 & 9.7 & -2.1 & -4.2 & -0.3 & -1.5 & 0.2 & -0.1 \\
\hline $1930 \mathrm{~s}$ & 2.2 & -0.5 & 9.7 & -3.5 & -2.9 & -0.2 & -2.2 & 0.3 & -0.3 \\
\hline $1940 \mathrm{~s}$ & 1.1 & -1.7 & 9.7 & -2.0 & -1.9 & -0.1 & -0.6 & 0.3 & 0.1 \\
\hline 1950s & 5.3 & -2.2 & 9.6 & -0.4 & -5.9 & 4.4 & -1.4 & 0.3 & 0.8 \\
\hline $1960 \mathrm{~s}$ & 4.7 & -2.2 & 9.6 & -1.8 & -5.8 & 3.1 & -2.1 & -1.2 & 0.1 \\
\hline 1970 s & 5.8 & -1.6 & 9.5 & -3.4 & -5.7 & 2.6 & -1.6 & -4.5 & -0.4 \\
\hline 1980s & 7.4 & -0.3 & 9.5 & 1.8 & -5.1 & 2.3 & -0.8 & -3.9 & 0.1 \\
\hline 1990s & 9.7 & 4.6 & 9.5 & 6.1 & -4.8 & 4.6 & -0.3 & -1.5 & 2.0 \\
\hline $2000 \mathrm{~s}$ & 9.7 & 6.1 & 9.5 & 7.3 & -4.8 & 5.4 & -0.2 & 2.9 & 3.0 \\
\hline
\end{tabular}

Note: For an assessment of data quality, see Table 9.2.

Source: Clio-Infra, www.clio-infra.eu.

StatLink 需正 http://dx.doi.org/10.1787/888933097205

Table 9.6. Regional averages of Index of Democracy scores, 1820s-2000s

Percentages, decadal averages

\begin{tabular}{|c|c|c|c|c|c|c|c|c|c|}
\hline & $\begin{array}{c}\text { Western } \\
\text { Europe } \\
\text { (WE) }\end{array}$ & $\begin{array}{c}\text { Eastern } \\
\text { Europe } \\
(\mathrm{EE}) \\
\end{array}$ & $\begin{array}{c}\text { Western } \\
\text { Offshoots } \\
\text { (W0) }\end{array}$ & $\begin{array}{l}\text { Latin } \\
\text { America } \\
\text { and } \\
\text { Caribbean } \\
\text { (LA) }\end{array}$ & $\begin{array}{c}\text { East Asia } \\
(\mathrm{EA})\end{array}$ & $\begin{array}{l}\text { South and } \\
\text { South-East } \\
\text { Asia } \\
\text { (SSEA) }\end{array}$ & $\begin{array}{l}\text { Middle East } \\
\text { and } \\
\text { North Africa } \\
\text { (MENA) }\end{array}$ & $\begin{array}{c}\text { Sub-Saharan } \\
\text { Africa } \\
\text { (SSA) }\end{array}$ & World \\
\hline $1820 \mathrm{~s}$ & 0.0 & 0.0 & 1.4 & 0.0 & 0.0 & 0.0 & 0.0 & 0.0 & 0.0 \\
\hline 1830s & 0.1 & 0.0 & 3.8 & 0.0 & 0.0 & 0.0 & 0.0 & 0.0 & 0.1 \\
\hline $1840 \mathrm{~s}$ & 0.5 & 0.0 & 6.0 & 0.0 & 0.0 & 0.0 & 0.0 & 0.0 & 0.2 \\
\hline $1850 \mathrm{~s}$ & 0.5 & 0.0 & 6.1 & 0.1 & 0.0 & 0.0 & 0.0 & 0.0 & 0.2 \\
\hline $1860 \mathrm{~s}$ & 0.8 & 0.1 & 6.2 & 0.1 & 0.0 & 0.0 & 0.0 & 0.0 & 0.3 \\
\hline 1870s & 2.7 & 0.2 & 7.3 & 0.1 & 0.0 & 0.0 & 0.0 & 0.0 & 0.7 \\
\hline $1880 \mathrm{~s}$ & 2.8 & 0.1 & 8.8 & 0.1 & 0.0 & 0.0 & 0.0 & 0.0 & 0.8 \\
\hline 1890s & 3.9 & 0.2 & 9.2 & 0.2 & 0.0 & 0.0 & 0.0 & 0.0 & 1.0 \\
\hline $1900 \mathrm{~s}$ & 4.9 & 0.2 & 7.9 & 0.3 & 0.0 & 0.0 & 0.0 & 0.0 & 1.2 \\
\hline 1910 s & 6.6 & 0.4 & 8.9 & 0.6 & 0.0 & 0.0 & 0.0 & 0.1 & 1.5 \\
\hline $1920 \mathrm{~s}$ & 14.2 & 2.3 & 11.7 & 1.2 & 0.1 & 0.0 & 0.0 & 0.1 & 2.8 \\
\hline 1930s & 13.5 & 2.2 & 14.1 & 1.1 & 0.2 & 0.0 & 0.0 & 0.2 & 2.8 \\
\hline $1940 \mathrm{~s}$ & 10.9 & 0.5 & 16.7 & 3.2 & 1.5 & 0.4 & 0.1 & 0.3 & 3.1 \\
\hline $1950 \mathrm{~s}$ & 18.9 & 0.2 & 16.6 & 6.1 & 3.2 & 7.3 & 0.9 & 0.4 & 6.5 \\
\hline $1960 \mathrm{~s}$ & 17.8 & 0.1 & 17.5 & 6.0 & 3.0 & 8.0 & 0.8 & 3.1 & 6.6 \\
\hline 1970s & 22.5 & 1.1 & 17.6 & 3.7 & 3.0 & 9.2 & 0.8 & 1.0 & 7.0 \\
\hline $1980 \mathrm{~s}$ & 27.3 & 4.6 & 17.4 & 7.6 & 3.0 & 9.9 & 1.2 & 2.1 & 7.9 \\
\hline 1990s & 34.4 & 15.0 & 19.9 & 18.3 & 3.6 & 13.5 & 1.3 & 4.1 & 12.7 \\
\hline $2000 \mathrm{~s}$ & 32.9 & 12.5 & 18.8 & 19.6 & 1.4 & 12.6 & 1.4 & 6.9 & 12.1 \\
\hline
\end{tabular}

Note: For an assessment of data quality, see Table 9.2.

Source: Clio-Infra, www.clio-infra.eu. 
Table 9.7. Regional averages of participation scores in democracy, 1820s-2000s

Percentages, decadal averages

\begin{tabular}{|c|c|c|c|c|c|c|c|c|c|}
\hline & $\begin{array}{c}\text { Western } \\
\text { Europe } \\
\text { (WE) }\end{array}$ & $\begin{array}{c}\text { Eastern } \\
\text { Europe } \\
\text { (EE) }\end{array}$ & $\begin{array}{l}\text { Western } \\
\text { Offshoots } \\
\text { (WO) }\end{array}$ & $\begin{array}{c}\text { Latin } \\
\text { America } \\
\text { and } \\
\text { Caribbean } \\
\text { (LA) }\end{array}$ & $\begin{array}{c}\text { East Asia } \\
(\mathrm{EA})\end{array}$ & $\begin{array}{c}\text { South and } \\
\text { South-East } \\
\text { Asia } \\
\text { (SSEA) }\end{array}$ & $\begin{array}{l}\text { Middle East } \\
\text { and } \\
\text { North Africa } \\
\text { (MENA) }\end{array}$ & $\begin{array}{l}\text { Sub-Saharan } \\
\text { Africa } \\
\text { (SSA) }\end{array}$ & World \\
\hline $1820 \mathrm{~s}$ & 0.0 & 0.0 & 2.9 & 0.0 & 0.0 & 0.0 & 0.0 & 0.0 & 0.0 \\
\hline 1830s & 0.3 & 0.0 & 8.1 & 0.0 & 0.0 & 0.0 & 0.0 & 0.0 & 0.2 \\
\hline $1840 \mathrm{~s}$ & 1.3 & 0.0 & 12.1 & 0.1 & 0.0 & 0.0 & 0.0 & 0.0 & 0.4 \\
\hline 1850s & 4.6 & 0.0 & 11.7 & 0.5 & 0.0 & 0.0 & 0.0 & 0.0 & 0.9 \\
\hline $1860 \mathrm{~s}$ & 5.7 & 0.2 & 12.1 & 0.6 & 0.0 & 0.0 & 0.0 & 0.0 & 1.2 \\
\hline $1870 \mathrm{~s}$ & 7.2 & 1.1 & 15.0 & 0.5 & 0.0 & 0.0 & 0.0 & 0.0 & 1.6 \\
\hline $1880 \mathrm{~s}$ & 7.4 & 0.3 & 17.0 & 0.9 & 0.0 & 0.0 & 0.0 & 0.0 & 1.8 \\
\hline 1890s & 8.8 & 0.8 & 17.8 & 1.4 & 0.0 & 0.0 & 0.0 & 0.0 & 2.2 \\
\hline $1900 \mathrm{~s}$ & 9.8 & 0.9 & 16.9 & 2.3 & 0.1 & 0.0 & 0.0 & 0.0 & 2.4 \\
\hline 1910s & 12.5 & 1.2 & 17.2 & 3.8 & 0.1 & 0.0 & 0.0 & 0.2 & 3.1 \\
\hline $1920 \mathrm{~s}$ & 24.5 & 4.6 & 26.4 & 6.4 & 0.4 & 0.0 & 0.1 & 0.3 & 6.0 \\
\hline 1930s & 27.6 & 11.8 & 33.0 & 7.0 & 0.9 & 0.0 & 0.0 & 0.4 & 6.7 \\
\hline 1940s & 20.8 & 27.3 & 35.2 & 10.9 & 2.8 & 1.3 & 0.3 & 0.7 & 7.3 \\
\hline $1950 \mathrm{~s}$ & 33.0 & 38.3 & 36.3 & 16.6 & 6.4 & 14.5 & 1.8 & 1.0 & 15.3 \\
\hline 1960s & 31.4 & 38.6 & 36.3 & 15.5 & 6.3 & 16.3 & 2.0 & 11.9 & 16.1 \\
\hline 1970s & 36.9 & 40.4 & 36.4 & 12.7 & 5.6 & 20.6 & 2.4 & 13.2 & 17.4 \\
\hline $1980 \mathrm{~s}$ & 44.2 & 43.4 & 37.4 & 19.9 & 5.8 & 24.5 & 4.3 & 16.5 & 20.1 \\
\hline 1990s & 56.1 & 33.8 & 37.3 & 36.1 & 5.6 & 27.5 & 3.7 & 14.3 & 25.0 \\
\hline $2000 \mathrm{~s}$ & 53.3 & 28.1 & 35.9 & 36.9 & 1.6 & 28.5 & 4.2 & 21.0 & 25.2 \\
\hline
\end{tabular}

Note: For an assessment of data quality, see Table 9.2.

Source: Clio-Infra, www.clio-infra.eu.

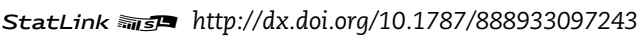

Table 9.8. Regional averages of competition scores in democracy, 1820s-2000s

Percentages, decadal averages

\begin{tabular}{|c|c|c|c|c|c|c|c|c|c|}
\hline & $\begin{array}{c}\text { Western } \\
\text { Europe } \\
\text { (WE) }\end{array}$ & $\begin{array}{c}\text { Eastern } \\
\text { Europe } \\
\text { (EE) }\end{array}$ & $\begin{array}{c}\text { Western } \\
\text { Offshoots } \\
\text { (W0) }\end{array}$ & $\begin{array}{l}\text { Latin } \\
\text { America } \\
\text { and } \\
\text { Caribbean } \\
\text { (LA) }\end{array}$ & $\begin{array}{c}\text { East Asia } \\
(\mathrm{EA})\end{array}$ & $\begin{array}{c}\text { South and } \\
\text { South-East } \\
\text { Asia } \\
\text { (SSEA) }\end{array}$ & $\begin{array}{l}\text { Middle East } \\
\text { and } \\
\text { North Africa } \\
\text { (MENA) }\end{array}$ & $\begin{array}{c}\text { Sub-Saharan } \\
\text { Africa } \\
\text { (SSA) }\end{array}$ & World \\
\hline $1820 \mathrm{~s}$ & 2.6 & 0.0 & 27.6 & 0.0 & 0.0 & 0.0 & 0.0 & 0.0 & 0.7 \\
\hline $1830 \mathrm{~s}$ & 12.0 & 0.0 & 40.2 & 0.0 & 0.0 & 0.0 & 0.0 & 0.0 & 2.2 \\
\hline $1840 \mathrm{~s}$ & 14.4 & 0.0 & 43.4 & 0.7 & 0.0 & 0.0 & 0.0 & 0.0 & 2.7 \\
\hline $1850 \mathrm{~s}$ & 11.6 & 0.0 & 45.4 & 7.2 & 0.0 & 0.0 & 0.0 & 0.0 & 2.8 \\
\hline $1860 \mathrm{~s}$ & 20.1 & 0.6 & 45.5 & 7.9 & 0.0 & 0.0 & 0.0 & 0.0 & 4.4 \\
\hline 1870 s & 32.0 & 3.2 & 45.7 & 8.8 & 0.0 & 0.0 & 0.0 & 0.0 & 6.7 \\
\hline $1880 \mathrm{~s}$ & 31.5 & 3.5 & 48.8 & 5.8 & 0.0 & 0.0 & 0.0 & 0.0 & 7.0 \\
\hline $1890 \mathrm{~s}$ & 35.4 & 3.9 & 48.8 & 9.7 & 2.1 & 0.0 & 0.0 & 0.0 & 8.6 \\
\hline $1900 \mathrm{~s}$ & 40.0 & 4.4 & 45.6 & 9.1 & 2.3 & 0.0 & 2.9 & 0.0 & 9.8 \\
\hline $1910 \mathrm{~s}$ & 44.1 & 6.1 & 51.0 & 14.9 & 9.0 & 0.0 & 1.9 & 3.3 & 13.7 \\
\hline $1920 \mathrm{~s}$ & 47.9 & 11.0 & 42.6 & 20.5 & 2.8 & 0.0 & 3.8 & 3.5 & 12.6 \\
\hline $1930 \mathrm{~s}$ & 36.6 & 10.9 & 41.2 & 13.9 & 3.2 & 0.0 & 0.0 & 4.3 & 10.3 \\
\hline $1940 \mathrm{~s}$ & 24.4 & 1.3 & 45.8 & 23.9 & 7.0 & 5.8 & 7.7 & 4.1 & 11.9 \\
\hline $1950 \mathrm{~s}$ & 37.5 & 0.3 & 44.2 & 35.7 & 8.0 & 32.8 & 5.6 & 4.9 & 22.3 \\
\hline $1960 \mathrm{~s}$ & 35.9 & 0.2 & 46.0 & 24.4 & 7.0 & 30.8 & 2.5 & 18.6 & 21.4 \\
\hline 1970 s & 41.9 & 2.1 & 45.9 & 16.0 & 6.1 & 34.1 & 2.2 & 7.3 & 21.4 \\
\hline $1980 \mathrm{~s}$ & 47.9 & 6.8 & 44.1 & 33.8 & 6.3 & 33.0 & 3.4 & 11.5 & 23.1 \\
\hline $1990 \mathrm{~s}$ & 59.5 & 30.8 & 50.4 & 51.5 & 7.0 & 42.1 & 3.8 & 17.6 & 32.9 \\
\hline $2000 \mathrm{~s}$ & 57.5 & 30.5 & 49.5 & 51.7 & 2.0 & 36.5 & 3.4 & 26.8 & 31.0 \\
\hline
\end{tabular}

Note: For an assessment of data quality, see Table 9.2.

Source: Clio Infra, www.clio-infra.eu. 


\section{Correlation with GDP per capita}

Figures 9.3 and 9.4 reveal similar patterns for both aggregate measures: statistically insignificant, close to zero correlation until the mid-19th century, followed by a period of stable, strong and positive correlation (around 0.5-0.6) from 1870s on, implying that democracy over this period was a privilege of wealthy countries. The positive correlation somewhat dropped in the second half of the 20th century in case of the polity2, which is a result of the democratisation process in Africa and the former Eastern-bloc countries.

The two figures show the linear (Pearson's) correlation coefficients between the different democracy indicators used in this chapter and per capita GDP. In all cases, the correlation coefficient was calculated per decade in order to avoid the problems resulting from non-stationarity. It should be noted that this type of correlation can be applied to variables measured as intervals or ratio scales. While this condition is met in case of the Index of Democracy as well as for GDP per capita, it is not met by the polity2 score, which is measured on an ordinal variable. Nevertheless for sake of comparability, and since polity scores are usually used in linear regression that require the same linearity assumption as the linear correlation, a linear correlation was applied here as well.

It should be stressed that the figures above show only co-movements among the variables, rather than causal relationship. Several theoretical and empirical studies have tried to reveal the causality between democracy and economic development. Early modernisation theory argued that a society must fulfil some social and economic prerequisites (economic development, urbanisation, education, mass media and communication, etc.) in order to reach political democracy (Roxborough, 1988; Lipset, 1959). Later studies recognised the possibility of reverse causality and analysed anomalies that do not fit into the general modernisation theory. Przeworski and Limongi (1993), for example, argued that democracy promotes GDP growth by limiting the predatory behaviour of autocratic leaders, but that it might also hinder it by increasing consumption and impeding investment. In the case of China, De Mesquita and Downs

Figure 9.3. Correlation between polity2 index and GDP per capita, 1820s-2000s

Pearson correlation coefficient and upper/lower bounds of $95 \%$ confidence interval per decade

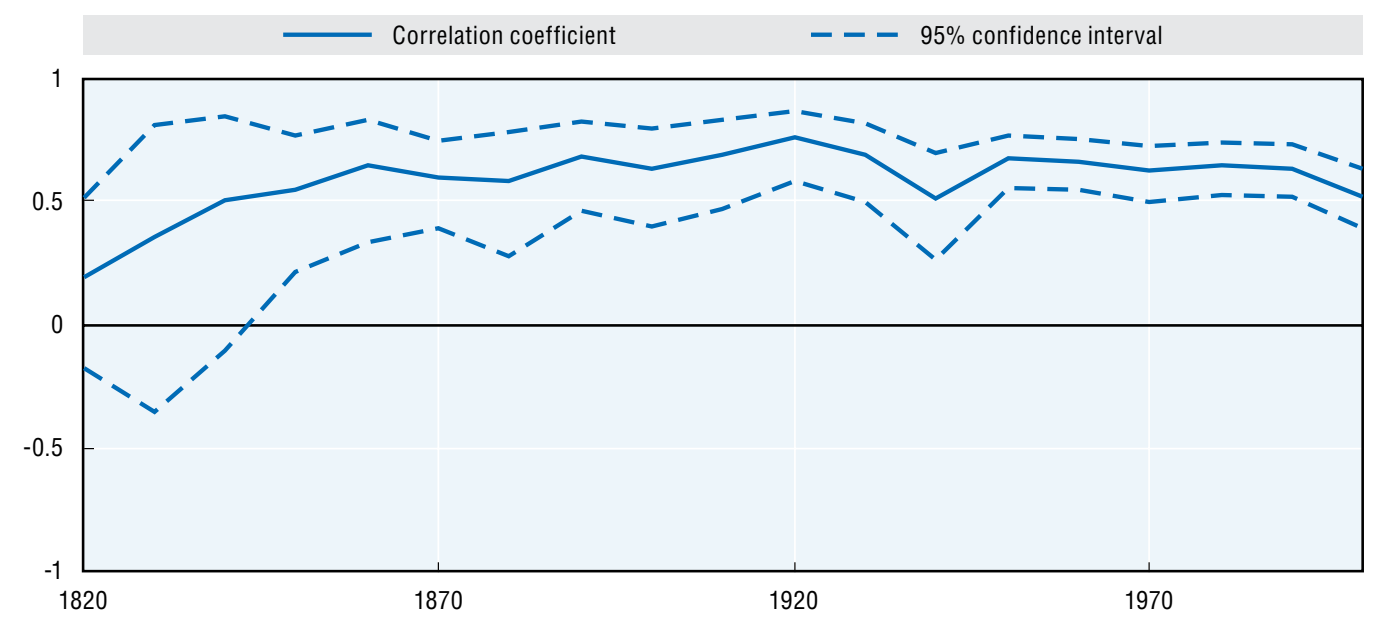

Note: For an assessment of data quality, see Table 9.2.

Source: Clio-Infra, www.clio-infra.eu. 
Figure 9.4. Correlation between Index of Democracy and GDP per capita, 1820s-2000s Pearson correlation coefficient and upper/lower bounds of $95 \%$ confidence interval per decade

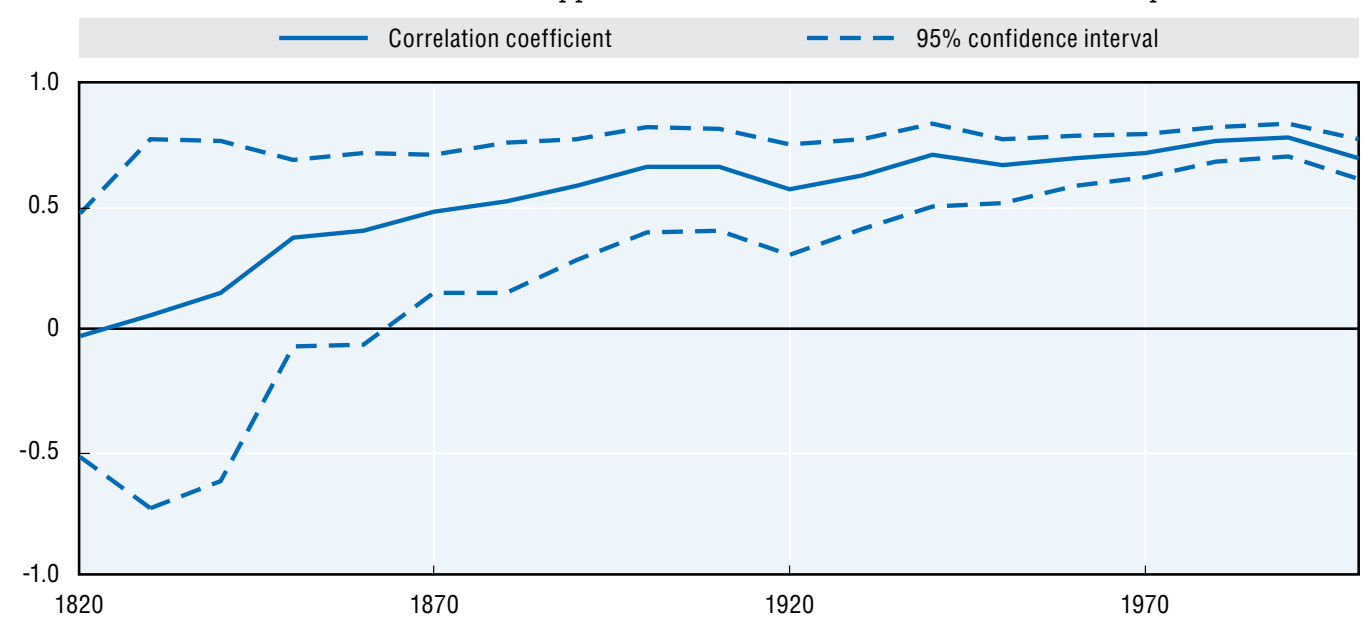

Note: For an assessment of data quality, see Table 9.2.

Source: Clio-Infra, www.clio-infra.eu.

(2005) argued that increasing economic development does not necessarily lead to greater democracy, since autocratic leaders are able to gain the benefits of development while avoiding pressures for loosening political control.

\section{Priorities for future research}

In this chapter, two aggregate indices (polity2 and the Vanhanen Index of Democracy) were used to review the main historical trends in political institutions. Even though there are significant differences in how these indicators measure democracy, they both suggest that a large wave of democratisation affected the world during the last 200 years. As for when the democratisation began, the two measures lead to differing conclusions: according to the polity2 indicator, the great wave of democratisation began in the mid-19th century, while the Index of Democracy suggests that it began only in the early 20th century. While both measures agree on the general trend, they lead to different conclusions when looking in more detail.

There are three main directions where further improvement could be of great importance. The most obvious one is the extension of available historical data on institutions. Currently, comparable historical datasets on political institutions exist only back to the early 1800s, and there is some data on the outcomes of the institutional system (like personal security, violent conflicts and parliamentary activity). It would be desirable, however, to have data on other aspects of institutions with comparable historical dimensions as well, such as the rule of law, including the protection of private property, the enforcement of contracts and the protection of intellectual property rights.

A second direction concerns an important technical issue, namely, the aggregation of institutional component indices into a single institutional variable. As was seen with polity2, it is often the case that either nominal or ordinal variables are aggregated into a single aggregate using arbitrary weights, which not only is problematic from a statistical point of view, but also lacks a clear theoretical justification. The latter applies to the Index 
of Democracy as well, where the components are metric, but there is no clear explanation of why multiplication the right way is to aggregate them.

Finally, it seems straightforward that using different imperfect measures of democracy would lead to different results. It should be kept in mind that the ability to measure democracy empirically is so limited that ultimately no indicators can be placed above the others. Hence, future research should consider the existence of a variety of alternative measures rather as an advantage, and so use different tools (e.g. meta-analysis, latent variable methods) to arrive at results that may get us closer to a consensus on the effects of democracy on a range of other socio-economic characteristics.

\section{Notes}

1. It is worthwhile distinguishing between social capital and institutions. Cote and Healy (2001) define social capital as "networks together with shared norms, values and understandings that facilitate co-operation within or among groups". On one level, this broad definition may be interpreted as encompassing institutions. On another level, the above definition refers only to "networks", i.e. interactions leading to improvement in well-being, while institutions refer to certain rules that govern interactions among individuals.

2. To gain a good practical overview of and insight into types of political institutions and ways to measure them, see Emory Libraries Electronic Data Center and Democracy Barometer.

3. The state antiquity index has been designed to test the hypothesis that current countries that have experienced statehood (nation-state, kingdoms or empires) for longer historical periods have been able to achieve higher economic development and growth in recent decades. Based on three features (the existence of government; indigenous or externally imposed government; the proportion of the territory covered) and data from the Encyclopaedia Britannica, each half-century is assigned a score of between 0 and 1 . The scores on the three questions are multiplied by one another and by 50 to account for the fifty-year periods. In order to get a more interpretable series, the sum computed based on the above method was divided by the maximum possible value that the series could take given a certain discount rate. Thus, the final state antiquity index in each period might assume a value between 0 and 1 .

4. These datasets are described in more detail in the next sub-section.

5. Dahl defined "polyarchy" as the existence of eight institutional guarantees (freedom of organization, freedom of expression, the right to vote, broad eligibility for public office, the right to compete for support and votes, the availability of alternative sources of information, free and fair elections, and the dependence of public policies on citizens' preferences), which can be classified into two underlying dimensions, namely "contestation or competition" and "inclusiveness or participation". Coppedge et al. (2008) further demonstrated the wide applicability of the concept of "polyarchy" by showing that the two principal components derived from the most popular democracy indicators (Banks, Gurr et al., Freedom House, Polity, Vanhanen, Przeworski et al.) correspond to the contestation or competition dimensions of polyarchy, which together account for about threequarters of the variation captured by the underlying measures.

6. The Freedom House index and the Economic Intelligence Unit's index of democracy are examples of maximalist approaches (Munck and Verkuilen, 2002; Kekic, 2007).

7. For the database and the user's manual, consult Polity IV Project.

8. Moreover, the six above-mentioned dimensions are also used to create three additional variables: executive recruitment, which combines the first three component variables; executive constraint, which is identical to the fourth component variable; and political competition, which combines information covered by the last two component variables.

9. See: Vanhanen's index of democracy.

10. Three other indicators could be used for long-term historical research but are not considered in this chapter. First, the Banks Cross-National Time Series (CNTS) Data Archive this is a collection of political, economic and demographic variables covering a range of countries from 1815 onwards. However, data on political institutions from this source are available only for the most recent period (time series on elections start from 1862, other political data such as party fractionalisation, number of constitutional changes, etc., have been compiled from 1919 onwards, and the observation 
of legislative process began in 1946). Second, the Boix et al. (2012) dataset, also inspired by Dahl's conceptual framework, is available for 219 countries from 1800 onwards, but it provides only a dichotomous measure, which is less suitable for showing historical trends. Finally, the Varieties of Democracy Project (https://v-dem.net/), which is expected to be completed by 2015, aims to provide data for 206 countries from 1900 onwards; the basic idea of this project is to gather indicators that can be related to at least one of the seven main dimensions of the scheme of Coppedge et al. (2011).

11. Vanhanen defended his strategy with the argument that the use of simple qualitative measures avoids the subjectivity involved in evaluating qualitative categories, even though the available statistics may be subject to measurement errors.

12. Rose and Shin (2001) and Diamond (1996) argue that the third wave might have come to an end.

13. The main regional trends are described by relying mostly on Huntington (1993).

\section{References}

Acemoglu, D. and Johnson, S (2005), “Unbundling Institutions”, Journal of Political Economy, Vol. 113/5, pp. 949-995.

Aslaksen, S. (2010), "Oil and democracy: more than a cross-section correlation?"Journal of Peace Research, Vol. 47/4, pp. 421-431.

Badawi, I. and S. Makdisi (2007), "Explaining the democracy deficit in the Arab world", The Quarterly Journal of Economics and Finance, Vol. 46/5, pp. 813-831.

Banks Cross-National Time Series (CNTS) Data Archive, www.databanksinternational.com.

Barro, R. (1999), “Determinants of democracy”, Journal of Political Economy, Vol. 107/6, pp. 158-183.

Bockstette, V., A Chanda and L. Putterman, (2002), "States and Markets: the advantage of an early start," Journal of Economic Growth, Vol. 7/4, pp. 347-369.

Boix, C., M. Miller and S. Rosato (2012), “A Complete Data Set of Political Regimes, 1800-2007." Comparative Political Studies, online version ahead of print, doi:10.1177/0010414012463905.

Borooah, V. K. and M. Paldam (2007), "Why is the world short of democracy? A cross-country analysis of barriers to representative government”, European Journal of Political Economy, Vol. 23/3, pp. 582-604.

Bowman, K., F. Lehoucq and J. Mahoney (2005), “Measuring Political Democracy, Case Expertise, Data Adequacy, and Central America", Comparative Political Studies, Vol. 38/8, pp. 939-970.

Chanda, A. and L. Putterman (2007), "Early Starts, Reversals and Catch-up in the Process of Economic Development", Scandinavian Journal of Economics, Vol. 109/2, pp. 387-413.

Dahl, R.A. (1972), Polyarchy: Participation and Opposition, Yale University Press, New Haven, CT.

Democracy Barometer, www.democracybarometer.org/links_en.html, accessed 17 January, 2014.

Diamond, L. (1996), “Is the third wave over?” Journal of Democracy, Vol. 7/3, pp. 20-37.

Eicher, T.S., C. García-Peñalosa and U. Teksoz, (2006), "How Do Institutions Lead Some Countries to Produce So Much More Output per Worker than Others?" Theo S. Eicher and Cecilia GarcíaPeñalosa (eds.), Institutions, Development, and Economic Growth, The MIT Press, pp. 65-80.

Emory Libraries Electronic Data Center, http://einstein.library.emory.edu/govinstlinks.html accessed 17 January 2014.

Frey, B.S. and A. Stutzer (2002), Happiness and Economics, Princeton University Press.

Glaeser, E.L., G.A.M. Ponzetto and A. Shleifer (2007), "Why does democracy need education", Journal of Economic Growth, Vol. 12/2, pp. 77-99.

Glaeser, E.L. and A. Shleifer, (2002), "Legal Origins", The Quarterly Journal of Economics, Vol. 117/4), pp. 1193-1229.

Glaeser, E.L. et al. (2004), "Do Institutions Cause Growth?" Journal of Economic Growth, Vol. 9/3, pp. 271-303.

Hall, Robert E. and C.I. Jones (1999), "Why Do Some Countries Produce So Much More Output Than Others?" Quarterly Journal of Economics, Vol. 114, pp. 83-116.

Huntington, S.P. (1991), “Democracy's third wave”, Journal of Democracy, Vol. 2/2, pp. 12-34. 
Huntington, S.P. (1993), The third wave: democratization in the late twentieth century, University of Oklahoma Press.

Keyssar, A. (2009), The Right to Vote: The Contested History of Democracy in the United States, New York: Basic Books (revised edition)

Knack, S. and P. Keefer (1995), "Institutions and Economic Performance: Cross-Country Tests Using Alternative Institutional Measures", Economics and Politics, Vol. 7/3, pp. 207-227.

Kubicek, P. (ed.) (2013), European Union and Democratization, Routledge.

La Porta, R. et al. (1999), "The Quality of Government”, The Journal of Law, Economics, and Organization, Vol. 15/1, pp. 222-279.

La Porta, R. et al. (2008), “The Economic Consequences of Legal Origins”, Journal of Economic Literature, Vol. 46/2, pp. 285-332.

Marshall, M.G.K. Jaggers and T.R. Gurr (2011), "POLITY IV project Political Regime Characteristics and Transitions, 1800-2010 Dataset Users' Manual”. www.systemicpeace.org/inscr/p4manualv2010.pdf.

Munck, G.L. and J. Verkuilen (2002), "Conceptualizing and measuring democracy”, Evaluating Alternative Indices. Comparative Political Studies, Vol. 35/1, pp. 5-34.

North, D. and R. Thomas (1973), The Rise of the Western World: A New Economic History, Cambridge University Press.

North, D. (1989), "Institutions and Economic Growth: an Historical Introduction", World Development, Vol. 17/9, pp. 1319-1332.

North, D. (1990), Institutions, Institutional Change and Economic Performance, Cambridge University Press.

OECD (2001), The Well-being of Nations: The Role of Human and Social Capital, OECD Publishing, http://dx.doi.org/10.1787/9789264189515-en.

OECD (2011), How's Life?: Measuring Well-being, OECD Publishing, Paris, http://dx.doi.org/10.1787/ 9789264121164-en.

Pacek, A.C., G. Pop-Eleches and J.A. Tucker (2009), "Disenchanted or Discerning: Voter Turnout in PostCommunist Countries”, The Journal of Politics, Vol. 71/2, pp. 473-491

Petrovic, M. (2013), The democratic transition of post-communist Europe: in the shadow of communist differences and uneven Europeanisation, Palgrave Macmillan.

Polity IV Project, http://www.systemicpeace.org/polity/polity4.htm accessed 11 June, 2013.

Potrafke, N. (2012), “Islam and democracy”, Public Choice, Vol. 151/1-2, pp. 185-192.

Przeworski, A. and F. Limongi (1993), "Political Regimes and Economic Growth", Journal of Economic Perspectives, Vol. 7/3, pp. 51-69.

Przeworski, A. et al. (2000), Democracy and Development. Political Institutions and Well-being in the World, 1950-1990, Cambridge University Press.

Reich, G. (2002), “Categorizing Political Regimes: New Data for Old Problems”, Democratization, Vol. 9/4, pp. 1-24.

Rose, R. and D.C. Shin (2001), "Democratization backwards: the problem of third-wave democracies," British Journal of Political Science, Vol. 31/2, pp. 331-354.

Ross, M.L. (2001), “Does oil hinder democracy?” World Politics, Vol. 53/3, pp. 325-361.

Sen, A. (1993), "Capability and Well-Being" in M. Nussbaum and A. Sen, eds. The Quality of Life, pp. 30-53, Oxford Clarendon Press, New York.

Vanhanen's index of democracy, www.prio.no/Data/Governance/Vanhanens-index-of-democracy/accessed 11 June, 2013.

Vanhanen, T. (2003), Democratization: A Comparative Analysis of 170 Countries, Routledge, London. 



\title{
Chapter 10
}

\section{Environmental quality since 1820}

\author{
by
}

Kees Klein Goldewijk,

Utrecht University and PBL Netherlands Environmental Assessment Agency

The quality of the environment is obviously important for well-being, not only because of the role it plays as a source of raw materials, now and in the future, but also for human health and because of humans' appreciation of nature. This chapter presents historical trends in sustainability and environmental quality based on measures of biodiversity and of emissions of $\mathrm{CO}_{2}$ and $\mathrm{SO}_{2}$. It documents long-term declines of biodiversity worldwide, as well as increasing emissions. These indicators are mostly model based: biodiversity measures are derived from the renowned GLOBIO model, while $\mathrm{CO}_{2}$ and $\mathrm{SO}_{2}$ emissions are mostly based on energy production. The chapter describes the assumptions and limitations of both indicators, including a warning about the partial and possibly biased nature of these indices, which give only a glimpse of the complex interactions between humanity and nature. 


\section{Introduction}

The quality of life of human beings is strongly affected by a healthy physical environment (OECD, 2011). Environmental pollution plays a role in more than $80 \%$ of major diseases, and about $25 \%$ of diseases and deaths globally are due to poor environmental conditions (OECD, 2011). The environment also has an intrinsic value because of the beauty of landscapes and because most humans care about the planet. Humans also directly benefit from environmental goods and services, such as water, clean air, and forest products (food, fibre, shelter, recreation, etc.). In the light of growing concerns about the sustainable use of the Earth's environmental resources, it is important to add a long-term dimension to these concerns by looking at the development of a number of key environmental indicators over the very long run. This chapter outlines some important trends in environmental quality over the past two hundred years, which reflect monumental changes in society, agriculture and mining.

In thinking about the environment, an important conceptual distinction needs to be made between environmental quality (the impact of the environment on people's immediate well-being) and sustainability (the capacity of the environment to sustain a given level of wellbeing into the future). This chapter will try to give a sense of the historical development of several important indicators of these two main dimensions, while also considering changes in biodiversity (the degree to which life on Earth is growing more or less varied). The data presented here about pollution and biodiversity loss relate to environmental quality as experienced directly by the world's inhabitants, while the data concerning climate change are relevant for understanding the determinants of global warming, and therefore relate more directly to environmental sustainability.

The relationship between environmental degradation and economic development has been the topic of much recent research. The World Development Report of 1992 (WDR, 1992) first launched the ideas behind an Environmental Kuznets Curve (EKC). Panatoyou (1993) gave the curve its name after the original curve proposed by Simon Kuznets, who hypothesised that income inequality first rises and then falls as economic development proceeds (Kuznets, 1955). The environmental Kuznets curve is a hypothesised relationship between environmental quality and economic development: indicators of environmental degradation tend to worsen as modern economic growth occurs until average income reaches a certain point (Panatoyou, 1993, 1994). In general, Kuznets curves have been found for some environmental health concerns (air pollutants), but not for others (landfills and biodiversity). Some suggest that there is little or no evidence that the relationship holds true for the use of natural resources or for biodiversity conservation (Stern et al., 1996; Stern, 2004). So it is possible that the inverted U-shaped curve applies to only a few environmental health indicators, such as emissions of $\mathrm{SO}_{2}, \mathrm{NOx}, \mathrm{CFCs}$, heavy metals (e.g. lead), pesticides (e.g. DDT) and sewage, all substances that are released directly into the air or water.

It is beyond the scope of this chapter to deal with this debate in much detail. Instead, the focus is on a number of key indicators of environmental quality (biodiversity and 
emissions of $\mathrm{SO}_{2}, \mathrm{CFC}$ and $\mathrm{CO}_{2}$ ) that represent various dimensions of environmental quality, and for which consistent historical data (or more or less plausible estimates) are available. For example, an increase in $\mathrm{SO}_{2}$ emissions has had an immediate impact on the well-being of people living in areas with increased $\mathrm{SO}_{2}$ pollution. The decline of biodiversity affects our well-being in a much more indirect, long-term way. $\mathrm{CO}_{2}$ emissions are harmful because they contribute to global warming, and therefore the well-being of future populations. By harming the ozone layer in the atmosphere, CFC emissions have also impacted human welfare indirectly (but rather immediately). Together these indicators give some impression of the magnitude of the problems involved, and the degree to which international and national economic policies succeeded in redressing their consequences.

\section{Description of the concepts used}

In 1987, the UN published the Brundtland report, "Our Common Future", which introduced the concept of sustainability. One widely-used definition describes sustainability as "meeting the needs of the present without compromising the ability of future generations to meet their own needs". Similarly, sustainable development (SD) is often described as a pattern of economic growth in which resource use aims to meet human needs while preserving the environment and other resources so that these needs can be met not only in the present, but also for generations to come. There are obvious relationships between environmental sustainability and the quality of the environment. More recently, the OECD's Environmental Outlook presented a set of key indicators to describe the state of the environment (OECD, 2012a, 2012b). The main categories were climate change (GHG emissions), biodiversity loss (deforestation, expansion of agricultural lands), health impacts (ozone, indoor air pollution, disability-adjusted life years (DALY), and water scarcity (drinking water, irrigation, sanitation). This approach cannot be replicated in this study because of the sheer lack of historical data about most categories, both spatially (most countries in the world are usually missing some data) and temporally (data series often do not go back in time very far, decades instead of centuries). Therefore, a limited selection had to be made based on data availability, with each indicator selected more or less as a representative proxy for different aspects of environmental quality (Table 10.1).

There are of course numerous other pollutants all over the world, such as detergents, asbestos, plastics and many other poisonous substances. However, these are not included in this study because of the lack of proper historical data series covering all the world's countries and regions for the past two hundred years.

Table 10.1. Overview of selected environmental themes in How Was Life?

\begin{tabular}{lll}
\hline \multicolumn{1}{c}{ Environmental Quality - local, direct } \\
Pollution & \multicolumn{1}{c}{ Indicators per theme } & \multicolumn{1}{c}{ Sub indicators } \\
& $\mathrm{SO}_{2}$ emissions & Coal \& Oil production, Copper smelting \\
Nature - local, direct & Lead production & Mining statistics \\
& \multicolumn{1}{c}{ Biodiversity loss } & Cropland expansion \\
Climate & Pasture expansion \\
& $\mathrm{CO}_{2}$ emissions & Coal, oil, gas production \\
& $\mathrm{CFC}$ 's emissions & CFC production \\
\hline
\end{tabular}




\section{Indicator I. Pollution: $\mathrm{SO}_{2}$}

Sulphur dioxide $\left(\mathrm{SO}_{2}\right)$ is a toxic gas that is released both in natural processes such as volcanic eruptions and in various human activities (e.g. industrial processes). Sulphur dioxide forms sulphate aerosols that can have significant climate effects globally and regionally. Sulphate aerosols reflect sunlight into space and also act as condensation nuclei, which tend to make clouds more reflective and change their lifetimes, causing a net cooling. This is in contrast to the Earth' radiative forcing (mainly caused by carbon dioxide), which is causing a net warming. Sulphur is ubiquitous in the biosphere and often occurs in relatively high concentrations in fossil fuels, with coal and crude oil deposits commonly containing 1-2\% sulphur by weight. The widespread combustion of fossil fuels has therefore greatly increased sulphur emissions into the atmosphere, with the anthropogenic component now substantially greater on a global basis than natural emissions (Smith et al. 2011). These anthropogenic emissions have resulted in greatly increased sulphur deposition and atmospheric sulphate loadings near most industrialised areas. Sulphuric acid deposition can be detrimental to ecosystems, harming aquatic animals and plants and damaging a wide range of terrestrial plant life. This is what is involved in "acid rain", a broad term referring to a mixture of wet and dry deposition (deposited material) from the atmosphere containing higher than normal amounts of nitric and sulfuric acids. It causes acidification of lakes and streams and contributes to damaging trees at high elevations and many sensitive forest soils. In addition, acid rain accelerates the decay of building materials and paints.

Although acid rain has been a serious problem in North America, Europe and East Asia, this particular problem can be solved. There are several options for reducing $\mathrm{SO}_{2}$ and $\mathrm{NO}_{\mathrm{x}}$ emissions, including using coal containing less sulphur, washing the coal, and using devices called "scrubbers" to chemically remove the $\mathrm{SO}_{2}$ from the gases leaving the smokestack (United States Environmental Protection Agency). Power plants can also switch fuels (gas instead of coal, or nuclear power, hydropower, wind energy, geothermal energy or solar energy), and cars have been forced by law to use catalytic converters to reduce $\mathrm{NO}_{\mathrm{x}}$ emissions. All these measures have led to a large decrease in $\mathrm{SO}_{2}$ and $\mathrm{NO}_{\mathrm{x}}$ emissions during the past decades, thus confirming the EKC curve for these pollutants.

\section{Indicator II. Nature}

Biodiversity - the variety of animals, plants and micro-organisms at the genetic, species and ecosystem levels - is necessary to sustain key functions of the ecosystem. A well-functioning ecosystem can supply ecosystem services, defined as "the benefits provided by ecosystems to humans". Key ecosystem services, including nutrient cycling, carbon sequestration, fresh air and water purification, pest regulation and pollination, sustain agricultural productivity. According to the Millennium Ecosystem Assessment project (MEA, 2005), biodiversity is a necessary underlying component of ecological goods and services, supporting biological control and genetic resources.

Biodiversity can be expressed as the remaining Mean Species Abundance (MSA) of original species, relative to their abundance in pristine vegetation, assumed not to be disturbed by human activities for a prolonged period. MSA is an indicator of naturalness or biodiversity intactness. An area with an MSA of $100 \%$ means a biodiversity that is similar to the natural situation. An MSA of $0 \%$ means a completely destroyed ecosystem with no original species remaining. 
This approach to biodiversity, based on the GLOBIO model, has been developed by the Netherlands Environmental Assessment Agency (Alkemade et al., 2009; see also http://www.globio.info/). The latest model version is built on a set of equations linking environmental drivers and biodiversity impact. The underlying causal relationships are derived from the available literature using meta-analyses. ${ }^{1}$ It should be emphasised that the MSA indicator does not completely cover the complex concept of biodiversity, and complementary indicators should be included when used in extensive biodiversity assessments (Faith et al., 2008). The MSA is widely used in integrated assessments, such as UNEP's Global Environmental Outlook (UNEP, 2012) and the OECD's Environmental Outlook (OECD, 2012a).

Global environmental drivers of biodiversity change are input for GLOBIO3. In this particular case, a simplified method is used since not all the drivers are available for the historical period. Therefore, historical land use changes are the main driver here. The long-term historical expansion of cropland, pastureland (land used for grazing livestock, intensively as well as extensively) and built-up area (urban sprawl, growth of cities and towns) are taken from the HYDE 3.1 database (Klein Goldewijk et al., 2011). GLOBIO3 calculates the overall MSAi value by subtracting the individual MSAX maps from the potential maximum available grid cell land area (and dividing with it so as to obtain a fraction):

$$
\text { MSAi,t }=\left(\text { Gareai }-0.7^{*} \text { Croplandi, } t-0.3{ }^{*} \text { Pasturei, } t-0.95^{*} \text { Built-upi,t }\right) / \text { Gareai }
$$

where $i$ is a grid cell, $t$ is the (historical) time step, MSAi is the overall value for grid cell $i$, and Gareai is the total available land area of grid cell i. Cropland, Pasture and Built-up are the corresponding historical land use areas at time step $t$. The multipliers are derived from expert judgment, indicating a very high negative impact on biodiversity (0.95), a severe impact (0.7) or a modest impact (0.3).

\section{Indicator III. Climate change}

Over the past millennia, human activities have seriously altered the global carbon cycle, most significantly in the atmosphere, through the conversion of natural ecosystems into agriculture and during the last three centuries through the burning of fossil fuels. Carbon in the Earth's atmosphere exists in two main forms: carbon dioxide $\left(\mathrm{CO}_{2}\right)$ and methane $\left(\mathrm{CH}_{4}\right)$. Both of these gases absorb and retain heat in the atmosphere and are partially responsible for the greenhouse effect. Methane produces a large greenhouse effect per volume as compared to carbon dioxide, but it exists in much lower concentrations and is more shortlived than carbon dioxide, making carbon dioxide the more important greenhouse gas of the two. Human activities have significantly increased the release of carbon into the atmosphere, mainly in the form of carbon dioxide, both by modifying ecosystems and by emitting it directly, (e.g. by burning fossil fuels and manufacturing concrete). Although $\mathrm{CO}_{2}$ levels have changed naturally over the past several thousand years, human emissions now exceed natural fluctuations, thus disturbing the Earth's atmospheric carbon balance (Le Quéré et al. 2012). Carbon dioxide emissions have been chosen as a proxy for the influence of humans on the climate, since historical time series on a country basis are available for $\mathrm{CO}_{2}$ (but not for $\mathrm{CH}_{4}$ ). The Carbon Dioxide Information and Analysis Center (CDIAC) has an elaborate database on $\mathrm{CO}_{2}$ emissions for all the world's countries for the period from 1751 to the present. These emissions are based purely on energy consumption statistics, the burning of fossil fuel only, so no land use emissions are included here. 


\section{Historical sources}

Sulphur dioxide. Sulphur aerosols impact human health, ecosystems, agriculture, and the global and regional climate. A new annual estimate of anthropogenic global and regional sulphur dioxide emissions has been constructed spanning the period 1850-2005 using a bottom-up mass balance method, calibrated to country-level inventory data (Smith et al., 2011). Global data for historical $\mathrm{SO}_{2}$ emission estimates were taken from Stern \& Kaufmann (1996), and country data from Smith et al. (2011). The sectors included were coal, oil and natural gas combustion, metal smelting, other industrial processes, traditional biomass combustion, land-use (changes), other and ocean bunker fuels. Coal, oil and natural gas combustion and metal smelting are responsible for more than $90 \%$ of $\mathrm{SO} 2$ emissions. Longterm historical statistics for coal, oil and natural gas production are available on a country basis for the period 1800-1980 from Etemad et al. 1991. They have been updated towards the present day with data from Mitchell, 1993a and 1993b, Mitchell, 1998. and IEA (2013). ${ }^{2}$

Biodiversity. Important drivers for computing biodiversity were taken from the HYDE database (Klein Goldewijk et al. 2010, 2011). The HYDE database provides historical estimates for the amount of cropland, pasture and built-up area for the period 10000 BC till the year 2000. These estimates are based partly on data from the United Nations Food and Agricultural Organisation (2012), which presents country data on cropland and pasture for the period from 1961 to the present. For the pre-1961 period, many different countryspecific statistical data sources have been used, varying in time and spatial extent (see Klein Goldewijk et al. 2011).

Carbon dioxide. The original source for carbon dioxide emissions is the estimates of the Carbon Dioxide Information and Analysis Center (CDIAC; Marland and Rotty, 1984). Global, regional and national annual estimates of $\mathrm{CO}_{2}$ emissions from fossil-fuel burning, cement production and gas-flaring have been calculated, some for as far back as 1751 . These estimates, derived primarily from energy statistics published by the United Nations, were calculated using the methods of Marland and Rotty (1984). Cement production estimates from the United States Department of Interior's Bureau of Mines were used to estimate $\mathrm{CO}_{2}$ emitted during cement production. Emissions from gas-flaring were derived primarily from UN data but were supplemented with data from the United States Department of Energy's Energy Information Administration (Rotty, 1974), and with a few national estimates provided by G. Marland. Time series were regularly updated till the current time (Boden et al., 2012; see also the Global Carbon Project at www.globalcarbonproject.org/). ${ }^{3}$

\section{Data quality}

Table 10.2 provides an overall assessment of the quality of the historical data on $\mathrm{SO}_{2}$ and $\mathrm{CO}_{2}$ emission used in this report. Estimates of $\mathrm{SO}_{2}$ emissions were not available on a country basis before 1850 . However, emissions before then were relatively low, so the error here is likely to be rather small. The $\mathrm{CO}_{2}$ emissions data are very well documented at the CDIAC, and are based on detailed energy statistics from the United Nations statistical office.

Table 10.3 provides a similar assessment of data quality for the biodiversity indicator used here. There is still a great deal of discussion about the exact definition of biodiversity loss and how to quantify it.The MSA approach is also under debate, but at least it is published and accepted as one way of describing this. The approach followed here is nevertheless hampered by the lack of some historical data sources (e.g. no historical infrastructure maps are used), but the major driving forces such as the expansion of agricultural lands are included, which justify the use of MSA as an indicator. 
Table 10.2. Quality of data on $\mathrm{SO}_{2}$ and $\mathrm{CO}_{2}$ emissions by region and benchmark year, 1820-2000

Based on coal, oil and gas production statistics

\begin{tabular}{ccccccccc}
\hline & \multicolumn{9}{c}{$\begin{array}{c}\text { Latin } \\
\text { America } \\
\text { and } \\
\text { Western } \\
\text { Europe } \\
\text { (WE) }\end{array}$} & $\begin{array}{c}\text { Eastern } \\
\text { Europe } \\
\text { (EE) }\end{array}$ & $\begin{array}{c}\text { Western } \\
\text { Offshoots } \\
\text { (W0) }\end{array}$ & $\begin{array}{c}\text { Cab-Saharan } \\
\text { (LA) }\end{array}$ & $\begin{array}{c}\text { Africa } \\
\text { (SSA) }\end{array}$ & $\begin{array}{c}\text { Middle East } \\
\text { and } \\
\text { North Africa } \\
\text { (MENA) }\end{array}$ & $\begin{array}{c}\text { East Asia } \\
\text { (EA) }\end{array}$ & $\begin{array}{c}\text { South and } \\
\text { South-East } \\
\text { Asia } \\
\text { (SSEA) }\end{array}$ \\
\hline 1820 & 3 & 3 & 3 & 3 & 4 & 4 & 3 & 3 \\
1860 & 3 & 3 & 2 & 3 & 4 & 4 & 3 & 3 \\
1900 & 2 & 2 & 2 & 2 & 3 & 3 & 2 & 2 \\
1950 & 2 & 2 & 2 & 2 & 3 & 3 & 2 & 2 \\
2000 & 1 & 1 & 1 & 1 & 2 & 2 & 1 & 1 \\
\hline
\end{tabular}

Note: 1. High quality; 2. Moderate quality; 3. Low quality; and 4. Estimates. See the section on "Data Quality" in Chapter 1 for a description of the quality criteria.

Source: Clio-Infra, www.clio-infra.eu.

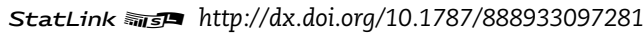

Table 10.3. Quality of data on biodiversity indicator by region and benchmark year, 1820-2000

Based on cropland and pasture statistics

\begin{tabular}{ccccccccc}
\hline & $\begin{array}{c}\text { Western } \\
\text { Europe } \\
\text { (WE) }\end{array}$ & $\begin{array}{c}\text { Eastern } \\
\text { Europe } \\
\text { (EE) }\end{array}$ & $\begin{array}{c}\text { Western } \\
\text { Offshoots } \\
\text { (WO) }\end{array}$ & $\begin{array}{c}\text { America } \\
\text { and } \\
\text { Caribbean } \\
(\text { LA) }\end{array}$ & $\begin{array}{c}\text { Sub-Saharan } \\
\text { Africa } \\
(\text { SSA })\end{array}$ & $\begin{array}{c}\text { Middle East } \\
\text { and } \\
\text { North Africa } \\
\text { (MENA) }\end{array}$ & $\begin{array}{c}\text { East Asia } \\
\text { (EA) }\end{array}$ & $\begin{array}{c}\text { South and } \\
\text { South-East } \\
\text { Asia } \\
\text { (SSEA) }\end{array}$ \\
\hline 1820 & 3 & 3 & 2 & 3 & 4 & 4 & 3 & 3 \\
1860 & 3 & 3 & 2 & 3 & 4 & 4 & 3 & 3 \\
1900 & 2 & 2 & 1 & 2 & 3 & 3 & 2 & 2 \\
1950 & 1 & 1 & 1 & 1 & 3 & 3 & 1 & 1 \\
2000 & 1 & 1 & 1 & 1 & 2 & 2 & 1 & 1 \\
\hline
\end{tabular}

Note: 1. High quality; 2. Moderate quality; 3. Low quality; and 4. Estimates. See the section on "Data Quality" in Chapter 1 for a description of the quality criteria.

Source: Clio-Infra, www.clio-infra.eu.

\section{Main highlights of trends in environmental quality}

Pollution - $\mathrm{SO}_{2}$ emissions. Pollution from $\mathrm{SO}_{2}$ emissions began early on in Europe, followed by the United States, with a peak in emissions in the 1970s and 1980s (Figure 10.1). A sharp decrease in emissions occurred especially in Europe due to the breakup of the USSR and the resulting economic crisis there, and in most other Central European countries. But along with the collapse of a great deal of heavy industry, many environmental policies were also put in place in Western Europe (e.g. closing of brown coal mining). The European Environmental Agency (2007) reported that for 32 European countries sulphur dioxide emissions decreased by $66 \%$ between 1990 and 2005. The overall reduction in $\mathrm{SO}_{2}$ emissions in Europe and the Western Offshoots since 1990 has been achieved as a result of a combination of measures, including fuel-switching in energy-related sectors away from high sulphur-containing fuels. In 2005, the most significant source of $\mathrm{SO}_{2}$ emissions was the energy industries sector (41\%), followed by industrial processes (35\%) and industrial energy use (13\%). Recently, many parts of Asia (China) have rapidly caught up and seem poised to undergo the same kind of problems with air pollution as Europe experienced in the 20th century. 
Figure 10.1. Regional totals of $\mathrm{SO}_{2}$ emissions, $\mathbf{1 8 2 0 - 2 0 0 0}$

Values in petagrams $\mathrm{SO}_{2}\left(\mathrm{Pg} \mathrm{SO}_{2}\right.$, where peta $\left.=10^{15}\right)$

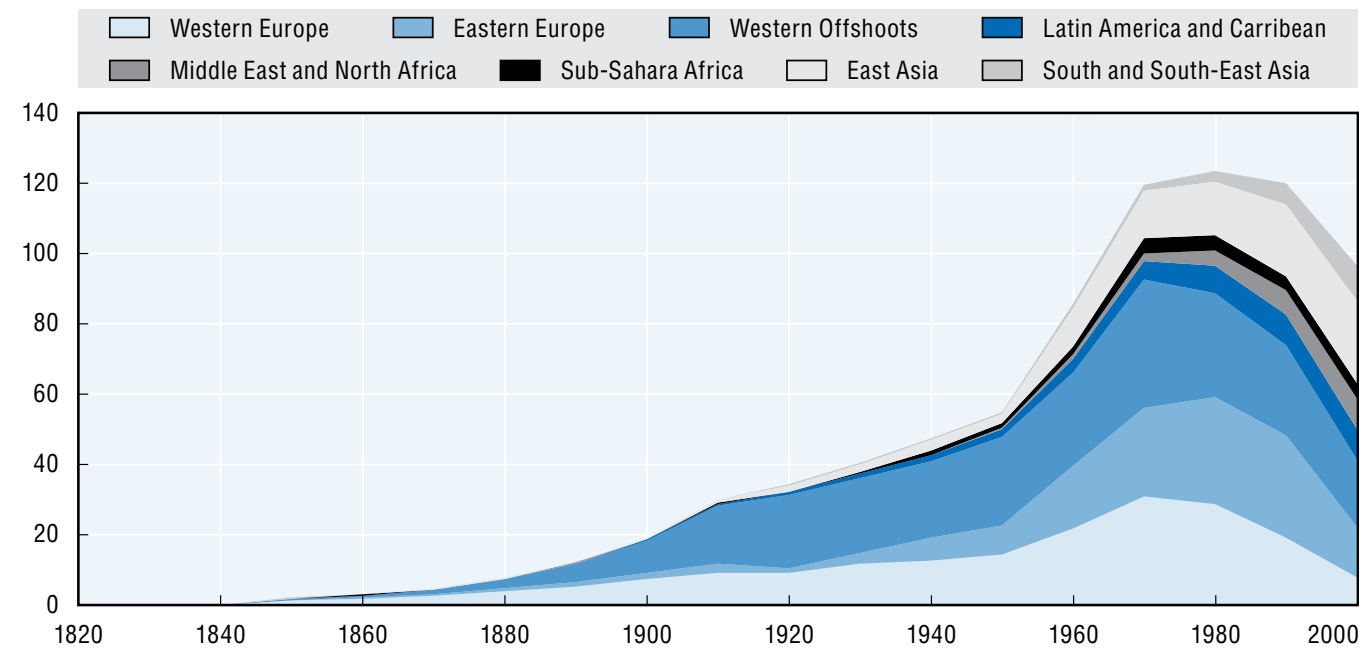

Note: For an assessment of data quality, see Tables 10.2 and 10.3 .

Source: Clio Infra, www.clio-infra.eu.

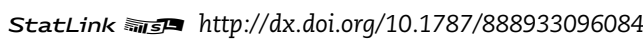

Sulphur production started during the mid-19th century in Europe and North America, and early in the 20th century in Latin America and Asia. $\mathrm{SO}_{2}$ production peaked in Europe $\left(31 \mathrm{Pg} \mathrm{SO}_{2}\right)$ and the United States $\left(30 \mathrm{Pg} \mathrm{SO}_{2}\right)$ during the second half of the 20th century, but is still increasing in Asia, Oceania and South America and to a much lesser extent in Africa. Global $\mathrm{SO}_{2}$ emissions increased from $0.2 \mathrm{Pg} \mathrm{SO}_{2}$ in $\mathrm{AD} 1850$ to a peak of $123 \mathrm{Pg} \mathrm{SO}_{2}$ in the 1980s, and slowly decreased to $96 \mathrm{Pg} \mathrm{SO}_{2}$ in 2000.

Tables 10.4 and 10.5 show that per capita $\mathrm{SO}_{2}$ emissions were already relative high in the Western Offshoots in the early 20th century, peaking at 0.17 ton $\mathrm{SO}_{2}$ per capita in the 1920s. Afterwards this slowly declined towards 0.06 ton $\mathrm{SO}_{2}$ per capita in 2000. Emissions per capita in Eastern European (Poland) peaked much later, around 1980, and Western Europe (UK, France, Sweden) followed a similar pattern. Latin America and Africa and the greater part of Asia still have very low $\mathrm{SO}_{2}$ emissions per capita.

Biodiversity loss due to land use change. As long as humans have been present on the Earth, they have been altering the global landscape. These historical changes in land use, primarily conversion (deforestation) of undisturbed ecosystems to other forms of land use (cropland, grazing land), have contributed considerably to the cumulative carbon dioxide $\left(\mathrm{CO}_{2}\right)$ increase in the atmosphere. Cropland occupied roughly less than $1 \%$ of the global icefree land area for a long time period, until the year 1000, which was a level comparable with pastureland. In the centuries that followed the share of cropland increased to $2 \%$ in 1700 (about 3 million sq.km) and 11\% in 2000 (15 million sq.km, Figure 10.2, top panel), while the share of pasture area grew from $2 \%$ in 1700 to $24 \%$ in 2000 (34 million sq.km, Figure 10.2, bottom panel; see also Klein Goldewijk et al. 2011).

Tables 10.6 and 10.7 show that biodiversity expressed as MSA has decreased in all regions of the world. Europe witnessed a much earlier loss of biodiversity than other regions, and a much larger loss as well. Williams, (2000) reports that Europe lost almost $90 \%$ of its forest during the period from 900 to 1900 . However, during the 20th century a process of forest transition (reversal of forest loss into gain of forest area) took place in the USA, parts of Europe 
Table 10.4. Regional averages of $\mathrm{SO}_{2}$ emissions per capita, 1820-2000

Metric ton $\mathrm{SO}_{2}\left(\right.$ t. $\mathrm{SO}_{2}$, where ton $=10^{3}$ )

\begin{tabular}{|c|c|c|c|c|c|c|c|c|c|}
\hline & $\begin{array}{l}\text { Western } \\
\text { Europe } \\
\text { (WE) }\end{array}$ & $\begin{array}{c}\text { Eastern } \\
\text { Europe } \\
\text { (EE) }\end{array}$ & $\begin{array}{l}\text { Western } \\
\text { Offshoots } \\
\text { (WO) }\end{array}$ & $\begin{array}{l}\text { Latin } \\
\text { America } \\
\text { and } \\
\text { Caribbean } \\
\text { (LA) }\end{array}$ & $\begin{array}{c}\text { East Asia } \\
(\mathrm{EA})\end{array}$ & $\begin{array}{c}\text { South and } \\
\text { South-East } \\
\text { Asia } \\
\text { (SSEA) }\end{array}$ & $\begin{array}{l}\text { Middle East } \\
\text { and } \\
\text { North Africa } \\
\text { (MENA) }\end{array}$ & $\begin{array}{l}\text { Sub-Saharan } \\
\text { Africa } \\
\text { (SSA) }\end{array}$ & World \\
\hline 1820 & .. & & .. & .. & .. & .. & .. & .. & \\
\hline 1830 &.. & .. & .. & .. & .. & .. & .. &.. & .. \\
\hline 1840 & .. & .. & .. & .. & .. & .. & .. & .. & .. \\
\hline 1850 & 0.007 & 0.001 & 0.012 & 0.001 & 0.000 & 0.000 & 0.000 & 0.000 & 0.002 \\
\hline 1860 & 0.010 & 0.001 & 0.020 & 0.002 & 0.000 & 0.000 & 0.000 & 0.000 & 0.002 \\
\hline 1870 & 0.014 & 0.002 & 0.031 & 0.002 & 0.000 & 0.000 & 0.000 & 0.000 & 0.004 \\
\hline 1880 & 0.019 & 0.005 & 0.048 & 0.002 & 0.000 & 0.000 & 0.000 & 0.000 & 0.005 \\
\hline 1890 & 0.023 & 0.007 & 0.076 & 0.002 & 0.000 & 0.000 & 0.001 & 0.000 & 0.008 \\
\hline 1900 & 0.029 & 0.010 & 0.110 & 0.002 & 0.001 & 0.000 & 0.001 & 0.000 & 0.012 \\
\hline 1910 & 0.034 & 0.012 & 0.160 & 0.006 & 0.001 & 0.002 & 0.002 & 0.000 & 0.017 \\
\hline 1920 & 0.033 & 0.008 & 0.170 & 0.007 & 0.001 & 0.002 & 0.003 & 0.001 & 0.018 \\
\hline 1930 & 0.040 & 0.014 & 0.152 & 0.009 & 0.001 & 0.003 & 0.003 & 0.001 & 0.019 \\
\hline 1940 & 0.041 & 0.026 & 0.143 & 0.011 & 0.003 & 0.007 & 0.004 & 0.001 & 0.020 \\
\hline 1950 & 0.044 & 0.035 & 0.138 & 0.012 & 0.006 & 0.008 & 0.003 & 0.001 & 0.022 \\
\hline 1960 & 0.061 & 0.072 & 0.123 & 0.017 & 0.008 & 0.012 & 0.014 & 0.002 & 0.030 \\
\hline 1970 & 0.081 & 0.097 & 0.148 & 0.018 & 0.012 & 0.014 & 0.014 & 0.002 & 0.033 \\
\hline 1980 & 0.072 & 0.112 & 0.108 & 0.022 & 0.016 & 0.012 & 0.013 & 0.002 & 0.028 \\
\hline 1990 & 0.047 & 0.101 & 0.085 & 0.020 & 0.019 & 0.008 & 0.015 & 0.004 & 0.023 \\
\hline 2000 & 0.019 & 0.048 & 0.057 & 0.016 & 0.020 & 0.006 & 0.016 & 0.005 & 0.016 \\
\hline
\end{tabular}

Note: For an assessment of data quality, see Tables 10.2 and 10.3 .

Source: Clio Infra, www.clio-infra.eu.

and Japan. This contrasted with the large losses in tropical Latin America, Asia and Africa due to logging, expansion for pasture (livestock grazing) and croplands, and plantations.

One should keep in mind that despite huge deforestation rates in the past, many (larger) countries still have a relatively high MSA. This is simply because in countries such as Canada, the USA, Russia, Australia and Brazil, large forests areas (and other ecosystems) are still present.

The MSA index will not capture biodiversity loss well for island environments where much of the flora and fauna is indigenous (e.g. most of the smaller Pacific islands). Here the impact of introduced species is a major driver of biodiversity loss and, importantly, the recovery of forested land will not bring back indigenous animals or plants predated upon or out-competed by imported animals. Obviously, the MSA index also does not cover the biodiversity losses of aquatic ecosystems.

Climate change and $\mathrm{CO}_{2}$ emissions. With the onset of the Industrial Revolution in the United Kingdom, Europe was the first region to have high fossil fuel $\mathrm{CO}_{2}$ emissions. Other European countries soon followed, and North America a bit later. This process continued throughout the 19th century, and then the world experienced an enormous increase in coal, oil and gas production after the Second World War, truly a Great Acceleration. America and Europe led the pack immediately after the war, helped by large-scale funding programmes (e.g. the Marshall Plan) to rebuild Europe. They were soon followed by Japan, and in the 1970s and 1980s by some other Asian Tigers. The growth in emissions in Europe seems 
Table 10.5. $\mathrm{SO}_{2}$ emissions per capita in selected countries, 1820-2000

Metric ton $\mathrm{SO}_{2}\left(\mathrm{t} \mathrm{SO}{ }_{2}\right.$, where ton $\left.=10^{3}\right)$

\begin{tabular}{|c|c|c|c|c|c|c|c|c|c|c|c|c|c|c|c|c|c|c|c|c|c|c|c|c|c|}
\hline & \multicolumn{7}{|c|}{ Western Europe (WE) } & \multicolumn{2}{|c|}{\begin{tabular}{|c} 
Eastern Europe \\
$(\mathrm{EE})$
\end{tabular}} & \multicolumn{3}{|c|}{$\begin{array}{l}\text { Western Offshoots } \\
\text { (W0) }\end{array}$} & \multicolumn{3}{|c|}{$\begin{array}{c}\text { Latin America and } \\
\text { Caribbean (LA) }\end{array}$} & \multicolumn{2}{|c|}{$\begin{array}{l}\text { Middle East } \\
\text { and North } \\
\text { Africa (MENA) }\end{array}$} & \multicolumn{3}{|c|}{$\begin{array}{c}\text { Sub-Saharan Africa } \\
\text { (SSA) }\end{array}$} & \multicolumn{2}{|c|}{ East Asia (EA) } & \multicolumn{3}{|c|}{$\begin{array}{c}\text { South and South-East } \\
\text { Asia (SSEA) }\end{array}$} \\
\hline & GBR & NLD & FRA & DEU & ITA & ESP & SWE & POL & RUS & AUS & CAN & USA & MEX & BRA & ARG & EGY & TUR & KEN & NGA & ZAF & $\mathrm{CHN}$ & JPN & IND & IDN & THA \\
\hline 1820 & & & .. & .. & .. & & & .. & .. & .. & & & .. & .. & .. & & & .. & .. & & & & .. & .. & \\
\hline 1830 & .. & .. & .. & .. & .. & .. & & .. & .. &.. & .. & & .. & .. & .. & .. & & .. & .. & .. & .. & & .. & .. & \\
\hline 1840 & .. & .. & .. & .. & .. & & & .. & .. & .. & & & .. & .. & .. & .. & & .. & .. & .. & & & .. & .. & \\
\hline 1850 & 0.041 & 0.007 & 0.003 & 0.003 & 0.000 & 0.002 & 0.004 & 0.002 & 0.001 & 0.016 & 0.002 & 0.013 & 0.000 & 0.000 & 0.000 & 0.000 & 0.000 & 0.000 & 0.000 & 0.005 & 0.000 & 0.001 & 0.000 & 0.000 & 0.000 \\
\hline 1860 & 0.051 & 0.010 & 0.005 & 0.007 & 0.000 & 0.003 & 0.004 & 0.003 & 0.001 & 0.020 & 0.002 & 0.022 & 0.000 & 0.000 & 0.000 & 0.000 & 0.000 & 0.000 & 0.000 & 0.003 & 0.000 & 0.001 & 0.000 & 0.000 & 0.000 \\
\hline 1870 & 0.060 & 0.010 & 0.006 & 0.012 & 0.001 & 0.004 & 0.005 & 0.006 & 0.001 & 0.018 & 0.004 & 0.035 & 0.000 & 0.000 & 0.000 & 0.000 & 0.001 & 0.000 & 0.000 & 0.002 & 0.000 & 0.001 & 0.000 & 0.000 & 0.000 \\
\hline 1880 & 0.069 & 0.014 & 0.009 & 0.018 & 0.002 & 0.008 & 0.006 & 0.008 & 0.002 & 0.020 & 0.010 & 0.052 & 0.000 & 0.000 & 0.000 & 0.000 & 0.001 & 0.000 & 0.000 & 0.005 & 0.000 & 0.001 & 0.000 & 0.000 & 0.000 \\
\hline 1890 & 0.076 & 0.016 & 0.011 & 0.026 & 0.005 & 0.013 & 0.009 & 0.011 & 0.002 & 0.015 & 0.022 & 0.084 & 0.001 & 0.000 & 0.003 & 0.000 & 0.002 & 0.000 & 0.000 & 0.007 & 0.000 & 0.003 & 0.000 & 0.000 & 0.000 \\
\hline 1900 & 0.082 & 0.020 & 0.014 & 0.036 & 0.006 & 0.017 & 0.016 & 0.015 & 0.004 & 0.032 & 0.036 & 0.120 & 0.004 & 0.000 & 0.003 & 0.000 & 0.003 & 0.000 & 0.000 & 0.007 & 0.000 & 0.006 & 0.000 & 0.000 & 0.000 \\
\hline 1910 & 0.086 & 0.025 & 0.018 & 0.043 & 0.008 & 0.019 & 0.023 & 0.020 & 0.004 & 0.047 & 0.086 & 0.172 & 0.014 & 0.002 & 0.008 & 0.000 & 0.006 & 0.000 & 0.000 & 0.031 & 0.001 & 0.011 & 0.001 & 0.001 & 0.000 \\
\hline 1920 & 0.088 & 0.021 & 0.026 & 0.044 & 0.005 & 0.016 & 0.021 & 0.018 & 0.001 & 0.031 & 0.119 & 0.183 & 0.018 & 0.002 & 0.004 & 0.001 & 0.002 & 0.000 & 0.000 & 0.040 & 0.001 & 0.019 & 0.001 & 0.001 & 0.000 \\
\hline 1930 & 0.087 & 0.040 & 0.036 & 0.051 & 0.010 & 0.015 & 0.043 & 0.029 & 0.006 & 0.043 & 0.169 & 0.158 & 0.020 & 0.002 & 0.006 & 0.001 & 0.004 & 0.000 & 0.000 & 0.030 & 0.001 & 0.021 & 0.001 & 0.001 & 0.000 \\
\hline 1940 & 0.093 & 0.029 & 0.021 & 0.069 & 0.011 & 0.011 & 0.039 & 0.045 & 0.017 & 0.056 & 0.268 & 0.139 & 0.021 & 0.003 & 0.006 & 0.002 & 0.007 & 0.000 & 0.000 & 0.039 & 0.002 & 0.022 & 0.001 & 0.001 & 0.000 \\
\hline 1950 & 0.092 & 0.038 & 0.038 & 0.060 & 0.011 & 0.016 & 0.061 & 0.042 & 0.025 & 0.051 & 0.240 & 0.134 & 0.024 & 0.004 & 0.005 & 0.005 & 0.007 & 0.001 & 0.001 & 0.043 & 0.002 & 0.013 & 0.001 & 0.001 & 0.000 \\
\hline 1960 & 0.107 & 0.056 & 0.042 & 0.095 & 0.029 & 0.020 & 0.102 & 0.071 & 0.055 & 0.082 & 0.235 & 0.116 & 0.020 & 0.006 & 0.006 & 0.006 & 0.007 & 0.002 & 0.001 & 0.048 & 0.013 & 0.023 & 0.002 & 0.001 & 0.001 \\
\hline 1970 & 0.114 & 0.065 & 0.066 & 0.104 & 0.074 & 0.042 & 0.105 & 0.106 & 0.075 & 0.114 & 0.237 & 0.142 & 0.019 & 0.008 & 0.007 & 0.005 & 0.011 & 0.002 & 0.005 & 0.066 & 0.009 & 0.051 & 0.002 & 0.001 & 0.003 \\
\hline 1980 & 0.085 & 0.035 & 0.060 & 0.096 & 0.061 & 0.076 & 0.059 & 0.156 & 0.094 & 0.110 & 0.165 & 0.104 & 0.029 & 0.013 & 0.005 & 0.009 & 0.010 & 0.002 & 0.007 & 0.064 & 0.012 & 0.011 & 0.002 & 0.001 & 0.007 \\
\hline 1990 & 0.065 & 0.012 & 0.024 & 0.067 & 0.031 & 0.056 & 0.013 & 0.128 & 0.097 & 0.093 & 0.111 & 0.082 & 0.033 & 0.011 & 0.003 & 0.012 & 0.028 & 0.002 & 0.005 & 0.062 & 0.015 & 0.008 & 0.004 & 0.002 & 0.012 \\
\hline 2000 & 0.020 & 0.004 & 0.011 & 0.008 & 0.013 & 0.036 & 0.005 & 0.055 & 0.057 & 0.124 & 0.073 & 0.051 & 0.030 & 0.010 & 0.004 & 0.008 & 0.028 & 0.002 & 0.004 & 0.053 & 0.017 & 0.007 & 0.005 & 0.005 & 0.016 \\
\hline
\end{tabular}

Note: For an assessment of data quality, see Tables 10.2 and 10.3.

Source: Clio Infra, www.clio-infra.eu.

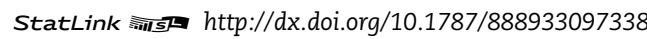




\section{Figure 10.2. Regional totals of cropland and pasture, 1820-2000}

Millions of hectares

$\square$ Western Europe $\square$ Eastern Europe $\square$ Western Offshoots $\square$ Latin America and Carribean
$\square$ Middle East and North Africa $\square$ Sub-Sahara Africa $\square$ East Asia $\square$ South and South-East Asia
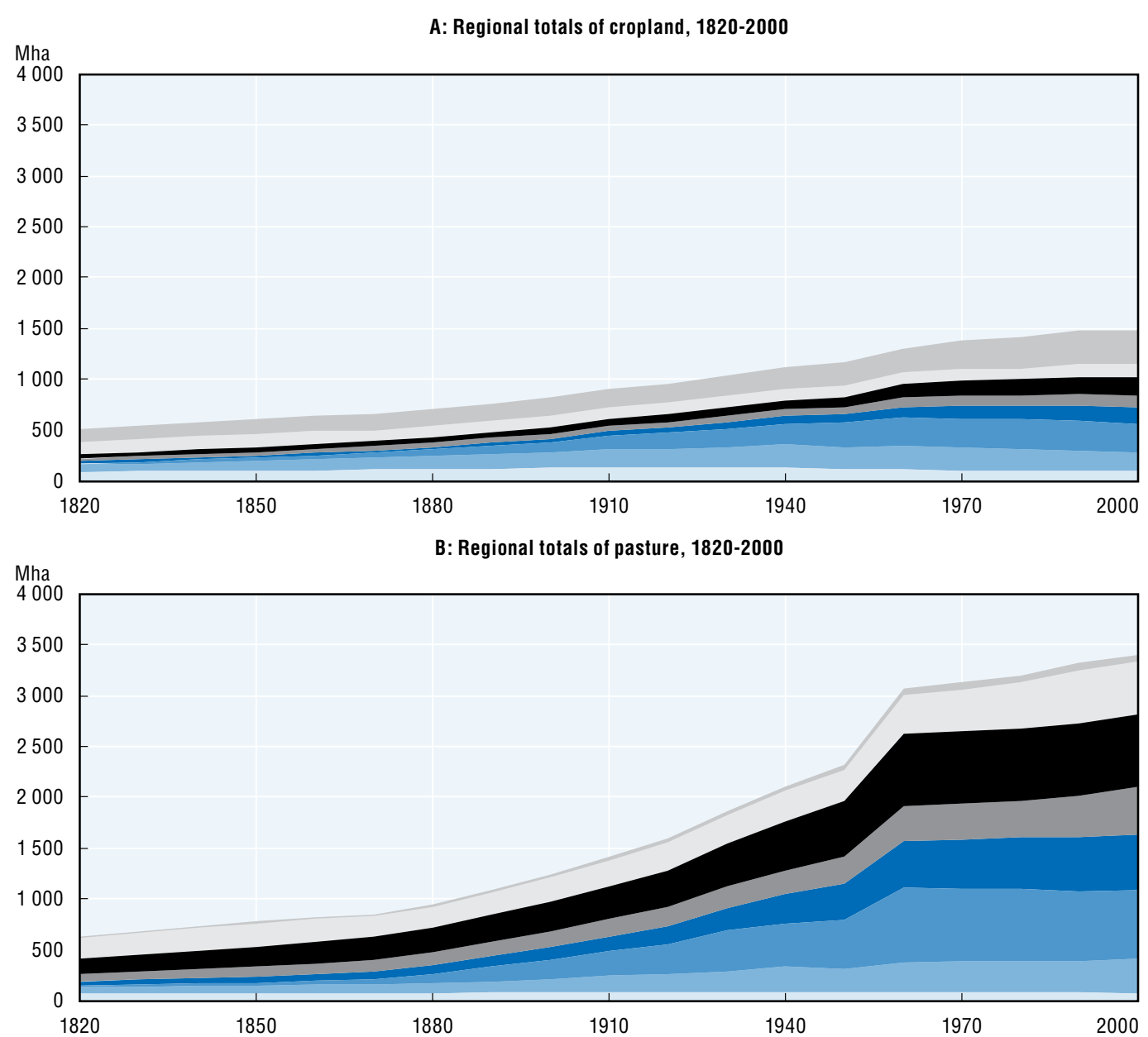

Note: For an assessment of data quality, see Tables 10.2 and 10.3

Source: Clio Infra, www.clio-infra.eu.

StatLink 司Is $h t t p: / / d x . d o i . o r g / 10.1787 / 888933096103$

to have reversed a bit recently, compared to the USA and China, partly due to emission reduction policies and partly because of the economic crisis in the early 21st century. China surpassed the United States during the mid-2010s as the largest emitter in absolute terms. Africa has very small emissions.

At the end of the 20th century further globalisation fuelled literally a large appetite for fossil combustibles, with most of the latest global growth in emissions due to the spectacular economic growth of China. There is ongoing debate as to whether we have already reached a so-called "Peak oil" point in time (i.e. when the maximum rate of petroleum extraction is reached), after which the production rate is expected to enter terminal decline. Global production of oil fell from a high point in 2005 at 74 million barrels/day, but has since rebounded, setting new records in both 2011 and 2012 due to new exploration and exploitation techniques made possible by high oil prices. Similar studies exist for natural gas, but not so much for coal reserves since they are, relative to oil and gas, still huge. 
Table 10.6. Regional averages of mean species abundance, 1820-2000

Values relative to pristine species abundance

\begin{tabular}{|c|c|c|c|c|c|c|c|c|c|}
\hline & $\begin{array}{c}\text { Western } \\
\text { Europe } \\
\text { (WE) }\end{array}$ & $\begin{array}{c}\text { Eastern } \\
\text { Europe } \\
\text { (EE) }\end{array}$ & $\begin{array}{c}\text { Western } \\
\text { Offshoots } \\
\text { (WO) }\end{array}$ & $\begin{array}{l}\text { Latin } \\
\text { America } \\
\text { and } \\
\text { Caribbean } \\
\text { (LA) }\end{array}$ & $\begin{array}{c}\text { East Asia } \\
(\mathrm{EA})\end{array}$ & $\begin{array}{c}\text { South and } \\
\text { South-East } \\
\text { Asia } \\
\text { (SSEA) }\end{array}$ & $\begin{array}{l}\text { Middle East } \\
\text { and } \\
\text { North Africa } \\
\text { (MENA) }\end{array}$ & $\begin{array}{c}\text { Sub-Saharan } \\
\text { Africa } \\
\text { (SSA) }\end{array}$ & World \\
\hline 1820 & 0.69 & 0.90 & 0.99 & 0.97 & 0.88 & 0.82 & 0.97 & 0.92 & 0.85 \\
\hline 1830 & 0.68 & 0.89 & 0.99 & 0.96 & 0.88 & 0.81 & 0.97 & 0.92 & 0.84 \\
\hline 1840 & 0.67 & 0.89 & 0.98 & 0.96 & 0.87 & 0.81 & 0.97 & 0.92 & 0.84 \\
\hline 1850 & 0.66 & 0.88 & 0.98 & 0.96 & 0.87 & 0.80 & 0.96 & 0.91 & 0.83 \\
\hline 1860 & 0.66 & 0.87 & 0.97 & 0.96 & 0.88 & 0.79 & 0.96 & 0.91 & 0.83 \\
\hline 1870 & 0.65 & 0.86 & 0.96 & 0.96 & 0.89 & 0.78 & 0.96 & 0.91 & 0.83 \\
\hline 1880 & 0.64 & 0.85 & 0.94 & 0.95 & 0.90 & 0.78 & 0.95 & 0.90 & 0.83 \\
\hline 1890 & 0.63 & 0.84 & 0.92 & 0.95 & 0.89 & 0.76 & 0.95 & 0.90 & 0.82 \\
\hline 1900 & 0.62 & 0.83 & 0.90 & 0.95 & 0.89 & 0.76 & 0.94 & 0.89 & 0.81 \\
\hline 1910 & 0.60 & 0.81 & 0.88 & 0.94 & 0.89 & 0.77 & 0.94 & 0.89 & 0.81 \\
\hline 1920 & 0.61 & 0.81 & 0.86 & 0.93 & 0.88 & 0.77 & 0.93 & 0.88 & 0.81 \\
\hline 1930 & 0.61 & 0.79 & 0.85 & 0.92 & 0.88 & 0.76 & 0.93 & 0.86 & 0.80 \\
\hline 1940 & 0.61 & 0.79 & 0.84 & 0.91 & 0.87 & 0.75 & 0.92 & 0.85 & 0.80 \\
\hline 1950 & 0.63 & 0.77 & 0.81 & 0.89 & 0.87 & 0.74 & 0.91 & 0.83 & 0.80 \\
\hline 1960 & 0.65 & 0.74 & 0.78 & 0.87 & 0.85 & 0.71 & 0.89 & 0.80 & 0.78 \\
\hline 1970 & 0.66 & 0.74 & 0.78 & 0.86 & 0.84 & 0.70 & 0.89 & 0.79 & 0.77 \\
\hline 1980 & 0.67 & 0.75 & 0.78 & 0.85 & 0.82 & 0.69 & 0.89 & 0.78 & 0.77 \\
\hline 1990 & 0.67 & 0.75 & 0.78 & 0.84 & 0.78 & 0.68 & 0.87 & 0.78 & 0.75 \\
\hline 2000 & 0.68 & 0.76 & 0.79 & 0.83 & 0.78 & 0.68 & 0.87 & 0.77 & 0.75 \\
\hline
\end{tabular}

Note: For an assessment of data quality, see Tables 10.2 and 10.3 .

Source: Clio Infra, www.clio-infra.eu.

Figure 10.3 shows that the Western Offshoots dominated the total regional $\mathrm{CO}_{2}$ emissions worldwide for a long time, but that recently (during the last decade) they have been overtaken by East Asia (i.e. China). These two regions contributed up to $50 \%$ of total global emissions in the year 2000, Europe $25 \%$ and the rest of the regions each less than $10 \%$. Note that in the last two decades total emissions in Western Europe and Eastern Europe and the Soviet Union do not increase, or even decrease. This is partly due to the break-up of the former USSR, but also to a process called de-carbonisation. This denotes the declining average carbon intensity of primary energy over time. The overall tendency towards lower carbon intensities is due to the continuous replacement of fuels with high carbon content by fuels with low carbon content. However, intensities are currently increasing in some developing regions. In general, decarbonisation involves the substitution of gas for other fossil fuels, i.e. given the limited growth of nuclear power and biofuels, the use of cleaner fossil fuels. Although de-carbonisation of the world's energy system has been comparatively slow $(0.3 \%$ per year), the trend has persisted throughout the past two centuries (Nakicenovic, 1996). Another effect contributing towards reduced carbon intensity of the economy is the declining energy requirements per unit of GDP, or the energy-intensity of GDP. Globally, energy intensity has been declining more rapidly than the carbon intensity of energy (0.9\% per year) during the past two centuries (Nakicenovic, 1996). Consequently, the carbon intensity of GDP has declined globally at about $1.2 \%$ per year (IPCC, 2007).

Tables 10.8 and 10.9 show the per capita $\mathrm{CO}_{2}$ emissions for selected countries. On a regional basis, the Western Offshoots and Western Europe had already reached the 
Table 10.7. Mean species abundance in selected countries, 1820-2000

Values relative to pristine species abundance

\begin{tabular}{|c|c|c|c|c|c|c|c|c|c|c|c|c|c|c|c|c|c|c|c|c|c|c|c|c|c|}
\hline & \multicolumn{7}{|c|}{ Western Europe (WE) } & \multicolumn{2}{|c|}{$\begin{array}{c}\text { Eastern Europe } \\
\text { (EE) }\end{array}$} & \multicolumn{3}{|c|}{$\begin{array}{l}\text { Western Offshoots } \\
\text { (W0) }\end{array}$} & \multicolumn{3}{|c|}{$\begin{array}{c}\text { Latin America and } \\
\text { Caribbean (LA) }\end{array}$} & \multicolumn{2}{|c|}{$\begin{array}{l}\text { Middle East } \\
\text { and North } \\
\text { Africa (MENA) }\end{array}$} & \multicolumn{3}{|c|}{$\begin{array}{c}\text { Sub-Saharan Africa } \\
(\mathrm{SSA})\end{array}$} & \multicolumn{2}{|c|}{ East Asia (EA) } & \multicolumn{3}{|c|}{$\begin{array}{c}\text { South and South-East } \\
\text { Asia (SSEA) }\end{array}$} \\
\hline & GBR & NLD & FRA & DEU & ITA & ESP & SWE & $\mathrm{POL}$ & RUS & AUS & CAN & USA & MEX & BRA & ARG & EGY & TUR & KEN & $\mathrm{NGA}$ & $\mathrm{ZAF}$ & $\mathrm{CHN}$ & JPN & IND & IDN & THA \\
\hline 820 & 0.80 & 0.76 & 0.71 & 0.65 & 0.63 & 0.56 & 0.97 & 0.82 & 0.98 & 1.00 & 1.00 & 0.99 & 0.96 & 1.00 & 0.99 & 1.00 & 1.00 & 0.93 & 0.84 & 1.00 & 0.88 & 0.95 & 0.79 & 0.99 & 0.99 \\
\hline 1830 & 0.79 & 0.75 & 0.70 & 0.63 & 0.62 & 0.54 & 0.96 & 0.81 & 0.98 & 1.00 & 1.00 & 0.98 & 0.96 & 1.00 & 0.99 & 1.00 & 1.00 & 0.93 & 0.84 & 1.00 & 0.87 & 0.95 & 0.78 & 0.98 & 0.99 \\
\hline 1840 & 0.77 & 0.74 & 0.69 & 0.62 & 0.60 & 0.54 & 0.96 & 0.80 & 0.98 & 1.00 & 1.00 & 0.98 & 0.96 & 1.00 & 0.99 & 1.00 & 1.00 & 0.92 & 0.83 & 1.00 & 0.87 & 0.95 & 0.78 & 0.98 & 0.98 \\
\hline 850 & 0.78 & 0.73 & 0.68 & 0.61 & 0.58 & 0.50 & 0.95 & 0.79 & 0.98 & 0.99 & 1.00 & 0.97 & 0.96 & 0.99 & 0.99 & 1.00 & 0.99 & 0.92 & 0.83 & 1.00 & 0.87 & 0.95 & 0.76 & 0.98 & 0.98 \\
\hline 1860 & 0.80 & 0.72 & 0.68 & 0.61 & 0.57 & 0.46 & 0.95 & 0.76 & 0.97 & 0.99 & 0.99 & 0.96 & 0.96 & 0.99 & 0.98 & 1.00 & 0.99 & 0.92 & 0.82 & 0.99 & 0.87 & 0.95 & 0.75 & 0.97 & 0.98 \\
\hline 1870 & 0.75 & 0.71 & 0.68 & 0.61 & 0.57 & 0.44 & 0.94 & 0.74 & 0.97 & 0.98 & 0.99 & 0.95 & 0.96 & 0.99 & 0.98 & 1.00 & 0.99 & 0.92 & 0.81 & 0.99 & 0.89 & 0.95 & 0.73 & 0.97 & 0.98 \\
\hline 1880 & 0.73 & 0.69 & 0.67 & 0.61 & 0.56 & 0.42 & 0.94 & 0.72 & 0.96 & 0.97 & 0.99 & 0.94 & 0.96 & 0.99 & 0.97 & 1.00 & 0.99 & 0.91 & 0.80 & 0.97 & 0.89 & 0.94 & 0.73 & 0.96 & 0.97 \\
\hline 1890 & 0.71 & 0.67 & 0.67 & 0.61 & 0.55 & 0.40 & 0.94 & 0.70 & 0.96 & 0.96 & 0.98 & 0.91 & 0.95 & 0.99 & 0.97 & 0.99 & 0.99 & 0.91 & 0.79 & 0.96 & 0.89 & 0.94 & 0.70 & 0.96 & 0.97 \\
\hline 1900 & 0.69 & 0.64 & 0.66 & 0.60 & 0.54 & 0.40 & 0.94 & 0.70 & 0.96 & 0.94 & 0.98 & 0.90 & 0.94 & 0.98 & 0.96 & 0.99 & 0.99 & 0.91 & 0.78 & 0.94 & 0.89 & 0.93 & 0.70 & 0.95 & 0.96 \\
\hline 1910 & 0.67 & 0.54 & 0.66 & 0.57 & 0.53 & 0.38 & 0.93 & 0.71 & 0.94 & 0.91 & 0.97 & 0.87 & 0.93 & 0.98 & 0.94 & 0.99 & 0.99 & 0.90 & 0.77 & 0.94 & 0.88 & 0.92 & 0.72 & 0.94 & 0.96 \\
\hline 1920 & 0.66 & 0.64 & 0.67 & 0.61 & 0.50 & 0.40 & 0.93 & 0.72 & 0.95 & 0.87 & 0.96 & 0.85 & 0.94 & 0.98 & 0.91 & 0.99 & 0.99 & 0.89 & 0.75 & 0.90 & 0.87 & 0.92 & 0.72 & 0.93 & 0.94 \\
\hline 1930 & 0.64 & 0.67 & 0.66 & 0.61 & 0.50 & 0.43 & 0.94 & 0.66 & 0.94 & 0.86 & 0.96 & 0.84 & 0.92 & 0.97 & 0.88 & 0.99 & 0.99 & 0.88 & 0.74 & 0.87 & 0.87 & 0.91 & 0.70 & 0.92 & 0.93 \\
\hline 1940 & 0.63 & 0.59 & 0.67 & 0.61 & 0.51 & 0.48 & 0.94 & 0.65 & 0.93 & 0.84 & 0.96 & 0.83 & 0.91 & 0.95 & 0.86 & 0.99 & 0.99 & 0.87 & 0.72 & 0.84 & 0.87 & 0.90 & 0.68 & 0.92 & 0.91 \\
\hline 1950 & 0.61 & 0.62 & 0.67 & 0.64 & 0.53 & 0.55 & 0.93 & 0.67 & 0.94 & 0.82 & 0.95 & 0.80 & 0.87 & 0.94 & 0.85 & 0.98 & 0.99 & 0.86 & 0.70 & 0.78 & 0.87 & 0.89 & 0.67 & 0.92 & 0.88 \\
\hline 1960 & 0.61 & 0.64 & 0.65 & 0.67 & 0.56 & 0.63 & 0.93 & 0.58 & 0.92 & 0.80 & 0.95 & 0.76 & 0.80 & 0.93 & 0.82 & 0.98 & 0.99 & 0.84 & 0.64 & 0.70 & 0.84 & 0.87 & 0.62 & 0.88 & 0.84 \\
\hline 1970 & 0.62 & 0.66 & 0.67 & 0.67 & 0.57 & 0.64 & 0.94 & 0.60 & 0.92 & 0.79 & 0.95 & 0.76 & 0.80 & 0.91 & 0.82 & 0.98 & 0.99 & 0.84 & 0.64 & 0.72 & 0.83 & 0.87 & 0.62 & 0.88 & 0.81 \\
\hline 1980 & 0.62 & 0.67 & 0.68 & 0.67 & 0.62 & 0.64 & 0.94 & 0.61 & 0.92 & 0.79 & 0.96 & 0.76 & 0.79 & 0.89 & 0.82 & 0.98 & 0.99 & 0.84 & 0.63 & 0.72 & 0.82 & 0.88 & 0.61 & 0.88 & 0.74 \\
\hline 1990 & 0.63 & 0.65 & 0.68 & 0.66 & 0.64 & 0.65 & 0.94 & 0.61 & 0.92 & 0.79 & 0.95 & 0.76 & 0.78 & 0.88 & 0.82 & 0.98 & 0.98 & 0.82 & 0.62 & 0.71 & 0.77 & 0.88 & 0.61 & 0.86 & 0.71 \\
\hline 2000 & 0.65 & 0.63 & 0.68 & 0.66 & 0.66 & 0.67 & 0.95 & 0.62 & 0.93 & 0.80 & 0.95 & 0.77 & 0.78 & 0.87 & 0.82 & 0.97 & 0.95 & 0.82 & 0.61 & 0.70 & 0.77 & 0.88 & 0.60 & 0.85 & 0.73 \\
\hline
\end{tabular}

Note: For an assessment of data quality, see Tables 10.2 and 10.3.

Source: Clio Infra, www.clio-infra.eu. 
Figure 10.3. Regional totals of $\mathrm{CO}_{2}$ emissions, $\mathbf{1 8 2 0 - 2 0 0 0}$

Values in petagrams Carbon (Pg. C, peta $=10^{15}$ )

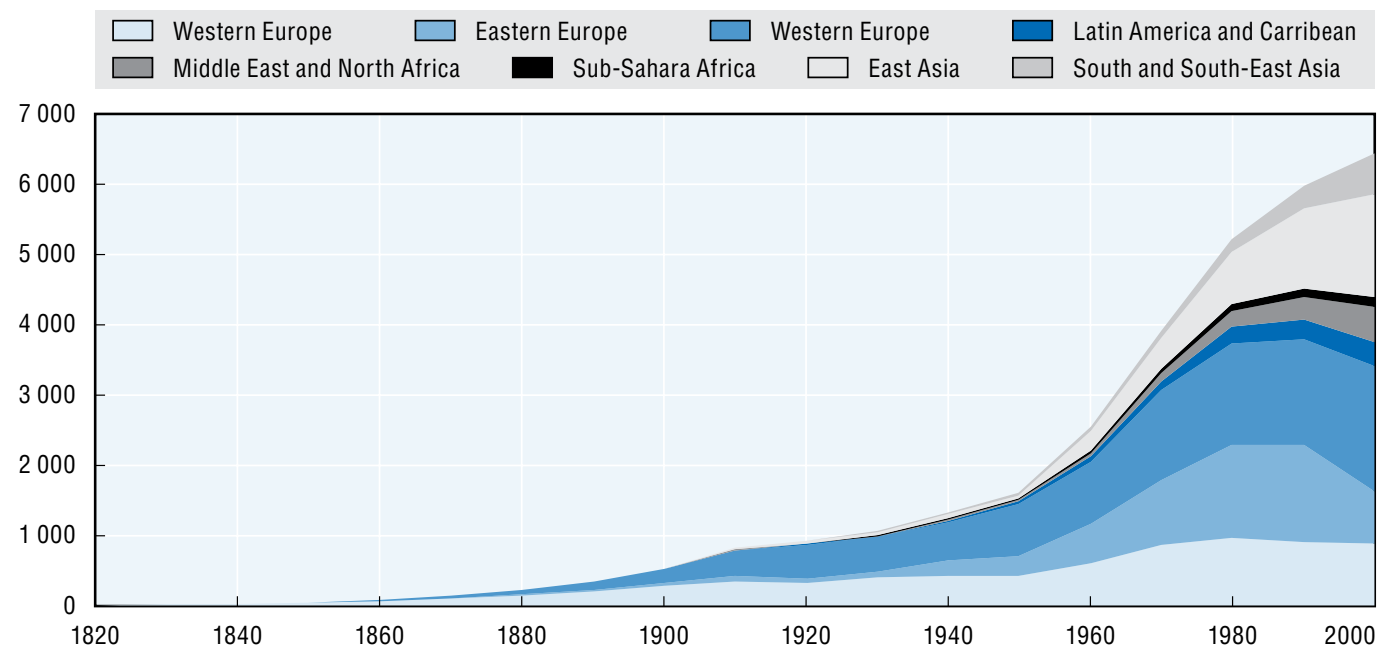

Note: For an assessment of data quality, see Tables 10.2 and 10.3.

Source: Clio Infra, www.clio-infra.eu.

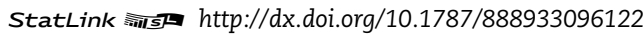

Table 10.8. Regional averages of $\mathrm{CO}_{2}$ emissions per capita, 1820-2000 Metric ton Carbon, (t C, ton $=10^{3}$ )

\begin{tabular}{|c|c|c|c|c|c|c|c|c|c|}
\hline & $\begin{array}{c}\text { Western } \\
\text { Europe } \\
\text { (WE) }\end{array}$ & $\begin{array}{c}\text { Eastern } \\
\text { Europe } \\
\text { (EE) }\end{array}$ & $\begin{array}{l}\text { Western } \\
\text { Offshoots } \\
\text { (W0) }\end{array}$ & $\begin{array}{l}\text { Latin } \\
\text { America } \\
\text { and } \\
\text { Caribbean } \\
\text { (LA) }\end{array}$ & $\begin{array}{c}\text { East Asia } \\
(\mathrm{EA})\end{array}$ & $\begin{array}{c}\text { South and } \\
\text { South-East } \\
\text { Asia } \\
\text { (SSEA) }\end{array}$ & $\begin{array}{l}\text { Middle East } \\
\text { and } \\
\text { North Africa } \\
\text { (MENA) }\end{array}$ & $\begin{array}{c}\text { Sub-Saharan } \\
\text { Africa } \\
\text { (SSA) }\end{array}$ & World \\
\hline 1820 & 0.10 & 0.00 & 0.02 & 0.00 & 0.00 & 0.00 & 0.00 & 0.00 & 0.01 \\
\hline 1830 & 0.15 & 0.00 & 0.04 & 0.00 & 0.00 & 0.00 & 0.00 & 0.00 & 0.02 \\
\hline 1840 & 0.18 & 0.01 & 0.08 & 0.00 & 0.00 & 0.00 & 0.00 & 0.00 & 0.03 \\
\hline 1850 & 0.27 & 0.01 & 0.20 & 0.00 & 0.00 & 0.00 & 0.00 & 0.00 & 0.04 \\
\hline 1860 & 0.40 & 0.02 & 0.36 & 0.00 & 0.00 & 0.00 & 0.00 & 0.00 & 0.07 \\
\hline 1870 & 0.56 & 0.07 & 0.61 & 0.00 & 0.00 & 0.00 & 0.00 & 0.00 & 0.11 \\
\hline 1880 & 0.74 & 0.14 & 0.97 & 0.00 & 0.00 & 0.00 & 0.00 & 0.00 & 0.17 \\
\hline 1890 & 0.91 & 0.20 & 1.59 & 0.01 & 0.00 & 0.00 & 0.00 & 0.00 & 0.23 \\
\hline 1900 & 1.13 & 0.33 & 2.20 & 0.02 & 0.01 & 0.01 & 0.01 & 0.01 & 0.32 \\
\hline 1910 & 1.30 & 0.38 & 3.51 & 0.07 & 0.01 & 0.04 & 0.03 & 0.02 & 0.47 \\
\hline 1920 & 1.20 & 0.24 & 4.09 & 0.07 & 0.01 & 0.06 & 0.05 & 0.03 & 0.49 \\
\hline 1930 & 1.36 & 0.39 & 3.53 & 0.09 & 0.03 & 0.07 & 0.06 & 0.04 & 0.51 \\
\hline 1940 & 1.35 & 0.95 & 3.58 & 0.15 & 0.10 & 0.09 & 0.11 & 0.04 & 0.58 \\
\hline 1950 & 1.30 & 1.15 & 4.14 & 0.25 & 0.14 & 0.11 & 0.08 & 0.04 & 0.64 \\
\hline 1960 & 1.74 & 2.30 & 4.04 & 0.36 & 0.27 & 0.14 & 0.37 & 0.07 & 0.88 \\
\hline 1970 & 2.28 & 3.52 & 5.20 & 0.46 & 0.54 & 0.21 & 0.47 & 0.10 & 1.08 \\
\hline 1980 & 2.43 & 4.90 & 5.28 & 0.66 & 0.80 & 0.27 & 0.65 & 0.14 & 1.19 \\
\hline 1990 & 2.21 & 4.85 & 4.99 & 0.65 & 0.88 & 0.25 & 0.84 & 0.21 & 1.15 \\
\hline 2000 & 2.09 & 2.55 & 5.21 & 0.67 & 1.12 & 0.23 & 0.98 & 0.30 & 1.06 \\
\hline
\end{tabular}

Note: For an assessment of data quality, see Tables 10.2 and 10.3.

Source: Clio Infra, www.clio-infra.eu. 
Table 10.9. $\mathrm{CO}_{2}$ emissions per capita in selected countries, $\mathbf{1 8 2 0 - 2 0 0 0}$

Values in ktons Carbon (kt C, kilo $=10^{3}$ )

\begin{tabular}{|c|c|c|c|c|c|c|c|c|c|c|c|c|c|c|c|c|c|c|c|c|c|c|c|c|c|}
\hline & \multicolumn{7}{|c|}{ Western Europe (WE) } & \multicolumn{2}{|c|}{$\begin{array}{l}\text { Eastern Europe } \\
\text { (EE) }\end{array}$} & \multicolumn{3}{|c|}{$\begin{array}{l}\text { Western Offshoots } \\
\text { (W0) }\end{array}$} & \multicolumn{3}{|c|}{$\begin{array}{c}\text { Latin America and } \\
\text { Caribbean (LA) }\end{array}$} & \multicolumn{2}{|c|}{$\begin{array}{l}\text { Middle East } \\
\text { and North } \\
\text { Africa (MENA) }\end{array}$} & \multicolumn{3}{|c|}{$\begin{array}{c}\text { Sub-Saharan Africa } \\
\text { (SSA) }\end{array}$} & \multicolumn{2}{|c|}{ East Asia (EA) } & \multicolumn{3}{|c|}{$\begin{array}{c}\text { South and South-East } \\
\text { Asia (SSEA) }\end{array}$} \\
\hline & GBR & NLD & FRA & DEU & ITA & ESP & SWE & $\mathrm{POL}$ & RUS & AUS & CAN & USA & MEX & BRA & ARG & EGY & TUR & KEN & NGA & ZAF & $\mathrm{CHN}$ & JPN & IND & IDN & THA \\
\hline 1820 & 0.76 & 0.00 & 0.03 & 0.04 & 0.00 & 0.00 & 0.00 & 0.02 & 0.00 & 0.00 & 0.00 & 0.02 & 0.00 & 0.00 & 0.00 & 0.00 & 0.00 & 0.00 & 0.00 & 0.00 & 0.00 & 0.00 & 0.00 & 0.00 & 0.00 \\
\hline 1830 & 1.06 & 0.00 & 0.05 & 0.05 & 0.00 & 0.00 & 0.00 & 0.02 & 0.00 & 0.00 & 0.00 & 0.04 & 0.00 & 0.00 & 0.00 & 0.00 & 0.00 & 0.00 & 0.00 & 0.00 & 0.00 & 0.00 & 0.00 & 0.00 & 0.00 \\
\hline 1840 & 1.04 & 0.00 & 0.09 & 0.08 & 0.00 & 0.00 & 0.00 & 0.04 & 0.00 & 0.00 & 0.00 & 0.09 & 0.00 & 0.00 & 0.00 & 0.00 & 0.00 & 0.00 & 0.00 & 0.00 & 0.00 & 0.00 & 0.00 & 0.00 & 0.00 \\
\hline 1850 & 1.51 & 0.28 & 0.15 & 0.12 & 0.00 & 0.01 & 0.02 & 0.07 & 0.00 & 0.00 & 0.01 & 0.23 & 0.00 & 0.00 & 0.00 & 0.00 & 0.00 & 0.00 & 0.00 & 0.00 & 0.00 & 0.00 & .00 & 0.00 & 0.00 \\
\hline 1860 & 1.89 & 0.39 & 0.28 & 0.28 & 0.00 & 0.03 & 0.06 & 0.14 & 0.00 & 0.06 & 0.03 & 0.41 & 0.00 & 0.00 & 0.00 & 0.00 & 0.00 & 0.00 & 0.00 & 0.00 & 0.00 & 0.00 & 0.00 & 0.00 & 0.00 \\
\hline 1870 & 2.30 & 0.37 & 0.37 & 0.53 & 0.03 & 0.05 & 0.10 & 0.27 & 0.02 & 0.09 & 0.09 & 0.69 & 0.00 & 0.00 & 0.00 & & 0.00 & 0.00 & 0.00 & 0.00 & 0.00 & 0.00 & 0.00 & 0.00 & 0.00 \\
\hline 1880 & 2.64 & 0.54 & 0.54 & 0.78 & 0.05 & 0.07 & 0.19 & 0.36 & 0.05 & 0.26 & 0.32 & 1.07 & 0.00 & 0.00 & 0.00 & 0.00 & 0.00 & 0.00 & 0.00 & 0.00 & 0.00 & 0.02 & 0.00 & 0.00 & 0.00 \\
\hline 1890 & 2.84 & 0.61 & 0.67 & 1.19 & 0.11 & 0.11 & 0.32 & 0.50 & 0.08 & 0.30 & 0.67 & 1.74 & 0.00 & 0.00 & 0.11 & & 0.01 & 0.00 & 0.00 & 0.03 & 0.00 & 0.05 & 0.00 & 0.00 & 0.00 \\
\hline 1900 & 3.03 & 0.77 & 0.87 & 1.64 & 0.12 & 0.16 & 0.54 & 0.70 & 0.21 & 0.72 & 1.02 & 2.37 & 0.02 & 0.00 & 0.11 & 0.00 & 0.02 & 0.00 & 0.00 & 0.15 & 0.00 & 0.12 & 0.01 & 0.01 & 0.00 \\
\hline 1910 & 3.07 & 0.96 & 1.00 & 1.93 & 0.20 & 0.20 & 0.71 & 0.97 & 0.21 & 1.07 & 1.95 & 3.78 & 0.07 & 0.06 & 0.34 & & 0.04 & 0.00 & 0.00 & 0.84 & 0.01 & 0.22 & 0.03 & 0.02 & 0.00 \\
\hline 1920 & 2.99 & 0.88 & 1.05 & 1.92 & 0.13 & 0.18 & 0.53 & 0.87 & 0.07 & 1.30 & 2.60 & 4.40 & 0.18 & 0.04 & 0.17 & 0.01 & 0.03 & 0.00 & 0.00 & 1.03 & 0.02 & 0.36 & 0.04 & 0.03 & 0.00 \\
\hline 1930 & 2.76 & 1.40 & 1.63 & 1.98 & 0.26 & 0.27 & 0.93 & 0.55 & 0.31 & 1.11 & 2.46 & 3.78 & 0.13 & 0.05 & 0.30 & 0.02 & 0.07 & 0.00 & 0.01 & 0.96 & 0.02 & 0.39 & 0.05 & 0.04 & 0.00 \\
\hline 1940 & 2.90 & 1.02 & 0.93 & 2.56 & 0.31 & 0.23 & 0.87 & 1.68 & 0.84 & 1.36 & 2.54 & 3.83 & 0.25 & 0.07 & 0.31 & 0.05 & 0.08 & 0.00 & 0.01 & 1.26 & 0.05 & 0.57 & 0.05 & 0.05 & 0.00 \\
\hline 1950 & 2.70 & 1.38 & 1.32 & 2.04 & 0.24 & 0.32 & 1.12 & 1.23 & 1.30 & 1.82 & 3.06 & 4.39 & 0.30 & 0.10 & 0.48 & 0.13 & 0.12 & 0.04 & 0.02 & 1.22 & 0.04 & 0.34 & 0.05 & 0.03 & 0.01 \\
\hline 1960 & 3.04 & 1.75 & 1.62 & 3.05 & 0.60 & 0.44 & 1.79 & 2.16 & 2.73 & 2.34 & 2.94 & 4.28 & 0.45 & 0.18 & 0.64 & 0.16 & 0.16 & 0.08 & 0.02 & 1.54 & 0.34 & 0.68 & 0.09 & 0.06 & 0.04 \\
\hline 1970 & 3.13 & 2.67 & 2.28 & 3.53 & 1.46 & 0.88 & 3.13 & 3.19 & 4.26 & 3.06 & 4.11 & 5.50 & 0.56 & 0.25 & 0.92 & 0.16 & 0.32 & 0.07 & 0.10 & 1.80 & 0.26 & 1.93 & 0.10 & 0.08 & 0.11 \\
\hline 1980 & 2.82 & 2.96 & 2.44 & 3.75 & 1.80 & 1.46 & 2.34 & 4.74 & 6.15 & 4.05 & 4.73 & 5.48 & 1.14 & 0.41 & 1.04 & 0.28 & 0.45 & 0.10 & 0.25 & 2.13 & 0.42 & 2.15 & 0.14 & 0.17 & 0.23 \\
\hline 1990 & 2.71 & 2.55 & 1.74 & 3.37 & 1.89 & 1.49 & 1.58 & 3.54 & 6.64 & 4.68 & 4.22 & 5.14 & 1.23 & 0.37 & 0.92 & 0.36 & 0.69 & 0.07 & 0.13 & 2.47 & 0.58 & 2.39 & 0.22 & 0.23 & 0.46 \\
\hline 2000 & 2.53 & 2.39 & 1.65 & 2.65 & 2.05 & 1.91 & 1.30 & 3.01 & 3.52 & 4.68 & 4.61 & 5.35 & 1.04 & 0.48 & 1.01 & 0.61 & 0.91 & 0.09 & 0.17 & 2.24 & 0.73 & 2.59 & 0.30 & 0.37 & 0.88 \\
\hline
\end{tabular}

Note: For an assessment of data quality, see Tables 10.2 and 10.3 .

Source: Clio Infra, www.clio-infra.eu. 
1 ton carbon emission per capita point at the turn of the 20th century. Western Europe per capita emissions continued to increase at a modest scale until the 1980s and then slowly decreased, while the Western Offshoots still continue on the high level attained. Eastern Europe emissions lagged Western Europe until WWII then grew almost to Western Offshoot levels, but experienced a steep decline towards Western Europe levels again after the break-up of the former USSR. The other regions still have very low carbon emissions per capita (less than 1 ton per capita), except Middle East and North Africa region which has reached just over that point recently. On a country basis, at present the USA is still by far the largest carbon per capita emitter, followed by Canada, Australia, former USSR, and Poland. Many Western Europe emissions are half that of the USA, however, the per capita emissions in many European countries have been declining (albeit slowly) since the 1980s and 1990s due to policy measures and, at present, due to the increasing share of clean renewable energy production (wind, solar, biofuels) and greater fuel efficiency in industry, including the automotive industry. Oceania (Australia) has reached the top five of carbon per capita emitters since the 1970s, followed by Japan and South Africa (more than 2 tons carbon per capita), Mexico and Argentina (around 1 ton per capita). East Asia (China) still has not reached that level, and large parts of Asia and Africa have relative low per capita emissions.

\section{Correlation with GDP per capita}

Per capita emissions of $\mathrm{CO}_{2}$ and $\mathrm{SO}_{2}$ show, as expected, a positive correlation with GDP per capita (Figures 10.4 and 10.6), so richer countries do have more emissions. The correlation with $\mathrm{CO}_{2}$ emissions shows a rising trend, which seems to end after 1970. However, the correlation between GDP and $\mathrm{SO}_{2}$ is becoming less strong and less significant over time. MSA is negatively correlated with real income (Figure 10.5), and this relationship is also becoming less strong over time. So earlier economic growth - early industrialisation - had a strong negative effect on the environment, but this is gradually changing, and the negative link between real income and environmental quality is now less clear than in the 19th century. This is consistent with the environmental Kuznets curve discussed in the introduction. Such a curve is most evident for $\mathrm{SO}_{2}$ emissions (which are now declining in most high-income countries) and for the MSA (for example, biodiversity measured in this way is recovering a bit in Western Europe, where the decline before 1900 was most dramatic). A "true" environmental Kuznets curve would imply that at some point the MSA would become positively related to real income, and $\mathrm{SO}_{2}$ and $\mathrm{CO}_{2}$ negatively, but this is clearly not (yet) the case.

\section{Priorities for future research}

The quality of the environment is obviously important for well-being, but very difficult to quantify, in particular at earlier points in history. This chapter presented three datasets that cover aspects of this complex phenomenon: $\mathrm{SO}_{2}$ emissions, which have a direct impact on the quality of the environment; biodiversity (measured as mean species abundance), which also directly affects well-being; and $\mathrm{CO}_{2}$ emissions, which have a long-term, indirect effect via global warming. To some extent $\mathrm{SO}_{2}$ emissions follow an environmental Kuznets curve, with declining emissions beyond a certain level of GDP per capita, and in recent periods biodiversity is also less directly (negatively) related to real income levels. Overall, there is still a rather strong negative link between environmental quality (as measured by these indicators) and GDP per capita, but this link has been weakening in recent years 


\section{Figure 10.4. Correlation between $\mathrm{SO}_{2}$ emissions per capita} and GDP per capita, 1820-2000

Pearson correlation coefficient and upper/lower bounds of $95 \%$ confidence interval

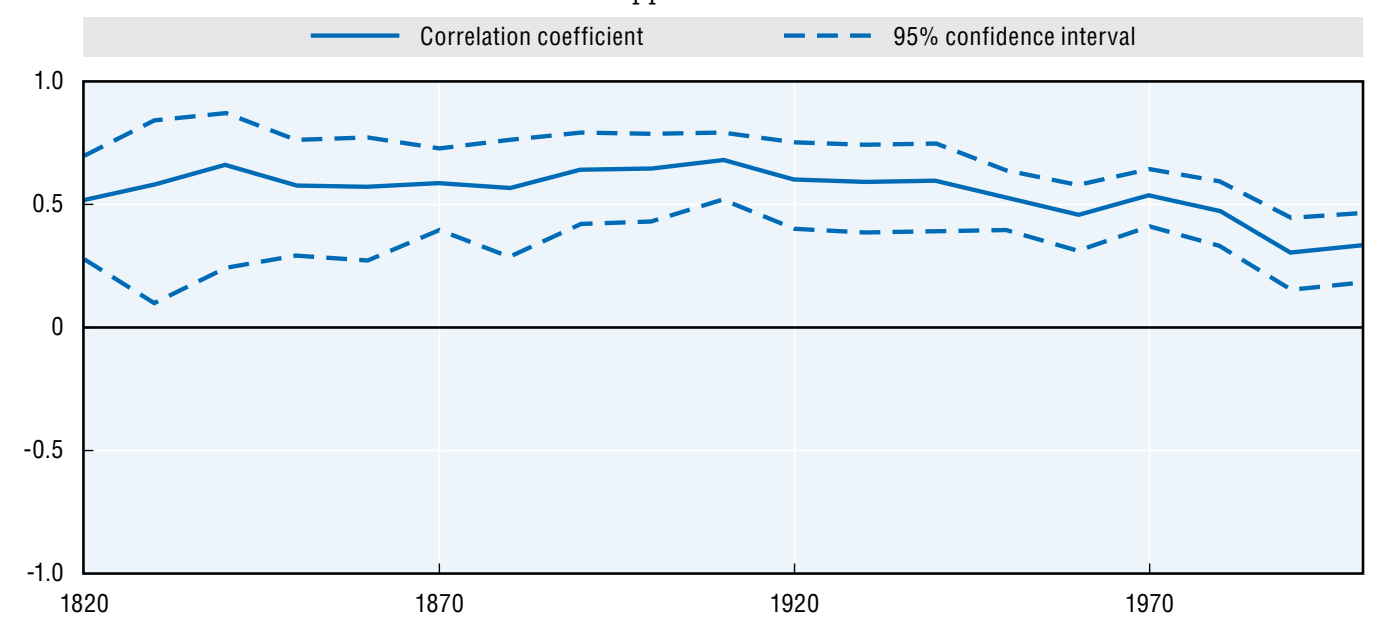

Note: For an assessment of data quality, see Tables 10.2 and 10.3 .

Source: Clio-Infra, www.clio-infra.eu.

Figure 10.5. Correlation between biodiversity (MSA) and GDP per capita, 1820-2000 Pearson correlation coefficient and upper/lower bounds of $95 \%$ confidence interval

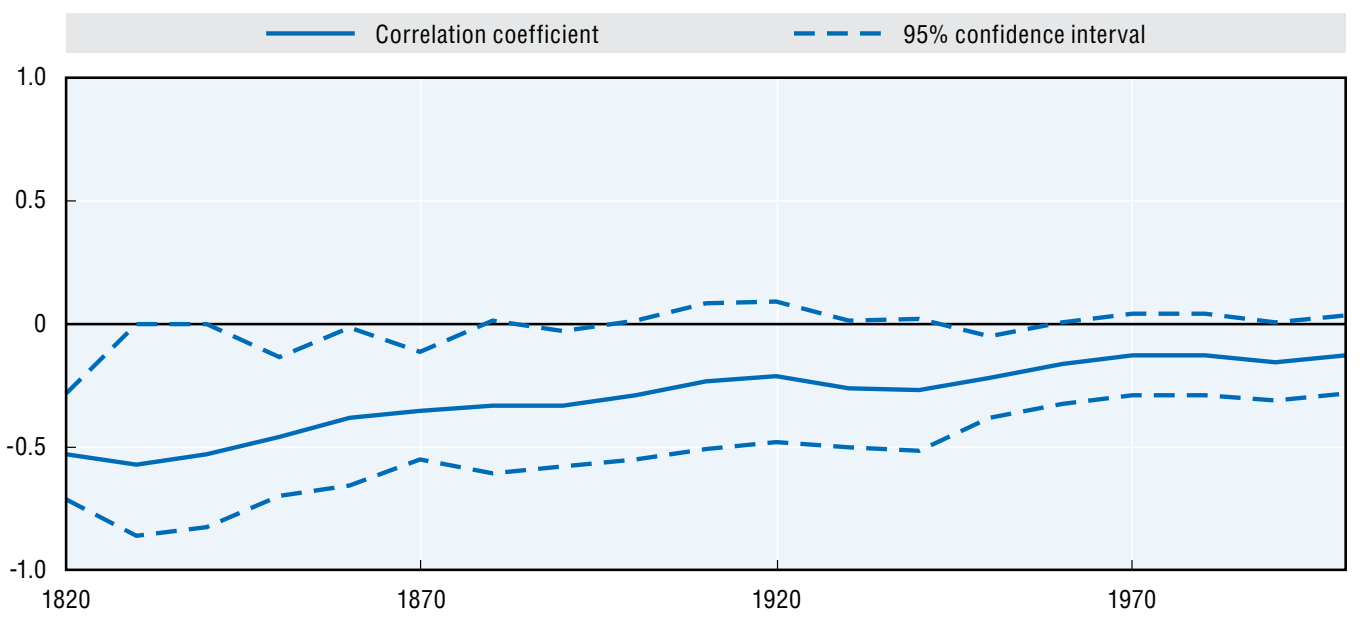

Note: For an assessment of data quality, see Tables 10.2 and 10.3

Source: Clio Infra, www.clio-infra.eu.

(since the 1970s), probably as a result of successful policies to lower emissions ( $\mathrm{SO}_{2}$ probably being the best example).

However, this overview also demonstrates how little we really know about the long-term development of environmental quality. If the approach as presented here is considered valuable, it could be expanded to include some other indicators with sufficient data coverage historically, such as copper, lead, zinc and iron production/consumption, CFC emissions, fertiliser use and subsequent leaching of nitrogen in surface water, as well 
Figure 10.6. Correlation between $\mathrm{CO}_{2}$ emissions per capita and GDP per capita, 1820-2000

Pearson correlation coefficient and upper/lower bounds of $95 \%$ confidence interval

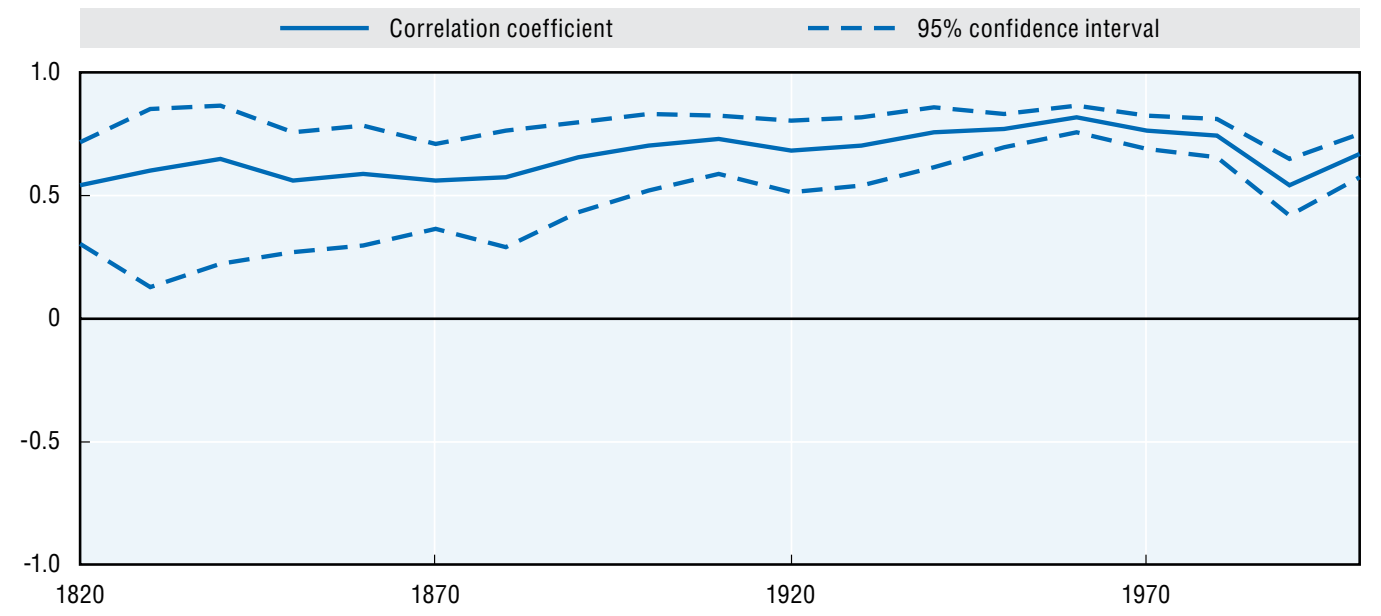

Note: For an assessment of data quality, see Tables 10.2 and 10.3.

Source: Clio Infra, www.clio-infra.eu.

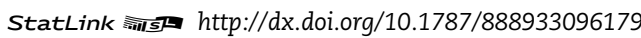

as a first (modelled) attempt to quantify historical water use, e.g. for irrigation as well as for sanitation (e.g. Kummu et al., 2010). But even such a much more detailed approach would at best give only a rough idea about the real historical evolution of the world's ecosystems. Much more research is needed to get a firm grip on that important issue.

\section{Notes}

1. MSA is similar to the Biodiversity Integrity Index (Majer and Beeston, 1996) and the Biodiversity Intactness Index (Scholes and Biggs, 2005) and can be considered as a proxy for the CBD indicator on trends in species abundance (UNEP, 2004). The main difference between MSA and BII is that every hectare is given equal weight in MSA, whereas BII gives more weight to species-rich areas. MSA is also similar to the Living Planet Index (LPI, Loh et al., 2005), which compares changes in populations to a 1970 baseline, rather than to primary vegetation.

2. In the working paper version, we also included estimates of copper and lead production taken from Schmitz (1979), who presents country data series for various metal production for the 1700-1976 period. These data series have been extended with mineral statistics publications of the United States Bureau of Mines; the United States Geological Survey Minerals Yearbook (MYB) and its predecessor, Mineral Resources of the United States (MR); Mineral Commodity Summaries (MCS); and the Statistical Compendium (SC) (USGS, 2009).

3. The working paper version also has data on CFC production for the period from 1930 to the present, taken from the Alternative Fluorocarbons Environmental Acceptability Study network, AFEAS (2009).

\section{References}

AFEAS (Alternative Fluorocarbons Environmental Acceptability Study) (2009) Annual Fluorocarbon Production Reported 1931-2008.

Alkemade, R. et al. (2009), "GLOBIO3: A framework to investigate options for reducing global terrestrial biodiversity loss”, Ecosystems, Vol. 12, pp. 374-390.

Beckerman W. (1974), Defence to Economic Growth, Jonathan Cape, London. 
Besso, A., F. Nyberg and G. Pershagen, (2003), "Air pollution and lung cancer mortality in the vicinity of a nonferrous metal smelter in Sweden”, International Journal of Cancer, Vol. 107, pp. 448-452.

Boden, T.A., G. Marland and R.J. Andres (2012), "Global, regional, and national fossil-fuel $\mathrm{CO}_{2}$ emissions" in, Carbon Dioxide Information Analysis Center, Oak Ridge National Laboratory, United States Department of Energy.

de Vries, H.J.M. and J. Goudsblom, (2002), Mappae Mundi, Human Society and their Habitats in a Long-Term Socio-Economic Perspective, 1st edition, Amsterdam University Press, Amsterdam.

Denevan, W.M. (1992), The native population of the Americas in 1492, 2nd edition, University of Wisconsin Press, Madison, United States.

Diamond, J. (1999), Guns, Germs and Steel, Norton Press, New York.

EEA (European Environment Agency) (2007). EMEP/CORINAIR Atmospheric Emission Inventory Guidebook.

Ellis, E.C. (2011), "Anthropogenic transformation of the terrestrial biosphere", Proceedings of the Royal Society of Mathematical, Physical and Engineering Science, Vol. 369, pp. 1010-1035.

Etemad, B.P. et al. (1991), World energy production 1800-1985, Librairie Droz, Geneva.

Goudsblom, J. (2002a), “Introductory overview: the expanding Anthroposphere”, Mappae Mundi, Humans and their habitats in a long-term socio-ecological perspective, B. De Vries and J. Goudsblom (eds.), pp. 2146, Amsterdam University Press, Amsterdam.

Goudsblom, J. (2002b), “The past 250 years: Industrialization and Globalization,” Mappae Mundi, Humans and their habitats in a long-term socio-ecological B. De Vries and J. Goudsblom (eds.), pp. 353-378, Amsterdam University Press, Amsterdam.

Hubbert, K. (1974), “UN Energy resources, a review as of 1972”, in United States Senate Committee on Interior Affaris, p. 267, Washington.

IEA (International Energy Agency) (2013), International Energy Statistics, www.iea.org/statistics/, accessed, June 2013

IPCC (Intergovernmental Panel on Climate Change) (2007), Climate Change, The Scientific Basis, Cambridge University Press, Cambridge.

Klein Goldewijk, K., A. Beusen and P. Janssen, (2010), “Long term dynamic modelling of global population and built-up area in a spatially explicit way: HYDE 3.1", The Holocene, Vol. 20, pp. 565-573.

Klein Goldewijk, K. et al. (2011), "The HYDE 3.1 spatially explicit database of human induced land use change over the past 12000 years," Global Ecology and Biogeography, Vol. 20, pp. 73-86.

Kubizewksi, I. et al. (2013), "Beyond GDP: Measuring and achieving global genuine progress", Ecological Economics, Vol. 93, pp. 57-68.

Kuznets, S. (1955), "Economic growth and income inequality," The American Economic Review, Vol. 45, pp. 1-28.

Lah, K. (2011), History of lead use, http://toxipedia.org/display/toxipedia/History+of+Lead+Use, accessed 1 July, 2013.

Le Quéré, C. et al. (2012), “The global carbon budget 1959-2011”, Earth System Science Data Discussion Paper, Vol. 5, pp. 1107-1157.

Markandya, A., A. Golub and S. Pedroso-Galinato (2006), "Empirical Analysis of National Income and $\mathrm{SO}_{2}$ Emissions in Selected European Countries", Environmental \& Resource Economics, Vol. 35, pp. 221-257.

Marland, G. and R.M. Rotty (1984), "Carbon dioxide emissions from fossil fuels: A procedure for estimation and results for 1950-82", Tellus, Vol. 36, pp. 759-765.

Millenium Ecosystem Assessment (2005), "Ecosystems and Human Well-being, Synthesis" in Millenium Ecosystem Assessment.

Meadows, D. et al. (1972), Limits to Growth, Universe Books, New York.

Mitchell, B.R. (1993a), International Historical Statistics, Africa, Asia \& Oceania: 1750-1993, Third Ed. MacMillan, London.

Mitchell, B.R. (1993b), International Historical Statistics, The Americas: 1750-1988, MacMillan.

Mitchell, B.R. (1998), International Historical Statistics, Europe: 1750-1993, Fourth Ed. MacMillan.

Nakicenovic, N. (1996), “Decarbonization: Doing more with Less", Technological Forecasting \& Social Change, Vol. 51, pp. 1-17. 
Nørgård, J.S., J. Peet and K.V Ragnarsdóttir (2010), The History of The Limits to Growth Solutions, Vol. 1, pp. 59-63.

OECD (2012a), OECD Environmental Outlook to 2050: The Consequences of Inaction, OECD Publishing, Paris, http://dx.doi.org/10.1787/9789264122246-en.

OECD (2012b), "Modelling Framework", in OECD, OECD Environmental Outlook to 2050: The Consequences of Inaction, OECD Publishing, Paris, http://dx.doi.org/10.1787/env_outlook-2012-10-en.

OECD (2011), "Environmental quality”, in OECD, How's Life?: Measuring Well-being, OECD Publishing, Paris, http://dx.doi.org/10.1787/9789264121164-12-en.

Panatoyou, T. (1994), "Empirical tests and policy analysis of environmental degradation at different stages of economic development", Pacific and Asian Journal of Energy, Vol. 4, pp. 23-42

Panatoyou, T. (1993), "Empirical tests and policy analysis of environmental degradation at different stages of economic development", Working Paper WP238, Technology and Employment Programme, International Labor Office.

Rotty, R.M. (1974), "First estimates of global flaring of natural gas," Atmospheric Environment Vol. 8, pp. 681-686.

Schmitz, C.J. (1979), World non-ferrous metal production and prices, 1700-1976. Frank Cass, London.

Scholes, R.J. and R. Biggs (2005), “A biodiversity intactness index”, Nature, Vol. 434, pp. 45-49.

Smith, S.J. et al. (2004) “Historical Sulfur Dioxide Emissions 1850-2000: Methods and Results," in PNNL Research Report 14537, Joint Global Change Research Institute, Maryland.

Smith, S.J. et al. (2011), "Anthropogenic sulfur dioxide emissions: 1850-2005," Atmospheric Chemistry and Physics, Vol. 11, pp. 1101-1116.

Spiro, P.A., D.J. Jacob and J.A. Logan (1992), "Global Inventory of Sulfur Emissions with $1^{\circ} \mathrm{x} 1^{\circ}$ Resolution", Journal of Geophysical Research, Vol. 97, pp. 6023-6036.

Steffen, W. et al. (2004), Global Change and the Earth System: A Planet Under Pressure, Springer-Verlag, Berlin Heidelberg, New York.

Stern, D.I. (2004), "The Rise and Fall of the Environmental Kuznets Curve”, World Development, Vol. 32, pp. 1419-1439.

Stern, D.I. and R.K. Kaufmann (1996), "Estimates of global anthropogenic sulphate emissions 18601993”, Working paper series 9602, Centre for Energy and Environmental Studies, Boston University.

Stern, D.I., M.S. Common, and E.B Barbier (1996), "Economic Growth and Environmental Degradation: The Environmental Kuznets Curve and Sustainable Development”, World Development, Vol. 24, pp. 1151-1160.

Turner, G. (2008), A Comparison of 'The Limits to Growth' with Thirty Years of Reality, Commonwealth Scientific and Industrial Research Organisation (CSIRO).

UNEP (United Nations Environmental Programme) (2012), GEO 5 - Fifth Global Environmental Outlook.

USGS (United States Geological Survey) (2009), "Mineral commodities”, in Kelly, T.D., and Matos, G.R., comps., Historical statistics for mineral and material commodities in the United States: U.S. Geological Survey Data Series 140, http://pubs.usgs.gov/ds/2005/140/.

Van Aardenne, J.A. et al. (2001), "A $1^{\circ} \times 1^{\circ}$ resolution data set of historical anthropogenic trace gas emissions for the period 1890-1990," Global Biogeochemical Cycles, Vol. 15, pp. 909-928.

WDR (World Development Report) (1992), World Bank, Washington D.C., USA.

Williams, M. (2000), "Dark ages and dark areas: Global deforestation in the deep past", Journal of Historical Geography, Vol. 26, pp. 28-46. 


\title{
Chapter 11
}

\section{Income inequality since 1820}

\author{
by \\ Michail Moatsos, Utrecht University, \\ Joery Baten, Tuebingen University \\ and
}

Peter Foldvari, Bas van Leeuwen and Jan Luiten van Zanden, Utrecht University

This chapter focuses on income inequality as measured by gross (i.e. pre-tax) household income across individuals within a country. It builds upon a number of large-scale initiatives to chart income inequality trends over time, supplementing them with data on wages and heights for the earlier period. Income inequality trends follow a U-shape in most Western European countries and the Western Offshoots. It declined between the end of the 19th century until about 1970, followed by a rise. In Eastern Europe, communism resulted in strong declines in income inequality, followed by a sharp increase after its disintegration in the 1980s. In other parts of the world (China in particular) income inequality is on the rise recently. The chapter also provides evidence on the global income distribution, i.e. assuming all people belong to the same community. This distribution was unimodal in the 19th century, became increasingly bi-modal between 1910 and 1970 and suddenly reverted back into a unimodal distribution between 1980 and 2000. 


\section{Introduction}

The importance of income inequality at the local, regional and global scale hardly needs to be stressed: the enormous increase of income inequality on a global scale is one of the most significant - and worrying - features of the development of the world economy in the past 200 years (van Zanden, et al., 2013). Several international organisations and commentators have drawn attention to the increase in income inequality in a number of developed and emerging countries in the run-up to the recent global financial crisis. For these reasons, the subject has become one of the most discussed topics in the social sciences; in particular, the debate on the measurement and interpretation of recent trends in global inequality - is it still increasing? and why or why not? - has attracted considerable attention (Anand and Segal, 2008; Bourguignon and Morrisson, 2002; Deininger and Squire, 1996; Jones, 1997; Milanovic, 2002 and 2007).

Levels and trends in income inequality are very relevant for people's and societies' well-being. In a sense, the information that income inequality provides is additional and complementary to that referring to average personal income. Since an increase in GDP per capita, by itself, gives us information only about average income gains, income inequality provides more detailed insights about how much the benefits of economic growth in a society or region are spread. It tells us who is getting the benefits of economic growth, and in what proportions. Besides this connection with well-being, an extensive literature investigates the impact of income inequality on a range of social outcomes, such as trust, crime, social mobility, health and educational achievement (Wilkinson and Pickett, 2007).

In what follows, we address and document the long-run trends in income inequality. First we present a new long-run dataset on income inequality (van Zanden et al., 2013) that has the benefit of internal consistency, but also makes it possible to describe, for the first time, historical developments in income inequality on a global scale spanning about two hundred years. Second, we use this dataset to describe historical developments in income inequality both within and between countries.

\section{Description of the concepts used}

The analysis presented in this chapter refers to the distribution of gross (i.e. pre-tax) household income across individuals, with inequality in this distribution described by the Gini coefficient. Both choices are not uncontroversial.

First, because alternative measures of household economic resources (e.g. post-tax income, consumption, including or excluding a range of more detailed components such as imputed rents or capital gains) and alternative units of analysis (e.g. households, or consumption units based on different "equivalence scales") are typically used to examine income inequality. We selected gross household income as the measure in focus due to the availability of historical data: the further back we go in time, the more data is available in gross (pre-tax) household income terms, rather than in other forms. As using different definitions can lead to different conclusions about trends in income inequality, the data 
we assembled in this dataset are either based on gross household income or have been converted to a gross household income basis using various adjustments (see below for details).

Second, because other inequality measures also exist, such as the Theil index, which do not always display similar levels or trends when applied to the same distribution. However, even though many other measures have interesting properties (for example, the Theil coefficient is additive), the use of the Gini coefficient is widespread in the literature on income inequality. In addition, the Gini coefficient is used in the data sources that we heavily rely upon as a primal source of income inequality data. Hence, in this chapter we will focus on this measure.

As it is explicitly developed as a measure of income inequality, the Gini coefficient has some particular properties that make it appealing. One is that it has a direct relationship with the so-called Lorenz curve, which is obtained by plotting the cumulative percentage of income held by the cumulative percentage of the reference population. The Gini is proportional to the area between the line indicating perfect equality and the Lorenz curve, and hence is increasing with the degree of inequality. So a Gini of 0 indicates perfect equality, while a Gini of 1 indicates perfect inequality. ${ }^{1}$ Another definition of the Gini coefficient is in terms of income differences between every pair of individuals in a population (Sen, 1973, 1976). An important property of the Gini coefficient is that any income transfer from the rich to the poor leads to a decline in the measure (i.e. the Gini coefficient moves in the "right" direction). However, as mentioned above, the Gini coefficient also has some less desirable properties, one of which is that the same Gini can be derived from very different income distributions. For example, two very different situations, one where the middle and upper classes have a much higher income than the lower class, and a second where the upper class is extremely rich compared to the other two strata, could in principle lead to the same Gini coefficient. More generally, the Gini coefficient is most sensitive to the part of the income distribution around the median (Buhmann et al., 1988).

Gini coefficients can be calculated on the basis of different income and population concepts. For example, they can refer to households or individuals, and be based on either gross (i.e. pre-tax) or net income, or on either income or consumption, or they can refer to either urban centres or the whole country. More generally, estimates of the Gini coefficient obviously depend on the data produced by statistical offices, as they require consistency over time in the concepts used and the underlying data sources (e.g. household surveys or administrative tax records), in measurement conventions, and other methodological choices. These difficulties are obviously compounded when trying to obtain historical estimates reaching back to 1820 .

Beyond providing an historical perspective on income inequality in individual countries, this chapter has an additional goal: to describe changes in the global distribution of household income, i.e. the distribution that one would observe when treating all people in the world as if they were living in a single country. This implies additional challenges relative to that of reconstructing historical series of within-country income inequality, as it requires combining information from both micro-sources (e.g. tax records or surveys) and macro-sources (e.g. national accounts). This is a challenge, and requires additional assumptions, e.g. that levels and trends in the reference income variable from micro- and macro-sources are the same, an assumption that in reality may not always hold true. In the database used in this chapter, the assumption made is that cross-country differences in average household income can be proxied by differences in GDP per capita. 


\section{Historical sources}

There is no single repository of Gini coefficients that contains estimates for every country and for every year. Hence, we relied on a variety of different sources to construct our dataset. For the post-1960 period most of our data came from the World Income Inequality Database (UNU-WIDER, 2008), a large compilation of country estimates coming from a variety of individual sources. For earlier periods, data were taken from a range of historical sources ${ }^{2}$ and from studies on the top-income share that have recently become more widely available (Atkinson, Piketty and Saez, 2011). A good overview of most of the historical work on income inequality can be found in Milanovic, Lindert and Williamson (2007), and at the Global Income and Prices website at UC Davis. ${ }^{3}$ Additional recent work has been done, for example, by Bertola et al. (2009) for parts of South America, Rossi et al. (2001) for Italy, Bergson (1984) for the Soviet Union, and Soltow and van Zanden (1998a) for the Netherlands.

As stressed by François and Rojas-Romagosa (2005), the Gini values that are available from the World Income Database refer to various concepts and data sources: both levels and the trends pertaining to particular series can be very different. They distinguish three main concepts, due to the differences in trends: gross household income, net household income and expenditure data.

In the construction of the dataset used in this chapter, we followed the methodology suggested by François and Rojas-Romagosa (2005), and converted all available estimates of Gini coefficients into a gross household income basis. To that end, we tested (across a large sample of countries) the hypothesis that trends in Gini coefficients for gross and net household income were similar to those for household income and consumption. These tests suggest that this hypothesis holds true in all countries, with the exception of a relatively short period after the Second World War. Beyond this, average consumption may evolve differently from household income through borrowing and lending, and average expenditures are not a linear function of income since wealthy people tend to save more. Changes in all these parameters probably account for diverging trends in various types of Ginis observed in the after-war period. In that sense, the post-Second World War period is special, since many countries expanded their system of income taxation and made it more progressive. After 1980, trends between gross and net household income and expenditure are again quite similar, although this may not hold in specific countries and sub-periods. ${ }^{4}$ Based on this empirical observation, we converted post-Second World War estimates of the Gini coefficient into a gross household income basis, by using regression techniques (the details are described in Van Zanden et al., 2013).

While using the World Income Database as a reference source, a range of other sources, including SEDLAC ${ }^{5}$ (2013) and Milanovic (2012), have been used to extend this information back in time. The first type of information used is related to top-income share estimates, and in particular to the historical development of the share of the richest $1 \%$ or $5 \%$ in total income, which was pioneered by the work of Piketty and Atkinson. ${ }^{6}$ These data, which basically refer to a single point on the Lorenz curve, can be converted into Gini coefficients using the assumption of log-normality in the underlying (and non-observed) income distribution. In other words, by assuming that the income distribution is lognormal, we can compute the Gini coefficient of a log-normal distribution that has a given income share for people at the very top. Like most of the assumptions made in historical analysis, the assumption of log-normality is not a perfect one, and there is room for error, 
particularly at the extremes of the income distribution. An alternative assumption that has been previously proposed in the literature is that household income follows a Pareto distribution. However, Soltow (1998) has demonstrated that when the entire income distribution is considered, the hypothesis of a log-normal distribution is preferable.

For the period before the Second World War, there are only a few direct estimates of income inequality, and these are available only for a small number of countries. ${ }^{7}$ For other countries in this period, we relied on a method inspired by the "extraction rate" concept (Milanovic et al., 2007) to derive additional estimates. According to this method, changes in the Gini coefficient are linked to the development of the Williamson index, i.e. the ratio between the average family income (measured by GDP per capita) and the real wage of unskilled labour. When this ratio goes up, income inequality may also be expected to rise, and vice versa. The link has been tested empirically and used to extrapolate and interpolate Gini coefficients (details are supplied in van Zanden et al., 2013). The sources used for the real wage of unskilled labour were Williamson (1999, 2000a, 2000b), Mitchell (1998a, 1998b, 1998c), Allen (2001), Mironov (2004) and Allen et al. (2010), while estimates of the average family income were based on estimates of GDP per capita from Maddison (2003). ${ }^{8}$

Another source of information on income inequality in the 19th century comes from a method based on evidence of the footprint of income inequality on the human body. Baten (2000, 1999), Pradhan et al. (2003), Moradi and Baten (2005), Sunder (2003) and Guntupalli and Baten (2006) have argued that the variance in height across individuals within a country (as measured by the coefficient of variation) can be used as a proxy for income distribution. As the studies included here use large samples, individual genetic differences average out. As higher-income people have access to better nutrition and shelter and suffer less from disease, they also tend to be taller, while the opposite applies to the lower-income strata. This fact can be used to link the variation in height of a certain cohort and the income distribution during the decade of their birth. ${ }^{9}$ Historical data on height are available from hundreds of previously published articles, as summarised in Chapter 7 of this report, and provided the basis for income inequality estimates for around one-third of our sample. Naturally, we excluded studies that referred to very small samples of height measurements, or to a special group within a given country. We were also cautious to avoid the distortion of our estimates by factors such as mixed-aged samples, military truncation, gender, prison or other sample selectivity issues. ${ }^{10}$ Finally, for cases where these methodological approaches to the estimation of income inequality could not be applied, some of the remaining missing data on income inequality were estimated using multiple imputation methods. Besides the direct and indirect sources for income inequality information, estimates of average household income per capita are also necessary for our analysis of global inequality. As mentioned above, the proxy that we used for this was GDP per capita expressed in 1990 international dollars (the same series that is used in Chapter 3).

Table 11.1 gives an overview of the various sources used in this chapter by type of method used. Out of the 869 estimates used here, the WIID database supplied $43 \%$ of the data-points, various historical studies provided another $8 \%$, changes in the Williamson index (the GDP/wage ratio) made it possible to estimate $6 \%$ of all estimates, and height data helped to make $33 \%$ of the country estimates. When both height data and GDP/wage ratio were available, Gini coefficients were estimated as the unweighted average of the two (8\%). 
Table 11.1. Estimates of income inequality by source and year, 1820-2000 Number of countries

\begin{tabular}{lcccccc}
\hline Year & All & WIID & 'New' ginis & GDP/wage ratio & Heights & Both 4\&5 (50/50) \\
\hline 1820 & 39 & 0 & 6 & 6 & 18 & 6 \\
1850 & 40 & 0 & 1 & 8 & 20 & 8 \\
1870 & 54 & 0 & 11 & 5 & 27 & 11 \\
1890 & 60 & 0 & 8 & 5 & 34 & 13 \\
1910 & 71 & 1 & 10 & 7 & 43 & 10 \\
1929 & 74 & 2 & 15 & 9 & 39 & 9 \\
1950 & 81 & 13 & 10 & 8 & 41 & 9 \\
1960 & 88 & 54 & 4 & 2 & 27 & 1 \\
1970 & 94 & 60 & 2 & 2 & 29 & 1 \\
1980 & 83 & 71 & 0 & 0 & 12 & 0 \\
1990 & 99 & 98 & 1 & 0 & 0 & 0 \\
2000 & 86 & 71 & 1 & 0 & 0 & 0 \\
Total & 869 & 370 & 69 & 52 & 290 & 68 \\
\hline
\end{tabular}

Note: For an assessment of data quality, see Table 11.2. Source: Clio-Infra, www.clio-infra.eu.

\section{Data quality}

Table 11.2 presents our assessment of the quality of the data used. Most data concerning income inequality in the 19th century are based on indirect sources and subject to large margins of error, and hence are classified as "estimates". Only recently does the quality improve a lot, reaching level one for many world regions in the most recent period. Income inequality at the regional level also requires the aggregation of income levels of individual countries, which greatly increases the problems involved.

\section{Table 11.2. Quality of data on income inequality by region} and benchmark year, 1820-2000

\begin{tabular}{ccccccccc}
\hline & $\begin{array}{c}\text { Western } \\
\text { Europe } \\
\text { (WE) }\end{array}$ & $\begin{array}{c}\text { Eastern } \\
\text { Europe (EE) }\end{array}$ & $\begin{array}{c}\text { Western } \\
\text { Offshoots } \\
\text { (W0) }\end{array}$ & $\begin{array}{c}\text { Latin } \\
\text { America and } \\
\text { Caribbean } \\
\text { (LA) }\end{array}$ & $\begin{array}{c}\text { Sub-Saharan } \\
\text { Africa } \\
\text { (SSA) }\end{array}$ & $\begin{array}{c}\text { Middle } \\
\text { East and } \\
\text { North Africa } \\
\text { (MENA) }\end{array}$ & $\begin{array}{c}\text { East Asia } \\
\text { (EA) }\end{array}$ & $\begin{array}{c}\text { South and } \\
\text { South- } \\
\text { East Asia } \\
\text { (SSEA) }\end{array}$ \\
\hline 1820 & 4 & 4 & 3 & 4 & 4 & $\ldots$ & 4 & 4 \\
1870 & 4 & 4 & 3 & 4 & 4 & 4 & 4 & 4 \\
1910 & 3 & 3 & 3 & 3 & 4 & 3 & 3 & 3 \\
1950 & $2 / 3$ & 3 & $2 / 3$ & 3 & 3 & 3 & 3 & 3 \\
1970 & 1 & 2 & 1 & 2 & 2 & 2 & 2 & 2 \\
2000 & 1 & 1 & 1 & 1 & 1 & 1 & 1 & 1 \\
\hline
\end{tabular}

Note: 1 . High quality; 2. Moderate quality; 3. Low quality; and 4. Estimates. See the section on «Data Quality» in Chapter 1 for a description of the quality criteria.

Source: Clio-Infra, www.clio-infra.eu.

Providing a historical perspective on income inequality at the global level is an even more demanding task. Although the United Nations (UNU-WIDER) now provides extensive data on within-country income inequality, they do not cover all countries for all years, 
and they are not necessarily from comparable sources (Milanovic, 2006). This data source provides inequality data gathered from various national sources and methodologies that vary across countries, and across periods for a given country. ${ }^{11}$ This implies that both crosscountry and inter-temporal comparability are an issue. Alternative sources, such as the estimates compiled by the OECD Income Distribution Database, are based on consistent definitions (e.g. in terms of the components included in the basic income concept) and treatments (e.g. in terms of treatment of negative income, or choice of equivalent scales), and are adjusted for breaks in statistical methodology. However, they are not used in this chapter, first, because the estimates are limited to OECD countries and, second, because the Gini coefficients available from the OECD refer to disposable income (i.e. net of taxes) and market income (i.e. net of taxes and public transfers), rather than to the gross income concept used in this chapter. As a result, the estimates shown here for individual countries since the 1970s and 1980s may differ significantly from those reported by the OECD in its own reports on the subject (e.g. Japan). The various methods we used to provide estimates for the missing values of our income inequality series, although quite elaborate, are also imperfect. A more straightforward approach to constructing a similar long-run dataset on income inequality is found in Bourguignon and Morrisson (2002). One feature of the methodology they applied for estimating income inequality values before 1950 was the assumption that within-country income inequality remained stable over time. Also, for large parts of the world, estimates from the post-1914 or post-1945 period were used to extrapolate the country-data available for the various time periods back to the 19th century. Despite these differences in methodology, the findings reported by Bourguignon and Morrisson are remarkably similar to those shown here.

\section{Main highlights of trends in income inequality}

In this section we highlight two main sets of results: the development of withincountry income inequality and the evolution of global income inequality.

\section{Within-country trends in inequality}

We begin by describing the long-run trends in income inequality in individual countries. A selection of the countries with data available for the long-run period from 1820 until 2000 is shown in Table 11.3. Values of the Gini coefficient on income inequality in 1820 ranged from the modest values of 33 for India, 35 for Poland and 38 for Spain, all the way up to 59 for the United Kingdom and France, 58 for Egypt and Turkey, and 57 for the United States. China (45), Canada (45), Germany (51), Japan (51) and Brazil (47) were among the countries in the middle ground. By 1850, all the countries shown in Table 11.3 experienced a decline in income inequality, followed by a renewed increase in the period up to 1870 . However, the ups and downs of the 19th century are probably less informative than the broad trends.

In the 20th century, the trends are more pronounced. In the period between the two world wars, income inequality in most countries in Western and Eastern Europe as well as in the Western Offshoot countries rose and then dropped again, considerably so after the Second World War. Egypt, China, South Africa, Brazil, Thailand and Mexico also follow this pattern closely. A notable departure from the pattern is Sweden, which experienced a decline in income inequality from 1890 until 1980. Among the Eastern European countries, Poland also defied this trend by recording a rather slowly declining level of inequality throughout the late 19th century and first half of the 20th century. India also joined the group of outliers by maintaining a very low level of slightly increasing income inequality until around the Second World War. Finally, Kenya followed the trend in the first half of the 
Table 11.3. Income inequality in selected countries, $\mathbf{1 8 2 0 - 2 0 0 0}$

Gini coefficient

\begin{tabular}{|c|c|c|c|c|c|c|c|c|c|c|c|c|c|c|c|c|c|c|c|c|c|c|c|c|c|}
\hline & \multicolumn{7}{|c|}{$\begin{array}{l}\text { Western Europe } \\
\text { (WE) }\end{array}$} & \multicolumn{2}{|c|}{\begin{tabular}{|c} 
Eastern Europe \\
$(\mathrm{EE})$
\end{tabular}} & \multicolumn{3}{|c|}{$\begin{array}{l}\text { Western Offshoots } \\
\text { (W0) }\end{array}$} & \multicolumn{3}{|c|}{$\begin{array}{l}\text { Latin America and } \\
\text { Caribbean } \\
(\text { LA) }\end{array}$} & \multicolumn{2}{|c|}{$\begin{array}{l}\text { Middle East } \\
\text { and North } \\
\text { Africa (MENA) }\end{array}$} & \multicolumn{3}{|c|}{$\begin{array}{l}\text { Sub-Saharan Africa } \\
\text { (SSA) }\end{array}$} & \multicolumn{2}{|c|}{$\begin{array}{c}\text { East Asia } \\
(\mathrm{EA})\end{array}$} & \multicolumn{3}{|c|}{$\begin{array}{c}\text { South and } \\
\text { South-East Asia } \\
\text { (SSEA) }\end{array}$} \\
\hline & GBR & NLD & FRA & DEU & ITA & ESP & SWE & POL & RUS & AUS & CAN & USA & MEX & BRA & ARG & EGY & TUR & KEN & NGA & ZAF & CHN & JPN & IND & IDN & THA \\
\hline 1820 & [59] & [56] & [59] & [51] & [54] & [38] & [55] & [35] & [58] & .. & [45] & [57] & [40] & [47] & [47] & [58] & [58] & .. & [55] & .. & [45] & [53] & [33] & [52] & [47] \\
\hline 1830 &.. & .. & .. & .. & .. & .. & .. & .. & .. & .. & .. &.. &.. & .. & .. & .. & .. & .. & .. & .. & .. & .. & .. & .. & .. \\
\hline 1840 & .. & .. & .. & .. & & .. & .. & .. & .. & & .. & .. & .. & .. & .. & .. & .. & .. & .. & .. & .. & & .. & .. & \\
\hline 1850 & [43] & [48] & [54] & [40] & [51] & [32] & [46] & [36] & [54] & [41] & [27] & [44] & [32] & [37] & [34] & [63] & [37] & .. & .. & .. & [33] & {$[46]$} & [39] & [42] & [42] \\
\hline 1860 & .. & .. & .. & .. & .. & .. & .. & .. & .. &.. & .. & .. &.. & .. & .. & .. & .. & .. & .. & .. & .. & .. & .. & .. & .. \\
\hline 1870 & [49] & [57] & [58] & [48] & [51] & [34] & [52] & [38] & [50] & [48] & [44] & [51] & [51] & [39] & [52] & [45] & {$[56]$} & [46] & .. & .. & [41] & [46] & {$[40]$} & [39] & {$[36]$} \\
\hline 1880 & .. & .. & .. & .. & .. & .. & .. & .. & .. & .. & .. & .. & .. & .. & .. & .. & & .. & .. & .. & & & .. & .. & .. \\
\hline 1890 & [37] & [42] & [48] & [39] & {$[46]$} & [31] & [59] & [30] & [38] & [39] & [41] & [46] & [44] & {$[36]$} & [45] & [33] & {$[.]$.} & [33] & [37] & [36] & [31] & [47] & [32] & [39] & [34] \\
\hline 1900 & .. & .. & .. & .. & .. & .. & .. & .. & .. & .. & .. & .. & .. & .. & .. & .. & .. & .. & .. & .. & .. & .. & .. & .. & .. \\
\hline 1910 & 42 & 47 & 55 & 44 & 49 & 35 & 57 & 28 & 40 & 41 & 41 & 51 & 51 & 38 & 51 & 42 & .. & [49] & .. & [45] & 39 & 52 & 31 & 42 & 42 \\
\hline 1920 & .. & .. & .. & .. & .. & .. & .. & .. & .. & .. & .. & .. & .. & .. & .. & .. & .. & .. & .. & .. & .. & .. & .. & .. & .. \\
\hline 1930 & 43 & 42 & 62 & 46 & 51 & 36 & 51 & 26 & 43 & 36 & 42 & 54 & 55 & 60 & 45 & 46 & 54 & [55] & .. & [59] & 44 & 52 & 31 & 50 & 47 \\
\hline 1940 & .. & .. & .. & .. & .. & .. & .. & .. & .. & .. & .. & .. & .. & .. & .. & .. & .. & .. & .. & .. & .. & .. & .. & .. & .. \\
\hline 1950 & 30 & 36 & 58 & 47 & 43 & 35 & 40 & 23 & 36 & 38 & 36 & 39 & 52 & 49 & 41 & 39 & 49 & 56 & .. & 52 & 32 & 36 & 35 & 54 & 39 \\
\hline 1960 & 29 & 43 & 52 & 39 & 44 & 28 & 40 & 26 & 28 & 35 & 35 & 38 & 53 & 55 & 42 & 43 & 55 & 68 & 51 & 69 & 31 & 38 & 37 & 40 & 43 \\
\hline 1970 & 29 & 36 & 45 & 40 & 39 & 35 & 37 & 29 & 23 & 32 & 34 & 36 & 56 & 58 & 35 & 43 & 52 & 50 & 38 & 70 & 28 & 35 & 40 & 44 & 44 \\
\hline 1980 & 34 & 30 & 35 & 38 & 39 & 41 & 29 & 30 & 25 & 39 & 34 & 37 & 51 & 57 & 42 & 50 & 50 & 57 & 35 & 67 & 30 & 37 & 31 & 40 & 46 \\
\hline 1990 & 39 & 32 & 37 & 49 & 33 & 34 & 31 & 31 & 26 & 42 & 32 & 40 & 48 & 59 & 43 & 54 & 44 & 49 & 44 & 63 & 34 & 36 & 40 & 39 & 50 \\
\hline 2000 & 40 & 32 & 37 & 51 & 37 & 33 & 35 & 35 & 40 & & 41 & 44 & 47 & 61 & 47 & 54 & 46 & 51 & 51 & 55 & 44 & 33 & 47 & 50 & 47 \\
\hline
\end{tabular}

Notes: For an assessment of data quality, see Table 11.2. RUS 1930-1970: refers to the Soviet Union.

Values in brackets [ ] indicate very tentative data.

Source: Clio-Infra, www.clio-infra.eu. 
20th century, by experiencing an increasing income inequality, with a more rapid increase in the second half of the 20th century.

In the 1950s, most countries in Latin America, Asia and Africa also experienced increased income inequality, but to varying degrees. China seems to be the sole exception to this pattern, with a small decrease in income inequality from an already low level. In Europe and the Western Offshoots, the situation is more diversified, as income inequality declined in most countries but increased in others. Income inequality declined in Canada and the United States, and even more so in France, Germany, the former USSR, Spain and Australia. Conversely, income inequality increased in the Netherlands, Italy, Poland and, to a lesser degree, Sweden. The United Kingdom stands out in this period with a rather stable level of income inequality. In the 1960s, most countries experienced rather stable income inequality, although this declined in France and Sweden and increased sharply in Kenya and South Africa.

France is notable for a continuous decline in income inequality in the period from the interwar years until 1980. South Africa, Brazil and Mexico kept a high level in the 1970s, but inequality dropped sharply in Mexico, from a coefficient of 59 in 1970 to 47 by 1980. The decline was smaller in the case of Brazil, but still substantial. In South Africa, the decline in income inequality was mostly recorded during the 1990s. Starting from the 1980s, most countries experienced a rise in their inequality levels, although, based on our series, Japan maintained low inequality levels from the 1950s onwards. In the group of countries with rising inequality in the period since the 1980s, one of the most striking increases was in China, whose Gini coefficient rose by about half between 1980 and 2000.

The country with the highest income inequality over the entire period is South Africa, with a peak of 70 in the 1970s. Among the other countries, only Kenya in 1960 came close to that level, with a Gini coefficient of 68. For a long period from the beginning of the 20th century up until the 1960s, Poland achieved the lowest income inequality, with values of around 25. In the period as a whole, Spain and Thailand had the most stable level of inequality, with values staying within a relatively small range. In contrast, the former Soviet Union experienced the largest changes in inequality, followed by South Africa and Sweden.

It is hard not to notice the sharp increase in income inequality experienced by the vast majority of countries from the 1980s. There are very few exceptions to this, with Japan being the most prominent one (i.e. a decline starting from a rather low level of income inequality). Another exception is South Africa, which started-off from a staggering Gini coefficient of 70 in 1970.

Looking beyond trends in individual countries and regions, we obtain a global perspective by considering income inequality as if the world were one country. This is shown in the second column of Table 11.4 (the World Gini). Although global income inequality rises throughout the period, the third column (within-country inequality) clearly shows the "egalitarian revolution" in the mid-20th century, which translated into significant declines in this measure. However, this trend reversed strongly in the last decade, as within-country inequality levels returned to the values recorded in 1820. Overall, the increase in global inequality experienced from 1820 to 2000 was largely caused by an increase in between-country inequality (fourth column) rather than within-country inequality (third column). The exceptions to this pattern are the years leading to 2000 , when the increase in within-country inequality just offset the decrease in between-country income inequality. Throughout the period as a whole from 1820 to 2000, global interpersonal income inequality increased by $30 \%$ (column 2), while between-country 
inequality increased from a very low level of 16 in 1820 to 56 by 1970. However, over the last 50 years, between-country inequality has remained broadly stable, dropping only in the last two decades of the 20th century, the second decline in the dataset since 1820.

Figure 11.1 presents the same information about the evolution of global inequality in a different way. Changes in the shape of this distribution in different periods reflect the combined effects of the increase in average income levels in individual countries, the

Table 11.4. Gini coefficients of within-country and between-country inequality, 1820-2000

\begin{tabular}{lccc}
\hline Year & World Gini & Within country inequality & Between country inequality \\
\hline 1820 & 49 & 45 & 16 \\
1850 & 46 & 38 & 23 \\
1870 & 55 & 45 & 32 \\
1890 & 52 & 36 & 38 \\
1910 & 58 & 40 & 44 \\
1929 & 63 & 44 & 49 \\
1950 & 65 & 38 & 55 \\
1960 & 64 & 38 & 54 \\
1970 & 65 & 37 & 56 \\
1980 & 65 & 36 & 56 \\
1990 & 66 & 39 & 56 \\
2000 & 66 & 45 & 54 \\
\hline
\end{tabular}

Note: For an assessment of data quality, see Table 11.2.

Source: Clio-Infra, www.clio-infra.eu.

Figure 11.1. Global income distributions in selected years, 1820-2000 Thousands of people at given level of income in US dollars at 1990 PPP

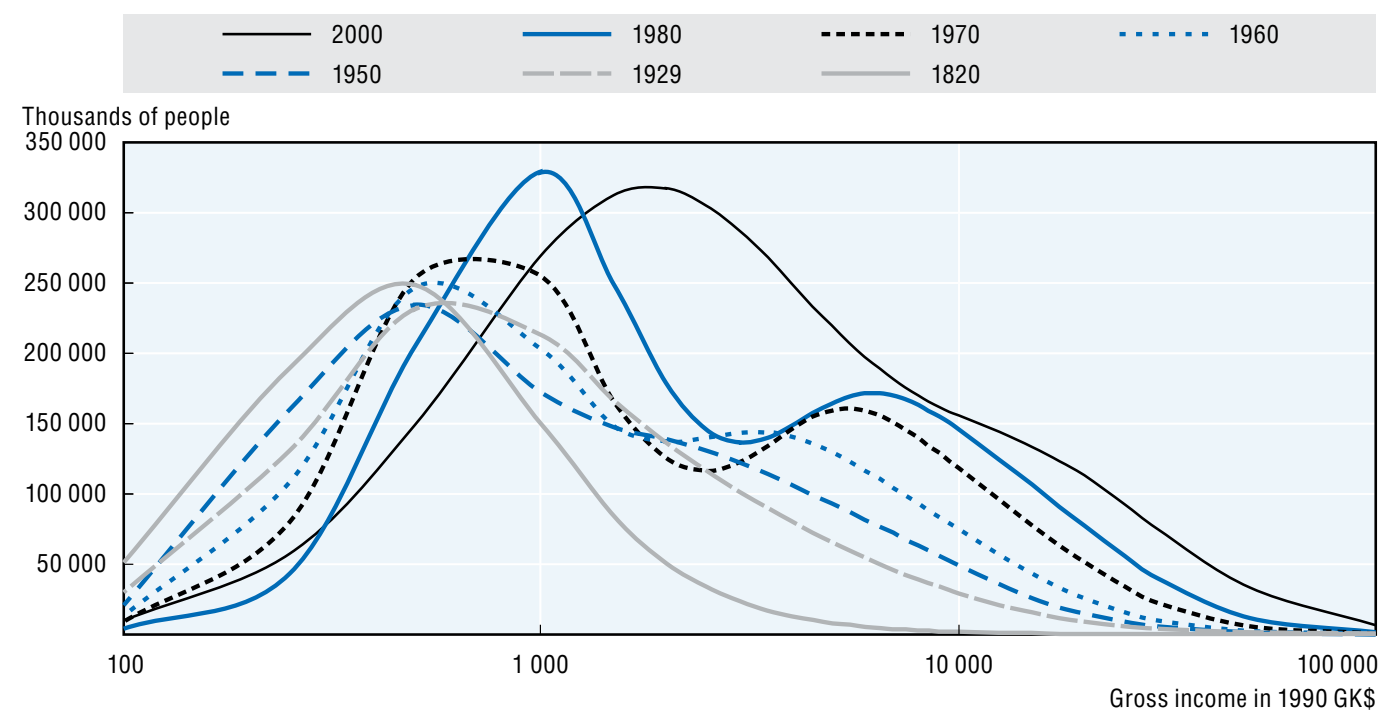

Note: For an assessment of data quality, see Table 11.2.

Source: Clio-Infra, www.clio-infra.eu. 
changes in its distribution within countries, and the growth of countries' population (all income levels are expressed in 1990 Geary-Khamis dollars). What is particularly striking is the change in the shape of the income distribution through time (for similar analyses of the more recent period, see Milanovic, 2002, and Sala-i-Martin, 2006). Between 1820 and 1950, the world income distribution is unimodal and basically log-normal, although, looking at the 1950 distribution, a thickening of its right "tail" can already be noticed. Over the next few decades, a different distribution starts to emerge, with two separate peaks; while this pattern is already distinguishable in 1950, it becomes more pronounced in the 1960s, 1970s and 1980s, when a big gap between the rich and poor "peaks" appears. However, in the 1990s the two peaks begin to get closer, and by 2000 the distribution has become unimodal again.

One might argue that the switch from a unimodal to a bimodal distribution in the 1960s was caused by the long wave of de-globalisation that set in after 1914, i.e. a decline in external trade caused by two world wars, a depression and a bi-polar world system. This, however, is a topic for further research - here we can observe only that this change from a unimodal world distribution towards a bimodal one was accompanied by the decline of within-country inequality: the "egalitarian revolution" of the 20th century seems to have been a phenomenon linked to the development of strong nation states, with more freedom to steer domestic policies in the de-globalised world of 1914-1960. However, almost simultaneously, these processes also gave rise to a bimodal income distribution globally. After 1980, globalisation contributed to higher income inequality within countries, while at the same time leading to a decline of income inequality between countries, again in a closely interrelated process.

When looking more closely at the different world regions (Table 11.5), Latin America and the Caribbean is one of the regions with the highest average within-country inequality for the 20th century, as many would expect. The levels of its Gini coefficients are matched by those recorded in Sub-Saharan Africa from 1950 onwards. Furthermore, there seems to be one major reversal: in the 19th century, both Asia and Latin America and the Caribbean showed the lowest levels of inequality; this completely changed by the end of the 20th century, which clearly suggests that economic growth has led to a widening of between-country inequality in both regions. The decline in income inequality is also very strong in Eastern Europe and the former Soviet Union during the period from 1950-1990. After the dissolution of the Soviet Union and the fall of the "iron curtain", this trend reversed and in the last two decades inequality has increased dramatically. Regional inequality in Western Europe and the Western Offshoots showed a major decrease in the period until 1980. Western Europe started off from a Gini of 55 in 1820 and went down to a more modest Gini of 37 in 1980. Since the 1980s, a small increase in the Gini coefficient has been observed. In the Western Offshoots, the pattern is very similar, but the rise in recent decades is much stronger. In Asia, the story is quite the opposite, at least in its beginning: starting from a low value in 1820 of 45 and 35, for East Asia and South and Southeast Asia respectively, both regions experienced a strong increase, which is most prominent in the 1960s for East Asia and in the 1980s for South and Southeast Asia. This rising trend also extended to the last three decades as well. 
Table 11.5. Regional averages of income inequality, 1820-2000

Gini coefficients, unweighted averages

\begin{tabular}{|c|c|c|c|c|c|c|c|c|c|}
\hline & $\begin{array}{c}\text { Western } \\
\text { Europe } \\
\text { (WE) }\end{array}$ & $\begin{array}{c}\text { Eastern } \\
\text { Europe } \\
\text { (EE) } \\
\end{array}$ & $\begin{array}{l}\text { Western } \\
\text { Offshoots } \\
\text { (WO) }\end{array}$ & $\begin{array}{l}\text { Latin } \\
\text { America } \\
\text { and } \\
\text { Caribbean } \\
\text { (LA) }\end{array}$ & $\begin{array}{c}\text { East Asia } \\
\text { (EA) }\end{array}$ & $\begin{array}{c}\text { South and } \\
\text { South-East } \\
\text { Asia } \\
\text { (SSEA) }\end{array}$ & $\begin{array}{l}\text { Middle East } \\
\text { and } \\
\text { North Africa } \\
\text { (MENA) }\end{array}$ & $\begin{array}{l}\text { Sub-Saharan } \\
\text { Africa } \\
\text { (SSA) }\end{array}$ & World \\
\hline 1820 & 54 & 51 & 56 & 45 & 45 & 35 & .. & 53 & 45 \\
\hline 1850 & 45 & 49 & 42 & 37 & 34 & 38 & 46 & 46 & 38 \\
\hline 1870 & 50 & 48 & 51 & 48 & 41 & 42 & 52 & 50 & 45 \\
\hline 1890 & 41 & 36 & 45 & 41 & 32 & 34 & 35 & 36 & 36 \\
\hline 1910 & 46 & 39 & 50 & 45 & 40 & 35 & 40 & 42 & 40 \\
\hline 1929 & 48 & 40 & 52 & 55 & 44 & 36 & 48 & 48 & 44 \\
\hline 1950 & 42 & 35 & 39 & 47 & 33 & 39 & 43 & 43 & 38 \\
\hline 1960 & 40 & 30 & 37 & 54 & 32 & 39 & 49 & 53 & 38 \\
\hline 1970 & 38 & 26 & 36 & 53 & 29 & 40 & 47 & 49 & 37 \\
\hline 1980 & 36 & 27 & 37 & 52 & 31 & 35 & 47 & 46 & 36 \\
\hline 1990 & 38 & 27 & 39 & 52 & 34 & 41 & 46 & 47 & 39 \\
\hline 2000 & 40 & 36 & 44 & 54 & 43 & 48 & 49 & 49 & 45 \\
\hline
\end{tabular}

Note: For an assessment of data quality, see Table 11.2.

Source: Clio-Infra, www.clio-infra.eu.

\section{Correlation with GDP per capita}

Figure 11.2 shows the correlation of GDP per capita with income inequality for all countries, with data being divided into three main periods and shown in a semi-logarithmic form. The first panel in the figure refers to the period before the 1930s, the next panel to the period from 1950 to 1970, and the last panel to the period from the 1980s onwards. In the first period, a negative correlation between GDP per capita and income inequality appears for countries with the lowest annual incomes; that correlation turns positive among countries with incomes from USD 800 up to about USD 2 000; from that point onward, the

\section{Figure 11.2. Correlation between Gini coefficients and GDP per capita in three time periods, $\mathbf{1 8 2 0 - 2 0 0 0}$ \\ Gini coefficients and US dollars at 1990 PPP (semi-logarithmic scale)}

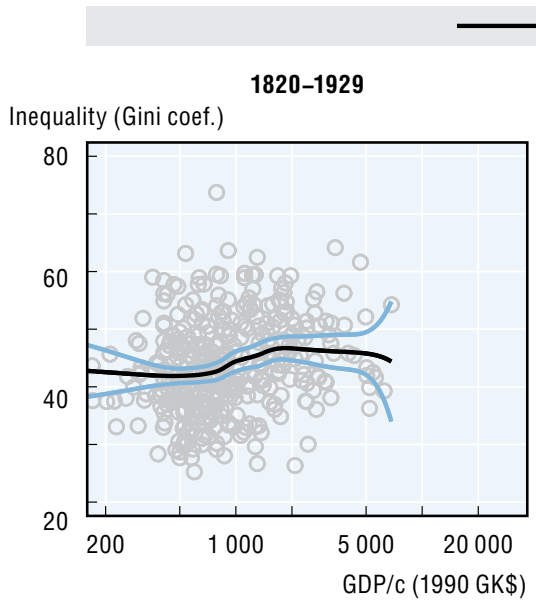

Loess fit

Inequality (Gini coef.)

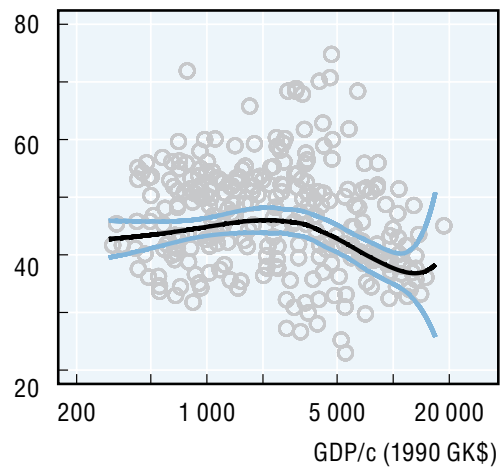

$95 \%$ confidence interval

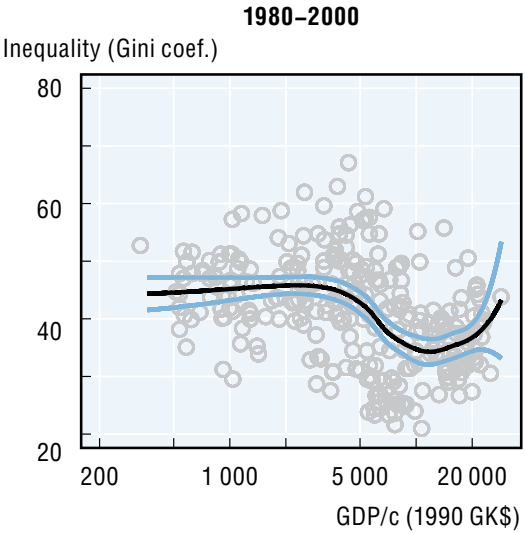

Note: For an assessment of data quality, see Table 11.2.

Source: Clio-Infra, www.clio-infra.eu 
relation is negative again. For the two post-Second World War periods, the relationship is positive until about USD 3 000, then turns strongly negative, and finally the relationship turns positive again among the countries in the highest income layers. However in both these periods, there are very few observations in the top income region. It is important to notice that for a large income span ranging from a bit below USD 10000 up until USD 20000 in the 1980-2000 period, the relation dissolves completely.

This demonstrates the real complexity of the link between income inequality and GDP per capita. Figure 11.3 shows the correlation of GDP per capita and the Gini coefficient across all the available countries over time. From 1820 until 1910, income inequality appears generally positively correlated with GDP per capita: the wealthiest countries are also relatively more unequal. This relationship reverses at the turn of the century, and after the Second World War the relation turns mostly negative, remaining negative for the entire period until the most recent available data.

Figure 11.3. Correlation between Gini coefficients and GDP per capita, 1820-2000 Pearson correlation coefficient and upper/lower bounds of $95 \%$ confidence interval

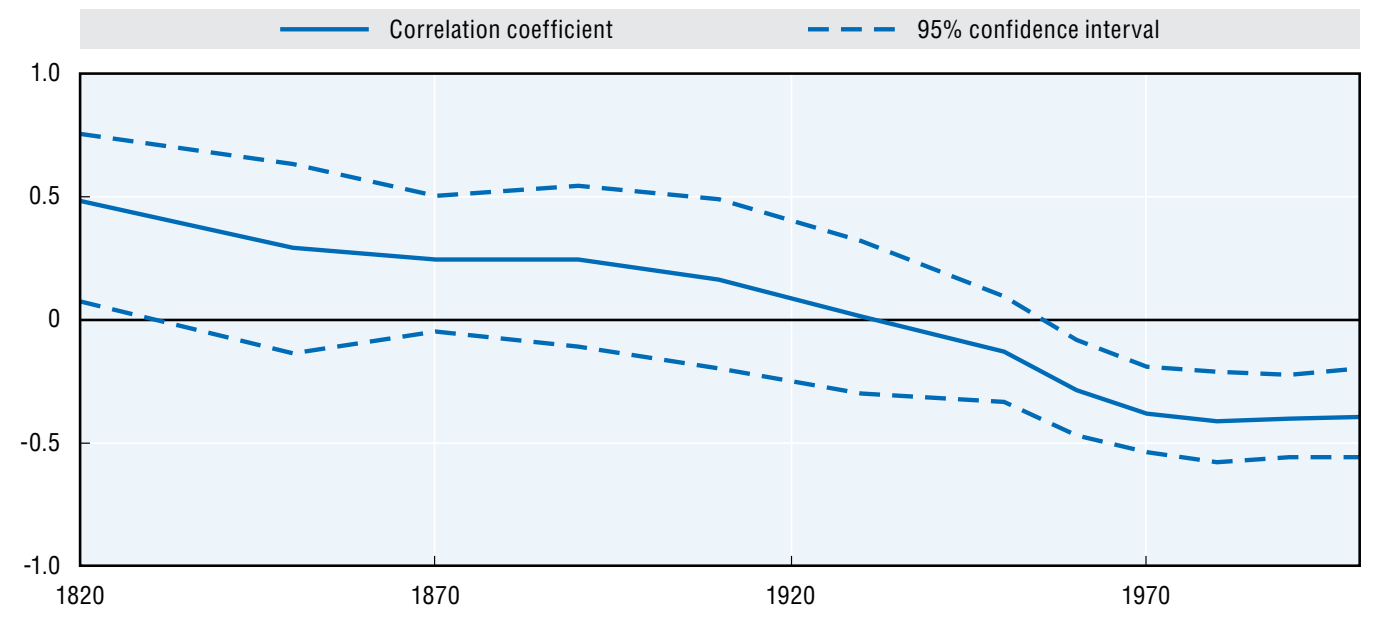

Note: For an assessment of data quality, see Table 11.2. Source: Clio-Infra, www.clio-infra.eu.

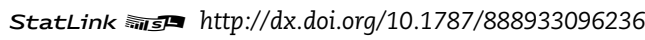

\section{Priorities for future research}

As the discussion of data limitations has suggested, more work on improving the comparability of the data sources and their findings would provide a more solid basis to draw conclusions about income inequality in a country or region or on a global scale. Historical estimates could be much improved by focusing more research on these issues. Whereas for most Western European countries and the Western Offshoots, we have relatively detailed studies that make use of the available historical sources, much more work can be done in this field for many Asian, African and Latin American countries (for examples of recent research see the website of the Global Price and Income History Group at UC Davis: http://gpih.ucdavis.edu/). The more recent work in this field also has its problems. Such work requires mobilising organisational resources on a world scale, orchestrated by international organisations. Inspiration for this type of work could be drawn from initiatives like the International Comparison Program that aims to collect comparative price data and to estimate purchasing power parity globally. 
Beyond this effort, further inter-temporal investigation of the relationship between income inequality and social outcomes will help improve our understanding of the mechanisms through which higher levels of income inequality tend to make us all worse-off (Wilkinson and Pickett, 2007). With the increased availability of data, the links between income inequality and other social indicators could be further researched, and extended to other dimensions of well-being. To that end, historical global datasets would need to be constructed and utilised.

\section{Notes}

1. So a Gini coefficient equal to zero implies perfect absolute equality - i.e. all individuals have the same income - and a Gini equal to one implies absolute inequality - i.e. one individual has all the income while the rest have none. The actual impossibility of having a Gini equal to one fits well with the idea of an inequality-possibility frontier, which takes into account the subsistence income as a frontier for minimum income for survival, and of maximum possible inequality if one individual were to receive all the remaining income (Milanovic, Lindert and Williamson, 2007).

2. Studies are available for Australia (1921-2003, A.B. Atkinson and Leigh, 2007); Canada (1920-2000, Saez and Veall, 2005); France (1905-1998, Piketty, 2007); Germany (1925-1998, Dell, 2007); India (19221999, Banerjee and Piketty, 2005); Indonesia (1920-2004, Leigh and der Eng, 2010); Ireland (1922-2000, Nolan, 2007); Japan (1886-2002, Moriguchi and Saez, 2006); Korea (1998, Cheong, 2001); Netherlands (1914-1999, Salverda and Atkinson, 2007); New Zealand (1921-2002, Atkinson and Leigh, 2005); Spain (1981-2002, Alvaredo and Saez, 2009); Sweden (1903-2004, Roine and Waldenström, 2006); Switzerland (1933-1996, Dell, Piketty and Saez, 2007); the United Kingdom (1908-2000, Atkinson, 2007); and the United States (1913-2004, Piketty and Saez, 2003).

3. Global Price and Income History Group

4. For example, income inequality increased significantly in the United States since the 1980s, while consumption inequality was rather stable.

5. Although SEDLAC sources in All The Ginis dataset are treated as "gross", the data exclude wage taxes and include direct taxes. This may introduce some additional bias.

6. The data available on income shares of the top $1 \%$ and top $5 \%$ can be found for a collection of countries at "The World Top Incomes Database" created by Facundo Alvaredo, Tony Atkinson, Thomas Piketty and Emmanuel Saez. We make use of these data, but we do not present them separately.

7. For China from Brandt and Sands (1992);for Japan, several estimates by Soltow and Van Zanden (1998b); for Indonesia, Van Leeuwen and Földvári (2012).

8. Both series are also used in Chapters 3 and 4 of this report.

9. The decade of birth is used, because the strongest environmental influence on the body growth process takes place after birth during the first three to five years.

10. This measure could be affected by survivor bias, since measures of inequality in height refer only to survivors. However, this is consistent with other measures of inequality, as the income earners who are the base for Gini coefficients of household income only refer to people who survived to the age of earning an income. For further discussion, see Moradi and Baten (2005).

11. Beyond various between-country differences, there are a number of concerns embedded in the survey's methodology per se, particularly the under-representation or under-reporting of the poorer and richer groups of the population within a country.

\section{References}

Allen, R. et al. (2010), “Wages, Prices, and Living Standards in China,1738-1925: in comparison with Europe, Japan, and India", Economic History Review.

Allen, R.C. (2001), “The Great Divergence in European Wages and Prices from the Middle Ages to the First World War", Explorations in Economic History, Vol. 38, pp. 411-447.

Alvaredo, F. and E. Saez (2009), "Income and wealth concentration in Spain from a historical and fiscal perspective", Journal of the European Economic Association, Vol. 7/5, pp. 1140-1167. 
Anand, S. and P. Segal, P. (2008), "What Do We Know about Global Income Inequality?", Journal of Economic Literature, Vol. 46/1 (1983), pp. 57-94, www.aeaweb.org/articles.php?doi=10.1257/jel.46.1.57.

Atkinson, A.B. (2007), "The distribution of top incomes in the United Kingdom", in Top Incomes over the Twentieth Century: A Contrast between Continental European and English-Speaking Countries, pp. 82-140.

Atkinson, A.B. and A. Leigh (2007), "The Distribution of Top Incomes in Australia", Economic Record, Vol. 83/262, pp. 247-261.

Atkinson, A.B. and A. Leigh (2005), "The distribution of top incomes in New Zealand", ANU Centre for Economic Policy Research Discussion Paper, Vol. 503.

Atkinson, A.B., T. Piketty and E. Saez (2011), “Top Incomes in the Long Run of History”, Journal of Economic Literature, Vol. 49/1, pp. 3-71.

Banerjee, A. and T. Piketty (2005), “Top Indian Incomes, 1922-2000”, The World Bank Economic Review, Vol. 19/1, pp. 1-20.

Baten, J. (1999), "Ernährung und wirtschaftliche Entwicklung", (Nutrition and Economic Development) in Bayern, 1730-1880, Steiner, Stuttgart.

Baten, J. (2000). Economic Development and the Distribution of Nutritional Resources in Bavaria, 1797-1839. Journal of Income Distribution, Vol. 9, 89-106.

Bergson, A. (1984), Income inequality under Soviet socialism. Journal of Economic Literature, 22(3), 1052-1099.

Bértola, L. et al. (2009), "Income distribution in the Latin American southern cone during the first globalization boom and beyond," International Journal of Comparative Sociology, Vol. 50/5-6), pp. 452-485.

Bourguignon, F. and Morrisson, C. (2002), "Inequality Among World Citizens : 1820-1992", The American Economic Review, Vol. 92/4, pp. 727-744.

Brandt, L. and B. Sands (1992), Land Concentration and Income Distribution in Republican China, T. Rawski and L. Lee (eds.), Chinese Hi., pp. 179-206), California University Press, Oakland.

Buhmann, B. et al. (1988), "Equivalence scales, well-being, inequality, and poverty: sensitivity estimates across ten countries using the Luxembourg Income Study (LIS) database", Review of Income and Wealth, Vol. 34/2, pp. 115-142. http://dx.doi.org/10.1111/j.1475-4991.1988.tb00564.x.

CEDLAS (Centro de Estudios Distributivos Laborales y Sociales) (Centre for Distributive Labour and Social Studies) (2013), Socio-Economic Database for Latin America and the Caribbean (CEDLAS and The World Bank), http://sedlac.econo.unlp.edu.ar/eng/statistics.php accessed 1 June, 2013,

Cheong, K.S. (2001), "Economic Crisis and Income Inequality in Korea”, Asian Economic Journal, Vol. 15/1, pp. 39-60.

Deininger, K. and L. Squire (1996), "A new dataset measuring income inequality", The World Bank Economic Review, Vol. 10/3, pp. 565-591.

Dell, F. (2007), “Top Incomes in Germany throughout the Twentieth Century”, Top Incomes over the Twentieth Century: A Contrast between Continental European and English-Speaking Countries, pp. 365-425.

Dell, F., T. Piketty and E. Saez, (2007), "Income and wealth concentration in Switzerland over the 20th century", Top Incomes over the Twentieth Century: A Contrast between Continental European and English-Speaking Countries, pp. 472-500.

Alvaredo F. et al. The World Top Incomes Database, http://topincomes.g-mond.parisschoolofeconomics.eu/.

François, J. F. and H. Rojas-Romagosa, (2005), The Construction and Interpretation of Combined Cross Section and Time-Series Inequality Datasets.

Global Price and Income History Group, http://gpih.ucdavis.edu.

Guntupalli, A.M. and J. Baten, (2006), “The Development and Inequality of Heights in North, West and East India, 1915-44", Explorations in Economic History, Vol. 43/4, pp. 578-608.

Jones, C.I. (1997), "On the Evolution of the World Income Distribution”, Journal of Economic Perspectives, Vol. 11(3), pp. 19-36.

Leigh, A., and P. der Eng, (2010), "Inequality in Indonesia: What can we learn from top incomes?" Top Incomes over the Twentieth Century: Volume II, A Global Perspective, pp. 171-219. 
Maddison, A. (2003), The World Economy: Historical Statistics, Development Centre Studies, OECD Publishing, Paris, http://dx.doi.org/10.1787/9789264104143-en

Milanovic, B. (2002), “True World Income Distribution , 1988 and 1993 : First Calculation Based on Household Surveys Alone", The Economic Journal, Vol. 112/476, pp. 51-92.

Milanovic, B. (2006), Global Income Inequality: What it is and why it matters, World Bank Policy Research Working Paper, No. 3865.

Milanovic, B. (2007), Worlds Apart. Measuring International and Global Inequality, Princeton University Press, Princeton.

Milanovic, B. (2012), All the Ginis dataset, http://go.worldbank.org/YOW9ERU7G0.

Milanovic, B., P. Lindert and J. Williamson (2007), Measuring Ancient Inequality, NBER (National Bureau of Economic Research) Working Paper No. 13550, Munich.

Mironov, B. (2004), "Prices and Wages in St. Petersburg for Three Centuries (1703-2003)", Towards a Global History of Prices and Wages, Utrecht 19-21 August 2004, St. Petersburg State University, St. Petersburg.

Mitchell, B.R. (1998a), International historical statistics: Africa, Asia \& Oceania, 1750-1993. Macmillan.

Mitchell, B.R. (1998b), International historical statistics: Europe, 1750-1993, Macmillan.

Mitchell, B.R. (1998c), International historical statistics: the Americas, 1750-1993, Macmillan.

Moradi, A. and J. Baten, (2005), "Inequality in Sub-Saharan Africa 1950-80: New Estimates and New Results”, World Development, Vol. 33/8, pp. 1233-1265.

Moriguchi, C., and E. Saez (2006), The Evolution of Income Concentration in Japan, 1886-2002: Evidence from Income Tax Statistics, NBER (National Bureau of Economic Research) Working Paper www.nber.org/ papers/w12558.

Nolan, B. (2007), "Long-term trends in top income shares in Ireland", Top Incomes over the Twentieth Century: A Contrast between Continental European and English-Speaking Countries, Oxford University Press, Oxford, pp. 501-530.

Piketty, T. (2007), "Income, wage and wealth inequality in France, 1901-98”, Top Incomes over the Twentieth Century, Oxford University Press, Oxford, pp. 43-81.

Piketty, T. and E. Saez (2003), "Income Inequality in the United States, 1913-1998”, The Quarterly Journal of Economics, Vol. CXVIII/1, pp. 1-39, http://emlab.berkeley.edu/users/saez/ accessed 6 December, 2006; Tables and Figures updated to 2004).

Pradhan, M., D. Sahn and S. Younger (2003), “Decomposing World Health Inequality”, Journal of Health Economics, Vol. 22(2), pp. 271-293.

Roine, J. and D. Waldenström (2006), “The Evolution of Top Incomes in an Egalitarian Society; Sweden, 1903-2004," Journal of Public Economics, Vol. 92, Nos. 1-2, Social Science Research Network.

Rossi, N., G. Toniolo and G. Vecchi (2001), "Is the Kuznets curve still alive? Evidence from Italian household budgets, 1881-1961", Journal of Economic History, Vol. 61(4), pp. 904-925.

Saez, E., and M.R. Veall (2005), "The evolution of high incomes in Northern America: lessons from Canadian evidence", The American Economic Review, Vol. 95/3, pp. 831-849.

Sala-i-Martin, X. (2006), "The World Distribution of Income: Falling Poverty and ... Convergence, Period”, The Quarterly Journal of Economics, Vol. 121(2), pp. 351-397.

Salverda, W. and A.B. Atkinson (2007), “Top incomes in the Netherlands over the twentieth century”, Top Incomes over the Twentieth Century: A Contrast between Continental European and English-Speaking Countries, pp. 426-471.

Sen, A. (1973), On Economic Inequality, Oxford University Press, Oxford.

Sen, A. (1976), "Poverty: An Ordinal Approach to Measurement", Econometrica, Vol. 44/2, pp. 219-231.

Soltow, L. and J.L. van Zanden (1998a), "Income and Wealth Inequality in the Netherlands 1500-1990", Het Spinhuis Publishers, Amsterdam.

Soltow, L. and J.L.van Zanden (1998b), "The measures of inequality”, in Income and wealth inequality in the Netherlands in the 16th-20th century, pp. 7-22, Het Spinhuis Publishers, Amsterdam.

Sunder, M. (2003), "The Making of Giants in a Welfare State: The Norwegian Experience in the 20th Century", Economics \& Human Biology, Vol. 1/2, pp. 267-276. 
Svedberg, P. (2004), “World Income Distribution: Which Way?" Journal of Development Studies, Vol. 40(5), pp 1-32.

UN (United Nations) (2011), Canberra Group Handbook on Household Income Statistics, Second edition, United Nations Economic Commission for Europe.

UNU-WIDER (United Nations University-World Institute for Development Economics Research) (2008), World Income Inequality Database. Version 2.0c, May.

Van Leeuwen, B. and P. Földvári (2012), The Development of Inequality and Poverty in Indonesia, 1932-1999, Centre for Economic Global History, University of Utrecht, Working paper No. 26

Wilkinson, R.G. and K.E. Pickett (2007), "The problems of relative deprivation: why some societies do better than others," Social Science \& Medicine, Vol. 65/9, pp. 1965-78, http://dx.doi.org/10.1016/j. socscimed, 2007.05.041.

Williamson, J. (1999), “Real Wages, Inequality, and Globalization in Latin America Before 1940”, Revista de Historia Economica, pp. 101-142.

Williamson, J. (2000a), "Globalization, factor prices and living standards in Asia before 1940", in A.J.H. Latham and H. Kawakatsu, (eds.), Asia Pacific Dynamism 1550-2000, Routledge, pp. 13-45.

Williamson, J. (2000b), "Real Wages and Factor Prices Around the Mediterranean 1500-1940", in S. Pamuk and J.G. Williamson (eds.) The Mediterranean Response to Globalization Before 1950, Routledge, pp. $45-75$.

Van Zanden, J.L. et al. (2013), “The Changing Shape of Global Inequality 1820-2000; Exploring a New Dataset", Review of Income and Wealth, pp. 1-19, http://dx.doi.org/10.1111/roiw.12014. 



\section{Chapter 12}

\section{Gender inequality since 1820}

by

Sarah Carmichael, Selin Dilli and Auke Rijpma, Utrecht University

Historically, gender inequalities in health status, socio-economic standing and political rights have been large. This chapter documents gender differences in life expectancy and birth rates (to cover health status); in average years of schooling, labour force participation, inheritance rights and marriage age (to cover socioeconomic status); and in parliamentary seats and suffrage (to cover political rights). A composite indicator shows strong progress in reducing gender inequality in the past 60 years in most regions. Only in East Asia and in Eastern Europe this decline stalled in the 1980s. Differences in levels of gender inequality between regions remained large, however: Europe (including Eastern Europe) and the Western Offshoots performed best, although no country reached full gender equality. The Middle East and North Africa (mainly due to weak political rights) and South and Southeast Asia (due to skewed sex ratios at birth) performed worst. 


\section{Introduction}

The previous chapters of this volume have given an overview of how the world's population has fared over the past 190 years, with the focus being either on the general population or on men (i.e. the real wages chapter, for which female data is unavailable). Women make up roughly $50 \%$ of the world's population. However when it comes to equality between men and women, the world remains an unequal playing field (Duflo, 2012). Given this, any view of global well-being is incomplete without taking into consideration inequalities between men and women. For example, property rights favouring male ownership persist throughout the developing world (Weldon and Htun, 2012). Furthermore, male-biased sex ratios, usually interpreted as a sign of mistreatment of women and above all female infants, remain in evidence, or have become more pronounced, particularly in Asian countries such as China (Klasen and Wink, 2003). In economically developed countries gender inequality persists in the form of gender pay differences, whereby women who are equally qualified continue to earn less than men at all levels of qualification (e.g. Arulampalam et al., 2007). Even in highly democratic countries women continue to be under-represented in the political sphere. As of July 2013, the proportion of seats held by women in single or lower houses of parliament was only $21.3 \%$ globally and only $22.7 \%$ in European countries (Inter-Parliamentary Union, 2011).

These gaps between the sexes are not just important from an intrinsic, social justice perspective, but also from an instrumental one. The results of a number of studies have shown the importance of women for a wide range of development outcomes, and because of this the international community has come to the conclusion that addressing gender equality is an important part of any development initiative. ${ }^{1}$ Improving women's rights in terms of access to resources and legal standing has been shown to improve, amongst other things, children's educational attainment (Currie and Moretti, 2003; King et al., 1986; Schultz, 1988), agricultural productivity (FAO, 2011), economic growth (Klasen, 2002; Klasen and Lamanna, 2009) and the quality of government, particularly by reducing corruption (Dollar, Fishman and Gatti, 2001). ${ }^{2}$ Striving for gender equality therefore appears to be a key driver in achieving many other development goals and to have effects across the board on various aspects of well-being for both men and women. ${ }^{3}$

Gender relations and roles are not phenomena that change overnight. Rather, gender inequality has historical roots. One author who demonstrates this is Katherine Lynch (2011). She concludes that the fact that Western Europe has not seen noticeable levels of "missing women" since the 16th century can be ascribed to family structures, opportunities for paid labour and elements of Christianity that had long been present. This stands in sharp contrast to both the historical and the present-day experience of countries such as India and China. Another example is that of the Western European marriage pattern, which emerged in the late Middle Ages, and was characterised by a shift from parental to individual consent to marriage decisions. The key characteristic of this European marriage pattern was that women had an equal say in the marriage decision and were involved 
in the household decision-making process on an equal footing with their husbands (Van Zanden and De Moor, 2010).

Although gender inequality is a persistent trait of many countries, there are also important differences between countries and regions of the world. A long-term perspective is essential to understanding gender inequality within and between countries. In addition to allowing us to understand where and how gender inequalities emerge and persist, a long-term perspective should also allow better exploration of the relationship between gender inequality and economic development (Lagerlöf, 2003).

In order to better understand gender equality and its relationship to the development process, it is thus necessary to find ways to measure gender relations over time. This chapter therefore seeks to address three interrelated questions. First, how can we measure gender inequality in a historical perspective and, second, using these measures, what trends do we observe in gender equality in the world economy over the last 200 years? Lastly, we also want to explore the question, to what extent does a relationship exist between gender equality and economic development in the long run? These questions are addressed by analysing a wide range of indicators of gender equality in the 20th century, based upon indicators used in currently available gender equality indices.

Even though the empowerment of women and closing the gap between the two genders have been widely acknowledged as important development objectives, for the reasons sketched above, finding "methods for systematically measuring and tracking changes in levels of gender equality" is not straightforward (Malhotra, 2003). There have been numerous efforts by researchers and international bodies to develop accurate measures of gender equality. The UNDP's Gender-related Development Index (GDI) and its replacement, the Gender Inequality Index (GII), are perhaps the best-known examples. ${ }^{4}$ Most of these measures have aspects and variables in common, though some focus more on gender inequalities in outcomes (such as gender disparities in human capital), and some focus more on the social institutions underlying gender inequality. One example of an index that focuses on the institutions underlying gender inequality is the Social Institutions and Gender Index (SIGI) compiled by the OECD's Development Centre (Branisa et al., 2009). This index looks at a wide range of institutional measures that capture different aspects of gender inequality, such as whether women have the same rights of legal guardianship of their children during marriage, women's legal protection from rape, and women's legal access to land.

The fact that women have started to be placed more prominently on the development agenda has resulted in different conceptualisations and measurements of women's empowerment. However, despite this proliferation of conceptualisations and measures, most studies are limited to the contemporary time period. None of the available indices start before 1995, meaning we lack a long-term perspective, which is crucial for understanding progress towards gender equality. For instance, these indices would miss the gains made by women in terms of life expectancy in the period since the 1950s, as everywhere in the world women now live longer than men. ${ }^{5}$ Similarly, one can see the impact of China's one-child policy on missing girls only if the evolution of sex ratios are also analysed for the period before 1980 (World Bank, 2011). Lastly, such a long-term perspective not only provides an overview of changes in gender inequalities, but also helps in comparing the experience of different countries in the long run. Some inequalities can be pinned on the level of economic development, while others are more institutional in nature, something that becomes apparent when comparing historical gender inequality across the spectrum of institutional and developmental variety in the historical record. 
In sum, the causes of gender equality and the prospects for improvement can be understood only by means of long-term, comparative analysis. This chapter aims to take a first step towards that goal. Though constrained by issues of data availability, we build on the ideas of the various gender indices available to choose variables that capture various aspects of gender inequality over time.

\section{Description of the concepts used}

Gender inequality manifests itself in many dimensions of daily life (from domestic violence in the household to unequal wage practices in the workplace, etc.) and results in unequal opportunities for participation in political and economic decision-making for men versus women (OECD, 2013). This chapter provides an overview of gender inequalities in various dimensions of well-being, following the conceptual framework of How Is Life? (OECD, 2013) and the current study on A Long-Term Perspective on Global Well-being and Development (OECD, 2014), whenever that data is available by gender. Furthermore, discrimination can take place throughout a woman's life cycle, from birth (resulting from sex-selective abortions, such as in the case of China) to access to education (for instance in school enrolment rates) and continuing through the rest of their life course (e.g. labour force participation and life expectancy) (OECD, 2013). For this reason, a range of indicators are selected that capture gender inequality at different stages of the life cycle. Lastly, the chapter focuses on the indicators that have been shown to matter for the overall development of the societies (e.g. World Bank, 2011).

In choosing indicators of gender inequality, the analysis in this chapter is constrained by the availability of historical data. For this reason, not all key issues that affect women's well-being and are included in contemporary gender inequality indices could be covered. It was not possible, for instance, to include measures such as income or access to highpaying jobs, which are crucial factors for the economic standing of women (Kabeer, 1999) 6 What is lost in comparability with present-day indices, however, is made up for in the long-term perspective 7 Despite constraints in data availability, there are theoretical and methodological criteria behind the choice of the gender equality variables employed. First, the focus is on internationally comparable measures since the aim is to produce a global picture of gender inequality 8 second, the chapter gives an indication of gender disparities that result from institutional, cultural and social influences (OECD, 2013). Branisa et al. (2013), for example, attribute cross-national differences in female schooling largely to the institutional structures affecting gender equality, in particular whether women can inherit. Another institutional indicator related to gender equality for which data is available is suffrage. The extension of voting rights to women is not only important for the intrinsic reason that it promotes equality of opportunities between the two genders, but also because it is associated with increases in the extent of social spending, particularly on education and health (see Lindert, 2004, for evidence on the United States in the early 20th century). Third, the chapter focuses on measures that are available over long time periods, as the intent is to capture the progress that countries have made towards gender equality. However, fertility, which is a commonly used measure in composite gender equality measures (see, for example, the UNDP's Gender Inequality Index), is excluded as it provides only an indirect indication of women's position. In doing this, the chapter follows, amongst others, Donno and Russet (2004: 588) who argue that although low fertility may be indicative of the degree of female reproductive rights, it may also "reflect coercive population policies enforced on women". 
Gender disparities are analysed along four dimensions that are commonly discussed in the literature. First, there is the very basic issue of women's health. For example, women's very existence may be threatened by sex-selective abortions and neglect in medical care. More generally, whether women have the same opportunities as men to live a long and healthy life is of fundamental importance to equality and well-being. Second, the chapter looks at socio-economic standing. Whether or not women are able to be economically independent not only has intrinsic importance, but can also have indirect effects on women's position in the household by strengthening their options beyond marriage and childbearing (Gray, 1998; Sen, 1990). The position of women in terms of socio-economic resources affects not only their own well-being but also that of their offspring. Generally speaking, the household (with special reference to the married couple at the head of the household) is where many important decisions relating to women's position are made (Klasen, 1998, p. 437). For this reason, the third field considered is the marital position of women. Fourth, in most countries, men have more influence in political decision-making processes because they are overrepresented in public office. This is therefore an arena where there is much to be gained in terms of gender equality.

In line with the Global Gender Gap Index, while presenting different dimensions of gender inequality we focus on gender gaps in development outcomes in individual countries rather than the actual levels of resources and opportunities available to women. This is so as to evaluate the gender differences independent of a country's level of development. However, a discussion of how women are performing in absolute terms is included when relevant, as it is important to understand whether gender gaps are closing over time due to improvements in women's position or the worsening of men's position (in the case of life expectancy in parts of Eastern Europe, for example).

The aim here is to capture the multidimensional nature of gender equality and at the same time to obtain a general view of countries' performances when gender disparities in outcomes are evaluated together. The chapter therefore includes a historical composite measure of gender equality, which takes its inspiration from the composite gender equality indices offered by the United Nations (the Gender Inequality Index) and the World Economic Forum (the Global Gender Gap Index). This composite measure focuses on gender disparities in societal outcomes related to the four dimensions described above, and excludes institutional measures such as inheritance practices 9 More detailed information on the theoretical background and the construction of the historical gender equality index can be found in Dilli et al. (2014a).

\section{Historical sources}

This section describes the data sources for the variables capturing different dimensions of gender inequality. Most of the measures go back to the beginning of the 20th century. The exceptions are the data on education and labour force participation, which are available from 1950 onwards. Table 12.1 presents an overview of the variables used in this chapter or in the composite index, along with their source and summary statistics.

Before turning to the variables for which there is annual data, first an overview is given of gender differences in institutional structure that can be compared globally throughout the 20th century. To start with, global patterns of inheritance practices are examined. These indicate the extent to which women could inherit and are available at three time points; 1920, 1980 and 2000. Information on inheritance practices at the start of the 20th century 
Table 12.1. Gender equality indicators, coverage and summary statistics

\begin{tabular}{llccccl}
\hline Dimension & \multicolumn{1}{c}{ Indicator } & Range & Mean $(\mathrm{sd})$ & Countries & Years & Source \\
\hline Health & Life expectancy ratio & $0.87-1.66$ & $1.08(0.05)$ & 130 & $1900-2003$ & $\begin{array}{l}\text { UN (2013); lifetable.de, Human Mortality } \\
\text { Database; Preston (1975) }\end{array}$ \\
& Sex ratio & $0.83-1.23$ & $0.97(0.02)$ & 130 & $1900-2003$ & Mitchell (2007); UN (2013) \\
$\begin{array}{l}\text { Socio-economic } \\
\text { standing }\end{array}$ & $\begin{array}{l}\text { Average years schooling } \\
\text { ratio }\end{array}$ & $0.03-1.46$ & $0.73(0.26)$ & 130 & $1950-2000$ & Barro and Lee (2013) \\
& $\begin{array}{l}\text { Labour force participation } \\
\text { ratio }\end{array}$ & $0.02-1.29$ & $0.6(0.24)$ & 130 & $1945-2003$ & ILO (2010) \\
& Inheritance & $0-1$ & $0.56(0.50)$ & 159 & $1920-2000$ & Murdock (1976); Hallward-Driemeier et al. (2013) \\
Household & Marriage age ratio & $0.61-0.98$ & $0.85(0.07)$ & 129 & $1900-2003$ & Carmichael (2013) \\
Political & Parliament seats ratio & $0-0.95$ & $0.06(0.10)$ & 130 & $1900-2003$ & Paxton et al. (2008), online electoral archives \\
& Suffrage & $0-1$ & $0.35(0.48)$ & 152 & $1900-2000$ & Paxton et al. (2008); Przeworski (2009) \\
\hline
\end{tabular}

Note: For an assessment of data quality, see Table 12.2.

comes from George Murdock's Ethnographic Atlas (1969), updated and turned into countrylevel variables by Jutta Bolt (2012). Murdock's Atlas includes information on 1267 societies for the period 1850-1950. It provides information on the gender distribution of inheritance of land and inheritance of movable property. Both are split into 8 possible classifications: missing data, absence of individual property rights, matrilineal (sisters' sons), other matrilineal (i.e. youngest brothers), children with daughters receiving less, children equally, other patrilineal, and patrilineal (sons). To compare these to contemporary data available from the World Bank's Fifty Years of Women's Legal Rights database, a dichotomous scheme had to be used where 0 indicates inequality and 1 equality. Next, data from the World Bank's legal rights database for the years 1980 and 2000 is used to show changes over time in gendered inheritance practices.

As a second measure of the institutional environment related to gender equality, data on the year women were granted the right to vote in national elections is employed. This data gives the year when legislation was introduced that allowed women to vote for the first time, even if they were granted this right on a narrower basis than men. The data comes from Paxton et al. (2008). Based on this information, a dummy variable was created where a score of 1 was given for the years where women have the right to vote. This information is then mapped for 1913, 1950 and 2000 to give an idea of changes in female suffrage over the past century. In order to have a better overview of gender inequalities related to suffrage, data on male suffrage has been gathered from Przeworski (2009). This can be used to compare the gap in years between when men and women respectively got the vote. ${ }^{10}$

To evaluate the ability of women to live a long (and healthy) life, the chapter first turns to gender differences in life expectancy. As discussed in Chapter 6 of this volume on Life Expectancy, UNWPP (United Nations World Population Prospects) data is used for the post-1950 period and Clio-infra data and various data sources for the earlier period (see Table 12.1). The ratio of men's life expectancy to women's is then calculated.

Next, to further capture the health dimension, Sen's (1992) concept of missing women is used. The ratio of women to men for the age category between 0 and 5 is calculated. The focus is on this age category rather than later stages of life for two reasons. The first is that three-fifths of missing women go missing during birth and infancy/childhood. 
Second, missing girls at birth reflects discrimination in the household, resulting from the combination of strong preferences for sons combined with declining fertility and the spread of technologies that allow parents to learn the sex of the child before birth. Missing girls/women at later stages of the life cycle reflect not only discriminatory practices against women, but also poor institutions, such as lack of healthcare or water and sanitation infrastructure (World Bank, 2011). Thus, the measure used here specifically focuses on a sex-selection bias in the period of early infancy, where the bias is caused by abortion, infanticide, and the possibility that young girls are systematically less cared for in early childhood (Anderson and Ray, 2010). The data comes from Mitchell (2007) and the UN (2013).

As an indication of the gender differences in marriage patterns, the ratio of female Singulate Mean Age at Marriage (SMAM) to male SMAM is taken. The data comes from Carmichael (2011), and is based on various resources, amongst which statistics from the United Nations, World Bank, Demographic Healthy Surveys, Hajnal (1965), Van Zanden and De Moor (2009) and national censuses. The SMAM statistic was developed by Hajnal (1965) and is a calculation of the average length of single life expressed in years among those who marry before age 50 (United Nations, 2008). On average men marry younger women; however, where the age gap between spouses is low it is more likely that the partnership will be an equal, companionate one. A large difference in marriage ages is therefore likely to reflect an unequal position of spouses, and even arranged and child marriages (Caldwell, Reddy and Caldwell, 1983).

Differences in the socio-economic position of men and women are highlighted by looking at educational attainment. This data comes from Barro and Lee (2010), as their dataset - to the best of our knowledge - has the highest level of global coverage on human capital by gender. ${ }^{11}$ Data on average years of schooling for the male and female population aged over 25 is employed. ${ }^{12}$ To highlight the educational differences between men and women, the ratio of women's to men's average years of schooling is used.

To capture the political position of women, the percentage of women in parliaments is used as an indicator. The data on the percentage of women in parliament comes largely from the Women in Parliament 1945-2003 dataset (Paxton et al., 2008). This data was extended back until the beginning of the 20th century in 1907 when the first woman MP was elected in Finland. Supplementary data was collected on all the countries that had women in parliament for the time period between 1907 and 1945 from various online electoral archives. Using the data on the percentage of women in parliament, the equivalent male value can easily be derived, and these two results were expressed as a ratio of women to men.

As mentioned earlier, it is also of interest to consider how these different dimensions of gender inequality come together and develop. This is done by employing the composite index of gender equality created by Dilli et al. (2014a, 2014b), which has been constructed by using the variables described above (excluding the institutional indicators) and which is available from 1950 onwards. ${ }^{13}$ The historical gender equality index is a continuous measure ranging between 0 and 100 where a score of 100 represents equality between the genders.

\section{Data quality}

Issues of comparability and data limitations are unavoidable in creating and compiling a series of historical measure on gender equality on a global scale. So while this study does provide an overview of how gender inequality has changed since the early 20th century, it does have limitations (Table 12.2). First of all, although trends in a number of indictors from 
the late 19th century onwards can be described, data coverage improves significantly from 1950 onwards. The geographic coverage is also a challenge, since historical data on gender equality is scarce for countries outside of Western Europe and a handful of other large countries. Furthermore, only an overview can be given for institutions related to gender equality in terms of inheritance and voting rights. It is, therefore, not possible to capture many other aspects that matter for gender equality, such as violence against women or freedom of movement, as the OECD (Branisa et al., 2009) does for the SIGI. Furthermore, it is not possible to provide a full overview of the economic well-being of women, as historical data on indicators such as female labour force participation and female wages are scarce or not systematically available on a cross-national scale 14 It is also not possible to capture the unequal allocation of time use in the home, which is closely related to the well-being of women outside the household, linked as it is to political participation and labour force participation (Verba et al., 1997).

Another issue that has to be acknowledged here is that the size of the gender disparities in various dimensions described above is likely to differ between groups within countries, depending on socio-demographic and economic status (e.g. age group, health status, country of origin, income, urban-rural). However, although a within-country comparison on gender equality between different socio-economic groups might shed further light on the causes for and mechanisms perpetuating gender inequality, the point of this study is to analyse such trends at the macro level. Individual or group level analysis is beyond the scope here, and so it is left to others to take up this gauntlet in future research.

A further concern that should be noted is the comparability of these measures in a cross-national setting, which requires cautious use of the data. For instance, for the marriage indicator, a comparison can be made only based on legally documented marriages. Definitions of marriage differ in different contexts, muddying the data somewhat. Similar issues occur when one wants to measure women's political participation. The only comparable data on a global scale are on the date of suffrage and the percentage of female seats in parliament, which provide a very limited overview of gender disparities in politics. Because data on conventional forms of political participation (such as voting trends) are not available due to secret ballot systems, and as a result of the difficulty of capturing unconventional forms of political participation, such as protesting, with quantitative methods, it is very difficult to measure other forms of women's political participation. A similar issue arises when using data on education. Although the chapter reflects on the overall performance in terms of closing the gender gap in average years of education, this measure hides any gender imbalances related to the choice of academic field (e.g. young women being less likely than young men to choose Science, Technology, Engineering, or Mathematics (STEM) subjects as a field of study at the tertiary level), which later in life translates into occupational segregation (OECD, 2013). Furthermore, to achieve the greatest coverage in terms of time period, different data sources had to be employed, which sometimes come at the cost of jumps in the estimates.

When available, the quality of the data is typically quite high. Most observations are estimates of official statistical agencies (1) or the product of historical research using the same sources and methods as these agencies (2). The quality of the data for sex ratios is similar to that of most other indicators used in this chapter. The only exception is the data on marriage ages. Here, the estimates for the period up to 1870 are usually based on the same kind of data and method as statistical agencies would use, but do not always cover the entire country. 
Table 12.2. Quality of data on ratios of boys to girls, parliamentary seats ratio, and marriage age ratio by region and benchmark year, 1820-2008

\begin{tabular}{|c|c|c|c|c|c|c|c|c|}
\hline \multicolumn{9}{|c|}{ Sex ratios } \\
\hline & $\begin{array}{c}\text { Western } \\
\text { Europe } \\
\text { (WE) }\end{array}$ & $\begin{array}{c}\text { Eastern } \\
\text { Europe } \\
\text { (EE) }\end{array}$ & $\begin{array}{c}\text { Western } \\
\text { Offshoots } \\
\text { (WO) }\end{array}$ & $\begin{array}{l}\text { Latin } \\
\text { America } \\
\text { and } \\
\text { Caribbean } \\
\text { (LA) }\end{array}$ & $\begin{array}{l}\text { Sub-Saharan } \\
\text { Africa } \\
\text { (SSA) }\end{array}$ & $\begin{array}{l}\text { Middle East } \\
\text { and } \\
\text { North Africa } \\
\text { (MENA) }\end{array}$ & $\begin{array}{c}\text { East Asia } \\
(\mathrm{EA})\end{array}$ & $\begin{array}{c}\text { South and } \\
\text { South-East } \\
\text { Asia } \\
\text { (SSEA) }\end{array}$ \\
\hline 1820 & 2 & 2 & 2 & 2 & 2 & 2 & 2 & 2 \\
\hline 1870 & 2 & 2 & 2 & 2 & 2 & 2 & 2 & 2 \\
\hline 1913 & 2 & 2 & 2 & 2 & 2 & 2 & 2 & 2 \\
\hline 1950 & 1 & 1 & 1 & 1 & 1 & 1 & 1 & 1 \\
\hline 1973 & 1 & 1 & 1 & 1 & 1 & 1 & 1 & 1 \\
\hline 2008 & 1 & 1 & 1 & 1 & 1 & 1 & 1 & 1 \\
\hline \multicolumn{9}{|c|}{ Parliament ratios } \\
\hline & $\begin{array}{c}\text { Western } \\
\text { Europe } \\
\text { (WE) }\end{array}$ & $\begin{array}{c}\text { Eastern } \\
\text { Europe } \\
\text { (EE) }\end{array}$ & $\begin{array}{c}\text { Western } \\
\text { Offshoots } \\
\text { (W0) }\end{array}$ & $\begin{array}{c}\text { Latin } \\
\text { America } \\
\text { and } \\
\text { Caribbean } \\
\text { (LA) }\end{array}$ & $\begin{array}{c}\text { Sub-Saharan } \\
\text { Africa } \\
\text { (SSA) }\end{array}$ & $\begin{array}{l}\text { Middle East } \\
\text { and } \\
\text { North Africa } \\
\text { (MENA) }\end{array}$ & $\begin{array}{c}\text { East Asia } \\
\text { (EA) }\end{array}$ & $\begin{array}{c}\text { South and } \\
\text { South-East } \\
\text { Asia } \\
\text { (SSEA) }\end{array}$ \\
\hline 1820 & 1 & 1 & 1 & 1 & 1 & 1 & 1 & 1 \\
\hline 1870 & 1 & 1 & 1 & 1 & 1 & 1 & 1 & 1 \\
\hline 1913 & 1 & 1 & 1 & 1 & 1 & 1 & 1 & 1 \\
\hline 1950 & 2 & 2 & 2 & 2 & 2 & 2 & 2 & 2 \\
\hline 1973 & 2 & 2 & 2 & 2 & 2 & 2 & 2 & 2 \\
\hline 2008 & 2 & 2 & 2 & 2 & 2 & 2 & 2 & 2 \\
\hline \multicolumn{9}{|c|}{ Marriage ratios } \\
\hline & $\begin{array}{c}\text { Western } \\
\text { Europe } \\
\text { (WE) }\end{array}$ & $\begin{array}{c}\text { Eastern } \\
\text { Europe } \\
\text { (EE) }\end{array}$ & $\begin{array}{c}\text { Western } \\
\text { Offshoots } \\
\text { (W0) }\end{array}$ & $\begin{array}{l}\text { Latin } \\
\text { America } \\
\text { and } \\
\text { Caribbean } \\
\text { (LA) }\end{array}$ & $\begin{array}{c}\text { Sub-Saharan } \\
\text { Africa } \\
\text { (SSA) }\end{array}$ & $\begin{array}{l}\text { Middle East } \\
\text { and } \\
\text { North Africa } \\
\text { (MENA) }\end{array}$ & $\begin{array}{c}\text { East Asia } \\
\text { (EA) }\end{array}$ & $\begin{array}{c}\text { South and } \\
\text { South-East } \\
\text { Asia } \\
\text { (SSEA) }\end{array}$ \\
\hline 1820 & 3 & 3 & 3 & .. & .. & .. & .. & .. \\
\hline 1870 & 2 & 3 & 2 & .. & .. & .. & .. & .. \\
\hline 1913 & 2 & 2 & 2 & 2 & .. & .. & .. & 2 \\
\hline 1950 & 1 & 1 & 1 & 1 & 1 & 1 & 1 & 1 \\
\hline 1973 & 1 & 1 & 1 & 1 & 1 & 1 & 1 & 1 \\
\hline 2008 & 1 & 1 & 1 & 1 & 1 & 1 & 1 & 1 \\
\hline
\end{tabular}

Note: 1. High quality; 2. Moderate quality; 3. Low quality; and 4. Estimates. See the section on "Data Quality" in Chapter 1 for a description of the quality criteria.

Source: Clio-Infra, www.clio-infra.eu.

\section{Main highlights of trends in gender inequality}

This section presents trends in gender equality, first for the individual variables, and then the composite index. First, however, to give an idea of how the position of both women and men has improved in absolute terms over the past 100 years, statistics on average women and men in the 1900s, 1950s and 2000s are provided in Figure 12.1. These estimates are population-weighted averages covering at least $40 \%$ of the world's population, where missing countries are imputed to alleviate a bias against developing countries for which less statistical material is available.

In 1900, the average woman got married shortly before her 18th birthday to a man almost five years older than herself. Based on her life expectancy at birth, she could expect to be married for 18 years seeing as average life expectancy at birth was 35.5 years (though 


\section{Figure 12.1. Average life expectancy at birth, marriage age and average} years of education for women and men in the 20th century

Values in years

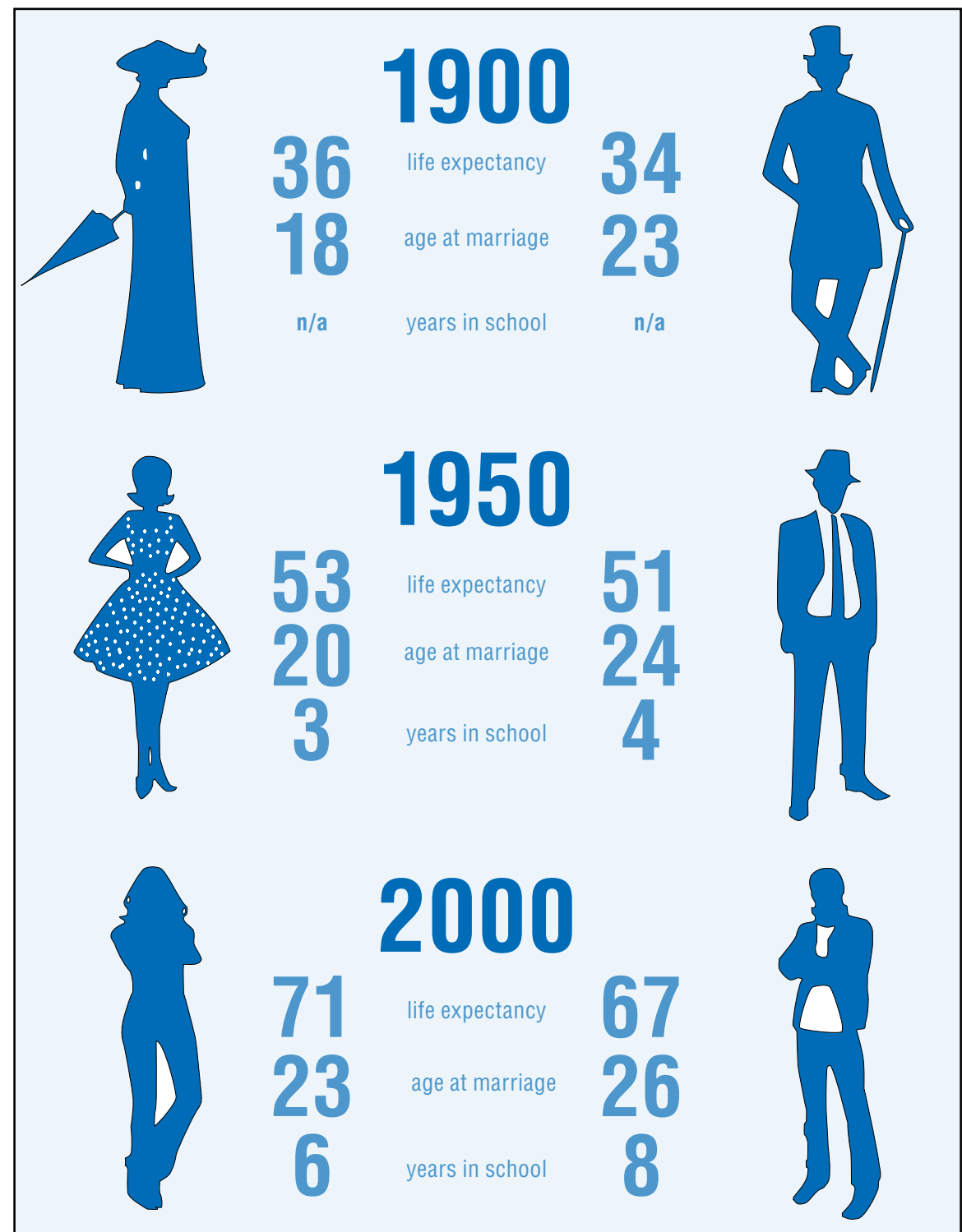

Note: For an assessment of data quality, see Table 12.2.

Source: Clio-Infra, www.clio-infra.eu.

StatLink ails $h t t p: / / d x . d o i . o r g / 10.1787 / 888933096255$

in actual fact she could be expected to be married for far longer, as life expectancy at age 18 will have been higher than that at birth). By the 1950s, however, she could expect to live 12 years longer and would marry just before her 20th birthday. Her educational attainment would be under 3 years compared to her husband's average educational attainment of just under 4 . As the benchmark for functional literacy is set in a range between 3 to 5 years of education (UNESCO has adopted the 5-year benchmark in its surveys on this issue), this means the average woman at this time would have limited literacy (Gray, 1969). Fifty years later the equivalent woman would have more than double the educational attainment of her 1950s sister, having spent on average almost 6.5 years in school. At birth she could expect to live 18 years longer than she would have in the 1950s, to halfway through her 
71st year. All in all, compared to her equivalent a century earlier, the average woman in the 2000s could expect to live nearly twice as long, marry almost six years later and be literate, thanks to 6.4 years of education attainment.

The average man's situation also improved over the course of the 20th century, but he made smaller gains in life expectancy, moving from not seeing his 35th birthday in the 1900 s to surpassing his 67 th in the 2000s. His level of education more than doubled from 3.64 years in the 1950s (just shy of functional literacy) to 7.64 years in the 2000s.

Moving from the abstract notion of the average male and female performance over the 20th century to the institutional environment in which they functioned, two measures of institutional inequality (which are not included in the composite measure), inheritance and voting rights, are presented in Figures 12.2 and 12.3. These measures give an idea of how the institutional/legislative environment is biased against women and thus of women's legal standing historically. The three panels presented in Figure 12.2 show gendered inheritance practices for immovables in 1920 (from the Murdock data), 1980 and 2000 (from the World Bank).

It becomes clear from the first map that gender equal inheritance systems were far from the norm in the early 20th century. Inheritance systems where daughters receive equal shares can be observed in some European countries, Brazil (likely because of the tradition of female inheritance in Portugal) and in a handful of countries in Southern Africa and Southeast Asia 15 By the 1980s substantial changes have taken place. A number of African, Eastern European, Central Asian and South American countries have shifted their legislation to require gender equal inheritance (possibly linked to the adoption of the Convention on the Elimination of Discrimination Against Women, CEDAW, by the UN General Assembly in 1979). Meanwhile, the countries that had gender egalitarian inheritance laws in the early 20th century have generally maintained them. Indonesia is an interesting exception to this rule. This is likely due to the Islamisation of Indonesian law following independence (Cammack and Feener, 2012; Lukito, 2013; and Salim, 2008). By 2000 , it can be observed that the majority of the world's countries for which there is data had equal inheritance rights, although the Middle East and North Africa (MENA) region remains as a belt of unequal rights.

Turning now to a different dimension of institutional arrangements, namely suffrage, the next three maps shown in Figure 12.3 present the geographical distribution of countries where women had the right to vote in 1913, 1950 and 2000.

It becomes clear from Figure 12.3 that the world has come a long way in providing equal rights to women in politics. In 1913, only New Zealand, Australia, Finland and Norway had granted women the vote. Among these countries, in 1893 New Zealand became the first to extend the franchise to women. The 1950 map makes clear that the interim period has seen a substantial extension of suffrage to women, as countries where women have the vote now outnumber those where only men could vote. Figure 12.4 below shows that the two big jumps in extending the vote to women came after the First and Second World Wars. Regional disparities are also present. All the countries in Western Europe and its Offshoots, except Switzerland, had granted women the right to vote by 1950, whereas this right was denied in most of the countries in the MENA and Sub-Saharan Africa. At the turn of the century, Qatar, Kuwait and Saudi Arabia were the only countries still denying this right to women. However, in 2011 Saudi Arabia, the last country in the world to deny this right, granted women the vote for the next elections, which will take place in 2015. 122 years after the first country granted women the vote, gender equality in this measure across the globe will have been achieved. 
Figure 12.2. Countries with gender-equal inheritance, 1920, 1980, 2000

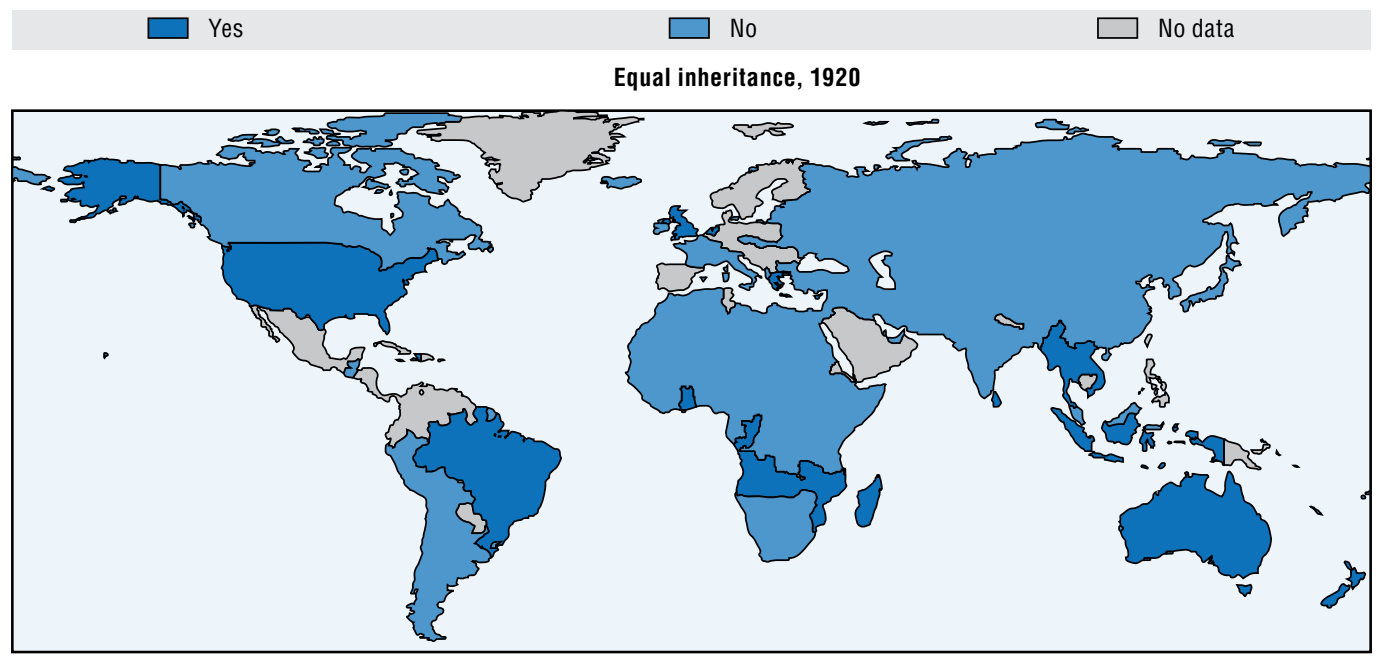

Equal inheritance, 1980

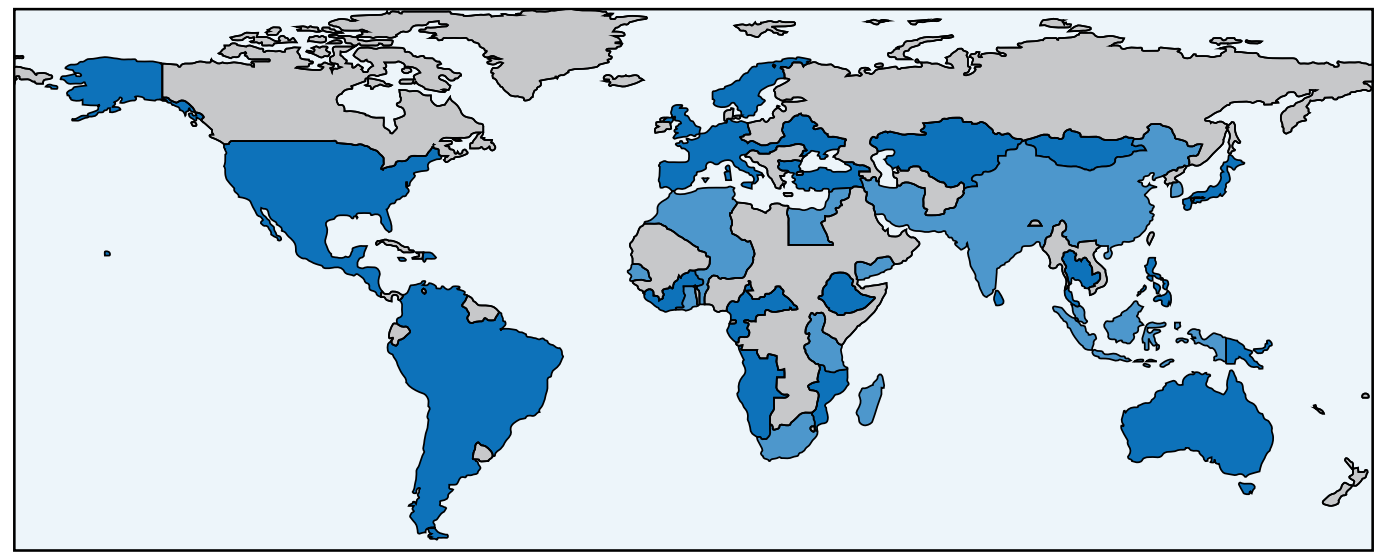

Equal inheritance, 2000

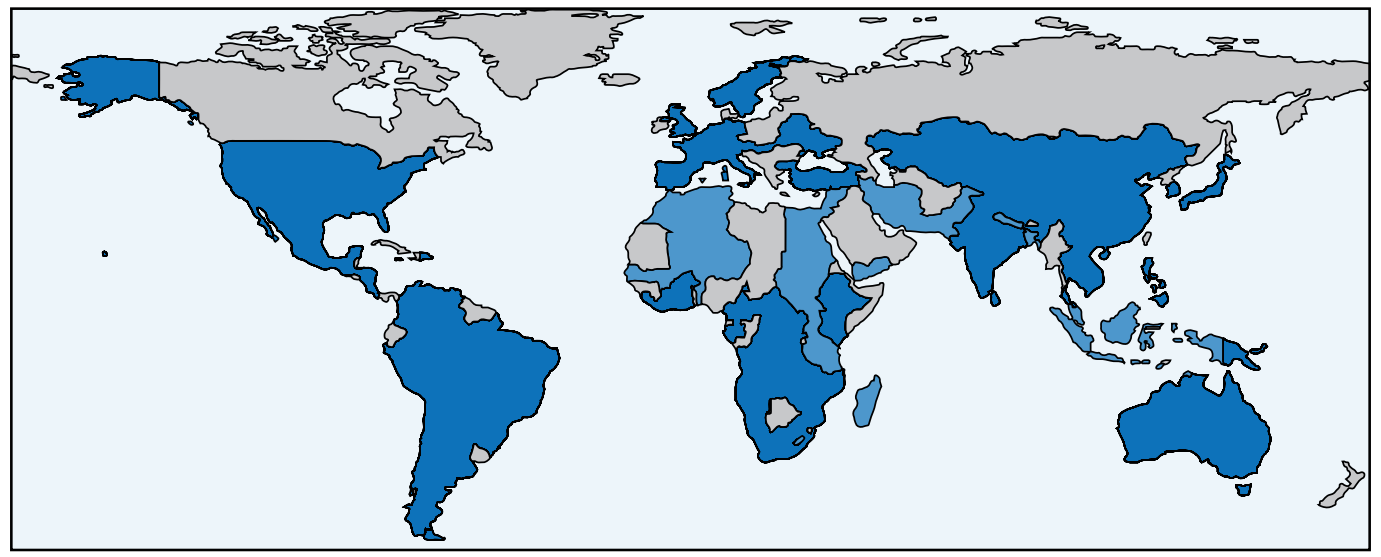

Note: For an assessment of data quality, see Table 12.2. Source: Clio-Infra, www.clio-infra.eu.

When considering the gap in years between when men and women recieved suffrage rights, the formal institutional structure and the overall inequality in a society are important explanatory factors. For instance, in Sub-Saharan Africa most of the post-colonial countries 
Figure 12.3. Countries with female suffrage, 1913, 1950, 2000

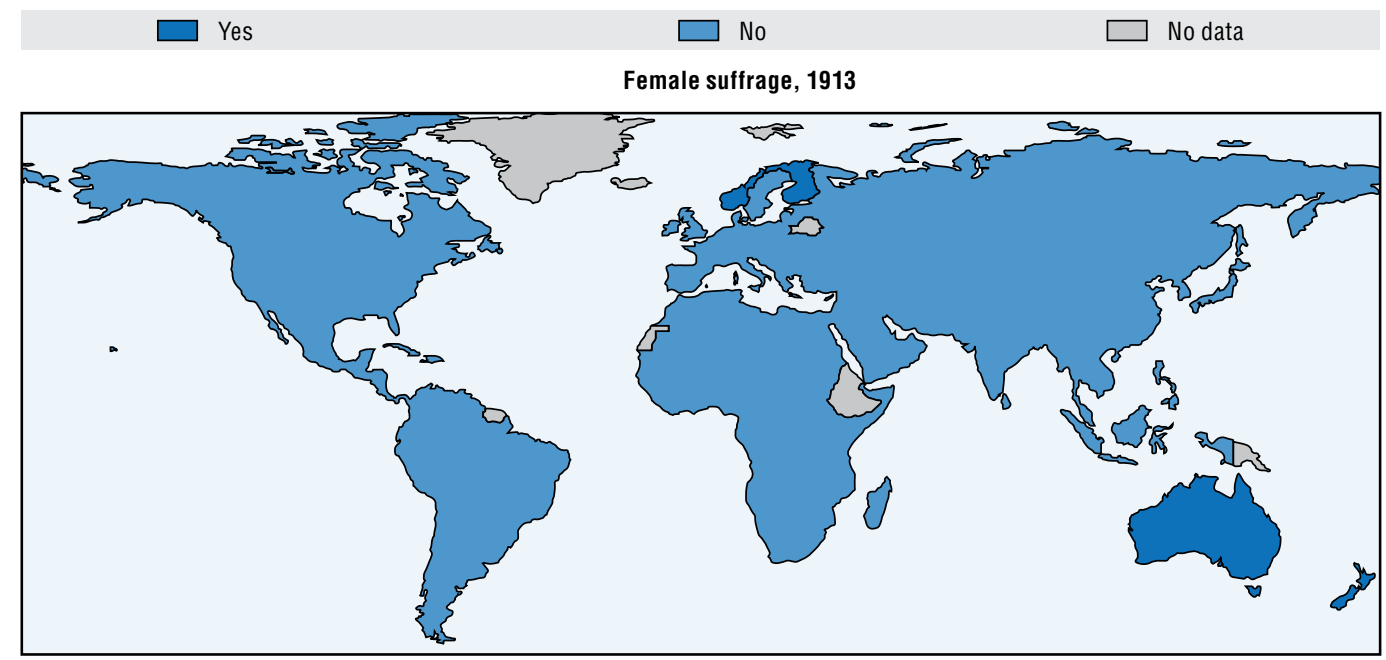

Female suffrage, 1950

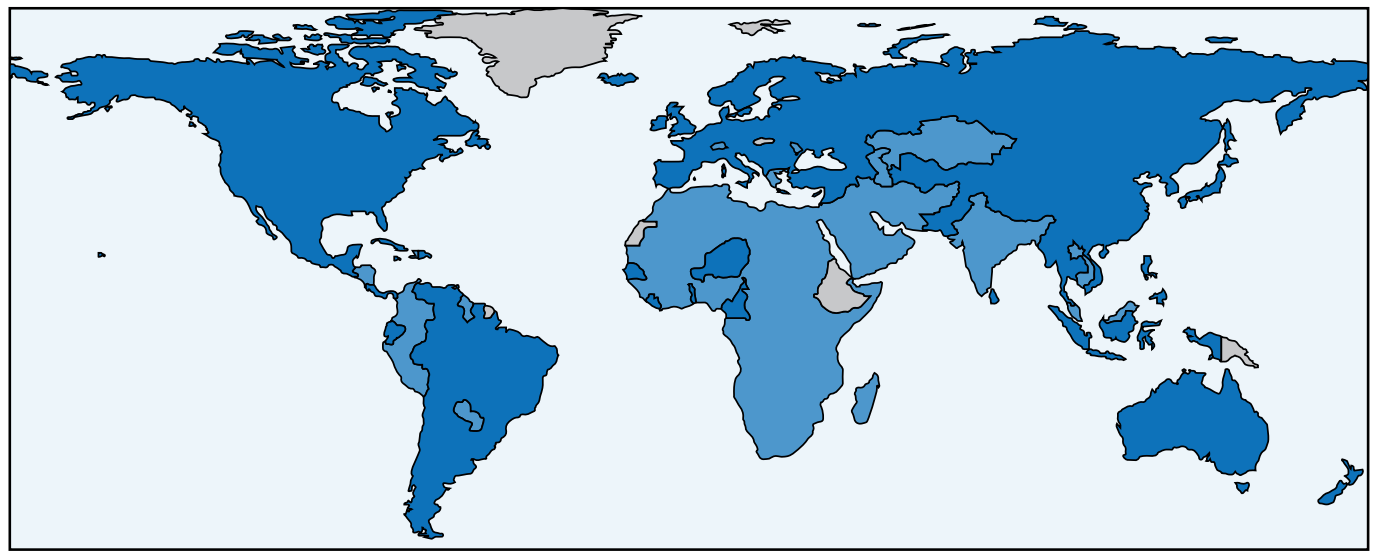

Female suffrage, 2000

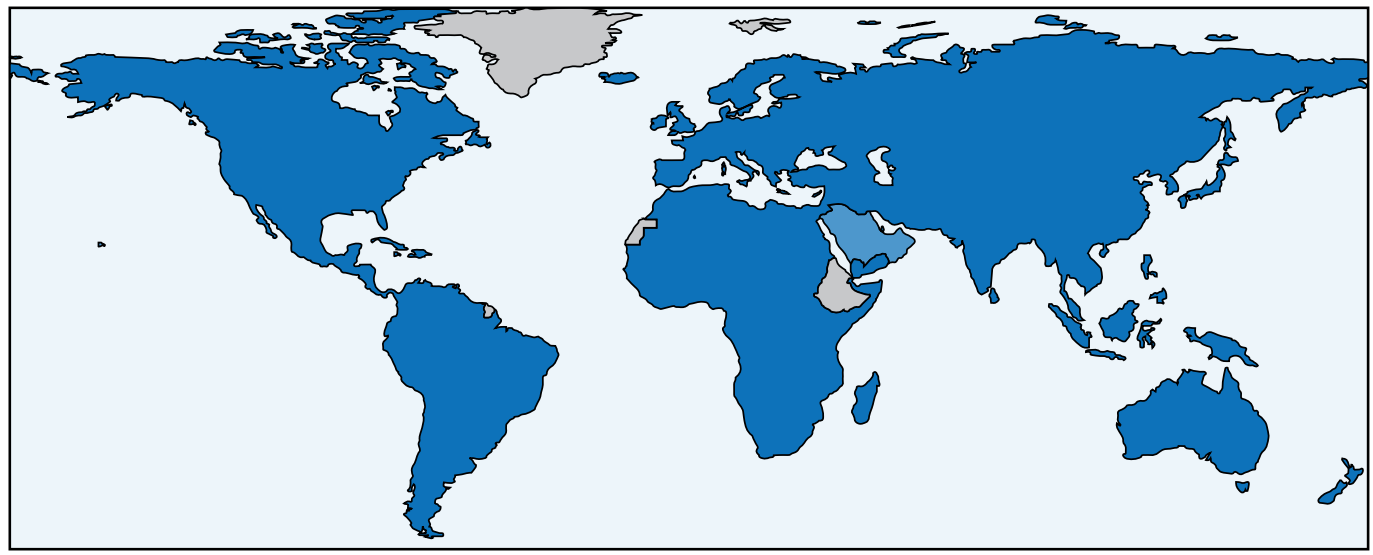

Note: For an assessment of data quality, see Table 12.2. Source: Clio-Infra, www.clio-infra.eu. 
Figure 12.4. Female suffrage, 1895-2000

Number of countries

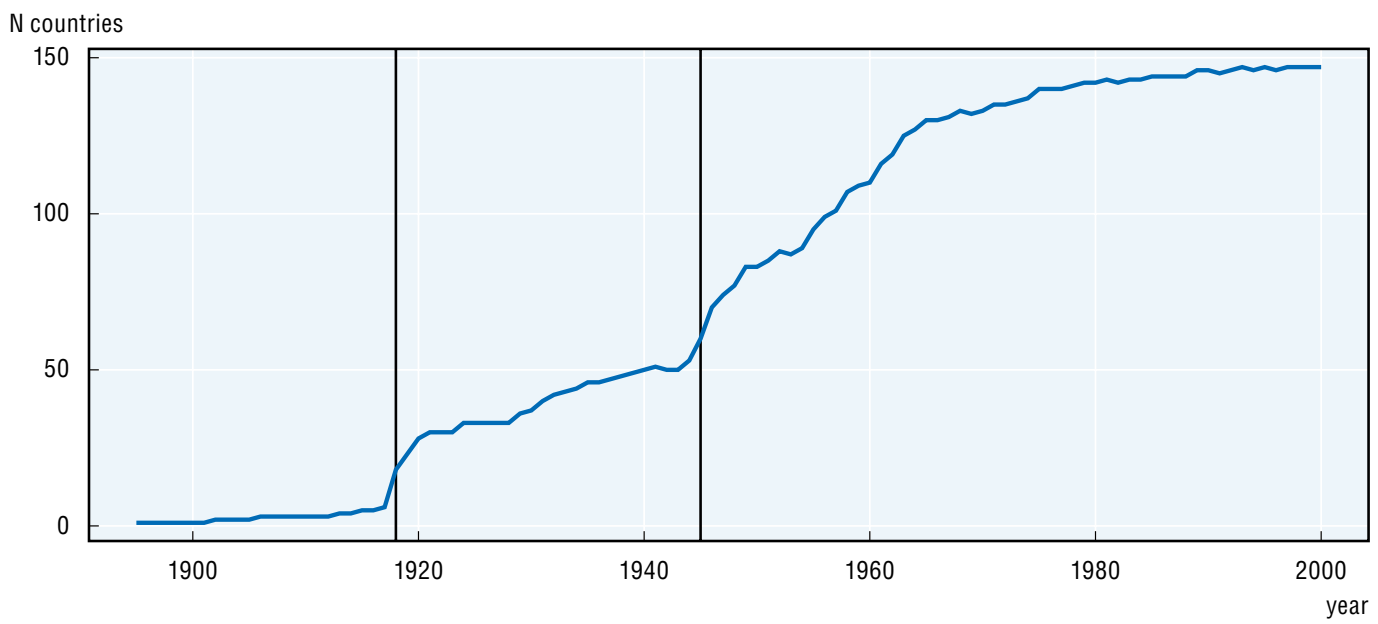

Note: For an assessment of data quality, see Table 12.2.

Source: Clio-Infra, www.clio-infra.eu.

granted men and women the vote either simultaneously (for the first democratic elections) or in quick succession (such as in the case of Gambia 16. whereas in Latin America and many Western European countries a large gap exists between when men and women got the vote (relying on the data from Przeworski, 2009). Some of these Western European countries (e.g. England) and its Offshoots (e.g. United States) had already established forms of liberal democracy in the early 19th century (Marshall et al., 2010). During most of the 19th century, however, countries that had a legislative election restricted the right to vote to adult men who owned property, had an income or paid taxes (Przeworski, 2009; Sokoloff and Engerman, 2000). Therefore in these cases it is hard to argue that gender-specific discrimination existed. Yet the democratisation experience of some countries hints at the fact that gender-related institutions are also a relevant factor in explaining the gap in voting rights between men and women. For instance, in the case of Switzerland, although the first parliament was established in 1848 and universal suffrage to men was granted in 1879 (i.e. without any eligibility restrictions), women gained the right to vote only in 1971. Similar examples can be found in the MENA region where there is a large gap between when the extension of male and female suffrage occurred, as in the case of Saudi Arabia.

Turning now to the variables for which there are data that can be plotted over time, the next section presents trends across regions and the world in the ratios of the various indicators and highlights absolute outcomes where they are of interest. The variables are discussed in the following order: life expectancy, sex ratios, marriage age ratios, educational attainment and then the composite indicator.

There have been significant improvements in life expectancy in recent decades (Table 12.3). This is visible both from the individual country trends and the overall world average. Since 1960, countries such as Afghanistan and India, which were characterised by lagre gender differences in life expectancy, have almost closed the gap. This can also be seen in the statistics for South and Southeast Asia, which move from a more than 1-year difference in life expectancy in favour of men in 1900 (28.92 compared to 27.66) to almost four years in favour of women in 2000 (65.3 compared to 69.3). 
Table 12.3. Gains in life expectancy at birth by gender, 1950-2000

Years

\begin{tabular}{lcc}
\hline \multirow{2}{*}{ Region } & \multicolumn{2}{c}{ Gain in life expectancy at birth } \\
\cline { 2 - 3 } & Men & Women \\
\hline Eastern Europe (EE) & 8.1 & 10.3 \\
Western Offshoots (WO) & 9.8 & 9.4 \\
Western Europe (WE) & 9.9 & 11.1 \\
Sub-Saharan Africa (SSA) & 10.2 & 9.2 \\
Latin America and Caribbean (LA) & 17.6 & 20.0 \\
South and South-East Asia (SSEA) & 19.7 & 21.7 \\
East Asia (EA) & 21.5 & 24.3 \\
Middle East and North Africa (MENA) & 23.2 & 23.6 \\
\hline
\end{tabular}

Note: For an assessment of data quality, see Table 12.2.

Source: Clio Infra, www.clio-infra.eu.

Looking at the gains that have been made in life expectancy over the last 50 years of the 20th century reveals some interesting patterns. It becomes immediately evident that the regions that have made the most progress in increasing both female and male life expectancy are the MENA, East Asia, and South and Southeast Asia. In East Asia and South and Southeast Asia, the progress in the life expectancy of women was more rapid than that of men. These countries also came from levels of male and female life expectancy of below 50 years (apart from East Asia where female life expectancy stood at 53 years in 1950). A disappointing performer in this context is Sub-Saharan Africa, where life expectancy for men in 1950 was just shy of 40 years and that for women stood at 42.78 years. The gains the region has made, relative to other regions with similarly low levels, are comparatively small and that for females is the lowest globally. There was less scope for improvement in Europe (both East and West) and in the Western Offshoots, as in 1950 life expectancies for both men and women were around 60 or above. Here Eastern Europe is the disappointing performer. In 1950, life expectancy there was just under 60 years for men and 65 for women (compared to 66.5 and 71 for Western Europe). Seen in this context the increase achieved in the period from 1950 to 2000 leaves it considerably behind its European counterpart. A different facet of this development can also be observed in Figure 12.5.

The regional graphs show that for Eastern Europe, Western Europe and the Western Offshoots, the ratio of women' to mens' life expectancy has converged on a ratio in the 1.05-1.08 range. Some argue that the lower male life expectancy reflected in such a ratio is due to societal factors that encourage men to adopt riskier life styles, and hence reflects an inherent gender bias against men (Waldron, 1967). However, the life expectancy difference is something that is found across mammal species, and there is evidence to show that it finds its origins in slower ageing by the female of the species and, at least in humans, to greater resistance to disease and lower mortality rates at all ages for women (CluttonBrock and Isvaran, 2007; Kalben, 2000; and Austad, 2006). The UNDP in its calculations of its gender equality indices even goes so far as to assume that due to biological advantages women will live on average five years longer than men, and the Global Gender Gap report uses a ratio of 1.06 as its benchmark for equality. This makes sense if gender equality is seen as a situation where men and women achieve equal development outcomes insofar as there are no sound biological reasons for them not to do so (for more information see Anand and Sen, 1993; Eskes and Haanen, 2007; and Austad, 2006). 
Figure 12.5. Ratio of life expectancy at birth of women to men by region, 1900s-2000s

Decadal averages
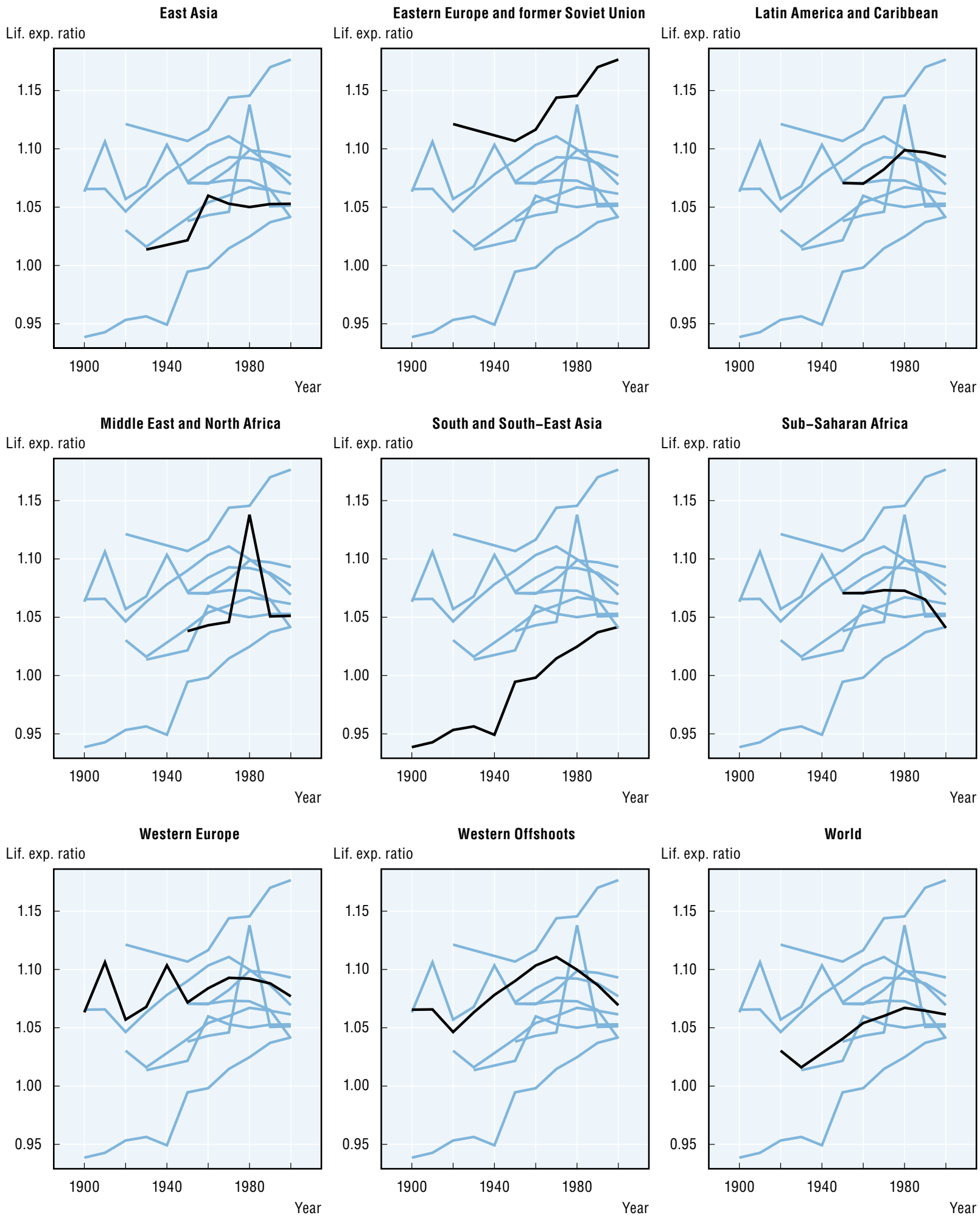

Note: For an assessment of data quality, see Table 12.2.

Source: Clio-Infra, www.clio-infra.eu. 
In the case of Eastern Europe this ratio has even been exceeded. Women in this region have made especially great progress in life expectancy, leading to one of those instances where gender inequality now even reflects a disadvantage for men, although male life expectancy has not fallen in this region. If we look at how the average life expectancy of Eastern European men (67.4 years in 2000) ranks against that of men in other regions of the world, only two regions score lower (Sub-Saharan Africa at 50.13 and South and Southeast Asia at 65.3). Western European men live almost ten years longer than their Eastern European counterparts, wheras the gap for women in the two regions is just under six years. Ours would not be the first study to show that Eastern European men are at a heightened risk of mortality. The reasons for this are often attributed to life style factors, largely related to tobacco and alcohol consumption (McKee and Shkolnikov, 2001; Rehm et al., 2007). All other regions (apart from Sub-Saharan Africa) have also made progress in closing the gap for this indicator, with South and Southeast Asia (SSEA) making the most marked progress. However the SSEA, the MENA and Sub-Saharan Africa have not managed to catch up with the rest of the world.Yet many of the world's regions can be observed to be converging towards a global average gap of 1.05 years, reflecting a nearuniversal advantage of women in life expectancy.

When we look at sex ratios, a different picture emerges (Figure 12.6). For instance, the position of women in both India and China, when measured this way, has declined sharply. China saw its sex ratio fall rapidly after the introduction of the one-child policy in 1979, from 0.94 female infants for every male infant to 0.83 female infants for every male in 2003. In India, the decline began in the 1930s, with a fall from 1.02 females to males at birth to 0.92 females to males in 2003. However, in other countries there was progress toward gender equality in terms of sex ratios. For instance, Brazil experienced progress starting from the 1870s, and Turkey started to close the gap in gender ratios from 1930 onwards. Both of these countries were initially below the world average.

Turning to the regional graphs two things become clear. First, in the modern literature it has been shown that at birth the ratio between females and males should be about 0.94. The data presented above is for infants aged 0-5. Therefore, presuming that the 0.94 ratio is a biological norm, what we see in the regional data is that in the early stages of development the higher sex ratios for children aged 0 to 5 illustrates that more boys than girls die in infancy. The arguments made as to why male-biased sex ratios at birth have emerged often revolve around higher male mortality in the early years of life. This aspect of the graphs is therefore not surprising, and the world average graph, to some extent, reflects the better survival chances of male infants thanks to modern medicine. However, the more important picture that emerges is the substantial worsening of sex ratios for women, reflected in the massive drops in East Asia, to a level where there are 85 girls for every 100 boys in the 0-5 age category, and the more moderate drop in South and Southeast Asia. This is driven by the behaviour in India and China described above.

Turning now to the ratio of marriage ages, there are large cross-national differences in the ages at which men and women marry on average (Figure 12.7). In the most recent observations, Gambia and Egypt have the largest gender differences in marriage ages, while the gap is smallest in Sweden and Japan. Moreover, although the cross-national differences seem to be the result of a long-term process, and progress towards gender equality has been limited, countries such as India, Japan, South Africa and Mexico have nevertheless made headway in this measure of equality. 
Figure 12.6. Ratio of girls to boys aged 0-5 by region, 1900s-2000s

Decadal averages
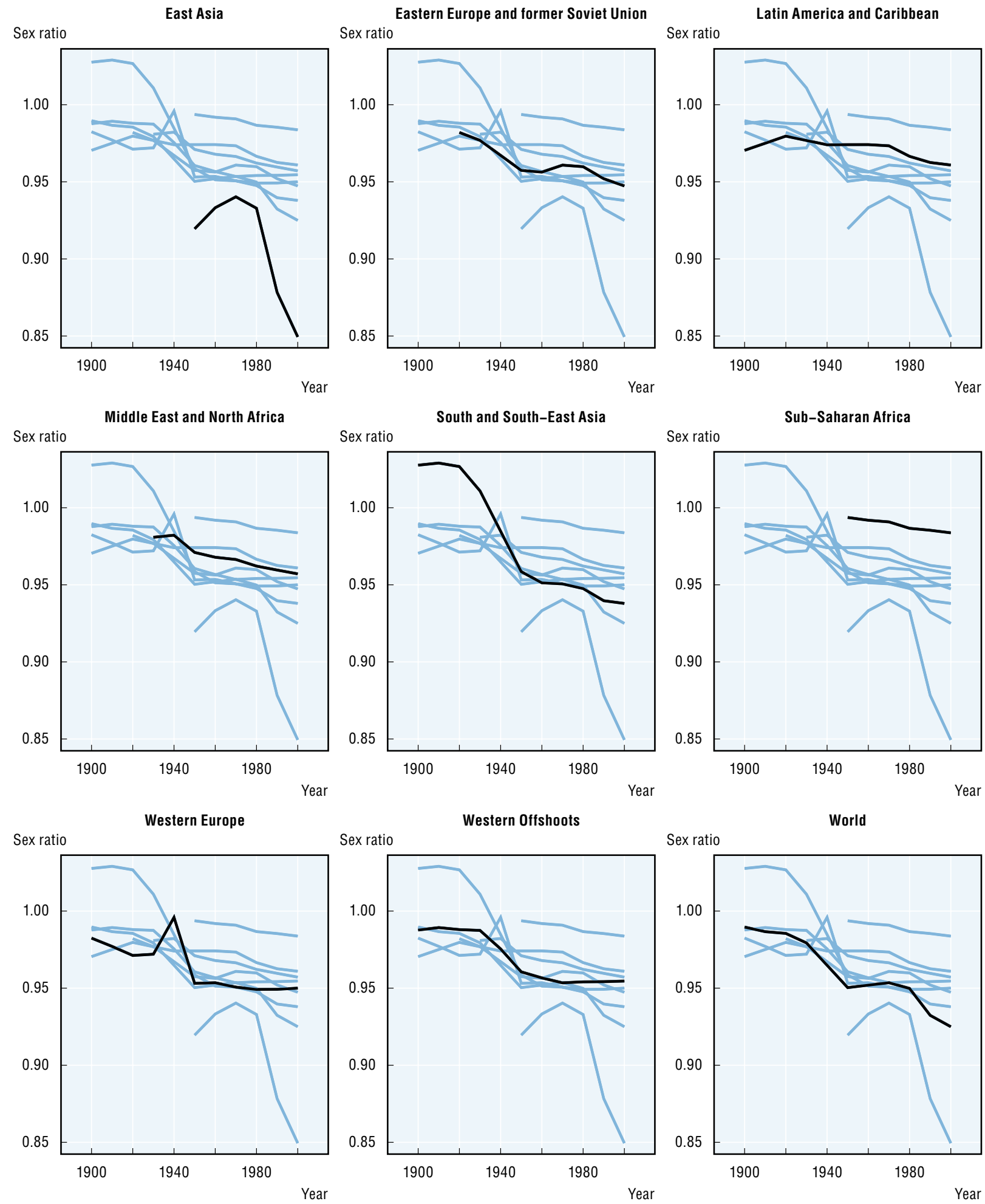

Note: For an assessment of data quality, see Table 12.2

Source: Clio Infra, www.clio-infra.eu. 
Figure 12.7. Ratio of ages at marriage between women and men by region, 1900s-2000s Decadal averages

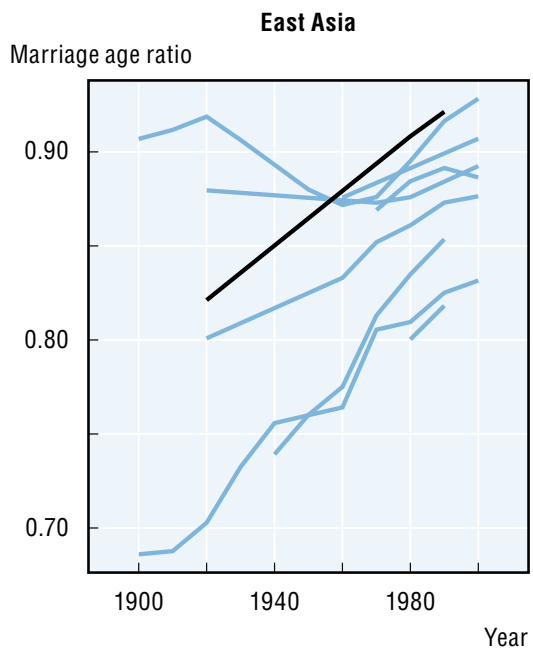

Middle East and North Africa Marriage age ratio

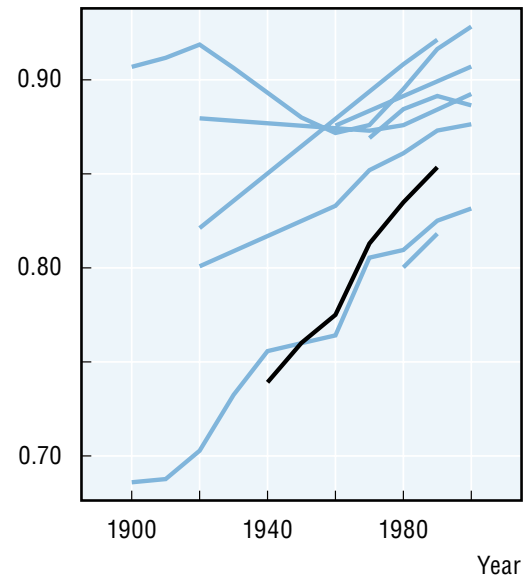

Western Europe

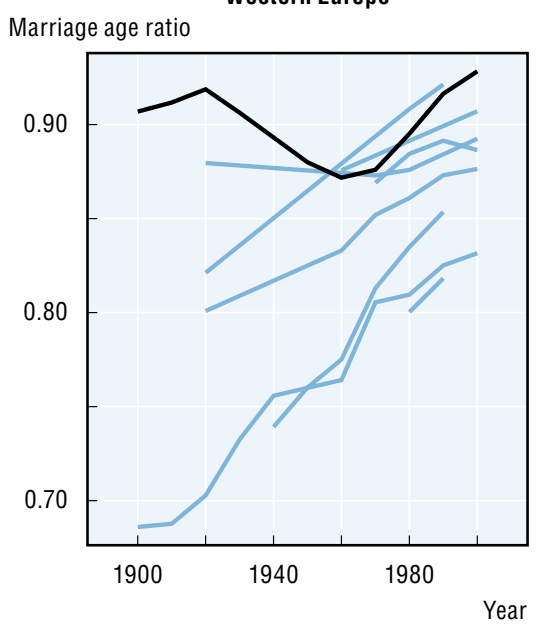

Eastern Europe and former Soviet Union Marriage age ratio

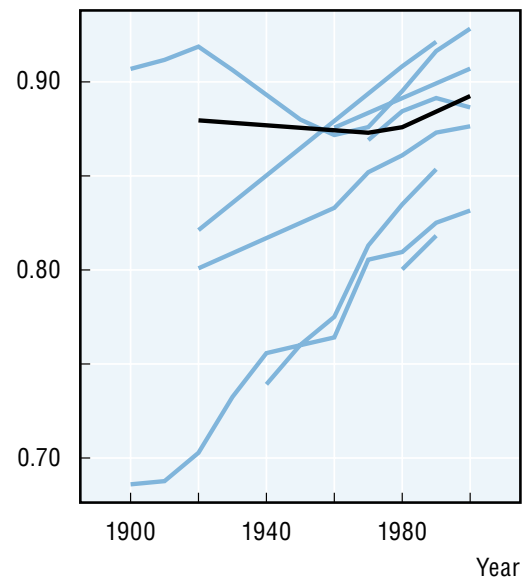

South and South-East Asia Marriage age ratio

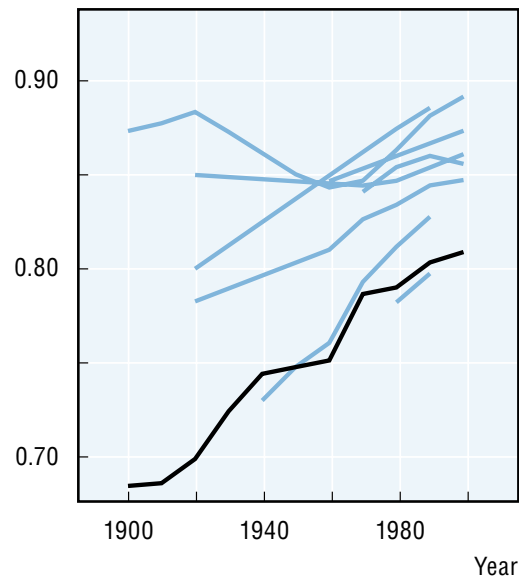

Western Offshoots

Marriage age ratio

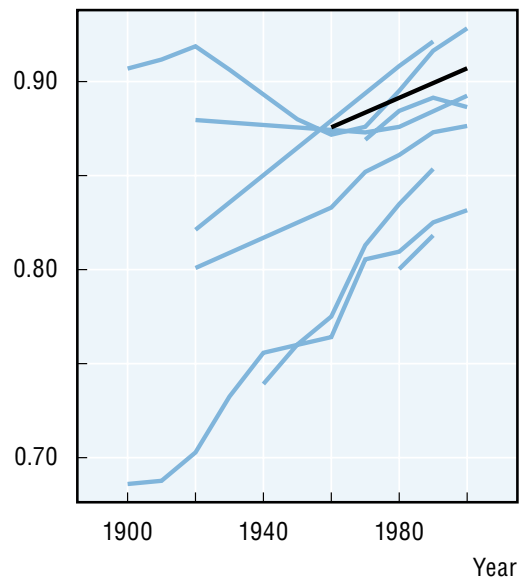

Latin America and Caribbean Marriage age ratio

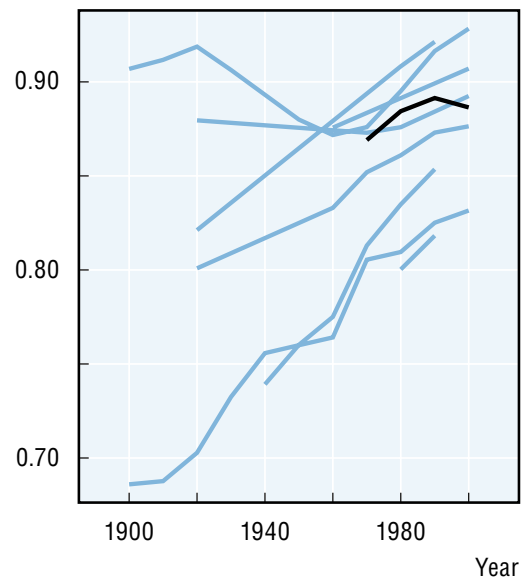

Sub-Saharan Africa Marriage age rati

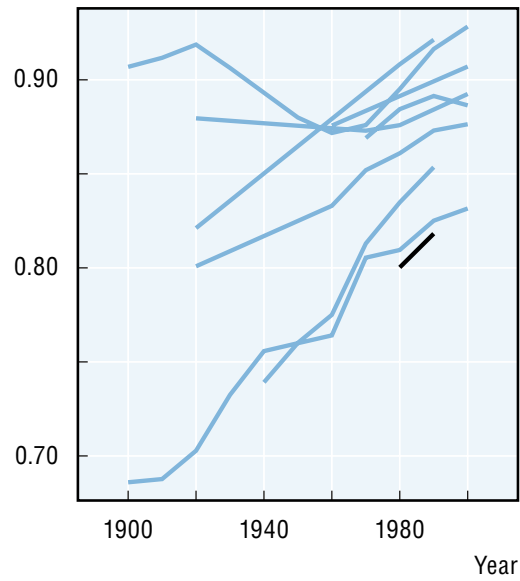

World

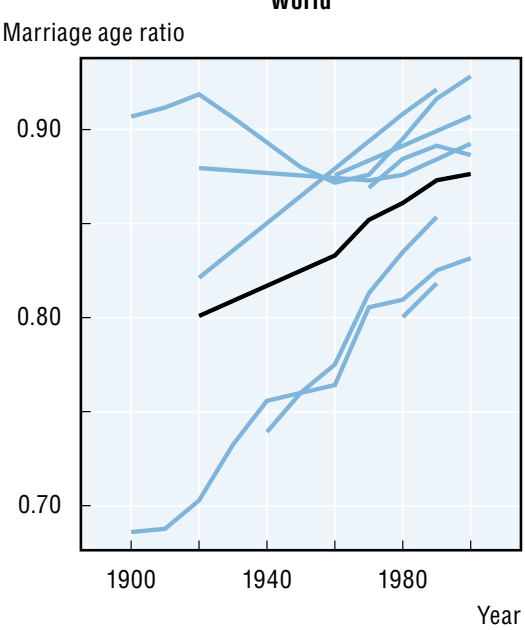

Note: For an assessment of data quality, see Table 12.2.

Source: Clio Infra, www.clio-infra.eu. 
The regional graphs present a mixed picture. East Asia and the MENA have made headway in narrowing the age gap between husand and wife, while Western Europe experienced first a decline and then an increase for this ratio. We see that Sub-Saharan Africa continues to hang behind the other regions. Lastly, a large difference continues to exist between the various regions of the world. This observation coincides closely with the findings of Casterline et al. (1986), who demonstrate that spousal age gaps reflect underlying cultural preferences closely related to concepts of patriarchy, which likely explain the persistent gaps. At the same time marriage ages themselves are sensitive to economic developments and therefore fluctuate over time.

Looking at gender inequalities in education (Figure 12.8), the last five decades have witnessed significant improvements in terms of closing the gender gap, except in the Western Offshoots where there was no gender gap in the 1950s to begin with. The greatest progress in closing the gap was made in the MENA region, although the countries of Asia and Sub-Saharan Africa have also shown remarkable progress. The countries of the former USSR, Latin America and Western Europe have also closed the gender gap in education over the last 50 years. Moreover, since the 1990s there has been a trend for women's outcomes in education to surpass those of men, and in some countries women achieve higher levels of education than men. This is the case in parts of Western Europe (e.g. England, Sweden) and its Offshoots (e.g. Australia, United States). Among the developing economies, Kenya and India made substantial progress in catching up with developed countries in terms of gender equality. In the MENA region, Egypt also made great progress in closing the gender gap in education, but progress was limited in Yemen and Afghanistan.

This progess toward gender equality in education is inextricably linked with the overall progress made in educational attainment, where inequality in years of schooling between and within countries is found to be rapidly decreasing (Murtin and Murrison, 2013). Since 1950, the average years of schooling of the population aged 25 and above has increased substantially around the world. In South and Southeast Asia and the MENA, average years of schooling have more than doubled since the 1980s. To take the example of female education, in South and Southeast Asia, educational attainment for the female population aged 25 and above increased from an average of 1.43 years in 1950 to 3.45 years in the 1980s, and was at a level of 5.15 years by the 2000s. The MENA region made the most progress in increasing average female education attainment, from an average of 0.91 years in the 1950s to an average of 5.71 years in the 2000s.

With respect to women's rights in politics, despite improvements over the course of the 20th century, women's participation in national parliaments remains one of the major challenges in achieving gender equality globally: not even one-quarter of the world's parliamentarians are women (Figure 12.9). Despite this persistent gap, the past century has been witness to some considerable progress. The most progress can be observed in Western Europe, Eastern Asia and Eastern Europe and the countries of the former Soviet Union. The case of Eastern Europe and the former Soviet Union is particularly interesting, considering the sharp decline in female members of parliament after the collapse of the Union and the subsequent widening gender gap. Former Soviet countries, which were once near the top in the world rankings of female representation, have now fallen far behind Western Europe, and even behind many developing countries. This marked decline is due to the removal of the quota system implemented by the Communists, after the Union had collapsed (Saxonberg, 2000). Other regions of the world have shown considerable progress 
Figure 12.8. Ratio of average years of education between women and men by region, 1950s-2000s Decadal averages

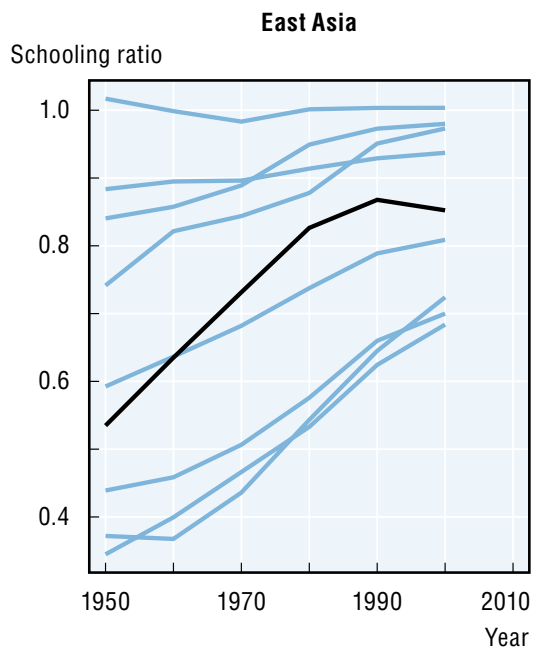

Middle East and North Africa

Schooling ratio

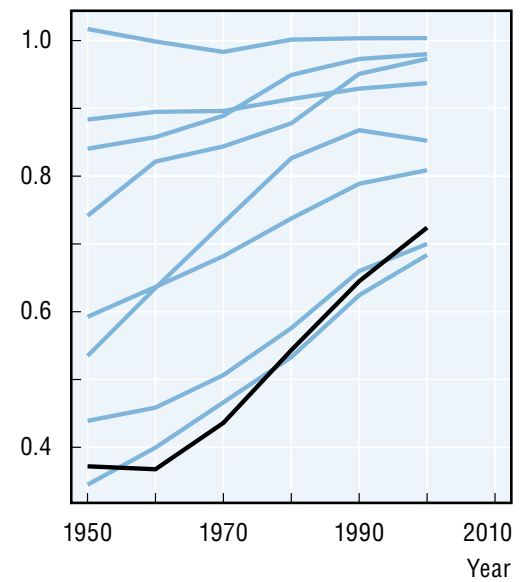

Western Europe

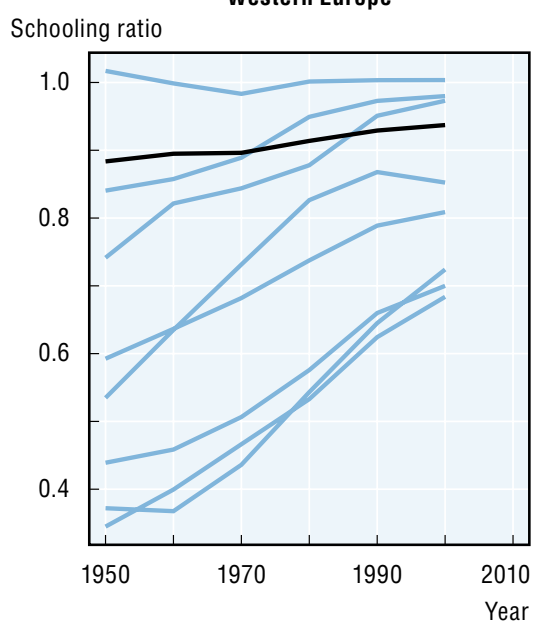

Eastern Europe and former Soviet Union Schooling ratio

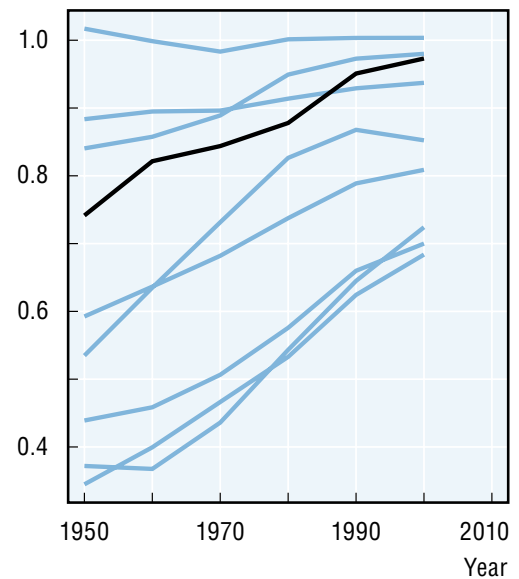

South and South-East Asia Schooling ratio

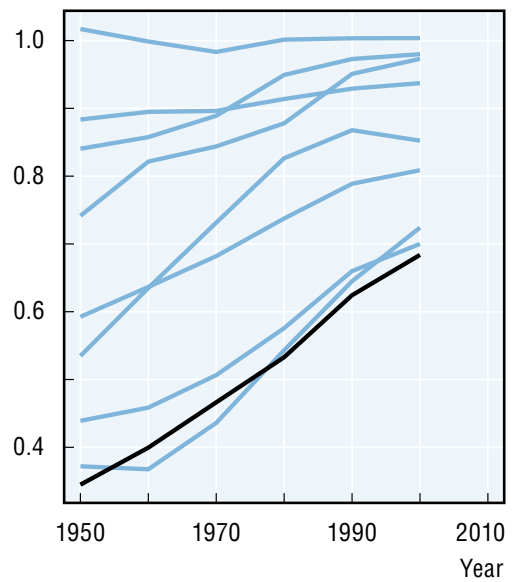

Western Offshoots

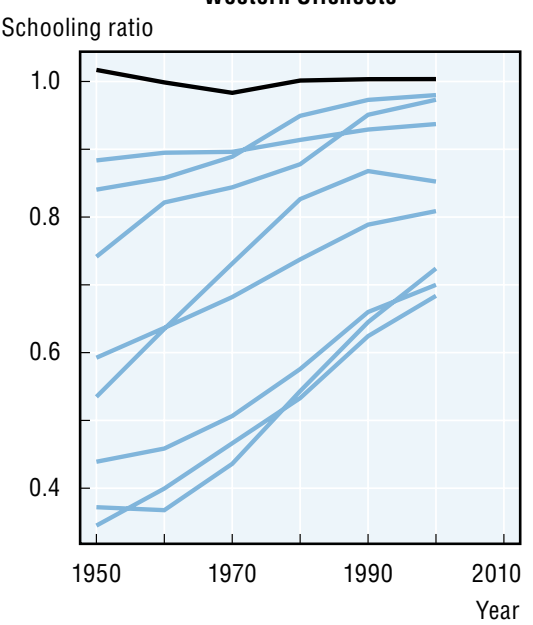

Latin America and Caribbean Schooling ratio

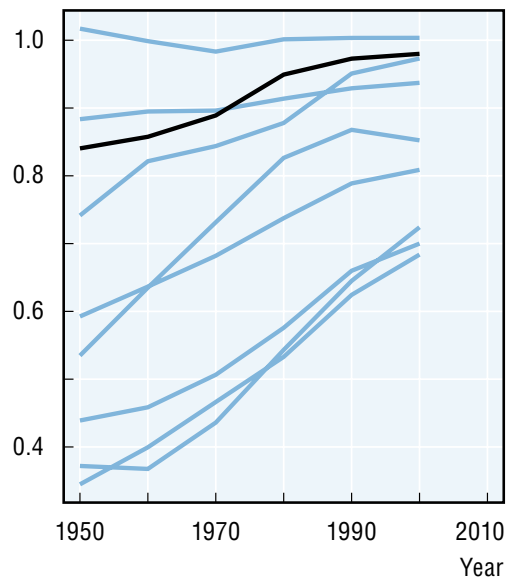

Sub-Saharan Africa

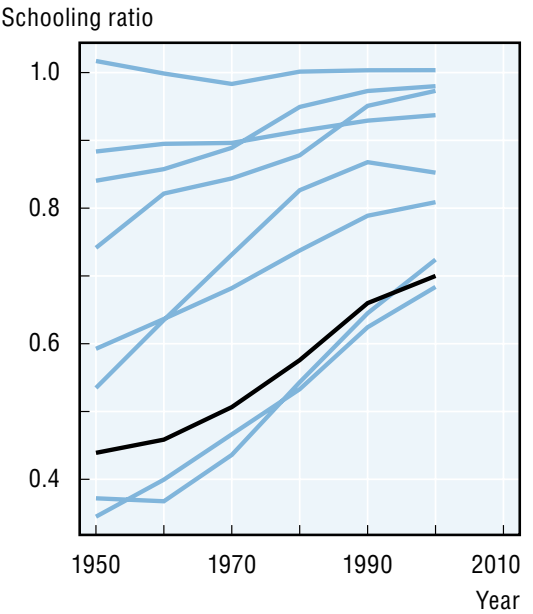

World

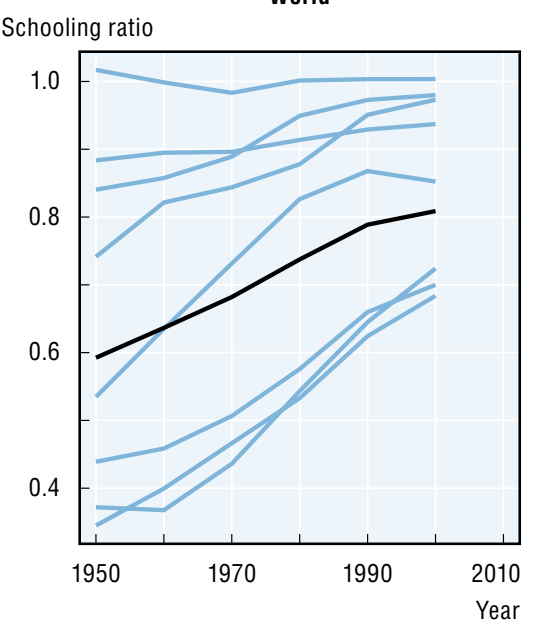

Note: For an assessment of data quality, see Table 12.2.

Source: Clio Infra, www.clio-infra.eu. 
Figure 12.9. Ratio of parliamentary seats held by women and men by region, 1900s-2000s

Decadal averages

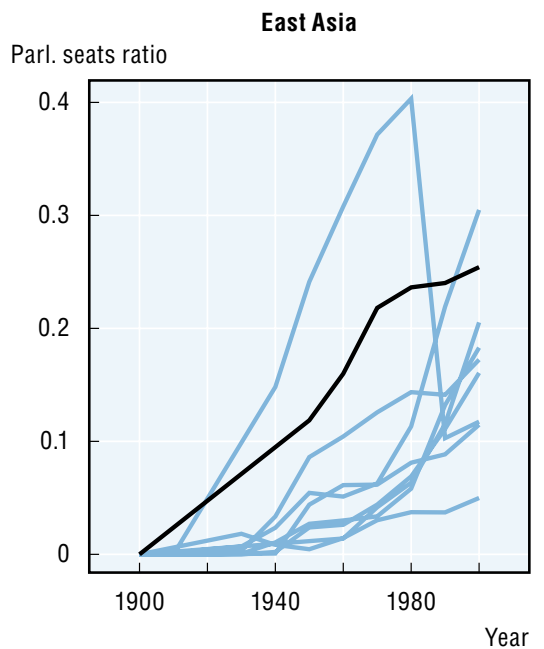

Middle East and North Africa

Parl. seats ratio

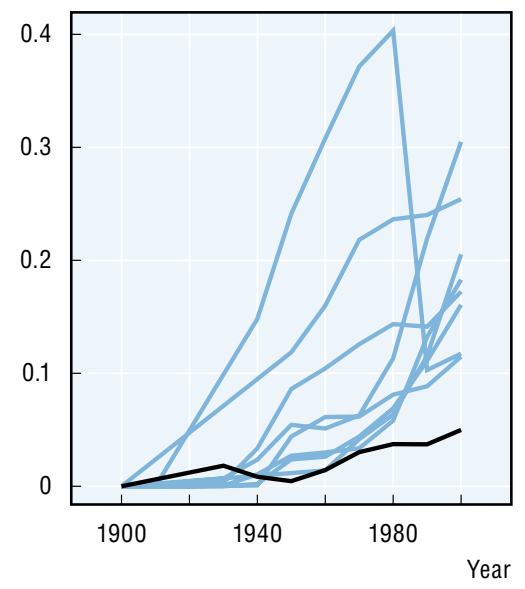

Western Europe

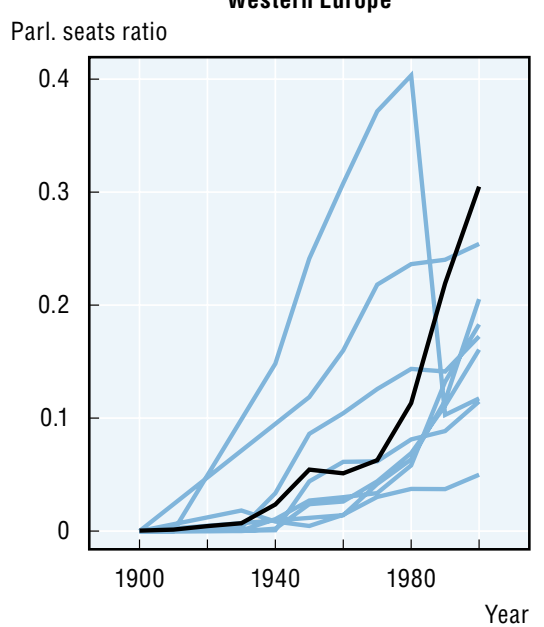

Eastern Europe and former Soviet Union Parl. seats ratio

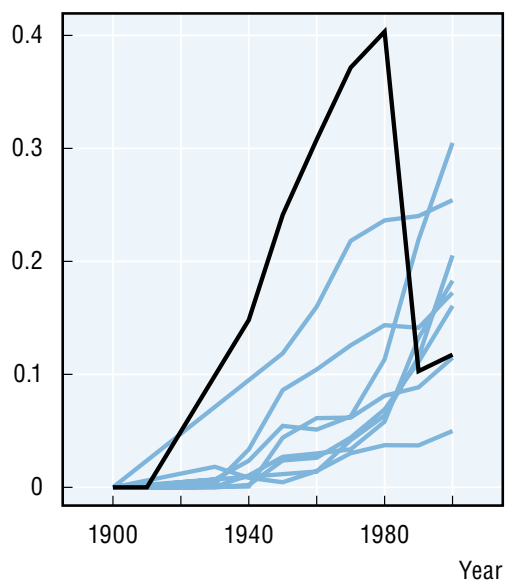

South and South-East Asia Parl. seats ratio

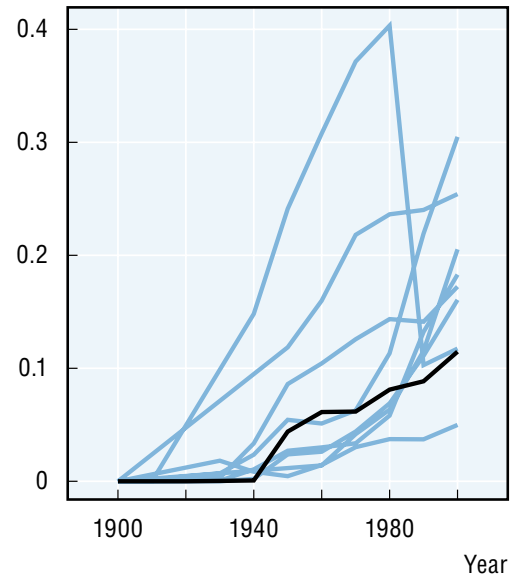

Western Offshoots Parl. seats ratio

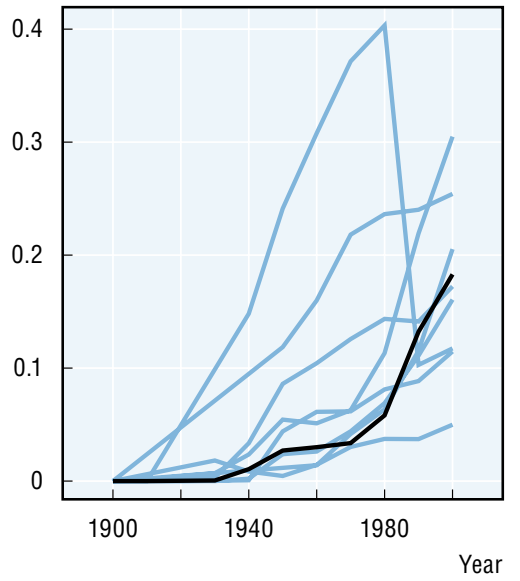

Latin America and Caribbean Parl. seats ratio

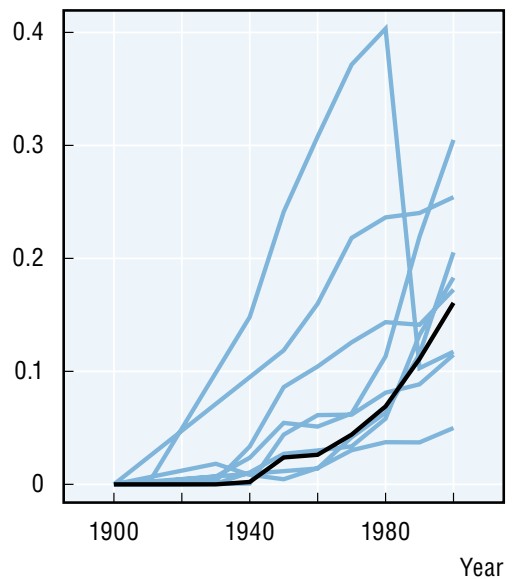

Sub-Saharan Africa

Parl. seats ratio

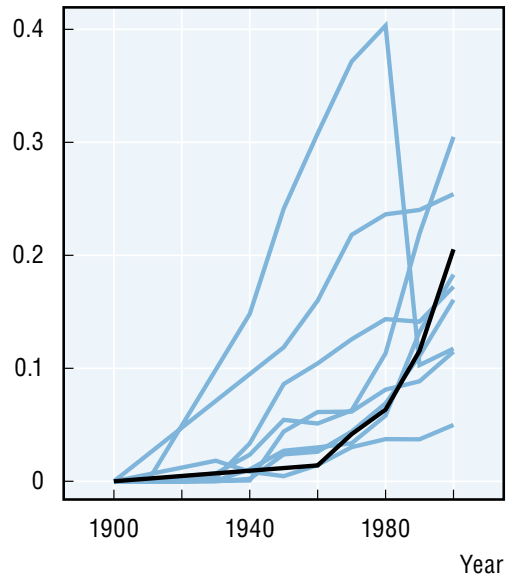

World

Parl. seats ratio

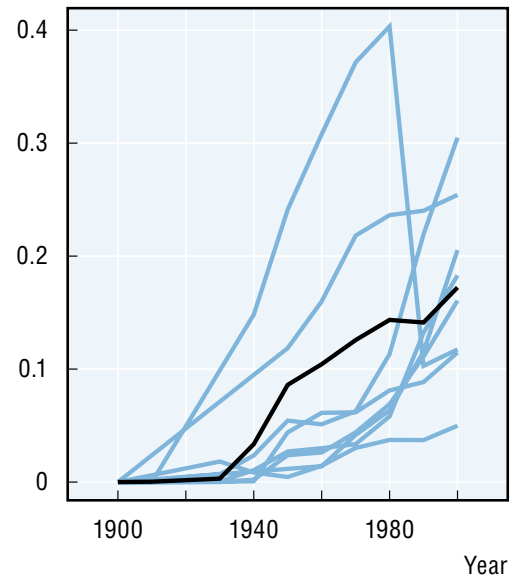

Note: For an assessment of data quality, see Table 12.2.

Source: Clio Infra, www.clio-infra.eu. 
on this measure from the 1950s onwards, except for the MENA. The quota system seems to be an important determinant of the position of women in parliament. This is exemplified in Rwanda, which achieved the highest percentages of women in parliament after the introduction of a quota system in 2002. With $44 \%$ of its parliamenterians being women, Rwanda outperformed even Sweden, one of the few countries that has made continous progress towards closing the gender gap in parliament (without a quota system).

Lastly, we provide an overall view of how countries are performing when the measures we describe above are evaluated together. This composite index is available from 1950 to 2003 (Figure 12.10). After a slow start in the 1950s, the gender equality measure exhibits a steady trend upwards, which can be observed for all the world's regions. However, it should also be noted that global progress was limited. At a global average of 68 (out of a possible 100 ) in 2000 , gender equality was still well short of the theoretical maximum. The regional averages reveal further failings in achieving gender equality. The figure shows that the highest gender equality scores are found in Western Europe, its Offshoots, and East Asia. Gender equality was substantially lower in the Middle East and North Africa, Latin America and Southern Asia. Remarkably, Sub-Saharan Africa is in the middle of the group of world regions, a reflection of measuring equality between genders, rather than their absolute performance.

Figure 12.10 shows, as do the individual components, that there was progress in terms of gender equality everywhere, but that there were important persistent regional differences. Only Latin America and the Caribbean closed the gap with Western Europe and its Offshoots. The MENA remained the least gender egalitarian region throughout the 19502003 period. Furthermore, although East Asia and Eastern Europe made some progress towards gender equality, after the 1980s these regions experienced a reversal of this trend. Though Sub-Saharan Africa is seen to make absolute progress towards gender equality over the period, the gap between it and the leading regions has increased. (Dilli et al. 2014b).

\section{Correlation with GDP per capita}

This section examines the relationship between gender equality indicators and economic development. As explained in the introduction, over the past 20 years researchers and policy-makers have started to pay more attention to gender equality as one of the core drivers of economic development. Tertilt (2005), for example, concludes that enforcing a ban on polygyny decreases fertility by $40 \%$, increases the savings rate by $70 \%$, and increases output per capita by $170 \%$. In another recent study, Branisa et al. (2013) provide empirical evidence that social institutions related to higher gender inequality are associated with lower female secondary education, higher fertility rates, higher child mortality, and a higher perceived level of corruption in a country. However, these studies mainly provide crossnational evidence rather than evidence over time. But has there been a positive association between gender equality and development, captured by GDP per capita, throughout the course of the 20th century?

Figure 12.11 illustrates that the relationships between the single indicators of gender inequality and GDP per capita differ from each other and change over time. The relationship between sex ratios and GDP per capita became weaker over time, and even negative after the 1940s (for a discussion, see below). The relationship between inequality in life expectancy and GDP per capita was positive and relatively strong from the early 20th century onwards. Among our indicators, marriage patterns seem to have the strongest persistent relationship with GDP per capita, starting from the 1850s onwards, with a positive link between the two 
Figure 12.10. Regional averages of the composite gender equality index, 1950s-2000s Index where 100 is perfect equality, decadal averages

East Asia

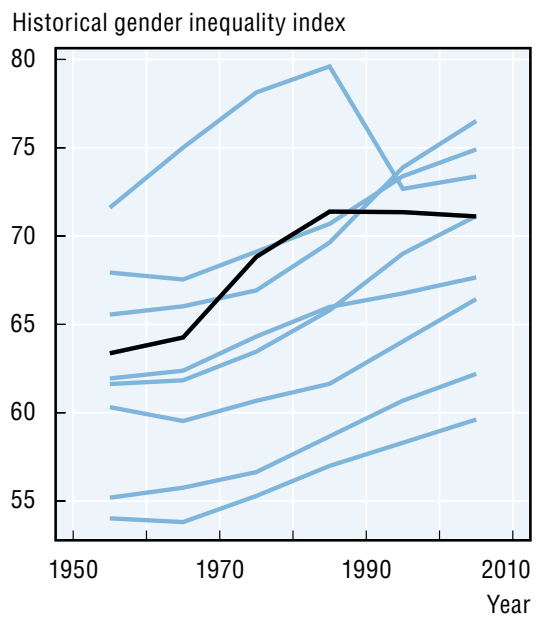

Middle East and North Africa

Historical gender inequality index

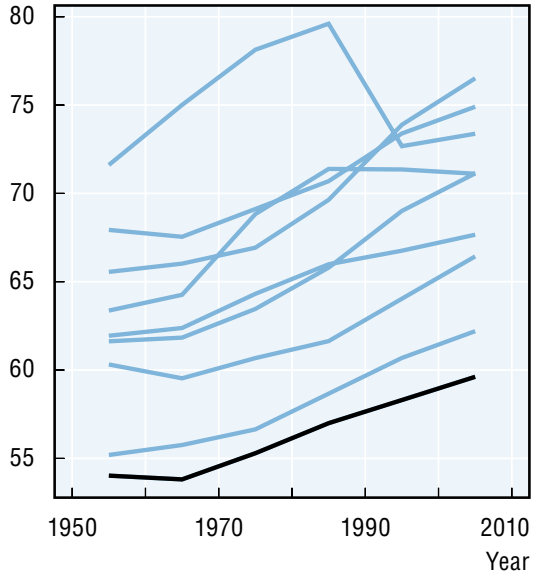

Western Europe

Historical gender inequality index

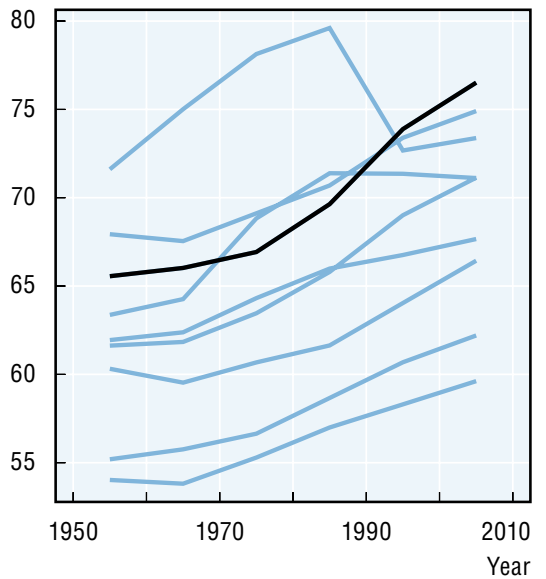

Eastern Europe and former Soviet Union Historical gender inequality index

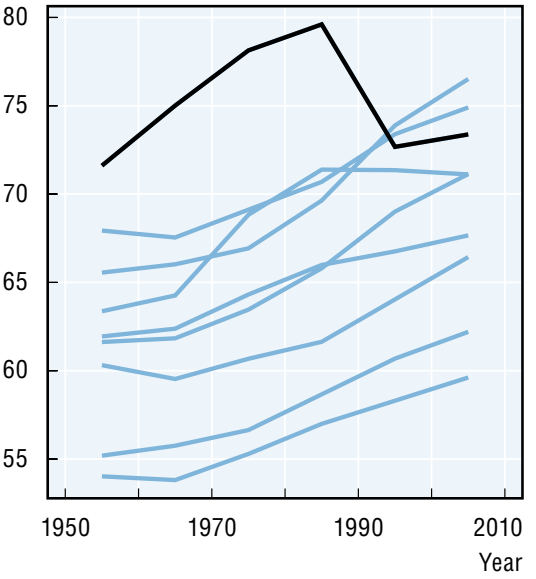

South and South-East Asia

Historical gender inequality index

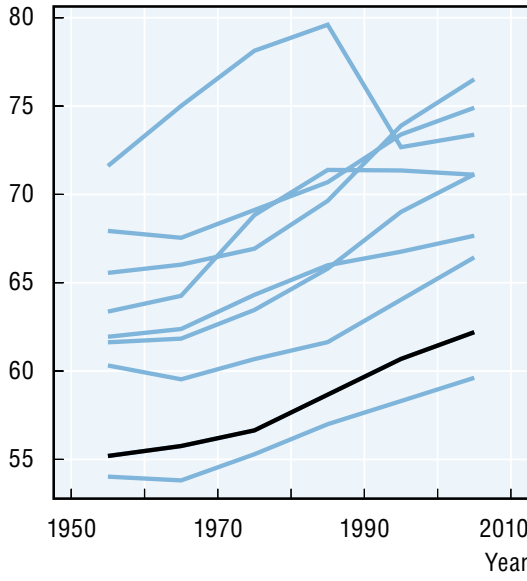

Western Offshoots

Historical gender inequality index

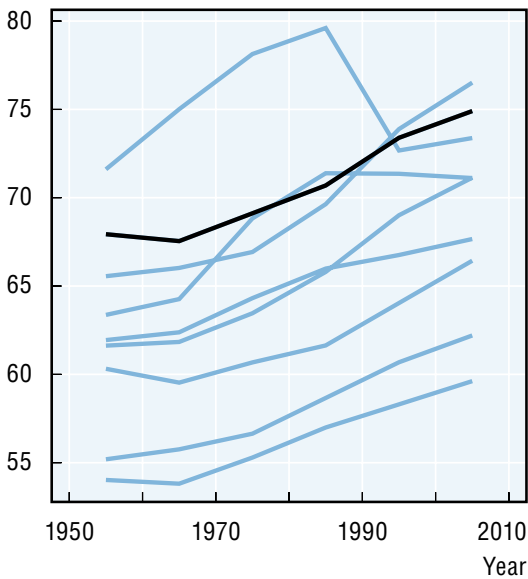

Latin America and Caribbean

Historical gender inequality index

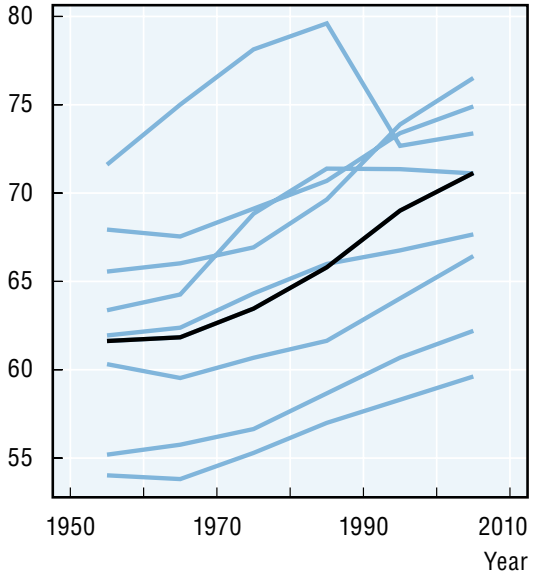

Sub-Saharan Africa

Historical gender inequality index

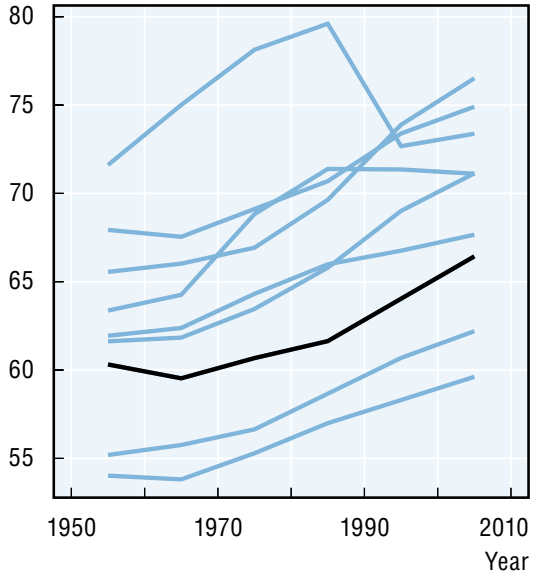

World

Historical gender inequality index

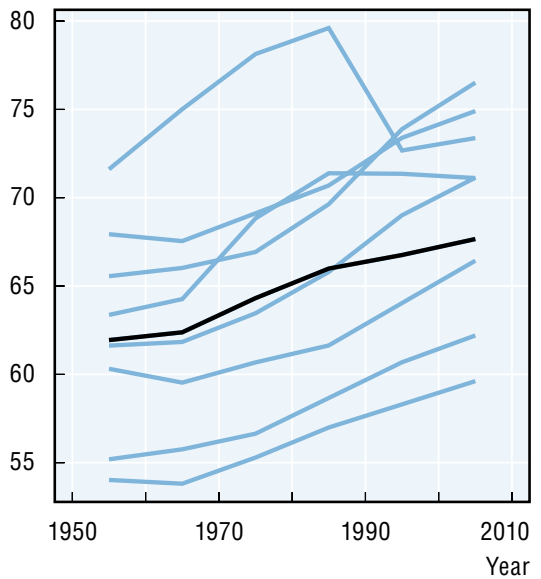

Note: For an assessment of data quality, see Table 12.2.

Source: Clio Infra, www.clio-infra.eu. 


\section{Figure 12.11. Correlation between gender equality indicators and GDP per capita, 1900s-2000s}

Pearson correlation coefficient and upper/lower bounds of $95 \%$ confidence interval per decade

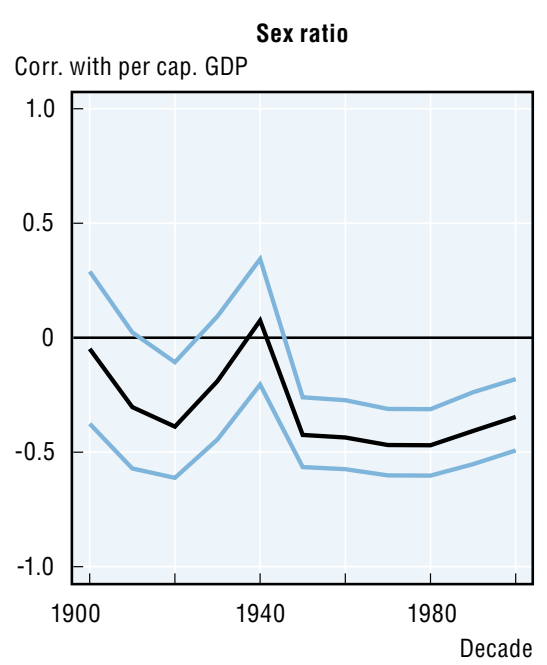

Schooling ratio

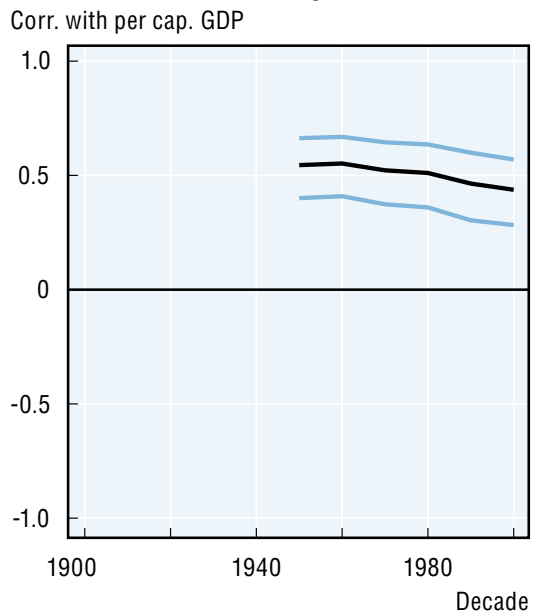

Lif. exp. ratio Corr. with per cap. GDP

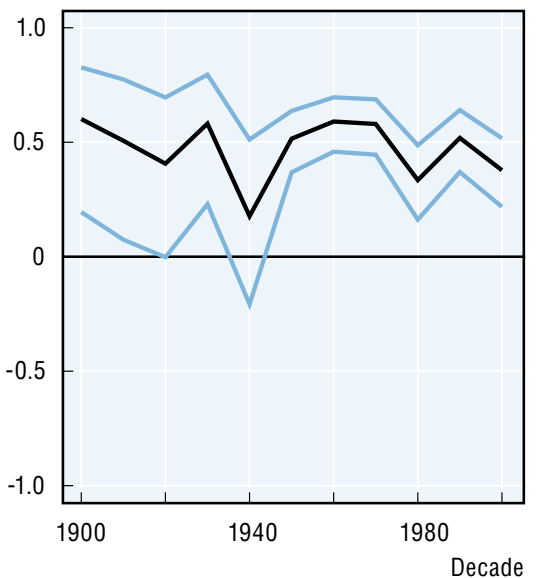

Parl. seats ratio Corr. with per cap. GDP

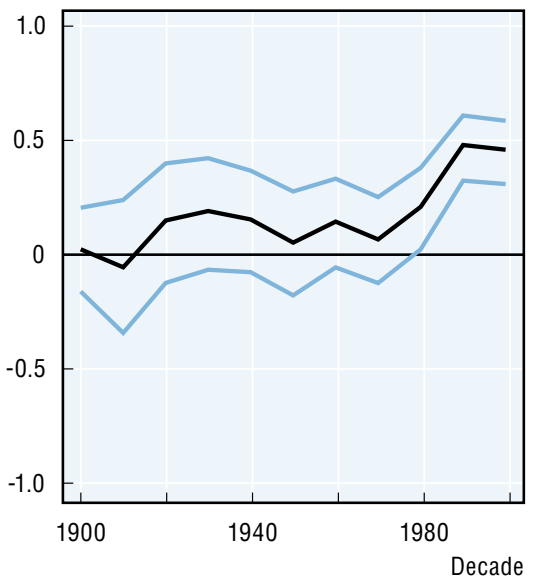

Marriage age ratio Corr. with per cap. GDP

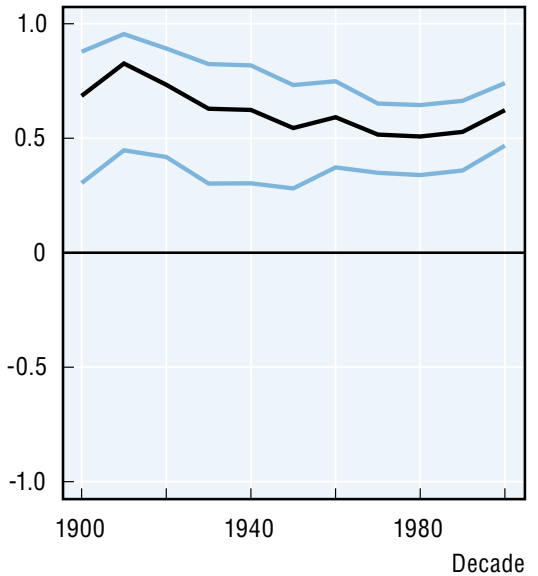

Historical Gender Equality Index Corr. with per cap. GDP

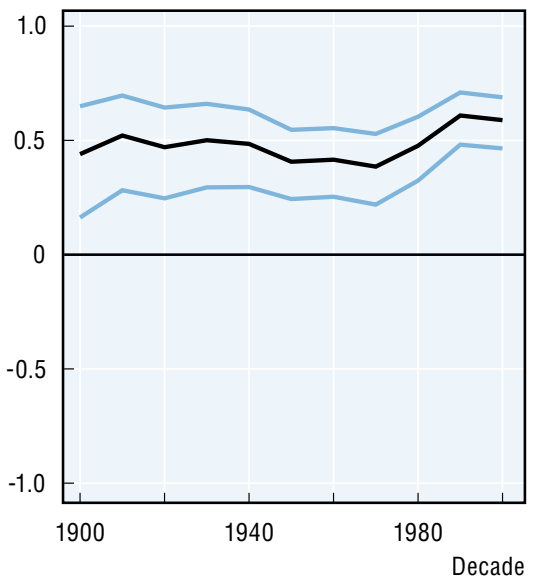

Note: For an assessment of data quality, see Table 12.2. Source: Clio Infra, www.clio-infra.eu.

remaining observable throughout the period. Gender equality in parliament also seems to be positively related to GDP per capita, but only after the 1970s. An explanation for this might be sought in the fact that the parliamentary activity of women remains limited everywhere. Looking at the relation between our overall composite index and GDP, again the relation between the two seems to get stronger after 1970, which is likely to be partly driven by the improvements in gender equality in terms of education and parliamentary activity.

The relationships between the various indicators of gender inequality and GDP per capita are largely positive. The weakly negative association of sex ratios with per capita GDP is the one exception to this rule. The reason for this negative relationship between GDP per capita and the ratio of female to male infants may lie in improved paediatric care. The sex ratio at birth is generally around 1.06 male infants to every female infant. 
Historically this ratio was balanced out over the life course by the fact that young boys had a higher mortality due to their biologically determined vulnerability at young age. However, modern medicine eliminated this mortality bias. This relationship is also likely to be due to the practices mentioned above in countries such as India and China, where increased wealth and access to modern technology are used to achieve unequal gender treatment of infants before they are even born by means of sex selective abortion.

Another way of presenting the relationship of the various measures of gender inequality and GDP per capita is to plot them against each other directly. This excludes a direct visualisation of the time element, so is not a dynamic analysis, but it gives a sense of how the various measures of gender inequality relate to GDP per capita across different levels of development. The results of plotting the data this way are shown in Figure 12.12. These plots can also reveal any nonlinear relationship between gender equality and economic development (Mammen and Paxson, 2000; Friesen et al., 2012), which are not directly evident from Figure 12.11. Note first that we do not look at female labour force participation, for which the non-linear relationship is well-established (Goldin, 1995). This investigation of the underlying data reveals a number of non-linearities. For one, the relation between per capita GDP and gender inequality is often strongest at lower income levels (below 5000 dollars per capita). Life expectancy ratios, sex ratios, schooling ratios and marriage age ratios all have a strong association with per capita GDP in this range. The relationships level off substantially at incomes above 5000 dollars. Taking the logarithm of GDP per capita can often capture this relationship well. The ratio of female to male members of parliament is the one exception and is characterised by a linear relationship with GDP per capita.

To sum up, this chapter has illustrated trends in the well-being of women compared to men across the globe over the past century. Although we still live in a world where women are, on average, disadvantaged relative to men, the situation seems to have improved in the second half of the 20th century, especially from the 1980s onwards. Looking at the dimensions separately, the good news is that gender equality has been achieved - and for some countries surpassed - in terms of life expectancy and that some progress has been made in closing the gender gap in marriage ages, although structural differences remain between different regions. In many developed countries, parity has also been achieved in educational attainment. However, there is still much scope for progress in all the other dimensions. Women's participation in politics remains a point of particular concern around the world, even for countries in Western Europe and its Offshoots. The lack of progress on this measure is even more striking once regional differences are taken into account. While worldwide average female parliamentary representation in 2010 stood at 17 per cent, the average for the MENA was only five per cent. Missing girls and the associated skewed sex ratios remain a major challenge for China and India.

Overall, two main messages can be taken from the current chapter. First, significant progress did take place over the 20th century in terms of achieving gender equality, but there is still a long way to go as gender gaps persist in many dimensions. Second, regional differences in gender equality are not a recent phenomenon but have deep historical roots.

\section{Priorities for future research}

This chapter provided an historical perspective on women's well-being. Clearly, the availability of historical data plays a crucial role in influencing which dimensions this overview could discuss. More historical data and analysis are needed to understand the development 


\section{Figure 12.12. Various indicators of gender equality and GDP per capita, 1900s-2000s}

Ratios and US dollars at 1990 PPP, decadal averages
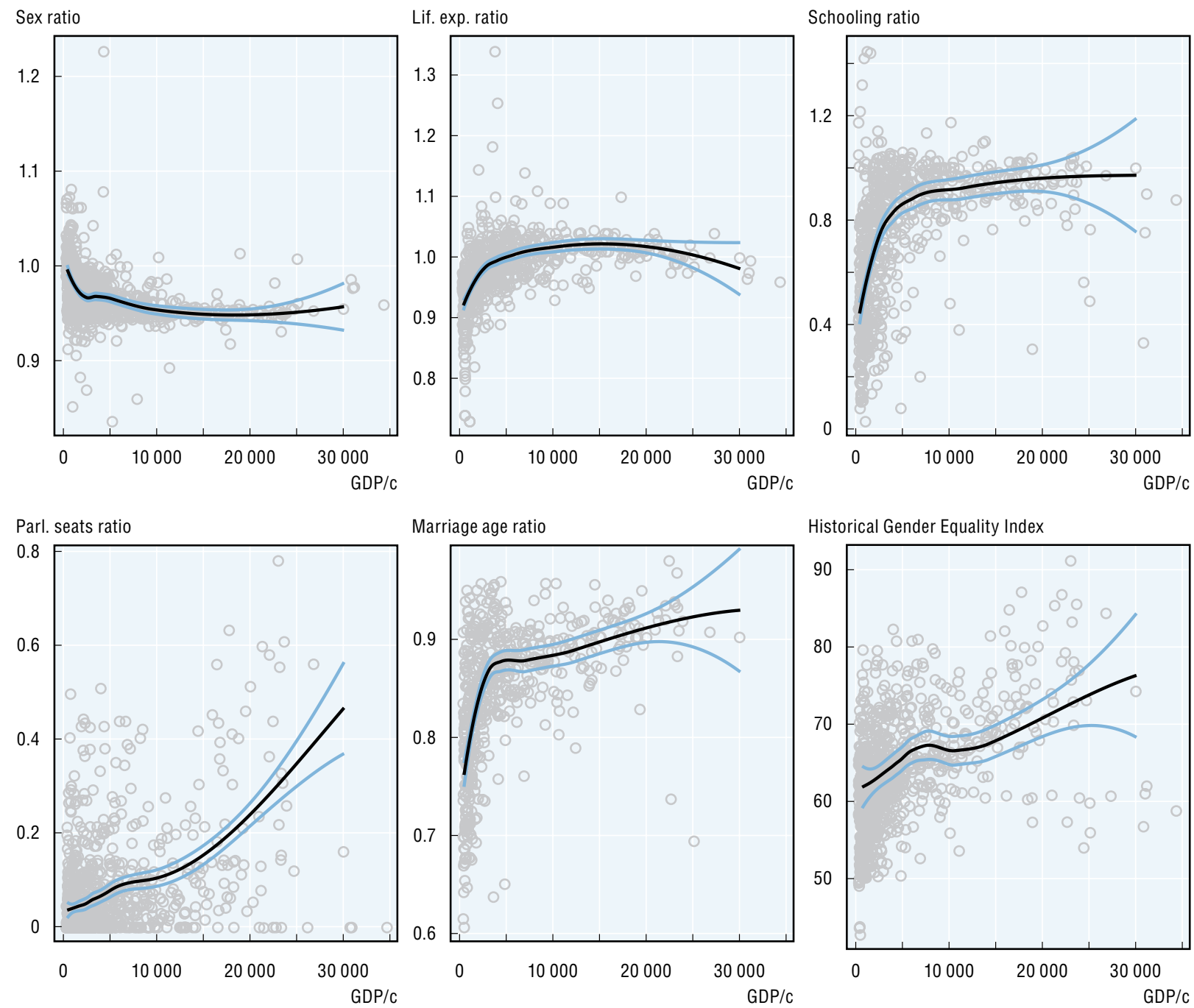

Note: For an assessment of data quality, see Table 12.2.

Source: Clio Infra, www.clio-infra.eu.

and the causes of gender equality/inequality over the past century. Areas where new data and analysis would be particularly useful include educational attainment disaggregated by gender before 1950 and female labour force participation. Another priority for future research is to collect data on female wages so as to have a better understanding of the socio-economic dimensions of women's well-being and position. Moreover, violence against women is one of the most crucial fields where gathering historical data is highly desirable. Although this aspect is harder to capture with quantitative data, mortality data, which indicate the cause of death, would be a good starting point to provide an historical perspective on this issue.

Geographical coverage is another issue that future research should ideally take into consideration, in particular for Sub-Saharan Africa. Generally, data only becomes available for Africa starting from the 1950s onwards, and data is still scarce for many countries in this region today. Similar issues of data scarcity exist for the East Asian and MENA 
regions. These regions are of particular importance as they are still poor performers in the various dimensions of women's well-being highlighted in this chapter. A longer historical perspective would provide insights to help researchers and policy-makers better understand the drivers of these gender inequalities so as to achieve the goal of gender equality in these regions.

Lastly, further valuable insights into the well-being of women could be gained by breaking down the national data on women's well-being into indicators that reflect sociodemographic and economic status. The size of the gender gap may differ significantly between different social groups, and therefore indicators at a less aggregate level could provide further understanding of the drivers of gender inequality. A good starting point would be censuses and/or micro data where detailed information on various aspects related to the well-being of women can be found.

\section{Notes}

1. Take the United Nations Millennium Development Goals as an example: of the 8 goals, 6 can be linked more or less directly to female empowerment, with the last two also having elements that can be achieved only through tackling female empowerment. See United Nations (2013) for an overview of how the UN perceives the gender dimension of the MDGs. For the World Bank's take on the matter, see the Gender Equality as Smart Economics Project, World Bank.

2. See Dilli et al. (2014a). This list is non-exhaustive. For example, improved female education has been shown to reduce infant mortality, improve household efficiency and reduce fertility (see Dollar and Gatti, 1999; King and Hill, 1997; Rosenzweig and Schultz, 1982).

3. It should be noted that gender inequality can also be used to denote a situation where men are disadvantaged vis-à-vis women (as nowadays can be observed in some countries in the case of certain measures of educational attainment or of health status); however, as this is historically almost never the direction in which the inequality runs, the bulk of this chapter looks at how gaps disadvantageous to women have been closed over the past century. This is also to address an imbalance in the rest of the book by which almost all the other chapters either are focused on men or provide no data on indicators disaggregated by gender.

4. Others include the Gender Empowerment Index by the UNDP, the Social Institutions and Gender Index by the OECD, the Global Gender Gap Index by the World Economic Forum and the Women's Economic Opportunity Index produced by the Economist Intelligence Unit.

5. The UN uses a correction of five years because there is some evidence to show that at a biological level women have a greater life expectancy. However, Klasen (2004) argues that, "[a]s no society, past or present, treated the two sexes equally and the two sexes did not differ in survival-related behaviours, it is hard to separate biology from behaviour. Thus it is hard to say whether females 'should' enjoy a longevity advantage of 3, 4, or five years".

6. Views vary on whether income and labour force participation are relevant indicators related to women's well-being. Klasen (2004) argues that it is not immediately clear that gender inequalities in labour force participation should necessarily be seen as relevant for a well-being assessment, as it might be the result of a consensual division of labour within the household.

7. While the UNDP's Gender Empowerment Measure and the World Economic Forum's Global Gender Gap Index take such factors as accessibility of skilled or high-paid jobs into consideration, the indicators used here cover the majority of the elements of the UN's Gender Related Development Index and the replacement Gender Inequality Index.

8. One issue with internationally comparable indicators is that they are insufficient for many purposes, because they do not provide information on the socio-cultural environment, including culture and embedded social relationships (Malhotra, Schuler and Boender, 2002; Bartlett, 2004; Oxaal and Baden, 1997; Ibrahim and Alkire, 2007).

9. For a more detailed discussion of the issue, see Branisa et al. (2009).

10. The year men were granted the right to vote is defined as the year where universal suffrage took place, meaning all men could vote regardless of their income, ethnicity or any restrictions, whereas such a distinction has not been made for women. 
11. The Clio-Infra human capital hub aims to create a database on education split by gender on a global basis extending back to the early 19th century. However, this project is not yet complete, and we therefore could not include this data in the current study.

12. More information on the data can be found at Barro-Lee Educational Attainment Dataset.

13. Labour force participation is included as an additional measure in the composite index to capture the socio-economic dimension of women's position. We believe labour force participation is an important aspect of gender equality, as it reflects what one can actually do with better education, etc. The example of the Middle East and North Africa is a case in point. In this region, although the educational level of women increased significantly from the 1980 s onwards, this did not translate into higher labour force participation. For further information on the composite index please see Dilli et al. (2014a).

14. There has been valuable work on women's labour force participation in the historical context for a handful of cases such as England and the Netherlands (see for example Horrell and Humphries, 1995; Schmidt and van Nederveen Meerkerk, 2012). However these studies are limited to a small number of cases, which makes them unsuitable for global comparison, the main focus of our study. In the future it might become possible to make such an analysis by using data to be made available through the History of Labour Relations project at the International Institute for Social History.

15. In the case of the Scandinavian countries we complemented the Murdock data with information on the year in which legislation was enacted to mandate equal inheritance.

16. The exception is Namibia, where universal male suffrage was granted in 1926, while it was extended to women only in 1989, following independence.

\section{References}

Anderon, S. and D. Ray (2010), "Missing women: Age and disease”, The Review of Economic Studies Vol. 77, pp 1262-1300.

Arulampalam, W., L.A. Booth and M.L. Bryan (2007), "Is There a Glass Ceiling over Europe? Exploring the Gender Pay Gap Across the Wage Distribution", Industrial and Labor Relations Review, Vol. 60, pp. 163-186.

Austad, S.N. (2006), "Why Women Live Longer than Men: Sex Differences in Longevity", Gender Medicine, Vol. 3/2, pp. 79-92.

Barro-Lee Educational Attainment Dataset, http://www.barrolee.com/.

Barro, R.J. and J.W. Lee (2010), "A New Data Set of Educational Attainment in the World, 1950-2010", National Bureau of Economic Research, www.nber.org/papers/w1590.

Bartlett, A. (2004), “Entry Points for Empowerment”, CARE Bangladesh, http://expert.care.at/downloads/ careexpert/CARE_Analytical_Toolbox.pdf.

Bolt, J. (2012), “A New Database on the Origins of Institutional Development”, University of Groningen working paper.

Branisa, B., S. Klasen and M. Ziegler, (2013), "Gender Inequality in Social Institutions and Gendered Development Outcomes", World Development ,Vol. 45, pp. 252-268.

Branisa, B., S. Klasen and M. Ziegler (2009), "The Construction of the Social Institutions and Gender Index (SIGI)", Background paper, University of Goettingen, http://genderindex.org/sites/default/files/ SIGI_background_paper.pdf.

Caldwell, J., P.H. Reddy and P. Caldwell (1983), “The Causes of Marriage Change in South India”, Population Studies, Vol. 37, pp. 343-61.

Cammack, M.E. and R.M. Feener (2012), “The Islamic Legal System in Indonesia”, Pacific Rim Law \& Policy Journal, Vol. 13, pp. 13-42.

Cammack, M.E. “Dossier 22: Inching Toward Equality: Recent Developments in Indonesian Inheritance Law" published on the Women Living Under Muslim Law website, http://www.wluml.org/node/336, accessed 19 January 2014.

Carmichael, S. (2011), "Marriage and Power: Age at First Marriage and Spousal Age Gap in Lesser Developed Countries", The History of the Family, Vol. 16/4, pp. 416-36.

Casterline, J. B., L. Williams and P. McDonals (1986), “The Age Difference Between Spouses: Variations among Developing Countries", Population Studies, Vol. 40, pp. 353-374. 
Clutton-Brock, T.H. and K. Isvaran (2007), "Sex differences in ageing in natural populations of vertebrates", Proceedings of the Royal Society, Vol. 274, pp. 3097-3104.

Currie, J. and E. Moretti. (2003). "Mother's Education and the Intergenerational Transmission of Human Capital: Evidence from College Openings." The Quarterly Journal of Economics, Vol. 118/4, pp. 1495-1532.

Dilli, S., A. Rijpma and S. Carmichael, (2014a). "The Gender Gap in a Historical Perspective”, CGEH working paper series, http://cgeh.nl/working-paper-series.

Dilli, S., A. Rijpma and S. Carmichael, (2014b). "Achieving gender equality: development various historical legacies", CESifo Economic Studies, forthcoming.

Dollar, D. and R. Gatti. (1999), “Gender Inequality, Income, and Growth: Are Good Times Good for Women?" Mimeographed, The World Bank.

Dollar, D., R. Fisman and R. Gatti (2001), "Are women really the 'fairer' sex? Corruption and women in government", Journal of Economic Behavior and Organization, Vol. 46/4, pp. 423-429.

Donno, D. and B. Russett. (2004), "Islam, Authoritarianism, and Female Empowerment: What Are the Linkages?” World Politics, Vol. 56/4, pp. 582-607.

Duflo, E. (2012), "Women Empowerment and Economic Development", Journal of Economic Literature, Vol. 50/4, pp. 1051-1079.

Eskes, T. and C. Haanen, "Why do women live longer than men?" European Journal of Obstetrics \& Gynaecology and Reproductive Biology, Vol. 133/2.

FAO (Food and Agriculture Organization of the United Nations) (2011), The State of Food and Agriculture 2010-2011 - Women in Agriculture.

Fish, M.S. (2002), "Islam and Authoritarianism”, World Politics, Vol. 55/1, pp. 4-37.

Friesen, J., J.Baten and V. Prayon, (2012), "Women Count. Gender (In-) Equalities in the Human Capital Development in Asia, 1900-60", University of Tubingen Working Paper Series in Economics and Finance, No. 29, http://tobias-lib.uni-tuebingen.de/volltexte/2012/6040/pdf/WPEF29Friesen_Baten_Prayon.pdf.

Goldin, C. (1995), “The U-Shaped Female Labour Force Function in Economic Development and Economic History", in Schultz, T.P. Investment in Women's Human Capital and Economic Development, University of Chicago Press, pp. 61-90.

Gray, J.S. (1998), “Divorce-Law Changes, Household Bargaining, and Married Women's Labor Supply”, The American Economic Review, Vol. 88, pp. 628-642.

Gray, W.S. (1969), The Teaching of Reading and Writing, Unesco, http://unesdoc.unesco.org/images/0000/ 000029/002929eo.pdf.

Hajnal, J. (1965), "European Marriage Patterns in Perspective”, In Population in History: Essays in Historical Demography, edited by D.V. Glass and D.E.C. Eversley, Edward Arnold.

Hallward-Driemeier, M., T. Hasan and A. Bogdana Rusu (2013), “Women's Legal Rights over 50 Years: Progress, Stagnation or Regression?” World Bank Policy Research Working Paper, 6616, http://papers. ssrn.com/sol3/papers.cfm?abstract_id=2330042.

Horrell, S. and J. Humphries (1995), “Women's Labour Force Participation and the Transition to the Male-Breadwinner Family, 1790-1865”, The Economic History Review, Vol. 48/1, pp. 89-117.

Ibrahim, S. and S. Alkire, (2007), "Agency and empowerment: A proposal for internationally comparable indicators," Oxford Development Studies, Vol. 35/4, pp. 379-403.

Inglehart, R. and P. Norris (2003), Rising Tide: Gender Equality and Cultural Change Around the World, Cambridge University Press.

International Institute for Social History, History of Labour Relations project http://socialhistory.org/en/ projects/history-labour-relations-1500-2000.

Inter-parliamentary Union (2011), Women in National Parliaments, http://www.ipu.org/wmn-e/world.htm, accessed July 2013.

Kabeer, N. (1999), “Resources, agency, achievement: reflections on the measurement of women's empowerment", Development and Change, Vol. 30, pp. 435-464.

Kalben, B.B. (2000), "Why Men Die Younger: Causes of Mortality Differences by Sex", North American Actuarial Journal. Vol. 4/4. 
King, E.M. and M.A. Hill (1997), "Women's Education in Developing Countries: An Overview," in Women's Education in Developing Countries: Barriers, Benefits, and Policies, edited by E. M. King and M.A. Hill, Chapter , pp. 1-50. World Bank Publications.

King, E.M. et al. (1986), Change in the Status of Women across Generations in Asia, Rand Corporation.

Klasen, S. (2002), "Low Schooling for Girls, Slower Growth for All? Cross-Country Evidence on the Effect of Gender Inequality in Education on Economic Development", The World Bank Economic Review, Vol. 16/3, pp. 345-73.

Klasen, S. (2004), “Gender-Related Indicators of Well-Being”, Working Paper Series UNU-WIDER Research Paper, World Institute for Development Economic Research (UNU-WIDER), http://ideas.repec.org/p/ got/iaidps/102.html, accessed January 2014.

Klasen, S. and F. Lamanna (2009), “The Impact of Gender Inequality in Education and Employment on Economic Growth: New Evidence for a Panel of Countries", Feminist Economics, Vol. 15/3, pp. 91-132.

Klasen, S. and C. Wink (2003), “Missing Women”: Revisiting the debate”, Feminist Economics, Vol. 9/2-3, pp. 263-299.

Lagerlöf, J. (2003), “Gender Equality and Long-Run Growth”, Journal of Economic Growth, Vol. 8, pp. 403-426.

Lindert, P.H. (2004). Growing Public: Social Spending and Economic Growth Since the Eighteenth Century, Volume I: The Story, Cambridge University Press.

Lukito, R. (2013), Legal Pluralism in Indonesia: Bridging the Unbridgeable. Routledge.

Lynch, K.A. (2011), “Why Weren't (many) European Women 'missing'?” The History of the Family, Vol. 16/3, pp. 250-266.

Malhotra, A. (2003), “Conceptualizing and measuring women's empowerment as a variable in international development" Measuring Empowerment: Cross-disciplinary Perspectives, Washington, DC, 4-5 February. http://siteresources.worldbank.org/INTEMPOWERMENT/Resources/486312-1095970750368/ 529763-1095970803335/malhotra2.pdf.

Malhotra, A., S.R. Schuler and C. Boender, (2002), Measuring women's empowerment as a variable in international development. World Bank, http://www4.worldbank.org/afr/ssatp/Resources/HTML/GenderRG/Source\%20\%20documents/Technical\%20Reports/Gender\%20Research/TEGEN5\%20Measuring\%20 Women's\%20Empowerment\%20ICRW\%202002.pdf.

Mammen, K. and C. Paxson, (2000), "Women's Work and Economic Development”, The Journal of Economic Perspectives, Vol. 14/4, pp. 141-164.

Marshall, M.G., K. Jaggers and T.R. Gurr (2010), Polity IV Project: Political Regime Characteristics and Transitions, 1800-2010. INSCR, http://www.systemicpeace.org/polity/polity4.htm, February 25, 2011.

McKee, M. and V. Shkolnikov, (2001), "Understanding the toll of premature death among men in eastern Europe”, British Medical Journal, Vol. 323/7320, pp. 1051-1055.

Morrisson, C. and F. Murtin (2013), "The Kuznets Curve of Human Capital Inequality: 1870-2010." The Journal of Economic Inequality, Vol. 11/3, pp. 283-301.

Murdock, G.P. (1969), Ethnographic Atlas. 2nd print, University of Pittsburgh Press.

OECD (2013), How's Life? 2013: Measuring Well-being, OECD Publishing, Paris, http://dx.doi. org/10.1787/9789264201392-en.

Oxaal, Z. and S. Baden (1997), "Gender and empowerment: definitions, approaches and implications for policy”, BRIDGE, Report No. 40, www.bridge.ids.ac.uk/reports/re40c.pdf.

Paxton, P., J. Green, and M. Hughes, (2008), “Women in Parliament, 1945-2003: Cross-National Dataset" ICPSR ed. Ann Arbor, MI: Inter-university Consortium for Political and Social Research.

Przeworski, A. (2009), "Conquered or Granted? A History of Suffrage Extensions", British Journal of Political Science Vol. 39, pp. 291-321.

Rehm, J. et al. (2007), "Alcohol accounts for a high proportion of premature mortality in central and eastern Europe", The International Journal of Epidemiology, Vol. 36/2.

Rosenzweig, M.R. and T.P. Schultz. (1982), “Market Opportunities, Genetic Endowments, and Intrafamily Resource Distribution: Child Survival in Rural India”, The American Economic Review, Vol.72/4, pp. 803-15.

Salim, A. (2008) Challenging the Secular State: The Islamization of Law in Modern Indonesia, University of Hawai'i Press. 
Saxonberg, S. (2000), "Women in East European Parliaments", Journal of Democracy, Vol. 11/2, pp. 145-58.

Schmidt, A. and E. van Nederveen Meerkerk (2012), "Reconsidering The 'First male-Breadwinner Economy': Women's Labor Force Participation in the Netherlands, 1600-1900”, Feminist Economics, Vol. 18/4, pp. 69-96.

Schultz, T.P. (1988), "Education Investments and Returns", Handbook of Development Economics 1/1, pp. 543-630.

Sen, A. (1990), "Gender and Cooperative Conflicts", in Persistent Inequalities: Women and World Development, edited by I. Tinker, 123-149.

Sen, A. (1992), “Missing Women”, British Medical Journal Vol. 304, pp. 587-588.

Sen, A. (1999), Development as Freedom, Oxford University Press.

Sokoloff, K.L. and S.L. Engerman (2000), "History Lessons: Institutions, Factor Endowments, and Paths of Development in the New World", Journal of Economic Perspectives, Vol. 14/3, pp. 217-232.

Tertilt, M. (2005), “Polygyny, Fertility, and Savings”, Journal of Political Economy, Vol. 113/6, pp. 1341-1371.

United Nations (2013), The gender dimension of the Millennium Development Goals Report 2013, www. unwomen.org/en/news/stories/2013/7/the-gender-dimension-of-the-millennium-development-goalsreport-2013/\#sthash.DczDShxJ.dpuf.

University of California, Berkeley and Max Planck Institute for Demographic Research, Human Mortality Database, www.mortality.org.

Verba, S., N. Burns and K. Lehman Schlozman (1997), "Knowing and Caring about Politics: Gender and Political Engagement", The Journal of Politics, Vol. 59/4, pp. 1051-1073.

Waldron, I. (1967), "Why do women live longer than men?" Social Science and Medicine, Vol. 10/7-8.

Weldon, L. and M. Htun (2012), "Sex Equality in Family Law: Historical Legacies, Feminist Activism, and Religious Power in 70 Countries," https://openknowledge.worldbank.org/handle/10986/9204.

The World Bank, The Gender Equality as Smart Economics Project, http://go.worldbank.org/FSV68RJ1F0.

The World Bank (2011), World development report 2012: Gender equality and development. http://econ. worldbank.org/WBSITE/EXTERNAL/EXTDEC/EXTRESEARCH/EXTWDRS/EXTWDR2012/0,,contentMDK: 22999750 pagePK:64167689 piPK:64167673 theSitePK:7778063,00.html.

van Zanden, J.L. and T. De Moor (2009), "Girlpower: The European marriage pattern (EMP) and labour markets in the North Sea Region in the late medieval period", in The Long Road to Industrial Revolution, Brill. 


\title{
Chapter 13
}

\section{A composite view of well-being since 1820}

\author{
by
}

Auke Rijpma, Utrecht University

This chapter provides a parsimonious overview of the trends in various well-being dimensions covered in the previous chapters by constructing a composite index of well-being. It discusses the crucial problem of choosing a set of weights to calculate such a composite index. Related problems include normalisation of individual indices and dealing with missing observations. The chapter discusses the advantages of various options, and their implications for the final results. It finds that empirically a wide range of aggregation methods generate comparable results. They all indicate that progress in well-being was commonplace since the early 20th century, with the possible exception of Sub-Saharan Africa. It is also found that since the 1970s between-country inequality in composite well-being is lower than in GDP per capita, while being more pronounced in the period before. 


\section{Introduction}

Economic historians have made great strides in expanding the long-term view of economic development in the decades since Angus Maddison (1982, 1995, 2001) began his historical reconstruction of the world economy. By measuring economic performance through GDP and real wages, the deep origins of global inequality are clearer than ever.

However, what ultimately matters for people is not economic performance per se, but the extent to which it improves their well-being. In turn, it is widely believed that the total production of goods and services in an economy, GDP, is an insufficient measure of wellbeing (Sen 1987, 1999, 2001). Focusing exclusively on GDP implies ignoring distributional issues, as well as the contribution to well-being of non-market goods and services such as health, education, security, governance and the environment. Attention to other aspects of well-being is therefore warranted (Stiglitz et al., 2009).

This book has explored the many aspects of well-being in a long-term perspective. After sketching the contours of world population from 1820 to 2010, the authors have looked at classic income measures such as GDP, real wages and income inequality. They have also analysed long-term changes in health and the biological standard of living by discussing life expectancy and population heights. Furthermore, safety, the quality of the environment, and institutions guaranteeing political freedoms have been analysed. Finally, there has been attention to gender equality in a wide range of well-being indicators.

Population developments matter not only because it is important to know how many people lived in the countries covered in this study, but also because population is a factor in other well-being indicators such as economic growth, health and pressure on the environment. The overall pattern is one of accelerating growth in the 19th century, with European populations showing strong growth at the beginning of the period. As population growth in the developed regions slowed down in recent decades, the population share of fast-growing Asia and Africa has increased.

Although the point of this book is to look beyond GDP per capita as a measure of wellbeing, the total productive capacity of an economy is still an important measure. Income allows people to consume and gives governments the opportunity to provide public goods and services relating to health and education. Historical national accounting has shown that Europe and its Offshoots already had higher levels of GDP per capita at the start of the 19th century, while much of the rest of the world was still at near-subsistence incomes. World income has increased eighteen-fold since then. However, the gap between rich and poor countries actually widened until the middle of the 20th century, after which a catchup process began.

Real wages are an important complementary measure of income. Because GDP per capita is an average for the economy as a whole, it does not necessarily capture the income of most people. Income may be measured more satisfactorily by looking at the purchasing power of wage income. Throughout the 19th and 20th centuries, real wages were highest 
in the Western Offshoots, with Europe catching up only well into the 20th century. Because progress in real wages was limited outside Europe, its Offshoots and the Middle East and North Africa, inequality between countries has increased strongly over the past two centuries.

Education is important for well-being because improved access to information is of intrinsic importance, but also because there are indirect effects through the impact of education on other well-being indicators, such as income, health and political stability. In respect to basic education, the world has progressed from low to near-universal literacy attainment. Whereas literacy was limited to Europe and its Offshoots in the late 19th century, reading and writing is now widespread throughout the globe. However, the gap in advanced educational attainment has decreased much less, an important fact given the higher educational requirements of today's technological world.

The ability to lead a long and healthy live is a prerequisite for achievements in all other aspects of well-being. Looking at life expectancy to see whether people can enjoy long lives shows that there was a strong, worldwide increase from the 1950s onwards. However, there are substantial inequalities due to the fact that the upwards trend in life expectancy in Europe and its Offshoots was already well underway in the second half of the 19th century. Asia and Latin America began to catch up from the early 20th century and Africa after that, but continued increases in life expectancy in the developed world mean that convergence is not complete.

Human height is determined by nutrition as well as the disease environment, thus capturing two important aspects of well-being. People's average height has generally tended to rise throughout the world. However, there was a temporary stagnation and even decline in height in Europe in the early 19th century and in the Western Offshoots and Asia in the second half of the 19th century.

Personal security, measured here by homicide rates, is also of great importance for well-being. The data coverage for this indicator is problematic, but what it does show is that homicide rates in Western Europe continued the decline started prior to the 19th century, to reach very low levels. One striking aspect of homicide rates is that the high United States rates did not decline to the lower European levels. Sub-Saharan Africa and Latin America stand out for still being very unsafe regions in recent years.

Political institutions matter for well-being because they determine people's control over government decisions, which affect their own lives. Moreover, decisions influencing many aspects of well-being are made in politics, making institutions instrumentally important as well. The tradition of statehood goes back furthest in Asia, Europe and its Offshoots. These regions also have the highest political stability. Democratic institutions and elections were found to have increased throughout the 19th and 20th centuries, though there were important intermezzos, notably in socialist countries. East Asia, the Middle East and North Africa, and Sub-Saharan Africa were late to develop democratic institutions.

The quality of the environment directly influences well-being, because people obtain enjoyment from their environment and often care about the planet they live on. Moreover, the environment also influences other well-being indicators such as health and the sustainability of other indicators. Looking at biodiversity, Europe was already at relatively low levels in 1820, and over time biodiversity declined further until the 1980s. In the 19th and 20th century, biodiversity deteriorated in North America too. Although biodiversity is deteriorating globally, the rest of the world is still at higher levels. 
Income inequality is important in order to assess whether total income has benefited large shares of the population. It matters indirectly as well, because high inequality has an adverse impact on other well-being indicators such as crime rates, health and education. Income inequality increased throughout the world over the course of the 19th and 20th centuries, though there was an egalitarian moment in the middle of the 20th century. Asia, Sub-Saharan Africa, and especially Latin America stand out as particularly unequal regions. Globally speaking however, the country in which a person was born became more important for his expected income.

Each chapter has investigated the correlation between per capita GDP and the wellbeing indicators considered in that chapter. Although many of them have a fairly high correlation with GDP, each indicator also differs sufficiently to warrant separate consideration from GDP per capita in a comprehensive view of well-being. The correlation coefficients are usually between 0.5 and 0.8 .

The correlation of the indicators with GDP changes over time (Figure 13.1). For a number of well-being indicators (real wages, height, life expectancy, education, political institutions), the correlation coefficients are closer to zero in the first half of the 19th century than they are in the 20th century, though their estimated values are less precise in this period as there are fewer observations and less variance in per capita GDP and the other well-being indicators. When trying to explain these changing correlations, it is important to keep in mind that these are unconditional correlations. A host of confounding variables could be driving changes in the relationship between per capita GDP and the other well-being indicators, so causal interpretations are not warranted. This change in correlation is not due to new countries entering the data as time moves on: doing the calculations for a smaller set of countries that enjoy good data coverage from an early moment onwards gives qualitatively similar, if more noisy developments. ${ }^{1}$ That said, the weaker relationship between per capita GDP and a number of important well-being indicators suggests that economic gains before roughly the 1870 s were less likely to be associated with broader improvements in well-being. Only by the turn of the century had a consistent positive correlation of most well-being indicators with GDP come into being. However, income inequality is seen to move from a positive correlation with GDP in the 19th century to a negative correlation by the end of the 20th century.

One prominent candidate for explaining these trends in the relation between per capita GDP and well-being indicators is technology. Preston (1975) famously observed that as medical technology improved and spread across the globe, the same income resulted in higher life expectancy than thirty years earlier. However, Preston observed an upward shift, not changes in the strength or direction of the relationship between per capita GDP and life expectancy. This is reflected in the correlation coefficients presented here, which hardly changed over the course of the 20th century. Preston's observation on the role of technology can, however, be extended backwards. Arguably, it took until the end of the 19th century before medical technology had advanced sufficiently and spread far enough throughout the globe so as to give rise to a relationship between health and per capita GDP (Cutler et al., 2006). This would explain the lower correlation during the 19th century.

A technological argument may also matter for the relation between education and per capita GDP. Early 19th century industrial technology did not require a highly skilled workforce and could thus limit educational attainment (Nicholas and Nicholas, 1992; Goldin and Katz, 1998). More generally, the finding that per capita GDP did not have a consistent positive relation with the other well-being indicators in the 19th century is not 
Figure 13.1. Correlation between well-being indicators and GDP per capita, 1820s-2000s

Pearson correlation coefficient and upper/lower bounds of $95 \%$ confidence interval per decade
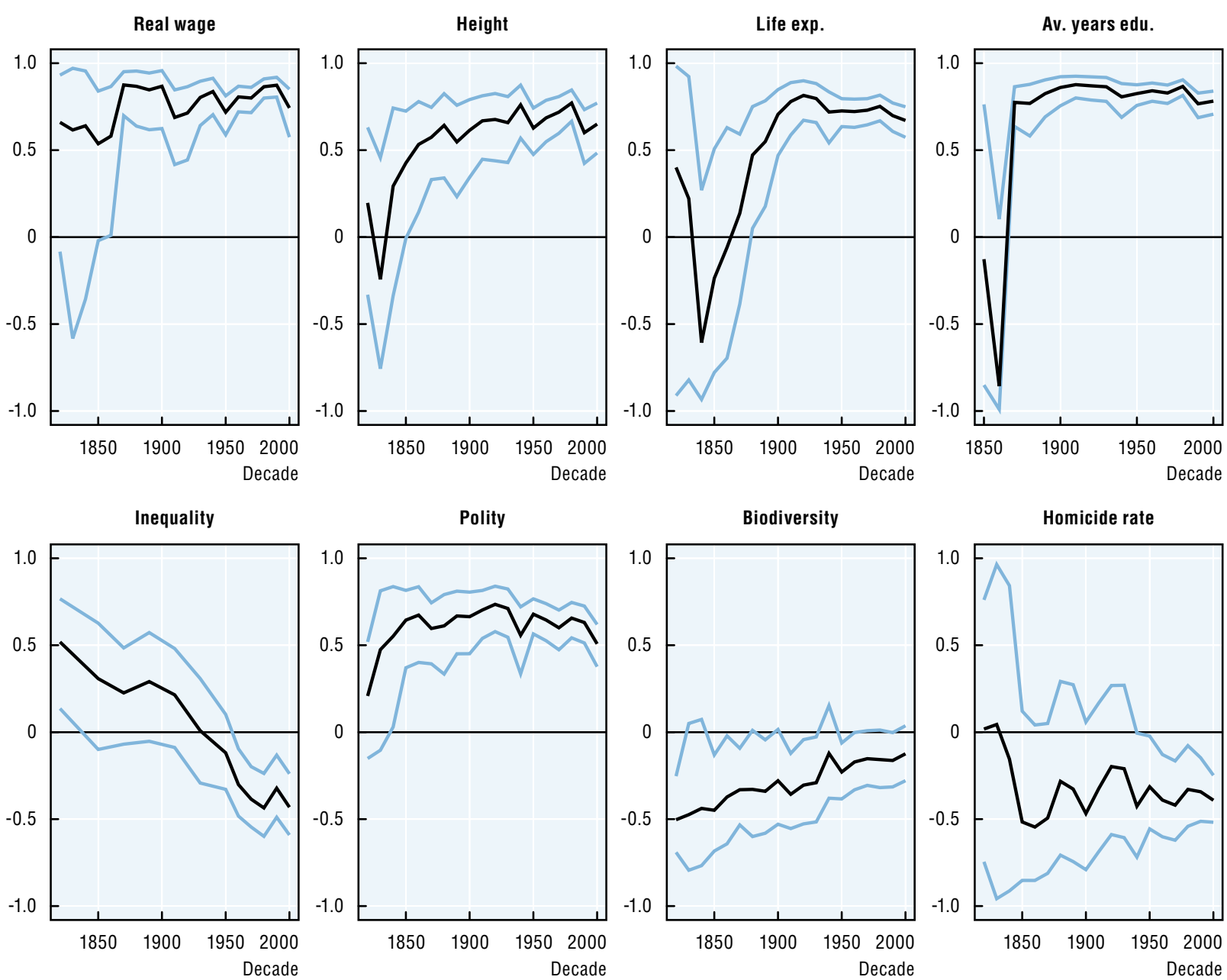

Source: Clio Infra, www.clio-infra.eu.

entirely unexpected. It has been claimed that the gains from economic growth among early industrialisers did not end up with the common workers, who made up the bulk of the population. For example, nutrition stagnated or even declined during the early decades of the Industrial Revolution (Komlos, 1998), and the disease environment worsened until around 1850 (Szreter, 2003). The data gathered here shows this to have been a pervasive pattern in the 19th century.

Although the value of considering multiple indicators of well-being is clear, the composite picture of well-being has not yet been explored. What does well-being look like when all the indicators are considered together? Do countries compensate a bad performance in one aspect of well-being with a good performance in another? A good example is a socialist country like Cuba, which had achieved only a modest level of income and lacked political freedoms but nonetheless managed to achieve impressive health outcomes (Cooper et al., 2006). However, it might also be the case that poor performance 
in one aspect of well-being is accompanied by low scores on other measures as well. The numerous problems befalling many Sub-Saharan Africa countries are prime examples.

These questions are pertinent not only to understanding well-being in the world today, but also for the long-term view of development. What happens to increasing betweencountry inequality since the Industrial Revolution - the Great Divergence - once the many dimensions of well-being are taken into consideration?

A common approach to questions like these is to aggregate multiple indicators into one composite indicator. Though very popular, such composite indicators are not without problems, and these will be discussed below. Each way of constructing a composite indicator has its own distinct advantages and disadvantages, but so far no fully satisfactory method exists. After discussing methodological issues, this chapter moves on to show the distribution, trends and regional differences in two composite indicators that have been constructed in different ways. Doing this shows a fairly positive picture. Progress is common, and the world is more equal than is indicated when per capita GDP alone is taken as the well-being indicator. However, this lower inequality between countries is also a fairly recent phenomenon, with signs of convergence beginning only in the second half of the 20th century. During the second half of the 20th century, divergence in terms of the composite indicators could well have been stronger than in terms of GDP alone. A number of robustness checks show that the main findings are fairly robust in relation to the way the composite indicator is constructed. The large number of indicators entering the index and their strong correlation mean the overall trends are unlikely to change much due to the weighting scheme. One important exception is the early 19th century, when the weaker correlations between the indicators and the need for imputations add considerable uncertainty. A discussion of the future research agenda into historical composite indicators concludes the chapter.

\section{Description of the concepts used}

A composite indicator can be constructed in many ways, and there is no clear consensus on how it should be done. The theoretical problems inherent in combining indicators based on different metrics have made this a topic of substantial debate in academic circles. Despite this, composite indicators have become quite popular. While recognising their theoretical difficulties, those in favour of them hold that they can make a valuable contribution in summarising the messages of the many variables by providing a parsimonious view (Nardo et al., 2005). However, the theoretical difficulties of a composite indicator indicate a need to closely examine how robust they are.

The academic debate on composite indicators usually focuses on the twin issues of weights and trade-offs. The indicators entering a composite indicator usually have widely different ranges and different units of measurement, and this needs to be addressed. For example, if average years of education are combined with life expectancy without any transformations, the range of 19 to 82 years for life expectancy makes a larger contribution to the composite indicator than does the 0-13 years for education. For this reason, the indicators are often normalised or standardised (e.g. Morris, 1980; UNDP, 2010; Boarini and Mira d'Ercole, 2013; Nardo et al., 2005). However, a normalisation procedure does not fully resolve the aggregation and weighting issue. Trade-offs exist in the composite indicator (Ravallion, 2011a, 2012a, 2012b). The core of the problem is that combining two or more indicators into one introduces the possibility of exchanging some amount of one indicator for some amount of another while keeping the overall score equal. This means 
that aggregation amounts to a statement on the relative importance of the indicators. For instance, four years of education might be worth as much as one additional year of life expectancy in the composite indicator.

One solution is to gather subjective information on the determinants of well-being. The study of subjective well-being (life satisfaction or "happiness") and its determinants is one way to obtain such insights (Fleurbaey et al., 2009; Schokkaert, 2007), though measurement of subjective well-being is not without its own challenges, particularly when making comparisons across cultures. These methods hold great promise, but historical public opinion is not available, thus limiting its use for the historical data discussed in this book. A final problem is that these surveys can give counterintuitive results. For example, broad agreement exists about the importance of longevity for well-being: one should be alive to experience any well-being. Though there is a relationship between subjective wellbeing and health status at the individual level (Dolan, Peasgood and White, 2008), Deaton (2008) finds that conditional on income, life expectancy has no significant effect on life satisfaction at the country level. The data gathered for this book give similar results when they are regressed on country-level life satisfaction scores from the World Value Surveys (Rijpma, 2014). Moreover, conditional on income, none of the other well-being indicators has a significant association with life satisfaction. Only average years of education and income inequality are statistically significant, but they have an unexpected sign (negative and positive, respectively). Regressing each well-being indicator separately on life satisfaction gives results that are more in line with expectations, though inequality still has a positive rather than a negative effect on well-being. Using individual-level survey data would probably allow for more accurate estimation of the contribution of the various indicators of well-being (e.g. Boarini et al., 2012), but the indicators gathered by these surveys do not match the (country-level) data in the present volume. Surveys among experts or the public can also provide information on the relative importance of indicators of well-being (Boarini and Mira d'Ercole, 2013).

Research in welfare economics has also made contributions by constructing composite indicators of well-being using economic theory (Becker et al., 2005; Dowrick et al., 2003). To achieve this goal, it is necessary to express other well-being indicators in monetary terms (Fleurbaey and Gaulier, 2009). The consistency with economic theory and the expression of the resulting indicator as a correction to GDP are useful properties of these approaches. However, setting prices on other dimensions of well-being requires a great deal of data, and results in complexity that hampers their interpretation.

Another line of research into composite indicators considers poverty measures from a multidimensional perspective. Poverty measures take a poverty line and count the number of people who fall below it and the extent of their poverty. The point of a multidimensional poverty line is to consider multiple indicators of poverty (Alkire and Foster, 2011). Since such measures are designed to count the number of poor, they require individual-level data and are not well suited to country-level data. Moreover, these poverty measures still require a decision about weights and, additionally, the poverty cut-off for each indicator.

One way to circumvent the issue of weighting altogether is to be content with only ranking the countries, rather than assigning an exact number to each of them. The most famous proponent of this approach is probably Amartya Sen (1999; 1987, pp. 32-3). This approach has been worked out in some detail (Atkinson and Bourguignon, 1982; Duclos et al., 2006). The basic idea is to rank a country higher than another country only if it scores as good or better on all indicators. In that case the country will score higher than the other 
regardless of the weighting procedure. The problem with this approach is that rankings can be incomplete when a country scores better on one indicator but worse on another. As the number of indicators and observations increases, an unambiguous ranking becomes more difficult to achieve. Since this book has considered over nine indicators and historical data provide many observations, this is especially problematic. Only 728 unambiguous rank relations could be established among 40200 possible complete-case comparisons (there are over 22 million comparisons if including incomplete cases). A further issue with using ranking techniques is that it makes comparisons over time difficult. If an improvement of rank between two decades is found, it is not known whether this is an actual improvement or a relative improvement.

A final set of methods is data-driven. Principal components analysis (PCA) is one popular example of these techniques (e.g. Slottje, 1991; Chakravarty, 2003). Other latent variable models such as factor models are very similar and are also widely used in the construction of composite indicators (Høyland et al., 2012; Kaufmann et al., 2004). These models can be used to construct a composite indicator that reflects as much as possible the information shared by the indicators (Nardo et al., 2005). One advantage of these methods is that a statistical model provides a coherent way of thinking about the issue of aggregation. Given assumptions about the relations between the indicators, the weights are chosen so that they differentiate between countries as best as possible. Moreover, statistical models make it possible to account for sources of uncertainty, such as measurement error in a composite indicator (Høyland et al., 2012; Kaufmann et al., 2004; Treier and Jackman, 2009). Allowing for the possibility of measurement error is very important in the context of historical data (Feinstein and Thomas, 2002).

The main disadvantage of a latent variable approach is that there is no reason to suppose that a statistical property, for instance, the correlation between variables, captures the correct trade-offs between the indicators. Moreover, the statistical justification behind a latent variable model is not without issues. Having each indicator capture only part of well-being seems to fit well with a multidimensional concept of well-being. Such concepts are frequently used, and examples include healthy condition, cognitive ability, ideological disposition and democracy (Treier and Jackman, 2008; Lee, 2007). However, this does require that the structure of the latent variable - well-being - is reflected in the covariance structure of the country-level indicators.

Two approaches to constructing a composite indicator will be used here. This will give a first assessment of the sensitivity of the composite indicator to the way it is constructed. The first approach is to calculate an arithmetic average of the standardised indicators with equal weights for each dimension. This is probably the most well-known way of constructing a composite indicator. The second approach is to estimate a composite indicator through a latent variable (factor) model. There is no guarantee that the latent variable captured by this procedure is well-being, especially not when the indicators are measured at the country-level (well-being is primarily an individual-level concept). Nonetheless, there are good reasons to consider such a model. First of all, the results turn out to be qualitatively similar to the equal-weighting approach. The weights this procedure gives turn out to be fairly similar to the equal-weighting case, thus giving some assurance about the robustness of the approach.

The second and most important reason to consider the factor analysis model separately is to explore the important issue of imputations. Computing a composite indicator requires observations of all indicators for a given country at a given point in time, which is not 
readily achieved with historical data. Only 159 such complete cases exist in the data. Imputations are therefore inevitable, and the way this is done can influence the results. The latent variable model allows for imputation of missing data using the covariance between the indicators. This is a useful property, since, if lacking data on one variable, say, height, it is desirable to estimate this missing value based on other highly correlated variables (and less so for variables with a lower correlation, such as political institutions). Furthermore, the underlying data structure of the latent-variable model can be specified. This allows the imputations to reflect the fact that countries in a region or period are expected to have similar scores on indicators (a multilevel structure) or that indicators within a country are correlated over time (a time-series cross-sectional structure). Finally, the latent variable model also allows the uncertainty caused by imputing to be reflected in the imputations and in the composite indicator itself.

\section{Main highlights of trends in composite indicators of human well-being}

The indicators used to construct the composite indicator are roughly equal to those considered in the preceding chapters. Some of the indicators capture a similar aspect of well-being and are thus grouped. First is income, which is captured through per capita GDP and real wages. Incorporating inequality is important for a good understanding of whether income benefits a large share of the population. However, income inequality enters the model separately, because it has a low and negative correlation with GDP per capita. Life expectancy serves as an indicator for the population's health. Height captures both income and health. Education is measured by average years of education. Next, political freedoms are incorporated through data on democratic institutions (Polity2). Finally, the environment and personal security are measured through mean species abundance (MSA) and homicide rates, respectively. Table 13.1 summarises some key statistical features of the well-being indicators used in this chapter.

The first method used here to construct a composite indicator is to calculate an equallyweighted average over all the indicators. The indicators are standardised so that the mean and standard deviations for the entire 1820-2000 period and all countries are zero and one respectively. No further transformations were performed on the data (following advice in Ravallion, 2012b, and Chakravarty, 2003). Multiple indicators for the same group (per capita GDP and real wages in the case of income; height and life expectancy in the case of health) are given half the weights of the other indicators so that each group of indicators has an equal

Table 13.1. Well-being indicators: coverage and summary statistics

\begin{tabular}{|c|c|c|c|c|c|c|}
\hline & Mean & SD & Min & $\operatorname{Max}$ & $\mathrm{N}$ & Period \\
\hline GDP per capita & 3702.59 & 4763.11 & 225.06 & 34440.92 & 1500 & $1820-2000$ \\
\hline Real wages & 24.50 & 32.29 & 0.48 & 349.38 & 1023 & $1820-2000$ \\
\hline Height & 167.75 & 4.57 & 152.36 & 183.20 & 1357 & $1820-2000$ \\
\hline Life expectancy & 56.09 & 14.57 & 18.90 & 82.19 & 1618 & $1820-2000$ \\
\hline Average years of education & 3.72 & 3.32 & 0.01 & 13.07 & 1638 & $1820-2000$ \\
\hline Income Inequality & 43.18 & 8.71 & 16.14 & 73.70 & 895 & $1820-2000$ \\
\hline Polity2 & 7.74 & 7.15 & 1.00 & 21.00 & 1896 & $1820-2000$ \\
\hline Mean species abundance & 0.86 & 0.15 & 0.05 & 1.00 & 3857 & $1820-2000$ \\
\hline Homicide rate & 5.93 & 8.61 & 0.00 & 71.75 & 812 & $1820-2000$ \\
\hline
\end{tabular}

Source: Clio Infra, www.clio-infra.eu. 
weight. Inequality and homicides are thought to contribute negatively to well-being, and they are given a negative weight. Composite indicator scores were calculated for each decade and country, which were then used to calculate population-weighted regional averages.

Because the composite indicator can be calculated only when all indicators are present, it is necessary to impute missing data. Here, the same procedure was used as elsewhere in this book to calculate regional averages. First, the growth rate of a similar country from the same region for which data on a given indicator was available was calculated. This growth rate was then applied to the country for which observations were missing so as to make projections. Although this is a transparent way of addressing missing observations, assuming growth for the imputations will make finding progress more likely. To prevent imputations driving the results too strongly, cases where more than half the composite indicator would consist of imputed values have been dropped. The influence of imputations will be tested extensively below by using other imputation techniques.

Regional population-weighted averages for this composite indicator are presented in Figure 13.2. Throughout the period, the composite indicator was highest in the Western Offshoots. Already in 1820, its scores on the composite indicator were higher there than they were in the worst-performing regions today - Sub-Saharan Africa and South and Southeast Asia. These are also the two regions showing the least progress since 1950. Elsewhere, there was substantial progress (about two standard deviations of the composite indicator). Convergence with the Western Offshoots was limited, however, with only Western Europe and East Asia making up substantial ground.

Though divergence between regions still exists, the development process looks different when the composite indicator is compared with trends in per capita GDP (Figure 13.3). The divergence in terms of the composite indicator until the 1950s is stronger than it is in terms of per capita GDP alone. The very populous regions of Asia even performed worse in terms of the composite indicator in this period. This changed from the 1970s onwards as progress in Europe and its Offshoots is substantially less than it was in terms of per capita GDP.

The second way of constructing a composite indicator used here is through a latent variable model. This approach has benefits in terms of dealing with missing data and accounting for the uncertainty this causes in the composite indicator, but this comes at the expense of transparency. To understand the results, it is therefore important to make the workings of a latent variable model explicit. At its core, the model is similar to the previous method in that the composite indicator is created by standardising the variables and calculating their average. The difference is in how the weights are determined. One way to think about the latent variable model is that it gives the weights to construct a composite indicator that reflects as much shared information between the variables as possible to differentiate between countries as best as possible. To do this, highly correlated indicators get higher weights, since this is a sign of shared information and increases the robustness of the rankings (Foster et al., 2013). For these weights to make sense, however, the key assumption of a latent variable model is that the indicators are correlated with each other because of their correlation with the latent variable. For this to hold, a unitary, underlying concept of well-being linked to the observable indicators has to be plausible at the cross-country level. This is not straightforward for all the variables. The model estimated here is a Bayesian variant of a multilevel latent variable model (Jackman, 2009; Høyland et al., 2012; Gelman and Hill, 2007; Merkle, 2011; Lee, 2007). More details on the estimation procedure can be found in the background paper to this chapter (Rijpma, 2014). 
Figure 13.2. Regional averages of a composite well-being indicator, 1820s-2000s

Standardised values (global mean equals zero), population-weighted decadal averages

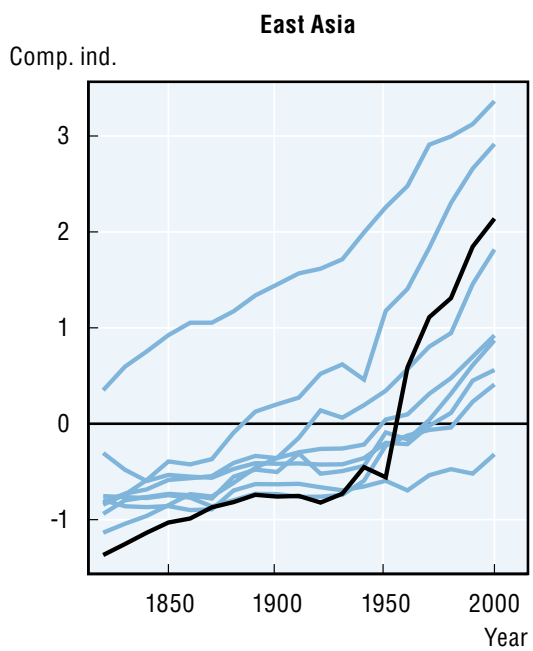
Comp. ind.

Eastern Europe and former Soviet Union

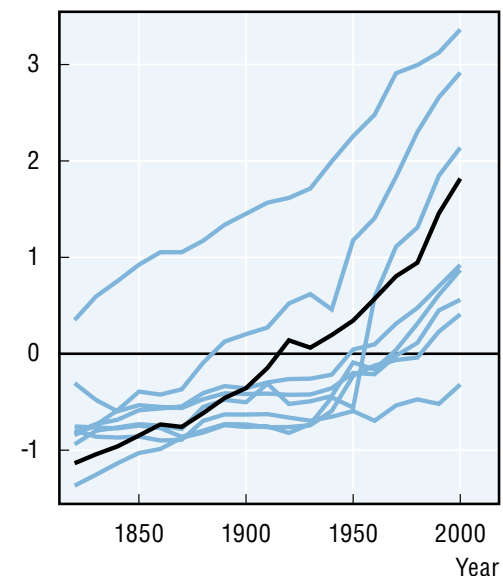
Comp. ind.

Latin America and Caribbean
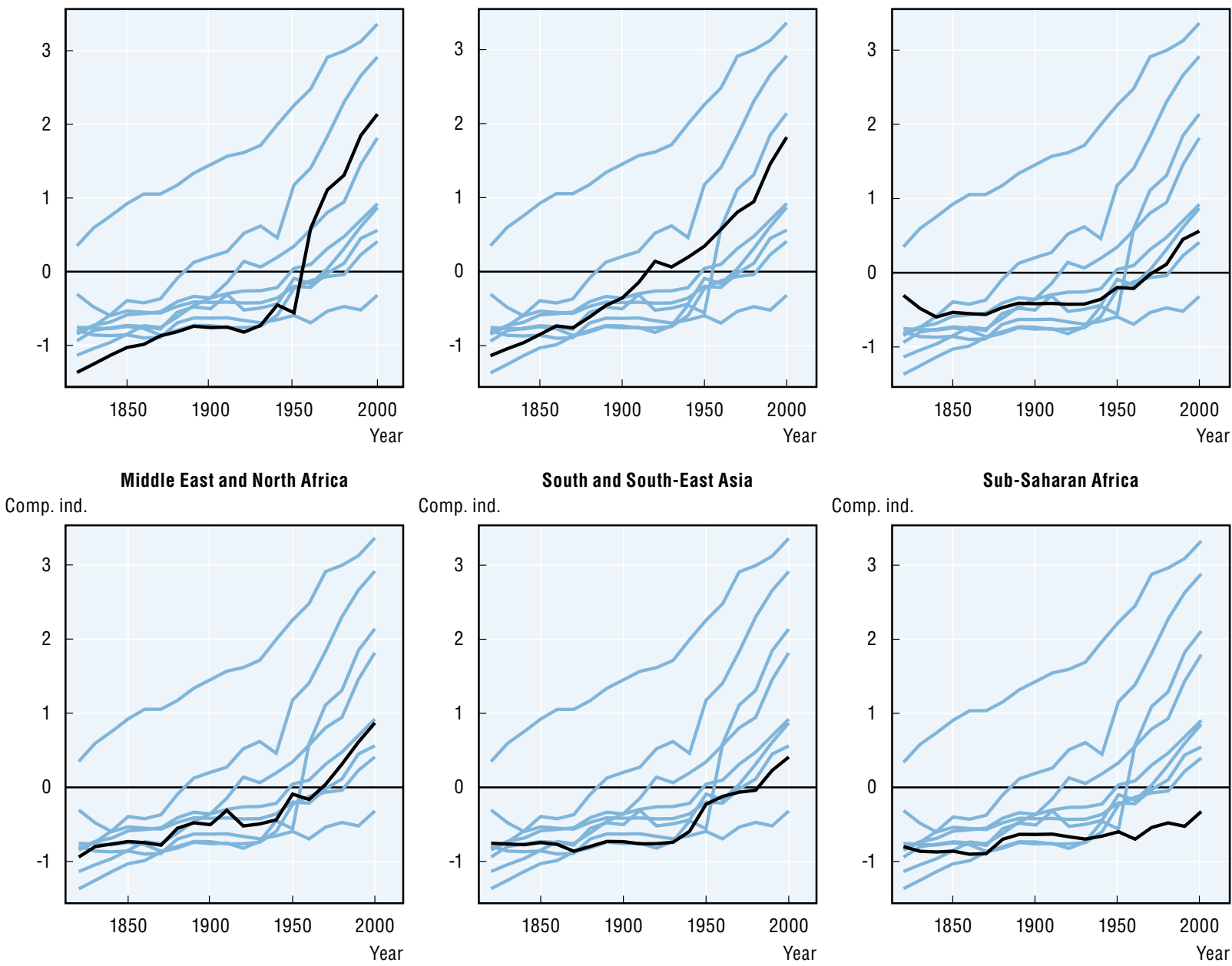

Comp. ind.

South and South-East Asia
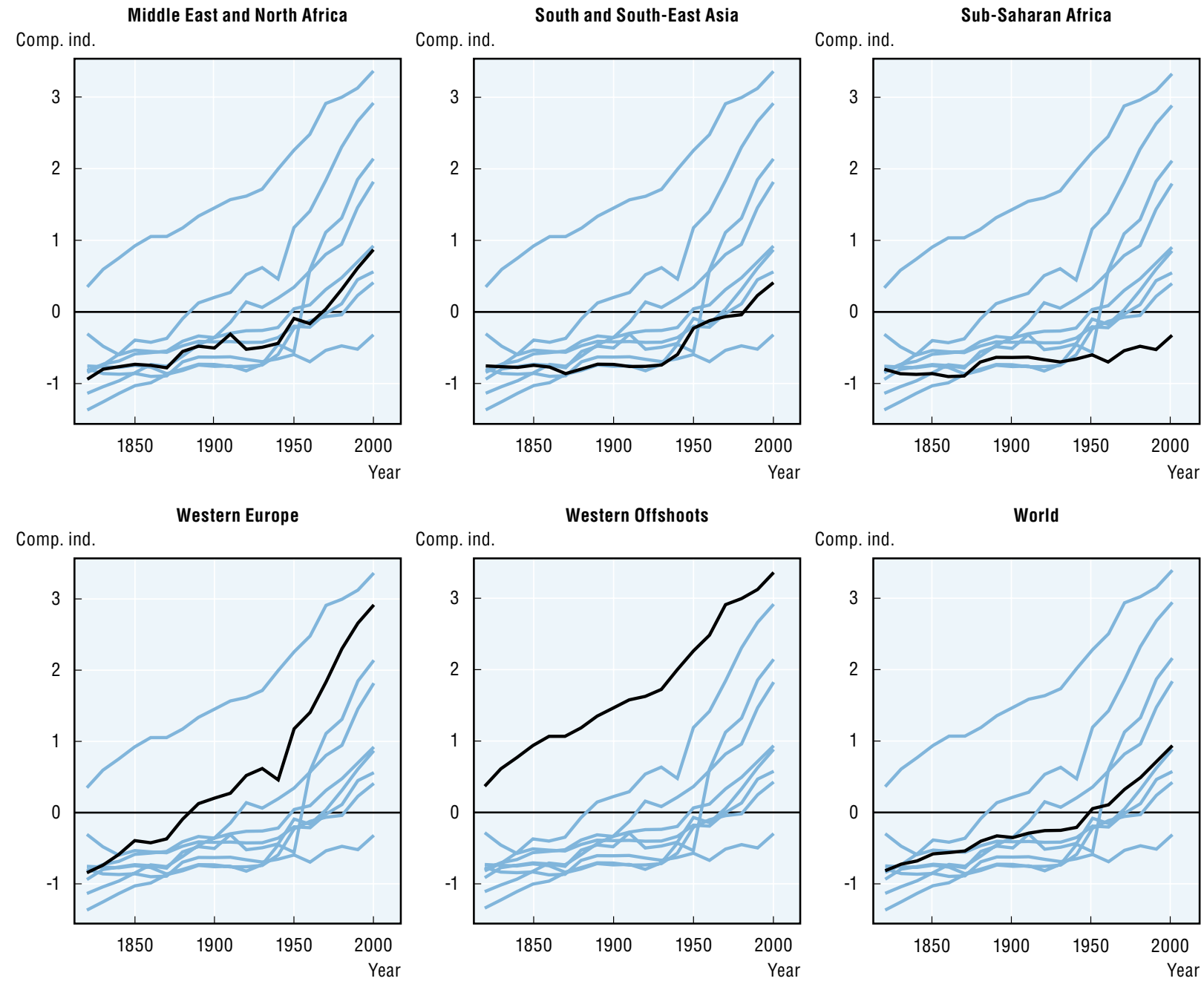

Source: Clio Infra, www.clio-infra.eu. 
Figure 13.3. Regional averages of a composite well-being indicator and standardised GDP per capita, 1820s-2000s

Standardised values (global mean equals zero), population-weighted decadal averages

$$
- \text { Eq. W. Comp. Ind. } \quad-\ominus-\text { Std. GDP/C }
$$

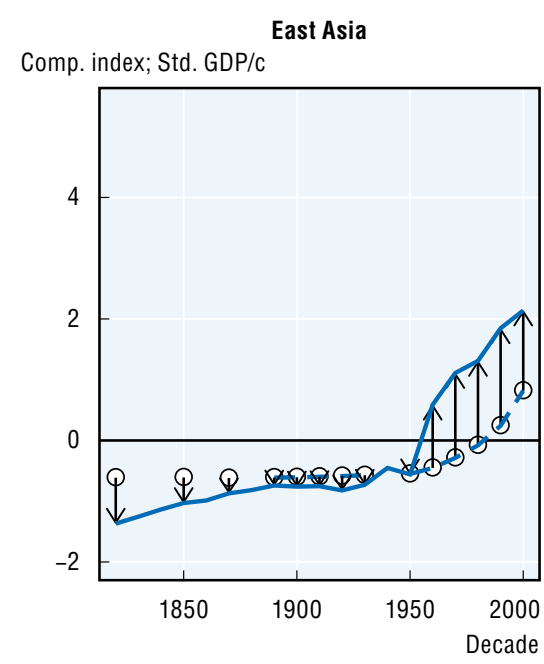

Middle East and North Africa

Comp. index; Std. GDP/c

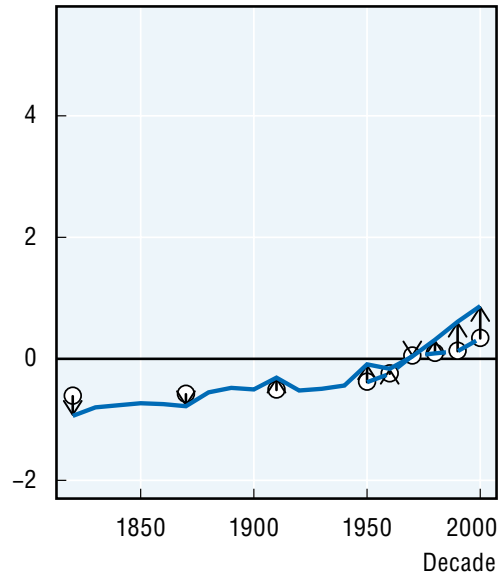

Western Europe

Comp. index; Std. GDP/c

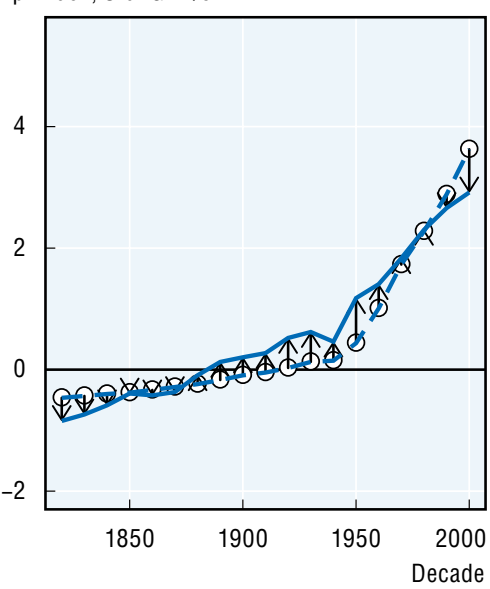

Source: Clio Infra, www.clio-infra.eu.
Eastern Europe and former Soviet Union Comp. index; Std. GDP/c

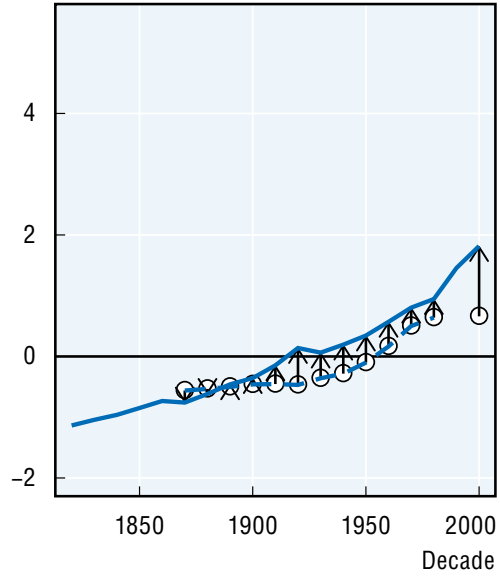

South and South-East Asia Comp. index; Std. GDP/c

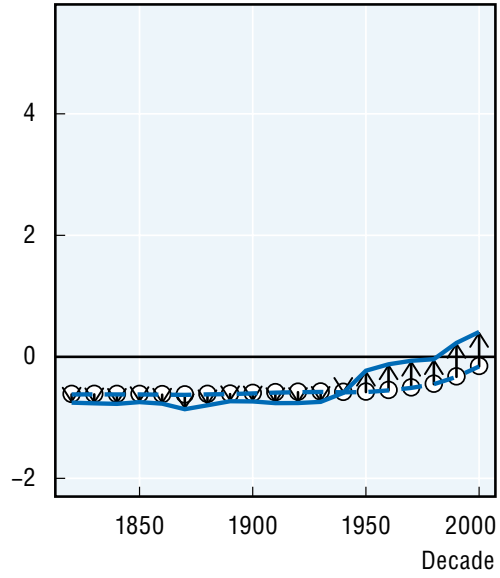

Western Offshoots

Comp. index; Std. GDP/c

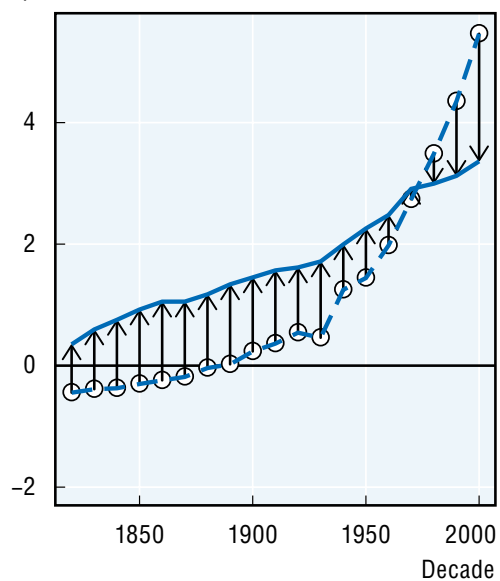

Latin America and Caribbean Comp. index; Std. GDP/c

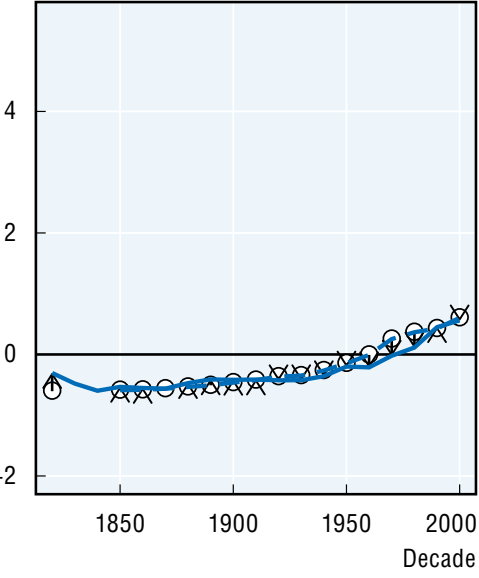

Sub-Saharan Africa

Comp. index; Std. GDP/c

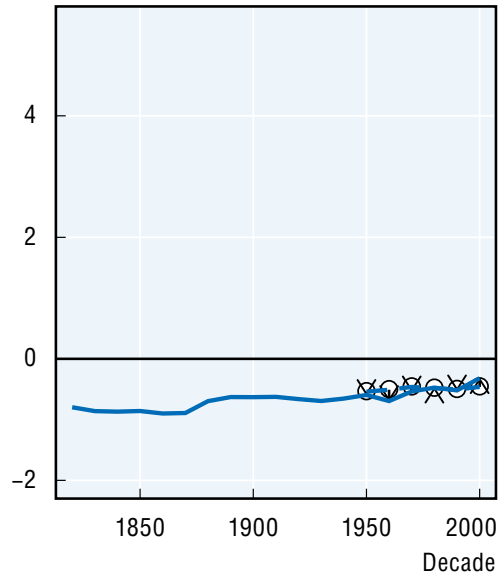

World

Comp. index; Std. GDP/c

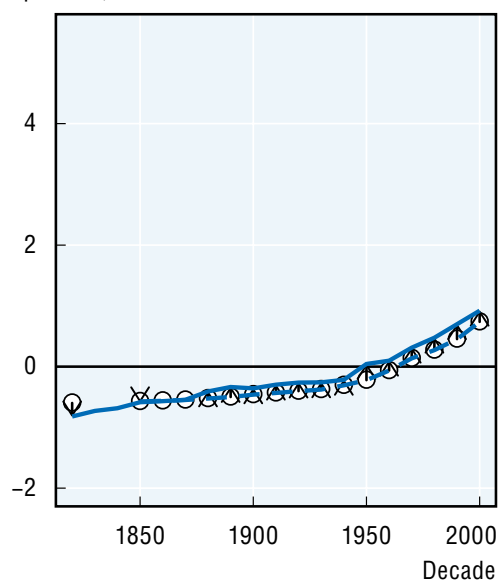


Table 13.2. Factor loadings for a composite well-being indicator

Posterior means and quantiles

\begin{tabular}{lcccc}
\hline & Mean & $q 05$ & $q 50$ & $q 95$ \\
\hline GDP per capita & 0.77 & 0.73 & 0.77 & 0.80 \\
Real wages & 0.70 & 0.66 & 0.70 & 0.74 \\
Height & 0.72 & 0.68 & 0.72 & 0.77 \\
Life expectancy & 0.88 & 0.85 & 0.88 & 0.90 \\
Average years of education & 0.92 & 0.90 & 0.92 & 0.94 \\
Income inequality & -0.22 & -0.27 & -0.23 & -0.18 \\
Polity2 & 0.67 & 0.64 & 0.67 & 0.70 \\
Mean species abundance & -0.36 & -0.39 & -0.36 & -0.34 \\
Homicide rate & -0.15 & -0.21 & -0.15 & -0.09 \\
\hline
\end{tabular}

Source: Clio Infra, www.clio-infra.eu.

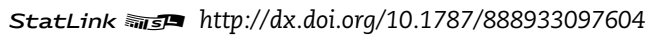

First, a look at the weights (factor loadings) is warranted. Most of the indicators contribute to the composite indicator in the expected direction. Moreover, the contributions are significantly different from zero. GDP, height, life expectancy, education, political institutions and the quality of elections all contribute positively to the composite indicator. Their weights are in the 0.7-0.9 range, meaning that the two grouped indicators (health and income) have a stronger contribution than in the equal-weighting scheme where they were at half the weights of the other indicators. As expected, income inequality and homicide rates contribute negatively to the composite indicator, though their contribution is smaller than that of the other indicators. Biodiversity turned out to be a problematic indicator. Because of its negative correlation with most of the other variables, it had a negative loading. This means higher biodiversity lowered the score on the composite indicator, which is opposite to how biodiversity is thought to affect well-being (though excluding the biodiversity indicator did not substantially change the results). This clearly shows that a statistical approach to a composite indicator can lead to counter-intuitive results. With one of the indicators working in an unexpected manner, there is some uncertainty about what concept the factor model measures: it could arguably be broader social progress rather than well-being. It is nonetheless worthwhile to explore the results of the factor model. For one, the results are generally very similar to the results obtained from other ways of constructing a composite indicator from this book's data. With this in mind, improved imputations are the main reason for estimating the latent variable model. The model estimated here is a multilevel model, which means that the imputations are driven not only by the correlations between the indicators, but also by observations from the same region and decade. However, unlike the previous imputations, there is no assumption of growth in the imputation procedure. Moreover, the number of imputations and their strength is reflected in the uncertainty of the estimates of the composite indicator.

Key results from this analysis are described below. First, consider developments at the level of the geographic regions (Figure 13.4). Wherever possible, the figures also give an indication of the precision of the estimates by providing $90 \%$ confidence intervals. Overall, the regional estimates of progress in the early 19th century are not precise, largely because of the number of observations that had to be imputed. The lack of precision makes it difficult to distinguish between regions in this period, clearly showing how important the imputations are for the earlier period. After about 1950, the precision on the regional 
Figure 13.4. Composite well-being indicator by region, latent variable model, 1820s-2000s

Median and 90\% confidence interval, standardised values (global mean equals zero), decadal averages
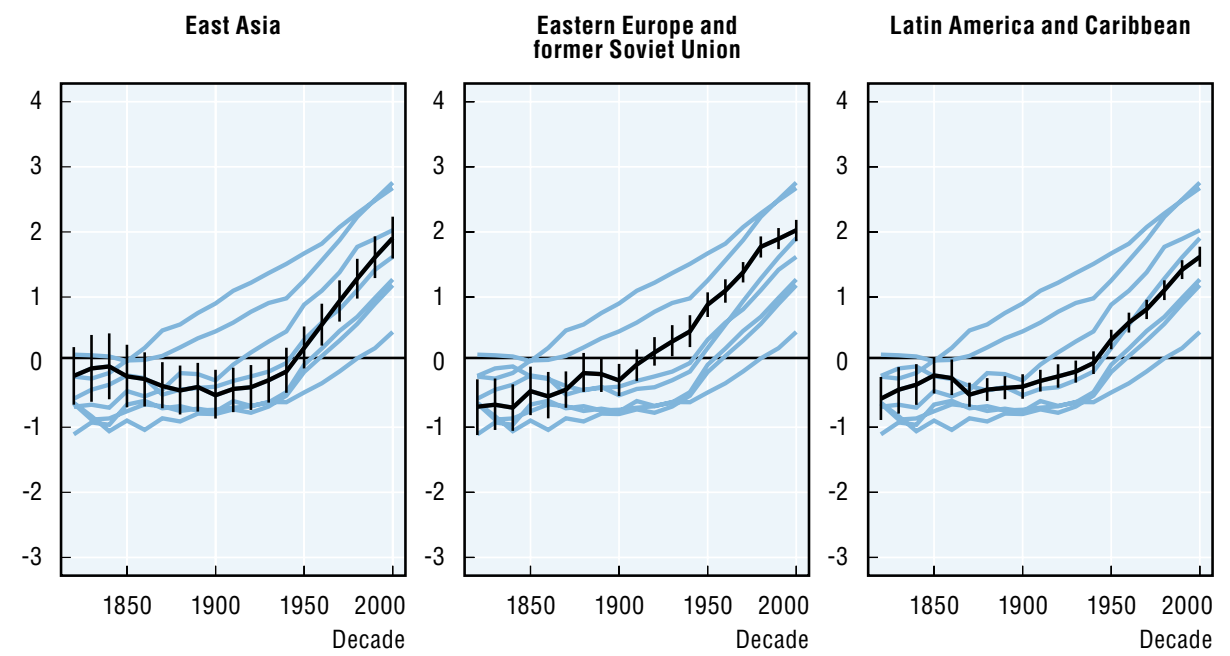

Middle East and North Africa
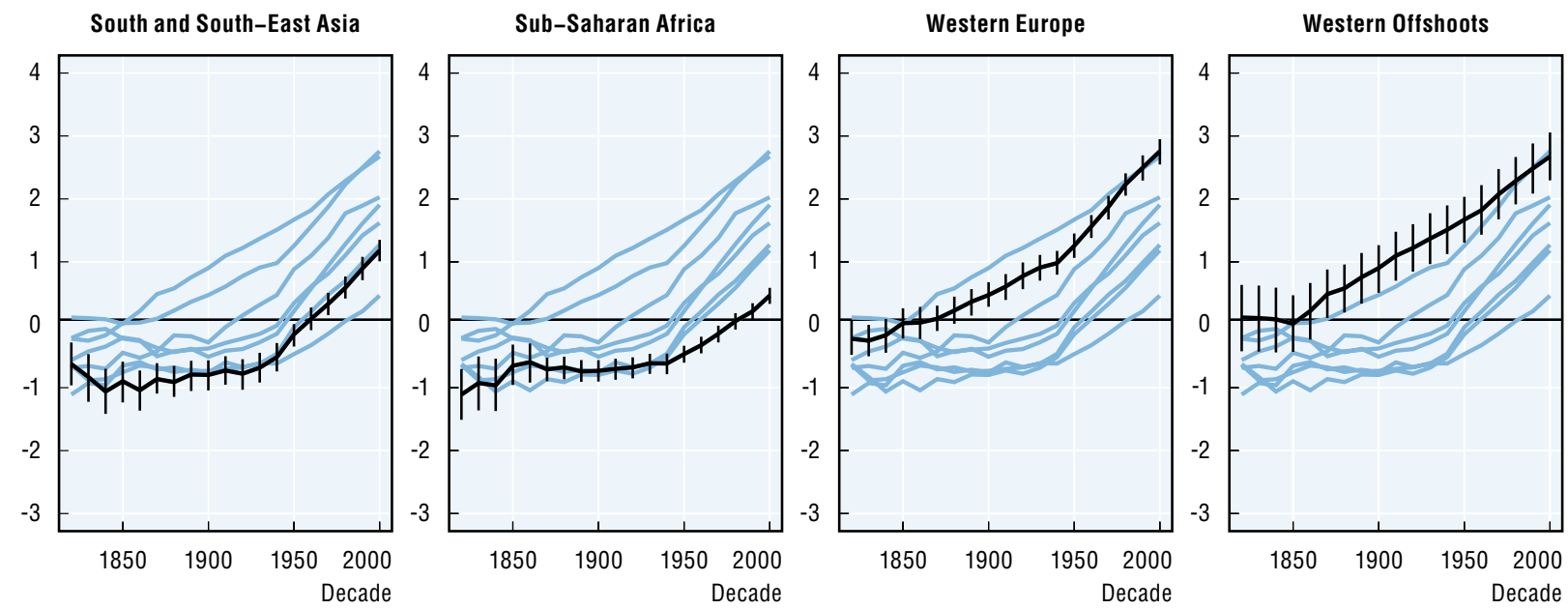

Source: Clio Infra, www.clio-infra.eu.

estimates is definitely good enough to distinguish between most regions. The influence of imputations is also reflected by the higher scores on the composite indicator in the early 19th century in East Asia, Sub-Saharan Africa and Latin America compared to the previous indicator. In these decades, there were very few observations, causing the overall mean (zero by definition) to have a strong impact on the imputations.

The global picture here is still one of progress, as all regions improve (though Sub-Saharan Africa to a much lesser extent). Yet it is also a picture of divergence, as some regions start from a higher level and also start advancing earlier. At the beginning of the 19th century, the Western Offshoots already had the highest scores on the composite indicator. They kept their lead until the last decades of the 20th century, when Western Europe caught up, though this result is sensitive to weighting. Halfway through the 19th century progress began in Europe and its Offshoots. Due to this early start, by the end of the 19th century a clear gap had arisen between Europe and its Offshoots on the one hand and the rest of the world on the other. 
The rest of the world only began catching up later. In the early 20th century, Eastern Europe and especially the Soviet Union witnessed substantial progress and closed some of the gap with the leaders. Convergence with the West is stronger there in terms of the composite indicator than what is shown by per capita GDP. Despite some flaws in socialist countries (for instance, the lack of political freedom), progress was nonetheless made in many well-being-indicators. Asia, Latin America, and the Middle East and North Africa began making up lost ground in the first half of the 20th century. Sub-Saharan Africa did not see any substantial progress until the 1950s, and even after that convergence with the rest was very limited.

These results are similar to those found by Leandro Prados de la Escosura $(2010,2014)$. His composite indicator shows substantial progress and convergence after the First World War, though he finds that these processes slowed down after the 1940s. Nicholas Crafts (2002) has also calculated Human Development Index (HDI) scores for the 1870-1990 period using the UNDP's pre-2010 procedure, which relied on the arithmetic mean of the normalised indicators. Crafts too observes that substantial convergence took place after 1950. A comparison of the country ranks with his scores is instructive. Broadly speaking, Craft's composite indicator and the one presented here rank countries similarly (rank correlation of 0.96). However, some substantial outliers exist, mostly a reflection of the larger number of indicators used here and the logarithmic transformation on per capita GDP used by the UNDP and Crafts.

Although there is a divergence in progress measured via this indicator between ca 1820 and 1950, it looks different compared to GDP alone. Strikingly, the divergence in the late 19th and early 20th century between Europe and the Western Offshoots on the one hand and the rest of the world on the other is more pronounced in the case of the composite indicator. From the early 20th century onwards, however, Eastern Europe and the former Soviet Union, Latin America and Asia make up more ground than GDP alone suggests. Looking at some of the most prominent countries in the debate on the Great Divergence (the United Kingdom, China and India, see Figure 13.5) confirms this picture in more detail. Only after about 1950 does the composite indicator show more convergence than GDP.

Progress in the composite indicator over the entire period was stronger than growth in per capita GDP. In terms of GDP, some of the worst-performing countries in 2000 are no better-off than the poorest countries in 1820 . The composite indicator paints a different picture. The countries with the lowest composite indicator scores in 2000 are generally better-off than the lowest-scoring countries in 1820. Many even do better than the countries with the highest scores in 1820. Indicators of well-being other than GDP are spread more evenly across the globe, and this is reflected in the composite indicator. This result is, however, sensitive to the way the composite indicator is constructed. In the equalweighting case more countries in Sub-Saharan Africa show very little improvement. This is due to the strong weight given to inequality and security and above all to the assumption of growth underlying the imputations in the equal-weighting case (using equal weights on the imputations of the latent-variable model shows qualitatively similar results to the composite indicator created by the latent-variable model itself).

Figure 13.6 presents the distribution of the composite indicators across countries at three years (1850, 1900 and 2000). In 1850, the distribution of the composite indicator was still fairly equal. Most countries in the middle and even at the bottom of the distribution have similar scores. Moreover, substantial uncertainty surrounds many of the estimates. 


\section{Figure 13.5. Composite well-being indicator and GDP per capita in the United Kingdom, China, and India, 1820s-2000s}

Standardised values (global mean equals zero), decadal averages

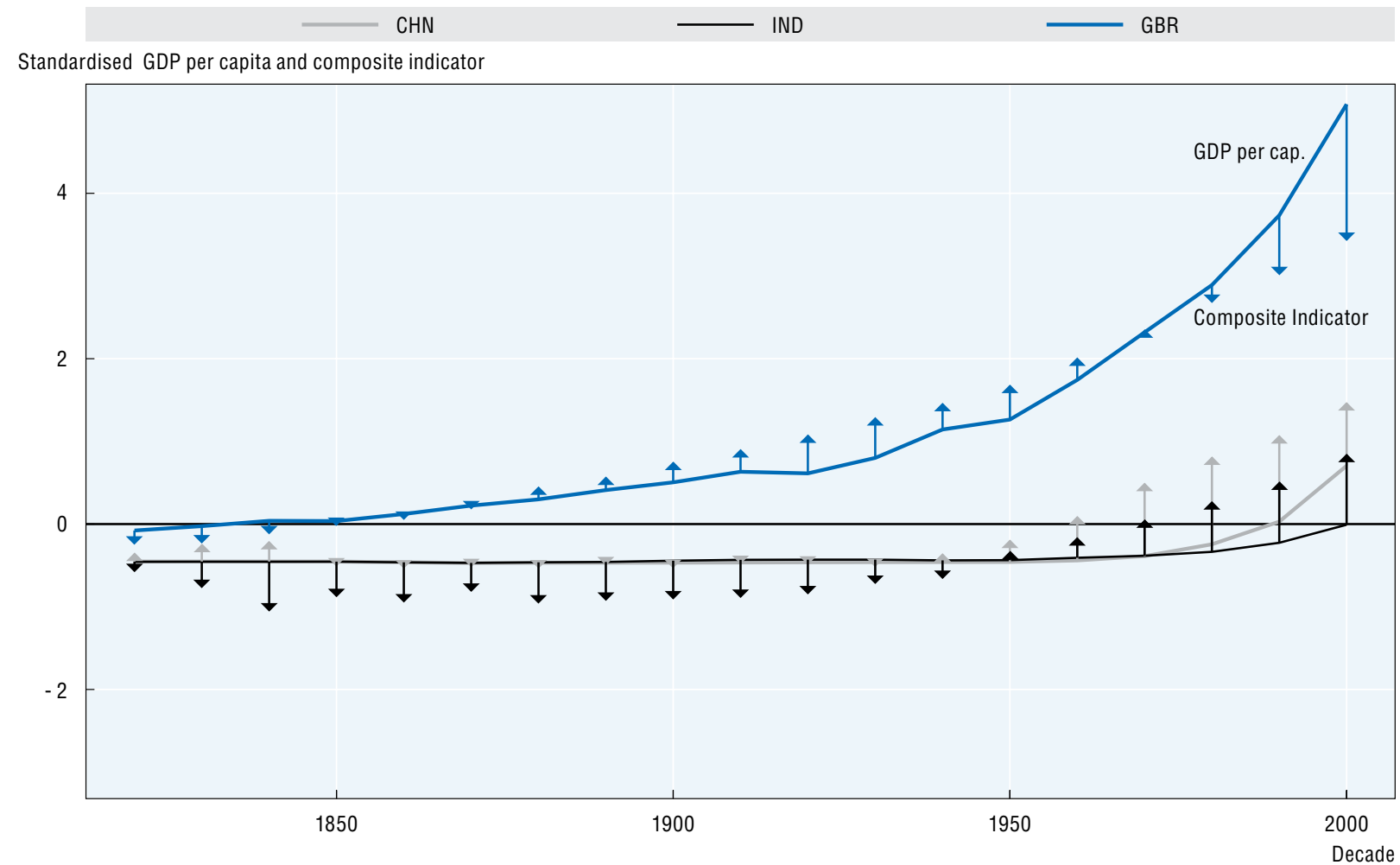

Note: The continuous line refers to GDP per capita; the arrows to the composite well-being indicator. Source: Clio Infra, www.clio-infra.eu.

This, and the relatively equal distribution, makes the countries difficult to distinguish in terms of their score on the composite indicator. Only at the very top do substantial differences start appearing.

By 1900, between-country inequality had increased as a clear group of frontrunners had arisen. In Western Europe and especially in its Offshoots, the composite indicator was much higher than in the rest of the world. The precision in the estimates has also increased substantially, meaning it is now possible to make distinctions between many more countries. By 1950, no clear group of leaders existed anymore. The highest scores were still found in north-western Europe and the Western Offshoots, but countries in southern Europe and Latin America as well as the Soviet Union and Japan had begun closing the gap. Generally, the scores on the composite indicator have increased substantially by this time, with half the countries having a score higher than zero, the overall mean for the entire period. At the same time, however, between-country inequality was at its highest at this point in time.

By 2000, there was further progress in the composite measure. Nearly all of the countries are now above the overall 1820-2000 mean. This represents considerable progress if it is remembered that in 1850 nearly all countries were still below that point. Furthermore, many countries experienced a substantial increase between 1950 and 2000, most by more than one standard deviation of the global 1820-2000 distribution. Although there was an increase in all countries between 1950 and 2000, progress was much lower in many 
Figure 13.6. Composite well-being indicator across countries, 1850, 1900 and 2000

Medians and $90 \%$ confidence intervals, standardised values (global mean equals zero), decadal averages
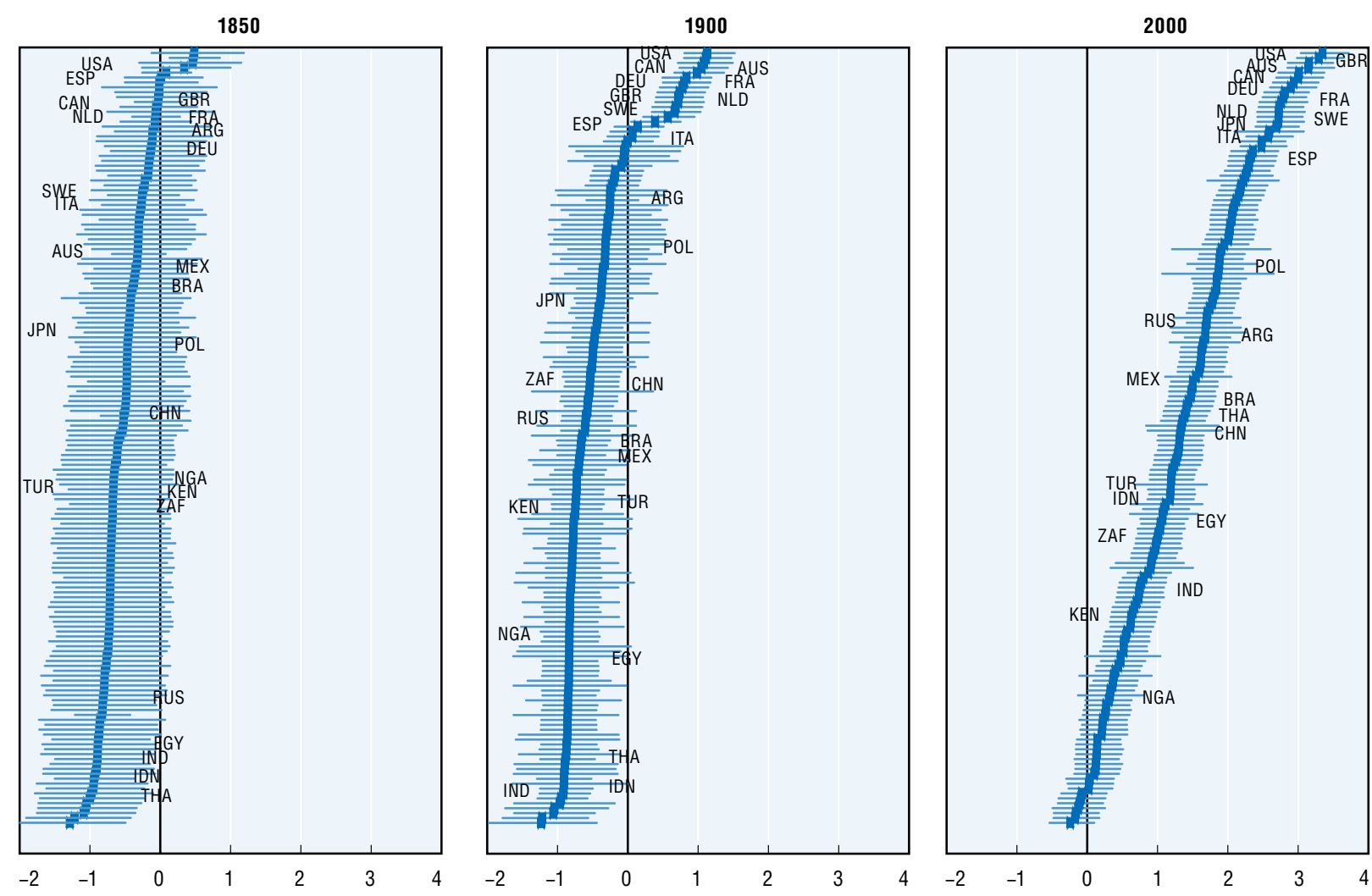

Source: Clio Infra, www.clio-infra.eu.

Sub-Saharan Africa countries as well as in Afghanistan and Haiti. Despite lagging development in these countries, however, between-country inequality as measured by the composite indicator in 2000 had declined relative to 1900 and 1950.

It is also useful to point out the uncertainty of the estimates. Generally speaking, it is difficult to distinguish countries that are close to each other in the rankings, especially when uncertainty is high due to missing observations. For example, the estimates suggest that the chance that two high-ranking countries in the 1850s like the United States and Norway had a different score on the composite indicator was $54 \%$, not much better than determining this by the flip of a coin. Only when the highest countries are compared to countries below the top of the ranking does the chance of the two being different become large. For instance, the chance of the composite indicator in the United States in 1850 being higher than in Britain in the same year is about $90 \%$. As for developments over time, only by about 1870 is it possible to state with some certainty that a country like Britain had improved its position relative to 1820 . More precision and higher increases after 1850 means it becomes easier to distinguish countries and progress.

An interesting question that arises from the composite indicator is the importance of GDP for achieving progress. In developing regions, the composite indicator improved in the second half of the 20th century despite slow growth in per capita GDP. Moreover, since the 1970s, per capita GDP rose much more than the composite measure in Europe and its Offshoots. It was also observed earlier that the correlation between per capita GDP and 
other well-being indicators was not very strong in the first half of the 19th century. Tests for a break in the relation between per capita GDP and the composite indicator indicate that their relation starts to change around USD 4000-5000 (Muggeo, 2008). Controlling for country and decade fixed-effects gives roughly the same results (Figure 13.7). Likewise, estimating the global trend in the composite indicator conditional on per capita GDP shows that higher scores on the composite indicator were attained each decade even if GDP had remained constant. These results can probably be ascribed to two phenomena. First is the inclusion of (weakly) negatively correlated well-being indicators (inequality, homicides). Second, the break reflects the concave relationships between per capita GDP and a few of the other indicators, an indication that well-being indicators other than per capita GDP are more equally distributed between countries.

\section{Figure 13.7. Segmented relation between a composite well-being indicator and GDP per capita}

Standardised values (global mean equals zero) and US dollars at 1990 PPP, decadal averages

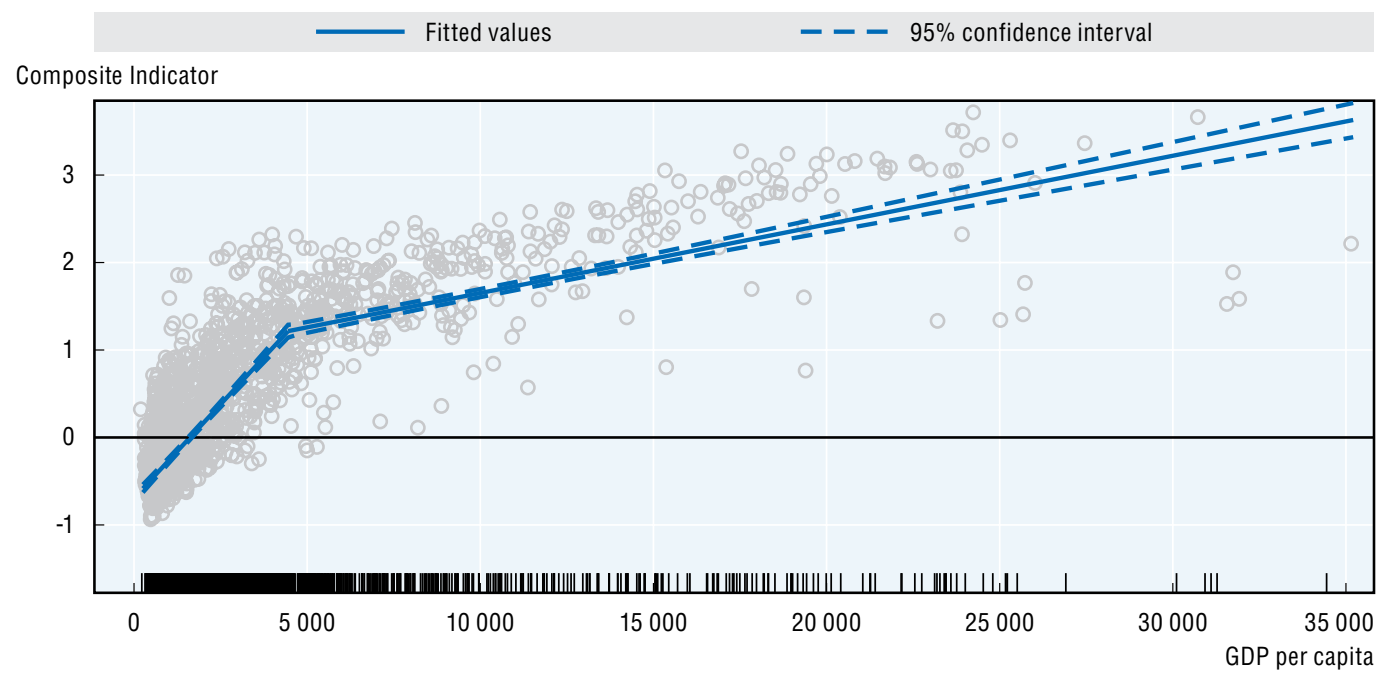

Source: Clio Infra, www.clio-infra.eu.

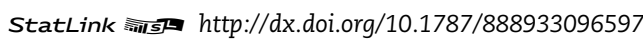

Finally, the robustness of the results to the aggregation method should be discussed. A large number of methods of constructing the composite indicator have been tried, both here and in the background paper (Rijpma, 2014). Overall, most approaches lead to similar results. Trying a large number of weighting schemes made only small differences to the regional results. The differences between the two aggregation methods employed here insofar as they were due to weighting were also small. However, the imputation method did have a substantial impact on the results for the early 19th century, as shown by the latent variable model approach. ${ }^{2}$ Overall, however, the results remain fairly robust, though care is warranted in making statements about differences regarding the composite indicator in the 19th century.

\section{Discussion}

A composite indicator is a tool that, while not without its share of problems, is very useful for summarising developments. Two methods for constructing such an indicator were explored here: a straightforward equal-weighting scheme and a statistical approach in the form of a latent variable model. 
The correlation between the various well-being indicators was generally high, meaning that low or high well-being often went hand in hand. Nonetheless, compared to per capita GDP, many of the indicators were distributed more equally across the globe. This means that, compared to per capita GDP, progress in the composite indicator was stronger and differences between countries were less pronounced. However, this lessened between-country inequality was largely a phenomenon of the 1970s and after. Before then, between-country inequality was actually more pronounced when looking at the composite indicator. The composite indicators measured an early lead for the Western Offshoots and Western Europe. They would continue to extend their lead in the late 19th and early 20th centuries. East Asia, Latin America, and Eastern Europe and the Soviet Union began to make up grounds sometime in the first half of the 20th century. South Asia and Sub-Saharan Africa made much less progress in the 20th century, though the composite indicator suggests that this lag was less stark than suggested by income alone. In short, moving away from solely considering GDP as a measure of well-being suggests less world poverty and less between-country inequality, though substantial differences continue to exist between countries. Most ways of constructing a composite indicators will probably give similar conclusions.

An important issue is the changing relations between GDP and the composite indicator. It shows that more economic activity and income does not necessarily imply progress in other domains of well-being. GDP alone may therefore be an imperfect measure of well-being, especially for societies in the past. Although this suggests that a multidimensional perspective is important, it also hints at the possibility that constructing a single composite indicator to cover such a long time period can be problematic.

\section{Priorities for future research}

Three elaborations of this view of well-being in the past seem important. First, more relevant indicators could be added. For example, unemployment is an important determinant of subjective well-being (Fleurbaey et al., 2009; Fleche et al., 2011). It could therefore be relevant for an historical composite indicator as well. Second, there is the possibility of systematically incorporating valuable expert and public opinion into the aggregation procedure. Although this made little difference to the resulting composite indicators here, it is a lead worth following. Finally, there has been little attention to distributional issues beyond the inclusion of income inequality as an indicator in composite indicator. However, inequalities can exist in many more dimensions of well-being, and they can be analysed in more sophisticated ways than has been done here. Harmonised micro-data, historical as well as contemporary, can be of great value for such an effort (e.g. Ruggles et al., 2003). Doing this could also cross the gap from country-level to individual conceptualisations of well-being.

\section{Notes}

1. These and other technical matters are treated in more depth in a background paper to this chapter (Rijpma, 2014).

2. A dynamic factor model that attributes more importance to the gradual developments of the indicators over time was also estimated to this end (Zhang and Nesselroade, 2007). 


\section{References}

Alkire, S. and J. Foster (2011), “Counting and Multidimensional Poverty Measurement”, Journal of Public Economics, Vol. 95, pp. 476-487.

Atkinson, A.B. and F. Bourguignon (1982), "The Comparison of Multi-Dimensioned Distributions of Economic Status”, The Review of Economic Studies, Vol. 49, pp. 183-201.

Becker, G.S., T.J. Philipson and R.R. Soares (2005), “The Quantity and Quality of Life and the Evolution of World Inequality”, The American Economic Review, Vol. 95, pp. 277-291.

Boarini, R. et al. (2012), "What Makes for a Better Life?:The Determinants of Subjective Well-Being in OECD Countries - Evidence from the Gallup World Poll”, OECD Statistics Working Papers, 2012/03, OECD Publishing, http://dx.doi.org/10.1787/5k9b9ltjm937-en.

Boarini, R. and M. Mira D’Ercole (2013), “Going Beyond GDP: An OECD Perspective”, Fiscal Studies, Vol. 34, pp. 289-314.

Chakravarty, S.R. (2003), "A Generalized Human Development Index”, Review of Development Economics, Vol. 7, pp. 99-114.

Cooper, R.S., J.F. Kennelly and P. Orduñez-Garcia (2006), "Health in Cuba", International Journal of Epidemiology, Vol. 35, pp. 817-824.

Crafts, N. (2002),“The Human Development Index, 1870-1999: Some Revised Estimates”, European Review of Economic History, Vol. 6, pp. 395-405.

Cutler, D., A. Deaton and A. Lleras-Muney (2006), "The Determinants of Mortality", Journal of Economic Perspectives, Vol. 20, pp. 97-120.

Deaton, A. (2008), "Income, Health and Well-being Around the World: Evidence from the Gallup World Poll," Journal of Economic Perspectives, Vol. 22/2, pp. 53-72.

Dowrick, S., Y. Dunlop and J. Quiggin (2003), "Social Indicators and Comparisons of Living Standards", Journal of Development Economics, Vol. 70, pp. 501-529.

Duclos, J., D.E. Sahn and S.D. Younger (2006), “Robust Multidimensional Poverty Comparisons”, The Economic Journal, Vol. 116, pp. 943-968.

Feinstein, C.H. and M. Thomas (2002), "A Plea for Errors", Historical Methods: A Journal of Quantitative and Interdisciplinary History, Vol. 35, pp. 155-165.

Fleche, S., C. Smith and P. Sorsa (2012), "Exploring Determinants of Subjective Well-being in OECD Countries: Evidence from the World Value Survey", OECD Statistics Working Papers, No. 2012/01, OECD Publishing, http://dx.doi.org/10.1787/5k9ffc6p1rub-en.

Fleurbaey, M., K. Decancq and E. Schokkaert (2009), "What Good Is Happiness?” www.gate.cnrs.fr/IMG/ pdf/Fleurbay_Oct_2009.pdf.

Foster, J.E., M. McGillivray and S. Seth (2013), “Composite Indices: Rank Robustness, Statistical Association, and Redundancy", Econometric Reviews, Vol. 32, pp. 35-56.

Gelman, A. and J. Hill (2007) Data Analysis Using Regression and Multilevel/hierarchical Models, Analytical Methods for Social Research, Cambridge University Press, New York.

Goldin, C. and L.F. Katz (1998), “The Origins of Technology-Skill Complementarity”, The Quarterly Journal of Economics, Vol. 113, pp. 693-732.

Honaker, J. and G. King (2010), "What to Do About Missing Values in Time-Series Cross-Section Data", American Journal of Political Science, Vol. 54, pp 561-581.

Høyland, B., K. Moene and F. Willumsen (2012), “The Tyranny of International Index Rankings”, Journal of Development Economics, Vol. 97, pp 1-14.

Jackman, S. (2009), Bayesian Analysis for the Social Sciences, Wiley Series in Probability and Statistics, John Wiley and Sons, Chichester.

Komlos, J. (1998), "Shrinking in a Growing Economy? The Mystery of Physical Stature During the Industrial Revolution", The Journal of Economic History Vol. 58 pp. 779-802.

Kaufmann, D., A. Kraay and M. Mastruzzi (2004), “Governance Matters III: Governance Indicators for 1996, 1998, 2000 and 2002”, The World Bank Economic Review Vol. 18, pp. 253-287.

Lee, S.-Y. (2007), Structural Equation Modeling: A Bayesian Approach, John Wiley and Sons, Chichester.

Maddison, A. (1982), Phases of Capitalist Development, Oxford University Press, Oxford.

Maddison, A. (1995), Monitoring the World Economy 1820-1992, Development Centre Studies, OECD Publishing, Paris. 
Maddison, A. (2001), The World Economy: A Millennial Perspective, Development Centre Studies, OECD Publishing, Paris, http://dx.doi.org/10.1787/9789264189980-en.

Merkle, E.C. (2011), "A Comparison of Imputation Methods for Bayesian Factor Analysis Models", Journal of Educational and Behavioral Statistics, Vol. 36, pp. 257-267.

Morris, M.D. (1980), “The Physical Quality of Life Index (PQLI)”, Development Digest, Vol. 18, pp. 95-109.

Nardo, M. et al. (2005), "Handbook on Constructing Composite Indicators: Methodology and User Guide", OECD Statistics Working Papers, No. 2005/03, OECD Publishing, http://dx.doi.org/10.1787/ 533411815016.

Nicholas, S.J. and J.M. Nicholas (1992), “Male Literacy, 'Deskilling,' and the Industrial Revolution”, The Journal of Interdisciplinary History, Vol. 23, pp. 1-18.

Plummer, M. (2003), "JAGS: A Program for Analysis of Bayesian Graphical Models Using Gibbs Sampling," DSC (Disability Services Commissioner) 2003 Working Papers, www.r-project.org/nosun/ conferences/DSC-2003/Drafts/Plummer.pdf.

Prados de la Escosura, L. (2010), "Improving Human Development: A Long-Run View”, Journal of Economic Surveys, Vol. 24, pp. 841-94.

Prados de la Escosura, L. (2014), “World Human Development: 1870-2007," Review of Income and Wealth, forthcoming.

Ravallion, M. (2011), "The Human Development Index: a Response to Klugman, Rodriguez and Choi”, The Journal of Economic Inequality, Vol. 9, pp. 475-478.

Ravallion, M. (2012a), "Mashup Indices of Development”, The World Bank Research Observer, Vol. 27, pp. 1-32.

Ravallion, M. (2012b), "Troubling Trade-offs in the Human Development Index", Journal of Development Economics, Vol. 99, pp. 201-209.

Rijpma, A. (2014), "A composite view of long-term well-being: construction and trends", CGEH (Centre for Global Economic History) Working paper series, http://cgeh.nl/working-paper-series.

Ruggles, S. et al. (2003), "Integrated Public Use Microdata Series (IPUMS): Version 3.0 Minneapolis: Historical Census Projects", University of Minnesota.

Schokkaert, E. (2007), "Capabilities and Satisfaction with Life”, Journal of Human Development, Vol. 8, pp. 415-430.

Sen, A. (2001), Development as Freedom, 1st Oxford University Press.

Sen, A. (1999), Commodities and Capabilities, Oxford University Press, India.

Sen, A. (1987), The Standard of Living: The Tanner Lectures, Cambridge University Press.

Slottje, D. J. (1991), "Measuring the Quality of Life across Countries”, The Review of Economics and Statistics, Vol. 73, pp. 684-693.

Stiglitz, J.E., A. Sen and J.P. Fitoussi (2009) "Report by the Commission on the Measurement of Economic Performance and Social Progress", www.stiglitz-sen-fitoussi.fr/documents/rapport_anglais.pdf.

Szreter, S. (2003), “The Population Health Approach in Historical Perspective”, American Journal of Public Health, Vol. 93, pp 421-431.

Treier, S. and S. Jackman (2008), "Democracy as a Latent Variable", American Journal of Political Science, Vol. 52, pp. 201-217.

UNDP (United Nations Development Programme) (2010), Human Development Report 2010: The Real Wealth of Nations: Pathways to Human Development, United Nations Development Programme.

Zhang, Z. and J.R. Nesselroade (2007), "Bayesian Estimation of Categorical Dynamic Factor Models", Multivariate Behavioral Research, Vol. 42, pp 729-56. 


\section{ORGANISATION FOR ECONOMIC CO-OPERATION AND DEVELOPMENT}

The OECD is a unique forum where governments work together to address the economic, social and environmental challenges of globalisation. The OECD is also at the forefront of efforts to understand and to help governments respond to new developments and concerns, such as corporate governance, the information economy and the challenges of an ageing population. The Organisation provides a setting where governments can compare policy experiences, seek answers to common problems, identify good practice and work to co-ordinate domestic and international policies.

The OECD member countries are: Australia, Austria, Belgium, Canada, Chile, the Czech Republic, Denmark, Estonia, Finland, France, Germany, Greece, Hungary, Iceland, Ireland, Israel, Italy, Japan, Korea, Luxembourg, Mexico, the Netherlands, New Zealand, Norway, Poland, Portugal, the Slovak Republic, Slovenia, Spain, Sweden, Switzerland, Turkey, the United Kingdom and the United States. The European Union takes part in the work of the OECD.

OECD Publishing disseminates widely the results of the Organisation's statistics gathering and research on economic, social and environmental issues, as well as the conventions, guidelines and standards agreed by its members.

\section{OECD DEVELOPMENT CENTRE}

The OECD Development Centre was established in 1962 as an independent platform for knowledge sharing and policy dialogue between OECD member countries and developing economies, allowing these countries to interact on an equal footing. Today, 24 OECD countries and 18 non-OECD countries are members of the Centre. The Centre draws attention to emerging systemic issues likely to have an impact on global development and more specific development challenges faced by today's developing and emerging economies. It uses evidence-based analysis and strategic partnerships to help countries formulate innovative policy solutions to the global challenges of development.

For more information on the Centre and its members, please see www.oecd.org/dev.

\section{CLIO Infra}

Clio Infra is a research project to document and analyse the various dimensions of global inequality between 1500 and the present. Scholars from the International Institute of Social History (IISH) and the universities of Utrecht, Groningen and Tuebingen supported by National Science Foundation (NWO) and Royal Academy of Sciences (KNAW) are organizing collaboratories aimed at collecting and standardizing economic-historical datasets to that purpose. An example of the Maddison project, which aims at continuing the international comparative work on historical national accounting organized by Angus Maddison in the past, resulting in his well-known global dataset. Similar networks of scholars working on measures of economic performance (real wages, heights, life expectancy) and their determinants (human capital, institutions, gender inequality) are producing high quality global datasets on these topics, covering the world in the past 500 years. Recently also indices of sustainability have been integrated into the Clio Infra framework. The project leader is Jan Luiten van Zanden, professor of economic history at Utrecht University. All data are made available on the website: www.clio-infra.eu.

OECD PUBLISHING, 2, rue André-Pascal, 75775 PARIS CEDEX 16 (30 2014041 P) ISBN 978-92-64-21406-4 - 2014 


\section{How Was Life?}

\section{GLOBAL WELL-BEING SINCE 1820}

How was life in 1820 , and how has it improved since then? What are the long-term trends in global well-being? Views on socio-economic developments since the Industrial Revolution are largely based on historical national accounting in the tradition of Kuznets and Maddison. But trends in real GDP per capita may not fully reflect changes in other dimensions of well-being such as life expectancy, education, personal security or gender inequality. Looking at these indicators usually reveals a more equal world than the picture given by economic growth alone, but has this always been the case? This report aims to fill this gap. It presents the first systematic evidence on long-term trends in global well-being since 1820 for 25 major countries and 8 regions in the world. This report not only shows the data but also discusses the underlying sources and their limitations, pays attention to country averages and inequality, and pinpoints avenues for further research.

This report is the product of collaboration between the OECD and the CLIO-INFRA project. It represents the culmination of work by a group of economic historians to systematically chart long-term changes in the dimensions of global well-being and inequality, making use of the most recent research carried out within the discipline. The historical evidence reviewed here is organised around 10 topics that mirror those used by the OECD in its own well-being report How's Life? and draws on the best sources and expertise currently available for historical perspectives in this field.

How Was Life? is part of the OECD Better Life Initiative, launched by the OECD on the occasion of its 50th Anniversary in 2011. The OECD Better Life Initiative aims to promote "Better Policies for Better Lives", in line with the OECD's overarching mission. One of the other pillars of the OECD Better Life Initiative is the Better Life Index (www.oecdbetterlifeindex.org), an interactive composite index of well-being that aims at involving citizens in the debate on societal progress.

Consult this publication on line at $\boldsymbol{h t t p : / / d x . d o i . o r g / 1 0 . 1 7 8 7 / 9 7 8 9 2 6 4 2 1 4 2 6 2 - e n . ~}$

This work is published on the OECD iLibrary, which gathers all OECD books, periodicals and statistical databases. Visit www.oecd-ilibrary.org for more information.

2014

OECDpublishing www.oecd.org/publishing
ISBN 978-92-64-21406-4 $302014041 \mathrm{P}$

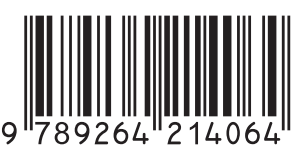

